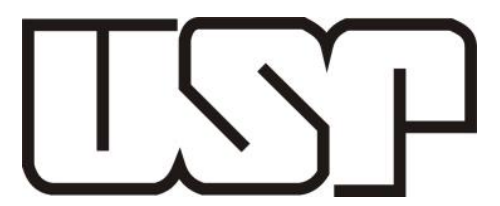

UNIVERSITY OF SÃO PAULO

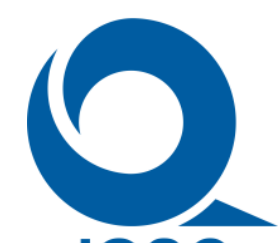

IQSC

INSTITUTE OF CHEMISTRY OF SÃO CARLOS

POST-GRADUATION PROGRAM IN CHEMISTRY

Medicinal Chemistry Group - NEQUIMED/IQSC/USP

Design, Synthesis and Evaluation of the Trypanocidal Activity of Cruzain Reversible-Covalent Inhibitors

FAPESP Thematic Project: 2013/18009-4

Scholarship FAPESP: 2016/07946-5

Lorenzo Cianni

Supervisor: Prof. Dr. Carlos A. Montanari

Supervisor in Germany: Prof. Dr. Jürgen Bajorath

SÃO CARLOS

2019

Lorenzo Cianni 


\title{
Design, Synthesis and Evaluation of the Trypanocidal Activity of Cruzain Reversible-Covalent Inhibitors
}

\author{
Ph.D. thesis presented to the post- \\ graduation program in chemistry of the \\ Institute of Chemistry of São Carlos, as a \\ partial requirement for the achievement of \\ the title of Doctor in Science with an \\ emphasis on organic and biological \\ chemistry.
}

Supervisor: Prof. Dr. Carlos A. Montanari Supervisor in Germany: Prof. Dr. Jürgen Bajorath

SÃO CARLOS

2019

Lorenzo Cianni 


\section{ACKNOWLEDGMENT}

Firstly, I would like to express my sincere gratitude to my supervisor Prof. Carlos Alberto Montanari for having invited me to work in his group and his continuous support for my Ph.D. study. His guidance helped me to gain a better knowledge of medicinal chemistry and to get a broader interdisciplinary overview. My sincere thanks also go to the entire NEQUIMED group, current and old members. It was such an excellent and funny time working together.

In particular, I would like to thank Daniela for helping me with the synthesis; Jean for teaching me about kinetic measurements; Geraldo for providing molecular dynamics simulation for my project; technician Fabiana Rosini for performing ITC analysis and taking care of the organization of the lab; (Saint) Pedro for performing HPLC analysis and purification; Fernanda for performing such a diligent work in kinetic measurements; Felipe and Gabriel for their dedications. A special thanks also go to Shamin and Bruna for your synthetic support and useful talks. I want to thank other collaborators as well: Prof. Andrei, Prof. Burtoloso, Dr. Kenny, Prof. Lameira and Prof. Juliano for their insightful comments and encouragement, but also for the shared projects, which encouraged me to widen my research from various perspectives. I would like to express my most profound appreciation to everyone involved in the biological assays, in particular to Daiane Y. Tezuka for testing all my compounds against T.cruzi. I thank the University of São Paulo, notably the Chemistry Institute of São Carlos, which is very well represented by the staff. I appreciate all the staff of the IQSC secretary for their friendly service and willingness to help. I thank the technicians of the Instrumental Analysis Center (CAQUI) for the NMR and HRMS analysis. Special thanks go to the São Paulo State Research Support Foundation (FAPESP) for the doctoral scholarship (2016/07946-5) and the BEPE exchange scholarship (2017/17386-0). I also appreciate the financial support for the execution of the projects and the participation in the congresses.

Furthermore, I would also like to acknowledge with appreciation Prof. Bajorath, Prof. Gütschow and Prof. Laufer for the opportunity to work in their laboratories, for their contribution to this work and my training process. In addition, I would like to thank Erik 
Gilberg, Christian Feldmann, and Carina Lemke for their critical scientific contributions to my research. It was a pleasure to work together. Special thanks also go to all the other people that help me inside and outside the laboratories over my period at University of Bonn and at University of Tübingen. Your help and support in the day-byday life were fundamental.

For the enormous moral support, unconditioned love and solid trust I would like to thank my girlfriend, Paula, and my family. Gratidão.

Finally yet importantly, a special acknowledgment goes to all the people that I have met over the previous four years who have made this experience in Brazil unalterable. 
EPIGRAPH

Oolli,

e volli sempre,

e fortissimamente volli.

(Oittorio Affieri, 1783) 


\section{RESUMO}

A doença de Chagas, causada pelo parasito protozoário Trypanosoma cruzi, continua sendo um grave problema de saúde devido à terapia inadequada e à falta de uma vacina eficaz. Novos fámacos que sejam seguros e eficazes são, portanto, criticamente necessários. A cruzaína $(\mathrm{Cz})$, principal protease cisteínica $(\mathrm{CP})$ do $T$. cruzi, é uma enzima essencial para o ciclo de vida do parasito e tem sido utilizada como alvo viável para a busca e identificação de novas entidades químicas (NCE) como agentes tripanossomicidas. Alguns resultados recentes demonstram que os inibidores covalentes reversíveis da $\mathrm{Cz}$ podem bloquear os passos de diferenciação celular no parasito e levá-lo à morte.

Nesta tese, por emprego de abordagem racional baseada em hipóteses, foram planejados e sintetizados diferentes séries de inibidores da $\mathrm{Cz}$ baseadas em dipeptidil nitrilas. Em especial, o esqueleto molecular foi modificado para compreender as interações S3/P3, o papel do grupo ciclopropila no processo de reconhecimento bimolecular e o mapeamento S1/S1' para melhorar a afinidade e avaliar a seletividade frente a outras CPs presentes em células de mamíferos.

A partir do protótipo Neq0570 ( $\left.\mathrm{p} K_{\mathrm{i}}=6,3\right)$, a afinidade para $\mathrm{Cz}$ foi aumentada em 1,6 unidades log para o Neq0922, $\mathrm{p} K_{i}=7,9$, por uma combinação de modificações estruturais em P3, P2 e P1.

Dos resultados relevantes obtidos, destacam-se três novos inibidores da $\mathrm{Cz}$ (Neq0877, Neq0938 and Neq0940) equipotentes ao Benzonidazol - Bz, (o fármaco atualmente usado no Brasil para o tratamento da doença de Chagas) em ensaios in vitro para a avaliação da atividade antitripanossomal sobre o T. cruzi. Considerandose que o índice de seletividade (SI) do Bz é > 20, como no caso desses inibidores, testes in vivo serão necessários para avaliar a potência frente à forma aguda da doença de Chagas.

Inibidores bioisostéricos de dipeptidil nitrilas estão sob investigação pré-clínica como agentes tripanossomicidas. Destarte, realizamos a síntese e os estudos de relação estrutura-atividade (SAR) de inibidores da Cz por substituição da amida em P3/P2 por trifluoroetilamina. Foram identificados três novos inibidores de $\mathrm{Cz}$ com afinidade em concentração nanomolar de um dígito (Neq0642, Neq0643 e Neq0659) com alta seletividade sobre a catepsina $L$ de humanos (CatL). Os efeitos da configuração do 
centro estereogênico em P3/P2 associados à substituição de diferentes grupos em P1 levam a fortes efeitos não-aditivos nas SARs.

A troca bioisostérica pelo grupo sulfonamida em P3/P2 resultou em uma nova série de inibidores que foi avaliada em um painel de CPs de agentes infecciosos e de seres humanos. Há uma reconhecida SAR na inibição da $\mathrm{Cz}$, ao mesmo tempo em que revelam uma inibição na ordem nanomolar para a CatS, com elevada seletividade para os outras CPs de mamíferos (CatB, CatK e CatL).

A exploração da SAR também incorpora os efeitos do grupo eletrofílico nitrila por inclusão de "warheads" alternativos. As constantes de inibição representadas por aldeídos e nitrilo-azadipeptídios são duas ordens de grandeza maiores para os melhores inibidores de $\mathrm{Cz}$. Além disso, o inibidor de $\mathrm{Cz}$ nitrilo-azadipeptídico (Neq0690) foi usado na primeira geração de inibidores da CPB de Leishmania mexicana (LmCPB) obtida na forma cristalina com alta resolução da estrutura cristalográfica. 


\begin{abstract}
Chagas disease, caused by the protozoan parasite Trypanosoma cruzi, remains a serious health problem due to inadequate therapy and lack of an effective vaccine. Therefore, new drugs that are safe and efficient are critically needed. Cruzain $(\mathrm{Cz})$, the main $T$. cruzi cysteine protease (CP), is an essential enzyme for the life cycle of the parasite and has been used as a viable target for the search and identification of new chemical entities (NCE) acting as trypanocidal agents. Recent literature results demonstrate that reversible covalent $\mathrm{Cz}$ inhibitors are able to block the cell differentiation steps in the parasite and to kill it.
\end{abstract}

To this end, by applying a knowledge-based design approach, we have designed and synthesized a new series of dipeptidyl nitrile inhibitors of $\mathrm{Cz}$ aimed at leveraging the S3/P3 interactions, understand the role of the cyclopropane in the bimolecular recognition process and map the $S 1 / S 1^{\prime}$ to enhance affinity and selectivity over other CPs. Herein, we report three new Cz inhibitors (Neq0877, Neq0938 and Neq0940) being equipotent with Benznidazole (the only current drug used to treat Chagas disease in Brazil) with SI (selective index) ratio over 20 (respect to the host cell) and therefore making them attractive synthetic targets for further in vivo testing against the acute form of Chagas disease.

Dipeptidyl nitrile bioisostere inhibitors are under preclinical investigation as trypanocidal agents. Therefore, we performed the synthesis and structure-activity relationship (SAR) investigation of nitrile-based $\mathrm{Cz}$ inhibitors incorporating a trifluoroethylamine moiety as P3/P2 amide replacement. Results display three new one-digit nanomolar $\mathrm{Cz}$ inhibitors (Neq0642, Neq0643 and Neq0659) with high selectivity over CatL. In addition, this works reveals that the effects of configuration at the P3/P2 amide replacement and different substitution in P1 lead to strong nonadditivity outcomes.

The bioisosteric exchange by a sulfonamide moiety on P3/P2 resulted in a new series of inhibitors that was evaluated on a panel of infectious and human CPs. Data displays an interesting flat SAR for $\mathrm{Cz}$ while disclosing strong CatS inhibition with high selectivity for other mammalian CPs (CatB, CatK, and CatL). 
SAR investigation also includes the effects of the nitrile electrophilic group by including alternative warheads. Inhibition constants represented by aldehydes and nitrile azadipeptides are two orders of magnitude larger for the best $\mathrm{Cz}$ inhibitors. Besides, the nitrile azadipeptide $\mathrm{Cz}$ inhibitor (Neq0690) was used in the first generation of Leishmania mexicana CPB (LmCPB) high-resolution x-Ray crystal structure. 


\section{FIGURE LIST}

Figure 1. Substrate binding to CPs.

Figure 2. (a) Representation of the three-dimensional structure of $\mathrm{Cz}$ in co-complex with the covalent inhibitor Neq0409 (PDB ID: 4QH6). (b) Cz binding site showing the subsites S1', S1, S2, and S3 (PDB ID: 2OZ2).

Figure 3. $2 \mathrm{D}$ chemical structures of covalent reversible and irreversible inhibitors of $\mathrm{Cz}$ arrived in preclinical phase for $C D$.

Figure 4. A) Representation of the chemical transformation from Neq0570 to Neq0710. Possible halogen interaction is represented with a red dashed line. B) The average pose obtained after the molecular dynamic simulation with Neq0710 covalently bond with cruzain.

Figure 5. Retrosynthetic analysis, general synthesis, structure representations, and Nequimed codes for compound present in chapter $\mathbf{I}$.

Figure 6. Affinity values and proposed mode of binding for Neq0803 against CatL. 35

Figure 7. A) SAR representation for compounds Neq0409, Neq0410, and Neq0570. The $\Delta p K_{i}$ was calculated as the difference of $\mathrm{p} K_{\mathrm{i}}$ values $(\mathrm{Cz})$ for the corresponding compounds. B) Net thermodynamic profile for cruzain inhibitors: Neq0409, Neq0410 and Neq0570. C) Representative structures obtained from the QM/MM free energy simulations for Neq0409. Structures named according to the locations along the 2D PMF. 39

Figure 8. A, C) Crystal structures and 2D interactions of vinyl sulfone derivative $\mathrm{K} 777$ with the active site of $\mathrm{Cz}$ (PDB-ID: 1F2B); B, D) Crystal structure and 2D interactions of dipeptidyl nitrile $33 \mathrm{~L}$ with the active site of $\mathrm{Cz}$ (PDB-ID 4QH6).

Figure 9. Putative orientation of novel P1 moieties in compounds Neq0937, Neq0940, Neq0921, and Neq0922 with residues of interest (PDB ID: 4QH6) from the pockets S1 and $\mathrm{S} 1^{\prime}$ of $\mathrm{Cz}$.

Figure 10. Schematic representation of the change in stereochemistry for compounds bearing Thr or Thr-O-Bn group in $\mathrm{P} 1$

Figure 11. Plot of $p K_{\mathrm{i}}(\mathrm{Cz})$ vs. $\mathrm{p} K_{\mathrm{i}}(\mathrm{LmCPB})$ for the series of dipeptidyl nitrile here discussed. A linear trendline fitted points. 53

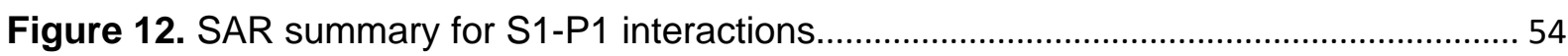

Figure 13. SAR summary starting from compound Neq0569. .............................................. 56

Figure 14. Nonadditivity of SAR for inhibition of $\mathrm{Cz}$, CatL, and LmCPB................................ 58

Figure 15. Selectivity pairwise plots. 
Figure 16. Schematic representation of physicochemical properties an SARs for trypanocidal activity.

Figure 17. Schematic representation for nonadditivity of SARs for trypanocidal activity from Neq0533.1 to Neq0877.

Figure 18. Schematic representation for nonadditivity of SARs from compound Neq0922 to compound Neq0944. 63

Figure 19. Schematic representation of bioisosteric replacement of the amide bond in P3/P2 position for the trifluoroethylamino group. Example of successful bioisosteric replacement for cruzain inhibitors.

Figure 20. The sensitivity of potency $\left(p K_{i}\right)$ to structural modifications $A, B$, and D (see Table 5 for key).

Figure 21. Nonadditivity in SAR for structural transformations $A, B$, and $C$ (see Table 5 for key).

Figure 22. (a) Newman project of a sulphonamide bond; (b) bioisosteric replacement of the amide bond to sulfonamide bond in P3/P2 region. Example of amide bond replacement from K777 to K777.S; (c) Torsional profile of Neq0830 performed with Molecular Operating Environment" (MOE), version 2018.0101.

Figure 23. Retrosynthetic scheme, synthetic scheme, structure representation and Nequimed codes $\mathrm{N}$-sulfonyl dipeptide nitriles.

Figure 24. Schematic representation of bioisosteric replacement of the P2/P3 amide and its effect on the affinity for $\mathrm{Cz}$.

Figure 25. Proposed binding mode of $\mathrm{N}$-sulfonyl dipeptide nitrile Neq0830 in the active site of CatS. 88

Figure 26. Proposed interactions of the $\mathrm{N}$-sulfonyl moiety in the active site cleft of cathepsin S (PDB-ID: 2FQ9). 89

Figure 27. Comparison of binding modes of compound Neq0831 (green) in (a) cathepsin S (PDB-ID: 2FQ9) and (b) cathepsin K (PDB-ID: 4X6H).

Figure 28. Up) energy diagrams of inhibition mechanisms for covalent inhibitors: black lines for the reversible mechanism, red lines for irreversible mechanism; Down) list of the most common reversible (blue) and irreversible (red) warheads used for CPs inhibition. 92

Figure 29. A) Schematic representation of the structure modification from Neq0410 to Neq0500; B) Schematic representation of the SAR considering molecular pairs between Neq0500 and the corresponding compound bearing a different warhead. Color highlights the difference in $\mathrm{p} K_{\mathrm{i}}$ for $\mathrm{Cz}$; Red area highlights a decrease in affinity; green area highlights increase in affinity. D) The table reports $\mathrm{p} K_{\mathrm{i}}$ for $\mathrm{Cz}, \mathrm{pEC} \mathrm{C}_{50}, \mathrm{pCC}_{50}$ and $k_{\text {on }}$ and $k_{\text {off }}$ in case of slow binding inhibition 
Figure 30. Crystallographic structure of Neq0690 in complex with LmCPB.

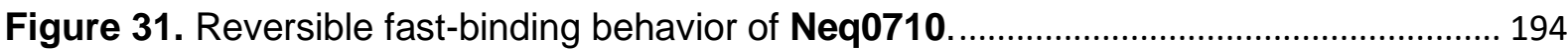

Figure 32. Slow-binding behavior of azadipeptide nitrile (Neq0677) ................................... 196

Figure 33. Reversibility plot of compound Neq0690 with Cz.............................................. 197

Figure 34. ${ }^{1} \mathrm{H}$ NMR $\left(500 \mathrm{MHz}\right.$, DMSO- $\left.d_{6}\right)$ of compound 4 (Neq0710)................................. 210

Figure 35. ${ }^{13} \mathrm{C}$ NMR (125 MHz, DMSO- $\left.d_{6}\right)$ of compound 4 (Neq0710)................................. 210

Figure 36. ${ }^{1} \mathrm{H}$ NMR $\left(500 \mathrm{MHz}\right.$, DMSO- $\left.d_{6}\right)$ of compound 6 (Neq0712)................................. 211

Figure 37. ${ }^{13} \mathrm{C}$ NMR (125 MHz, DMSO- $d_{6}$ ) of compound 6 (Neq0712) ............................... 211

Figure 38. ${ }^{1} \mathrm{H}$ NMR $\left(500 \mathrm{MHz}\right.$, DMSO- $\left.d_{6}\right)$ of compound 7 (Neq0717) ................................. 212

Figure 39. ${ }^{13} \mathrm{C}$ NMR (100 MHz, DMSO- $d_{6}$ ) of compound 7 (Neq0717) ................................ 212

Figure 40. ${ }^{1} \mathrm{H}$ NMR $\left(500 \mathrm{MHz}\right.$, DMSO- $\left.d_{6}\right)$ of compound 9 (Neq0809)................................. 213

Figure 41. ${ }^{13} \mathrm{C}$ NMR (125 MHz, DMSO- $d_{6}$ ) of compound 9 (Neq0809)................................ 213

Figure 42. ${ }^{1} \mathrm{H}$ NMR (500 MHz, DMSO- $d_{6}$ ) of compound 10 (Neq0804)............................... 214

Figure 43. ${ }^{13} \mathrm{C}$ NMR $\left(125 \mathrm{MHz}\right.$, DMSO- $\left.d_{6}\right)$ of compound 10 (Neq0810)............................. 214

Figure 44. ${ }^{1} \mathrm{H}$ NMR $\left(500 \mathrm{MHz}, \mathrm{DMSO}-d_{6}\right)$ of compound 24 (Neq0865)................................ 215

Figure 45. ${ }^{13} \mathrm{C}$ NMR (125 MHz, DMSO- $d_{6}$ ) of compound 24 (Neq0865)................................ 215

Figure 46. ${ }^{1} \mathrm{H}$ NMR $\left(200 \mathrm{MHz}, \mathrm{CDCl}_{3}\right)$ of compound 29 (Neq0956).................................. 216

Figure 47. ${ }^{13} \mathrm{C}$ NMR $\left(50 \mathrm{MHz}, \mathrm{CDCl}_{3}\right.$ ) of compound 29 (Neq0956).................................... 216

Figure 48. ${ }^{1} \mathrm{H}$ NMR (400 MHz, DMSO- $\left.d_{6}\right)$ of compound 31 (Neq0775) ............................... 217

Figure 49. ${ }^{13} \mathrm{C}$ NMR (100 MHz, DMSO- $d_{6}$ ) of compound 31 (Neq0775)............................... 217

Figure 50. ${ }^{1} \mathrm{H}$ NMR (200 MHz, $\mathrm{CD}_{3} \mathrm{OD}$ ) of compound 36 (Neq0957) ................................... 218

Figure 51. ${ }^{13} \mathrm{C}$ NMR $\left(50 \mathrm{MHz}, \mathrm{CD}_{3} \mathrm{OD}\right)$ of compound 36 (Neq0957) ................................... 218

Figure 52. ${ }^{1} \mathrm{H}$ NMR $\left(400 \mathrm{MHz}, \mathrm{CDCl}_{3}\right)$ of compound 67 (Neq0937) ................................... 219

Figure 53. ${ }^{13} \mathrm{C} \mathrm{NMR}\left(50 \mathrm{MHz}, \mathrm{CDCl}_{3}\right)$ of compound 29 (Neq0956)...................................... 219

Figure 54. ${ }^{1} \mathrm{H}$ NMR (200 MHz, $\mathrm{CD}_{3} \mathrm{OD}$ ) of compound 71 (Neq0953) ................................... 220

Figure 55. ${ }^{13} \mathrm{C}$ NMR $\left(50 \mathrm{MHz}, \mathrm{CD}_{3} \mathrm{OD}\right)$ of compound 71 (Neq0953) .................................. 220

Figure 56. ${ }^{1} \mathrm{H}$ NMR $\left(400 \mathrm{MHz}, \mathrm{CD}_{3} \mathrm{OD}\right)$ of compound 72 (Neq0954) .................................. 221

Figure 57. ${ }^{13} \mathrm{C}$ NMR (100 MHz, DMSO- $d_{6}$ ) of compound 72 (Neq0954).............................. 221

Figure 58. ${ }^{1} \mathrm{H}$ NMR $\left(400 \mathrm{MHz}\right.$, DMSO- $d_{6}$ ) of compound 75 (Neq0922) ................................. 222

Figure 59. ${ }^{13} \mathrm{C}$ NMR (100 MHz, DMSO- $d_{6}$ ) of compound 75 (Neq0922)............................ 222

Figure 60. ${ }^{1} \mathrm{H}$ NMR $\left(400 \mathrm{MHz}, \mathrm{CDCl}_{3}\right)$ of compound 77 (Neq0877) .................................. 223

Figure $61 .{ }^{13} \mathrm{C}$ NMR $\left(100 \mathrm{MHz}, \mathrm{CDCl}_{3}\right.$ ) of compound 77 (Neq0877) .................................... 223

Figure 62. ${ }^{1} \mathrm{H}$ NMR $\left(400 \mathrm{MHz}, \mathrm{CDCl}_{3}\right)$ of compound 84 (Neq0942). .................................. 224

Figure 63. ${ }^{13} \mathrm{C} \mathrm{NMR} \mathrm{(100} \mathrm{MHz,} \mathrm{CDCl}_{3}$ ) of compound 84 (Neq0942).................................. 224

Figure 64. ${ }^{1} \mathrm{H}$ NMR $\left(400 \mathrm{MHz}, \mathrm{CD}_{3} \mathrm{OD}\right)$ of compound 85 (Neq0944) ................................ 225 
Figure 65. $\left.{ }^{13} \mathrm{C} \mathrm{NMR} \mathrm{(100} \mathrm{MHz,} \mathrm{CDCl}_{3}\right)$ of compound 85 (Neq0944).................................. 225

Figure 66. ${ }^{1} \mathrm{H}$ NMR $\left(400 \mathrm{MHz}, \mathrm{CD}_{3} \mathrm{OD}\right)$ of compound 86 (Neq0948). ................................. 226

Figure 67. ${ }^{13} \mathrm{C}$ NMR $\left(100 \mathrm{MHz}, \mathrm{CDCl}_{3}\right)$ of compound 86 (Neq0948) .................................. 226

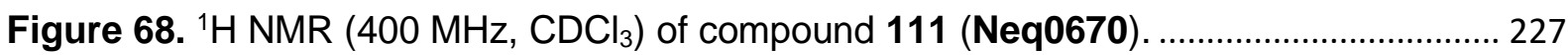

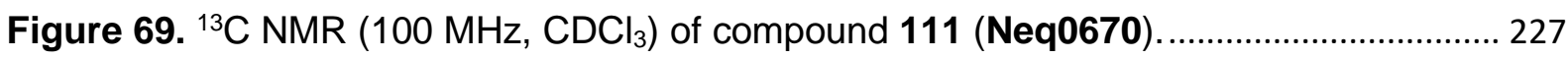

Figure 70. ${ }^{1} \mathrm{H}$ NMR $\left(400 \mathrm{MHz}, \mathrm{CDCl}_{3}\right)$ of compound 112 (Neq0643) ................................... 228

Figure 71. $\left.{ }^{13} \mathrm{C} \mathrm{NMR} \mathrm{(100} \mathrm{MHz,} \mathrm{CDCl}_{3}\right)$ of compound 112 (Neq0643)................................ 228

Figure 72. ${ }^{1} \mathrm{H}$ NMR $\left(400 \mathrm{MHz}, \mathrm{CDCl}_{3}\right)$ of compound 113 (Neq0658) .................................. 229

Figure 73. ${ }^{13} \mathrm{C}$ NMR $\left(100 \mathrm{MHz}, \mathrm{CDCl}_{3}\right.$ ) of compound 113 (Neq0658).................................. 229

Figure 74. ${ }^{1} \mathrm{H}$ NMR $\left(400 \mathrm{MHz}, \mathrm{CDCl}_{3}\right)$ of compound 121 (Neq0820)................................. 230

Figure 75. $\left.{ }^{13} \mathrm{C} \mathrm{NMR} \mathrm{(100} \mathrm{MHz,} \mathrm{CDCl}_{3}\right)$ of compound 121 (Neq0820)................................ 230

Figure 76. ${ }^{19} \mathrm{~F} \mathrm{NMR} \mathrm{(376} \mathrm{MHz,} \mathrm{CDCl}_{3}$ ) of compound 121 (Neq0820)................................ 231

Figure 77. ${ }^{1} \mathrm{H}$ NMR $\left(400 \mathrm{MHz}\right.$, DMSO- $d_{6}$ ) of compound 124 (Neq0819). ............................ 232

Figure 78. ${ }^{13} \mathrm{C}$ NMR $\left(100 \mathrm{MHz}\right.$, DMSO- $\left.d_{6}\right)$ of compound 124 (Neq0819)............................ 232

Figure 79. ${ }^{1} \mathrm{H}$ NMR (400 MHz DMSO- $d_{6}$ ) of compound 125 (Neq0781) ............................. 233

Figure 80. ${ }^{13} \mathrm{C}$ NMR (100 MHz, DMSO- $d_{6}$ ) of compound 125 (Neq0781) ............................. 233

Figure 81. ${ }^{1} \mathrm{H}$ NMR (500 MHz DMSO- $d_{6}$ ) of compound 126 (Neq0782) .............................. 234

Figure 82. ${ }^{13} \mathrm{C}$ NMR $\left(125 \mathrm{MHz}\right.$, DMSO- $d_{6}$ ) of compound 126 (Neq0782) ........................... 234

Figure 83. ${ }^{1} \mathrm{H}$ NMR (400 MHz DMSO- $d_{6}$ ) of compound 127 (Neq0831) ............................. 235

Figure 84. ${ }^{13} \mathrm{C}$ NMR (100 MHz, DMSO- $d_{6}$ ) of compound 127 (Neq0831) ............................. 235

Figure 85. ${ }^{1} \mathrm{H}$ NMR (400 MHz DMSO- $d_{6}$ ) of compound 131 (Neq0830)................................ 236

Figure 86. ${ }^{13} \mathrm{C}$ NMR (100 MHz, DMSO- $\left.d_{6}\right)$ of compound 131 (Neq0830)............................ 236

Figure 87. ${ }^{1} \mathrm{H}$ NMR (400 MHz DMSO- $d_{6}$ ) of compound 134 (Neq0838)............................... 237

Figure 88. ${ }^{13} \mathrm{C}$ NMR (100 MHz, DMSO- $\left.d_{6}\right)$ of compound 134 (Neq0838)............................. 237

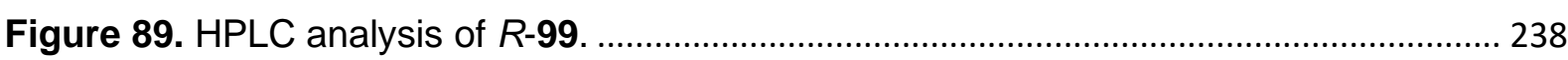

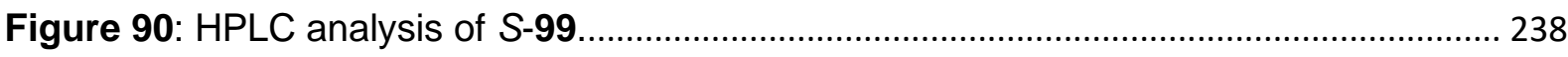

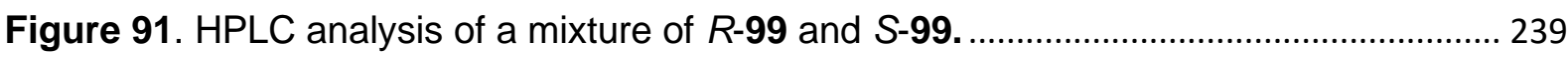

Figure 92. HPLC analysis of 67 (Neq0937) with Diacel column (IC-chiralpak, $250 \times 4.6 \mathrm{~mm}, 5$

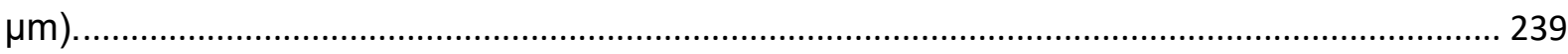

Figure 93. HPLC analysis of 68 (Neq0866.1) with Diacel column (IC-chiralpak, $250 \times 4.6 \mathrm{~mm}$, $5 \mu \mathrm{m})$. 240

Figure 94. HPLC analysis for a mixture of 67 (Neq0937) and 68 (Neq0866.1) with Diacel column (IC-chiralpak, $250 \times 4.6 \mathrm{~mm}, 5 \mu \mathrm{m}$ ). 240

Figure 95. HPLC analysis of 73 (Neq0921) with Diacel column (IC-chiralpak, $250 \times 4.6$ mm, 5 $\mu \mathrm{m})$. 
Figure 96. HPLC analysis of 74 (Neq0938) with Diacel column (IC-chiralpak, $250 \times 4.6 \mathrm{~mm}, 5$ $\mu \mathrm{m})$. 241

Figure 97. HPLC analysis for a mixture of 73 (Neq0921) and 74 (Neq0938) with Diacel column (IC-chiralpak, $250 \times 4.6 \mathrm{~mm}, 5 \mu \mathrm{m}$ ). 242

Figure 98. HPLC analysis of 82 (Neq0941) with Diacel column (IC-chiralpak, $250 \times 4.6 \mathrm{~mm}, 5$ $\mu \mathrm{m})$ 242

Figure 99. HPLC analysis of 83 (Neq0943) with Diacel column (IC-chiralpak, $250 \times 4.6 \mathrm{~mm}, 5$ $\mu \mathrm{m})$. 243

Figure 100. HPLC analysis for a mixture of 82 (Neq0941) and 83 (Neq0943) with Diacel column (IC-chiralpak, 250 x $4.6 \mathrm{~mm}, 5 \mu \mathrm{m}$ ). 


\section{SCHEME LIST}

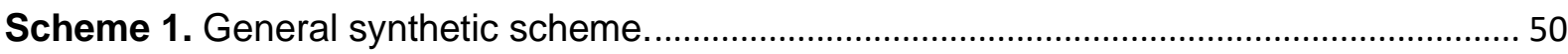

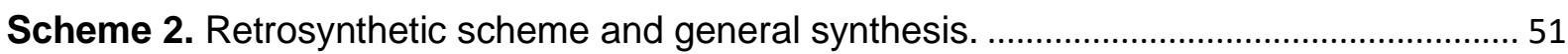

Scheme 3. Retrosynthetic analysis for non-peptidic nitrile described in this chapter............. 70

Scheme 4. Synthetic scheme of 2,2,2-trifluorophenyl amino acid intermediates. ................... 70

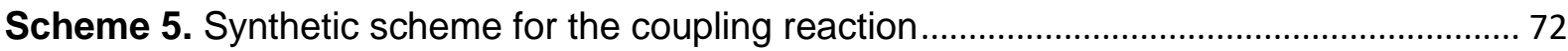

Scheme 6. Synthetic scheme for Suzuki cross-coupling reaction. ….......................................... 72

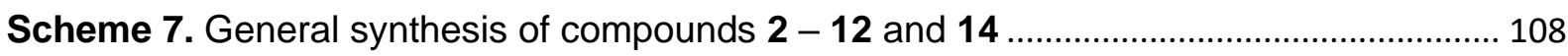

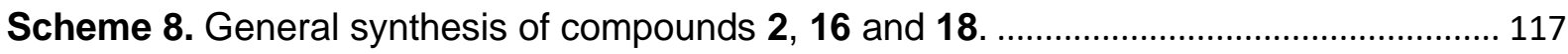

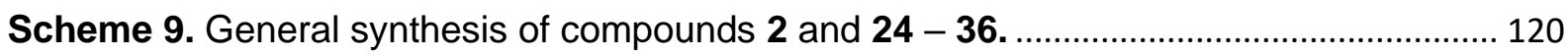

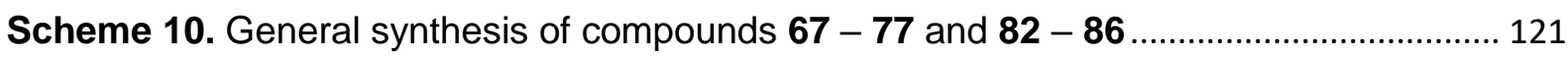

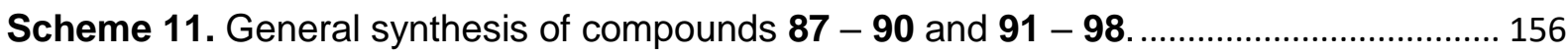

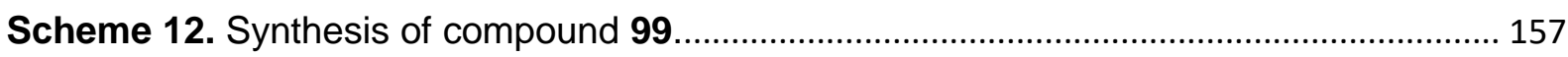

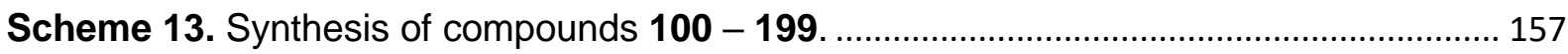

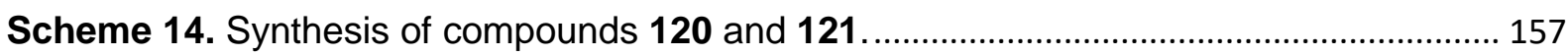

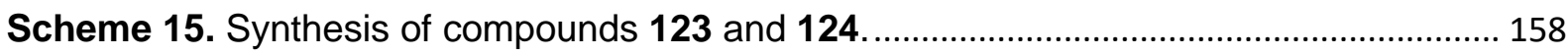

Scheme 17. General synthetic scheme for compounds present in chapter VI.................... 181 


\section{TABLE LIST}

Table 1-. Kinetic parameters $\left(\mathrm{pK}_{\mathrm{i}}\right), \mathrm{pK}_{\mathrm{d}}$ and thermodynamic characterization of cruzain inhibitors.

Table 2- Structures representation, number identification, $\mathrm{pK}_{\mathrm{i}}$ values for CatB, CatK, CatL, CatS, $\mathrm{Cz}$ and LmCPB.

Table 3. Nequimed codes and structure representation of compounds designed and synthesized. Green area highlights dipeptidyl nitrile scaffold.

Table 4. Enzyme inhibition and lipophilicity. 73

Table 5. Key for structural transformations depicted in Figures 20 75

Table 6. Nonadditivity in SAR for structural transformations A, B, and C (see Table 5 for key).

Table 7. Nequimed code, substitution definitions, and $p K_{i}$ values. 85

Table 8. Inhibition of human cathepsins by $\mathrm{N}$-sulfonyl dipeptide nitriles.

Table 9. List of Nequimed code for compounds described in chapter III.

Table 10. List of Nequimed codes of compounds described in chapter IV. 158

Table 11- List of Nequimed codes of compounds described in chapter V 181 


\section{EXORDIUM}

This Ph.D. thesis is composed of six main chapters identified with bold Latin numerals (I to VI). Each chapter represents a scientific article in a peer-reviewed international scientific journal (see list below) where the Ph.D. candidate is the first author or coauthor.

List of the main papers presented in this thesis:

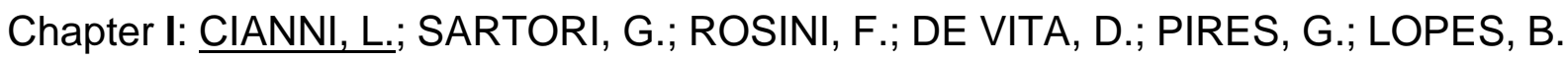
R.; LEITÃO, A.; BURTOLOSO, A. C. B.; MONTANARI, A. C. Leveraging the cruzain S3 subsite to increase affinity for reversible covalent inhibitors. Bioorganic Chemistry, v. 79, p. 285-292, set. 2018.

Chapter II: DOS SANTOS, A. M.; CIANNI, L.; DE VITA, D.; ROSINI, F.; LEITÃO, A.; LAUGHTON, C. A.; JERÔNIMO, L.; MONTANARI A. C. Experimental study and computational modeling of cruzain cysteine protease inhibition by dipeptidyl nitriles. Physical Chemistry Chemical Physical, v. 20, p. 24317-24328, set. 2018.

Chapter III: CIANNI, L.; LEMKE, C.; GILBERG, E.; FELDMANN, W. C.; ROSINI, F.; ROCHO, R. F.; RIBEIRO, F. R. J.; TEZUKA, D. Y.; LOPES, D. C.; ALBUQUERQUE, S.; BAJORATH, J.; LAUFER, S.; LEITÃO, A.; GÜTSCHOW, M.; MONTANARI A. C. Mapping the $S 1$ and $S 1$ ' subsites of cysteine proteases for the synthesis of new dipeptidyl nitriles as trypanocidal agents. PLOS Neglected Tropical Disease, submitted, aug. 2019.

Chapter IV: GOMES, J. C.; CIANNI, L.; RIBEIRO, F. R. J.; SILVA, M. C. S.; BATISTA, J. H. P.; MORAES, B. C.; FRANCO, H. C.; FREITAS-JUNIOR, L. H.; KENNY, P. W.; LEITÃO, A.; BURTOLOSO, A. C. B.; DE VITA, D.; MONTANARI A. C. Synthesis and structure-activity relationship of nitrile-based cruzain inhibitors incorporating a trifluoroethylamine-based P2 amide replacement. Bioorganic \& Medicinal Chemistry, v. 27, n. 22, p. 115083, nov. 2019.

Chapter V: LEMKE, C.; CIANNI, L.; GILBERG, E.; YIN, J.; ROCHO, R. F.; DE VITA, D.; BAJORATH, J.; MONTANARI A. C.; GÜTSCHOW, M. N-Sulfonyl dipeptide nitriles as inhibitors of human cathepsin $\mathrm{S}$ : in silico design, synthesis and biochemical 
characterization. Bioorganic \& Medicinal Chemistry Letters, submission process, aug. 2019.

Chapter VI: SILVA, G. D.; RIBEIRO, J. F. R.; DE VITA, D.; CIANNI, L.; FRANCO, C. H.; FREITAS-JUNIOR, L. H.; MORAES, C. B.; ROCHA, J. R.; BURTOLOSO, A. C. B.; KENNY, P. W.; LEITÃO, A.; MONTANARI A. C. A Comparative study of warheads for design of cysteine protease inhibitors. Bioorganic \& Medicinal Chemistry Letters, v. 27 , p. $5031-5035$, oct. 2017.

Related articles:

CIANNI, L.; FELDMANN, W. C.; GILBERG, E.; GÜTSCHOW, M.; JULIANO, L.; LEITÃO, A.; BAJORATH, J.; MONTANARI A. C. Can cysteine protease cross-class inhibitors achieve selectivity? Journal of Medicinal Chemistry, jul. 2019. https://doi.org/10.1021/acs.jmedchem.9b00683

RIBEIRO, J. F. R.; CIANNI, L.; Li, C.; WARWICK, T. G.; DE VITA, D.; ROSINI, F.; ROCHO, R. F.; KENNY, W. P.; LAMEIRA, J.; LEITÃO, A.; EMSLEY, J.; MONTANARI, A. C. Crystal structure of Leishmania mexicana cysteine protease B in complex with a highly potent azadipeptide nitrile inhibitor. Scientific Reports, submitted, jul. 2019.

JERÔNIMO, L.; BONATTO, V.; CIANNI, L.; ROCHO, R F.; LEITÃO, A.; MONTANARI, A. C. Predicting the affinity of halogenated reversible covalent inhibitors through relative binding free energy. Physical Chemistry Chemical Physical, accepted, aug. 2019. 
LIST OF ABBREVIATIONS AND ACRONYMS

\begin{tabular}{|c|c|}
\hline ACN & Acetonitrile \\
\hline AcOEt & Ethyl acetate \\
\hline $\mathrm{Bn}$ & Benzyl \\
\hline Boc & tert-Butoxycarbonyl \\
\hline Boc-AA-OH & $\begin{array}{l}\text { N-tert-Butoxycarbonyl-Amino Acid- } \\
\text { carboxyl acid }\end{array}$ \\
\hline DCM & Dichloromethane \\
\hline $\mathrm{DDQ}$ & $\begin{array}{l}\text { 2,3-Dichloro-5,6-dicyano-1,4- } \\
\text { benzoquinone }\end{array}$ \\
\hline DIPEA & N,N-Diisopropylethylamine \\
\hline DME & 1,2-Dimethoxyethane \\
\hline DMF & Dimethylformamide \\
\hline DMSO & Dimethyl sulfoxide \\
\hline ESI-MS & $\begin{array}{l}\text { Electrospray lonization Mass } \\
\text { Spectrometry }\end{array}$ \\
\hline FT-IR & $\begin{array}{c}\text { Fourier-Transform Infrared } \\
\text { Spectroscopy }\end{array}$ \\
\hline $\mathrm{h}$ & Hour \\
\hline HATU & $\begin{array}{c}\text { (1-[Bis(dimethylamino)methylene]-1H- } \\
\text { 1,2,3-triazolo[4,5-b]pyridinium 3-oxid } \\
\text { hexafluorophosphate) }\end{array}$ \\
\hline HPLC & $\begin{array}{c}\text { High-performance liquid } \\
\text { chromatography }\end{array}$ \\
\hline HRMS & High Resolution Mass Spectrometry \\
\hline LC-MS & $\begin{array}{c}\text { Liquid Chromatography-Mass } \\
\text { Spectrometry }\end{array}$ \\
\hline $\log P$ & $\begin{array}{c}\text { The 10-based logarithm of partition } \\
\text { coefficient }\end{array}$ \\
\hline Leu & Leucine \\
\hline LogS & $\begin{array}{c}\text { The calculated 10-based logarithm of } \\
\text { the solubility }\end{array}$ \\
\hline $\min$ & Minute \\
\hline MM & Molecular Mass \\
\hline MW & Molecular Weight \\
\hline PDB ID & Protein Databank Identification \\
\hline Phe & Phenyalanine \\
\hline
\end{tabular}




\begin{tabular}{|c|c|}
\hline PMF & Potential of Mean Force \\
\hline$p-T s C l$ & 4-Toluenesulfonyl chloride \\
\hline Py & Pyridine \\
\hline QM/MM & $\begin{array}{c}\text { Quantum Mechanics / Molecular } \\
\text { Mechanics }\end{array}$ \\
\hline rt & Room temperature \\
\hline TBTU & $\begin{array}{c}2-(1 \text { H-Benzotriazole-1-yl)-1,1,3,3- } \\
\text { tetramethylaminium tetrafluoroborate }\end{array}$ \\
\hline TFA & Trifluoroacetic Acid \\
\hline TFAA & Trifluoroacetic anhydride \\
\hline THF & Tetrahydrofuran \\
\hline Thr & Threonine \\
\hline TLC & Thin Layer Chromatography \\
\hline TPSA & Topological Polar Surface Area \\
\hline Trp & Ultraviolet \\
\hline UV & Ultraviolet Diode Array Detection \\
\hline UV DAD
\end{tabular}


ACKNOWLEDGMENT

EPIGRAPH

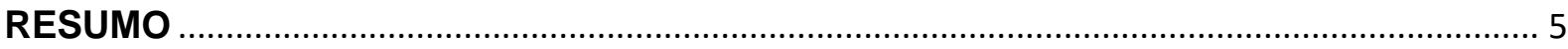

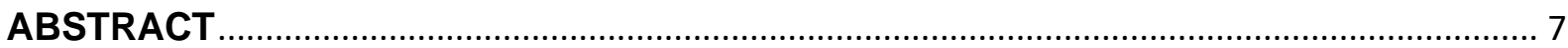

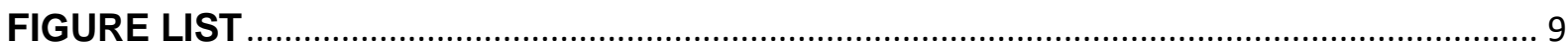

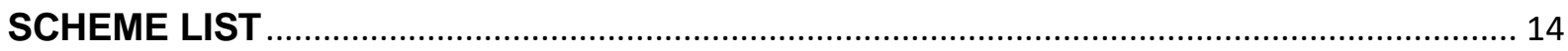

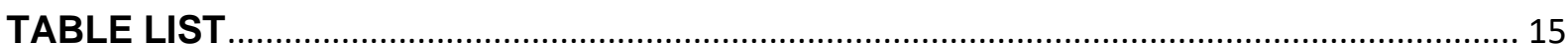

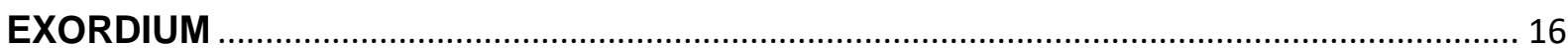

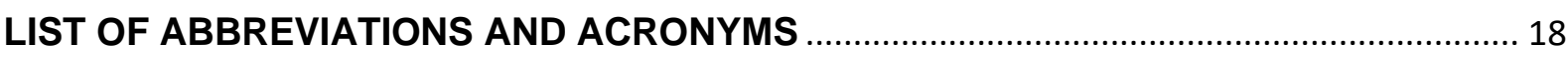

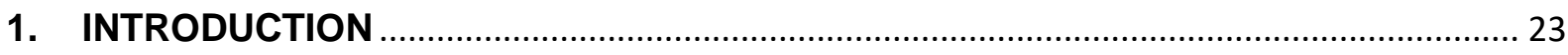

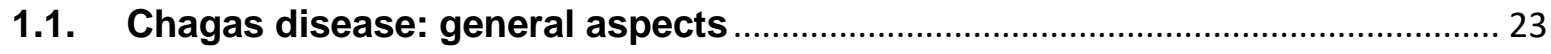

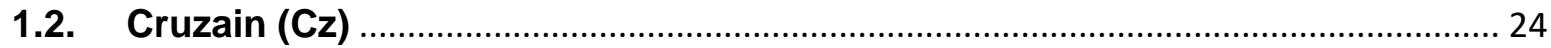

2. CHAPTER I - Leveraging the Cruzain S3 Subsite to Increase Affinity for Reversible

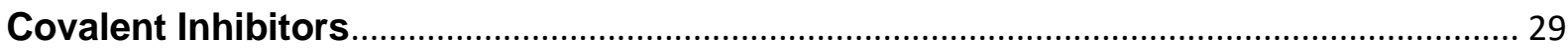

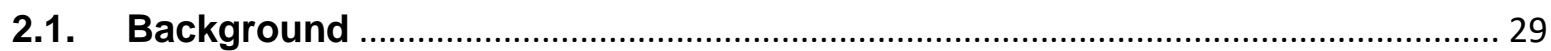

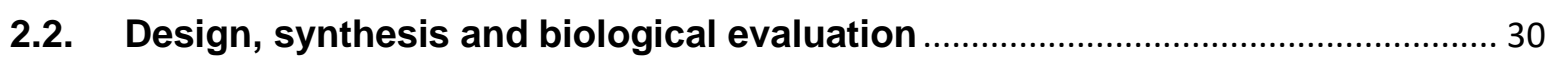

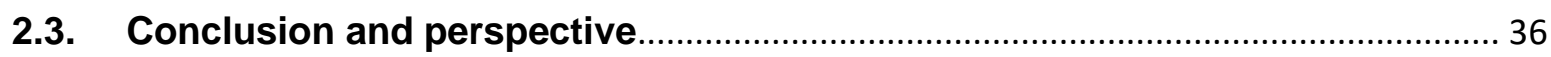

3. CHAPTER II - Experimental Study and Computational Modelling of Cruzain

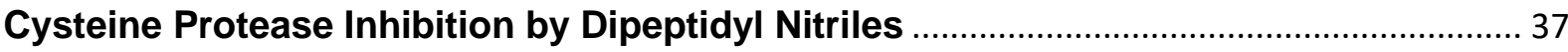

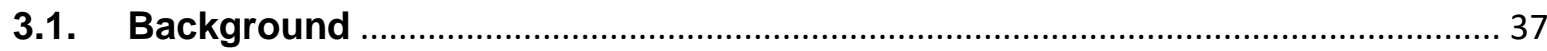

3.2. Design, synthesis, computational study, and biochemical evaluation ............ 37

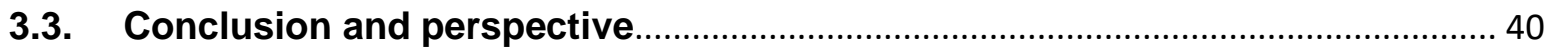

4. CHAPTER III - Mapping The S1 and S1' Subsites of Cysteine Proteases for The Synthesis of New Dipeptidyl Nitriles as Trypanocidal Agents......................................... 41

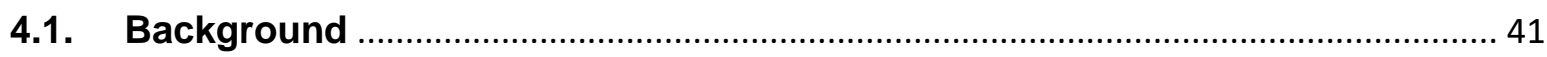

4.2. Design, synthesis and kinetic evaluation of new dipeptidyl nitriles as cysteine

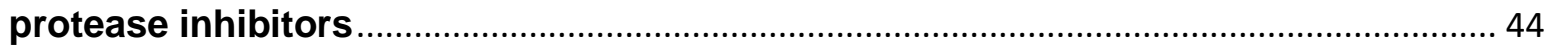

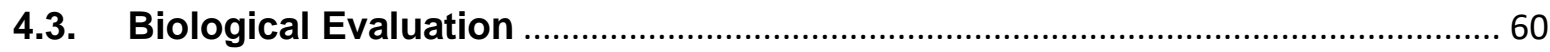

4.4. Conclusion and perspective ........................................... Error! Bookmark not defined.

5. CHAPTER IV - Synthesis and structure-activity relationship of nitrile-based cruzain inhibitors incorporating a trifluoroethylamine-based P2 amide replacement .. 64

5.1. Background 
5.2. Design, synthesis, and SAR of nitrile based cruzain inhibitors 67

5.3. Conclusion and perspective

6. CHAPTER V - N-Sulfonyl Dipeptide Nitriles as Inhibitors of Human Cathepsin S: In silico Design, Synthesis and Biochemical Characterization ............................................. 82

6.1. Background

6.2. Design, synthesis and biological evaluation of $N$-Sulfonyl dipeptide nitriles . 83

6.3. Conclusion and perspective. 90

7. CHAPTER VI - A comparative study of warheads for the design of cysteine protease inhibitors

7.1. Background 91

7.2. Design, synthesis and biological evaluation for warhead replacement 93

7.3. Conclusion and perspective. 99

8. MATERIAL AND METHODS 100

8.1. Synthetic Chemistry 100

8.1.1. General Consideration 100

8.1.2. General procedure for amide synthesis 102

8.1.3. General procedure for removal of the Boc protecting group 103

8.1.4. General procedure for dehydration of primary amide to nitrile 103

8.1.5. General procedure for removal of the benzyl protecting group 104

8.1.6. General procedure for the synthesis of amine esters 105

8.1.7. General procedure for imine synthesis 105

8.1.8. General procedure for imine reduction to amine 106

8.1.9. General procedure for Suzuki cross-coupling reaction 106

8.1.10. General procedure for the synthesis of primary sulfonamide 107

8.1.11. Synthesis and characterization of compounds present in chapter I 108

8.1.12. Synthesis and characterization of compounds present in chapter II 117

8.1.13. Synthesis and characterization of compounds present in chapter III $\quad 120$

8.1.14. Synthesis and characterization of compounds present in chapter IV. $\quad 156$

8.1.15. Synthesis and characterization of compounds present in chapter V181

8.2. Enzyme inhibition studies. 192

8.2.1. Determination of the Michaelis-Menten constants for cruzain and CatL 192

8.2.2. Determination of the inhibition constant $\left(K_{i}\right)$ for cruzain and CatL 192

8.2.3. Kinetic parameters determination of fast-binding inhibitors 193

8.2.4. Kinetic parameters determination of slow-binding inhibitors 194

8.2.5. Assessment of reversibility mode of binding 197 


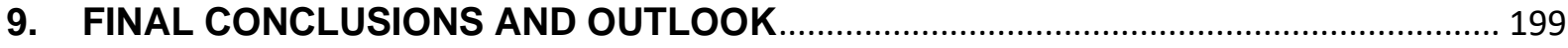

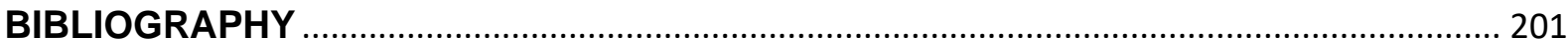

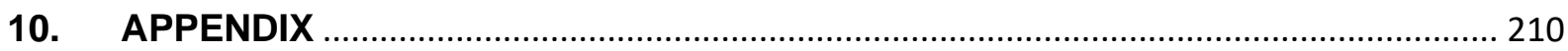




\section{INTRODUCTION}

\subsection{Chagas disease: general aspects}

Chagas disease (CD), which was discovered in 1909 by the Brazilian physician Carlos Chagas (COURA, 2013), is one of the main socio-economic problems faced in Latin American countries. Among the 21 states where this disease is endemic, Bolivia stands out with the highest rates of people infected with the parasite (BERN et al., 2011; JACKSON; PINTO; PETT, 2014; PEREIRA; NAVARRO, 2013). Due to immigration, this disease also affects people in other continents. Currently, cases have been detected in the United States, Canada and some European countries. According to the World Health Organization (WHO), the number of people infected with this parasite is likely to be between 7 and 8 million. Over 10.000 people die annually because of this disease ("Chagas disease (American trypanosomiasis)").

The etiological agent is the protozoa parasite Trypanosoma cruzi, which is transmitted by blood-sucking reduviid bugs of the subfamily Triatominae (PRATA, 2001). Clinically, the CD is characterized by an acute phase that has an average duration of two months, being followed by a chronic stage that typically lasts throughout the life of the host. In most cases, especially in adults, the acute phase of the disease is oligosymptomatic and thereby not being detected by sufferers or by the health agent. The only two existing drugs in the market, Benznidazole and Nifurtimox, show high toxic side effects and inefficiency in the chronic stage of the disease (CASTRO; DEMECCA; BARTEL, 2006; COURA; VIÑAS, 2010). Beyond doubt, new drugs that are safe and efficacious are critically needed. Consequently, initiatives such as Drugs for Neglected Diseases Initiative (DNDi) have led to collaborative efforts worldwide in the discovery of new macromolecular targets (URBINA, 2010) and in the identification of new trypanocidal agents . 


\subsection{Cruzain $(\mathrm{Cz})$}

Enzymes classified as proteases are responsible for the catalysis of peptide bond hydrolysis reactions. They play an essential role in various pathological processes such as rheumatoid arthritis, cardiovascular diseases, bacterial and viral infections, cancer and Alzheimer's disease (SALISBURY; ELLMAN, 2006). Proteases are also key enzymes in the pathogenicity of many parasitic diseases and are significant targets because they are involved in the survival and replication of the parasites, inducing damage to the host tissue, facilitating the invasion of the parasite or enhancing the use of host protein metabolites. Hence, elucidation/description of the biological function of proteases and acquisition of complete knowledge of biochemistry and structure are requirements for designing antiparasitic drugs that specifically modulate the proteolytic action (MCKERROW, 1989; (RENSLO; MCKERROW, 2006).

Cruzain (Cz), a recombinant form of the enzyme cruzipain (EC 3.4.22.51; CAZZULO et al., 1990; GILLMOR; CRAIK; FLETTERICK, 1997), is the most abundant cysteine protease present in the T. cruzi. It is essential for the development and survival of the parasite inside and outside the host cell in all forms of its life cycle, which makes it a desirable target for the development of new chemotherapeutic agents for CD (VIEIRA et al., 2005).

Like other CPs, $\mathrm{Cz}$ is small (22.7 kDa), monomeric and composed of two folded and equally sized domains (EAKIN et al., 1993). These domains are divided by the enzyme's active site, which is $V$-shaped and primarily exposed to solvent. A catalytic triad cysteine-histidine-asparagine forms the active site. A water molecule between cysteine and histidine enables a proton transfer, forming a thiolate-imidazolium ion pair (PAASCHE; SCHIRMEISTER; ENGELS, 2013). The thiolate ion acts as nucleophile on the peptide carbonyl carbon, forming the acyl-enzyme intermediate, which undergoes subsequent hydrolysis.

The substrate binds in the active site cleft in an extended conformation, interacting with residues in both directions from the scissile bond (Figure 1) in between the two domains of the enzyme. The non-primed side refers to the $\mathrm{N}$-terminal part and the primed side to the C-terminal region of the substrate. 
Figure 1. Substrate binding to CPs.

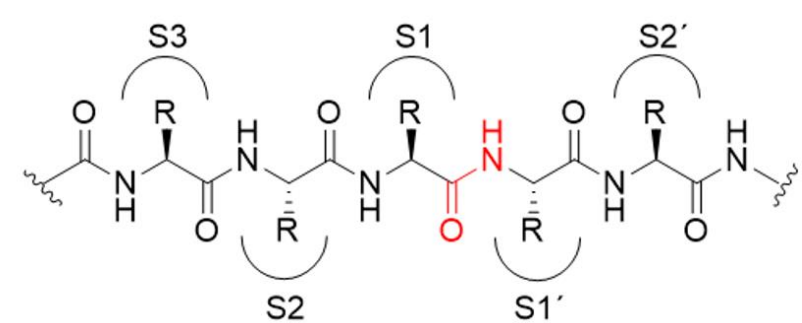

The corresponding amino acid residues in position P3, P2, P1, P1', P2', P3' occupy the subsites (specificity pockets) S3, S2, S1, S1', S2', S3'. The bond cleaved by the endopeptidase protease is represented in red. Source: CIANNI, L. et al. Can Cysteine Protease Cross-Class Inhibitors Achieve Selectivity? Can cysteine protease cross-class inhibitors achieve selectivity? Journal of Medicinal Chemistry, jul. 2019. https://doi.org/10.1021/acs.jmedchem.9b00683.

The three-dimensional structure of the Cz enzyme, shown in Figure 2, consists of a polypeptide chain with 215 amino acid residues enveloped in two domains, one $\alpha$ helicoidal and the other composed of extensive $\beta$-sheets interactions. Residues of the catalytic triad are identified as Cys25, His159 and Asn175.

Several classes of covalent inhibitors effectively modulate $\mathrm{Cz}$ as well as other cysteine proteases, although the development of non-covalent inhibitors is still a vital strategy for inhibition of the enzyme. Among covalent inhibitors, there are compounds with reactive groups containing an electrophilic carbon (warhead) susceptible to the nucleophilic attack by the activated cysteine of the enzyme (FERREIRA et al., 2009; WIGGERS et al., 2013). 
Figure 2- (A) Representation of the three-dimensional structure of $\mathrm{Cz}$ in co-complex with the covalent inhibitor Neq0409 (PDB ID: 4QH6). (B) Cz binding site showing the subsites S1', S1, S2, and S3 (PDB ID: 2OZ2).

(A)

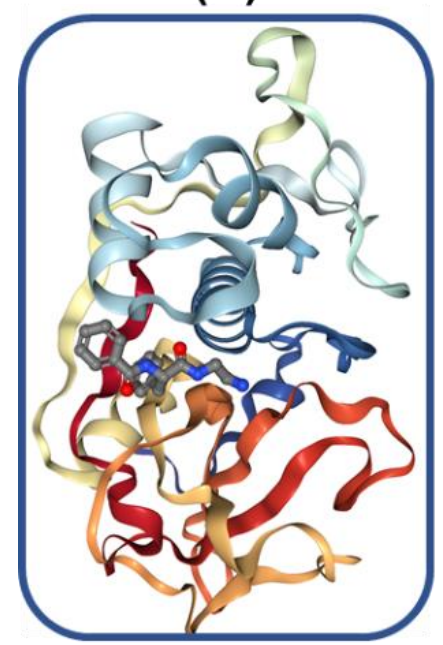

(B)

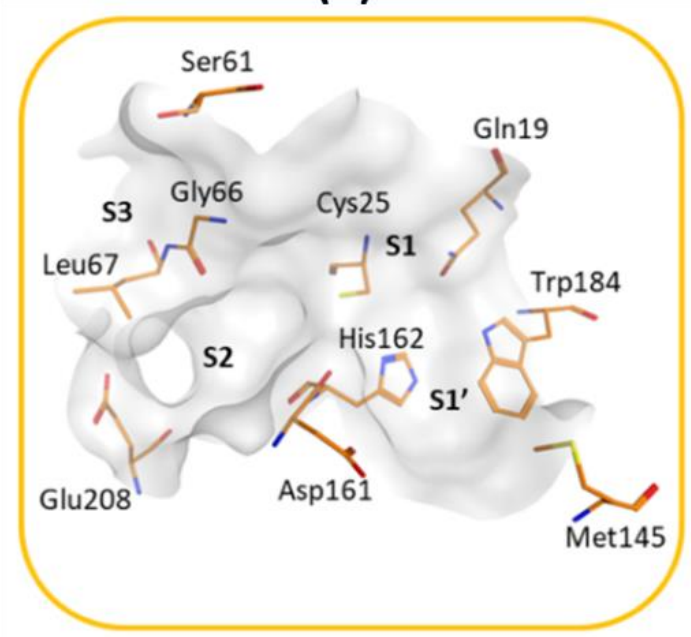

The catalytic Cys25 and the central residues involved in binding to the inhibitor are also shown. Water molecules and ligands were removed for clarity. Source: Adapted from AVELAR, L. A. A. et al. Molecular Design, Synthesis and Trypanocidal Activity of Dipeptidyl Nitriles as Cruzain Inhibitors. PLOS Neglected Tropical Diseases, v. 9, n. 7, p. e0003916, 14 jul. 2015; CIANNI, L. et al. Can Cysteine Protease Cross-Class Inhibitors Achieve Selectivity? Can cysteine protease cross-class inhibitors achieve selectivity? Journal of Medicinal Chemistry, jul. 2019. https://doi.org/10.1021/acs.jmedchem.9b00683.

This attack, depending on the nature of the warhead, can both promote irreversible or reversible binding interaction of such compounds. Usually, reversible inhibition involves non-covalent interaction between the enzyme and the inhibitor, but in the case of reversible cysteine protease inhibitors, inhibition typically includes the reversible formation of a covalent bond between inhibitor and active-site cysteine. Examples of covalent inhibitors are aldehyde peptides, $\alpha$-diketones, $\alpha$-ketoesters, $\alpha$-ketoamides, $\alpha$ keto acids and nitriles (CIANNI et al., 2019). On the other hand, compounds such as peptidyl diazomethyl ketones, fluoromethyl ketones, epoxides and vinyl sulfones, are capable of binding irreversibly to the catalytic cysteine of $\mathrm{Cz}$ by acting as "suicidal" inhibitors (SCHEIDT et al., 1998). K777 was the leader of the first generation of irreversible $\mathrm{Cz}$ inhibitors and initially characterized by the Sandler Center for Research in Tropical Parasitic Disease (University of California, San Francisco; SAJID et al., 2011). Besides the ability of this compound to rescue mice of a lethal experimental $T$. cruzi infection and reduce parasite growth in dogs, preclinical safety and toxicology studies revealed substantial side effects when low doses were administered in 
primates and dogs (“K777 (Chagas) | DNDi”, 2011; URBINA, 2010). Nowadays, drug repurposing programs of different pharmaceutical companies have recently put forward reversible inhibitors of $\mathrm{Cz}$ such as Balicatib (LU et al., 2018), Cz007 (BEAULIEU et al., 2010), Cz008 (BEAULIEU et al., 2010; NDAO et al., 2014; Figure 3 ) .

Figure 3. $2 \mathrm{D}$ chemical structures of covalent reversible and irreversible inhibitors of $\mathrm{Cz}$ arrived in preclinical phase for CD.

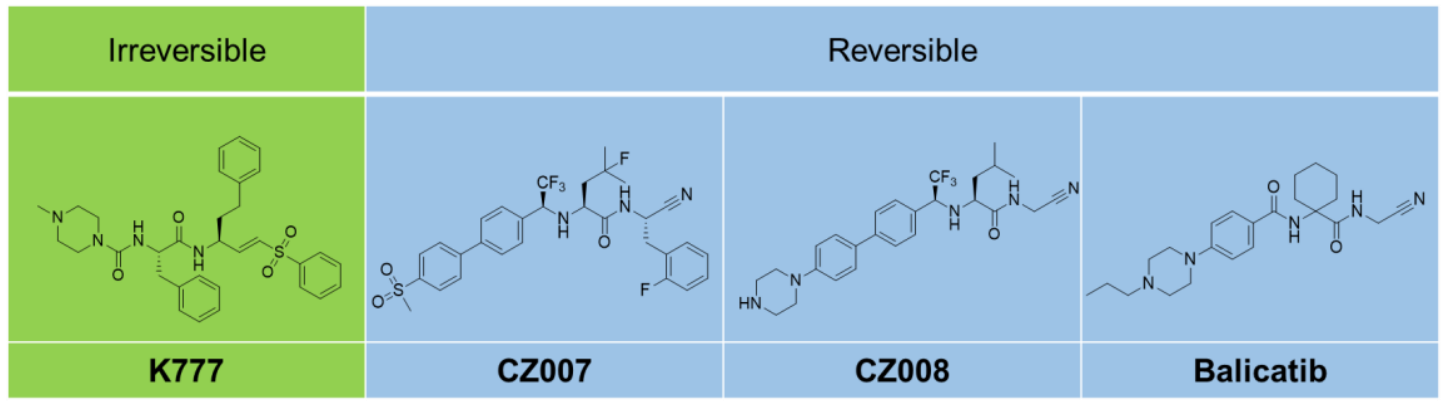

Source: Own author.

This enzyme has a high degree of structural identity with the human enzymes cathepsin $\mathrm{K}$, cathepsin $\mathrm{L}$, cathepsin $\mathrm{S}$ and high sequence homology with cathepsin $\mathrm{B}$ that are involved in many physiological processes (KRAMER; TURK; TURK, 2017). Therefore, the knowledge generated from $\mathrm{Cz}$ inhibition can be transposed to its mammalian counterparts and vice-versa (CIANNI et al., 2019). The same concept can be applied to another protozoan parasite CPs recently used as a pharmacological target based on in vitro and in vivo models, as the cysteine protease $B$ of the Leishmania mexicana (LmCPB), the obligate intracellular protozoan parasite that causes the cutaneous form of leishmaniasis (CROFT; COOMBS, 2003; SIQUEIRANETO et al., 2018).

The main objective of this Ph.D. thesis is focused on the design, synthesis and biological evaluation of new covalent inhibitors of $\mathrm{Cz}$ as trypanocidal agents. In particular, six different key points are taken into consideration:

1. Ponder the influence and importance of S3-P3 interactions for the inhibition of Cz; 
2. Understand the role of the cyclopropane moiety in $\mathrm{P} 1$ in the bimolecular recognition process between the archetype dipeptidyl nitrile and $\mathrm{Cz}$;

3. Expand the previous series of dipeptidyl nitrile by mapping the $S 1-S 1^{\prime}$ subsite of $\mathrm{Cz}$ and other CPs;

4. Evaluate the inhibition ability of $\mathrm{Cz}$ and the trypanocidal activity of new deconstructed derivatives of $\mathrm{Cz008}$ and Cz009;

5. Estimate sulfonamides as bioisostere of the amides in P2/P3 for the inhibition of $\mathrm{Cz}$ and other CPs;

6. Assess the influence of different warheads for a prototype $\mathrm{Cz}$ inhibitor compound. 


\section{CHAPTER I - Leveraging the Cruzain S3 Subsite to Increase Affinity for Reversible Covalent Inhibitors ${ }^{1}$}

\subsection{Background}

As discussed above, the inhibition of $\mathrm{Cz}$ is an essential strategy for the treatment of CD. In particular, our recent study (AVELAR et al., 2015) showed fundamental interactions of P1, P2 and P3 portions of dipeptidyl nitrile ligand (Neq0570) with the respective subsites of the enzyme (S1, S2, S3). Unambiguously, three critical hydrogen bonds were observed between the ligand and the residues Asp161, Gly66 located at S2 and Gln19 located at S1. While P2 and P3 moieties formed mostly hydrophobic interactions with the respective S2 and S3 pockets (WIGGERS et al., 2013).

The S3 region is an open-flat water accessible surface area and therefore usually challenging to exploit the affinity, the $\mathrm{S} 2$ pocket has been already used to enhance $\mathrm{Cz}$ affinity. However, it has been reported that the residue Ser61, situated at the top of the S3 region, is able to form hydrogen bond interaction with different inhibitors cocrystallized with $\mathrm{Cz}$ (for instance, see PDB code 1ME3; (HUANG; BRINEN; ELLMAN, 2003). Accordingly, we performed the design and synthesis of a new series of dipeptidyl nitrile, aimed to evaluate the regioselective interaction with residue Ser61 in the S3 subsite (Figure 4).

\footnotetext{
1 This chapter describes joint work with M. Sc. Fabiana Rosini (NEQUIMED/IQSC/USP, University of São Paulo, Brazil) for ITC studies and with Dr. Geraldo Sartori (NEQUIMED/IQSC/USP, University of São Paulo, Brazil) for Molecular Dynamics simulations.
} 
Figure 4. A) Representation of the chemical transformation from Neq0570 to Neq0710.

Possible halogen interaction is represented with a red dashed line. B) The average pose obtained after the molecular dynamic simulation with Neq0710 covalently bond with cruzain.
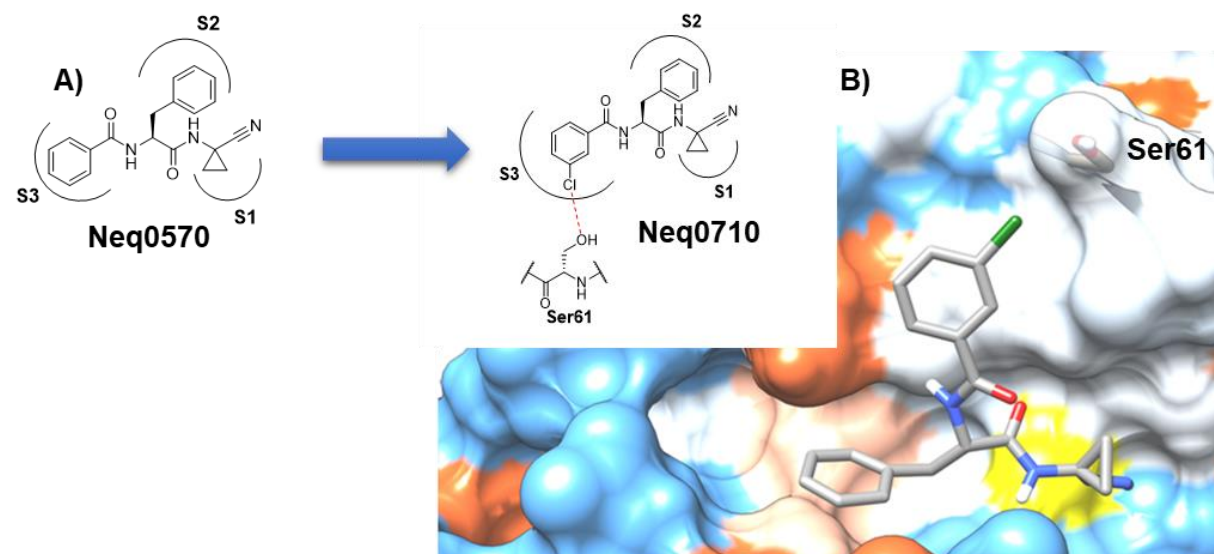

PDB code 1ME3; Color for Neq0710: Carbon chain is gray; Chlorine is green; Oxygen is red. Protein is represented as a polar surface; from white to red, there is an increment of polarity. The catalytic residue of Cysteine is spotted with yellow color. P1, P2, and P3 represent the substituents of the compound that interact with their respective subsites (S1, S2, and S3) at the enzyme. Source: Figures adapted from: CIANNI, L. et al. Leveraging the cruzain S3 subsite to increase affinity for reversible covalent inhibitors. Bioorganic Chemistry, v. 79, p. 285292, sep. 2018.

\subsection{Design, synthesis and biological evaluation}

To understand the possibility of halogen and hydrogen bond interaction of metasubstituted phenyl derivatives with Ser61, molecular dynamic (MD) simulations were performed for derivatives of Neq0570 with different substituents $\left(-\mathrm{OH} ;-\mathrm{Cl} ;-\mathrm{CH}_{3}\right)$ in meta, ortho or para position of the phenyl ring. Simulations displayed possible hydrogen or halogen bond with the Ser61 when the hydroxyl group or the chlorine atom is in meta, as for Neq0710 and Neq0717.

For a better understanding of this hypothesis, we also evaluated the influence of different halogen atoms in meta-position of P3 ring. The fluorine derivative molecule (Neq0802) and the trifluoromethyl derivative molecule (Neq0805) showed high rotational flexibility of ring, similar to that found for Neq0570. This phenomenon is an indication of the interaction lost between S3 subsite and P3 ring and thus, between the fluorine atom and Ser61 side chain. On the other hand, for the bromine-derivative compound (Neq0803), we observed more sampling for smaller distance, which is 
similar to those found for Neq0710. Based on these simulations, molecules Neq0710, Neq0717, Neq803 and Neq0804 can probably perform a hydrogen bond or halogen bond interaction with residue Ser61 of the cruzain S3 cavity. Therefore, we synthesized a set of molecular pairs to evaluate in silico results by using inhibitor constants $\left(K_{\mathrm{i}}\right)$ and thermodynamic profiles (ITC; Figure 5 and Table 1).

Figure 5. Retrosynthetic analysis, general synthesis, structure representations, and Nequimed codes for compound present in chapter I.

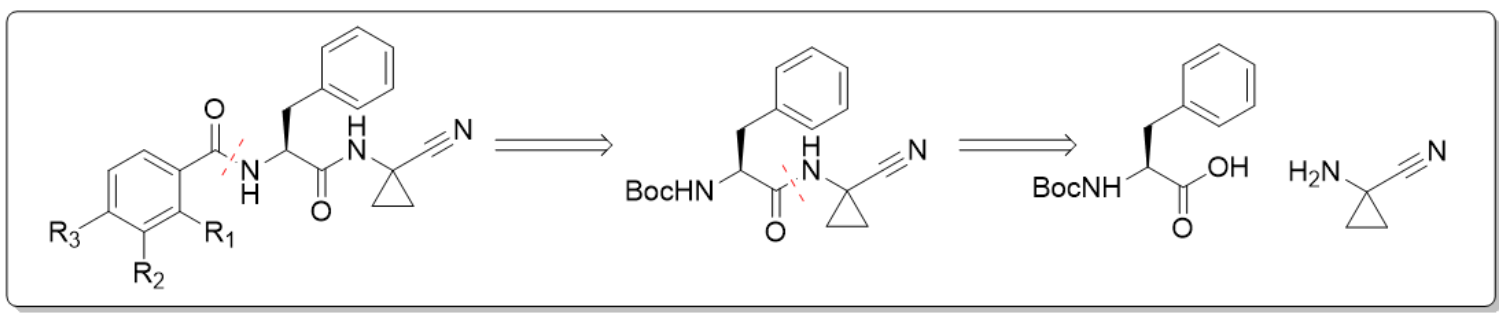

\begin{tabular}{|c|c|c|c|}
\hline $\mathbf{N}^{\circ}$ & $\mathbf{R}_{\mathbf{1}}$ & $\mathbf{R}_{\mathbf{2}}$ & $\mathbf{R}_{\mathbf{3}}$ \\
\hline Neq0709 & $-\mathrm{Cl}$ & $-\mathrm{H}$ & $-\mathrm{H}$ \\
\hline Neq0710 & $-\mathrm{H}$ & $-\mathrm{Cl}$ & $-\mathrm{H}$ \\
\hline Neq0711 & $-\mathrm{H}$ & $-\mathrm{H}$ & $-\mathrm{Cl}$ \\
\hline Neq0712 & $-\mathrm{H}$ & $-\mathrm{CH}_{3}$ & $-\mathrm{H}$ \\
\hline Neq0717 & $-\mathrm{H}$ & $-\mathrm{OH}$ & $-\mathrm{H}$ \\
\hline Neq0802 & $-\mathrm{H}$ & $-\mathrm{F}$ & $-\mathrm{H}$ \\
\hline Neq0803 & $-\mathrm{H}$ & $-\mathrm{Br}$ & $-\mathrm{H}$ \\
\hline Neq0804 & $-\mathrm{H}$ & $-\mathrm{I}$ & $-\mathrm{H}$ \\
\hline Neq0805 & $-\mathrm{H}$ & $-\mathrm{CF}_{3}$ & $-\mathrm{H}$ \\
\hline
\end{tabular}<smiles>CC(C)(C)OC(=O)N[C@@H](Cc1ccccc1)C(=O)O</smiles>

(a)

Reagents and conditions: (a)HATU, DIPEA, DMF, rt, $18 \mathrm{~h}$; b) formic acid, rt, $18 \mathrm{~h}$; c) HATU, carboxylic acid, DMF, rt, 18 h. Source: Own author.

The synthetic route was developed to optimize the set of substituents to be placed in P1, P2 and P3 that have been defined after the planning and designing studies. All 
syntheses were started with enantiopure amino acids. Due to the diversity of building blocks, it was necessary to evaluate different coupling reagents, aiming at the best yield and lower racemization. The peptide coupling reaction was performed twice: first to bind the amino acid (enantiomeric pure, amine-Boc-protected) to the nitrile moiety, and secondly (after removing Boc group) to the corresponding benzoyl acids.

To ensure that no racemization occurred we have synthesized the $(R)$ analogs of Neq0710. Enantiomeric purity was analyzed by HPLC equipped with a chiral column (see appendix B).

Kinetic measurements were performed for substances in Scheme 1 to evaluate the affinity of the synthesized compounds. Using $\mathrm{p} K_{i}$ affinity values from Table 1 , we performed a Matched Molecular Pair Analysis (MMPA) that provides the opportunity to evaluate molecular modifications for significant structure-activity relationships (SAR; KENNY; SADOWSKI, 2005; TYRCHAN; EVERTSSON, 2017).

The most substantial difference in the observed $\mathrm{p} K_{\mathrm{i}}$ values is found in the $m-\mathrm{H} / \mathrm{m}-\mathrm{I}$ substitution (Neq570 vs. Neq0804) with the benefit of $0.8 \mathrm{log}$ units in favor of the iodine atom in meta-position. Moreover, the inclusion of the chlorine atom in the meta-position resulted in the second significant difference observed in the series with affinity gain about $0.7 \mathrm{log}$ units (Neq0570 vs. Neq0710). As we expected, the replacement of chlorine, bromine or iodine atom by a trifluoromethyl substituent resulted in a loss of affinity. The inclusion of the nitrogen heteroatom for the formation of the pyridine moiety did not represent the right approach.

In summary, these results point out the direct influence of the $\mathrm{Cl}, \mathrm{Br}$ and I regiochemistry in the $\mathrm{P} 3$ phenyl ring as an adequate strategy to gather a possible halogen bond with the hydroxy group from Ser61. In order to better evaluate this trend, we employed isothermal titration calorimetry to determine thermodynamic parameters of cruzain-dipeptidyl nitrile interactions (Table 1).

As already described in our recent study (PROKOPCZYK et al., 2014), isothermal titration calorimetry (ITC) is a technique used for the thermodynamic characterization of interactions between biomolecules and small molecules, which is vital for understanding the process of molecular recognition. The values of $\mathrm{K}_{d}$ (Table 1) showed the same trend as depicted by $p K_{i}$, with substance Neq0804 having the highest affinity for $\mathrm{Cz}$, followed by substances $\mathrm{Neq0803}$ and Neq0710. The thermodynamic 
signatures gathered from ITC data reveal that binding of cruzain inhibitors was driven by favorable enthalpy contributions, with detrimental entropy for all study substances.

Table 1 reports the thermodynamic signatures of the interactions that have, mostly, the same free energy $(\Delta G)$ of interaction. The interaction energy relates to the affinity, which is a combination of enthalpy $(\Delta \mathrm{H})$ and entropy $(\Delta S)$. Classically, enthalpy reflects the strength of the interactions due to the formation of hydrogen bonds and van der Waals, while the binding entropy is a combination of the change in the desolvation and conformational changes after the formation of the bimolecular ligand-cruzain complex (DENG et al., 2011). Results unveil a quasi-perfect omnipresent phenomenon of enthalpy-entropy compensation. Interestingly, the effect of the m-chlorophenyl moiety on binding affinity decreases both binding enthalpy and entropy contributions. To sum up, ITC studies pictured that the mechanism of binding of cruzain inhibitors is driven by favorable enthalpy contributions with a strong phenomenon of enthalpy-entropy compensation.

Table 1-. Kinetic parameters $\left(\mathrm{p} K_{\mathrm{i}}\right), \mathrm{pK}_{\mathrm{d}}$ and thermodynamic characterization of cruzain inhibitors.

\begin{tabular}{|c|c|c|c|c|c|}
\hline ID & \multicolumn{1}{|c|}{$\mathrm{pK}_{\mathrm{i}}^{\mathrm{a}}$} & $\mathrm{pK}_{\mathrm{d}}^{\mathrm{b}}(\mathrm{nM})$ & $\begin{array}{c}\Delta \mathrm{G}\left(\mathrm{kcal} \mathrm{mol}^{-}\right) \\
{ }^{2}\end{array}$ & $\begin{array}{c}\Delta \mathrm{H} \\
\left(\mathrm{kcal} \mathrm{mol}^{-1}\right)\end{array}$ & $\begin{array}{c}-\mathrm{T} \Delta \mathrm{S} \\
\left(\mathrm{kcal} \mathrm{mol}^{-1}\right)\end{array}$ \\
\hline Neq0570 & $6.4(0.026)$ & $6.6(0.04)$ & -9.00 & -14.6 & 5.6 \\
\hline Neq0709 & $6.6(0.058)$ & $\mathrm{ND}$ & $\mathrm{ND}$ & $\mathrm{ND}$ & $\mathrm{ND}$ \\
\hline Neq0710 & $7.1(0.020)$ & $6.9(0.06)$ & -9.43 & -10.7 & 1.32 \\
\hline Neq0711 & $6.4(0.018)$ & $\mathrm{ND}$ & $\mathrm{ND}$ & $\mathrm{ND}$ & $\mathrm{ND}$ \\
\hline Neq0712 & $6.6(0.0099)$ & $6.8(0.03)$ & -9.29 & -12.8 & 3.55 \\
\hline
\end{tabular}




\begin{tabular}{|c|c|c|c|c|c|}
\hline \multirow{2}{*}{ ID } & $\mathrm{p} K_{\mathrm{i}}^{\mathrm{a}}$ & $\mathrm{pK} \mathrm{d}^{\mathrm{b}}(\mathrm{nM})$ & $\Delta \mathrm{G}$ & $\Delta \mathrm{H}$ & $-\mathrm{T} \Delta \mathrm{S}$ \\
\hline Neq0717 & $7.0(0.019)$ & 6.8 & -9.22 & -11.9 & 2.64 \\
\hline Neq0714 & $5.9(0.017)$ & $6.5(0.11)$ & -8.83 & -12.1 & 3.30 \\
\hline Neq0802 & $6.3(0.023)$ & $6.6(0.005)$ & $-9.11(0,005)$ & $-13.9(0.60)$ & $5.96(0.59)$ \\
\hline Neq0803 & $6.9(0.032)$ & $7.0(0.06)$ & $-9.58(0,015)$ & $-11.3(0.35)$ & $1.77(0.39)$ \\
\hline Neq0804 & $7.2(0.02)$ & $7.1(0.03)$ & $-9.76(0.035)$ & $-12.0(0.30)$ & $2.28(0,33)$ \\
\hline Neq0805 & $6.6(0.02)$ & $6.9(0.01)$ & $-9.45(0.015)$ & $-12.7(0.35)$ & $3.29(0.38)$ \\
\hline & & & & & \\
\hline
\end{tabular}

Affinity $\left(\mathrm{p} K_{\mathrm{i}}\right)$ values against $\mathrm{Cz}$. ND - Not Determined. Standard deviations are reported in brackets. Deviations for $\Delta \mathrm{G}$ are lower than $0.4 \% ; \Delta \mathrm{H}<4.5 \% ;-\mathrm{T} \Delta \mathrm{S}<15 \%$. ${ }^{\mathrm{a}} \mathrm{p} K_{\mathrm{i}}=-\log K_{\mathrm{i}}$; Uncertainty = desvpad $/\left(K_{i}^{*} \ln (10)\right) ;{ }^{b} \mathrm{pK}_{d}=-\log \mathrm{K}_{d}$; Uncertainty $=$ desvpad $/\left(\mathrm{K}_{d}{ }^{*} \ln (10)\right)$. Source: Own author.

The closest structural related mammalian cysteine to $C z$ is cathepsin $L$ (CatL). It is a lysosomal ubiquitous cysteine proteinase (KIRSCHKE et al., 1977) that plays a vital role in degrading endocytosed and intracellular proteins. CatL knockout mice studies provided a series of alterations in the biological processes. (KRAMER; TURK; TURK, 2017) Moreover, CatL upregulation has been reported for many human cancers including ovarian, breast, prostate, lung, gastric, colon, and pancreatic tumours (CHAUHAN; GOLDSTEIN; GOTTESMAN, 1991; SUDHAN; SIEMANN, 2015).

We evaluated the affinity to CatL for the same set of molecules (Figure 6). Results display the same trend found for $\mathrm{Cz}$ but with a larger magnitude in $\Delta \mathrm{p} K_{\mathrm{i}}$ which is due to a stronger halogen bond formation with the backbone peptide carbonyl of Gly66 as already described for a similar class of inhibitors (HARDEGGER et al., 2011).

We could speculate that this carbonyl group is more prone to form a halogen bond for three factors: it can easily create an angle of $180^{\circ}$ with the halogen; it has a lower 
intrinsic mobility than the hydroxyl group of Gly66 in Cz; it cannot act as hydrogen bond donor leading to be less solvated than a hydroxyl group.

Figure 6. Affinity values and proposed mode of binding for Neq0803 against CatL.

(A)

\begin{tabular}{c|c}
$\mathrm{ID}$ & $\mathrm{pK}_{\mathrm{i}}^{\mathrm{a}}$ \\
\hline Neq0570 & $7.4(0.03)$ \\
\hline Neq0709 & $7.2(0.05)$ \\
\hline Neq0710 & $8.0(0.04)$ \\
\hline Neq0711 & $7.5(0.04)$ \\
\hline Neq0712 & $7.7(0.02)$ \\
\hline Neq0717 & $8.0(0.01)$ \\
\hline Neq0802 & $7.2(0.05)$ \\
\hline Neq0803 & $8.5(0.02)$ \\
\hline Neq0804 & $9.1(0.03)$ \\
\hline Neq0805 & $7.8(0.08)$
\end{tabular}

(C)

\begin{tabular}{c|c}
$\mathrm{X}$ & $\Delta \mathrm{pK}_{\mathrm{i}}$ \\
\hline$-\mathrm{H}$ & 0.0 \\
\hline$-\mathrm{F}$ & -0.2 \\
\hline$-\mathrm{Cl}$ & +0.6 \\
\hline$-\mathrm{Br}$ & +1.1 \\
\hline$-\mathrm{I}$ & +1.7
\end{tabular}
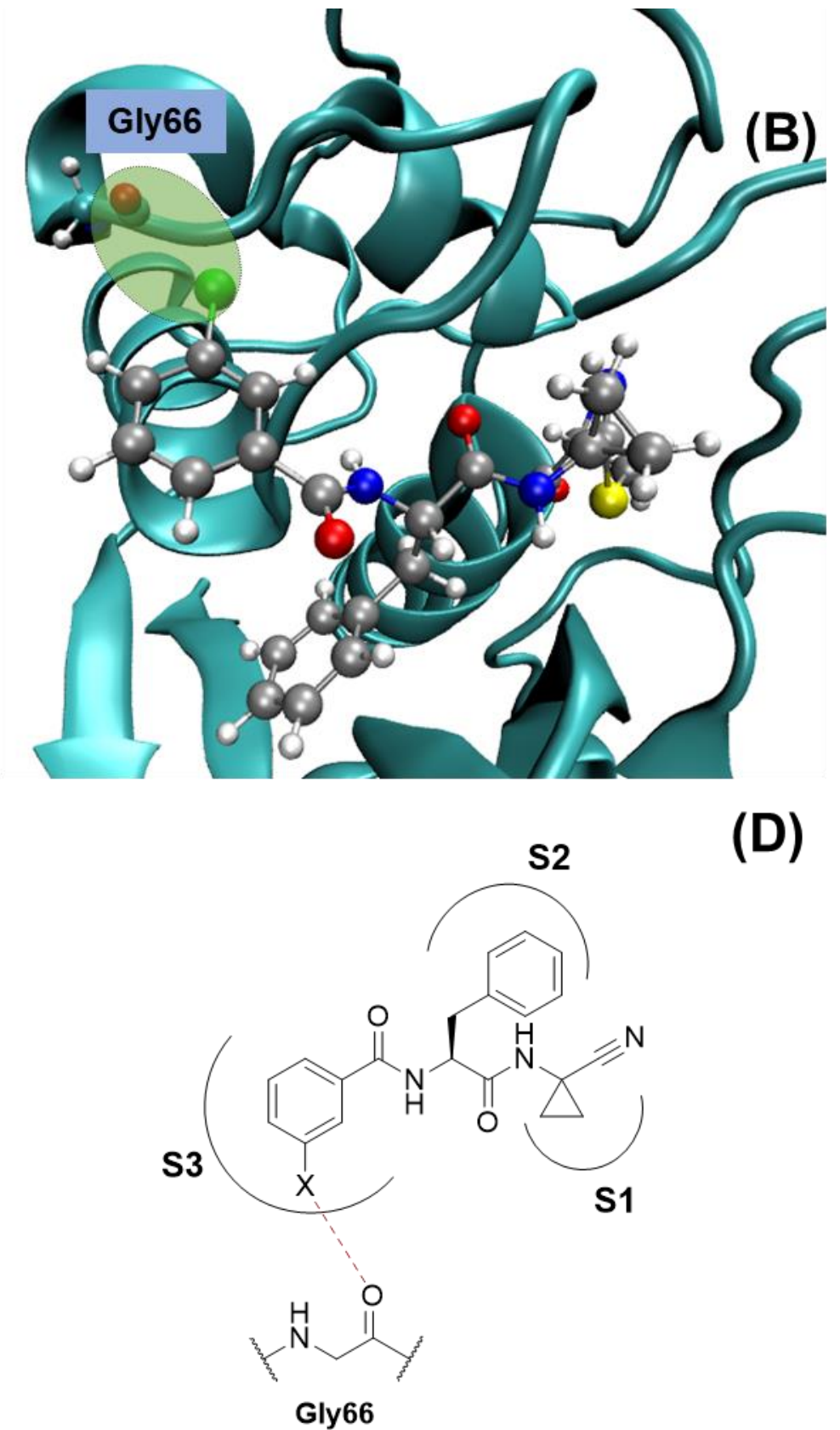

(D)

(A) Affinity $\left(\mathrm{p} K_{\mathrm{i}}\right)$ values against CatL. ${ }^{\mathrm{a}} \mathrm{p} K \mathrm{i}=-\log \left(K_{\mathrm{i}}\right)$; Uncertainty $=\operatorname{desvpad} /\left(K_{\mathrm{i}}^{*} \ln (10)\right)$; (B) The average pose obtained after the molecular dynamic simulation with Neq0803 covalently bond with CatL (PDB code 2XU1). Color for Neq0803 and Gly66: Carbon chain is gray; Bromine is green; Oxygen is red. Protein is colored in blue the residue Gly66 is represented as balls and sticks (C) $\Delta \mathrm{p} K_{\mathrm{i}}$ is calculated as the difference between $\mathrm{p} K_{\mathrm{i}}$ values; (D) schematic representation of the halogen bond (red dashed line) between Gly66 and the prototype dipeptidyl nitrile bearing a halogen in meta position in P3. Source: Own author. 


\subsection{Conclusion and perspective}

Visual inspection and molecular dynamics simulation have shown that the $\mathrm{m}$ chlorophenyl, $m$-bromophenyl, and $m$-hydroxyphenyl moieties have the right orientation inside P3 to interact with the oxygen of Ser61 for $\mathrm{Cz}$ or the Gly66 for CatL residue. The results are in good agreement with the MD simulations, once the better compounds are precisely those who present a lesser variation of P3 ring. Indeed, the substitution of a hydrogen atom to an iodine atom in meta position in P3 increased the pKi of $0.8 \log$ unit for $\mathrm{Cz}$ and 1.7 for CatL inhibition. Moreover, ITC studies pictured that the mechanism of binding of cruzain inhibitors was driven by favorable enthalpy contributions and with the quasi-perfect omnipresent phenomenon of enthalpyentropy compensation. This finding is of particular interest to guide further SAR for inhibition of cysteine proteases when halogen bonding is implemented in the bimolecular recognition process to increase affinity. Overall, this study underlines the feasibility of achieving higher affinity or selectivity for the desired CP by benefit from structural singularity present in the S3 subsite. Unfortunately, even if we were able to increase the affinity to $\mathrm{Cz}$, none of the compounds described until here exhibit an improvement in trypanocidal activity, respect to the prototype compound Neq0570. Nevertheless, results suggest that the design of new cysteine protease inhibitors driven by molecular dynamics is a valuable approach when considering less druggable subsites of the enzyme. Nonetheless, these studies were uniquely crucial in guiding the molecular modifications implemented in the scaffold under investigation, which will be presented in the following chapters. 


\section{CHAPTER II - Experimental Study and Computational Modelling of Cruzain Cysteine Protease Inhibition by Dipeptidyl Nitriles ${ }^{2}$}

\subsection{Background}

In the previous chapter (chapter I), we have focused our attention on the P3-S3 interaction for a series of dipeptidyl nitrile with $\mathrm{Cz}$ and CatL inhibition. In this chapter, the aim is to understand what the role of the cyclopropane moiety in P1 for the bimolecular recognition process with $\mathrm{Cz}$ is. In general, the 1aminocyclopropanecarbonitrile is a well-known building block used for the synthesis of nitrile CP inhibitors. This moiety is also found in Odanacatib, the only cysteine protease inhibitor to reach clinical phase III (BOGGILD et al., 2015). The cyclopropane moiety confers higher metabolic stability to the 2-aminoacetonitrile group, but its influence on the bimolecular recognition process and in the mode of action (MoA) for the inhibition of $\mathrm{Cz}$ was still not fully understood.

\subsection{Design, synthesis, computational study, and biochemical evaluation}

Structurally similar molecules can present significant differences in potency (or affinity). These discontinuities are known as "activity cliffs" (DIMOVA; BAJORATH, 2016), and it is precisely this phenomenon that we have observed when small changes are applied to the P1 moiety of our prototype dipeptidyl nitrile inhibitor Neq0570. Indeed, to better understand the role of the cyclopropane (P1 moiety) in the bimolecular recognition process, we have designed and synthesized two molecular pairs: Neq0410 and Neq0409.

The general synthesis of these two compounds was performed as previously described (Figure 5).

\footnotetext{
2 This chapter describes joint work with M. Sc. Fabiana Rosini (NEQUIMED/IQSC/USP, University of Sao Paulo, Brazil) for ITC studies and with the group of Prof. Jerônimo Lameira (Federal University of Pará, Brazil) for QM/MM calculations.
} 
The modifications implemented in the Neq0570 inhibitor (Figure 7) negatively modified the binding affinity and the thermodynamic profile of the ligands when co-complexed with cruzain. Substitution of the cyclopropane for geminal dimethyl (Neq0410) reduced the affinity over one log unity. Insertion of the cyclopropane in P1 on Neq409 increased the potency of $0.3 \mathrm{log}$ units. For comparisons between the pairs to be significant, the thermodynamic parameters were evaluated. The pair Neq0410-Neq0409 presents a thermodynamic signature in which the introduction of the geminal methylene results in a total detrimental contribution towards binding and the three thermodynamic parameters are unfavorable to the spontaneity of the bimolecular interaction process. On the other hand, the elimination of the cyclopropane moiety in Neq0570 thereby yielding to Neq409 contributes positively for the entropic contribution that makes the spontaneous process happen even at the expense of the detrimental contribution of its net enthalpy (Figure 7B). The transformation of the geminal dimethyl moiety to the cyclopropane is favorable for the enthalpy and the entropy of the bimolecular interaction between the inhibitor and $\mathrm{Cz}$. 
Figure 7. A) SAR representation for compounds Neq0409, Neq0410, and Neq0570. The $\Delta \mathrm{p} K_{\mathrm{i}}$ was calculated as the difference of $\mathrm{p} K_{\mathrm{i}}$ values $(\mathrm{Cz})$ for the corresponding compounds. B) Net thermodynamic profile for cruzain inhibitors: Neq0409, Neq0410 and Neq0570. C) Representative structures obtained from the QM/MM free energy simulations for Neq0409. Structures named according to the locations along the 2D PMF.

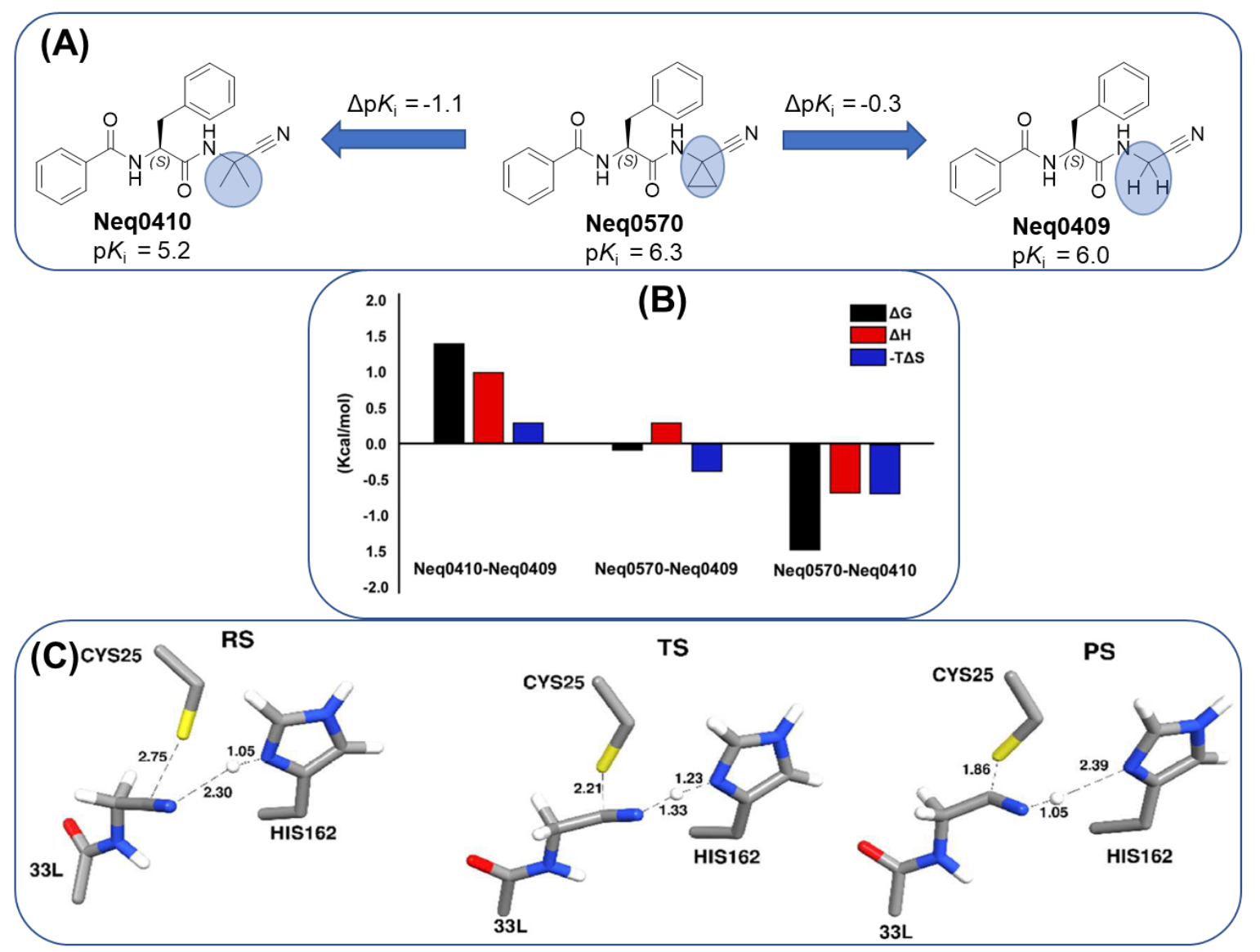

Colours for the atoms in (C): Carbon chain is grey; Hydrogen is white; Nitrogen is blue; Oxygen is red; Sulfur is yellow. Source: Adapted from DOS SANTOS, A. M. et al. Experimental study and computational modelling of cruzain cysteine protease inhibition by dipeptidyl nitriles. Physical Chemistry Chemical Physical, v. 20, p. 24317-24328, set. 2018.

Noteworthy, the insertion of the cyclopropane or geminal dimethyl in the P1 of Neq0410 led to the same difference in affinity for CatL. To better evaluate the influence of difference substituent in P1 Prof. Lameira and its collaborators have performed a QM/MM calculation to estimate the kinetics and thermodynamics of reversible covalent inhibition of CPs. Briefly, simulation of the reaction inhibition of $\mathrm{Cz}$ reveals that reaction proceeds via a concerted mechanism, where the proton transfer from His162 to N1 of Neq0409 co-occurs with a nucleophilic attack from negatively charged Cys25 at C1 of Neq0409 (Figure 7C). We could postulate that the difference in potency amongst Neq0409, Neq0410 and Neq0570 derived from two effects: steric effects of the 
dimethyl geminal group and ability of the cyclopropane moiety to conjugate with acceptor substituents (i.e., nitrile)(CRUZ-CABEZA; ALLEN, 2011), herein increasing the nucleophilicity of the vicinal carbon atom.

\subsection{Conclusion and perspective}

Overall, ITC analysis showed that the cruzain inhibition by Neq0409, Neq0410 and Neq0570 is enthalpy driven with a clear detrimental contribution of the entropy difference to the free binding energy. Furthermore, an important conclusion from the hybrid QM/MM approach and FESs obtained is that the inhibition reaction of cruzain by Neq0409, Neq0410, and Neq0570 follows a concerted mechanism.

These results lead us to explore the $\mathrm{S} 1 / \mathrm{S} 1^{\prime}$ of $\mathrm{Cz}$ and other $\mathrm{CPs}$ to enhance the affinity of dipeptidyl nitrile inhibitors (see chapter III).

Also, considering that nitrile inhibitors of CPs in clinical trials are bearing cyclopropane nitrile as a warhead, we hope that these results may provide valuable information for designing new inhibitors of $\mathrm{Cz}$ and other relevant cysteine proteases as biological targets. 


\section{CHAPTER III - Mapping The S1 and S1' Subsites of Cysteine Proteases for The Synthesis of New Dipeptidyl Nitriles as Trypanocidal Agents ${ }^{3}$}

\subsection{Background}

A variety of studies have been conducted on optimization strategies for the interactions of different classes of inhibitors with the S1, S2 and S3 binding sites of cruzain and related cysteine proteases. (see chapter I)(AVELAR et al., 2015; CIANNI et al., 2019; SCHMITZ et al., 2019). Nonetheless, far less is known about the possible interactions at $\mathrm{S} 1^{\prime}$ for dipeptidyl nitrile inhibitors. The high-resolution crystal structure of $\mathrm{Cz}$ shows that there is a large open hydrophobic surface characterized by Trp177 in the primed binding site region (MCGRATH et al., 1995). The design of compounds to exploit this cavity would provide the potential for enhanced enzyme-inhibitor interactions. This concept has already been applied to a class of different dipeptidic vinyl sulfone inhibitors (BRINEN et al., 2000). As Figures $8 \mathrm{~A}$ and $8 \mathrm{C}$ exemplarily illustrates, hydrophobic moieties accommodate in the $\mathrm{P} 3$ and $\mathrm{P} 2$ pockets while forming hydronge bonds with Gly66. In particular, the substituents in the current series of the vinyl-sulfone inhibitors predominantly sit on top of the shelf formed by residues Ser139, Met142 and Asp158 rather than adopting an orientation for a strong aromatic-aromatic interactions with Trp177. The nitrile inhibitor 33L (Figure 8B and 8D) does not bear an appropriate substituent that would allow for an interaction with the primed binding region of cruzain. As discussed above (see chapter II) small changes, as the insertion of the bulky substituent, in the $\mathrm{P} 1$ position could lead to drastic fluctuation in the $\mathrm{p} K_{\mathrm{i}}$ values. By applying a knowledge-based design approach, we have explored different amino acids as possible building blocks for the P1 moiety. Based on a template crystal structure of the dipeptidyl nitrile inhibitor 33L bound to Cz (NEQUIMED/IQSC/USP PDB ID: 4QH6),

\footnotetext{
${ }^{3}$ This chapter describes joint work with the group of Prof. Jürgen Bajorath (University of Bonn, B-it, Germany) for modelling studies and with the group of Prof. Michael Gütschow (University of Bonn, Pharmaceutical Institute, Germany) and with M. Sc. student Fernanda dos Reis Rocho (NEQUIMED/IQSC/USP, University of São Paulo, Brazil) for kinetics measurements. Biological activities were performed by Ph.D. student Daiane Tezuka (NEQUIMED/IQSC/USP, University of São Paulo, Brazil).
} 
structural modifications were explored that might increase the affinity towards the S1' specificity pocket.

Besides that, we have tested this same set of compounds against four human cysteine cathepsins, (CatB, CatL, CatK, CatS) important therapeutic targets for human diseases (KRAMER; TURK; TURK, 2017), and against the cysteine protease LmCPB, novel macromolecular target for Leishmania mexicana (MOTTRAM; BROOKS; COOMBS, 1998). 
Figure 8. A, C) Crystal structures and 2D interactions of vinyl sulfone derivative $K 777$ with the active site of $\mathrm{Cz}$ (PDB-ID: 1F2B); residual number corresponding to cruzain sequences; $\mathrm{B}, \mathrm{D})$ Crystal structure and 2D interactions of dipeptidyl nitrile 33L with the active site of $\mathrm{Cz}$ (PDB-ID 4QH6); residual number corresponding to cruzipain sequences .

A)

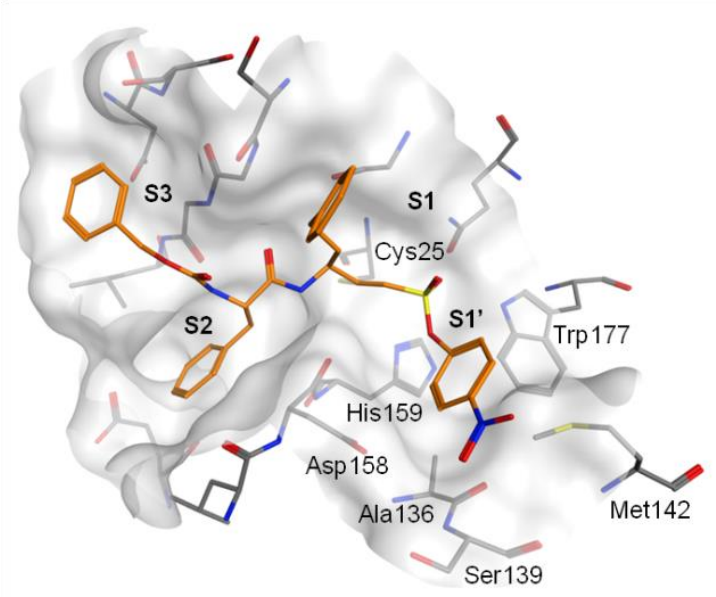

C)

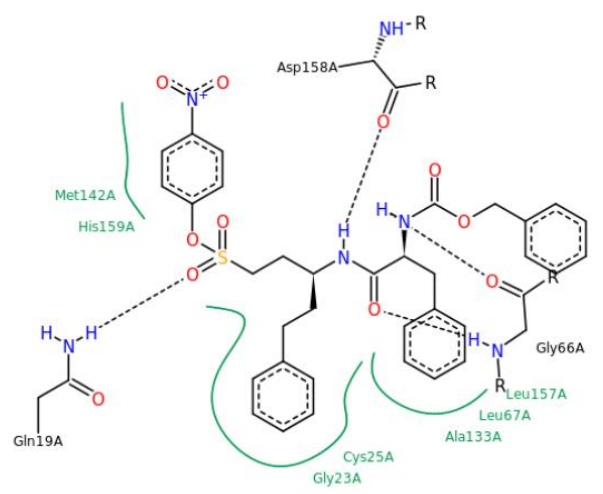

B)

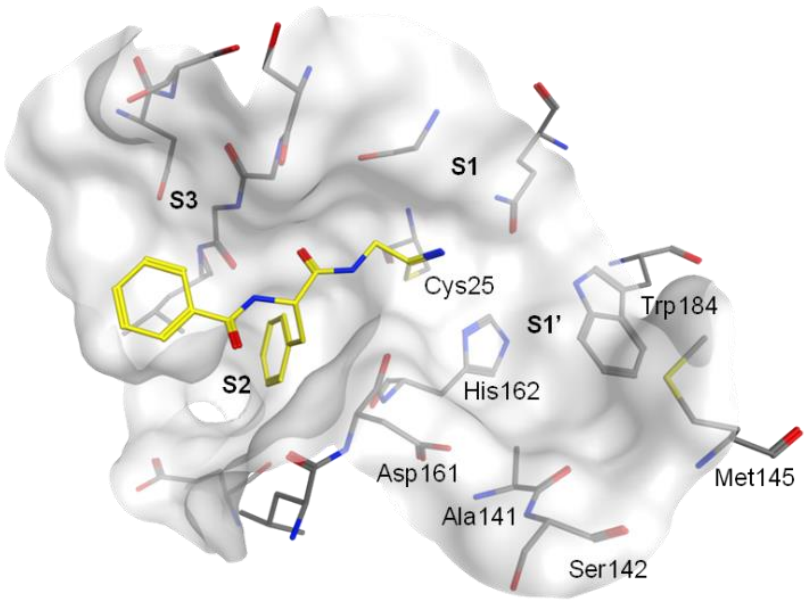

D)<smiles>[R]C(=O)CN([R])[IH][IH][IH]OC(=O)[C@H](Cc1ccccc1)NC(=O)c1ccccc1</smiles>

Gly66A

Colours for the atoms in A, B: Carbon chain of the ligand is magenta (left picture) or yellow (right picture); Carbon chain of the protein is grey; Nitrogen is blue; Oxygen is red; Sulfur is yellow. Source: Provided by Christian Feldmann (University of Bonn, B-it, Germany). In pictures C, D: Black dashed lines indicate hydrogen bonds. Green solid lines show hydrophobic interactions.

Therefore, having all of this in our mind, we expanded our previous series of $\mathrm{Cz}$ inhibitors to map the $\mathrm{S} 1 / \mathrm{S} 1^{\prime}$ subsites. 
4.2. Design, synthesis and kinetic evaluation of new dipeptidyl nitriles as cysteine protease inhibitors

By having all this in mind we have applied a knowledge-based design approach, by exploring different amino acids as possible building blocks for the P1 moiety (Figure 9). Modelling studies revealed that dipeptidyl nitriles Neq0937, Neq0940, Neq0921, and Neq0922 with different lipophilic substitution patterns at the P1 position were assumed to accommodate on the surface of $\mathrm{S1}^{\prime}$ through hydrophobic interactions without interfering in the general mode of binding (Figure 9). 
Figure 9. Putative orientation of novel P1 moieties in compounds Neq0937, Neq0940,

Neq0921, and Neq0922 with residues of interest (PDB ID: 4QH6) from the pockets S1 and $\mathrm{S} 1^{\prime}$ of $\mathrm{Cz}$.

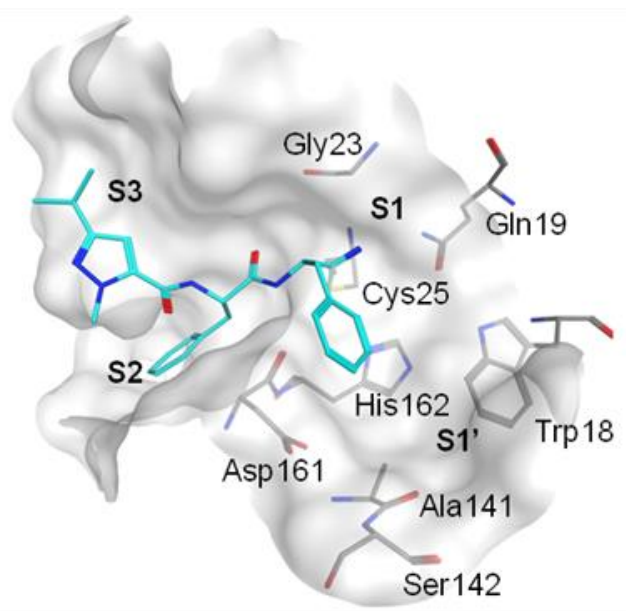

Neq0937

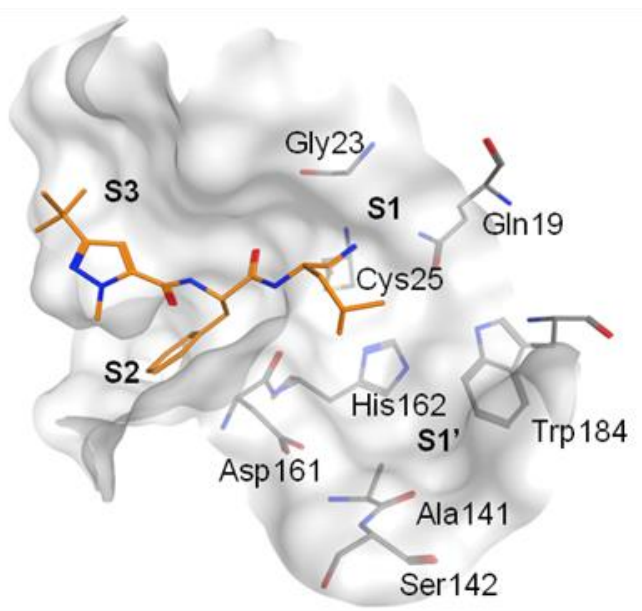

Neq0940

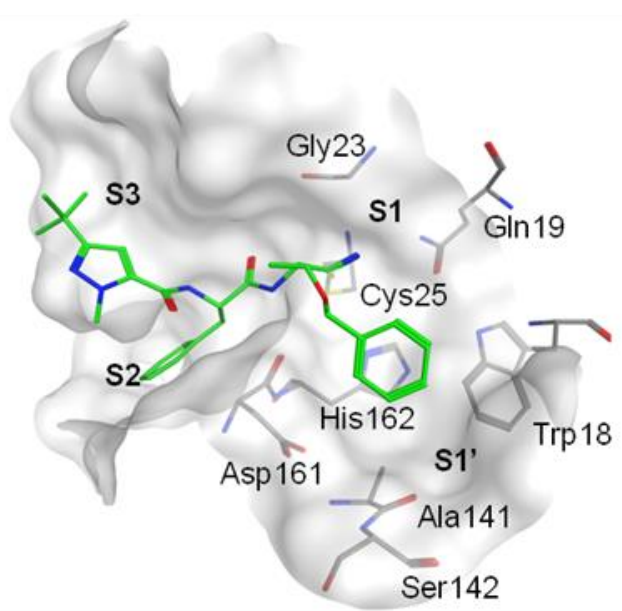

Neq0921

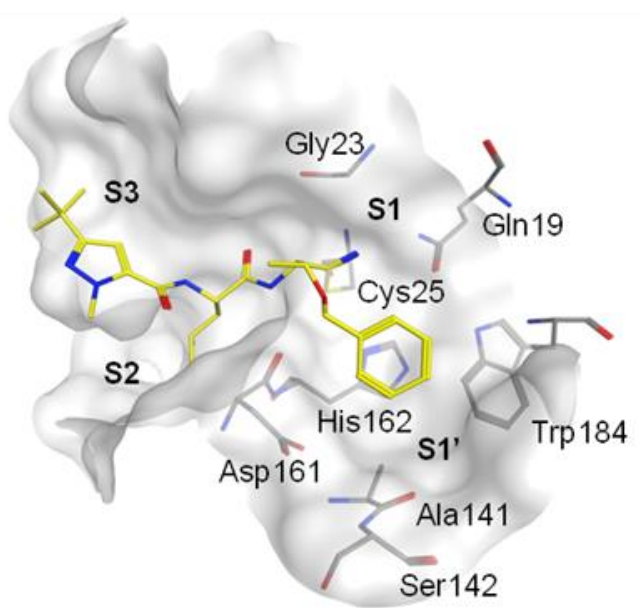

Neq0922

Colours for the atoms: Carbon chain of the ligand is blue (up-left picture), magenta (up-right picture), green (down-left picture), yellow (down-right picture); Carbon chain of the protein is grey; Nitrogen is blue; Oxygen is red; Sulfur is yellow. Source: Provided by Christian Feldmann (University of Bonn, B-it, Germany).

Compound Neq0533.1 was adopted as an archetype, with the cyclopropane group at P1 position and phenylalanine as well as a pyrazole moiety for advantageous interactions with the non-primed binding region of the target protease. We mainly used different natural and unnatural amino acids for the P1 moiety and maintained the nitrile warhead. Leucine (Leu) and phenylalanine (Phe) were incorporated (for example, Neq0937 and Neq0940) for aliphatic and aromatic interactions (Table 2). 4pyridylalanine was implemented to leveraging the affinity by polar interaction with 
Asp161 (Neq0953 and Neq0954). Thr-O-Bzl, a great building block for peptide inhibitors, was used as chimera for aliphatic and aromatic interactions (Neq0921). Also, removal of the benzyl protecting group from Thr-O-Bzl the so produced alcoholic moiety should allow to evaluate whether a hydrogen bond donor is tolerated in the S1/S1' area. Moreover, it was intended to investigate how the stereochemistry in this region will influence the affinity with $\mathrm{Cz}$ (Neq0941). Furthermore, to estimante possible non-additivity features in the SARs, the Thr-O-Bzl role in the bimolecular recognition process, we exchanged Phe to Leu and 3-Cl-Phe in P2 by keeping the same fragment in $\mathrm{P} 1$ (as Neq0922 and Neq0877).

3-(tert-Butyl)-1-methyl-1H-pyrazole-5-carboxylic acid is a privileged building block applied for the inhibition of $\mathrm{Cz}$ and CatL (ASAAD et al., 2009). Thus, we have explored some possible bioisosteres to increase the affinity and the selectivity towards $\mathrm{Cz}$, such as 7 -chloroquinoline carboxylic acid, $1 \mathrm{H}$-indole-5-carboxylic acid, or 6-aminonicotinic acid. Also considering the possibility to form a hydrogen bond or halogen bond interaction with the Ser61 as reported in the previous study (chapter I).

Table 2- Structures representation, number identification, $\mathrm{p} K_{\mathrm{i}}$ values for $\mathrm{CatB}$, CatK, CatL, CatS, $\mathrm{Cz}$ and LmCPB.

\begin{tabular}{|c|c|c|c|c|c|c|c|}
\hline & & \multicolumn{6}{|c|}{$\mathrm{p} K_{\mathrm{i}}$ values or remaining activity $(\%)$ at $10 \mu \mathrm{M}^{\mathrm{b}, \mathrm{c}}$} \\
\hline Cmpd. & Structure & CatB & CatK & CatL & Cats & $\mathrm{Cz}$ & LmCPB \\
\hline Neq0570 & & $73 \%^{b}$ & 6.4 & 7.4 & 7.1 & 6.3 & 6.6 \\
\hline Neq0865 & & 5.5 & 6.2 & 7.3 & 7.7 & 6.9 & 6.2 \\
\hline Neq0543 & & 5.4 & 6.4 & 8.6 & 6.7 & 7.4 & 6.7 \\
\hline Neq0533.1 & & 4.8 & 6.5 & 8.2 & 6.8 & 7.3 & 7.1 \\
\hline
\end{tabular}




\begin{tabular}{|c|c|c|c|c|c|c|c|}
\hline Cmpd. & Structure & CatB & CatK & CatL & CatS & $\mathrm{Cz}$ & LmCPB \\
\hline Neq0945 & & $93 \%{ }^{\mathrm{b}}$ & 5.0 & 7.6 & 5.6 & 6.6 & 6.4 \\
\hline Neq0569 & & 4.5 & 8.3 & 7.6 & 7.4 & 7.8 & 7.3 \\
\hline Neq0956 & & 4.4 & $96 \%{ }^{b}$ & 5.9 & 5.9 & 5.1 & 5.5 \\
\hline Neq0719 & & 4.9 & $81 \%^{\mathrm{b}}$ & 7.2 & 6.7 & 6.7 & 6.9 \\
\hline Neq0775 & & $89 \%^{b}$ & 6.9 & 6.6 & 6.9 & 7.8 & 7.3 \\
\hline Neq0708 & & 4.7 & n.i. ${ }^{c}$ & 5.7 & 6.0 & 6.2 & 5.7 \\
\hline Neq0777 & & 5.2 & 6.2 & 6.3 & 7.3 & 6.9 & 7.0 \\
\hline Neq0955 & & n.i. ${ }^{c}$ & 8.0 & 6.5 & 7.6 & 7.1 & 6.8 \\
\hline Neq0958 & & 4.5 & 8.7 & 7.1 & 7.3 & 7.7 & 7.2 \\
\hline Neq0957 & & 4.6 & 5.5 & 5.2 & 5.0 & $51 \%^{\mathrm{b}}$ & $67 \%{ }^{b}$ \\
\hline Neq0937 & & 4.5 & 6.3 & 8.5 & 7.3 & 7.7 & 7.8 \\
\hline
\end{tabular}




\begin{tabular}{|c|c|c|c|c|c|c|c|}
\hline Cmpd. & Structure & CatB & CatK & CatL & CatS & $\mathbf{C z}$ & LmCPB \\
\hline Neq0866.1 & & $94 \%^{b}$ & 5.6 & 6.9 & 5.9 & 6.3 & 6.1 \\
\hline Neq0940 & & 5.1 & 6.7 & 8.3 & 6.9 & 7.5 & 7.4 \\
\hline Neq0952 & & $90 \%$ & 6.0 & 7.0 & 6.0 & 6.5 & 6.4 \\
\hline Neq0953 & & 4.9 & 6.3 & 8.3 & 7.1 & 7.5 & 7.5 \\
\hline Neq0954 & & 4.8 & 6.5 & 8.3 & 7.2 & 7.5 & 7.2 \\
\hline Neq0921 & & 5.2 & 5.7 & 7.0 & 6.0 & 6.3 & 6.5 \\
\hline Neq0938 & & n.i. ${ }^{\mathrm{c}}$ & $97 \%^{\mathrm{b}}$ & $85 \%^{b}$ & n.i. ${ }^{c}$ & $75 \%^{b}$ & $72 \%{ }^{b}$ \\
\hline Neq0922 & & 5.1 & 7.8 & 7.2 & 7.3 & 7.9 & 7.7 \\
\hline Neq0939 & & n.i. ${ }^{c}$ & n.i. ${ }^{\mathrm{c}}$ & $90 \%^{b}$ & $85 \%^{b}$ & $60 \%^{b}$ & $75 \%^{\mathrm{b}}$ \\
\hline & & & & & & & \\
\hline
\end{tabular}




\begin{tabular}{|c|c|c|c|c|c|c|c|}
\hline Cmpd. & Structure & CatB & CatK & CatL & CatS & Cz & LmCPB \\
\hline Neq0877 & & 6.3 & 6.0 & 8.1 & 6.5 & 7.2 & 6.8 \\
\hline Neq0941 & & $92 \%^{\mathrm{b}}$ & $86 \%^{\mathrm{b}}$ & 5.3 & 5.3 & $68 \%^{\mathrm{b}}$ & $69 \%^{\mathrm{b}}$ \\
\hline Neq0943 & & $89 \%{ }^{\mathrm{b}}$ & $81 \%^{\mathrm{b}}$ & 5.6 & 4.7 & 5.4 & 4.8 \\
\hline Neq0942 & & $92 \%^{\mathrm{b}}$ & 7.8 & 7.0 & 5.0 & 7.1 & 6.7 \\
\hline Neq0944 & & $93 \%{ }^{b}$ & 5.1 & $88 \%{ }^{\mathrm{b}}$ & $83 \%{ }^{b}$ & 5.4 & $54 \%^{\mathrm{b}}$ \\
\hline Neq0948 & & 5.2 & 6.1 & 8.2 & 6.6 & 6.9 & 6.0 \\
\hline
\end{tabular}

aThe standard deviation is lower than $15 \%$ for all reported $\mathrm{p} K_{\mathrm{i} .}{ }^{\mathrm{b}}$ Percentage of remaining activity at $10 \mu \mathrm{M} .{ }^{\mathrm{c}}$ n.i. $=$ no inhibition observed at $10 \mu \mathrm{M}$. Source: Own author.

Accordingly, we synthesized a new series of dipeptidyl nitriles (Scheme 1 and 2). For final compounds bearing a cyclopropane residue/moiety in $\mathrm{P} 1$, the synthesis was carried out as already reported before (see chapter I). The peptide coupling reaction was performed twice: first to connect the enantiomerically pure, Boc-protected P2 amino acid with the aminonitrile moiety, and secondly, after removing the Boc group, to introduce the corresponding aroyl acids (Scheme 1). 
Scheme 1- General synthetic scheme.

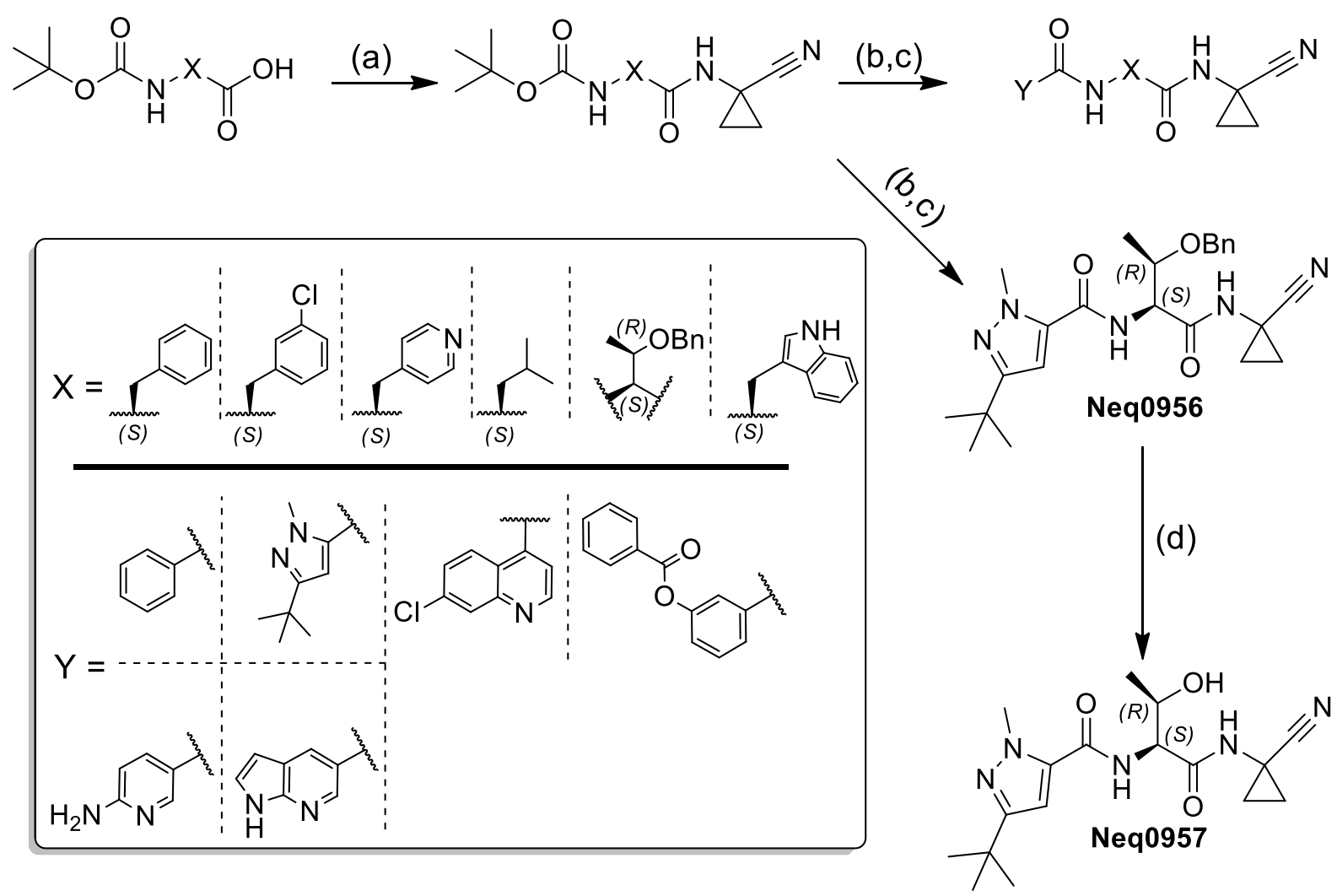

Reagents and conditions: a) HATU, DIPEA, 1-amino-1-cyclopropanecarbonitrile, DMF, rt, 18 h; b) formic acid, rt, $18 \mathrm{~h}$; c) HATU or TBTU, DIPEA, carboxylic acid, DMF, rt, $18 \mathrm{~h}$; d) DDQ, DCM, rt, 18 h. Source: Own author. 
Scheme 2- Retrosynthetic scheme and general synthesis.

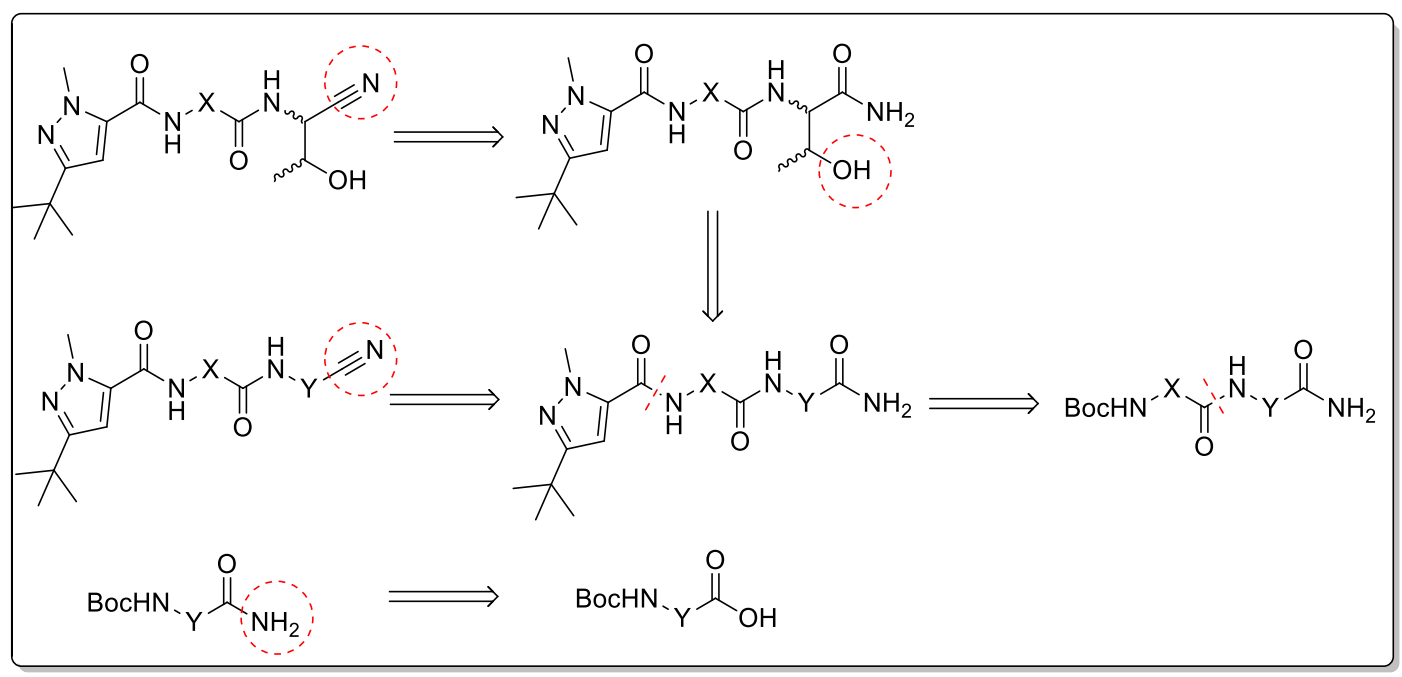

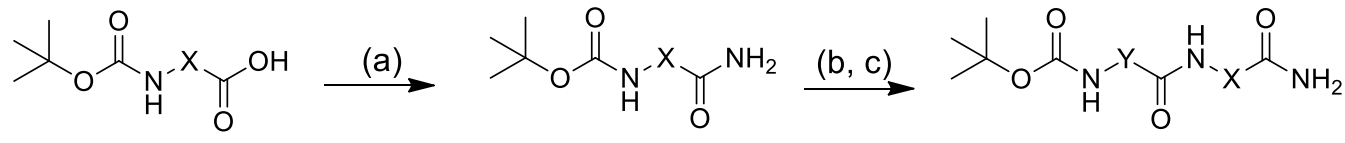

$\stackrel{(d, e)}{\longrightarrow}$

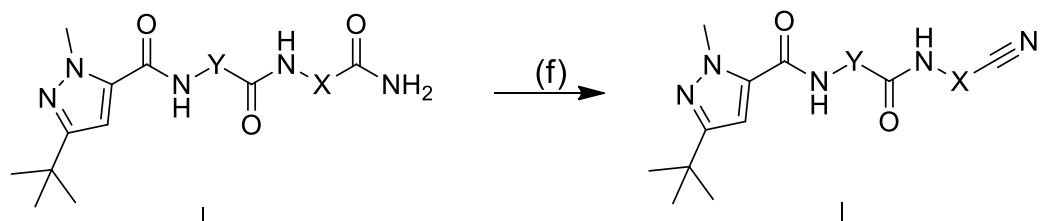

$(\mathrm{g})$

(h)
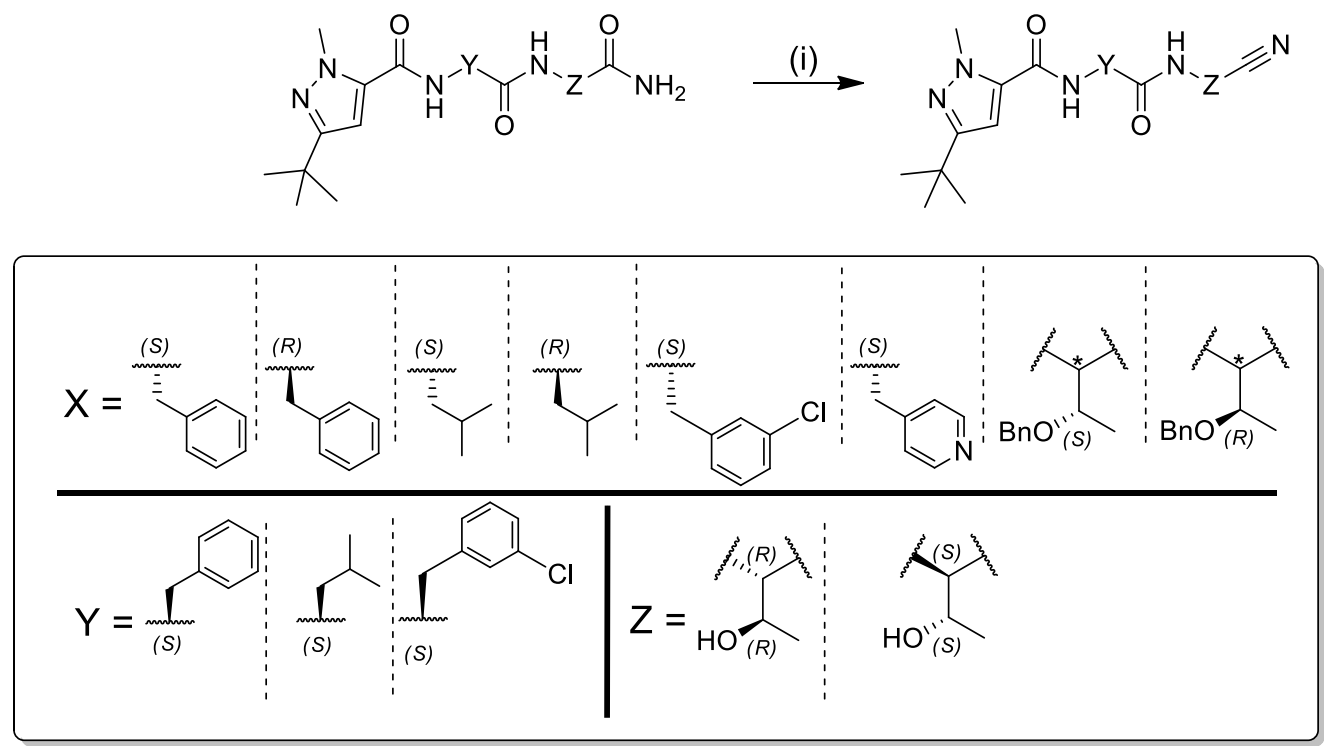

Reagents and conditions: a) Isobutyl chloroformate, $\mathrm{NH}_{4} \mathrm{Cl} 2 \mathrm{M}$, DIPEA, DMF, $0{ }^{\circ} \mathrm{C}$ to rt, $20 \mathrm{~h}$; b) TFA, $\mathrm{CH}_{2} \mathrm{Cl}_{2}, 0^{\circ} \mathrm{C}$ to rt, $2 \mathrm{~h}$; c) HATU, DIPEA, Boc-AA-OH, DMF, rt, $18 \mathrm{~h}$; d) TFA, $\mathrm{CH}_{2} \mathrm{Cl}_{2}$, $0{ }^{\circ} \mathrm{C}$ to rt, $2 \mathrm{~h}$; e)TBTU, DIPEA, 3-(tert-butyl)-1-methyl-1H-pyrazole-5-carboxylic acid, $\mathrm{DMF} / \mathrm{CH}_{2} \mathrm{Cl}_{2}$, rt, $18 \mathrm{~h}$; f) Cyanuric chloride, DMF, $0^{\circ} \mathrm{C}$ to rt; g) $\mathrm{H}_{2}(1 \mathrm{~atm}), \mathrm{Pd} / \mathrm{C}$, rt, $18 \mathrm{~h}$; h) $p$ $\mathrm{TsCl}, \mathrm{Py}$, rt, 3-5 days; i) TFAA, DIPEA, THF, $0{ }^{\circ} \mathrm{C}$ to rt, $2 \mathrm{~h}$. Source: Own author. 
Compound Neq0957 was synthesized from compound Neq0956 by removing the benzyl group. As a result of promiscuity of the nitrile group under hydrogenolysis, we performed the cleavage under mild oxidative conditions (Scheme 1; WRIGHT; YU; SPENCER, 2001).

To insert different groups in P1, we adopted a different synthetic strategy (Scheme 2). In general, the desired dipeptidyl primary amide was synthesized, followed by dehydration to form the desired dipeptidyl nitrile. Due to the diversity of building blocks, it was necessary to evaluate different dehydrating reagents, aiming at the best yield and prevention racemization. The cleavage of the benzyl protecting group was performed by hydrogenolysis before the conversion of the primary amide to the nitrile, due to the instability of the nitrile group in hydrogen atmosphere. While for compound Neq0948, considering the lability of the chlorine atom under hydrogenolysis, we first transformed the primary amide to the nitrile and then removed the benzyl group under mild oxidative conditions (WRIGHT; YU; SPENCER, 2001). The absolute geometry of the P1 group did not change, but, owing to CIP priority rules, the configuration at the $\alpha$-carbon for the Thr-O-Bzl building block changed two times: (i) in the dehydration step to form the nitrile group and (ii) when the catalytic cysteine attacks the carbon atom of the nitrile warhead to form a covalent bond (Figure 10).

Figure 10. Schematic representation of the change in stereochemistry for compounds bearing Thr or Thr-O-Bn group in $\mathrm{P} 1$.

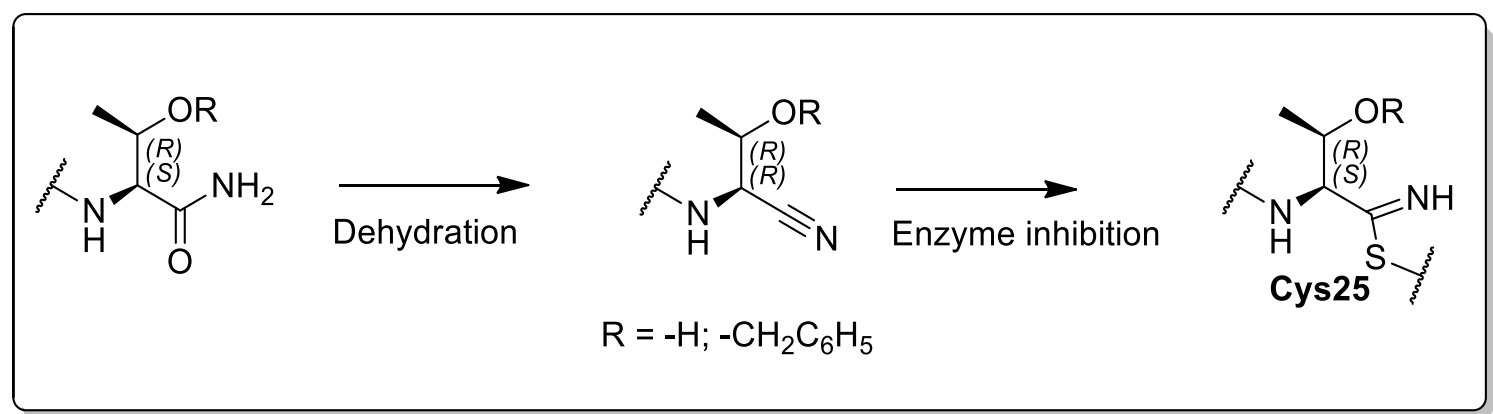

Source: Own author.

The $\mathrm{p} K_{\mathrm{i}}$ values were determined for parasite cysteine proteases $(\mathrm{Cz}, \mathrm{LmCPB})$ and for human cysteine cathepsins (CatB, CatK, CatL, CatS). They are reported in Table 2. Compounds Neq0570, Neq0543, Neq0533.1 and Neq0569 have already been described as competitive inhibitors that bind reversibly to Cz (AVELAR et al., 2015). 
Some of the compounds are $\mathrm{Cz}$ nanomolar inhibitors and also exhibit good affinity for LmCPB, CatL and CatK. The application of such inhibitors extends as candidates for antiprotozoal agents and as cysteine cathepsins inhibitors of the human host cell in various disease states. One crucial question is the cross-reactivity of inhibitors for CPs, for which an extrathermodynamic relationship can be formulated for a set of derivatives (MONTANARI et al., 2000; NÚÑEZ; VENHORST; KRUSE, 2012). The nature of the ligand-target interaction governed by the thermodynamic parameter of the free energy change (via the estimation of the dissociation constant) results in extrathermodynamic relationships for the set of derivatives. So, we investigated the degree of linear correlation between $\mathrm{Cz}$ and the other CPs by plotting the $\mathrm{p} K_{\mathrm{i}}$ data against each other. Results indicated an extrathermodynamic relationship between $\mathrm{Cz}$ and $\mathrm{LmCPB}$, while this was not observed for all the other CPs (Figure 11). This finding highlights that the modes of inhibition for this series of compounds are similar to $\mathrm{Cz}$ and LmCPB, corroborating the fact that all the structural transformations of prototype compounds Neq0533.1 and Neq0569 affected the affinity towards the two protozoa CPs with the same magnitude (Figure 11 and 12).

Figure 11. Plot of $\mathrm{p} K_{\mathrm{i}}(\mathrm{Cz}) v s$. $\mathrm{p} K_{\mathrm{i}}(\mathrm{LmCPB})$ for the series of dipeptidyl nitrile here discussed. A linear trendline fitted points.

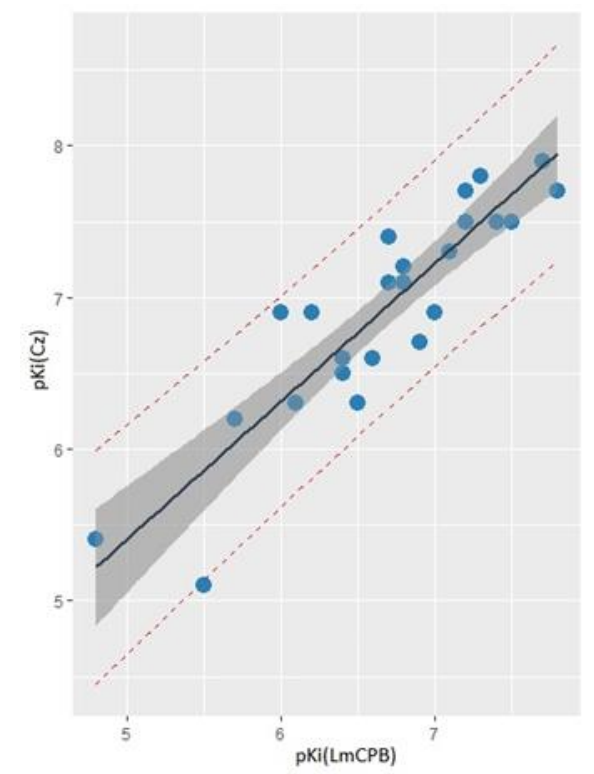

Multiple $\mathrm{R}^{2}=0.809$; Adjusted $\mathrm{R}^{2}=0.800$. F-statistic: 97.2 on 1 and 23 DF; p-value: $1 \times \mathrm{e}^{-09}$. Gray hatch: $95 \%$ confidence limit; Dashed red line: prediction interval Source: Own author. 
One common approach to SAR analysis is to examine $\Delta \mathrm{p} K_{\mathrm{i}}$ values associated with particular structural transformations, and these can be specified concisely using the square bracket notation previously described (SILVA et al., 2017). For example, the structural change of the cyclopropane in P1 of compound Neq0533.1 to the corresponding benzyl (Neq0937) can be noted as the [Neq533.1 $\rightarrow$ Neq0937] (Figure 12).

As already described for Cz (AVELAR et al., 2015), the exchange of benzoyl to 1methyl-3-tert-butyl-pyrazolyl-carbonyl [Neq0570 $\rightarrow$ Neq0533] led to potency increases of 0.5 log units. Following this path, we inserted a meta-benzoic ester in the P3 position in the attempt to design a prodrug analogue Neq0717 (see chapter I). The transformation [Neq0570 $\rightarrow$ Neq0955] unfortunately displayed a slight increment as compared to the change [Neq0570 $\rightarrow$ Neq0775]. Hence, compound Neq0533.1 ( $\mathrm{p} K_{\mathrm{i}}$ of 7.4 for $\mathrm{Cz}$ ) has been used as a prototype for mapping S1-P1 interaction on different targets (Figure 12).

Figure 12. SAR summary for S1-P1 interactions.

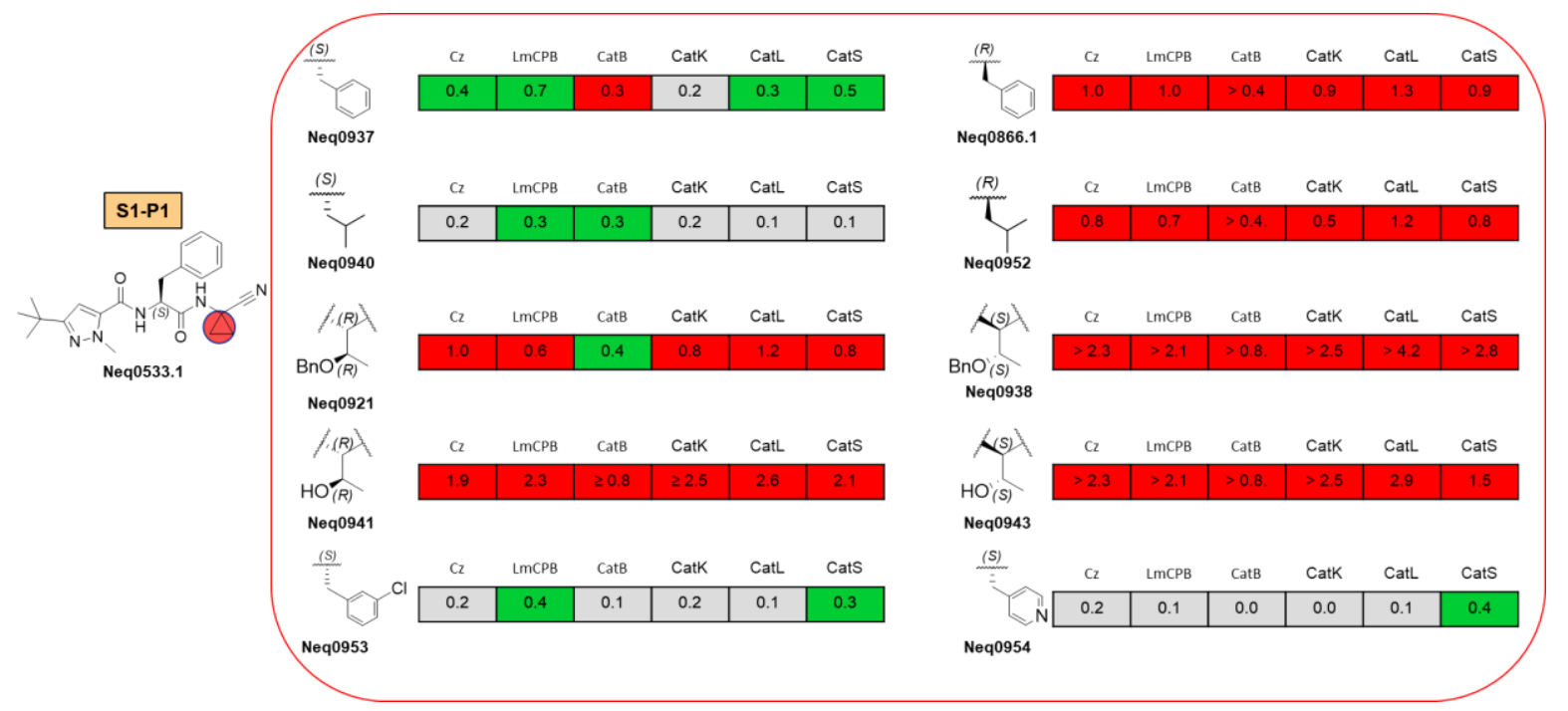

Values are reported as differences in $\mathrm{p} K_{\mathrm{i}}$ and color-coded as red (negative), green (positive), grey (no significant difference, $\Delta \mathrm{p} K_{\mathrm{i}}<0.2$ ). Source: Own author.

The effects on affinity resulting from stereochemical modifications in $\mathrm{P} 1$ of the structural prototype Neq0533.1 are shown in Figure 12. In general, the stereochemistry of P1 moiety strongly influences the affinity towards all the CPs. The chemical 
transformations [Neq937 $\rightarrow$ Neq0866.1] and [Neq0940 $\rightarrow$ Neq0952] decrease the $p K_{i}$ values for $\mathrm{Cz}$ and $\mathrm{LmCP}$ both by about one log unit. Likewise, the double stereochemical modification from $(R, R)$ benzyl-protected threonine to the $(S, S)$ diastereomer [Neq0921 $\rightarrow$ Neq0938] led to a complete all-target affinity loss. Instead, the structural transformation from the cyclopropane unit to $\mathrm{CH}$ attached with a benzyl group [Neq0533.1 $\rightarrow$ Neq0937] resulted in a significant affinity increment for $\mathrm{Cz}$ and LmCPB of 0.4 and 0.7 log units, respectively. Replacement of the P1 cyclopropane linker with $\mathrm{CH}$ attached to isopropyl [Neq0533.1 $\rightarrow$ Neq0940], 3-chlorobenzyl [Neq0533.1 $\rightarrow$ Neq0953], or even 4-pyridyl [Neq0533.1 $\rightarrow$ Neq0954] led to a small increase or no significant difference in potency against those two protozoa enzymes. Moreover, the insertion of the benzyl protected threonine in P1 [Neq0533.1 $\rightarrow$ Neq0937] decreased the affinity towards $\mathrm{C} z$ by tenfold and threefold for LmCPB. Remarkably, replacement by the hydroxybutyl residues led to an almost one hundredfold affinity loss for both enzymes. Mostly, the same trend in affinity was observed for the four mammalian CPs, when the structural modifications in P1 were realized starting from the prototype compound Neq0533.1 as illustrated in Figure 12. Singularly, the introduction of a benzyl-protected threonine [Neq0533.1 $\rightarrow$ Neq0937] resulted in a $p K_{i}$ decrease of $0.4 \log$ units towards CatB. It is possible to speculate that the positive effect is due to a hydrophobic interaction with the $\mathrm{S1}$ ' subsite as already reported for another series of dipeptidyl nitriles (SCHMITZ et al., 2016).

As previously described (AVELAR et al., 2015), the effects on affinity when replacing the P2 phenylalanine (Neq0533.1) with leucine (Neq0569) on affinity appears to depend on the substructural context, and this relates to nonadditivity in the SAR. Accordingly, we used compound Neq0569 as a starting scaffold for another SAR considering P1, P2 and P3 for structural modifications as summarized in Figure 13. 
Figure 13. SAR summary starting from compound Neq0569.

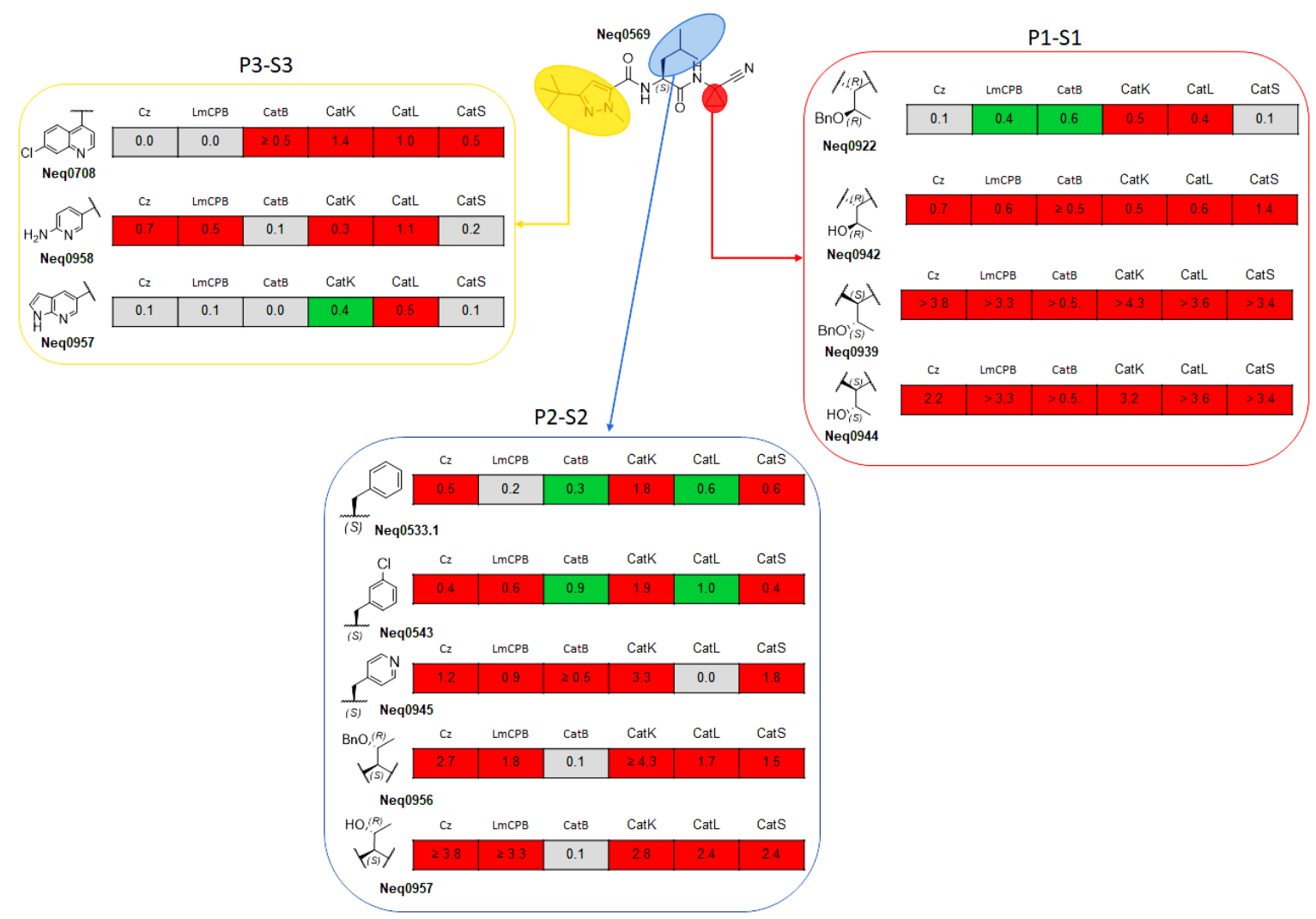

Values are reported as differences in $\mathrm{p} K_{\mathrm{i}}$ and color-coded as red (negative), green (positive), grey (no significant difference, $\Delta p K_{i}<0.2$ ).

Substitution in P3 positioned 1-methyl-3-tert-butyl-pyrazole ring with 7-chloro-quinoline (Neq0708), or $1 \mathrm{H}$-indole (Neq0958) preserved the high affinity towards $\mathrm{Cz}$ and LmCPB, and it is particularly striking given that this substitution leads to decrease of 1.0 and 0.5 in the $p K_{i}$ value for CatL. Noteworthy, when the 7-chloro-quinoline moiety was retained in P3 and leucine was exchanged with tryptophan in P2 [Neq0775 $\rightarrow$ Neq0708], a significant loss in affinity and selectivity was observed. Insertion of a basic moiety, i.e. 2-amino pyridine [Neq0569 $\rightarrow$ Neq0955], produced a substantial reduction in potency for $\mathrm{Cz}(-0.7)$ and $\operatorname{LmCPB}(-0.5)$. It is worth mentioning that inhibitor Neq0958 showed a high affinity for CatK ( $p K_{i}$ of 8.7) with a significant selectivity of 1.5 log units for CatK and CatL and over 3 log units for CatB.

In P2 position, the transformation of the leucine moiety to phenylalanine or its derivatives resulted in a loss in affinity up to one log unit for $\mathrm{Cz}$. A similar replacement led to a gain in affinity towards CatL and CatB, and is consistent with previously reported data (SCHMITZ et al., 2016). 
For compound Neq0569, as for compound Neq0533.1, the stereochemistry of the substituent in $\mathrm{P} 1$ is fundamental for the bimolecular recognition process. Moreover, the transformation [Neq0569 $\rightarrow$ Neq0922] retained the $\mathrm{p} K \mathrm{i}$ in the same range for $\mathrm{Cz}$ while increasing of 0.4 log units for LmCPB.

Nonadditivity in SAR is of considerable interest for testing and validation of models for binding affinity of ligands (CALABRÒ et al., 2016; KRAMER; FUCHS; LIEDL, 2015) and this is illustrated for the six cysteine proteases in Figure 14.

Nonadditivity can be quantified by comparing the $\Delta \mathrm{p} K_{\mathrm{i}}$ value resulting from a pair of substructural transformations with the sum of $\Delta \mathrm{p} K_{\mathrm{i}}$ values that result from the individual transformations. The $\mathrm{Cz} \Delta \mathrm{p} K_{\mathrm{i}}$ values for [Neq0533.1 $\rightarrow$ Neq0569] (0.5) and [Neq0533.1 $\rightarrow$ Neq0921] (-1.0) are shown in Figure 14.A sum up to -0.5. Nevertheless, [Neq0533.1 $\rightarrow$ Neq0922], which corresponds the simultaneous application of the pair transformations, is associated with a $\Delta \mathrm{p} K_{\mathrm{i}}$ value increase of +0.6 , thus indicating that the effects of this pair of transformations on $\mathrm{Cz}$ affinity are superadditive. The same was true for the effects of these two transformations on the other five CPs. Analogous analysis of the results in Figure 14B displays the effects of two transformations to be superadditive for the entire CP targets investigated herein. These results show that molecular recognition in $\mathrm{P} 2$ drives $\mathrm{P} 1$-S1 and $\mathrm{P} 1$-S1' interactions. 
Figure 14. Nonadditivity of SAR for inhibition of $\mathrm{Cz}$, CatL, and LmCPB.
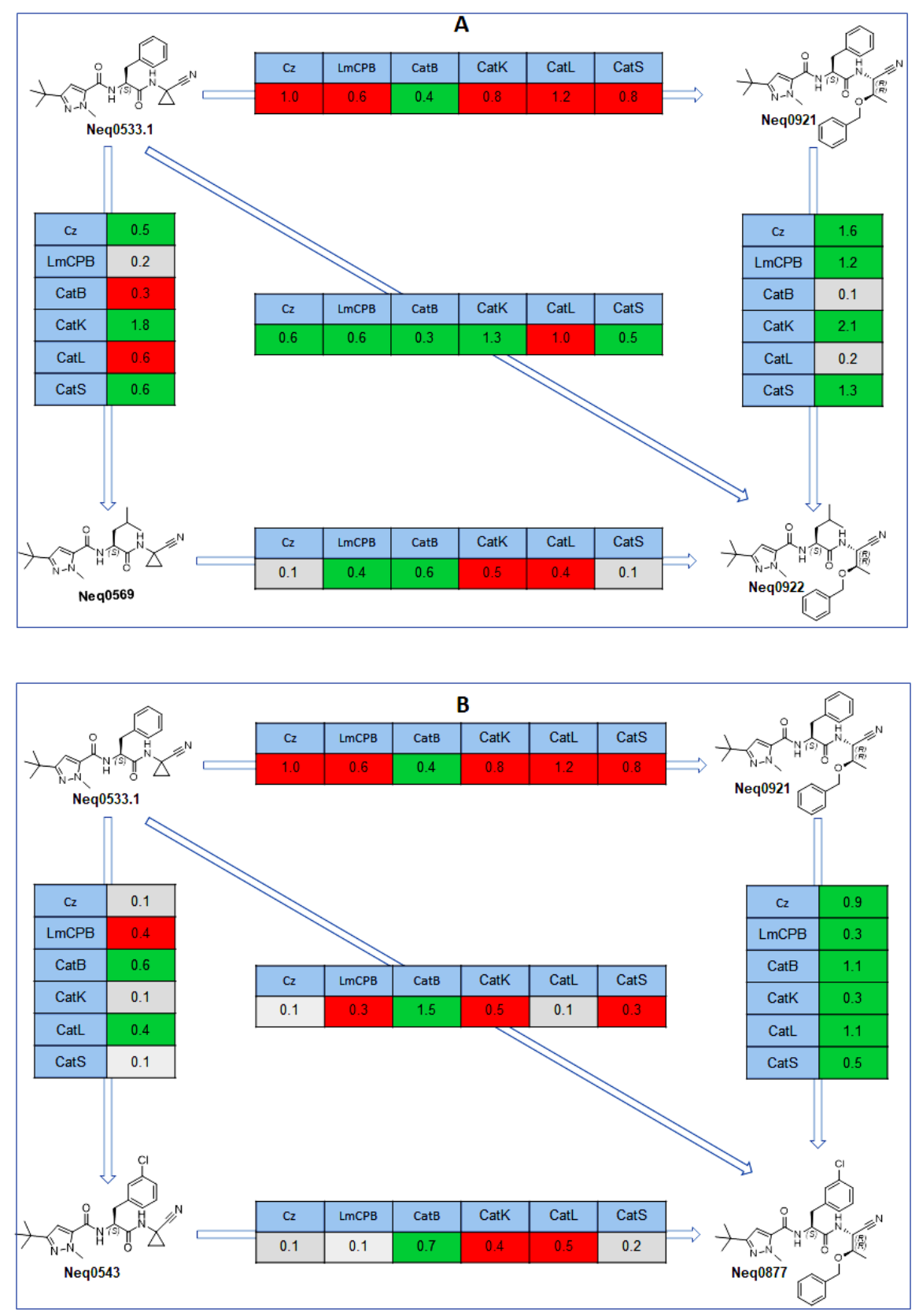

Values are reported as differences in $\mathrm{p} K_{\mathrm{i}}$ and color-coded as red (negative), green (positive), grey (no significant difference, $\Delta \mathrm{p} K_{\mathrm{i}}<0.2$ ).

Pairwise plots for the selectivity towards $\mathrm{Cz}$ in relation to other human cathepsins are provided in Figure 15. Chiefly, it is not trivial to achieve a significant selectivity for $\mathrm{Cz}$ inhibitors $\left(\Delta \mathrm{p} K_{\mathrm{i}}>1.0\right)$ over mammalian CPs due to their high structural similarity of the active site. Undeniably, CatB has a different mode of binding due to the larger S2 and S3 pockets (SCHMITZ et al., 2016). 
Compounds Neq0775 and Neq0942 displayed a significant selectivity toward CatL and CatS, respectively. The selectivity for $\mathrm{Cz}$ in case of compound Neq0775 is driven by the S3-P3 interaction, while for the second is driven by S1-P1. Likewise, the hydrophobic interaction in S1 and S1' with P1 of compounds Neq0937, Neq0953, and Neq0877 resulted in a good selectivity over CatK. On the other hand, results indicate how, in general, CatL, CatS and CatK inhibitors could be repurposed for the inhibition of protozoa CPs.

Figure 15. Selectivity pairwise plots.

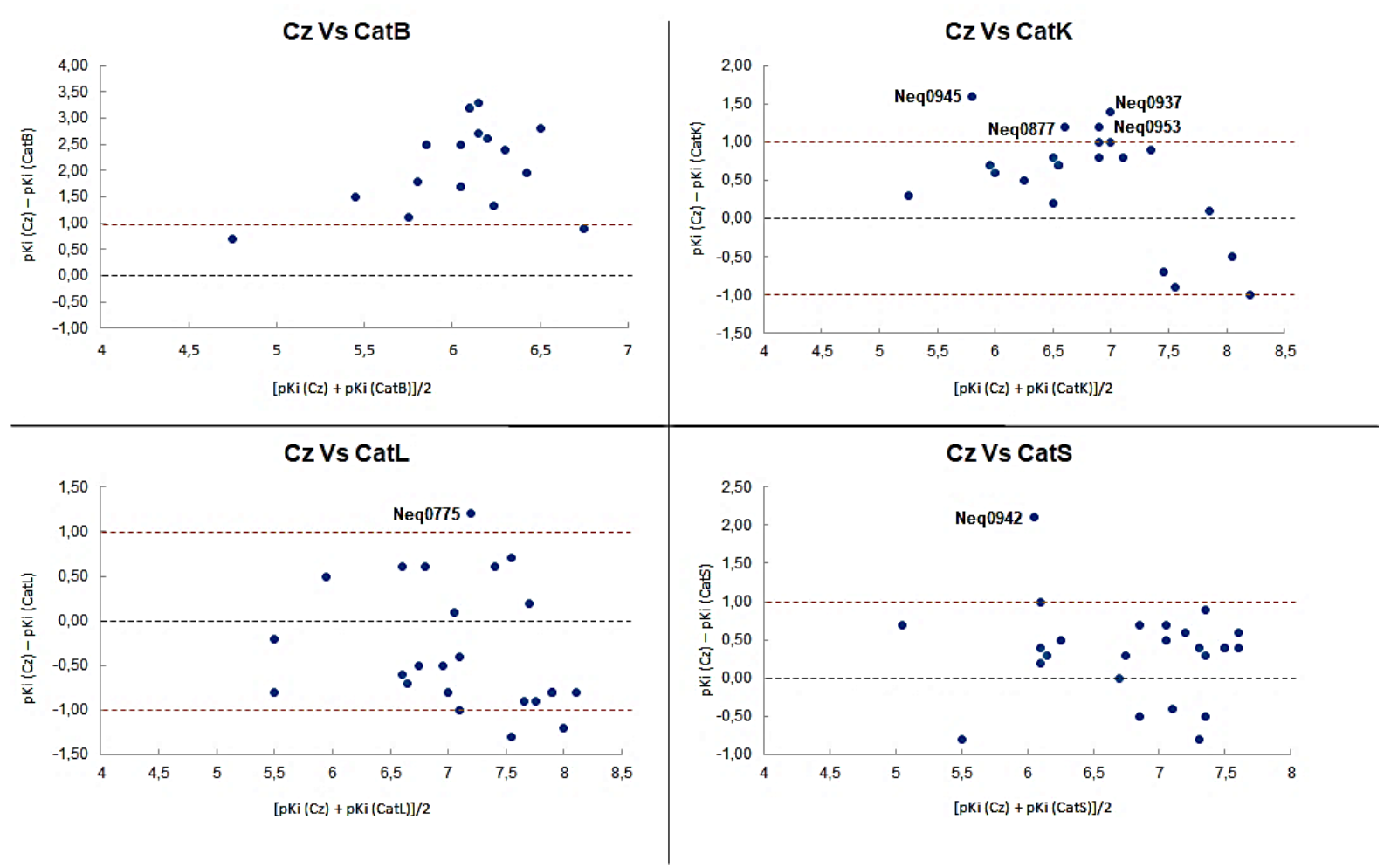

Values are given in $\mathrm{p} K_{\mathrm{i}} . \mathrm{X}$-axis represents the difference in $\mathrm{p} K_{\mathrm{i}}$ for the same inhibitor for a pair of CPs. Y-axis represents the mean value of $\mathrm{p} K_{\mathrm{i}}$ for the same inhibitor for a pair of CPs. Black dashed line highlights no selectivity. The magenta dashed line highlight a significant selectivity. Positive differences correspond to $\mathrm{Cz} p K_{\mathrm{i}}$ values that are greater than those for CatB, CatK, CatL or CatS. 


\subsection{Biological evaluation}

All compounds synthesized were evaluated for their trypanocidal activity against the amastigote form of the Tulahuen $T$. cruzi strain, and the results are presented in Figures 16, 17 and 18. Three compounds (Neq0940, Neq0938 and Neq0877) were equipotent with benznidazole as trypanocidal agents. In particular, compounds Neq0940 and Neq0877 are both low nanomolar Cz inhibitors and one-digit nanomolar for CatL. Compound Neq0938 had no affinity for any of the six CPs reported herein, which excluded the possibility that its mechanism of action is similar to compound Neq0940 and Neq0877. Physiochemical properties (i_logP, MW, TPSA, LogS) play an essential role for molecular discovery activities. As well, for potential trypanocidal agents, which had been designed as protozoan cysteine proteases inhibitors, physiochemical properties can influence their outcome. Therefore, we have included TPSA, calculated logP and LogS in this discussion.

In general, the substitution of the P3 or P2 moieties from the prototype compound (Neq0533.1) did not result in any increment in potency, except compound Neq0956 (Figure 16). Substitution of Phe for $(\mathrm{S}, \mathrm{R})$-Thr-O-Bn led to a modest trypanocidal potency. Modification in P1 strongly modulates the trypanocidal effect. If considering physicochemical properties, we can detect a trend for this small set where the reduction in lipophilicity corresponds to higher potency, as seen for compound Neq0940 ( $\mathrm{EC}_{50}=15.8 ;$ i_logP = 2.3). 
Figure 16. Schematic representation of physicochemical properties an SARs for trypanocidal activity.
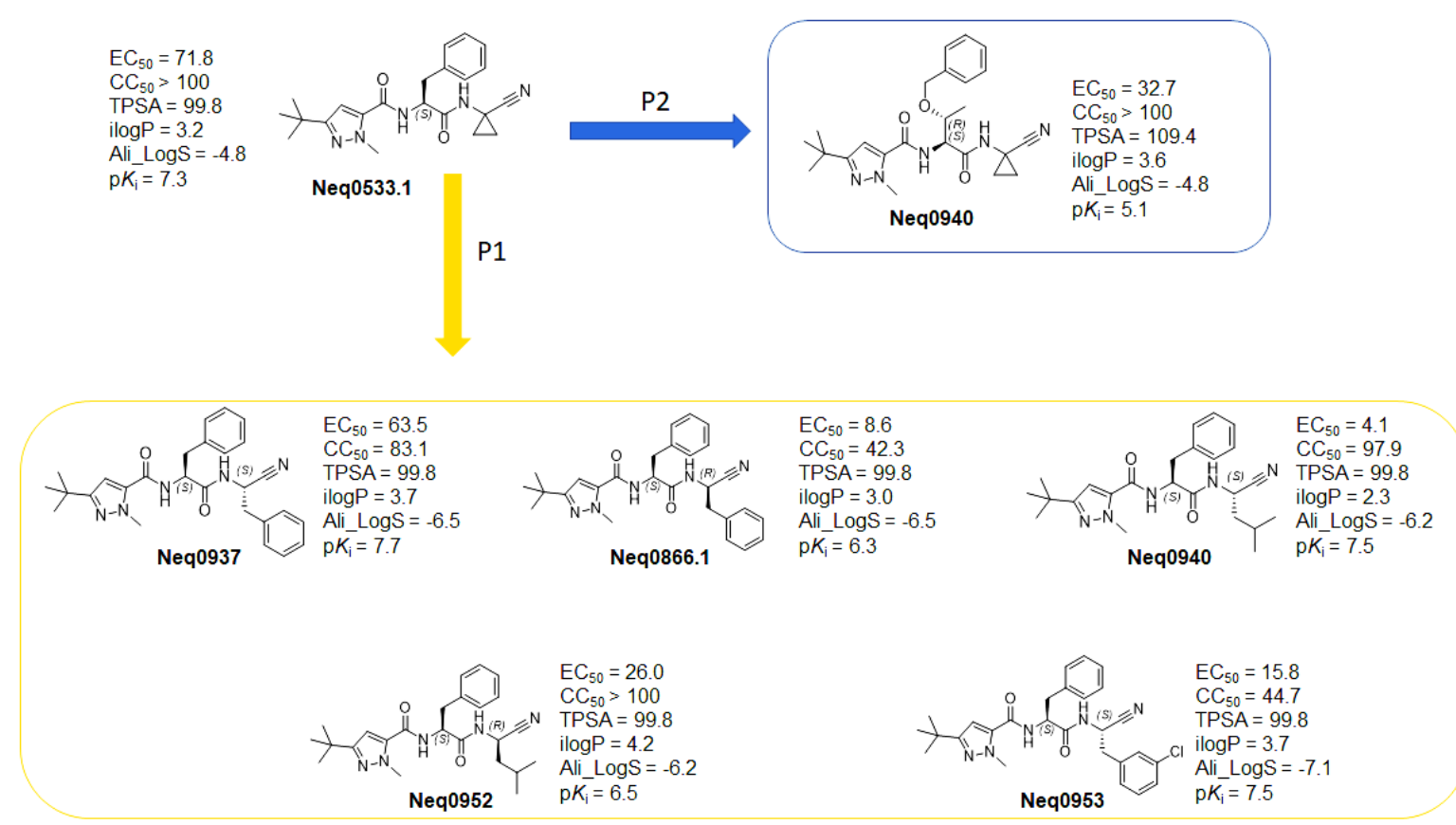

$\mathrm{EC}_{50}$ calculated for amastigote forms of $T$. cruzi (Tuhaluen strain). $\mathrm{CC}_{50}$ calculated for LLCMK2 strain (host cell). TPSA, ilogP, and Ali_Logs have been computed with the swissADME on-line service (DAINA; MICHIELIN; ZOETE, 2017). $\mathrm{p} K_{\mathrm{i}}$ is referring to $\mathrm{Cz}$ inhibition. Source: Own author.

Single modification in P2 or P3 of compound Neq0533.1 did not produce any beneficial effect on the trypanocidal potency. However, considering both changes [Neq0533.1 $\rightarrow$ Neq0877], compound (Neq0877) exhibits an excellent trypanocidal potency (Figure 17). In this case, the ilogP is the highest of this series and more than one log unit bigger than for compound Neq0953. Noteworthy, compound Neq0938 has no affinity for CPs and displays the same value for TPSA and ilogP as compound Neq0877. 
Figure 17. Schematic representation for nonadditivity of SARs for trypanocidal activity from Neq0533.1 to Neq0877.

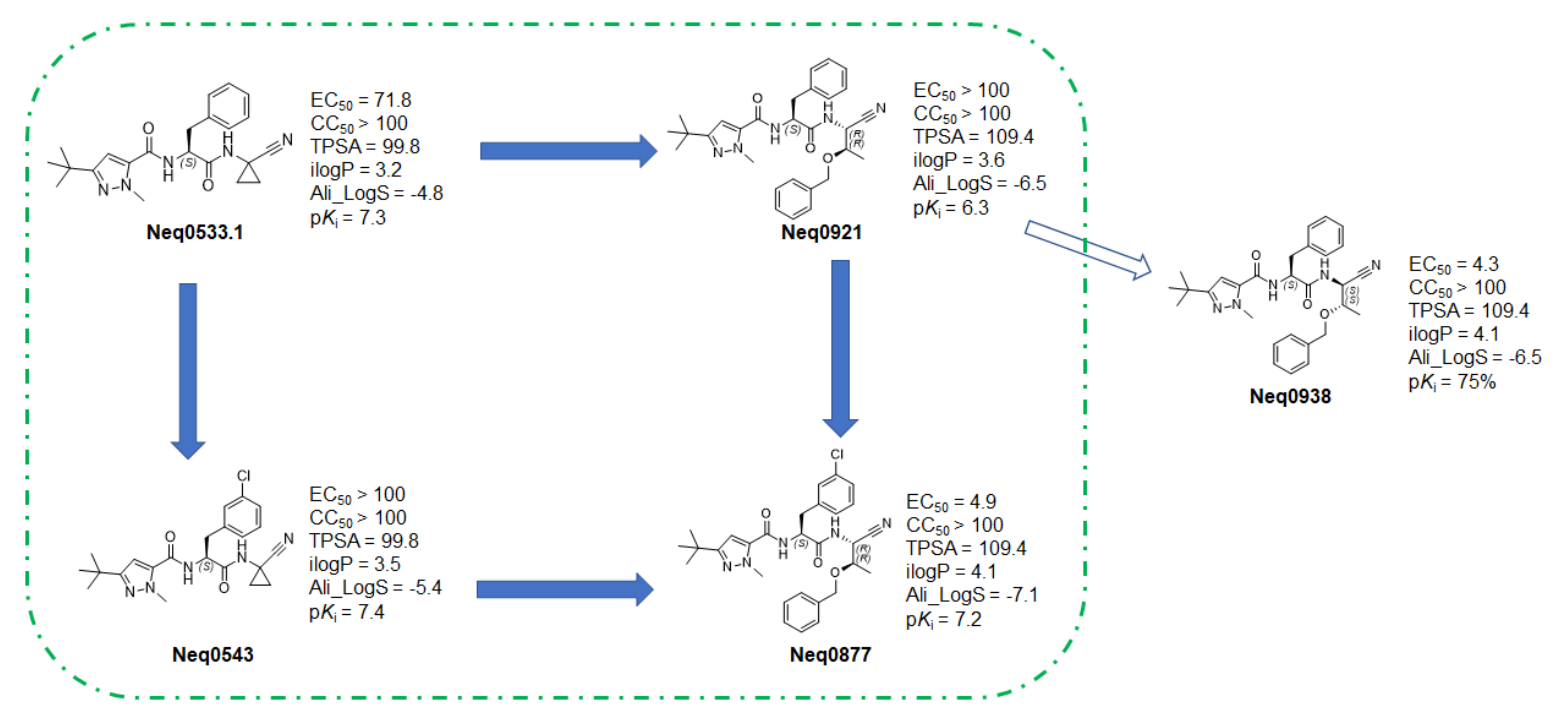

$\mathrm{EC}_{50}$ calculated for amastigote forms of $T$. cruzi (Tuhaluen strain). $\mathrm{CC}_{50}$ calculated for LLCMK2 strain (host cell). TPSA, ilogP, and Ali_Logs have been computed with the swissADME on-line service (DAINA; MICHIELIN; ZOETE, 2017). $\mathrm{p} K_{\mathrm{i}}$ values are referring to $\mathrm{Cz}$ inhibition.

Compounds bearing a leucine moiety in P2 displayed a peculiar behavior (Figure 18). Indeed, debenzylation of the threonine moiety in P1 led to an increase in potency [Neq0922 $\rightarrow$ Neq0943] and [Neq939 $\rightarrow$ Neq0942]. The trypanocidal potency for this set of compounds seems to have no direct correlation with $\mathrm{Cz}$ affinity. But again, active compounds have an ilogP lower than 3.0, which appears to be favourable for action on $T$. cruzi but without much reflection on $\mathrm{Cz}$ action. However, this surprising result should be pursued when synthesizing new trypanocidal agents. 
Figure 18. Schematic representation for nonadditivity of SARs from compound Neq0922 to compound Neq0944.

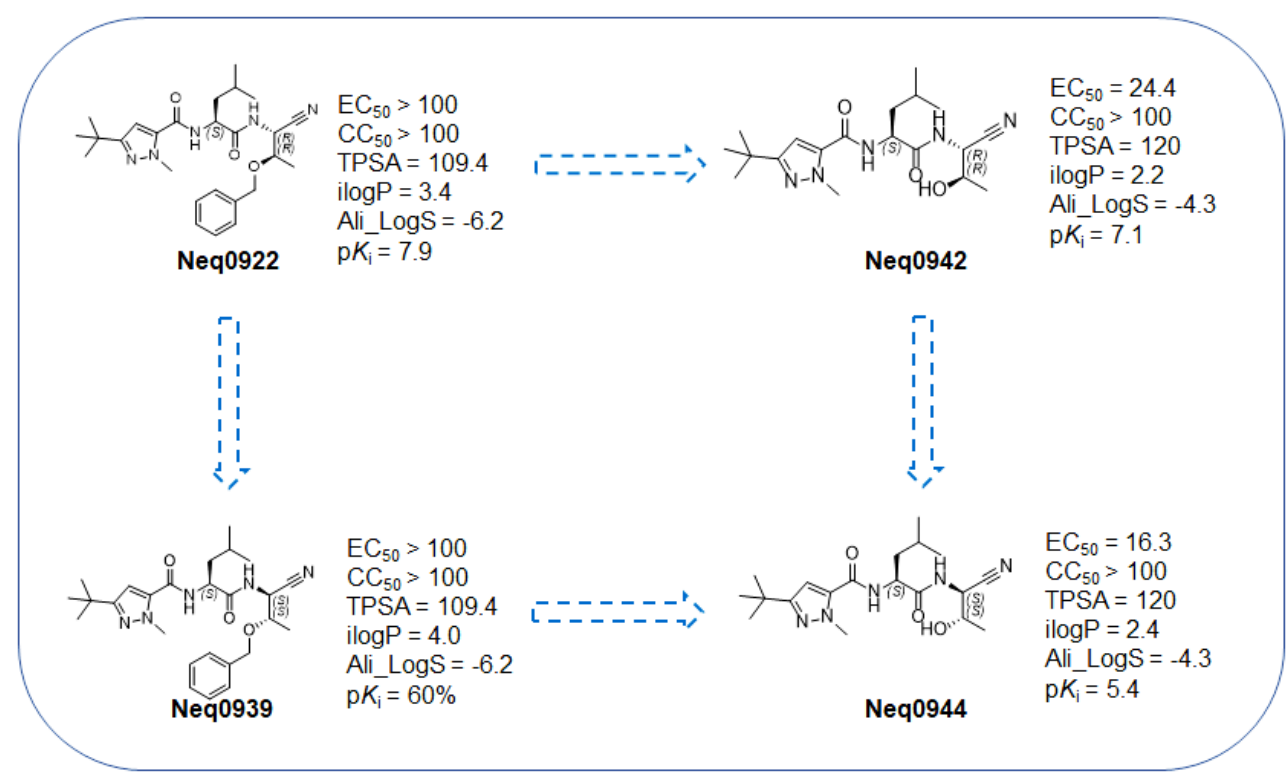

$E_{50}$ calculated for amastigote forms of $T$. cruzi (Tuhaluen strain). $C_{50}$ calculated for LLCMK2 strain (host cell). TPSA, ilogP, and Ali_Logs have been computed with the swissADME on-line service (DAINA; MICHIELIN; ZOETE, 2017). $\mathrm{p} \bar{K}_{\mathrm{i}}$ is referring to $\mathrm{Cz}$ inhibition.

Potential cytotoxicity of inhibitors was assessed with the LLCMK2 cell-based assay, and compounds were evaluated over three days using benznidazole as a control. Cytotoxicity at the highest concentration tested, which did not lead to precipitation (250 $\mu \mathrm{M})$, was low for the majority of test compounds. The most potent inhibitors of the amastigote T. cruzi Tulahuen strains (Neq0877, Neq0938 and Neq0940) showed the same range of cytotoxicity $(S I>20)$ when compared to benznidazole. Therefore, these compounds should be considered as new candidates for in vivo test against the infective form of amastigote T. cruzi Tulahuen strains. 


\subsection{Conclusion and perspective}

A series of 26 new dipeptidyl nitriles were designed, synthesized and tested against the recombinant cruzain $(\mathrm{Cz})$ to map its $\mathrm{S} 1 / \mathrm{S} 1^{\prime}$ subsites. Considering the possible interchangeability with another cysteine protease, the same series of dipeptidyl nitriles was also tested in LmCPB of Leishmania mexicana. Other potential targets of such inhibitors are human cysteine cathepsins, which are involved in different disease states affecting human beings. Thus, again, the same series of inhibitors have been tested in cathepsins B, L, K and S (CatB, CatL, CatK and CatS, respectively) that are involved, for instance, in cardiovascular diseases, which may be relevant to Chagas heart disease (MARIN-NETO et al., 2007). Our results demonstrate that inhibition of these cysteine proteases can be achieved by appropriate manipulation of the modeling skeleton of dipeptidyl nitriles. In addition, it was possible to identify trypanocidal agents with effects comparable to benznidazole, the drug of choice used for the treatment of Chagas disease. However, it is essential to underline the difficulties in transferring the enzymatic action to the trypanocidal action. Considering our recent works on $\mathrm{Cz}$ inhibition, we should investigate from a biological point of view if the mere inhibition of intracellular cruzipain by dipeptidyl nitriles is likely insufficient to cause cell death. In a perspective way, more efforts should be made to clarify the unfeasibility (up to now) to translate inhibition of $\mathrm{Cz}$ to trypanocidal activity. 


\section{CHAPTER IV - Synthesis and Structure-Activity Relationship of Nitrile-Based Cruzain Inhibitors Incorporating a Trifluoroethylamine-Based P2 Amide Replacement ${ }^{4}$}

\subsection{Background}

Up to this point, we have discussed structure-activity relationships of dipeptidyl nitriles as $\mathrm{Cz}$ covalent reversible inhibitors. However, the dipeptidyl nitrile scaffold could be cleaved by different proteases due to its structural similarity with endogenous substrates of proteases (LOFFET, 2002). Hence, the design and synthesis of metabolically stable peptide analogs is an essential issue in bioorganic and medicinal chemistry research. Recently, a powerful new strategy was adopted for replacing the peptide bond with a very useful surrogate: the stereogenic trifluoroethylamine function (SANI; VOLONTERIO; ZANDA, 2007; Figure 19). Undeniably, a trifluoroethyl group can replace the carbonyl of an amide and generate a metabolically stable, poorly basic amine that maintains the excellent hydrogen bond of an amide. The main properties featured by the trifluoroethylamino group are:

1) very low $\mathrm{NH}$ basicity

2) $\mathrm{CF}_{3} \mathrm{CH}(\mathrm{R}) \mathrm{NHR}$ ' backbone angle close to $120^{\circ}$

3) $\mathrm{C}_{-} \mathrm{CF}_{3}$ bond is substantially polar as to the $\mathrm{C}=\mathrm{O}$ (SANI; VOLONTERIO; ZANDA, 2007).

The $\mathrm{NH}$ of the trifluoroethylamine unit is an excellent hydrogen-bond donor (HBD), because of the strong electron-withdrawing effect exerted by the CF3 group and could always be considered a good mimic of a peptidic $\mathrm{NH}$. In spite of that, the trifluoromethyl group, contrary to the carbonyl oxygen, is a weak hydrogen-bond acceptor (HBA) (DUNITZ; TAYLOR, 1997). The trifluoroethylamine function can be an adequate peptide bond replacement only if the carbonyl group of the original ligand

\footnotetext{
4 This chapter describes joint work with Dr. Juliana Gomes (NEQUIMED/IQSC/USP, University of São Paulo, IQSC, Brazil) and Dr. Daniela de Vita (NEQUIMED/IQSC/USP, University of São Paulo, IQSC, Brazil) for the synthesis of compounds, Biological activities were performed by the group of Prof. Lucio Freitas Junior (Institute of Biomedical Sciences, ICB, University of São Paulo, Brazil).
} 
amide/peptide-bond is not involved in essential hydrogen- bonding interaction with the receptor.

Odanacatib (to date, the only cysteine protease inhibitor to reach clinical phase III) is an excellent example of this replacement, showing sub nanomolar $\mathrm{IC}_{50}$ values against cathepsin $\mathrm{K}$ and outstanding selectivity toward other cathepsins. It displays superior pharmacokinetics and efficacy in an appropriate rhesus monkey model (LI et al., 2006). On the other hand, the substitution of the carbonyl group for the trifluoroethyl group produces a new stereogenic center and two possible diasteroisomers from the same dipeptidyl nitrile (Figure 19).

Figure 19. Schematic representation of bioisosteric replacement of the amide bond in P3/P2 position for the trifluoroethylamino group. Example of successful bioisosteric replacement for cruzain inhibitors.

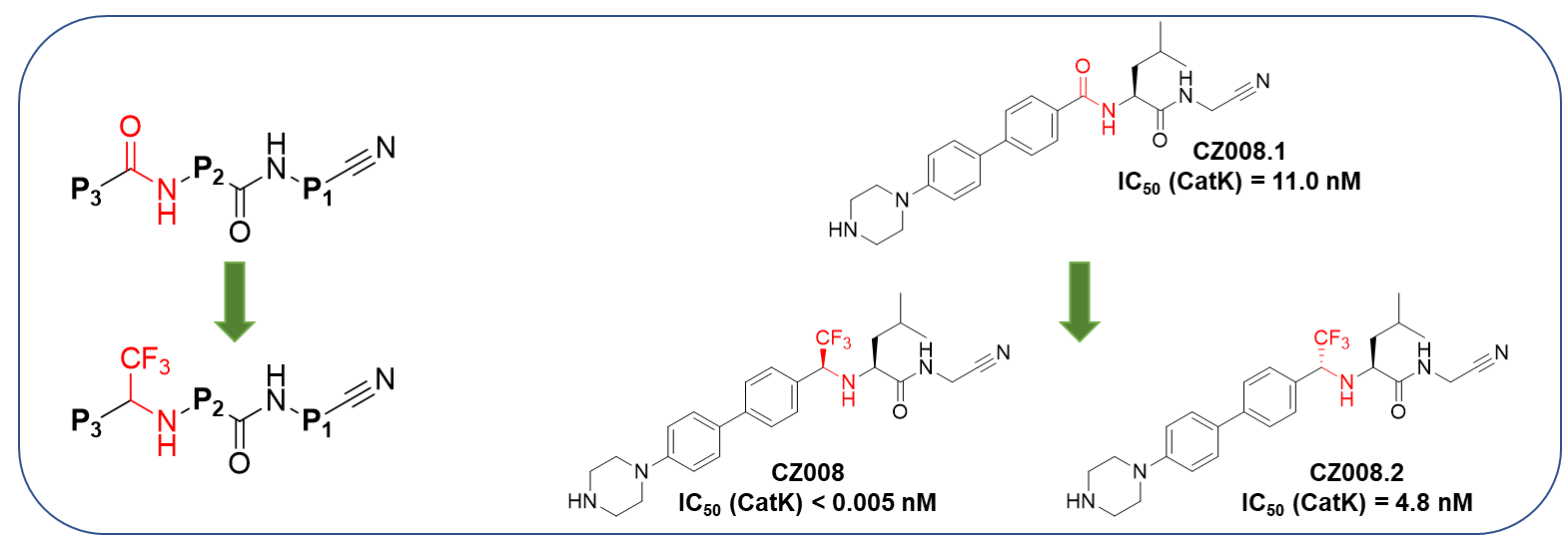

Data retrieved from: BEAULIEU, C. et al. Identification of potent and reversible cruzipain inhibitors for the treatment of Chagas disease. Bioorganic \& Medicinal Chemistry Letters, v. 20, n. 24, p. 7444-7449, dez. 2010.Source: Own author.

A published series of nitrile-based cruzain inhibitors as active trypanocidal agents (BEAULIEU et al., 2010) that are structurally related to the cathepsin $\mathrm{K}$ inhibitor Odanacatib (GAUTHIER et al., 2008) provided the starting point for this study. The compounds in this series typically feature a substituted biphenyl group at P3. The principal objective of the study was to establish structure-activity relationships (SAR) for cruzain inhibition by the deconstruction of the published inhibitor structures. Secondary goals were to explore non-additivity effects in the SAR and to assess the anti-trypanosomal activity of the compounds against an intracellular form of the of $T$. cruzi Y strain. 


\subsection{Design, synthesis and SAR of nitrile based cruzain inhibitors}

In light of that, we designed and synthesized 24 non-dipeptidyl nitrile covalent inhibitors of $\mathrm{Cz}$ and two new dipeptidyl nitriles (Table 3).

Table 3. Nequimed codes and structure representation of compounds designed and synthesized. Green area highlights dipeptidyl nitrile scaffold.

Number




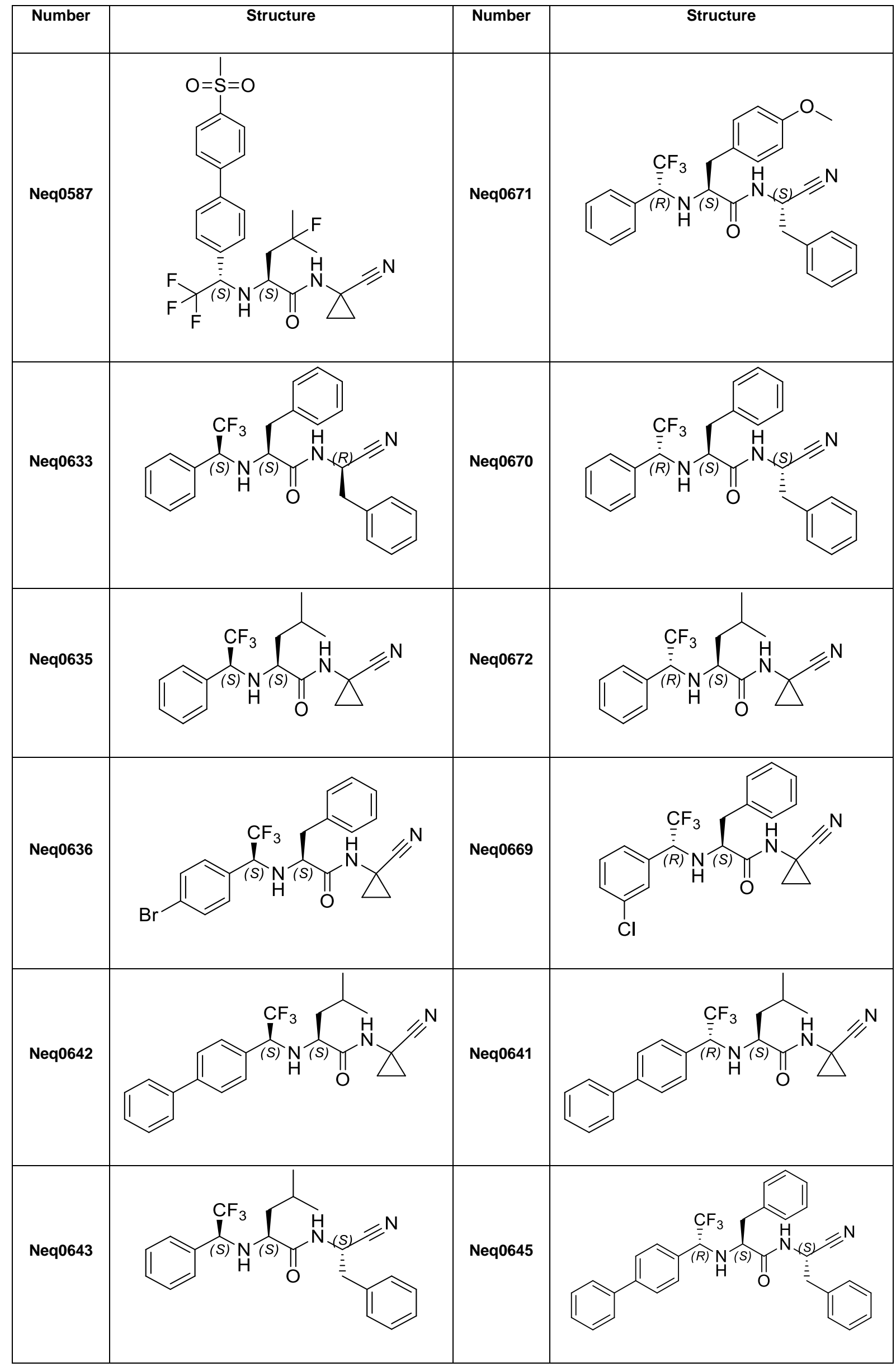




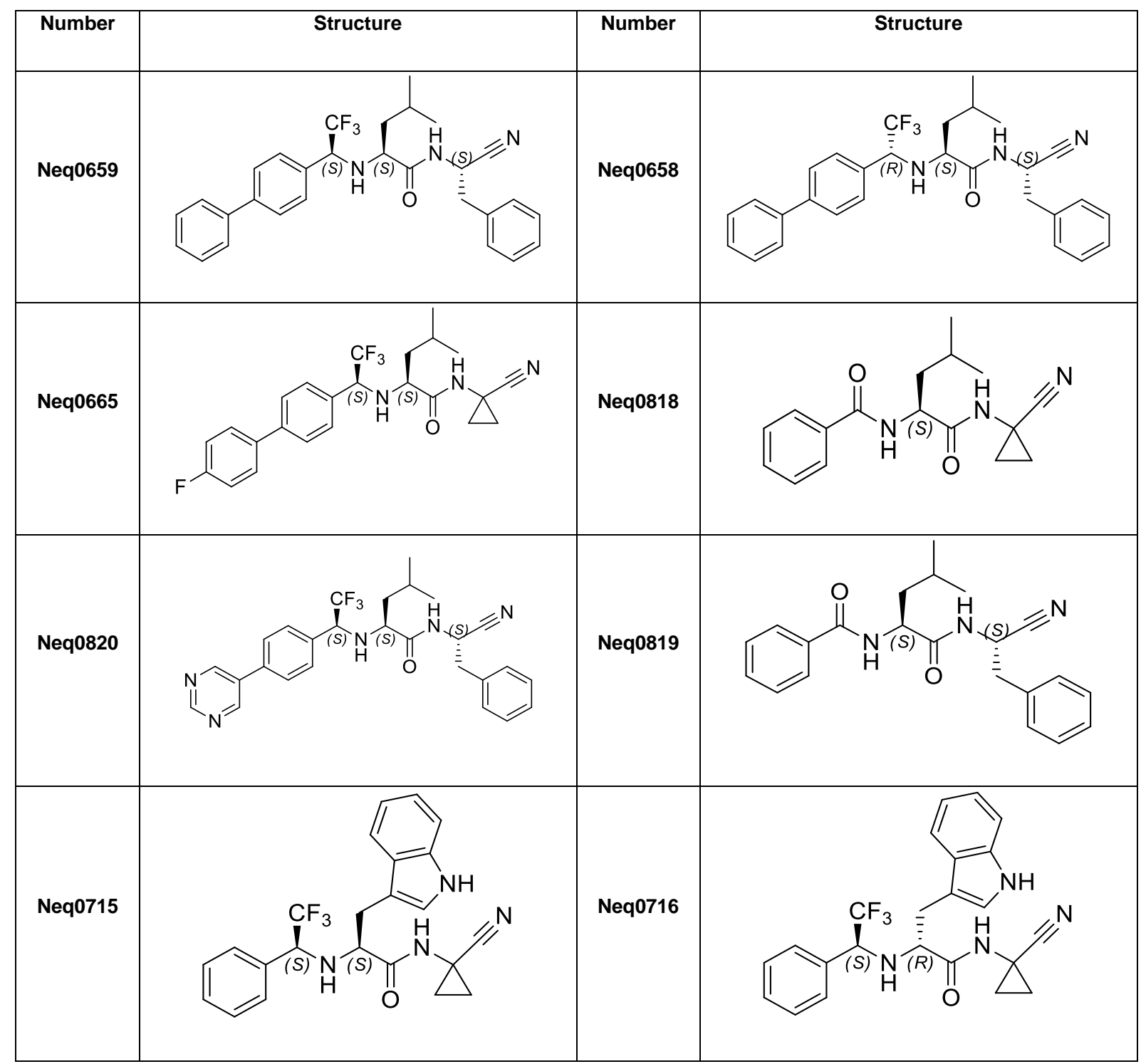

Source: Adapted from GOMES, J. et al. Synthesis and structure-activity relationship of nitrilebased cruzain inhibitors incorporating a trifluoroethylamine-based P2 amide replacement. Bioorganic \& Medicinal Chemistry, v. 27, n. 22, p. 115083, nov. 2019.

The synthesis of Neq0818 and Neq0819 were carried out as described in Chapters I and III. Synthesis of non-peptidic nitrile described in the following chapter was carried in two main steps: formation of 2,2,2-trifluorophenyl amino acid intermediates by reductive amination and then amide synthesis by coupling reagents (Scheme 3 ). 
Scheme 3. Retrosynthetic analysis for non-peptidic nitrile described in this chapter.

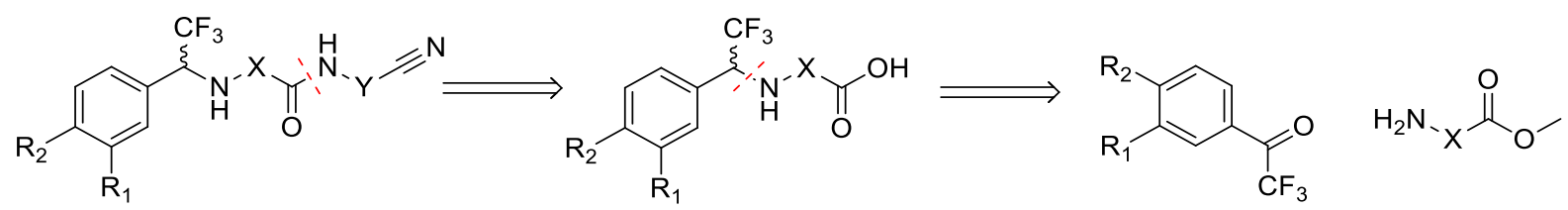

Source: Adapted from GOMES, J. et al. Synthesis and structure-activity relationship of nitrilebased cruzain inhibitors incorporating a trifluoroethylamine-based P2 amide replacement. Bioorganic \& Medicinal Chemistry, v. 27, n. 22, p. 115083, nov. 2019.

Methyl esters were produced from the commercial $D$ - or $L$-amino acids, using thionyl chloride in dry methanol, following the procedure previously described (BURTOLOSO et al., 2017). The following step consisted in the preparation of the 2,2,2-trifluorophenyl amino acid intermediates, as previously described with slight modifications such as completely absence of water, and use of DME as a solvent for diastereoselective reduction of the imine to the desired amine with $\mathrm{Zn}\left(\mathrm{BH}_{4}\right)_{2}$ (HUGHES et al., 2007).

Scheme 4. Synthetic scheme of 2,2,2-trifluorophenyl amino acid intermediates.

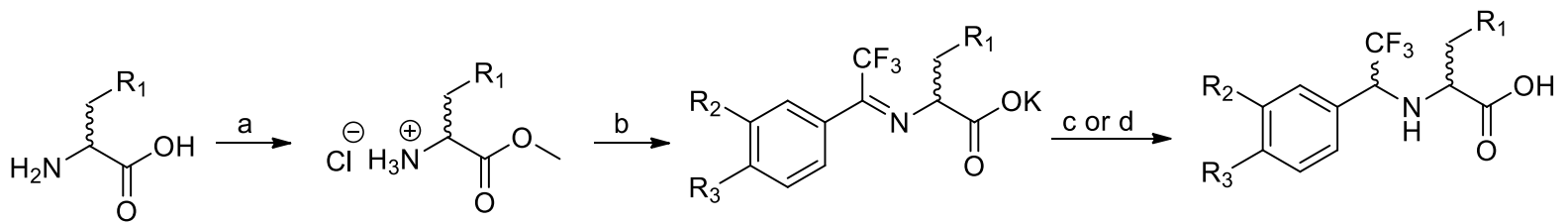

Reagents and conditions: (a) $\mathrm{SOCl}_{2}, \mathrm{CH}_{3} \mathrm{OH}$, reflux, $1 \mathrm{~h} \rightarrow \mathrm{rt}$, overnight; (b) $\operatorname{ArC}(=\mathrm{O}) \mathrm{CF}_{3}$, $\mathrm{K}_{2} \mathrm{CO}_{3}, \mathrm{CH}_{3} \mathrm{OH}, 50{ }^{\circ} \mathrm{C}, 18 \mathrm{~h}$; (c) $1 \mathrm{M} \mathrm{Zn}\left(\mathrm{BH}_{4}\right)_{2}$ in DME, ACN/CH $\mathrm{CH}_{3} \mathrm{OH}(5: 1),-40 /-45^{\circ} \mathrm{C}, 3 \mathrm{~h}$; (d) $\mathrm{NaBH}_{4}$, THF, rt, 6 h. Source: Adapted from GOMES, J. et al. Synthesis and structure-activity relationship of nitrile-based cruzain inhibitors incorporating a trifluoroethylamine-based P2 amide replacement. Bioorganic \& Medicinal Chemistry, v. 27, n. 22, p. 115083, nov. 2019.

Briefly, the amino esters were reacted with the appropriate 2,2,2trifluoroacetophenone, in the presence of potassium carbonate and methanol at $50^{\circ} \mathrm{C}$ for $18 \mathrm{~h}$, to afford the respective imines. The presence of water, resulting from imine formation, in the basic reaction medium at $50^{\circ} \mathrm{C}$ allows the hydrolysis of the methyl ester group, providing the potassium salts of the 2,2,2-trifluorophenyl imines. Due to their instability, all imines were used in the next step (diastereoselective reduction) without purification. 
The reduction with $\mathrm{NaBH}_{4}$ afforded, for the L-amino acid derivatives, the $R, S$ diastereoisomers (anti isomers), reflecting the fact that: the re face is sterically more hindered than the si face for the more stable conformation of these salts (HUGHES et al., 2007). This is due to the presence of the $R_{1}$ group of the $L$-amino acid moiety (phenyl, aryl, isopropyl), allowing the attack of the hydride ion to be, preferably, on the si side of the imine (HUGHES et al., 2007). On the contrary, to obtain the S,S diastereoisomers (syn isomers) the imines were reduced with $\mathrm{Zn}\left(\mathrm{BH}_{4}\right)_{2}$. In that case, the formation of the syn isomer as a major diastereoisomer can be explained by complexation of $\mathrm{Zn}^{2+}$ with the nitrogen and oxygen atoms at the 1,3-positions of the imine, respectively, making the si face sterically more hindered. When the starting material is the $D$-amino acid, the reduction of the corresponding imine gives the $S, R$ diastereoisomer (anti isomer) with $\mathrm{NaBH}_{4}$ and the R,R diastereoisomer (syn isomer) with $\mathrm{Zn}\left(\mathrm{BH}_{4}\right)_{2}$.

In general, we observed that $\mathrm{NaBH}_{4}$ reduction of the imine produced the desired amines with a diastereomeric excess over $95 \%$, while when using $\mathrm{Zn}\left(\mathrm{BH}_{4}\right)_{2}$ in $\mathrm{THF}$ the diastereomeric excess was lower than $80 \%$. Optimization of the reaction lead us to discover DME, $\mathrm{ACN} / \mathrm{CH}_{3} \mathrm{OH}(5: 1)$ as the best solution to increase the diastereomeric excess up to $90 \%$. The diastereomeric excesses in favor of the syn or anti isomer were measured by HPLC of the final compounds. If necessary, final products were purified by HPLC, equipped with a chiral column, to afford the desired outcome with a d.e. > $99 \%$ and e.e. $>99 \%$. To confirm the absence of epimerization in the chiral center of the amino acids during the synthetic steps, phenylalanine was employed as a model in this study. Therefore, racemic phenylalanine was used as a starting material, and the final compounds, after reduction (with $\mathrm{NaBH}_{4}$ or $\mathrm{Zn}\left(\mathrm{BH}_{4}\right)_{2}$ ) and amine coupling, were analyzed by HPLC which confirmed the integrity of the stereogenic center with an enantiomeric excess $>99 \%$ (see appendix).

After imine reduction, the amino acids were coupled with the appropriate amine, using HATU as a coupling agent to afford the desired product in good yield (Scheme 5). 
Scheme 5. Synthetic scheme for the coupling reaction.<smiles>[R]CC(N[C@@H](C[R])c1ccc([R3])c([R])c1)C(=O)O</smiles><smiles>N#CC(N)Cc1ccccc1</smiles>

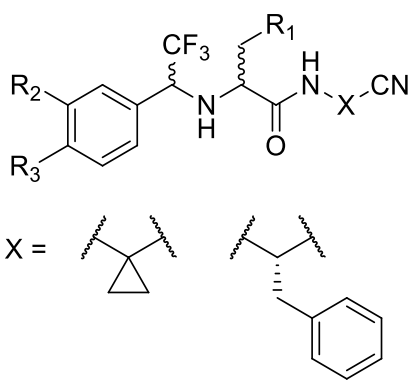

Reagents and conditions: (a) HATU, DIPEA, rt 22, h. Source: Adapted from GOMES, J. et al. Synthesis and structure-activity relationship of nitrile-based cruzain inhibitors incorporating a trifluoroethylamine-based P2 amide replacement. Source: Adapted from GOMES, J. et al. Synthesis and structure-activity relationship of nitrile-based cruzain inhibitors incorporating a trifluoroethylamine-based P2 amide replacement. Bioorganic \& Medicinal Chemistry, v. 27, n. 22, p. 115083, nov. 2019.

Finally, compounds Neq0665 and Neq0820 were obtained by a Suzuki cross-coupling reaction of the aryl bromide intermediates (Scheme 6). According to the procedure (BANDINI et al., 2009), the bromides reacted in the presence of sodium carbonate with the suitable boronic acid pinacol ester, using $\mathrm{PdCl}_{2} \mathrm{dppf}$ as a catalyst in $\mathrm{DMF}$, at $80^{\circ} \mathrm{C}$ for $3 \mathrm{~h}$.

Scheme 6. Synthetic scheme for Suzuki cross-coupling reaction.

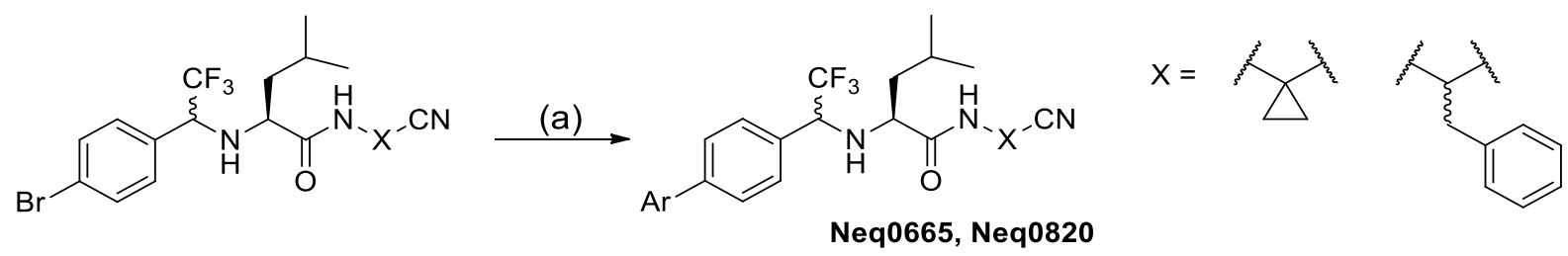

Reagents and conditions: (a) suitable boronic acid pinacol ester, $\mathrm{PdCl}_{2} \mathrm{dppf}, \mathrm{DMF}, 80^{\circ} \mathrm{C}, 3 \mathrm{~h}$, argon atmosphere. Source: Adapted from GOMES, J. et al. Synthesis and structure-activity relationship of nitrile-based cruzain inhibitors incorporating a trifluoroethylamine-based P2 amide replacement. Source: Adapted from GOMES, J. et al. Synthesis and structure-activity relationship of nitrile-based cruzain inhibitors incorporating a trifluoroethylamine-based P2 amide replacement. Bioorganic \& Medicinal Chemistry, v. 27, n. 22, p. 115083, nov. 2019.

Measured $p K_{i}$ values for inhibition of $\mathrm{Cz}$ and CatL are given in Table 4. The most potent compound (Neq0659; $p K_{i}=9.2$ ) synthesized in the course of the current study is the 
des-methylsulfonyl analog of a cruzain inhibitor for which a plC $\mathrm{C}_{50}$ value of 9.7 has been reported (CHENG CHEN et al., [s.d.]).

Table 4. Enzyme inhibition.

\begin{tabular}{|c|c|c|}
\hline Nequimed Code & $\mathrm{p} K_{\mathrm{i}}(\mathrm{Cz})^{\mathrm{a}}$ & $\mathrm{p} K_{\mathrm{i}}(\text { CatL) })^{\mathrm{a}}$ \\
\hline Neq0570 & 6.6 & 7.4 \\
\hline Neq0587 & 6.9 & 5.9 \\
\hline Neq0594 & 5.6 & ND \\
\hline Neq0595 & 5.1 & ND \\
\hline Neq0629 & 5.0 & 5.0 \\
\hline Neq0630 & 6.4 & 6.2 \\
\hline Neq0631 & 6.0 & 6.8 \\
\hline Neq0633 & 5.6 & 6.2 \\
\hline Neq0635 & 7.4 & ND \\
\hline Neq0636 & 5.7 & 6.6 \\
\hline Neq0641 & 7.2 & 6.2 \\
\hline Neq0642 & 8.1 & 6.1 \\
\hline
\end{tabular}




\begin{tabular}{|c|c|c|}
\hline Nequimed Code & $\mathrm{p} K_{\mathrm{i}}(\mathrm{Cz})^{\mathrm{a}}$ & $\mathrm{p} K_{\mathrm{i}}(\mathrm{CatL})^{\mathrm{a}}$ \\
\hline Neq0643 & 8.8 & 8.3 \\
\hline Neq0645 & $<5.0$ & ND \\
\hline Neq0658 & 6.6 & ND \\
\hline Neq0659 & 9.2 & 5.8 \\
\hline Neq0665 & 7.1 & 6.0 \\
\hline Neq0668 & 5.4 & ND \\
\hline Neq0669 & 5.5 & ND \\
\hline Neq0670 & 6.4 & 6.6 \\
\hline Neq0671 & 5.4 & 5.8 \\
\hline Neq0672 & 6.7 & ND \\
\hline Neq0715 & $<5.0$ & 5.9 \\
\hline Neq0716 & $<5.0$ & 6 \\
\hline Neq0818 & 7.3 & ND \\
\hline Neq0819 & 7.3 & ND \\
\hline Neq0820 & 8.8 & 7.6 \\
\hline
\end{tabular}


For all compounds, the standard error of the $K_{\mathrm{i}}$ is lower than $10 \%$. ${ }^{a} \mathrm{p} K_{\mathrm{i}}=-\log _{10}\left(K_{\mathrm{i}}\right)$; ND $=$ not determinate. Source: Own author.

The principal objective of this study was to perform a SAR around known trifluoroethylamine-based cruzain inhibitors to achieve structures of lower molecular complexity (HANN; LEACH; HARPER, 2001) with high affinity for $\mathrm{Cz}$ and good antiparasitic activity.

What's more, we used different SAR representations in this study, and Table 5 provides the key for the analyses.

Table 5. Key for structural transformations depicted in Figures 20.

\begin{tabular}{|c|c|c|c|c|}
\hline Label & Transformation & $\Delta \mathrm{N}_{\mathrm{nH}}{ }^{\mathrm{a}}$ & $\begin{array}{c}\text { Representation } \\
\text { in Figure } 20\end{array}$ & $\begin{array}{c}\text { Representation } \\
\text { in Figure } 21\end{array}$ \\
\hline$A$ & $\begin{array}{c}{[\mathrm{P} 1-} \\
\text { cyclopropane } \rightarrow \mathrm{P} 1- \\
\text { benzyl(S)] }\end{array}$ & 5 & & \\
\hline B & $\begin{array}{c}{[\text { P3-phenyl } \rightarrow \text { P3-4- }} \\
\text { biphenyl }]\end{array}$ & 6 & & \\
\hline $\mathrm{C}$ & {$[\mathrm{P3}-\mathrm{S} \rightarrow \mathrm{P3}-\mathrm{R}]$} & 0 & $N / A^{b}$ & $\Longrightarrow$ \\
\hline $\mathrm{D}$ & [P2-Leu $\rightarrow$ P2-Phe] & 3 & $\longrightarrow$ & $N / A^{b}$ \\
\hline
\end{tabular}

a Change in the number of non-hydrogen atoms. ${ }^{b}$ Not applicable. Source: Adapted from GOMES, J. et al. Synthesis and structure-activity relationship of nitrile-based cruzain inhibitors incorporating a trifluoroethylamine-based P2 amide replacement. Bioorganic \& Medicinal Chemistry, v. 27, n. 22, p. 115083, nov. 2019.

The basis of the lead-likeness concept is that optimization of leads typically results in increased lipophilicity and molecular size.These parameters may be regarded as the primary physicochemical risk factors in drug design (KENNY, 2019; TEAGUE et al., 1999). The structural modifications for which the most substantial increases in affinity 
are accompanied by the smallest increases in risk can be regarded being the most efficient in the context of hit or lead optimization (KENNY, 2019). This is the basis of group efficiency (GE; SAXTY et al., 2007). A highly efficient structural transformation can also be seen as a type of activity cliff (MAGGIORA, 2006; STUMPFE; BAJORATH, 2012). One limitation of GE as a tool for $S A R$ analysis is that it is not defined for structural transformations such as inversion of configuration, aza-substitution and amide reversal for which there is no net change in the number of non-hydrogen atoms. The published cruzain inhibitors (BEAULIEU et al., 2010) were deconstructed to the structural prototype Neq0635 by truncation of P3 biphenyl substituents to phenyl and by replacement of the benzyl substituted P1 linker with cyclopropane moiety. Compound Neq0672, in which the P3 chiral center of Neq0635 is $S$ rather than $R$, and the dipeptide nitrile Neq0818 were also used as structural references. The effects of synthetic elaboration are summarized by plotting $p K_{i}$ versus the change in number $\left(\Delta \mathrm{NnH}_{\mathrm{H}}\right)$ of non-hydrogen atoms relative to the reference structure (Table 5). Plotting against $\Delta \mathrm{N}_{n H}$ rather than $\mathrm{N}_{n H}$ allows the dipeptide nitrile $\mathrm{SAR}$ to be visualized in the same frame of reference as the other inhibitors. The gradient of the line linking two points quantifies the sensitivity of affinity to an increase in molecular size (KENNY, 2019). For a structural transformation associated with a net change in molecular size, the extent to which the different lines, represent the structural transformation, are parallel gives a visual indication of the degree to which SAR is additive (Figure 20). 
Figure 20. The sensitivity of potency $\left(\mathrm{p} K_{\mathrm{i}}\right)$ to structural modifications $\mathrm{A}, \mathrm{B}$, and $\mathrm{D}$ (see Table 5 for key).

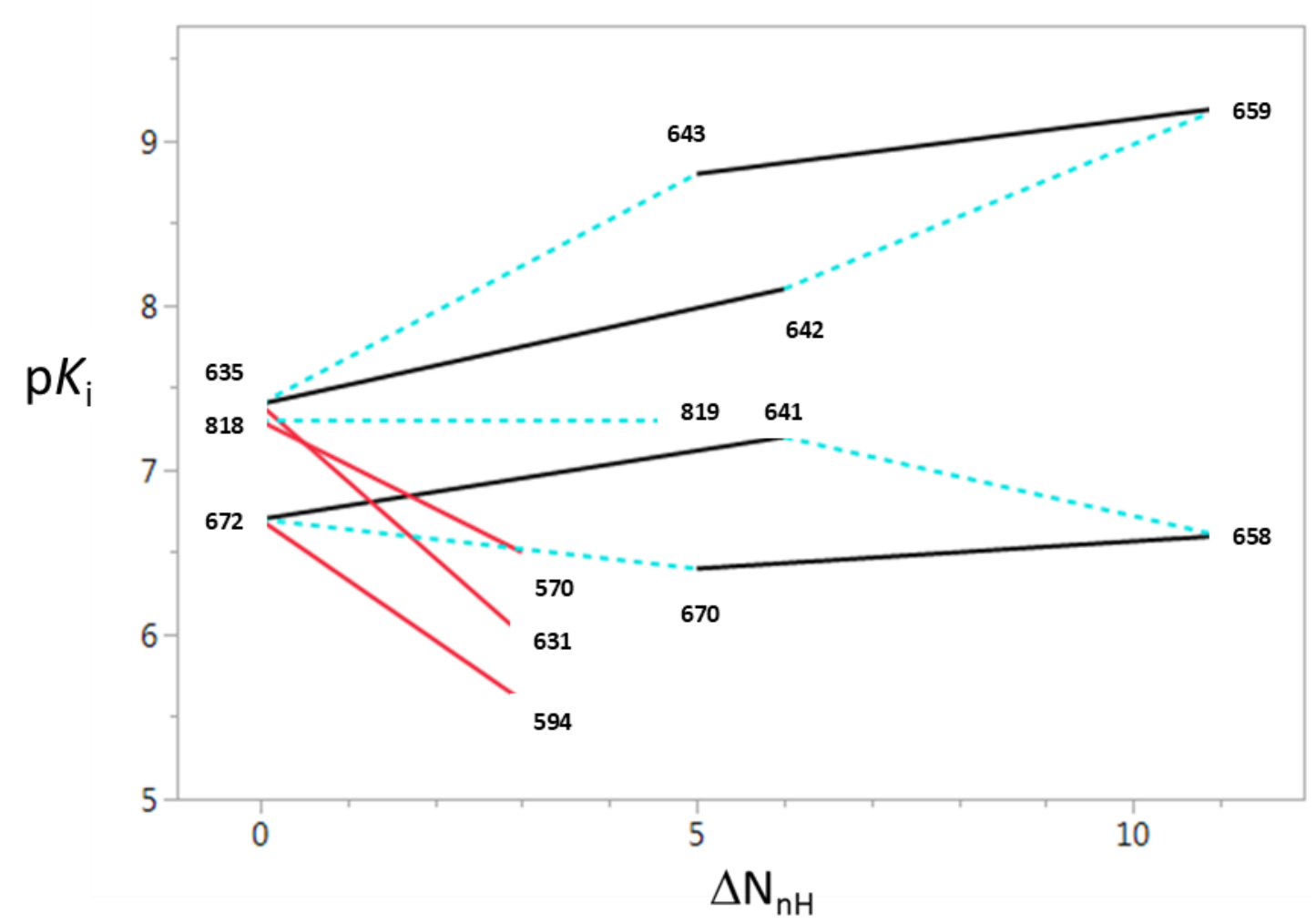

Numbers in bold refer to Nequimed numbers. Source: Adapted from GOMES, J. et al. Synthesis and structure-activity relationship of nitrile-based cruzain inhibitors incorporating a trifluoroethylamine-based P2 amide replacement. Bioorganic \& Medicinal Chemistry, v. 27, n. 22, p. 115083, nov. 2019.

The [phenyl $\rightarrow$ 4-biphenyl] transformation at P3 (solid black line) leads to increases in $\mathrm{p} K_{\mathrm{i}}$ for trifluoroethylamines regardless of the P3 stereochemistry. In contrast, the [cyclopropane $\rightarrow$ S-benzylmethylene] transformation at P1 leads to a rise in $\mathrm{p} K \mathrm{i}$ when the $\mathrm{P} 3$ configuration is $\mathrm{S}$ but a decrease in $\mathrm{p} K_{\mathrm{i}}$ when this is $\mathrm{R}$. The [cyclopropane $\rightarrow \mathrm{S}$ benzylmethylene] transformation at P1 does not affect the affinity of the dipeptide nitrile Neq0818. Exchange of the P2 leucine (solid red line) for phenylalanine leads to decreases in affinity ranging from 0.7 to 1.4 for the three reference compounds; as already reported above for dipeptidyl nitrile (see chapter III).

Substitution of the P3 substituents with a halogen typically leads to small decreases in affinity, in contrast to the positive trend displayed in chapter I for dipeptidyl nitrile. The $\mathrm{p} K_{\mathrm{i}}$ values for Neq0665, Neq0636 and Neq0669 are all within 0.3 log units of the respective values for the compounds from which they were derived. Aza-substitution 
of the P3-biphenyl is well tolerated, and Neq0820 is only $0.4 \log$ units less potent than Neq0659. Despite no significant change, a pyrimidine is a fascinating group in the medicinal chemistry field. The pyrimidine increased the solubility of the molecule, without modifying the primary interaction with the hydrophobic pockets of the protein. Replacement of the P2 phenylalanine by O-methyltyrosine for Neq0594 and Neq0631 resulted in decreases in $\mathrm{p} K_{\mathrm{i}}$ of 0.5 and 0.6 respectively. In contrast, the [Neq0633 $\rightarrow$ Neq0630] transformation leads to an increase in $p K_{i}$ of 0.8 log units, which illustrates how the P1-substituent can influence the P2-substituent SAR. Compound Neq0671 was observed to be at least 0.4 log units more potent than Neq0629 and this preference for the $\mathrm{S}$ configuration at $\mathrm{P} 1$ is consistent with what has been reported for analogs substituted with 2-fluoro-4-cyanobenzyl at P1.

The cruzain inhibition SAR associated with the structural transformations $A, B$ and $C$ (defined in Table 5) is illustrated in Figure 21. Opposite faces of the cube in Figure 21 represent the application of the two structural transformations to starting points that are connected by the third structural transformation. The difference between $\Delta \mathrm{p} K$ values associated with parallel sides of each cube face quantifies the extent to which the associated SAR is non-additive while the dependence of the $\Delta p K_{i}$ values on the order in which structural transformations are applied indicates whether the SAR is subadditive or superadditive. This can be illustrated by the effects of using structural transforms $A$ and $C$ to Neq0672, which are depicted in the front face of the cube in Figure 21 . The difference (1.7 log units) between the $\Delta p K_{i}$ values corresponding to each structural transformation shows that the associated SAR is strongly non-additive. 
Figure 21. Nonadditivity in SAR for structural transformations $A, B$, and $C$ (see Table 5 for key).

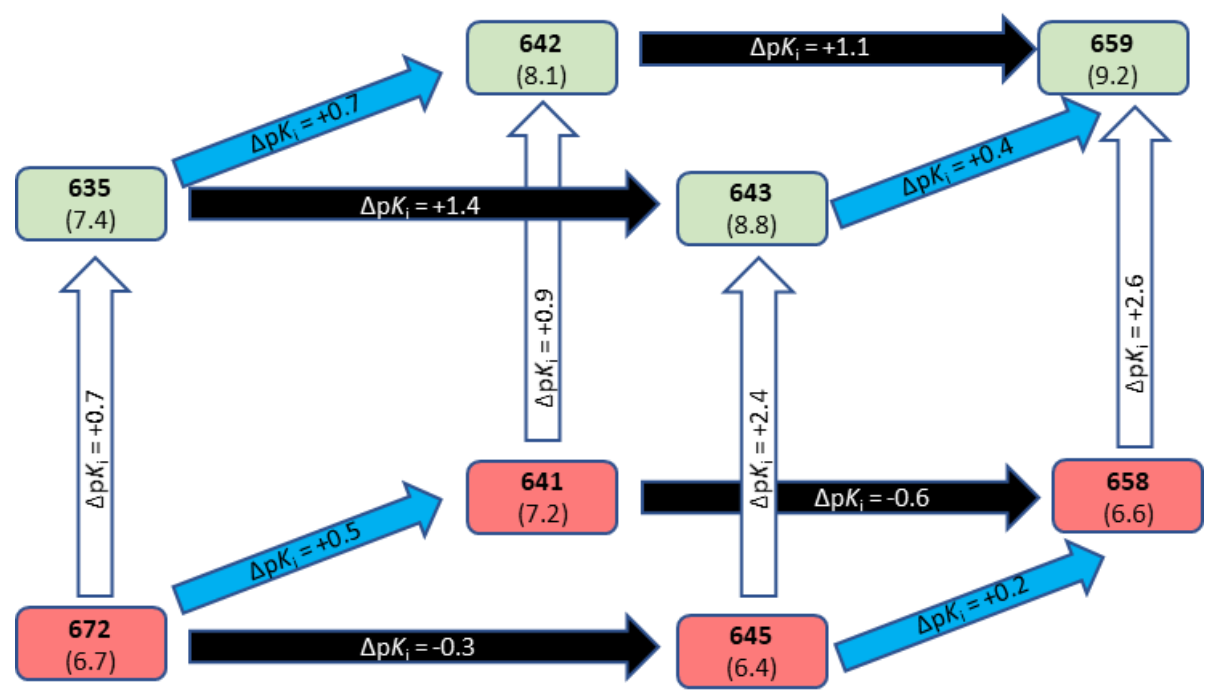

Numbers in bold refer to Nequimed numbers. Number in brackets refer to $\mathrm{pK}_{\mathrm{i}}$ values.

The results shown in Figure 21 are presented in Table 6 with the corresponding values of $\delta$ which quantify the non-additivity for each pair of transformations. Source: Adapted from GOMES, J. et al. Synthesis and structure-activity relationship of nitrile-based cruzain inhibitors incorporating a trifluoroethylamine-based P2 amide replacement. Bioorganic \& Medicinal Chemistry, v. 27, n. 22, p. 115083, nov. 2019.

Table 6. Nonadditivity in SAR for structural transformations A, B, and C (see Table 5 for key).

\begin{tabular}{|c|c|c|c|c|c|c|}
\hline \multirow{2}{*}{$\begin{array}{c}\text { Initial } \\
\text { structure }\end{array}$} & \multicolumn{2}{|c|}{ Transformations $^{a}$} & \multirow{2}{*}{$\Delta \mathrm{p} K_{\mathrm{i}}[\mathrm{I}]^{\mathrm{b}}$} & \multirow{2}{*}{$\Delta \mathrm{p} K_{\mathrm{i}}[\mathrm{II}]^{\mathrm{c}}$} & \multirow{2}{*}{$\Delta \mathrm{p} K_{\mathrm{i}}[\mathrm{I} \text { and II }]^{\mathrm{d}}$} & \multirow{2}{*}{$\delta^{\mathrm{e}}$} \\
\hline & I & II & & & & \\
\hline Neq0672 & A & $B$ & -0.3 & +0.5 & -0.1 & -0.3 \\
\hline Neq0635 & $A$ & B & +1.4 & +0.7 & +1.8 & -0.3 \\
\hline Neq0672 & $A$ & $\mathrm{C}$ & -0.3 & +0.7 & +2.1 & +1.7 \\
\hline Neq0641 & $A$ & $\mathrm{C}$ & -0.6 & +0.9 & +2.0 & +1.7 \\
\hline Neq0672 & $B$ & $\mathrm{C}$ & +0.5 & +0.9 & +1.4 & 0 \\
\hline Neq0645 & $B$ & C & +0.2 & +2.4 & +2.8 & +0.2 \\
\hline
\end{tabular}

${ }^{a}$ Defined in Table $5 ;{ }^{b} \Delta \mathrm{p} K$ referring to the transformation I; ${ }^{\mathrm{c}} \Delta \mathrm{p} K \mathrm{i}$ referring to transformation II; ${ }^{d} \Delta \mathrm{pKi}$ referring to the change I and II applied to initial structure; ${ }^{e}$ Degree of nonadditivity, if 
$\delta<0$ subadditive, if $\delta>0$ superadditive. Source: Adapted from GOMES, J. et al. Synthesis and structure-activity relationship of nitrile-based cruzain inhibitors incorporating a trifluoroethylamine-based P2 amide replacement. Bioorganic \& Medicinal Chemistry, v. 27, n. 22, p. 115083, nov. 2019.

One interpretation of the superadditive SAR observed for the A and $C$ transformations is that having the P3 substituent with the $S$ configuration enables the P1 benzyl substituent to interact more effectively with the protein than for the $R$ configuration. Nevertheless, caution is needed when interpreting nonadditivity in terms of molecular interactions, because the phenomenon is inherently non-local in nature.

Compound Neq0659 shows significant selectivity for $\mathrm{Cz}$ over cathepsin $\mathrm{L}$, and the $\mathrm{p} K_{\mathrm{i}}$ values against these cysteine proteases differ by 3.4 log units. This is consistent with what has been reported for structural analogs of this compound (BEAULIEU et al., 2010). The corresponding $p K_{i}$ differences (Cz - CatL) for compounds Neq0642 (2.0) and Neq0643 (0.5) show that both P3 biphenyl and P1 benzyl influence selectivity. The P3 configuration also influences selectivity as exemplified by the $\mathrm{p} K_{\mathrm{i}}$ differences $(\mathrm{Cz}$ CatL) for Neq0641 (1.0) and Neq0645 (-0.2). Aza-substitution of the P3 biphenyl of Neq0659 leads to reduced selectivity as shown by the $\mathrm{pKi}$ values of 8.8 (cruzain) and 7.6 (CatL) measured for Neq0820.

Unfortunately, meaningful SAR cannot be derived for the cell-based assay results, because it was only possible to measure $\mathrm{EC}_{50}$ values for the two compounds Neq0715 and Neq0716, (11 $\mu \mathrm{M}$ and $26 \mu \mathrm{M}$ respectively) evaluated in this study. In general, failure of enzyme inhibitory activity to translate to activity in a cell-based assay should be anticipated, especially for an intracellular parasite, and may reflect poor permeability or an enzyme inhibition model that is not relevant in the cellular context (AVELAR et al., 2015). Although neither compound shows significant cruzain inhibition $\left(\mathrm{p} K_{\mathrm{i}}<5\right)$, the $\mathrm{EC}_{50}$ values for Neq0715 $(11 \mu \mathrm{M})$ and Neq0716 $(26 \mu \mathrm{M})$ are too high to allow inferences to be drawn as to whether or not their effects in the cell-based assay are due to cruzain inhibition. As for the class of inhibitors described above, it is not possible to predict trypanocidal activity by $\mathrm{Cz}$ inhibition ability. 


\subsection{Conclusion and perspective}

The structure-activity relationship for a series of cruzain inhibitors reveals a significant degree of superadditivity, which can be visualized by plotting $p K_{i}$ against several nonhydrogen atoms. Moreover, we show that plotting affinity against molecular size provides a means to visualize both the molecular size efficiency of structural transformations and the nonadditivity Analysis of the structure-activity relationship shows that the biphenyl P3-substituent that is present in the fundamental starting point for the study can be truncated to phenyl with the loss of only 0.4 log units of affinity. It is also shown how the stereochemistry of the trifluoromethyl group in P2/P3 strongly influences the affinity to $\mathrm{Cz}$ and the selectivity toward CatL. When comparing with the dipeptidyI nitrile reported above (chapter I, II and III) the bioisostere replacement of the amide bond with the trifluoromethylamine group and (?) lead to one-digit nanomolar inhibitors of $\mathrm{Cz}$ with over one-thousand-fold selectivity for CatL. However, it is important to stress that for this class of compound, as for dipeptidyl nitrile (see chapter III), no direct translation from $\mathrm{Cz}$ inhibition to anti-trypanosomal activity was observed. 


\section{CHAPTER V - N-Sulfonyl Dipeptide Nitriles as Inhibitors of Human Cathepsin} S: In silico Design, Synthesis and Biochemical Characterization ${ }^{5}$

\subsection{Background}

As mentioned before (chapter IV), over the last year our group focused on the synthesis of new derivates where the carbonyl group in P3/P2 position is replaced with a trifluoromethyl group (-CF3) (BURTOLOSO et al., 2017) and where the affinity is maintained or increased. However, this kind of replacement brought two challenges: increase number of chiral centers and higher cost of production. Therefore, we focused our attention on the synthesis of new inhibitors by reducing the number of stereogenic centers and synthetic feasibility of sulfonamides. Sulfonamide motif appears in 111 approved drugs or agents in clinical trials. The total number of organic molecules containing this functional group is enormous (SEHGELMEBLE et al., 2012). Besides that, sulfonamides are not conventional bioisostere of amide due to the presence of two oxygen bind to the Sulfur atom and due to the loss of planarity. Sulfonamides are known to have conformational preferences in which the nitrogen lone pair bisects the $\mathrm{O}=\mathrm{S}=\mathrm{O}$ angle in the Newman projection (SEHGELMEBLE et al., 2012). Moreover, it has been already reported that the structural replacement of the peptide bond for a sulfonamide maintained the affinity toward Cz (Figure 22; SCHEIDT et al., 1998).

\footnotetext{
5 This chapter describes joint work with the group of Prof. Jürgen Bajorath (University of Bonn, B-it, Germany) for modelling studies and with the group of Prof. Michael Gütschow (University of Bonn, Pharmaceutical Institute, Germany) for kinetics measurements on human cathepsins and for the synthesis of Neq0934, Neq0935, Neq0936 and Neq0937.
} 
Figure 22. (a) Newman project of a sulphonamide bond; (b) bioisosteric replacement of the amide bond to sulfonamide bond in P3/P2 region. Example of amide bond replacement from K777 to K777.S; (c) Torsional profile of Neq0830 performed with "Molecular Operating Environment" (MOE), version 2018.0101.

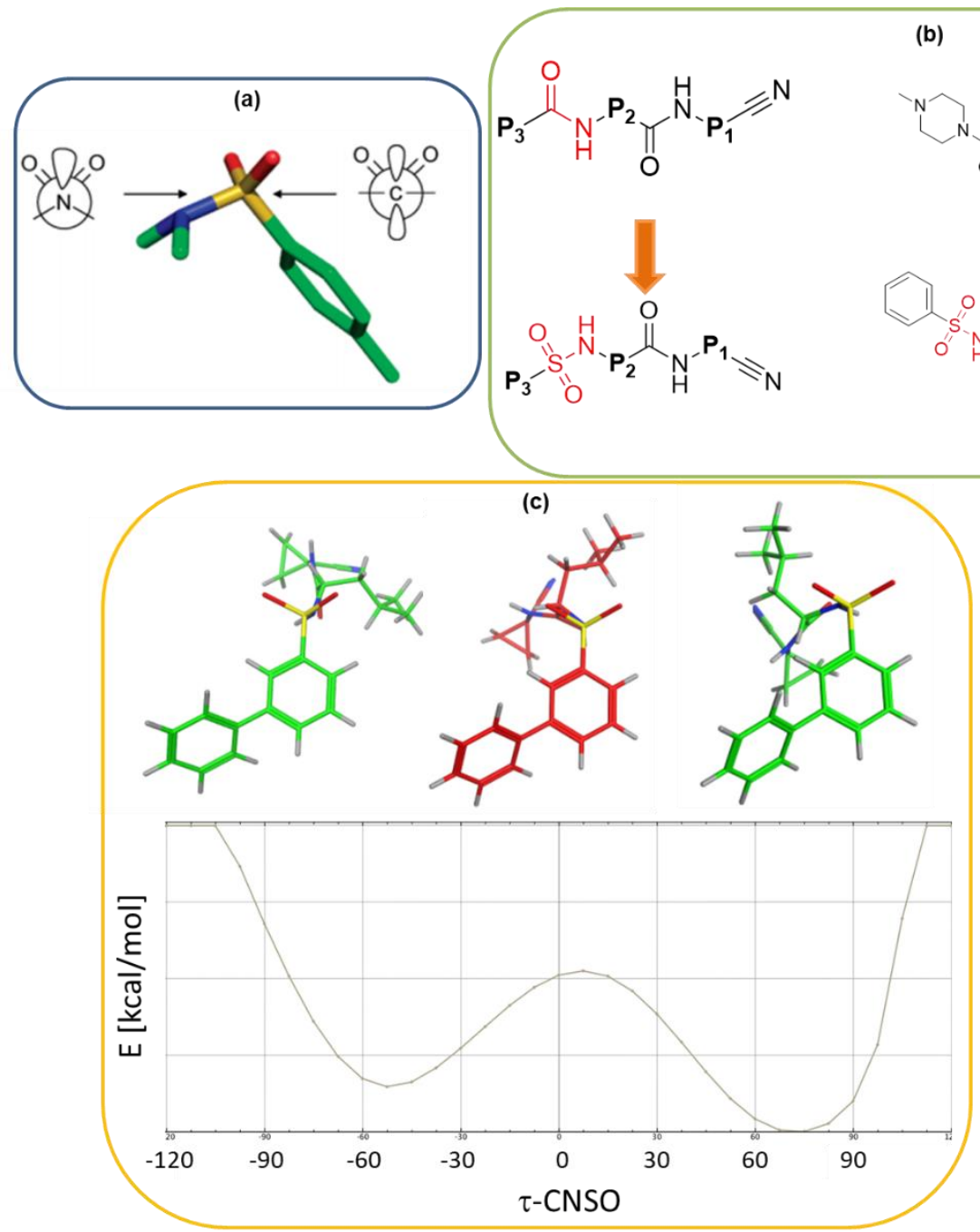

Source of (a) and (b): Own author. Source of (c): Calculated by Erik Gilberg (University of Bonn, b-it, Germany).

\subsection{Design, synthesis and biological evaluation of $\mathbf{N}$-Sulfonyl dipeptide nitriles}

For a better assessment of the effect of the sulphonamide bond, we designed and synthesized 15 new $N$-sulfonyl dipeptide nitriles. Assuming that $N$-sulfonyl dipeptide nitriles will have the same mode of binding on $\mathrm{Cz}$ as on dipeptidyl nitriles, we used our previous results to choose different moieties in P1, P2 and P3(see chapter III). 
Cyclopropane or benzyl moieties have been selected for P1 position, while L-Leu or LPhe have been inserted in P2. As a result of the loss of planarity when the amide bond is replaced with a sulfonamide bond, 8 distinct modifications have been used in P3 to evaluate their contributions to the affinity of $\mathrm{N}$-sulfonyl dipeptide nitrile for $\mathrm{Cz}$ (Figure 23). The synthesis of $N$-sulfonyl dipeptide nitriles is forthright. As for the synthesis of dipeptidyl nitriles (see chapter I and III) it consists of two main steps: the free amine nitrile building block was coupled with the Boc-amino acid; after removal of the Boc protecting group, the free amine reacted with the corresponding sulfonyl chloride (Figure 23).

Figure 23. Retrosynthetic scheme, synthetic scheme, structure representation and Nequimed codes $\mathrm{N}$-sulfonyl dipeptide nitriles.

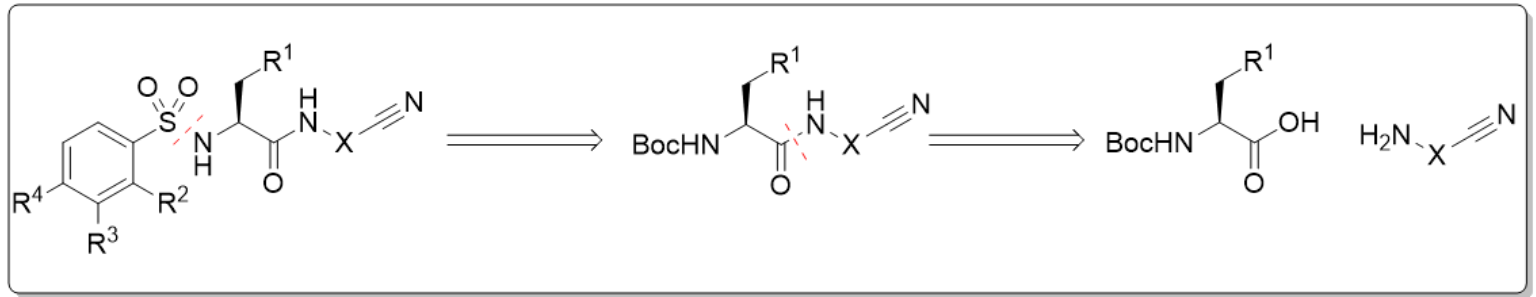<smiles>CC(C)(C)OC(=O)N[C@@H](Cc1ccccc1)C(N)=O</smiles>

(b)<smiles>[R]C[C@H](NC(=O)OC(C)(C)C)C(=O)N[C@@H]([R])Cc1ccccc1</smiles>

(c)

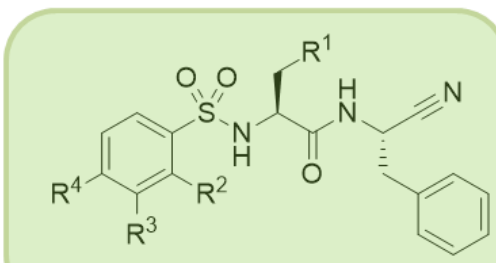<smiles>N#CC1(N)CC1</smiles>

(b)

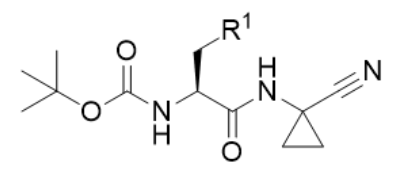

(c)

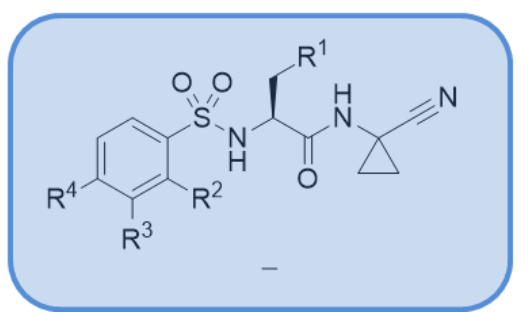

Source: Own author. 
In general, $\mathrm{p} K_{\mathrm{i}}$ values display an almost flat SAR for the $\mathrm{N}$-sulfonyl dipeptide nitriles against $\mathrm{Cz}$, where 12 compounds out of 15 have a $\mathrm{p} K_{\mathrm{i}}$ of about 6.5 ( $\Delta= \pm 0.4$; Table 7).

Table 7. Nequimed code, substitution definitions, and $p K_{\mathrm{i}}$ values.

\begin{tabular}{|c|c|c|c|c|c|}
\hline Compound & $\mathrm{R}^{1}$ & $\mathrm{R}^{2}$ & $\mathrm{R}^{3}$ & $\mathrm{R}^{4}$ & $p K \mathrm{I}^{\mathrm{a}}(\mathrm{Cz})$ \\
\hline Neq0781 & $i-\mathrm{Pr}$ & $\mathrm{H}$ & $\mathrm{H}$ & $\mathrm{H}$ & 6.5 \\
\hline Neq0782 & $i-\mathrm{Pr}$ & $\mathrm{H}$ & $\mathrm{Cl}$ & $\mathrm{H}$ & 6.5 \\
\hline Neq0831 & $i-\mathrm{Pr}$ & $\mathrm{H}$ & $\mathrm{Ph}$ & $\mathrm{H}$ & 7.0 \\
\hline Neq0832 & $i-\mathrm{Pr}$ & $\mathrm{H}$ & $4-\mathrm{F}-\mathrm{Ph}$ & $\mathrm{H}$ & 6.9 \\
\hline Neq0827 & $i-\mathrm{Pr}$ & $\mathrm{H}$ & $\mathrm{H}$ & $\mathrm{Ph}$ & 5.4 \\
\hline Neq0780 & $i-\mathrm{Pr}$ & $\mathrm{H}$ & $\mathrm{Cl}$ & $\mathrm{H}$ & 6.4 \\
\hline Neq0830 & $i-\mathrm{Pr}$ & $\mathrm{H}$ & $\mathrm{Ph}$ & $\mathrm{H}$ & 6.7 \\
\hline Neq0848 & $i-\mathrm{Pr}$ & $\mathrm{H}$ & $\mathrm{Br}$ & $\mathrm{H}$ & 6.6 \\
\hline Neq0838 & $i-\mathrm{Pr}$ & $\mathrm{H}$ & $\mathrm{H}$ & $\mathrm{Ph}$ & 6.8 \\
\hline Neq0829 & $i-\mathrm{Pr}$ & $\mathrm{H}$ & $\mathrm{H}$ & $4-\mathrm{F}-\mathrm{Ph}$ & 6.5 \\
\hline Neq0936 & $i-\mathrm{Pr}$ & $\mathrm{Cl}$ & $\mathrm{H}$ & $\mathrm{H}$ & 5.9 \\
\hline Neq0779 & $\mathrm{Ph}$ & $\mathrm{H}$ & $\mathrm{Cl}$ & $\mathrm{H}$ & 6.1 \\
\hline Neq0934 & $\mathrm{Ph}$ & $\mathrm{H}$ & $\mathrm{Ph}$ & $\mathrm{H}$ & 6.4 \\
\hline Neq0935 & $\mathrm{Ph}$ & $\mathrm{H}$ & $\mathrm{H}$ & $\mathrm{Ph}$ & 6.1 \\
\hline Neq0933 & $\mathrm{Ph}$ & $\mathrm{Cl}$ & $\mathrm{H}$ & $\mathrm{H}$ & 6.5 \\
\hline
\end{tabular}

Reagents and conditions. a) trifluoroacetic anhydride, $\mathrm{CH}_{2} \mathrm{Cl}_{2}$; b) i) formic acid, rt, $20 \mathrm{~h}$, (ii) corresponding (L)-amino acid, HATU, DIPEA, DMF, rt, $22 \mathrm{~h}$; b) formic acid, rt, $18 \mathrm{~h}$; c) (i) formic acid, rt, $20 \mathrm{~h}$, (ii) corresponding sulfonyl chloride, DIPEA, $\mathrm{CH}_{2} \mathrm{Cl}_{2}, 0{ }^{\circ} \mathrm{C}$ to rt, $20 \mathrm{~h} .{ }^{\mathrm{a}} \mathrm{p} K_{\mathrm{i}}=-$ $\log _{10}\left(K_{\mathrm{i}}\right)$. The standard error is lower than $10 \%$ for all the measurement. Source: Own author.

We can hypothesize that this effect is due to the torsional profile of the sulfonamide bond.It probably induces a different mode of binding respect to dipeptidyl nitrile inhibitors. Indeed, replacement of the amide bond or trifluoromethilamine moiety for a sulphonamide is detrimental for the affinity as depicted in Figure 24. On the other hand, insertion of the meta biphenyl moiety in P3 exhibits an increase of $0.3 \log$ units [Neq0934 $\rightarrow$ Neq0830] or 1.6 log units [Neq0827 $\rightarrow$ Neq0831] in affinity (Figure 24). Overall, we found an interesting positive nonadditivity SAR for the double transformation [Neq0934 $\rightarrow$ Neq0830] which evidences how the S1 group can shape 
the general mode of binding of the P3 meta biphenyl group. In addition, none of the new $\mathrm{N}$-sulfonyl dipeptide nitriles showed any significant trypanocidal activity when tested against the amastigote form of $T$. cruzi.

Figure 24. Schematic representation of bioisosteric replacement of the P2/P3 amide and its effect on the affinity for $\mathrm{Cz}$.

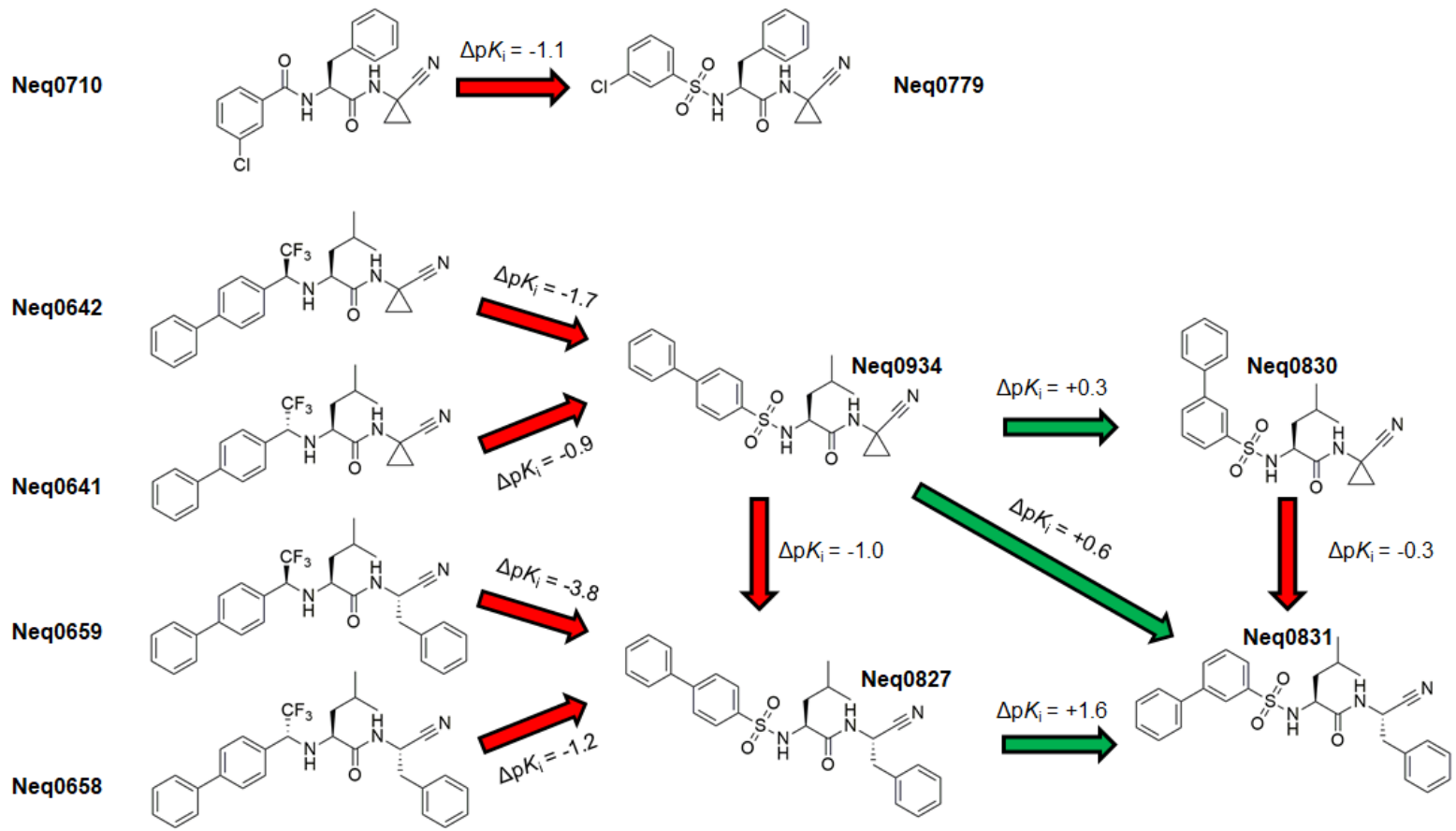

$\Delta \mathrm{p} K_{\mathrm{i}}$ was calculated as the difference of $\mathrm{p} K \mathrm{i}$ values. Source: Own author.

The same set of compounds was tested against four human cathepsins (CatB, CatK, CatL and CatS). Results show that most of the $N$-sulfonyl dipeptide nitriles are nanomolar inhibitors to CatS. Theydisplay a good selectivity as well toward CatK, CatL and CatB (Table 8). 
Table 8. Inhibition of human cathepsins by N-sulfonyl dipeptide nitriles.

\begin{tabular}{|c|c|c|c|c|}
\hline \multicolumn{5}{|c|}{$p K_{\mathrm{i}}(\mu \mathrm{M})^{1}$ or residual activity $(\%)^{2}$} \\
\hline Compound & CatB & CatK & CatL & CatS \\
\hline Neq0781 & $84 \%$ & 7.2 & 6.3 & 7.2 \\
\hline Neq0782 & 4.6 & 7.5 & 6.9 & 7.4 \\
\hline Neq0831 & 4.3 & 7.4 & 6.4 & 7.1 \\
\hline Neq0832 & 4.3 & 6.9 & 6.0 & 6.9 \\
\hline Neq0827 & $92 \%$ & 6.2 & 6.3 & 5.9 \\
\hline Neq0780 & 3.8 & 7.3 & 6.6 & 7.5 \\
\hline Neq0830 & $87 \%$ & 7.6 & 6.6 & 8.4 \\
\hline Neq0848 & $83 \%$ & 7.1 & 6.8 & 7.1 \\
\hline Neq0838 & $86 \%$ & 7.6 & 6.6 & 7.0 \\
\hline Neq0829 & $97 \%$ & 5.7 & $99 \%$ & $59 \%$ \\
\hline Neq0936 & $82 \%$ & 6.7 & 6.6 & 6.8 \\
\hline Neq0779 & 4.5 & 6.0 & 7.0 & 7.6 \\
\hline & & & & \\
\hline Neq0934 & $86 \%$ & 5.9 & 7.0 & 7.6 \\
\hline & 5.1 & 6.3 & 5.6 & 6.8 \\
\hline
\end{tabular}

${ }^{1} \mathrm{p} K_{\mathrm{i}}=-\log _{10}\left(K_{\mathrm{i}}\right)$. The standard error is lower than $10 \%$ for all the measurements. ${ }^{2}$ The remaining activity at $10 \mu \mathrm{M}$ inhibitor concentration obtained in duplicate measurements is noted. Source: Own author.

Through modelling studying, we have evaluated how these compounds could interact with S1, S2 and S3 of CatS. We proposed a mode of binding of the $\mathrm{N}$-sulfonyl dipeptide nitrile, Neq0831, where P2 group is flipping to the S3 subsite and the P3 is interacting 
with the P2 moiety as seen as for crystallized sulfonyl nitrile inhibitor in the active site of cathepsin S (PDB-ID: 2FQ9; Figure 25). In this proposed conformation the oxygen atoms of the sulfonamide bond could form hydrogen bonds with aliphatic polarized $\mathrm{CH}$ groups of Gly133, Asn158 and Gly160. Too, the biphenyl moiety in P3 could form edgeto-face and $\pi$-stacking interactions with Phe67 and Phe205, while the dihedral angle of the sulfonamide bond is in an ideal conformation ( 55-65'; Figure 25 and Figure 26). As for $\mathrm{Cz}$ inhibition, Neq0831 is the most potent inhibitor against CatS $\left(K_{\mathrm{i}}<10.0\right.$ $\mathrm{nM}$ ), while $\mathrm{N}$-sulfonyl dipeptide nitriles bearing $\mathrm{Phe}$ in P2 illustrate the highest selectivity against CatK. This is probably due to the bulky effect generated by the Phe in P2 (Figure 27).

Figure 25. Proposed binding mode of $\mathrm{N}$-sulfonyl dipeptide nitrile Neq0830 in the active site of CatS.

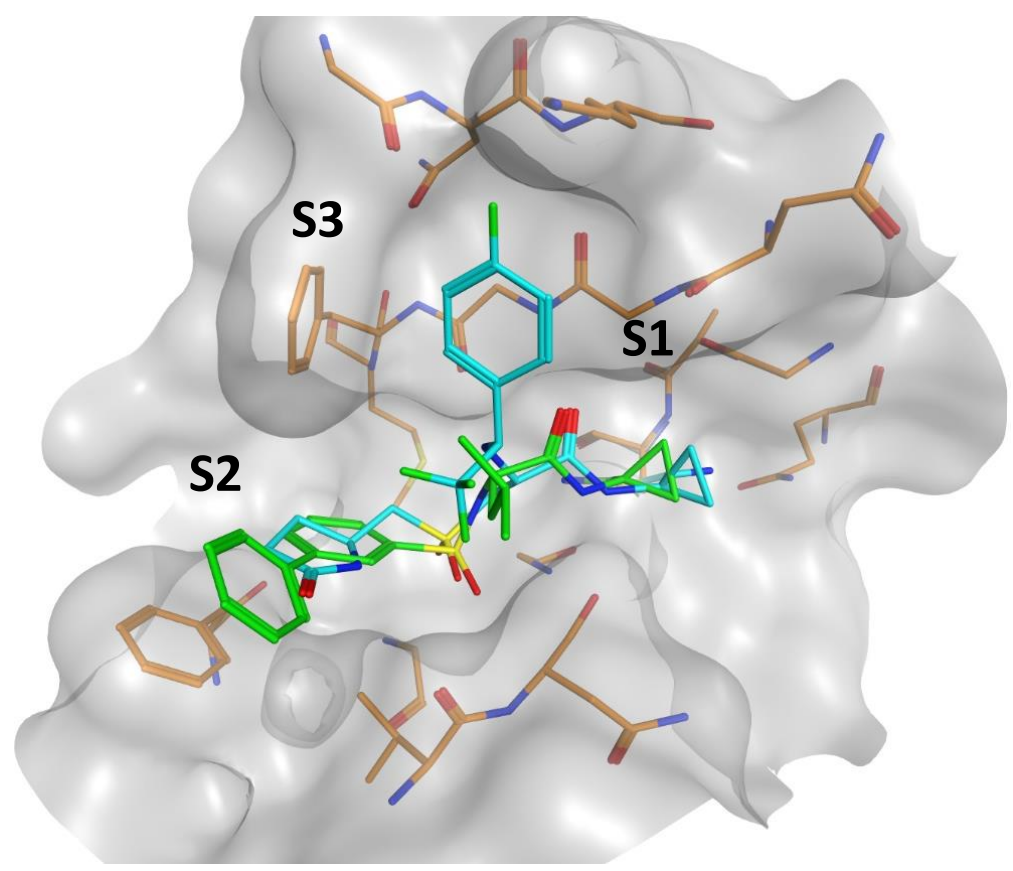

Proposed binding mode of $\mathrm{N}$-sulfonyl dipeptide nitrile Neq0830 (green) superposed with a crystallized sulfonyl nitrile inhibitor (cyan) in the active site of cathepsin S (PDB-ID: 2FQ9). The protein surface is depicted in transparent grey. Ligand- and residue atoms are shown in stick representation, and specificity pockets are numbered according to the Schechter-Berger nomenclature. Source: Created by Erik Gilberg (University of Bonn, b-it, Germany). 
Figure 26. Proposed interactions of the $\mathrm{N}$-sulfonyl moiety in the active site cleft of cathepsin S (PDB-ID: 2FQ9).

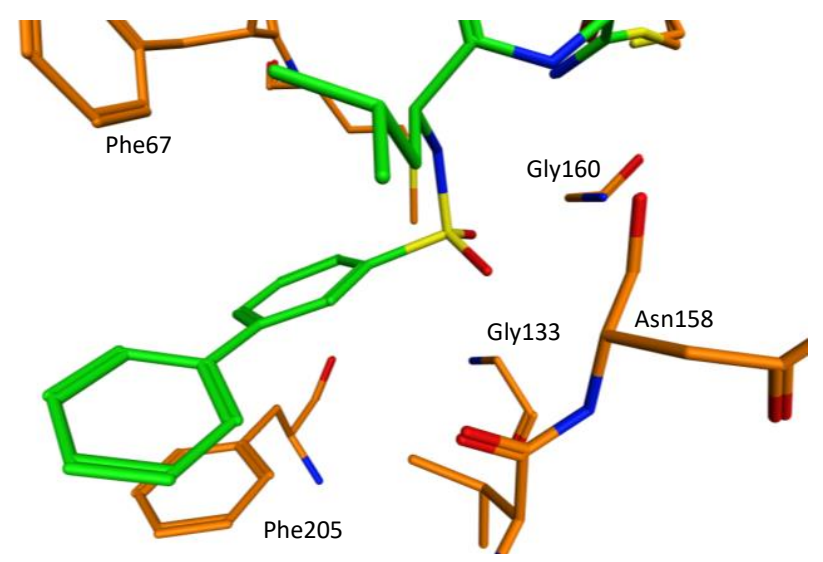

The oxygens of the sulfonyl substructure are forming a hydrogen bond network with polarized carbon atoms of residues Gly133, Asn158 and Gly160 of the S2 pocket with a preferred torsion angle of the sulfonamide. Source: Created by Erik Gilberg (University of Bonn, b-it, Germany).

Figure 27. Comparison of binding modes of compound Neq0831 (green) in (a) cathepsin S (PDB-ID: 2FQ9) and (b) cathepsin K (PDB-ID: 4X6H).
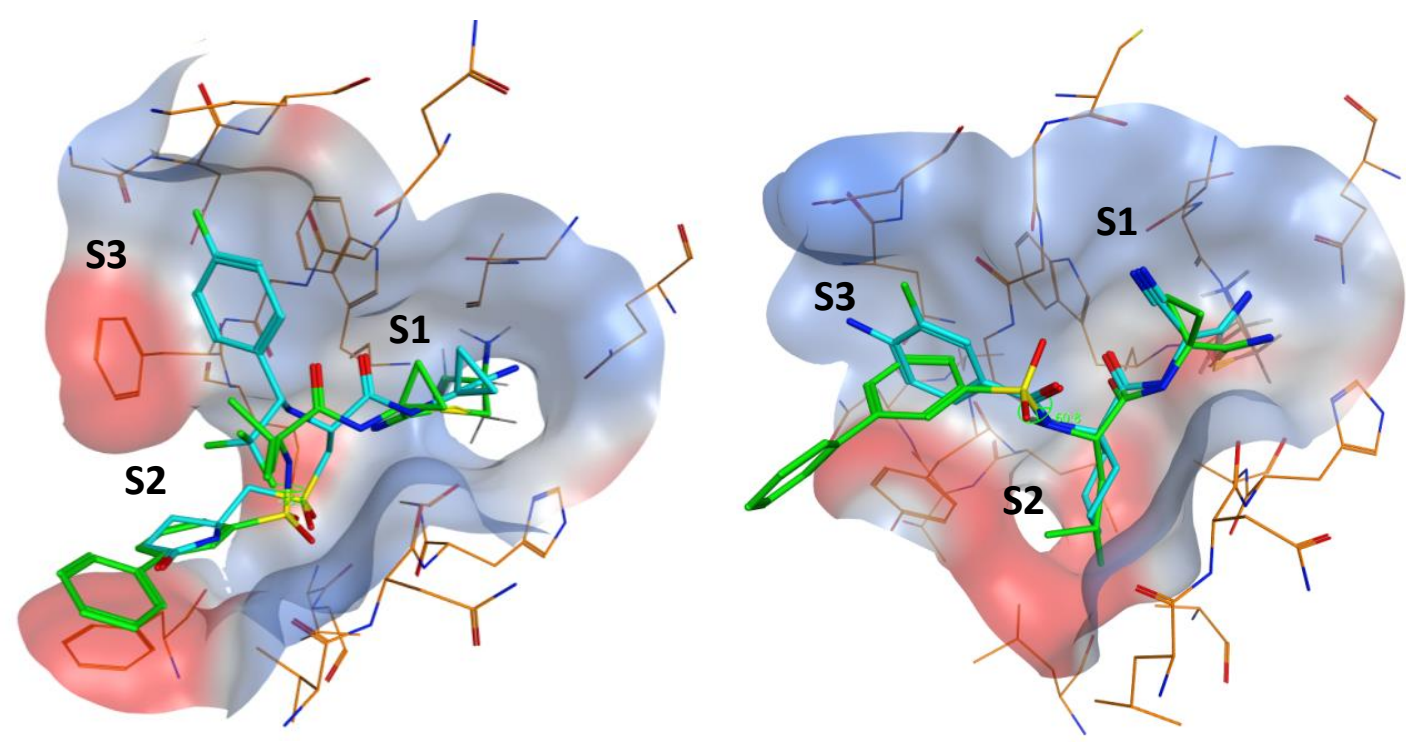

Crystallized ligands are shown in cyan. The surface representation of the proteins is colored according to their lipophilicity (lipophilic: red, hydrophilic: blue). Specificity pockets are numbered according to the Schechter-Berger nomenclature. Source: Created by Erik Gilberg (University of Bonn, b-it, Germany). 


\subsection{Conclusion and perspective}

We have designed and synthesized 15 new non-dipeptidyl nitriles, bearing a sulphonamide bond in P2-P3 position to evaluate the sulfonamide amide as possible bioisostere for $\mathrm{Cz}$ inhibition. Most of the new $\mathrm{N}$-sulfonyl dipeptide nitriles displayed an excellent affinity for $\mathrm{Cz}$. This underlines the possibility of replacing the amide for a sulphonamide bond. However, the comparison of this set of inhibitors with others (presented in chapters III and IV) results in a general loose of affinity and a flat SAR. These phenomena can arise from a different mode of binding of the $\mathrm{N}$-sulfonyl dipeptide nitriles. Indeed, the optimal bond angle of the sulphonamide is around $60^{\circ}$ while for amide or trifluoroethylamine bond is about $110-120^{\circ}$. At the same time, the same set of compounds displayed a great ability to inhibit CatS with excellent selectivity over the other human cathepsins. Modelling studies and visual inspection of different crystallographic structures of CatS co-crystallized with nitrile inhibitors suggested a different mode of binding.

Overall, this work creates the base for a new class of nitrile $\mathrm{Cz}$ inhibitors.In future it needs to be more exploited to enhance the affinity toward protozoan CPs and to demonstrate the hypothetical mode of binding here proposed. Considering the synthetic accessibility of $\mathrm{N}$-sulfonyl dipeptide nitriles, we conclude that a more extensive library of compounds should be created to supplant the use of highly not metabolic stable dipeptidyl nitriles as $\mathrm{Cz}$ inhibitors. 


\section{CHAPTER VI - A comparative study of warheads for the design of cysteine protease inhibitors ${ }^{6}$}

\subsection{Background}

In general, cysteine protease inhibitors can be divided into two categories: covalent and non-covalent inhibitors. Also, covalent inhibitors can be sub-divided into reversible or irreversible inhibitors. As already described (SCHNEIDER et al., 2015), the difference between reversible and irreversible inhibitors can be expressed as the free reaction energy (Figure 27a). Indeed, for a strongly exergonic reaction, the half-time of the covalently bound adduct $(E-I)$ tends to be infinite (irreversible warhead): By contrast, for a weakly exergonic reaction, the half-time is longer than for a non-covalent interaction, but the reaction remains reversible (Figure 28a).

The nitrile group is considered to be a particularly useful warhead for cysteine protease inhibition on account of its metabolic stability and polarity, and a small contribution to molecular size (DEATON; KUMAR, 2004). For those reasons, our research group focused mainly on inhibitors of $\mathrm{Cz}$ bearing nitrile as a warhead. Concurrently, even if the reversibility of binding may reduce the risk of adverse effects, irreversible binding can result in prolonged duration of action (GEHRINGER; LAUFER, 2019), as for vinyl sulfone derivatives (K777). Figure 28b shows the most employed warheads for cysteine protease inhibition. Not surprisingly, nitrile is the most widely used warhead in crystallographic structures, followed by vinyl sulfone, halomethyl ketone and epoxysuccinate (CIANNI et al., 2019).

\footnotetext{
${ }^{6}$ This chapter describes joint work with Dr. Jean F. R. Ribeiro (NEQUIMED/IQSC/USP, University of São Paulo, Brazil) for kinetic characterization. Compounds were synthesized by Dr. Daniel G. Silva (NEQUIMED/IQSC/USP, University of São Paulo, Brazil).
} 
Figure 28. A) energy diagrams of inhibition mechanisms for covalent inhibitors: black lines for the reversible mechanism, red lines for irreversible mechanism; B) list of the most common reversible (blue) and irreversible (red) warheads used for CPs inhibition.

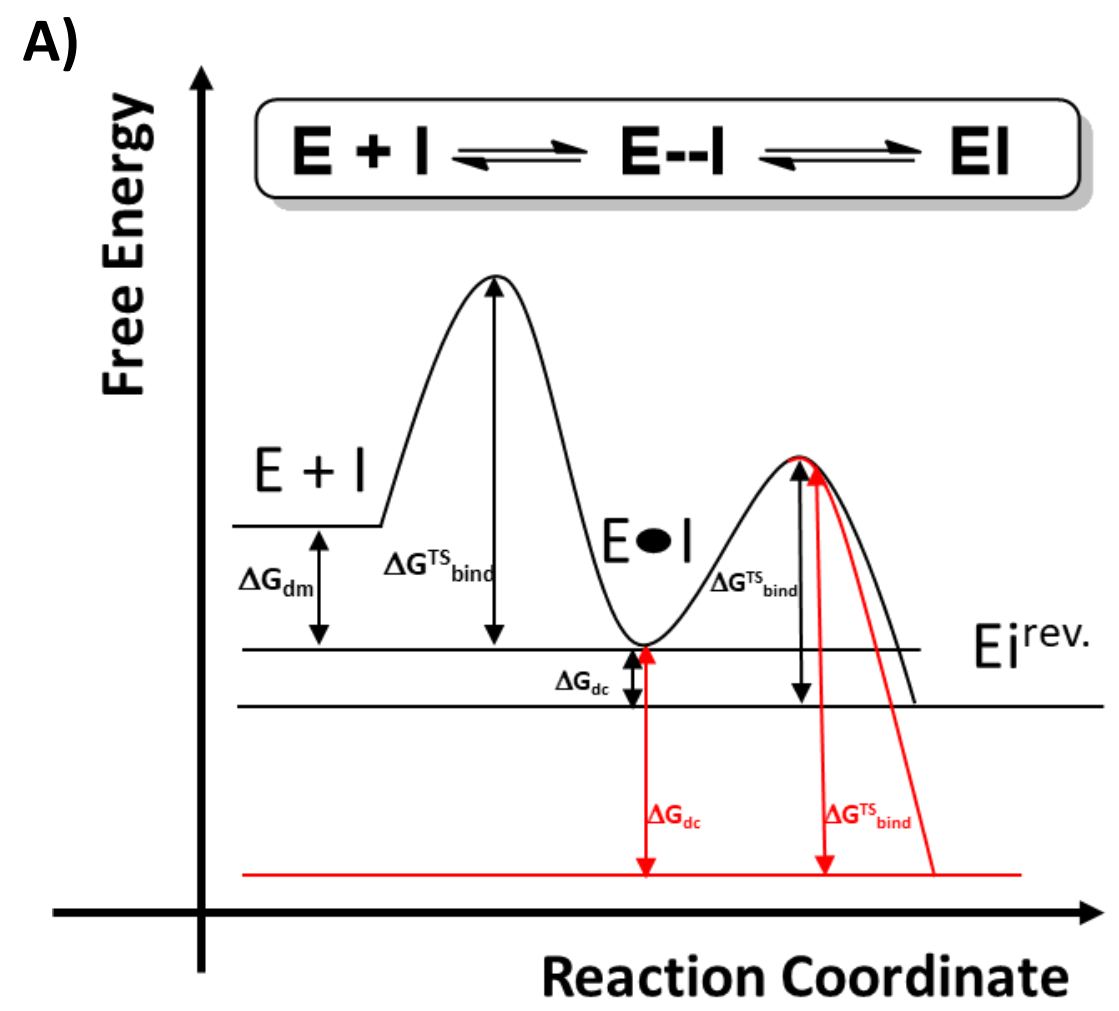

B)

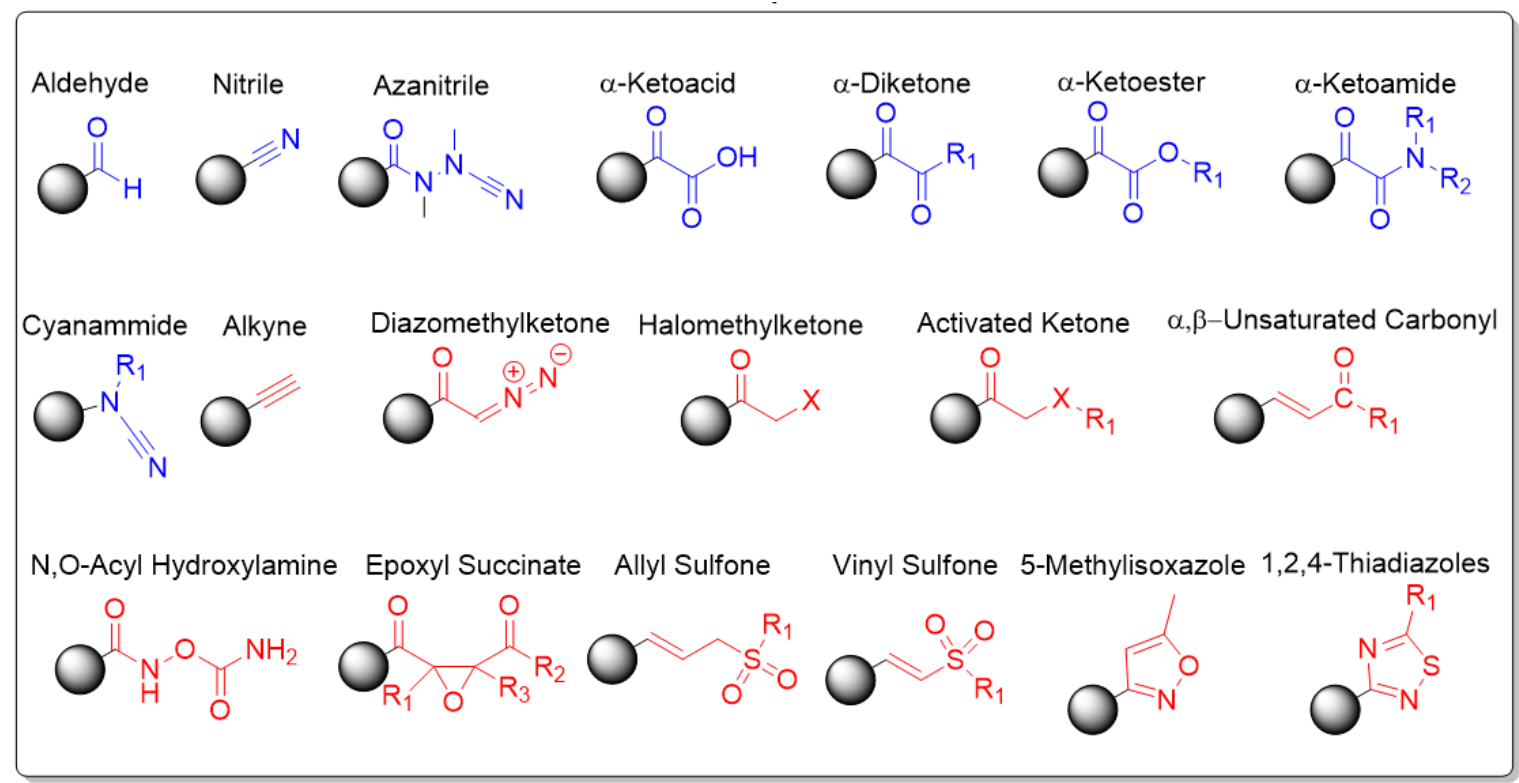

Source: Figure adapted from CIANNI, L. et al. Can Cysteine Protease Cross-Class Inhibitors Achieve Selectivity? Can cysteine protease cross-class inhibitors achieve selectivity? Journal of Medicinal Chemistry, jul. 2019. https://doi.org/10.1021/acs.jmedchem.9b00683. 
In this study, we wanted to explore how different warheads affect the affinity to $\mathrm{Cz}$ and their trypanocidal potency. Therefore, we first investigated the transferability of the published effects of warhead replacement. Secondly, we evaluated warheads such as the oxime that are based on a carbon-nitrogen double bond. Thirdly, we explored the potential of substitution for mitigating potential liabilities (e.g. instability or irreversible binding) associated with warheads.

\subsection{Design, synthesis and biological evaluation for warhead replacement}

First, we replaced the benzoic acid group in P3 (Neq0409) to form the equivalent NCbz-protected (Neq0500) to facilitate the synthesis of compounds bearing different warheads (Figures 29A, 29B). This transformation did not result in any loss of affinity to $\mathrm{Cz}$. Therefore, the nitrile Neq0500 ( $p K_{i}=6.3$ ) was used as the reference compound for this study. On the contrary of what described above for the pair Neq0570 Neq0409 (see chapter II), the cyclopropane analog of Neq0500, so-called Neq0655 $\left(\mathrm{p} K_{\mathrm{i}}=5.2\right)$, is an order of magnitude less potent (Figure 29). 
Figure 29. A) Schematic representation of the structure modification from Neq0410 to Neq0500; B) Schematic representation of the SAR considering molecular pairs between Neq0500 and the corresponding compound bearing a different warhead. Color highlights the difference in $\mathrm{p} K_{\mathrm{i}}$ for $\mathrm{Cz}$; red area highlights a decrease in affinity; green area highlights an increase in affinity. D) Table reports $\mathrm{p} K_{\mathrm{i}}$ for $\mathrm{Cz}, \mathrm{pEC} \mathrm{C}_{50}, \mathrm{pCC}_{50}$ and $k_{\mathrm{on}}$ and $k_{\text {off }}$ in case of slow binding inhibition.

(A)
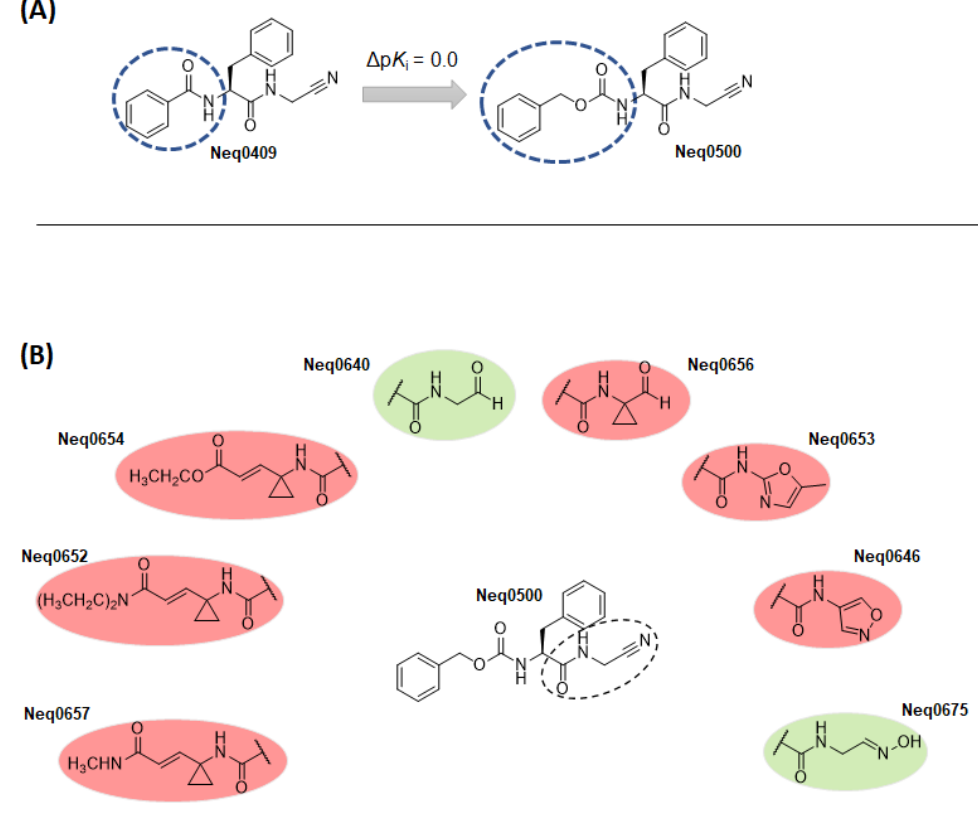
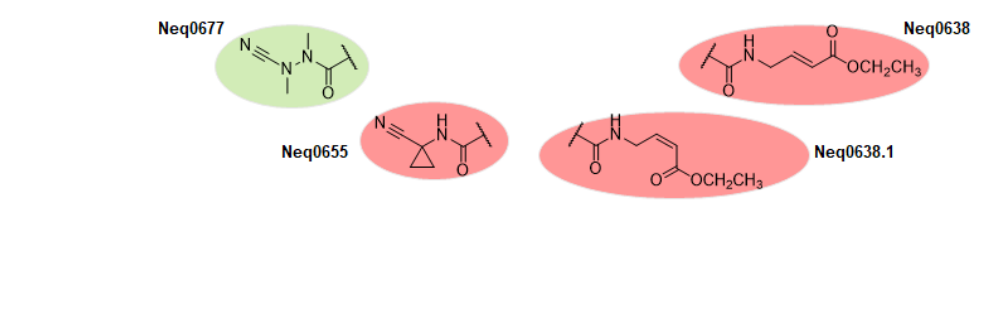

${ }^{a}$ Reversibility assayed; ${ }^{b}$ Irreversibility assayed. Source: Own author.

The aldehyde Neq0640 ( $\left.p K_{i}=8.1\right)$ is almost two orders of magnitude more potent than Neq0500, while replacement of the P1 methylene linked with cyclopropane (Neq0656) resulted in a reduction in affinity by nearly one log unit respect to Neq0500.

The differing effects of the [nitrile $\rightarrow$ aldehyde] replacement for Neq0500 illustrate the importance of substructural context and can be interpreted as nonadditivity in the SAR. The substitution of the nitrile for an oxime group, Neq0675 ( $\left.p K_{i}=7.0\right)$, increased the affinity toward Cz. However, it was not possible to separate the geometric isomers, so Neq0675 was isolated as a 54/46 E/Z mixture. Therefore, this result needs to be taken with caution. Further studies are on the way in our research group. 
We also evaluated isoxazole (Neq0646) as possible prodrugs for having an oxime embedded in it. As expected, the absence of a covalent bond formation led to a reduction in affinity. Unsurprisingly, the oxazole Neq0657 is even less potent than the isoxazole.

Vinyl sulfones have been widely studied for the inhibition of $\mathrm{Cz}$ and other cysteine proteases and their antichagasic activities (RENSLO; MCKERROW, 2006). To test the hypothesis that replacement of the sulfonyl with a less strong electron-withdrawing group would lead to reversible inhibition, several vinyl amide and esters were synthesized and tested against $\mathrm{Cz}$.

In general, vinyl esters and amides do not appear to offer any advantage over the more potent nitriles since they are of higher molecular weight. They would be associated with increased risk of poor pharmacokinetics on account of the hydrolytically unstable ester and amide functional groups. The vinyl ester Neq0638 $\left(k_{\text {inact }} / K_{\mathrm{i}}=9.8 \times 10^{3} \mathrm{~s}^{-1} \mathrm{M}^{-}\right.$ $\left.{ }^{1}\right)$ is an irreversible inhibitor of cruzain although less potent than the vinyl sulfone K$777\left(k_{\text {inact }} / K_{\mathrm{i}}=5.1 \times 10^{5} \mathrm{~s}^{-1} \mathrm{M}^{-1}\right)$.

Azadipeptide nitriles have been reported to exhibit antitrypanosomal activity and appear useful as activity-based probes due to their potency and proteolytically stability as papain-like cysteine proteases inhibitors (ASAAD et al., 2009; LÖSER et al., 2008; YANG et al., 2012). The azadipeptide nitrile Neq0677 ( $\left.K_{i}=8.7\right)$ is two orders of magnitude more potent against cruzain than the corresponding nitrile Neq0500 $(\mathrm{p} K \mathrm{i}=$ 6.3). Moved by these promising results, we synthesized two derivatives of Neq0677 by insertion of the N-tert-butyl-pyrazolic acid in P3 that led to Neq0689 and Neq0690. Different from what we have seen before (see chapter III), results suggest that the binding modes of Neq0689 and Neq0690 to cruzain prevent the full benefit of this P3 substituent from being realized.

Azadipeptide nitrile displayed a slow binding kinetic, as reported in the literature (LÖSER et al., 2008), probably due to the presence of the methylamino group as an electron-releasing group. The significant difference in potency between the dipeptide nitrile and their aza analogs could be linked to the imine nitrogen protonation after the rate-determining step.

Biological results were performed for the amastigote form of the T. cruzi $Y$ strain infecting U2OS host cells (Figure 29). Results displayed that no selectivity between parasite and the host cell was observed for the azadipeptide nitriles (Neq0677, Neq0689 and Neq0690) due to their high intrinsic reactivity and their off-targets lability. 
Also, the weak potency of compound Neq0653 $\left(\mathrm{pEC}_{50}=4.4\right)$ should not be correlated with its cruzain inhibition.

At the same time, we evaluated the affinity of Neq0689 and Neq690 on the corresponding human cathepsin of cruzain (CatL) and Leishmania mexicana CPB. Cysteine protease LmCPB is essential for the virulence of the Leishmania mexicana (intracellular protozoan parasite causative agent of the cutaneous form of leishmaniasis), and therefore it is an appealing meaningfull target as an antiparasitic therapy. These inhibitors showed an affinity higher than $10 \mathrm{nM}$ for both targets. A 1.3 $\AA$ X-ray crystal structure, the first to be reported for LmCPB, was determined for the complex of this enzyme covalently bound to an azadipeptide nitrile (Neq0690, Figure $30)$. 
Figure 30. Crystallographic structure of Neq0690 in complex with LmCPB.)

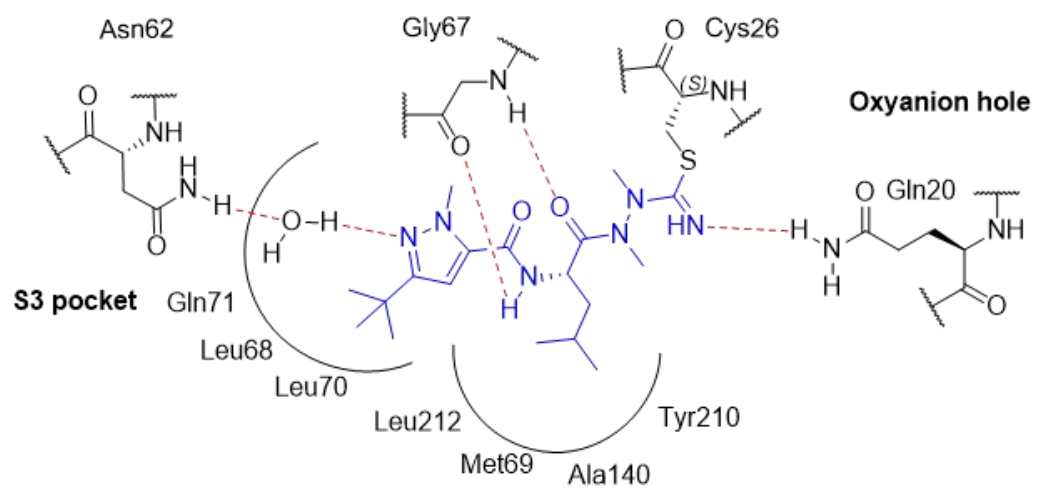

S2 pocket
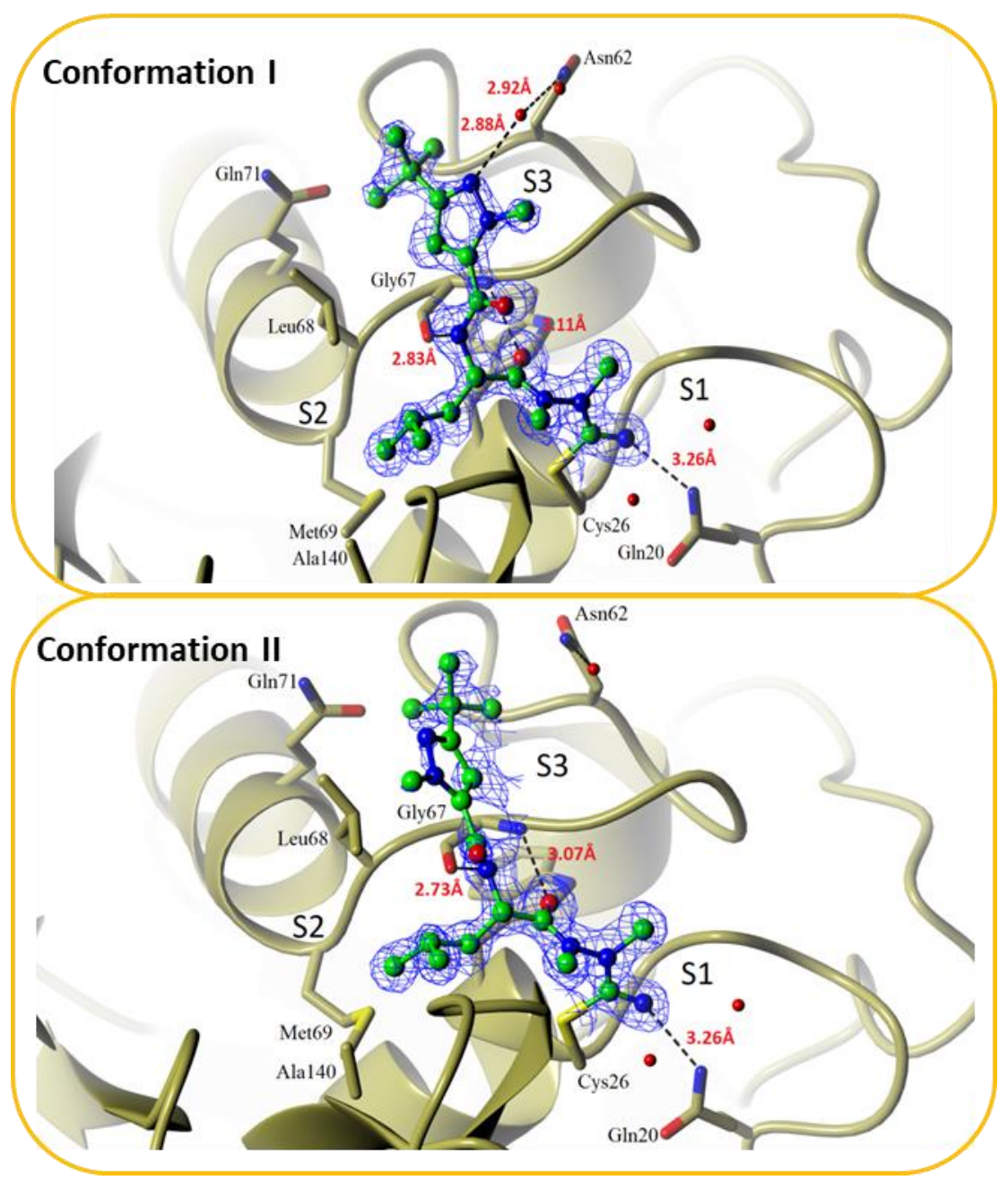

\begin{tabular}{|c|c|c|c|}
\hline $\mathbf{N}^{\circ}$ & $\mathrm{p} K_{\mathrm{i}}(\mathrm{LmCPB})$ & $\mathrm{p} K_{\mathrm{i}}(\mathrm{CatL})$ & $\mathrm{p} K_{\mathrm{i}}(\mathrm{Cz})$ \\
\hline NEQ0689 & $9.7(0.04)$ & $9.9(0.04)$ & $8.8(0.04)$ \\
\hline NEQ0690 & $9.7(0.06)$ & $9.3(0.04)$ & $8.8(0.04)$ \\
\hline
\end{tabular}

(From top to bottom). Schematic 2D binding mode of Neq0690 in complex with LmCPB, showing the covalent bond between Cys26 and the azanitrile nitrile head group and the stabilization of the formed thioimidate by the oxyanion hole. The residues from LmCPB are labeled in black. Hydrogen bonds are represented as red dashed lines structure compound 
Neq0690 in complex with LmCPB. Electron density maps (2F $F_{\text {obs }}-F_{\text {calc }}$ coefficients in blue) are displayed for the ligand only and are contoured at $1.5 \mathrm{\sigma}$. The inhibitor displays partial two-fold rational disorder and is covalently linked to catalytic cysteine (Cys26). The major component is shown above (conformation I) while the minor part is shown below (conformation II). H-bonds are represented by black dashed lines, and their lengths are displayed in red. Ligand binding subsites, S1, S2 and S3 are also shown along with critical residues. $\mathrm{p} K_{\mathrm{i}}$ values for Neq0689 and Neq0690 for LmCPB, CatL and Cz. Source: Figures adapted from RIBEIRO, J. F. R.; Crystal structure of Leishmania mexicana cysteine protease B in complex with a highly potent azadipeptide nitrile inhibitor. Scientific Reports, submitted, jul. 2019.

The mode of binding of Neq0690 (Figure 30) shows that this inhibitor is covalently bound to the catalytic cysteine (Cys26) by the nucleophilic attack of the thiolate group on the carbon of the nitrile group.

The inhibitor exhibits partial two-fold rotational alternate conformations along the axis of the C-N bond of the chiral carbon atom. The refined occupancy of each conformer is 0.58 and 0.42 for the major (conformation I) and minor (conformation II) components, respectively. The major part is stabilized by two $\mathrm{H}$-bonds in the $\mathrm{S} 3$ subsite between the lone pair-bearing nitrogen on the 1-methylpyrazole ring on the inhibitor, and carboxamide nitrogen of Asn62 side chain, to a single water atom.

Two additional $\mathrm{H}$-bonds between the inhibitor and the enzyme at the S2 subsite are observed. The first occurs between amide nitrogen on the inhibitor to the carbonyl oxygen on Gly67. The second occurs between carbonyl oxygen on the inhibitor to the backbone amide of Gly67. Both of these $\mathrm{H}$-bonds are present in the major and minor orientations of the inhibitor and display only a small shift $(\leq 0.1 \AA)$ on switching between the two directions. We could speculate that conformation I, due to an additional hydrogen bond, led to the difference in affinity between $\mathrm{Cz}$ and LmCPB of almost one $\log$ unit. 


\subsection{Conclusion and perspective}

In this chapter, we have compared different warheads for $\mathrm{Cz}$ inhibition, and we have demonstrated that dipeptide aldehydes and azadipeptide nitriles are significantly more potent inhibitors than dipeptidyl nitriles. Also, we have displayed that the substitution of the nitrile for the oxime group as a warhead improves the $\mathrm{Cz}$ affinity and can better the access to the prime region of the catalytic site. Moreover, we have shown how slow binding reversible inhibitors as azadipeptide nitrile are strongly cytotoxic, and therefore, their application is limited as $T$. cruzi killers. In addition, this work should be considered as the first step for long-term research of a warhead with a balanced reactive profile, as they should be sufficiently reactive to form a covalent bond with the cysteine protease in the active site. At the same time, their inherent reactivity should be reduced to a necessary minimum to prevent nonspecific off-target labelling or reaction with any other CPs (CIANNI et al., 2019). A possible strategy could be the application of $\alpha$-cyano acrylamide as a warhead, as already successfully applied in the near medicinal chemistry field of kinase inhibition (LONSDALE et al., 2017). Or as recently reported for CatK inhibition alkyne was used as latent electrophile warhead (MONS et al., 2019). 


\section{MATERIAL AND METHODS}

\subsection{Synthetic chemistry}

\subsubsection{General consideration}

Melting points were determined on a Büchi 510 oil bath apparatus or in a Kofler apparatus and are uncorrected. Infrared spectra were obtained from FT-IR Thermo Scientific Nicolet 380 or FT-IR Bomen Hartman \& Braun mod MB-102. Specific rotations $\left([\alpha]^{\top}=100 \alpha / \mathrm{lc}\right.$, in deg $\mathrm{mL} \mathrm{g}^{-1} \mathrm{dm}^{-1}$, but reported herein in degrees) were observed at the wavelength $589 \mathrm{~nm}$, the $\mathrm{D}$ line of a sodium lamp. T was set to be $25^{\circ} \mathrm{C}$. Samples were weight using a precision balance (Sartorius, Model CPA26P) and were fully dissolved in methanol (HPLC grade, Panreac). The rotations were measured using a Digital Polarimeter (P2000, Jasco): $\alpha=$ observed rotation in degrees; $I=$ cell path length of 0.1 decimeter in length; $\mathrm{c}=$ concentration in $\mathrm{g} 100 \mathrm{~mL}^{-1}$. Values were calculated using 5 measurements for each compound.

Reagents, starting materials and solvents were of commercial quality and were used without further purification unless otherwise stated. All syntheses were started with enantiopure amino acids. TLC analysis was carried out on Merck $60 F_{254}$ silica gel plates and visualized under UV light at $254 \mathrm{~nm}$ and $365 \mathrm{~nm}$ or by staining solutions such as ninhydrin, ethanolic 5\% phosphomolybdic acid solution and aqueous $\mathrm{KMnO}_{4}$. Purification by column chromatography was carried out on silica gel (Merck 60, particle size $0.040-0.063 \mathrm{~mm}$ ). Preparative column chromatography was carried out on Grace Davison Davisil LC 60A (particle size 0.020 - $0.045 \mathrm{~mm}$ ) or Merck Geduran Si 60 (particle size $0.063-0.200 \mathrm{~mm}$ ) using an Interchim PuriFlash 430 automated flash chromatography system. The purity of all tested compounds was determined with one of the three $(A-C)$ protocols noted below:

A) Purity was determined using an LC-MS instrument (AmaZon SL ESI-MS, Shimadzu LC) with a Diacel column (IC-chiralpak, $250 \times 4.6 \mathrm{~mm}, 5 \mu \mathrm{m}$ ). The 
detection was performed by a UV DAD $(200-440 \mathrm{~nm})$. An isocrate elution ACN and water as specified, stop time $60 \mathrm{~min}$, flow $0.5 \mathrm{~mL} / \mathrm{min}$ were used.

B) Purity was determined using RP-HPLC on a Hewlett Packard 1090 Series II LC with a Phenomenex Luna C18 column (150 x $4.6 \mathrm{~mm}, 5 \mu \mathrm{m})$ and detection was performed by a UV DAD (200 - $440 \mathrm{~nm})$. Elution was carried out with the following gradient: $0.01 \mathrm{M} \mathrm{KH}_{2} \mathrm{PO}_{4}, \mathrm{pH} 2.30$ (solvent A), $\mathrm{MeOH}$ (solvent $\mathrm{B}$ ), $40 \%$ $B$ to $85 \%$ B in 8 min, $85 \%$ B for $5 \mathrm{~min}, 85 \%$ to $40 \%$ B in $1 \mathrm{~min}, 40 \%$ B for $2 \mathrm{~min}$, stop time $16 \mathrm{~min}$, flow $1.5 \mathrm{~mL} / \mathrm{min}$.

C) Purity was determined using an LC-MS instrument (ABSCIEX API 2000 LCMS/MS, HPLC Agilent 1100) with a Phenomenex Luna C18 HPLC column (50 $x 2.00 \mathrm{~mm}, 3 \mu \mathrm{m})$ and detection was performed by a UV DAD $(200-440 \mathrm{~nm})$. Elution was carried out with the following gradient: $0.02 \mathrm{M} \mathrm{NH}_{4} \mathrm{CH}_{3} \mathrm{CO}_{2}, \mathrm{pH} 7.0$ (solvent A), $\mathrm{MeOH}$ (solvent B) start with $100 \%, 10 \% \mathrm{~B}$ in 20 min to $100 \% \mathrm{~B}, 10$ min $100 \%$ B, stop time $20 \mathrm{~min}$, flow $0.25 \mathrm{~mL} / \mathrm{min}$.

NMR spectra were recorded on Bruker Avance $200 \mathrm{MHz}$, Bruker Avance $400 \mathrm{MHz}$ and Bruker Avance DRX $500 \mathrm{MHz}$ NMR spectrometers. Chemical shifts are reported in ppm relative to TMS or the residual proton peak of the re-protonated deuterated solvent. The spectra were calibrated against the residual proton peak of the used deuterated solvent. Spin multiplicities are indicated by the following symbols: $s$ (singlet), $s$ br (broad singlet), d (doublet), dd (doublet of doublet), $t$ (triplet), tt (triplet of triplet), q (quartet), sept (septet) and $m$ (multiplet). Standard mass spectra were obtained either as ESI-MS (pos. and/or neg. mode) from a Advion DCMS interface (settings as follows: ESI voltage 3,50 kV, capillary voltage $187 \mathrm{~V}$, source voltage $44 \mathrm{~V}$, capillary temperature $250^{\circ} \mathrm{C}$, desolvation gas temperature $250^{\circ} \mathrm{C}$, gas flow $5 \mathrm{~L} / \mathrm{min}$ ) or by an API 2000 mass spectrometer (electron spray ion source, ABSCIEX, Darmstadt, Germany) coupled to an Agilent 1100 HPLC system.

HRMS spectra were recorded on a Bruker microTOF-Q mass spectrometer connected to a Thermo Scientific Dionex UltiMate 3000 LC via an ESI interface using a Nucleodur C18 Gravity column $(50 \times 2.0 \mathrm{~mm}, 3 \mu \mathrm{m})$ or were recorded on Thermo Scientific LTQ Velos Orbitrap, in electrospray ionization (ESI) mode by direct injection.

The synthetic route was developed to optimize the set of substituents to be placed in P1, P2, and P3 that have been defined after the planning and design studies. Due to 
the diversity of building blocks, it was necessary to evaluate different methods for the same reaction, aiming at the best yield and preventing racemization.

\subsubsection{General procedure for amide synthesis}

Method A: The free primary amine ( $1.0 \mathrm{mmol}, 1.0$ equiv.) was added to a solution of the carboxylic acid (1.3 mmol, 1.3 equiv.), HATU (490 mg, $1.3 \mathrm{mmol}, 1.3$ equiv.) and DIPEA (364 mg, $0.45 \mathrm{~mL}, 2.60 \mathrm{mmol}, 2.6$ equiv.) in dry DMF ( $5 \mathrm{~mL}$ ) under argon atmosphere. The resulting solution was stirred at room temperature for $20 \mathrm{~h}$. The reaction mixture was diluted with ethyl acetate $(10 \mathrm{~mL})$ and washed with a saturated $\mathrm{NaHCO}_{3}$ solution $(3 \times 20 \mathrm{~mL})$ and brine $(3 \times 20 \mathrm{~mL})$. The organic phase was dried over $\mathrm{Na}_{2} \mathrm{SO}_{4}$ and evaporated to give a crude residue that was purified by flash column chromatography (CIANNI et al., 2018).

Method B: The free primary amine $(1.0 \mathrm{mmol}, 1.0$ equiv.) was added to a solution of the carboxylic acid (1.3 mmol, 1.3 equiv.), TBTU ( $410 \mathrm{mg}, 1.3 \mathrm{mmol}, 1.3$ equiv.) and DIPEA (364 mg, $0.45 \mathrm{~mL}, 2.60 \mathrm{mmol})$ in dry $\mathrm{DMF} / \mathrm{CH}_{2} \mathrm{Cl}_{2}(1: 1,10 \mathrm{~mL})$ under argon atmosphere. The resulting solution was stirred at room temperature for $20 \mathrm{~h}$. The reaction mixture was diluted with ethyl acetate $(10 \mathrm{~mL})$ and washed with a saturated $\mathrm{NaHCO}_{3}$ solution $(3 \times 20 \mathrm{~mL})$ and brine $(3 \times 20 \mathrm{~mL})$. The organic phase was dried over $\mathrm{Na}_{2} \mathrm{SO}_{4}$ and evaporated to give a crude residue that was purified by flash column chromatography (IVANOV; ZHALNINA; SHISHKOV, 2009).

Method C: Isobutyl chloroformate (790 mg, $0.75 \mathrm{~mL}, 5.5 \mathrm{mmol}, 1.1$ equiv) was added dropwise to a solution of Boc-( $R$ or $S$ ) amino acid (5.0 mmol, 1.0 equiv.), DIPEA (1.6 $\mathrm{g}, 2.28 \mathrm{~mL}, 13.0 \mathrm{mmol}, 2.6$ equiv.) in dry DMF $(20 \mathrm{~mL})$ under argon atmosphere, at $30^{\circ} \mathrm{C}$ and it was stirred for $0.5 \mathrm{~h}$. Then, an aqueous $2 \mathrm{M} \mathrm{NH}_{4} \mathrm{Cl}$ solution (294 mg, 2.75 $\mathrm{mL}, 5.5 \mathrm{mmol}, 1.1$ equiv.) was added. The resulting solution was stirred at room temperature for $20 \mathrm{~h}$. The reaction mixture was dried under reduced pressure. Ethyl acetate $(100 \mathrm{~mL})$ was added and it was washed with a saturated $\mathrm{NaHCO}_{3}$ solution (3 $\times 50 \mathrm{~mL})$ and brine $(1 \times 50 \mathrm{~mL})$. The organic phase was dried over $\mathrm{Na}_{2} \mathrm{SO}_{4}$ and evaporated under reduced pressure to give a crude residue that was purified by flash column chromatography (BOWER et al., 2003). 
8.1.3. General procedure for removal of the Boc protecting groups

Method A: The Boc-protected amino compound ( $0.25 \mathrm{mmol}, 1.0$ equiv.) was treated with an excess of formic acid ( $2.44 \mathrm{~g}, 47.9 \mathrm{mmol}, 47.9$ equiv.) at room temperature. The resulting solution was stirred for $18 \mathrm{~h}$. The reaction mixture was evaporated under reduced pressure to get a yellowish oil. It was treated with an aqueous solution of 1.0 $\mathrm{M} \mathrm{NaOH}$ until pH 9 was reached. The product was extracted with ethyl acetate $(4 \times 20$ $\mathrm{mL}$ ) and then washed with brine $(1 \times 20 \mathrm{~mL})$. The organic phase was evaporated to obtain a colorless oil. The formation of the product was confirmed by TLC (ethyl acetate). The product was used for the next step without further purification (CIANNI et al., 2018).

Method B: To a solution of Boc-protected amino compound (1.0 mmol, 1.0 equiv.) in dry $\mathrm{CH}_{2} \mathrm{Cl}_{2}\left(3 \mathrm{~mL}\right.$ ) was added TFA (912 mg, $0.91 \mathrm{~mL}, 8.00 \mathrm{mmol}, 8.0$ equiv.) at $0{ }^{\circ} \mathrm{C}$. The mixture was stirred and allowed to reach room temperature within $2 \mathrm{~h}$. The progress of the reaction was monitored by TLC (ethyl acetate). The reaction mixture was evaporated under reduced pressure to eliminate the excess of TFA to get a yellowish solid. The product was used for the next step without further purification (SHENDAGE; FRÖHLICH; HAUFE, 2004).

8.1.4. General procedure for dehydration of primary amides to nitriles

Method A: The primary amide (1.0 mmol, 1.0 equiv.) was dissolved in dry DMF (5 mL) at $0{ }^{\circ} \mathrm{C}$. Then, cyanuric chloride ( $73 \mathrm{mg}, 0.4 \mathrm{mmol}, 1.1$ equiv.) was slowly added to the solution under argon atmosphere. The resulted solution was stirred for $0.5 \mathrm{~h}$. Saturated $\mathrm{NaHCO} 3$ solution $(30 \mathrm{~mL})$ was added and it was stirred at room temperature for further $2 \mathrm{~h}$. The product was extracted with ethyl acetate $(2 \times 50 \mathrm{~mL})$ and then the reunited organic phases were washed with an aqueous solution of $1.0 \mathrm{M} \mathrm{KHSO}_{4}(3 \times 20 \mathrm{~mL})$, brine $(4 \times 30 \mathrm{~mL})$ and dried over $\mathrm{Na}_{2} \mathrm{SO}_{4}$. The solvent was removed, and the crude product was purified by flash silica gel chromatography (MAETZ; RODRIGUEZ, 1997). 
Method B: The primary amide (1.0 mmol, 1.0 equiv.) was dissolved in dry THF $(5 \mathrm{~mL})$ and DIPEA (364 mg, $0.45 \mathrm{~mL}, 2.6 \mathrm{mmol}, 2.6$ equiv.) was added. Trifluoroacetic anhydride (273 mg, $0.18 \mathrm{~mL}, 1.30 \mathrm{mmol}, 1.3$ equiv.) was added over $5 \mathrm{~min}$ at $0{ }^{\circ} \mathrm{C}$. The mixture was stirred and allowed to reach roomtemperature within $2 \mathrm{~h}$. Then the reaction was quenched with $\mathrm{H}_{2} \mathrm{O}(20 \mathrm{~mL})$, THF removed in vacuo, and the product was extracted into ethyl acetate $(2 \times 50 \mathrm{~mL})$. The organic phase was washed with a solution $1.0 \mathrm{M}$ of $\mathrm{KHSO}_{4}(3 \times 20 \mathrm{~mL})$ and with a saturated $\mathrm{NaHCO}_{3}$ solution $(3 \times 20 \mathrm{~mL})$ and brine $(3 \times 20 \mathrm{~mL})$ and dried over $\mathrm{Na}_{2} \mathrm{SO}_{4}$. The solvent was removed, and the crude product was purified by flash silica gel chromatography (WIKLUND; ROMERO; BERGMAN, 2003).

Method C: The primary amide ( $1.0 \mathrm{mmol}, 1.0$ equiv.) was dissolved in dry pyridine (5 $\mathrm{mL}$ ) at room temperature. Then, p-toluenesulfonyl chloride $(572 \mathrm{mg}, 3.0 \mathrm{mmol}, 3.0$ equiv.) was added to the solution under argon atmosphere. The resulting solution was stirred for 3 days. Upon addition of saturated $\mathrm{NaHCO}_{3}$ solution $(30 \mathrm{~mL})$, the reaction mixture was stirred at room temperature for $2 \mathrm{~h}$. The solution was dried under reduced pressure. The product was extracted with ethyl acetate $(2 \times 50 \mathrm{~mL})$ and then the reunited organic phases were washed with a $1.0 \mathrm{M}$ solution of $\mathrm{KHSO}_{4}(2 \times 20 \mathrm{~mL})$, brine $(4 \times 30 \mathrm{~mL})$ and dried over $\mathrm{Na}_{2} \mathrm{SO}_{4}$. The solvent was removed, and the crude product was purified by flash silica gel chromatography (TSUCHIYA et al., 2013).

\subsubsection{General procedure for removal of the benzyl protecting group}

Method A: The corresponding protected threonine $(1.0 \mathrm{mmol}, 1.0$ equiv.) was dissolved in abs. ethanol $(20 \mathrm{~mL})$ in argon atmosphere. Upon addition of $10 \% \mathrm{Pd} / \mathrm{C}$, $\mathrm{H}_{2}$ was bubbled in the solution for $0.5 \mathrm{~h}$. The resulting solution was stirred under $\mathrm{H}_{2}$ atmosphere for $12 \mathrm{~h}$. The progress of the reaction was monitored by TLC. The solution was filtered on celite two times and dried under reduced pressure to afford the desired product as a colorless wax. The product was used for the next step without further purification(CRISTAU et al., 2003).

Method B: The corresponding protected threonine $(1.0 \mathrm{mmol}, 1.0$ equiv.) was dissolved in dry $\mathrm{CH}_{2} \mathrm{Cl}_{2}(20 \mathrm{~mL})$ under argon atmosphere. Then, DDQ (908 mg, 4.0 
mmol, 4.0 equiv) was added and the resulting solution was stirred for 4 days at room temperature. The progress of the reaction was monitored by TLC (ethyl acetate). The reaction was quenched with an aqueous $1.0 \mathrm{M}$ solution of $\mathrm{NaHSO}_{3}(20 \mathrm{~mL})$. Then, $\mathrm{CH}_{2} \mathrm{Cl}_{2}$ was removed under reduced pressure. The product was extracted with ethyl acetate $(2 \times 50 \mathrm{~mL})$ and the reunited organic phases were washed with an aqueous solution of $1.0 \mathrm{M} \mathrm{KHSO}_{4}(2 \times 20 \mathrm{~mL})$, brine $(4 \times 30 \mathrm{~mL})$ and dried over $\mathrm{Na}_{2} \mathrm{SO}_{4}$. The solvent was removed, and the crude product was purified by flash silica gel chromatography (WRIGHT; YU; SPENCER, 2001).

\subsubsection{General procedure for the synthesis of amine esters}

The starting amino acid (18 mmol, 1.0 equiv.) was dissolved in $\mathrm{MeOH}$ or anhydrous $\mathrm{EtOH}$ under argon atmosphere. Then fresh distilled $\mathrm{SOCl}_{2}$ (19.8 mmol, 1.1 equiv.) was added slowly at $0{ }^{\circ} \mathrm{C}$. The reaction was brought at room temperature and stirred for 4 h. The progress of the reaction was followed by TLC. The solvent was evaporated, and the residue was washed with ethyl acetate $(3 \times 50 \mathrm{~mL})$ to afford the desired product and it was used for the next step without further purification.

\subsubsection{General procedure for imine synthesis}

To a solution of amino ester hydrochloride $(2.21 \mathrm{mmol}, 1.0$ equiv.) in dry methanol (5 $\mathrm{mL}$ ), under argon atmosphere, dried potassium carbonate ( $4.42 \mathrm{mmol}, 2.0$ equiv.) and the appropiate trifluoroacetophenone $(2.43 \mathrm{mmol}, 2.0$ equiv.) were added. The mixture was stirred at $50^{\circ} \mathrm{C}$ for $18 \mathrm{~h}$. Then the reaction was cooled to root temperature and filtered and the solvent was removed under reduced pressure. The collected oil was used in the next step without further purification. 
8.1.8. General procedure for imine reduction to amine

Reduction with $\mathrm{Zn}\left(\mathrm{BH}_{4}\right)_{2}$ : To a solution of imine/potassium carboxylate $(2.21 \mathrm{mmol}$, 1.0 equiv.) in $\mathrm{ACN}(15 \mathrm{~mL})$ and $\mathrm{MeOH}(1.5 \mathrm{~mL})$, a freshly prepared solution of $\mathrm{Zn}\left(\mathrm{BH}_{4}\right)_{2}$ in DME ( $1 \mathrm{mmol} / \mathrm{mL}, 1.5 \mathrm{~mL}, 0.7$ equiv.) was added at $-40 /-45^{\circ} \mathrm{C}$. After $3 \mathrm{~h}$ at $-40 /-45$ ${ }^{\circ} \mathrm{C}$, the reaction mixture was allowed to warm until $0^{\circ} \mathrm{C}$ and $1 \mathrm{~N} \mathrm{HCl}$ was added until $\mathrm{pH}$ 2-3. The aqueous mixture was extracted with ethyl acetate $(3 \times 25 \mathrm{~mL})$; the reunited organic phases were dried on $\mathrm{Na}_{2} \mathrm{SO}_{4}$, evaporated under vacuum and purified by flash column chromatography.

Reduction with $\mathrm{NaBH}_{4}$ : The imine/potassium carboxylate ( $2.21 \mathrm{mmol}, 1.0$ equiv.) was suspended in dry THF $(25 \mathrm{~mL})$ and $\mathrm{MeOH}(1.5 \mathrm{~mL})$, stirred at $0{ }^{\circ} \mathrm{C}$ and then $\mathrm{NaBH}_{4}$ (12.15 mmol, 5.6 equiv.) was added. After stirring for $6 \mathrm{~h}$ at room temperature, the system was cooled to $0^{\circ} \mathrm{C}$ and quenched with $2 \mathrm{M} \mathrm{HCl}$ solution until stopping the gas release (final $\mathrm{pH} 2-3$ ). Next, the organic solvent was evaporated under vacuum and the crude extracted with ethyl acetate $(3 \times 10 \mathrm{~mL})$. The reunited organic phases were dried on $\mathrm{Na}_{2} \mathrm{SO}_{4}$, evaporated under vacuum and purified by flash column chromatography.

\subsubsection{General procedure for Suzuki cross-coupling reaction}

A stream of nitrogen was passed through a suspension of aryl bromide $(0.18 \mathrm{mmol}$, 1.0 equiv.), the opportune boronic acid pinacol ester ( $0.25 \mathrm{mmol}, 1.4$ equiv. $), 2 \mathrm{M}$ $\mathrm{Na}_{2} \mathrm{CO}_{3}(0.26 \mathrm{~mL})$ and DMF $(2 \mathrm{~mL})$ for $10 \mathrm{~min}$. $\mathrm{PdCl}_{2} \mathrm{dppf}(8 \% \mathrm{~mol})$ was then added and the reaction was warmed to $80{ }^{\circ} \mathrm{C}$ and stirred under nitrogen for $3 \mathrm{~h}$. When the reaction was complete, the mixture was cooled to room temperature and extracted with ethyl acetate $(3 \times 15 \mathrm{~mL})$. The combined ethyl acetate extracts were dried with sodium sulfate and dried under vacuum to give a residue that was purified by chromatography column to afford the desired compounds. 
8.1.10. General procedure for the synthesis of primary sulfonamide

The corresponding free amine $\left(0.2 \mathrm{mmol}, 2.0\right.$ equiv) was dissolved in $\mathrm{CH}_{2} \mathrm{Cl}_{2}(10 \mathrm{~mL})$ and DIPEA (52 mg, $68 \mu \mathrm{L}, 0.4 \mathrm{mmol}, 2.0$ equiv.). Under argon atmosphere, this mixture was injected into a solution of the corresponding sulfonyl chloride $(0.4 \mathrm{mmol}, 2.0$ equiv.) in $\mathrm{CH}_{2} \mathrm{Cl}_{2}(10 \mathrm{~mL})$ at $0{ }^{\circ} \mathrm{C}$. The mixture was stirred for $20 \mathrm{~h}$. After evaporation of the solvent, the remaining crude material was partitioned between ethyl acetate (30 $\mathrm{mL}$ ) and saturated $\mathrm{NaHCO}_{3}$ solution $(30 \mathrm{~mL})$ and extracted. The organic layer was further washed with sat. $\mathrm{NaHCO}_{3}$ solution $(2 \times 30 \mathrm{~mL})$ and brine $(3 \times 30 \mathrm{~mL})$. The reunited organic phases were dried on $\mathrm{Na}_{2} \mathrm{SO}_{4}$, evaporated under vacuum and purified by flash column chromatography. 
8.1.11. Synthesis and characterization of compounds presented in chapter I

Scheme 7. General synthesis of compounds 2-12 and 14.<smiles>CC(C)(C)OC(=O)N[C@@H](Cc1ccccc1)C(=O)O</smiles><smiles>CC1(C#N)CC1</smiles><smiles>CC(C)(C)OC(=O)N[C@@H](Cc1ccccc1)C(=O)NC1(C#N)CC1</smiles>

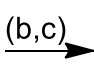<smiles>[X]C(=O)N[C@@H](Cc1ccccc1)C(=O)NC1(C#N)CC1</smiles><smiles>CC(C)(C)OC(=O)N[C@@H](Cc1ccccc1)C(=O)O</smiles><smiles>N#CC1(N)CC1</smiles>

(a)<smiles>CC(C)(C)OC(=O)N[C@@H](Cc1ccccc1)C(=O)NC1(C#N)CC1</smiles><smiles>N#CC1(NC(=O)[C@H](Cc2ccccc2)NC(=O)c2cc(Cl)cc(Br)c2)CC1</smiles>

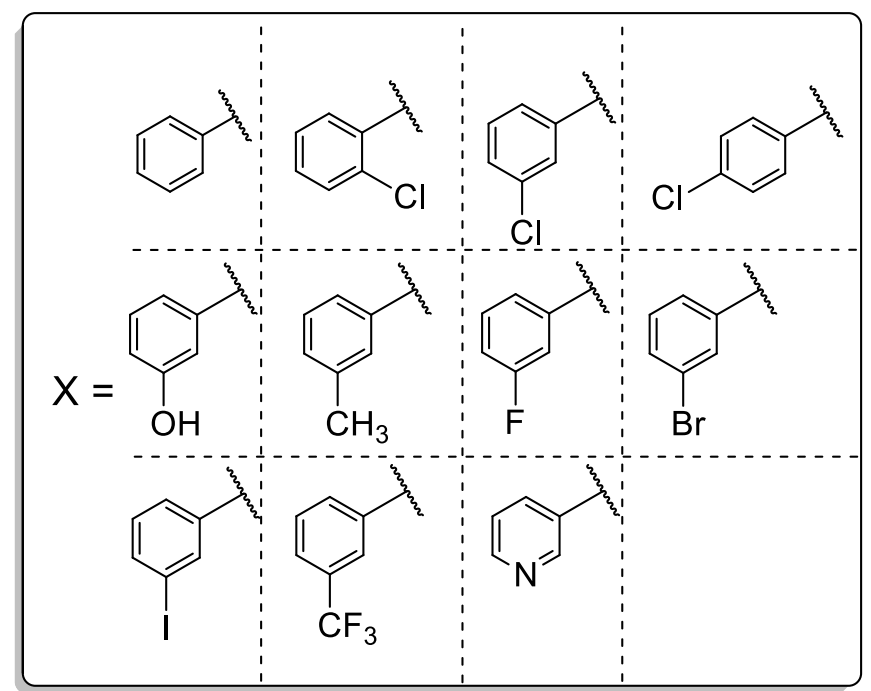

\begin{tabular}{|l|l|}
\hline Number & Nequimed Code \\
\hline 2 & Neq0570 \\
\hline 3 & Neq0709 \\
\hline 4 & Neq0710 \\
\hline 5 & Neq0711 \\
\hline 6 & Neq0712 \\
\hline 7 & Neq0717 \\
\hline 8 & Neq0802 \\
\hline 9 & Neq0803 \\
\hline 10 & Neq0804 \\
\hline 11 & Neq0805 \\
\hline 12 & Neq0714 \\
\hline 14 & Neq0710.1 \\
\hline
\end{tabular}

Reagents and conditions: (a) HATU, DIPEA, DMF, rt, $18 \mathrm{~h}$; b) formic acid, rt, $18 \mathrm{~h}$; c) HATU, carboxylic acid, DMF, rt, $18 \mathrm{~h}$. Source: Own author.

Compounds 1 and 13 were synthesized from N-(tert-Butoxycarbonyl)-L-phenylalanine and 1-amino-1-cyclopropanecarbonitrile following the general procedure for amide synthesis (method $A$ ). 
(S)-tert-butyl (1-((1-cyanocyclopropyl)amino)-1-oxo-3-phenylpropan-2-yl)carbamate (1)<smiles>CC(C)(C)OC(=O)N[C@@H](Cc1ccccc1)C(=O)NC1(C#N)CC1</smiles>

Yield 92\%. White solid. $R_{f}=0.9$ (ethyl acetate: $n$-hexane; 7:3). Mp. $146-147{ }^{\circ} \mathrm{C} .{ }^{1} \mathrm{H}$ $\operatorname{NMR}\left(500 \mathrm{MHz}, \mathrm{CDCl}_{3}\right) \delta 7.27-7.04(\mathrm{~m}, 5 \mathrm{H}), 4.58-4.54(\mathrm{~m}, 1 \mathrm{H}), 3.19$ (dd, J=13.8, $5.0 \mathrm{~Hz}, 1 \mathrm{H}), 2.88(\mathrm{dd}, J=9.5,5.0 \mathrm{~Hz}, 1 \mathrm{H}), 1.31(\mathrm{~s}, 9 \mathrm{H}), 1.25-1.19(\mathrm{~m}, 2 \mathrm{H}), 1.04-$ 0.98 (m, 2H). ${ }^{13} \mathrm{C}$ NMR. (125 MHz, $\left.\mathrm{CDCl}_{3}\right) \delta$ 173.06, 155.30, 137.73, 129.35, 128.19, 126.45, 120.80, 78.30, 55.54, 37.36, 28.26, 19.77, 15.80, 15.75. Reference (AVELAR et al., 2015).

(D)-tert-butyl (1-((1-cyanocyclopropyl)amino)-1-oxo-3-phenylpropan-2-yl)carbamate (13)<smiles>CC(C)(C)OC(=O)N[C@@H](Cc1ccccc1)C(=O)NC1(C#N)CC1</smiles>

Yield 92\%. White solid. $R_{f}=0.9$ (ethyl acetate: $n$-hexane; 7:3). Mp. $141-143{ }^{\circ} \mathrm{C} .{ }^{1} \mathrm{H}$ $\operatorname{NMR}\left(500 \mathrm{MHz}, \mathrm{CDCl}_{3}\right) \delta 7.21-7.02(\mathrm{~m}, 5 \mathrm{H}), 4.55-4.52(\mathrm{~m}, 1 \mathrm{H}), 3.17(\mathrm{dd}, \mathrm{J}=13.8$, $5.0 \mathrm{~Hz}, 1 \mathrm{H}), 2.89$ (dd, J = 9.5, $5.0 \mathrm{~Hz}, 1 \mathrm{H}), 1.31(\mathrm{~s}, 9 \mathrm{H}), 1.22-1.15(\mathrm{~m}, 2 \mathrm{H}), 1.03-$ $0.96(\mathrm{~m}, 2 \mathrm{H})$.

Compounds 2 - 12 and 14 were synthesized in two steps from compounds 1 and 13, respectively. First, the Boc group was removed (general procedure for removal of the Boc procteting group, method A), and then the free amine was coupled to the selected carboxylic acid following the general procedure for amide synthesis (method A). 
(2S)-N-(1-cyanocyclopropyl)-3-phenyl-2-(phenylformamido)propanamide (2)<smiles>N#CC1(NC(=O)[C@H](Cc2ccccc2)NC(=O)c2ccccc2)CC1</smiles>

Yield 70\%. White solid. $R_{f}=0.4$ (ethyl acetate: $n$-hexane; 7:3). Mp. $189-190^{\circ} \mathrm{C}$. NMR ${ }^{1} \mathrm{H}\left(500 \mathrm{MHz}, \mathrm{DMSO}-\mathrm{d}_{6}\right) \delta 9.02(\mathrm{~s}, 1 \mathrm{H}), 8.64(\mathrm{~d}, J=8.1 \mathrm{~Hz}, 1 \mathrm{H}), 7.82(\mathrm{~d}, J=7.2 \mathrm{~Hz}$, 2H), 7.52 (t, J=7.3 Hz, 1H), 7.44 (t, J=7.5 Hz, 2H), 7.30 (d, J = 7.2 Hz, 2H), 7.25 (t, $J=7.5 \mathrm{~Hz}, 2 \mathrm{H}), 7.17(\mathrm{t}, J=7.2 \mathrm{~Hz}, 1 \mathrm{H}), 4.60-4.57(\mathrm{~m}, 1 \mathrm{H}), 3.17(\mathrm{dd}, J=13.8,5.0$ $\mathrm{Hz}, 1 \mathrm{H}), 2.89(\mathrm{dd}, J=9.5,5.0 \mathrm{~Hz}, 1 \mathrm{H}), 1.46-1.42(\mathrm{~m}, 2 \mathrm{H}), 1.04-1.01(\mathrm{~m}, 2 \mathrm{H})$. NMR ${ }^{13} \mathrm{C}\left(125 \mathrm{MHz}\right.$, DMSO- $\left.d_{6}\right) \delta 173.18,166.71,138.29,134.26,131.81,129.61,128.61$, 128.55, 127.93, 126.80, 121.18, 55.05, 37.39, 20.19, 16.15, 16.13. HRMS (+) Calc. for $\left[\mathrm{C}_{20} \mathrm{H}_{20} \mathrm{~N}_{3} \mathrm{O}_{2}\right]$ 334.1550, found: $334.1550[\mathrm{M}+\mathrm{H}]^{+}$. HPLC (protocol A, 50:50 ACN: water): $t_{R}(\min )=8.39$. Purity: 97.3\%. Reference (AVELAR et al., 2015).

(S)-2-chloro-N-(1-((1-cyanocyclopropyl)amino)-1-oxo-3-phenylpropan-2-yl)benzamide (3)<smiles>N#CC1(NC(=O)[C@H](Cc2ccccc2)NC(=O)c2ccccc2Cl)CC1</smiles>

Yield $80 \%$. White solid. $R_{f}=0.4$ (ethyl acetate: $n$-hexane; 8:2). Mp. $175-176{ }^{\circ} \mathrm{C} .{ }^{1} \mathrm{H}$ NMR (500 MHz, DMSO-d6) $\delta 8.95(\mathrm{~s}, 1 \mathrm{H}), 8.71(\mathrm{~d}, J=10.0 \mathrm{~Hz}, 1 \mathrm{H}), 7.42-7.38(\mathrm{~m}$, $3 \mathrm{H}), 7.35$ (dt, $J=9.5,3.0 \mathrm{~Hz}, 1 \mathrm{H}), 7.28-7.17(\mathrm{~m}, 5 \mathrm{H}), 4.57(\mathrm{~m}, 1 \mathrm{H}), 3.06(\mathrm{dd}, J=$ 13.5, $5.0 \mathrm{~Hz}, 1 \mathrm{H}$ ), 2.98 (dd, $J=19.0,13.5 \mathrm{~Hz}, 1 \mathrm{H}), 1.44-1.26(\mathrm{~m}, 2 \mathrm{H}), 1.02-0.96(\mathrm{~m}$, $2 \mathrm{H}) .{ }^{13} \mathrm{C}$ NMR $\left(125 \mathrm{MHz}\right.$, DMSO- $\left.d_{6}\right) \delta 172.21,166.27,137.53,136.38,131.05,130.21$, 129.75, 129.42, 129.17, 128.28, 127.07, 126.62, 120.81, 54.30, 37.22, 19.89, 15.89. FT-IR (KBr, cm $\left.{ }^{-1}\right)$ 3300.12, 3284.56, 3030.64, 2247.67, 1663.44, 1650.51, 1525.45, 1502.12, 1329.89, 1053.44, 744.62, 698.87. ESI-MS (-) Calc. for $\left[\mathrm{C}_{20} \mathrm{H}_{18} \mathrm{CIN}_{3} \mathrm{O}_{2}\right]$ 367.83, found: 366.25 [M-H]. HPLC (protocol A, 50:50 ACN: water): $t_{R}(\min )=12.01$. Purity: $97.2 \%$. 
((S)-3-chloro-N-(1-((1-cyanocyclopropyl)amino)-1-oxo-3-phenylpropan-2yl)benzamide (4)<smiles>N#CC1(NC(=O)[C@H](Cc2ccccc2)NC(=O)c2cccc(Cl)c2)CC1</smiles>

Yield $75 \%$. White solid. $R_{f}=0.4$ (ethyl acetate: $n$-hexane; 8:2). Mp. $214-215{ }^{\circ} \mathrm{C} .{ }^{1} \mathrm{H}$ NMR (500 MHz, DMSO-d $\left.d_{6}\right) \quad 9.03(\mathrm{~s}, 1 \mathrm{H}), 8.83(\mathrm{~d}, J=10.0 \mathrm{~Hz}, 1 \mathrm{H}), 7.87(\mathrm{t}, J=2.6$ $\mathrm{Hz}, 1 \mathrm{H}$ ), 7.77 (dt, J= 7.5, 1.5 Hz, 1H), 7.59 (ddd, J= 8.0, 2.5, $1.4 \mathrm{~Hz}, 1 \mathrm{H}$ ), 7.48 (t, $J=$ $8.0 \mathrm{~Hz}, 1 \mathrm{H}), 7.27-7.18(\mathrm{~m}, 4 \mathrm{H}), 7.17-7.15(\mathrm{~m}, 1 \mathrm{H}), 4.60-4.58(\mathrm{~m}, 1 \mathrm{H}), 3.06(\mathrm{dd}, J$ $=13.5,5.0 \mathrm{~Hz}, 1 \mathrm{H}), 2.98(\mathrm{dd}, J=19.0,13.5 \mathrm{~Hz}, 1 \mathrm{H}), 1.47-1.45(\mathrm{~m}, 2 \mathrm{H}), 1.03-0.95$ $(\mathrm{m}, 2 \mathrm{H}) .{ }^{13} \mathrm{C}$ NMR $(125 \mathrm{MHz}$, DMSO-d 6$) \delta 172.95,165.31,138.21,136.21,133.49$, 131.66, 130.68, 129.57, 128.56, 127.73, 126.84, 126.71, 121.16, 55.12, 37.32, 20.20, 16.14, 16.12. FT-IR (KBr, cm$\left.{ }^{-1}\right) 3302.43$, 2924.67, 2243.11, 1672.5, 1649.47, 1537.36, $1525.64,1319.78,1076.55,750.8,696.32,686.91$. ESI-MS (-) Calc. for $\left[\mathrm{C}_{20} \mathrm{H}_{18} \mathrm{CIN}_{3} \mathrm{O}_{2}\right]$ 367.83, found: 366.25 [M-H] . HPLC (protocol A, 50:50 ACN: water): $\operatorname{tr}(\min )=14.77$. Purity: $94.6 \%$.

(S)-4-chloro-N-(1-((1-cyanocyclopropyl)amino)-1-oxo-3-phenylpropan-2-yl)benzamide (5)<smiles>N#CC1(NC(=O)[C@H](Cc2ccccc2)NC(=O)c2ccc(Cl)cc2)CC1</smiles>

Yield $75 \%$. White solid. $R_{f}=0.4$ (ethyl acetate: $n$-hexane; 8:2). Mp. $218-219{ }^{\circ} \mathrm{C} .{ }^{1} \mathrm{H}$ NMR (500 MHz, DMSO-d $\left.d_{6}\right) \quad 9.03(\mathrm{~s}, 1 \mathrm{H}), 8.78(\mathrm{~d}, J=10.0 \mathrm{~Hz}, 1 \mathrm{H}$ ), $7.83(\mathrm{dt}, J=10.5$, $2.5 \mathrm{~Hz}, 2 \mathrm{H}$ ), $7.52(\mathrm{dt}, J=10.5,2.5 \mathrm{~Hz}, 2 \mathrm{H}), 7.28-7.22(\mathrm{~m}, 4 \mathrm{H}), 7.16(\mathrm{tt}, J=7,1.5 \mathrm{~Hz}$, $1 \mathrm{H}$ ), $4.58-4.52(\mathrm{~m}, 1 \mathrm{H}), 3.05$ (dd, $J=13.5,5.0 \mathrm{~Hz}, 1 \mathrm{H}$ ), 2.96 (dd, $J=19.0,13.5 \mathrm{~Hz}$, $1 \mathrm{H}), 1.45-1.39(\mathrm{~m}, 2 \mathrm{H}), 1.01-0.94(\mathrm{~m}, 2 \mathrm{H}) .{ }^{13} \mathrm{C}$ NMR (125 MHz, DMSO-d $\left.d_{6}\right) \delta 172.74$, 165.38, 137.92, 136.35, 132.69, 129.58, 129.29, 128.43, 128.26, 126.53, 120.87, 54.81, 37.06, 19.89, 15.85, 15.82. FT-IR $\left(\mathrm{KBr}, \mathrm{cm}^{-1}\right) 3300.12,3284.67,3030.21$, $2247.24,1663.59,1649.13,1525.34,1502.88,1329.33,1053.11,744.67,698.48$. ESI- 
MS (-) Calc. for [ $\left.\mathrm{C}_{20} \mathrm{H}_{18} \mathrm{CIN}_{3} \mathrm{O}_{2}\right]$ 367.83, found: 366.25 [M-H]- HPLC (protocol A, 50:50 ACN: water): th $(\min )=16.12$. Purity: $99.9 \%$.

(S)-N-(1-((1-cyanocyclopropyl)amino)-1-oxo-3-phenylpropan-2-yl)-3methylbenzamide (6)<smiles>Cc1cccc(C(=O)N[C@@H](Cc2ccccc2)C(=O)NC2(C#N)CC2)c1</smiles>

Yield $73 \%$. White solid. $R_{f}=0.6$ (ethyl acetate: $n$-hexane; 8:2). Mp. $140-141^{\circ} \mathrm{C}{ }^{1} \mathrm{H}$ NMR (500 MHz, DMSO-d $)) \delta 8.87(\mathrm{~s}, 1 \mathrm{H}), 8.39(\mathrm{~d}, J=10.0 \mathrm{~Hz}, 1 \mathrm{H}), 7.61-7.57(\mathrm{~m}$, 2H), $7.22-7.12(\mathrm{~m}, 7 \mathrm{H}), 4.64-4.60(\mathrm{~m}, 1 \mathrm{H}), 3.06$ (dd, J=13.5, $5.0 \mathrm{~Hz}, 1 \mathrm{H}), 2.99$ (dd, $J=19.0,13.5 \mathrm{~Hz}, 1 \mathrm{H}), 2.33(\mathrm{~s}, 3 \mathrm{H}) 1.37-1.31(\mathrm{~m}, 2 \mathrm{H}), 1.06-0.96(\mathrm{~m}, 2 \mathrm{H}) .{ }^{13} \mathrm{C} \mathrm{NMR}$ $\left(125 \mathrm{MHz}, \mathrm{DMSO}-d_{6}\right) \delta 173.00,166.93,137.90,137.67,133.47,132.09,130.08$, 129.49, 128.38, 128.31, 126.78, 124.92, 120.71, 78.68, 54.77, 37.56, 21.36, 20.13, 16.13. FT-IR $\left(\mathrm{KBr}, \mathrm{cm}^{-1}\right)$ 3303.67, 3285.43, 3030.11, 2247.27, 1663.44, 1650.21, 1525.8, 1502.62, 1329.47, 1053.28, 744.36, 698.71. ESI-MS (-) Calc. for $\left[\mathrm{C}_{21} \mathrm{H}_{21} \mathrm{~N}_{3} \mathrm{O}_{2}\right]$ 347.42, found: $346.31[\mathrm{M}-\mathrm{H}]^{-}$. HPLC (protocol A, 50:50 ACN: water): $t_{R}(\min )=13.5$. Purity: $95.8 \%$.

(S)-N-(1-((1-cyanocyclopropyl)amino)-1-oxo-3-phenylpropan-2-yl)-3-

hydroxybenzamide (7)<smiles>N#CC1(NC(=O)[C@H](Cc2ccccc2)NC(=O)c2cccc(O)c2)CC1</smiles>

Yield 65\%. White solid. $R_{f}=0.3$ (ethyl acetate). Mp. $228-229{ }^{\circ} \mathrm{C} .{ }^{1} \mathrm{H}$ NMR $(500 \mathrm{MHz}$, DMSO-d $)_{6} \delta 9.24-9.22(\mathrm{~m}, 1 \mathrm{H}), 8.99(\mathrm{~d}, J=10.0 \mathrm{~Hz}, 1 \mathrm{H}), 8.11(\mathrm{~d}, J=5.3 \mathrm{~Hz}, 1 \mathrm{H})$, $7.74(\mathrm{~d}, J=10.0 \mathrm{~Hz}, 1 \mathrm{H}), 7.59$ (dd, $J=7.5,3.2 \mathrm{~Hz}, 1 \mathrm{H}), 7.46(\mathrm{~d}, J=9.8 \mathrm{~Hz}, 1 \mathrm{H}), 7.35$ - $7.30(\mathrm{~m}, 5 \mathrm{H}), 5.75(\mathrm{~s}, 1 \mathrm{H}), 4.77-4.74(\mathrm{~m}, 1 \mathrm{H}), 3.12(\mathrm{dd}, J=13.5,5.0 \mathrm{~Hz}, 1 \mathrm{H}), 2.90$ $(\mathrm{dd}, J=19.0,13.5 \mathrm{~Hz}, 1 \mathrm{H}), 1.53-1.51(\mathrm{~m}, 2 \mathrm{H}), 1.13-1.09(\mathrm{~m}, 2 \mathrm{H}) .{ }^{13} \mathrm{C}$ NMR $(125$ $\left.\mathrm{MHz}, \mathrm{DMSO}-d_{6}\right) \delta 172.72,165.11,156.77,137.94,135.98,133.27,131.43,130.46$, 
129.34, 128.34, 127.50, 126.62, 120.93, 54.88, 37.10, 19.95, 15.90. FT-IR (KBr, cm $\left.{ }^{-1}\right)$ 3416.66, 3324.13, 3305.56, 2246.94, 1673.25, 1649.72, 1525.16, 1284.44, 1027.1, 706.86. ESI-MS (-) Calc. for $\left[\mathrm{C}_{20} \mathrm{H}_{19} \mathrm{~N}_{3} \mathrm{O}_{3}\right] 349.39$, found: $348.23[\mathrm{M}-\mathrm{H}]-$ The substance was subjected to semi-preparative chromatography using the following conditions: $\mathrm{C} 18$ column ( $250 \times 10 \mathrm{~mm} ; 10 \mu \mathrm{m} ; 100 \mathrm{~A}$; LUNA $\AA$ ); isocratic elution with ACN/water, 30:70; flow rate $2.5 \mathrm{~mL} / \mathrm{min}$; injection volume $100 \mu \mathrm{L}$; stock solution of compound was 10.0 $\mathrm{mg} / \mathrm{mL}$ in mobile phase. HPLC (protocol A, 50:50 ACN: water): $\mathrm{tR}_{\mathrm{R}}(\mathrm{min})=14.53$. Purity: $98.6 \%$.

(S)-N-(1-((1-cyanocyclopropyl)amino)-1-oxo-3-phenylpropan-2-yl)-3-fluorobenzamide (8)<smiles>N#CC1(NC(=O)[C@H](Cc2ccccc2)NC(=O)c2cccc(F)c2)CC1</smiles>

Yield 75\%. White solid. $R_{f}=0.4$ (ethyl acetate: $n$-hexane; 8:2). Mp. $219-220{ }^{\circ} \mathrm{C} .{ }^{1} \mathrm{H}$ NMR (500 MHz, DMSO-d $) \delta 9.02(\mathrm{~s}, 1 \mathrm{H}), 8.76(\mathrm{~d}, J=6.5 \mathrm{~Hz}, 1 \mathrm{H}), 7.68-7.67(\mathrm{~m}$, $1 \mathrm{H}), 7.63-7.59(\mathrm{~m}, 1 \mathrm{H}), 7.50(\mathrm{dt}, J=10.0,7.5 \mathrm{~Hz}, 1 \mathrm{H}), 7.40-7.35(\mathrm{~m}, 1 \mathrm{H}), 7.30-$ $7.23(\mathrm{~m}, 4 \mathrm{H}), 7.16(\mathrm{tt}, J=6.0,1.5 \mathrm{~Hz}, 1 \mathrm{H}), 4.62-4.56(\mathrm{~m}, 1 \mathrm{H}), 3.08(\mathrm{dd}, J=13.2,5.1$ $\mathrm{Hz}, 1 \mathrm{H}), 2.98(\mathrm{dd}, \mathrm{J}=19.0,12.5 \mathrm{~Hz}, 1 \mathrm{H}), 1.47-1.44(\mathrm{~m}, 2 \mathrm{H}), 1.04-1.01(\mathrm{~m}, 2 \mathrm{H}) .{ }^{13} \mathrm{C}$ NMR (125 MHz, DMSO-d $)$ ) $172.95,165.38,163.49,161.06,138.17,136.59,136.53$, 130.78, 129.57, 128.55, 126.83, 124.09, 121.15, 55.11, 37.34, 20.17, 16.13. FT-IR $\left(\mathrm{KBr}, \mathrm{cm}^{-1}\right) 3271.24,3064.33,3026.76,2297.61,2237.51,1676.75,1664.27,1587.44$, 1541.38, 1523.48, 1485.64, 1435.56, 1377.47, 1325.36, 1300.06, 1288.57, 1271.12, 1224.7, 1215.21, 1180.09, 750.22, 702.98. ESI-MS (+) Calc. for $\left[\mathrm{C}_{20} \mathrm{H}_{18} \mathrm{FN}_{3} \mathrm{O}_{2}\right] 351.14$, found: $352.03[\mathrm{M}+\mathrm{H}]^{+}$. HPLC (protocol A, 50:50 ACN: water): $\mathrm{tR}_{\mathrm{R}}(\mathrm{min})=12.41$. Purity: $96.8 \%$. 
(S)-3-bromo-N-(1-((1-cyanocyclopropyl)amino)-1-oxo-3-phenylpropan-2yl)benzamide (9)<smiles>N#CC1(NC(=O)[C@H](Cc2ccccc2)NC(=O)c2cccc(Br)c2)CC1</smiles>

Yield $72 \%$. White solid. $R_{f}=0.5$ (ethyl acetate: $n$-hexane; 8:2). Mp. $229-230{ }^{\circ} \mathrm{C} .{ }^{1} \mathrm{H}$ NMR (500 MHz, DMSO-d $) \delta 9.05$ (s, 1H), $8.86(\mathrm{~d}, J=8.0 \mathrm{~Hz}, 1 \mathrm{H}), 8.04(\mathrm{t}, J=1.5 \mathrm{~Hz}$, $1 \mathrm{H}), 7.84-7.82(\mathrm{~m}, 1 \mathrm{H}), 7.76-7.74(\mathrm{~m}, 1 \mathrm{H}), 7.46(\mathrm{t}, J=8.0 \mathrm{~Hz}, 1 \mathrm{H}), 7.32-7.26(\mathrm{~m}$, $4 \mathrm{H}), 7.21(\mathrm{tt}, J=6.0,1.5 \mathrm{~Hz}, 1 \mathrm{H}), 4.64-4.60(\mathrm{~m}, 1 \mathrm{H}), 3.15(\mathrm{dd}, J=13.2,5.1 \mathrm{~Hz}, 1 \mathrm{H})$, $3.01(\mathrm{dd}, J=19.0,12.5 \mathrm{~Hz}, 1 \mathrm{H}), 1.50-1.47(\mathrm{~m}, 2 \mathrm{H}), 1.08-1.03(\mathrm{~m}, 2 \mathrm{H}) .{ }^{13} \mathrm{C}$ NMR $\left(125 \mathrm{MHz}\right.$, DMSO-d $\left.d_{6}\right) \delta 172.95,165.23,138.19,136.41,134.54,130.94,130.60$, 129.57, 128.56, 128.01, 127.09, 126.84, 121.97, 121.16, 55.11, 37.32, 20.18, 16.12. FT-IR $\left(\mathrm{KBr}, \mathrm{cm}^{-1}\right) 3302.04,3029.21,3024.23,2243.54,1672.86,1649.28,1539.01$, 1525.6, 1377.43, 1319.11, 1303.56, 1219.81, 1064.77, 896.55, 848.14, 746.33, 700.88, 684.95. ESI-MS (+) Calc. for $\left[\mathrm{C}_{20} \mathrm{H}_{18} \mathrm{BrN}_{3} \mathrm{O}_{2}\right]$ 412.29, found: $413.50[\mathrm{M}+\mathrm{H}]^{+}$. HPLC (protocol A, 50:50 ACN: water): $t_{R}(\min )=18.33$. Purity: $99.5 \%$.

(S)-N-(1-((1-cyanocyclopropyl)amino)-1-oxo-3-phenylpropan-2-yl)-3-iodobenzamide (10)<smiles>N#CC1(NC(=O)[C@H](Cc2ccccc2)NC(=O)c2cccc(I)c2)CC1</smiles>

Yield $86 \%$. White solid. $R_{f}=0.8$ (ethyl acetate: $n$-hexane; 8:2). Mp. $205-207{ }^{\circ} \mathrm{C} .{ }^{1} \mathrm{H}$ NMR (500 MHz, DMSO-d $) \delta 9.00(\mathrm{~s}, 1 \mathrm{H}), 8.78(\mathrm{~d}, J=8.0 \mathrm{~Hz}, 1 \mathrm{H}), 8.17(\mathrm{t}, J=1.5 \mathrm{~Hz}$, $1 \mathrm{H}), 7.88-7.86(\mathrm{~m}, 1 \mathrm{H}), 7.28-7.22(\mathrm{~m}, 5 \mathrm{H}), 7.16(\mathrm{dt}, J=7.0,2.0 \mathrm{~Hz}, 1 \mathrm{H}), 4.60-$ $4.55(\mathrm{~m}, 1 \mathrm{H}), 3.05(\mathrm{dd}, J=15.0,5.0 \mathrm{~Hz}, 1 \mathrm{H}), 2.96(\mathrm{dd}, J=14.0,10.0 \mathrm{~Hz}, 1 \mathrm{H}), 1.47$ $1.42(\mathrm{~m}, 2 \mathrm{H}), 1.04-1.00(\mathrm{~m}, 2 \mathrm{H}) .{ }^{13} \mathrm{C}$ NMR (125 MHz, DMSO-d $) \delta 172.97,165.23$, $140.32,138.19,136.34,136.26,130.85,129.57,128.55,127.41,126.83,121.16$, 94.96, 55.06, 37.32, 20.18, 16.12. FT-IR $\left(\mathrm{KBr}, \mathrm{cm}^{-1}\right)$ 3286.55, 3029.03, 3022.13, $2241.91,1672.16,1649.55,1522.71,1317.97,1284.88,1299.03,1219.16,1066.1$, 
883.41, 792.65, 744.55, 684.09. ESI-MS (+) Calc. for $\left[\mathrm{C}_{20} \mathrm{H}_{18} \mathrm{IN}_{3} \mathrm{O}_{2}\right]$ 460.39, found: 461.32 $[\mathrm{M}+\mathrm{H}]^{+}$. HPLC (protocol A, 50:50 ACN: water): $t_{R}(\min )=22.26$. Purity: 99.1\%.

(S)-N-(1-((1-cyanocyclopropyl)amino)-1-oxo-3-phenylpropan-2-yl)-3(trifluoromethyl)benzamide (11)<smiles>N#CC1(NC(=O)[C@H](Cc2ccccc2)NC(=O)c2cccc(C(F)(F)F)c2)CC1</smiles>

Yield 62\%. White solid. $R_{f}=0.7$ (ethyl acetate: $n$-hexane; 7:3). Mp. $193-195{ }^{\circ} \mathrm{C} .{ }^{1} \mathrm{H}$ NMR (500 MHz, DMSO-d6) $\delta 9.04(\mathrm{~s}, 1 \mathrm{H}), 8.98$ (d, J = 8.0 Hz, 1H), 8.15 (s, 1H), 8.10 $(\mathrm{d}, J=8.0 \mathrm{~Hz}, 1 \mathrm{H}), 7.90(\mathrm{~d}, J=7.5 \mathrm{~Hz}, 1 \mathrm{H}), 7.70(\mathrm{t}, J=8.0 \mathrm{~Hz}, 1 \mathrm{H}), 7.29-7.22(\mathrm{~m}$, 4H), 7.19 (t, J=7.5, Hz, 1H), $4.64-4.60$ (m, 1H), 3.09 (dd, J=13.5, 5.0 Hz, 1H), 2.98 $(\mathrm{dd}, J=13.5,10.0 \mathrm{~Hz}, 1 \mathrm{H}), 1.47-1.41(\mathrm{~m}, 2 \mathrm{H}), 1.04-1.03(\mathrm{~m}, 2 \mathrm{H}) .{ }^{13} \mathrm{C}$ NMR $(125$ $\left.\mathrm{MHz}, \mathrm{DMSO}-d_{6}\right) \delta 172.91,165.32,138.13,135.13,132.06,130.01,129.58,129.33$, 128.56, 128.39, 126.86, 125.51, 124.57, 121.15, 55.12, 37.37, 20.19, 16.14. FT-IR $\left(\mathrm{KBr}, \mathrm{cm}^{-1}\right)$ 3273.11, 3025.79, 2296.1, 2243.78, 1683.64, 1674.09, 1645.19, 1539.33, 1489.13, 1440.91, 1325.58, 1303.14, 1282.86, 1170.12, 1124.32, 1097.06, 1072.51, 748.66, 696.96, 684.37. ESI-MS (+) Calc. for $\left[\mathrm{C}_{21} \mathrm{H}_{18} \mathrm{~F}_{3} \mathrm{~N}_{3} \mathrm{O}_{2}\right]$ 401.14, found: 402.15 $[\mathrm{M}+\mathrm{H}]^{+}$. HPLC (protocol A, 50:50 ACN: water): $\mathrm{t}_{\mathrm{R}}(\min )=14.75$. Purity: $97.9 \%$.

(S)-N-(1-((1-cyanocyclopropyl)amino)-1-oxo-3-phenylpropan-2-yl)nicotinamide (12)<smiles>N#CC1(NC(=O)[C@H](Cc2ccccc2)NC(=O)c2cccnc2)CC1</smiles>

Yield 65\%. White solid. $R_{f}=0.3$ (ethyl acetate). Mp. $180-181^{\circ} \mathrm{C} .{ }^{1} \mathrm{H}$ NMR $(500 \mathrm{MHz}$, DMSO-d $)) \quad 0.11(\mathrm{~s}, 1 \mathrm{H}), 8.97-8.94(\mathrm{~m}, 2 \mathrm{H}), 8.70$ (dd, $J=10.5,5.5 \mathrm{~Hz}, 1 \mathrm{H}$ ), 8.15 (dt, $J=10.5,5.5 \mathrm{~Hz}, 2 \mathrm{H}), 7.49$ (ddd, $J=15.5,10,55.0 \mathrm{~Hz}, 1 \mathrm{H}), 7.29-7.20(\mathrm{~m}, 4 \mathrm{H}), 7.18$ - $7.12(\mathrm{~m}, 1 \mathrm{H}), 4.62(\mathrm{~m}, 1 \mathrm{H}), 3.11$ (dd, $J=13.5,5.0 \mathrm{~Hz}, 1 \mathrm{H}), 3.10(\mathrm{dd}, J=19.0,13.5$ $\mathrm{Hz}, 1 \mathrm{H}), 1.47(\mathrm{~m}, 2 \mathrm{H}), 1.05(\mathrm{~m}, 2 \mathrm{H}) .{ }^{13} \mathrm{C}$ NMR (125 MHz, DMSO-d6) $\delta 172.91,165.31$, 152.40, 149.04, 138.11, 135.61, 129.80, 129.60, 128.55, 126.83, 123.77, 121.16, 55.07, 39.77, 37.40, 20.19, 16.14, 16.09. FT-IR (KBr, cm-1) 3561.30, 3332.46, 2246.20, 
1674.28, 1649.50, 1535.40, 1524.40, 1484.95, 1027.14, 705.0. ESI-MS (-) Calc. for [ $\left.\mathrm{C}_{19} \mathrm{H}_{18} \mathrm{~N}_{4} \mathrm{O}_{2}\right]$ 401.14, found: 333.21 [M-H]. HPLC (protocol A, 50:50 ACN: water): th $(\min )=8.27$. Purity: $98.03 \%$.

((R)-3-chloro-N-(1-((1-cyanocyclopropyl)amino)-1-oxo-3-phenylpropan-2yl)benzamide (14)<smiles>N#CC1(NC(=O)Cc2ccccc2)CC1</smiles>

Yield 68\%. White solid. $R_{f}=0.5$ (ethyl acetate: $n$-hexane; 7:3) Mp. $210-211^{\circ} \mathrm{C} .{ }^{1} \mathrm{H}$ NMR (500 MHz, DMSO-d $\left.d_{6}\right) \quad 9.02(\mathrm{~s}, 1 \mathrm{H}), 8.83(\mathrm{~d}, J=10.0 \mathrm{~Hz}, 1 \mathrm{H}), 7.87(\mathrm{t}, J=2.5$ $\mathrm{Hz}, 1 \mathrm{H}), 7.77$ (dt, $J=10.0,5.0 \mathrm{~Hz} 1 \mathrm{H}), 7.60-7.58(\mathrm{~m}, 1 \mathrm{H}), 7.48(\mathrm{t}, J=10.0 \mathrm{~Hz}, 1 \mathrm{H})$, $7.29-7.25(\mathrm{~m}, 3 \mathrm{H}), 7.23-7.18(\mathrm{~m}, 2 \mathrm{H}), 4.62-4.57(\mathrm{~m}, 1 \mathrm{H}), 3.02(\mathrm{dd}, J=14.0,5.5$ $\mathrm{Hz}, 1 \mathrm{H}), 2.69$ (dd, $J=19.0,13.5 \mathrm{~Hz}, 1 \mathrm{H}), 1.47-1.44(\mathrm{~m}, 2 \mathrm{H}), 1.04-1.01(\mathrm{~m}, 2 \mathrm{H}) .{ }^{13} \mathrm{C}$ NMR $\left(125 \mathrm{MHz}\right.$, DMSO- $\left.d_{6}\right) \delta 172.95,165.31,138.21,136.21,133.49,131.66,130.68$, $129.57,128.56,127.73,126.84,126.71,121.16,55.12$, 37.32, 20.20, 16.14, 16.12. FT-IR $\left(\mathrm{KBr}, \mathrm{cm}^{-1}\right) 3302.48,2924.86,2243.21,1672.31,1649.95,1537.06,1525.49$, 1319.15, 1076.04, 750.5, 696.16, 686.12. ESI-MS (-) Calc. for $\left[\mathrm{C}_{20} \mathrm{H}_{18} \mathrm{CIN}_{3} \mathrm{O}_{2}\right] 367.83$, found: 366.25 [M-H] . HPLC (protocol A, 35:65 ACN: water): tR $(\min )=37.35$. Purity: $97.95 \%$ 
8.1.12. Synthesis and characterization of compounds presented in chapter II

Scheme 8. General synthesis of compounds 2, 16 and 18.

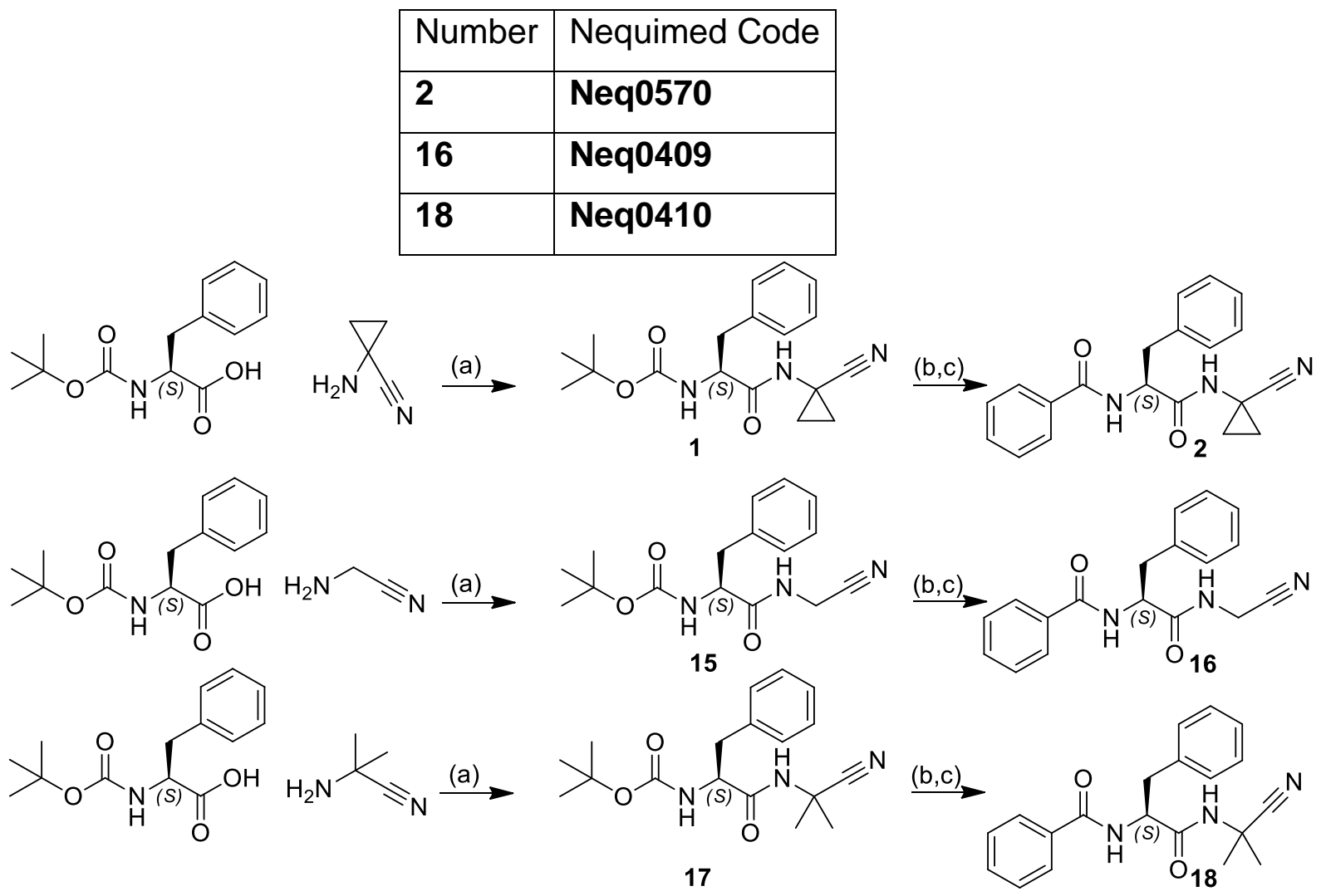

Reagents and conditions: a) HATU, DIPEA, DMF, rt, 18h; b) formic acid, rt, 18h; c) HATU, carboxylic acid, DMF, rt, 18h. Source: Own author.

Synthesis and characterization of compound $\mathbf{1}$ and $\mathbf{2}$ have been already reported above.

Compounds 15 and 17 were synthesized from $\mathrm{N}$-(tert-Butoxycarbonyl)-Lphenylalanine and 2-aminoacetonitrile or 2-amino-2-methylpropanenitrile following the general procedure for amide synthesis (method A). 
(S)-tert-butyl (1-((cyanomethyl)amino)-1-oxo-3-phenylpropan-2-yl)carbamate (15)<smiles>CC(C)(C)OC(=O)N[C@@H](Cc1ccccc1)C(=O)NCC#N</smiles>

Yield $89 \%$. White solid. $R_{f}=0.4$ (ethyl acetate: $n$-hexane; 5:5). Mp. $125-127{ }^{\circ} \mathrm{C} .{ }^{1} \mathrm{H}$ $\operatorname{NMR}\left(400 \mathrm{MHz}, \mathrm{DMSO}-d_{6}\right) \delta 8.39(\mathrm{t}, J=5.0 \mathrm{~Hz}, 1 \mathrm{H}), 7.30-7.15(\mathrm{~m}, 5 \mathrm{H}), 4.18-4.13$ $(\mathrm{m}, 1 \mathrm{H}), 4.11$ (d, $J=5.6 \mathrm{~Hz}, 2 \mathrm{H}), 2.99$ (dd, $J=13.8,5.0 \mathrm{~Hz}, 1 \mathrm{H}), 2.80$ (dd, $J=13.8$, $9.5 \mathrm{~Hz}, 1 \mathrm{H}), 1.31$ (s, 9H). Reference (AVELAR et al., 2015).

(S)-tert-butyl (1-((2-cyanopropan-2-yl)amino)-1-oxo-3-phenylpropan-2-yl)carbamate (17)<smiles>CC(C)(C)NC(=O)[C@H](Cc1ccccc1)NC(=O)OC(C)(C)C#N</smiles>

Yield 85\%. White solid. $R_{f}=0.5$ (ethyl acetate: $n$-hexane; $5: 5$ ). Mp. $120-123{ }^{\circ} \mathrm{C} .{ }^{1} \mathrm{H}$ $\operatorname{NMR}\left(400 \mathrm{MHz} \mathrm{CDCl}_{3}\right) \delta 7.33-7.16(\mathrm{~m}, 5 \mathrm{H}), 4.15-4.13(\mathrm{~m}, 1 \mathrm{H}), 3.05$ (dd, J = 13.8, $5.0 \mathrm{~Hz}, 1 \mathrm{H}), 2.94(\mathrm{dd}, J=13.8,9.5 \mathrm{~Hz}, 1 \mathrm{H}), 1.53(\mathrm{~s}, 6 \mathrm{H}),(\mathrm{s}, 9 \mathrm{H})$. Reference (AVELAR et al., 2015).

Compounds 16 and 18 were synthesized in two steps from compounds 15 and 17, respectively. First, the Boc group was removed (procedure A), and then the free amine was coupled to the carboxylic acid following the general procedure for amide synthesis (method A).

(S)-N-(1-((cyanomethyl)amino)-1-oxo-3-phenylpropan-2-yl)benzamide (16)<smiles>N#CCNC(=O)[C@H](Cc1ccccc1)NC(=O)c1ccccc1</smiles> 
Yield $88 \%$. White solid. $R_{f}=0.7$ (ethyl acetate: $n$-hexane; 8:2). Mp. $170-171{ }^{\circ} \mathrm{C} .{ }^{1} \mathrm{H}$ NMR (400 MHz, DMSO-d $)$ ס $9.02(\mathrm{~s}, 1 \mathrm{H}), 8.64(\mathrm{~d}, J=8.1 \mathrm{~Hz}, 1 \mathrm{H}), 7.82$ (d, J = 7.2 Hz, 2H), 7.52 (t, J=7.3 Hz, 1H), 7.44 (t, J=7.5 Hz, 2H), 7.30 (d, J= $7.2 \mathrm{~Hz}, 2 \mathrm{H}), 7.25$ (t, $J=7.5 \mathrm{~Hz}, 2 \mathrm{H}), 7.17(\mathrm{t}, J=7.2 \mathrm{~Hz}, 1 \mathrm{H}), 4.60-4.58(\mathrm{~m}, 1 \mathrm{H}), 4.11(\mathrm{~d}, J=5.6 \mathrm{~Hz}, 2 \mathrm{H})$, 3.05 (dd, $J=13.8,5.0 \mathrm{~Hz}, 1 \mathrm{H}$ ), 2.89 (dd, $J=9.5,5.0 \mathrm{~Hz}, 1 \mathrm{H})$. ESI-MS (+) Calc. for $\left[\mathrm{C}_{18} \mathrm{H}_{17} \mathrm{~N}_{3} \mathrm{O}_{2}\right]$ 307.13, found: $308.21[\mathrm{M}+\mathrm{H}]^{+}$. HPLC (protocol A, 50:50 ACN: water): $t_{R}$ $(\min )=11.7$. Purity: 98.95\%. Reference (AVELAR et al., 2015).

(S)-N-(1-((2-cyanopropan-2-yl)amino)-1-oxo-3-phenylpropan-2-yl)benzamide (18)<smiles>CC(C)(C#N)NC(=O)[C@H](Cc1ccccc1)NC(=O)c1ccccc1</smiles>

Yield $78 \%$. White solid. $R_{f}=0.7$ (ethyl acetate: $n$-hexane; 8:2). Mp. $130-133{ }^{\circ} \mathrm{C} .{ }^{1} \mathrm{H}$ NMR (400 MHz, DMSO-d $)$ ס $9.05(\mathrm{~s}, 1 \mathrm{H}), 8.68(\mathrm{~d}, J=8.1 \mathrm{~Hz}, 1 \mathrm{H}), 7.86(\mathrm{~d}, J=7.2 \mathrm{~Hz}$, 2H), 7.55 (t, J=7.3 Hz, 1H), 7.44 (t, J=7.5 Hz, 2H), 7.30 (d, J = 7.2 Hz, 2H), 7.25 (t, $J=7.5 \mathrm{~Hz}, 2 \mathrm{H}), 7.17(\mathrm{t}, J=7.2 \mathrm{~Hz}, 1 \mathrm{H}), 4.55-4.54(\mathrm{~m}, 1 \mathrm{H}), 3.08$ (dd, $J=13.8,5.0$ $\mathrm{Hz}, 1 \mathrm{H}$ ), 2.89 (dd, $J=9.5,5.0 \mathrm{~Hz}, 1 \mathrm{H}), 1.58$ (s, 6H). ESI-MS (+) Calc. for [ $\mathrm{C}_{20} \mathrm{H}_{22} \mathrm{~N}_{3} \mathrm{O}_{2}$ ] 336.17, found: $338.32[\mathrm{M}+\mathrm{H}]^{+}$. HPLC (protocol A, 50:50 ACN: water): $t_{R}(\min )=11.34$. Purity: 95.95\%. Reference (AVELAR et al., 2015). 
8.1.13. Synthesis and characterization of compounds presented in chapter III

Scheme 9. General synthesis of compounds 2 and $24-36$.<smiles>[Y]C(=O)NC(=O)NC1(C#N)CC1</smiles>

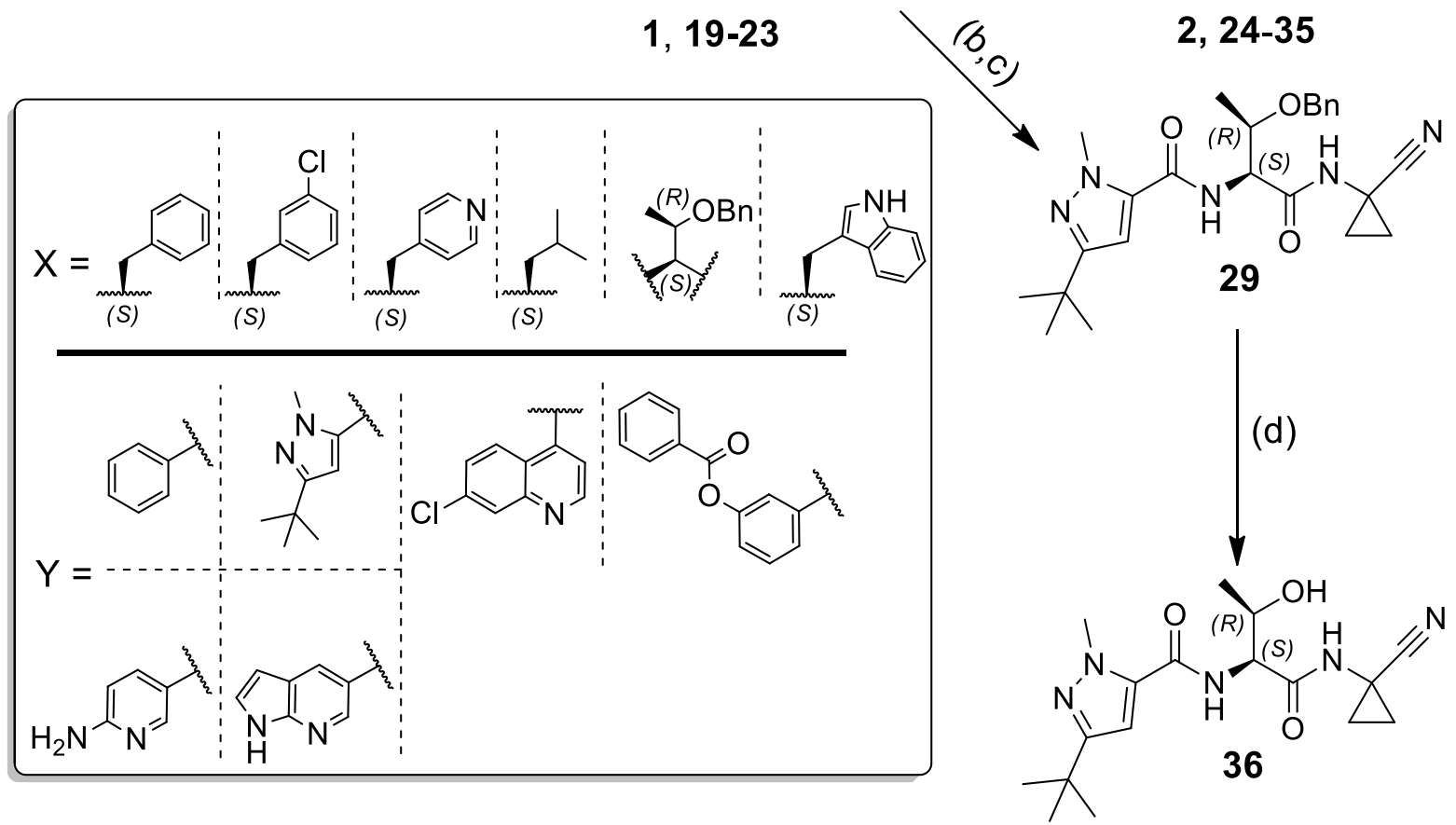

Reagents and conditions: a) HATU, DIPEA, 1-amino-1-cyclopropanecarbonitrile, DMF, rt, 18h; b) formic acid, rt, 18h; c) HATU or TBTU, DIPEA, carboxylic acid, DMF, rt, 18h; d) DDQ, $\mathrm{CH}_{2} \mathrm{Cl}_{2}$, rt, 18 h. Source: Own author. 
Scheme 10. General synthesis of compounds $67-77$ and $82-86$.

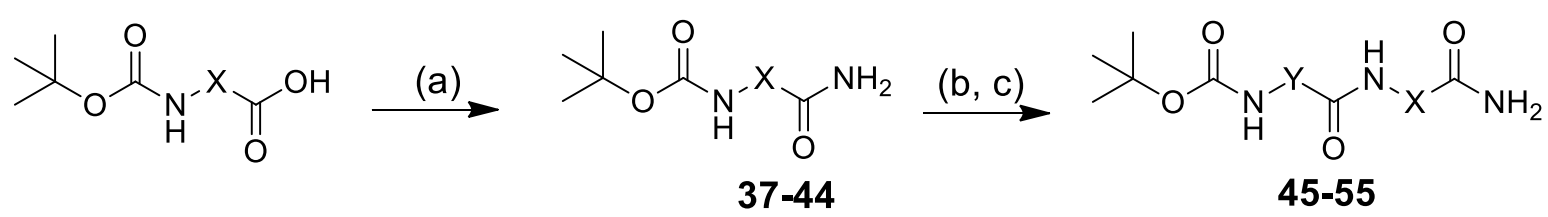

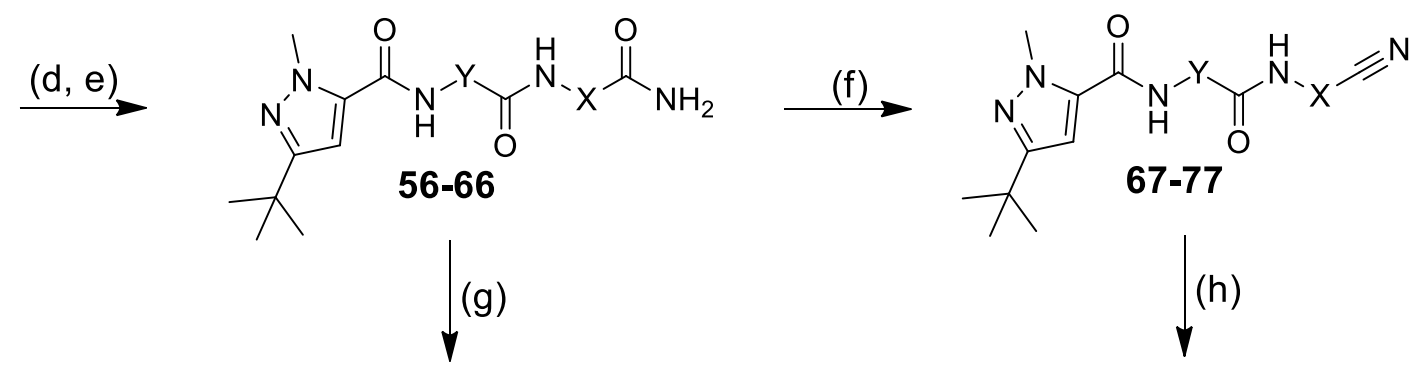

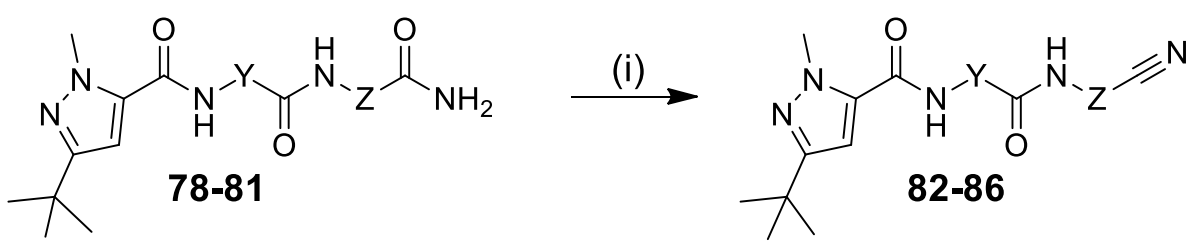

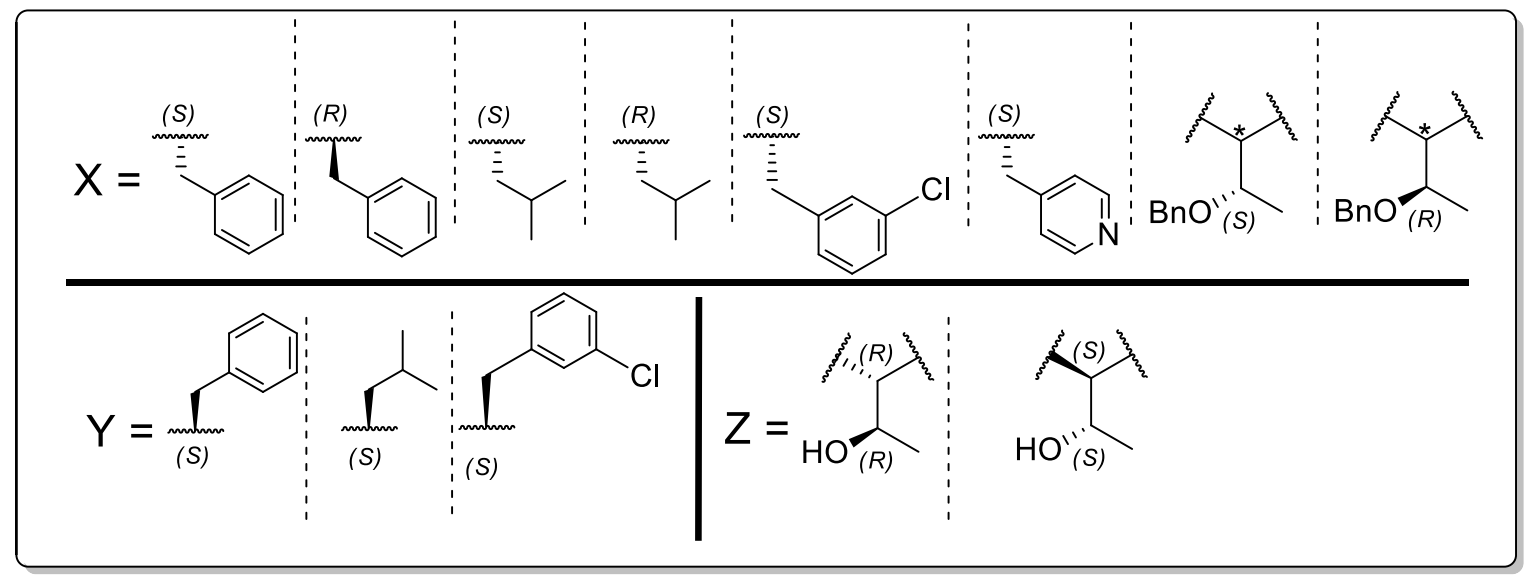

Reagents and conditions: a) Isobutyl chloroformate, $\mathrm{NH}_{4} \mathrm{Cl} 2 \mathrm{M}$, DIPEA, DMF, $0{ }^{\circ} \mathrm{C}$ to rt, $20 \mathrm{~h}$; b) TFA, $\mathrm{CH}_{2} \mathrm{Cl}_{2}, 0^{\circ} \mathrm{C}$ to rt, $2 \mathrm{~h}$; c) HATU, DIPEA, Boc-AA-OH, DMF, rt, $18 \mathrm{~h}$; d) TFA, $\mathrm{CH}_{2} \mathrm{Cl}_{2}$, $0{ }^{\circ} \mathrm{C}$ to rt, $2 \mathrm{~h}$; e)TBTU, DIPEA, 3-(tert-butyl)-1-methyl-1H-pyrazole-5-carboxylic acid, $\mathrm{DMF} / \mathrm{CH}_{2} \mathrm{Cl}_{2}$, rt, $18 \mathrm{~h}$; f) Cyanuric chloride, DMF, $0^{\circ} \mathrm{C}$ to rt, $\left.0.5 \mathrm{~h} ; \mathrm{g}\right) \mathrm{H}_{2}(1 \mathrm{~atm}), \mathrm{Pd} / \mathrm{C}, \mathrm{rt}, 18 \mathrm{~h}$; h) $p$-TOSCl, Py, rt, 3-5 days; i) TFAA, DIPEA, THF, $0^{\circ} \mathrm{C}$ to rt, $2 \mathrm{~h}$. Source: Own author. 
Table 9. List of Nequimed code for compounds described in chapter III.

\begin{tabular}{|c|c|c|c|}
\hline \multicolumn{2}{|c|}{ Scheme 9} & \multicolumn{2}{|c|}{ Scheme 10} \\
\hline Number & $\begin{array}{c}\text { Nequimed } \\
\text { Code }\end{array}$ & Number & $\begin{array}{c}\text { Nequimed } \\
\text { Code }\end{array}$ \\
\hline 2 & Neq0570 & 67 & Neq0937 \\
\hline 24 & Neq0865 & 68 & Neq0866.1 \\
\hline 25 & Neq0543 & 69 & Neq0940 \\
\hline 26 & Neq0533.1 & 70 & Neq0952 \\
\hline 27 & Neq0945 & 71 & Neq0953 \\
\hline 28 & Neq0569 & 72 & Neq0954 \\
\hline 29 & Neq0956 & 73 & Neq0921 \\
\hline 30 & Neq0719 & 74 & Neq0938 \\
\hline 31 & Neq0775 & 75 & Neq0922 \\
\hline 32 & Neq0708 & 76 & Neq0939 \\
\hline 33 & Neq0777 & 77 & Neq0877 \\
\hline 34 & Neq0955 & 82 & Neq0941 \\
\hline 35 & Neq0958 & 83 & Neq0943 \\
\hline 36 & Neq0957 & 84 & Neq0942 \\
\hline & & 85 & Neq0944 \\
\hline & & 86 & Neq0948 \\
\hline
\end{tabular}

Source: Own author.

Compounds 1 and 19 - 23 were synthesized from the selected amino acid and 1amino-1-cyclopropanecarbonitrile following the general procedure for amide synthesis (method A). Synthesis and characterization of compound 1 have been already reported above.

(S)-tert-Butyl

(3-(3-chlorophenyl)-1-((1-cyanocyclopropyl)amino)-1-oxopropan-2-

yl)carbamate (19)<smiles>CC(C)(C)OC(=O)N[C@@H](Cc1cccc(Cl)c1)C(=O)NC1(C#N)CC1</smiles> 
Yield $83 \%$. White solid. $R_{f}=0.7$ (ethyl acetate: $\mathrm{n}$-hexane; 6:4). Mp. $146-147^{\circ} \mathrm{C} .{ }^{1} \mathrm{H}$ $\operatorname{NMR}\left(500 \mathrm{MHz}_{,} \mathrm{CDCl}_{3}\right) \delta 7.26$ - $7.25(\mathrm{~m}, 1 \mathrm{H}), 7.23$ - $7.21(\mathrm{~m}, 1 \mathrm{H}), 7.08$ - $7.03(\mathrm{~m}$, 2H), $4.27-4.24(\mathrm{~m}, 1 \mathrm{H}), 3.10$ (dd, $J=13.8,5.0 \mathrm{~Hz}, 1 \mathrm{H}), 2.83(\mathrm{dd}, J=9.5,5.0 \mathrm{~Hz}, 1 \mathrm{H}$ ), $1.52-1.44(\mathrm{~m}, 2 \mathrm{H}), 1.41(\mathrm{~s}, 9 \mathrm{H}), 1.13-1.05(\mathrm{~m}, 2 \mathrm{H}) .{ }^{13} \mathrm{C}$ NMR $\left(125 \mathrm{MHz}, \mathrm{CDCl}_{3}\right)$ 172.02, 155.61, 138.23, 134.32, 129.29, 127.49, 127.25, 119.48, 80.55, 55.28, 37.87, 28.18, 20.14, 16.68, 16.56. ESI-MS (+) Calc. for $\left[\mathrm{C}_{18} \mathrm{H}_{22} \mathrm{CIN}_{3} \mathrm{O}_{3}\right] 363.83$, found: 364.3 $[\mathrm{M}+\mathrm{H}]^{+}$.

(S)-tert-Butyl (1-((1-cyanocyclopropyl)amino)-1-oxo-3-(pyridin-4-yl)propan-2-

yl)carbamate (20)<smiles>CC(C)(C)OC(=O)N[C@@H](Cc1ccncc1)C(=O)NC1(C#N)CC1</smiles>

Yield $75 \%$. White solid. $R_{f}=0.5$ (ethyl acetate: $n$-hexane; 4:6). Mp. $134-135{ }^{\circ} \mathrm{C} .{ }^{1} \mathrm{H}$ NMR (200 MHz, CD 3 OD) $\delta 8.45(\mathrm{~d}, J=4.9 \mathrm{~Hz}, 2 \mathrm{H}), 7.34(\mathrm{~d}, J=5.8 \mathrm{~Hz}, 2 \mathrm{H}), 4.36-$ $4.23(\mathrm{~m}, 1 \mathrm{H}), 2.96(\mathrm{dd}, J=14.0,5.0 \mathrm{~Hz}, 2 \mathrm{H}), 1.53-1.46(\mathrm{~m}, 1 \mathrm{H}), 1.38(\mathrm{~s}, 9 \mathrm{H}), 1.20$ $1.14(\mathrm{~m}, 2 \mathrm{H}) .{ }^{13} \mathrm{C}$ NMR $\left(50 \mathrm{MHz}, \mathrm{CDCl}_{3}\right) \delta 174.74,149.95,149.15,126.52,121.09$, $80.79,56.03,38.88,38.31,28.55,21.21,17.05$. ESI-MS (+) Calc. for $\left[\mathrm{C}_{17} \mathrm{H}_{22} \mathrm{~N}_{4} \mathrm{O}_{3}\right]$ 330.38, found: $331.2[\mathrm{M}+\mathrm{H}]^{+}$.

(S)-tert-Butyl (1-((1-cyanocyclopropyl)amino)-4-methyl-1-oxopentan-2-yl)carbamate (21)<smiles>CC(C)C[C@H](NC(=O)OC(C)(C)C)C(=O)NC1(C#N)CC1</smiles>

Yield 61\%. White solid. $R_{f}=0.7$ (ethyl acetate: $n$-hexane; 4:6). Mp. $162-164{ }^{\circ} \mathrm{C} .{ }^{1} \mathrm{H}$ NMR (500 MHz, DMSO-d6) $\delta 8.76(\mathrm{~s}, 1 \mathrm{H}), 6.86(\mathrm{~d}, J=7.9 \mathrm{~Hz}, 1 \mathrm{H}), 3.86(\mathrm{dt}, J=8.7$, $5.5 \mathrm{~Hz}, 1 \mathrm{H}), 1.55-1.54(\mathrm{~m}, J=6.6 \mathrm{~Hz}, 1 \mathrm{H}), 1.46-1.42(\mathrm{~m}, 2 \mathrm{H}), 1.37-1.42(\mathrm{~m}, 2 \mathrm{H})$, $1.36(\mathrm{~s}, 9 \mathrm{H}), 1.07$ (dd, $J=7.7,5.3 \mathrm{~Hz}, 2 \mathrm{H}), 0.84(2 \mathrm{~d}, J=6.6 \mathrm{~Hz}, 6 \mathrm{H}) .{ }^{13} \mathrm{C}$ NMR $(125$ $\mathrm{MHz}$, DMSO-d6) $\delta 174.17,155.50,120.92,78.22,52.58,40.49,28.31,24.38,23.01$, 21.66, 19.91, 15.87, 15.75. ESI-MS (+) Calc. for $\left[\mathrm{C}_{15} \mathrm{H}_{25} \mathrm{~N}_{3} \mathrm{O}_{3}\right] 295.37$, found: 318.3 $[\mathrm{M}+\mathrm{Na}]^{+}$. 
tert-Butyl ((2S,3R)-3-(benzyloxy)-1-((1-cyanocyclopropyl)amino)-1-oxobutan-2yl)carbamate (22)<smiles>CC(O)[C@H](NC(=O)OC(C)(C)C)C(=O)NC1(C#N)CC1</smiles>

Yield 89\%. White solid. $R_{f}=0.7$ (ethyl acetate: $n$-hexane; 4:6). Mp. $88-90{ }^{\circ} \mathrm{C} .{ }^{1} \mathrm{H}$ NMR $\left(200 \mathrm{MHz} \mathrm{CDCl}_{3}\right) \delta 7.36-7.32(\mathrm{~m}, 5 \mathrm{H}), 4.78-4.60(\mathrm{~m}, 3 \mathrm{H}), 4.22-4.12(\mathrm{~m}, 1 \mathrm{H}), 1.57$ - $1.44(\mathrm{~m}, 2 \mathrm{H}), 1.30-1.27(\mathrm{~m}, 9 \mathrm{H}), 1.17-1.13(\mathrm{~m}, 5 \mathrm{H})$. ESI-MS (+) Calc. for $\left[\mathrm{C}_{20} \mathrm{H}_{27} \mathrm{~N}_{3} \mathrm{O}_{4}\right]$ 373.44, found: $396.4[\mathrm{M}+\mathrm{Na}]^{+}$.

(S)-tert-butyl

(1-((1-cyanocyclopropyl)amino)-3-(1H-indol-3-yl)-1-oxopropan-2yl)carbamate (23)<smiles>CC(C)(C)OC(=O)NC(Cc1c[nH]c2ccccc12)C(=O)NC1(C#N)CC1</smiles>

Yield 59\%. Yellowish oil. $R_{f}=0.7$ (ethyl acetate: $n$-hexane; 9:1). ${ }^{1} \mathrm{H}$ NMR (200 MHz, $\left.\mathrm{CDCl}_{3}\right) \delta 8.10(\mathrm{~s}, 1 \mathrm{H}), 7.66-7.31(\mathrm{~m}, 4 \mathrm{H}), 4.92-4.88(\mathrm{~m}, 1 \mathrm{H}), 3.22-3.02(\mathrm{~m}, 2 \mathrm{H})$, $1.57-1.44(\mathrm{~m}, 2 \mathrm{H}), 1.17-1.13(\mathrm{~m}, 2 \mathrm{H})$. ESI-MS (+) Calc. for $\left[\mathrm{C}_{20} \mathrm{H}_{24} \mathrm{~N}_{4} \mathrm{O}_{4}\right]$ 368.43, found: $369.32[\mathrm{M}+\mathrm{H}]^{+}$. Reference (AVELAR et al., 2015)

Compounds 2 and $\mathbf{2 4}$ - $\mathbf{3 5}$ were synthesized in two steps from compounds 1, 19 - 23 . First, the Boc group was removed (method A for removal of the Boc protecting group), and then the free amine was coupled to the selected carboxylic acid following the general procedure for amide synthesis (method A or B, as indicated). Synthesis and characterization of compounds 2 has been already reported above. 
(S)-N-(3-(3-Chlorophenyl)-1-((1-cyanocyclopropyl)amino)-1-oxopropan-2yl)benzamide (24)<smiles>N#CC1(NC(=O)[C@H](Cc2cccc(Cl)c2)NC(=O)c2ccccc2)CC1</smiles>

Method A. Yield 86\%. White solid. $R_{f}=0.7$ (ethyl acetate: $n$-hexane; 6:4). Mp. $213-$ $215^{\circ} \mathrm{C} .{ }^{1} \mathrm{H}$ NMR $\left(500 \mathrm{MHz}, \mathrm{DMSO}-d_{6}\right) \delta 9.04(\mathrm{~s}, 1 \mathrm{H}), 8.67(\mathrm{~d}, J=8.1 \mathrm{~Hz}, 1 \mathrm{H}), 7.84-$ $7.83(\mathrm{~m}, 2 \mathrm{H}), 7.56-7.54(\mathrm{~m}, 1 \mathrm{H}), 7.53(\mathrm{t}, J=7.7 \mathrm{~Hz}, 2 \mathrm{H}), 7.41(\mathrm{~s}, 1 \mathrm{H}), 7.32-7.25$ (m, 3H), $4.65-4.60$ (m, 1H), 3.09 (dd, $J=13.6,5.0$ Hz, 1H), 3.02 (dd, $J=15.2,5.0$ $\mathrm{Hz}, 1 \mathrm{H}), 1.51-1.49(\mathrm{~m}, 2 \mathrm{H}), 1.12-1.06(\mathrm{~m}, 2 \mathrm{H}) .{ }^{13} \mathrm{C}$ NMR (125 MHz, DMSO-d6) $\delta$ $172.57,166.48,140.62,132.82$, 131.52, 130.04, 129.18, 128.31, 128.05, 127.58, 126.50, 120.81, 54.47, 36.60, 19.90, 15.82. HRMS (+) Calc. for $\left[\mathrm{C}_{20} \mathrm{H}_{19} \mathrm{CIN}_{3} \mathrm{O}_{2}\right]^{+}$ 368.11658, found: $368.11615[\mathrm{M}+\mathrm{H}]^{+}$. HPLC (protocol C): th $(\min )=10.29$. Purity: $99.6 \%$.

(S)-3-(tert-Butyl)-N-(3-(3-chlorophenyl)-1-((1-cyanocyclopropyl)amino)-1-oxopropan2-yl)-1-methyl-1H-pyrazole-5-carboxamide (25)

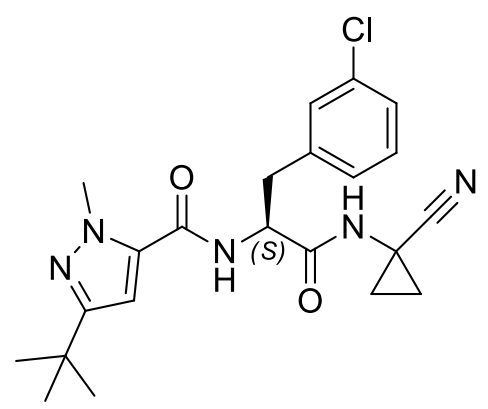

Method B. Yield 72\%. Yellowish solid. $R_{f}=0.7$ (ethyl acetate: $n$-hexane; 5:5). Mp. 152

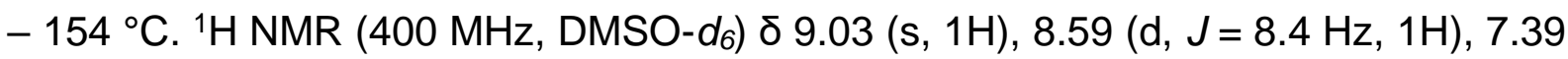
(s, 1H), $7.31-7.24(\mathrm{~m}, 3 \mathrm{H}), 6.79(\mathrm{~s}, 1 \mathrm{H}), 4.57-4.53(\mathrm{~m}, 1 \mathrm{H}), 3.88(\mathrm{~s}, 3 \mathrm{H}), 3.08$ (dd, $J=13.6,5.1 \mathrm{~Hz}, 1 \mathrm{H}), 2.94(\mathrm{dd}, J=13.6,10.2 \mathrm{~Hz}, 1 \mathrm{H}), 1.50-1.47(\mathrm{~m}, 2 \mathrm{H}), 1.28$ (s, $9 \mathrm{H}), 1.10-1.05(\mathrm{~m}, 2 \mathrm{H}) .{ }^{13} \mathrm{C}$ NMR (100 MHz, DMSO-d $) \delta 172.10,159.46,158.70$, 140.26, 134.95, 132.64, 129.94, 129.15, 127.85, 126.39, 120.63, 103.82, 55.21, 36.38, 31.58, 30.36, 19.75, 15.67, 15.61. HRMS (+) Calc. for $\left[\mathrm{C}_{22} \mathrm{H}_{27} \mathrm{CIN}_{5} \mathrm{O}_{2}\right]^{+}$428.18533, found: $428.1864[\mathrm{M}+\mathrm{H}]^{+}$. HPLC (protocol B): tR $(\min )=11.17$. Purity: $98.3 \%$. 
(S)-3-(tert-butyl)-N-(1-((1-cyanocyclopropyl)amino)-1-oxo-3-phenylpropan-2-yl)-1methyl-1H-pyrazole-5-carboxamide (26)<smiles>Cn1nc(C(C)(C)C)cc1C(=O)N[C@@H](Cc1ccccc1)C(=O)NC1(C#N)CC1</smiles>

Method B. Yield 78\%. White solid. $R_{f}=0.8$ (ethyl acetate: $n$-hexane; 8:2). Mp. $175-$ $177^{\circ} \mathrm{C} .{ }^{1} \mathrm{H}$ NMR $\left(200 \mathrm{MHz}, \mathrm{CDCl}_{3}\right) \delta 7.59(\mathrm{~s}, 1 \mathrm{H}), 7.32-7.22(\mathrm{~m}, 5 \mathrm{H}), 6.47(\mathrm{~s}, 1 \mathrm{H})$, $4.88-4.85(\mathrm{~m}, 1 \mathrm{H}), 4.01(\mathrm{~s}, 3 \mathrm{H}), 3.25-3.08(\mathrm{~m}, 2 \mathrm{H}), 1.45-1.43(\mathrm{~m}, 2 \mathrm{H}), 1.29(\mathrm{~s}$, 9H), $1.04-1.00$ (m, 2H). ESI-MS (+) Calc. for [ $\left.\mathrm{C}_{22} \mathrm{H}_{27} \mathrm{~N}_{5} \mathrm{O}_{2}\right]$ 393.48, found: 394.18 $[\mathrm{M}+\mathrm{H}]^{+}$. HPLC (protocol B): tR $(\min )=7.99$. Purity: 97.9\%. Reference (AVELAR et al., 2015).

(S)-3-(tert-Butyl)-N-(1-((1-cyanocyclopropyl)amino)-1-oxo-3-(pyridin-4-yl)propan-2-yl)1-methyl-1H-pyrazole-5-carboxamide (27)<smiles>Cn1nc(C(C)(C)C)cc1C(=O)N[C@@H](Cc1ccncc1)C(=O)NC1(C#N)CC1</smiles>

Method B. Yield 56\%. Yellowish oil. $R_{f}=0.4$ (ethyl acetate: $n$-hexane; $5: 5$ ). ${ }^{1} \mathrm{H}$ NMR (200 MHz, CD $\left.{ }_{3} \mathrm{OD}\right) \delta 8.48-8.46(\mathrm{~m}, 2 \mathrm{H}), 7.43$ (d, J=4.9 Hz, 2H), 6.69 (s, 1H), 4.86 - $4.78(\mathrm{~m}, 1 \mathrm{H}), 3.95(\mathrm{~s}, 3 \mathrm{H}), 3.04-3.02(\mathrm{~m}, 1 \mathrm{H}), 2.89-2.84(\mathrm{~m}, 1 \mathrm{H}), 1.56-1.50(\mathrm{~m}$, $2 \mathrm{H}), 1.31(\mathrm{~d}, J=4.3 \mathrm{~Hz}, 9 \mathrm{H}), 1.22-1.18(\mathrm{~m}, 2 \mathrm{H}) .{ }^{13} \mathrm{C} \mathrm{NMR}\left(50 \mathrm{MHz}, \mathrm{CD}_{3} \mathrm{OD}\right) \delta 172.80$, $160.35,160.05,148.62,147.59,134.80$, 125.00, 119.66, 103.60, 53.18, 37.37, 36.45, 31.42, 29.44, 19.92, 15.60, 15.28. FT-IR (KBr, cm-1) 3297.16, 2966.17, 2242.31, 1670.63, 1601.36, 1531.90, 1425.65, 1352.10, 1278.55, 1241.77, 1049.72, 988.42, 808.63, 755.51, 722.82, 511.19, 506.24, 489.90. HRMS (+) Calc. for $\left[\mathrm{C}_{21} \mathrm{H}_{27} \mathrm{~N}_{6} \mathrm{O}_{2}\right]^{+}$ 395.21955, found: $395.21973[\mathrm{M}+\mathrm{H}]^{+}$. HPLC (protocol $\left.\mathrm{B}\right): \mathrm{t}_{\mathrm{R}}(\mathrm{min})=3.68$. Purity: $94.7 \%$. 
(S)-3-(tert-butyl)-N-(1-((1-cyanocyclopropyl)amino)-4-methyl-1-oxopentan-2-yl)-1methyl-1H-pyrazole-5-carboxamide (28)<smiles>CC(C)C[C@H](NC(=O)c1cc(C(C)(C)C)nn1C)C(=O)NC1(C#N)CC1</smiles>

Method B. Yield 73\%. Yellowish solid. $R_{f}=0.4$ (ethyl acetate: $n$-hexane; 9:1). Mp. 175 $-177^{\circ} \mathrm{C}{ }^{1} \mathrm{H} \mathrm{NMR}\left(200 \mathrm{MHz}, \mathrm{CD}_{3} \mathrm{OD}\right) \delta 6.78(\mathrm{~s}, 1 \mathrm{H}), 4.58-4.50(\mathrm{~m}, 1 \mathrm{H}), 4.04(\mathrm{~s}, 3 \mathrm{H})$, $1.88-1.45(\mathrm{~m}, 5 \mathrm{H}), 1.30(\mathrm{~s}, 9 \mathrm{H}), 1.27-1.20(\mathrm{~m}, 2 \mathrm{H}), 1.02-0.95(\mathrm{~m}, 2 \mathrm{H})$. ESI-MS (+) Calc. for $\left[\mathrm{C}_{19} \mathrm{H}_{29} \mathrm{~N}_{5} \mathrm{O}_{2}\right] 359.47$, found: $382.32[\mathrm{M}+\mathrm{Na}]^{+}$. HPLC (protocol B): $t_{R}(\mathrm{~min})=$ 8.05. Purity $>99.9 \%$.Reference (AVELAR et al., 2015)

N-((2S,3R)-3-(Benzyloxy)-1-((1-cyanocyclopropyl)amino)-1-oxobutan-2-yl)-3-(tertbutyl)-1-methyl-1H-pyrazole-5-carboxamide (29)

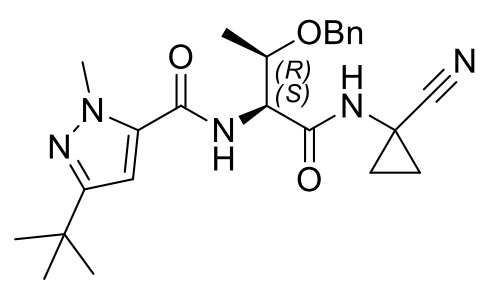

Method B. Yield 53\%. Yellowish solid. $R_{f}=0.4$ (ethyl acetate: $n$-hexane; 6:4). Mp. 100 - $101{ }^{\circ} \mathrm{C} .{ }^{1} \mathrm{H}$ NMR $\left(200 \mathrm{MHz}, \mathrm{CDCl}_{3}\right) \delta 7.36-7.32(\mathrm{~m}, 5 \mathrm{H}), 6.45(\mathrm{~s}, 1 \mathrm{H}), 4.76-4.62$ $(\mathrm{m}, 3 \mathrm{H}), 4.22-4.12(\mathrm{~m}, 1 \mathrm{H}), 4.09(\mathrm{~s}, 3 \mathrm{H}), 1.57-1.44(\mathrm{~m}, 2 \mathrm{H}), 1.30-1.27(\mathrm{~m}, 9 \mathrm{H})$, $1.20-1.13(\mathrm{~m}, 5 \mathrm{H}) .{ }^{13} \mathrm{C} \mathrm{NMR}\left(50 \mathrm{MHz}, \mathrm{CDCl}_{3}\right) \delta 170.36,160.18,159.74,137.15$, 134.06, 128.48, 127.98, 127.68, 119.25, 103.18, 74.03, 71.48, 54.81, 38.38, 31.66, 30.16, 28.68, 20.24, 16.91, 15.85. FT-IR $\left(\mathrm{KBr}, \mathrm{cm}^{-1}\right)$ 3288.99, 2953.92, 2917.14, 2214.31, 1646.31, 1589.10, 1495.12, 1049.31, 1294.89, 1200.91, 1033.37, 922.51, 755.51, 681.95. HRMS (+) Calc. for $\left[\mathrm{C}_{24} \mathrm{H}_{32} \mathrm{~N}_{5} \mathrm{O}_{3}\right]^{+} 437.25051$, found: 438.25102 $[\mathrm{M}+\mathrm{H}]^{+}$. HPLC (protocol B): $\mathrm{t}_{\mathrm{R}}(\mathrm{min})=8.77$. Purity: $97.0 \%$. 
(S)-7-Chloro-N-(1-((1-cyanocyclopropyl)amino)-1-oxo-3-phenylpropan-2-yl)quinoline4-carboxamide (30)<smiles>N#CC1(NC(=O)[C@H](Cc2ccccc2)NC(=O)c2ccnc3cc(Cl)ccc23)CC1</smiles>

Method A. Yield 74\%. White solid. $R_{f}=0.7$ (ethyl acetate: $n$-hexane; 8:2). Mp. $260-$ $262{ }^{\circ} \mathrm{C} .{ }^{1} \mathrm{H}$ NMR $(400 \mathrm{MHz}$, DMSO-d $)$ ס $9.15(\mathrm{~d}, J=10.2 \mathrm{~Hz}, 1 \mathrm{H}), 9.13(\mathrm{~s}, 1 \mathrm{H}), 8,97$ (d, $J=10.2 \mathrm{~Hz}, 1 \mathrm{H}), 8.10(\mathrm{~d}, J=2.1 \mathrm{~Hz}, 1 \mathrm{H}), 7.72(\mathrm{~d}, J=15 \mathrm{~Hz}, 1 \mathrm{H}), 7.56$ (dd, $J=$ 15.1, 10.2 Hz, 1H), $7.44(\mathrm{~d}, J=10.2 \mathrm{~Hz}, 1 \mathrm{H}), 7.28-7.24(\mathrm{~m}, 5 \mathrm{H}), 4.75-4.73(\mathrm{~m}, 1 \mathrm{H})$, 3.11 (dd, $J=13.8,5.0 \mathrm{~Hz}, 1 \mathrm{H}$ ), 2.87 (dd, $J=9.5,5.0 \mathrm{~Hz}, 1 \mathrm{H}), 1.51-1.49(\mathrm{~m}, 2 \mathrm{H}), 1.09$ - $1.07(\mathrm{~m}, 1 \mathrm{H}) \cdot{ }^{13} \mathrm{C}$ NMR (100 MHz, DMSO- $\left.d_{6}\right) \delta 172.34,166.33,151.74,148.36$, 141.88 , 137.63, 134.53, 129.45, 128.42, 128.00, 127.86, 126.74, 122.89, 120.91, 119.69, 54.56, 37.26, 20.02, 15.89. FT-IR ( $\left.\mathrm{KBr}, \mathrm{cm}^{-1}\right)$ 3254.05, 2926.14, 2247.17, 1672.36, 1668.36, 1523.83, 846.79, 831.36. HRMS (+) Calc. for $\left[\mathrm{C}_{23} \mathrm{H}_{20} \mathrm{CIN}_{4} \mathrm{O}_{2}\right]^{+}$ 418.12748, found: $419.12813[\mathrm{M}+\mathrm{H}]^{+}$. HPLC (protocol A, 50:50 ACN: water): $t_{R}$ (min) $=17.32$. Purity: $99.9 \%$.

(S)-7-Chloro-N-(1-((1-cyanocyclopropyl)amino)-4-methyl-1-oxopentan-2-yl)quinoline4-carboxamide (31)<smiles>CC(C)C[C@H](NC(=O)c1ccnc2cc(Cl)ccc12)C(=O)NC1(C#N)CC1</smiles>

Method A. Yield 68\%. White solid. $R_{f}=0.7$ (ethyl acetate). Mp. $169-170{ }^{\circ} \mathrm{C} .{ }^{1} \mathrm{H}$ NMR (400 MHz, DMSO-d6) $\delta 9.10(\mathrm{~s}, 1 \mathrm{H}), 9.05$ (s, 1H), 9.02 (d, J = 5.5 Hz, 1H) 8.20 (d, J = $11.5 \mathrm{~Hz}, 1 \mathrm{H}), 8.15(\mathrm{~d}, J=2.5 \mathrm{~Hz}, 1 \mathrm{H}), 7.72(\mathrm{dd}, J=11.5,2.5 \mathrm{~Hz}, 1 \mathrm{H}), 7.60(\mathrm{~d}, J=5.5$ $\mathrm{Hz}, 1 \mathrm{H}), 4.48-4.46(\mathrm{~m}, 1 \mathrm{H}), 1.70-1.63(\mathrm{~m}, 3 \mathrm{H}), 1.52-1.48(\mathrm{~m}, 2 \mathrm{H}), 1.19-1.14(\mathrm{~m}$, $2 \mathrm{H}), 0.92(2 \mathrm{~d}, J=10.5 \mathrm{~Hz}, 6 \mathrm{H}) .{ }^{13} \mathrm{C}$ NMR (100 MHz, DMSO- $\left.d_{6}\right) \delta 173.63,166.83$, 152.05, 148.70, 142.06, 134.83, 131.26, 128.38, 123.35, 121.21, 120.20, 51.97, 24.87, 23.38, 21.79, 20.34, 16.22, 16.06. FT-IR (KBr, cm$\left.{ }^{-1}\right)$ 3402.4, 3257.7, 3030.1, 2960.7, 2247.0, 1674.2, 1633.7, 1529.5, 1296.1, 831.31. HRMS (+) Calc. for $\left[\mathrm{C}_{20} \mathrm{H}_{22} \mathrm{CIN}_{4} \mathrm{O}_{2}\right]^{+}$ 384.14313, found: $385.14503[\mathrm{M}+\mathrm{H}]^{+}$. HPLC (protocol A, 65:35 ACN: water): tR (min) $=11.81$. Purity: $96.2 \%$. 
(S)-7-Chloro-N-(1-((1-cyanocyclopropyl)amino)-3-(1H-indol-3-yl)-1-oxopropan-2yl)quinoline-4-carboxamide (32)<smiles>N#CC1(NC(=O)[C@H](Cc2c[nH]c3ccccc23)NC(=O)c2ccnc3cc(Cl)ccc23)CC1</smiles>

Method A.Yield 49\%. Yellowish solid. $R_{f}=0.3$ (ethyl acetate). Mp. $196-197{ }^{\circ} \mathrm{C} .{ }^{1} \mathrm{H}$ NMR (400 MHz, DMSO-d $) \delta 10.88$ (s, 1H), 9.15 (s, 1H), 9.08 (d, J=10.2 Hz, 1H), $8.97(\mathrm{~d}, J=4.2 \mathrm{~Hz}, 1 \mathrm{H}), 8.10(\mathrm{~d}, J=2.2 \mathrm{~Hz}, 1 \mathrm{H}), 7.68(\mathrm{t}, J=7.5 \mathrm{~Hz}, 1 \mathrm{H}), 7.54-7.52$ (m, 1H), $7.46(\mathrm{~d}, J=4.5 \mathrm{~Hz}, 1 \mathrm{H}), 7.38(\mathrm{~d}, J=10.2 \mathrm{~Hz} 1 \mathrm{H}), 7.16(\mathrm{~d}, J=2.4 \mathrm{~Hz}, 1 \mathrm{H})$, $7.09(\mathrm{t}, J=5.5 \mathrm{~Hz}, 1 \mathrm{H}), 7.00(\mathrm{t}, J=5.8 \mathrm{~Hz}, 1 \mathrm{H}), 4.81-4.79(\mathrm{~m}, 1 \mathrm{H}), 3.20(\mathrm{dd}, J=13.8$, $5.0 \mathrm{~Hz}, 1 \mathrm{H}), 3.05(\mathrm{dd}, J=9.5,5.0 \mathrm{~Hz}, 1 \mathrm{H}), 1.51-1.48(\mathrm{~m}, 2 \mathrm{H}), 1.11-1.08(\mathrm{~m}, 2 \mathrm{H})$. ${ }^{13} \mathrm{C}$ NMR $\left(100 \mathrm{MHz}, \mathrm{DMSO}-d_{6}\right) \delta 173.02,166.59,151.94,148.61,142.38,136.57$, 134.72, 128.23, 128.05, 128.03, 127.52, 124.56, 123.19, 121.46, 121.26, 119.97, 119.03, 118.76, 111.81, 110.02, 54.26, 27.79, 20.33, 16.20. FT-IR (KBr, $\left.\mathrm{cm}^{-1}\right)$ 3254.05, 2926.14, 2247.17, 1672.36, 1665.34, 1522.83, 831.30, 732.98. HRMS (+) Calc. for $\left[\mathrm{C}_{25} \mathrm{H}_{21} \mathrm{ClN}_{5} \mathrm{O}_{2}\right]^{+}$458.13838, found: $458.13703[\mathrm{M}+\mathrm{H}]^{+}$. HPLC (protocol A, 50:50 ACN: water $): t_{R}(\min )=18.64$. Purity: $99.6 \%$.

(S)-3-((1-((1-Cyanocyclopropyl)amino)-1-oxo-3-phenylpropan-2-yl)carbamoyl)phenyl benzoate (33)

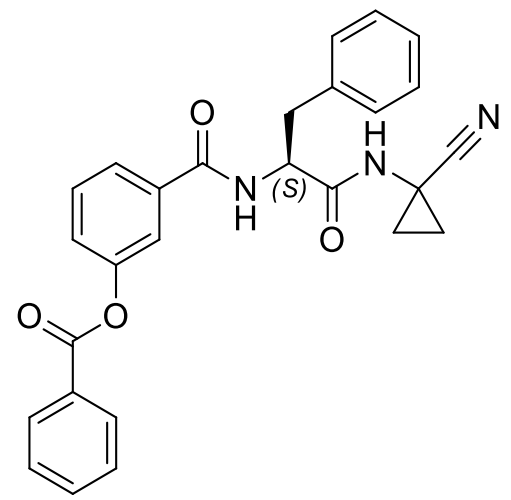

Method A. Yield 89\%. White solid. $R_{f}=0.7$ (ethyl acetate: $n$-hexane; 6:4). Mp. $185-$ $187^{\circ} \mathrm{C} .{ }^{1} \mathrm{H}$ NMR $\left(400 \mathrm{MHz}, \mathrm{DMSO}-d_{6}\right) \delta 9.05$ (s, $\left.1 \mathrm{H}\right), 8.79(\mathrm{~d}, J=8.0 \mathrm{~Hz}, 1 \mathrm{H}), 8.18-$ $8.16(\mathrm{~m}, 2 \mathrm{H}), 7.81-7.78(\mathrm{~m}, 3 \mathrm{H}), 7.64(\mathrm{t}, J=8.5 \mathrm{~Hz}, 2 \mathrm{H}), 7.57$ (t, J=8.5 Hz, 2H), 7.50 - $7.48(\mathrm{~m}, 1 \mathrm{H}), 7.31-7.23(\mathrm{~m}, 4 \mathrm{H}), 7.18(\mathrm{tt}, J=7.0,1.5 \mathrm{~Hz}, 1 \mathrm{H}), 4.64-4.59(\mathrm{~m}, 1 \mathrm{H})$, $3.06(\mathrm{dd}, J=13.6,5.0 \mathrm{~Hz}, 1 \mathrm{H}), 3.00$ (dd, $J=13.5,8.5 \mathrm{~Hz}, 1 \mathrm{H}), 1.49-1.45(\mathrm{~m}, 2 \mathrm{H})$, 
$1.06-1.01(\mathrm{~m}, 2 \mathrm{H}) .{ }^{13} \mathrm{C}$ NMR $\left(100 \mathrm{MHz}\right.$, DMSO- $\left.d_{6}\right) \delta 173.04,165.60,165.02,150.88$, $138.21,135.72$, 134.66, 130.27, 129.98, 129.57, 129.51, 129.16, 128.57, 126.83, $125.69,125.53,121.47,121.15,55.10,37.36,20.18,16.15,16.10,14.55$. FT-IR $(\mathrm{KBr}$, $\mathrm{cm}^{-1}$ ) 3254.05, 2926.14, 2247.17, 1672.36, 1668.36, 1523.83, 846.79, 831.36. HRMS (+) Calc. for $\left[\mathrm{C}_{27} \mathrm{H}_{24} \mathrm{~N}_{3} \mathrm{O}_{4}\right]^{+}$453.17668, found: $454.17800[\mathrm{M}+\mathrm{H}]^{+}$. HPLC (protocol A, 65:35 ACN: water): $t_{R}(\min )=19.62$. Purity: $99.9 \%$.

(S)-6-Amino-N-(1-((1-cyanocyclopropyl)amino)-4-methyl-1-oxopentan-2yl)nicotinamide (34)<smiles>CC(C)C[C@H](NC(=O)c1ccc(N)nc1)C(=O)NC1(C#N)CC1</smiles>

Method B. Yield 48\%. Yellowish solid. $R_{f}=0.3$ (ethyl acetate: methanol; 8:2). Mp. 100 $-101^{\circ} \mathrm{C} .{ }^{1} \mathrm{H}$ NMR $\left(200 \mathrm{MHz}, \mathrm{CD}_{3} \mathrm{OD}\right) \delta 8.43(\mathrm{~s}, 1 \mathrm{H}), 7.88(\mathrm{~d}, J=8.8,2.1 \mathrm{~Hz}, 1 \mathrm{H})$, $6.54(\mathrm{~d}, J=8.9 \mathrm{~Hz}, 1 \mathrm{H}), 4.53-4.46(\mathrm{~m}, 1 \mathrm{H}), 1.82-1.51(\mathrm{~m}, 3 \mathrm{H}), 1.47-1.43(\mathrm{~m}, 2 \mathrm{H})$, $1.24-1.17(\mathrm{~m}, 2 \mathrm{H}), 0.96-0.93(\mathrm{~m}, 6 \mathrm{H}) .{ }^{13} \mathrm{C}$ NMR (50 MHz, CD $\left.3 \mathrm{OD}\right) \delta 176.59,168.58$, 162.86, 149.21, 138.44, 121.42, 119.42, 109.12, 41.60, 26.13 23.54, 21.98, 21.41, 17.15, 16.78. FT-IR (KBr, $\left.\mathrm{cm}^{-1}\right)$ 3288.99, 2953.92, 2917.14, 2214.31,1647.63, 1496.06, 1409.33, 1294.89, 1202.33, 1075.33, 1030.81, 922.54, 763.49, 667.21. ESIMS (+) Calc. for $\left[\mathrm{C}_{16} \mathrm{H}_{22} \mathrm{~N}_{5} \mathrm{O}_{2}\right]^{+} 316.17735$, found: $316.17713[\mathrm{M}+\mathrm{H}]^{+}$. HPLC (protocol $B): t_{R}(\min )=8.77$. Purity: $97.0 \%$.

(S)-N-(1-((1-Cyanocyclopropyl)amino)-4-methyl-1-oxopentan-2-yl)-1H-pyrrolo[2,3b]pyridine-5-carboxamide (35)<smiles>CC(C)C[C@H](NC(=O)c1cnc2[nH]ccc2c1)C(=O)NC1(C#N)CC1</smiles>

Method B. Yield 45\%. White solid. $R_{f}=0.3$ (ethyl acetate: methanol; 8:2). Mp. $79-80$ ${ }^{\circ} \mathrm{C} .{ }^{1} \mathrm{H}$ NMR (200 MHz, CD $\left.{ }_{3} \mathrm{OD}\right) \delta 8.71(\mathrm{~d}, J=1.8 \mathrm{~Hz}, 1 \mathrm{H}), 8.47(\mathrm{~d}, J=2.0 \mathrm{~Hz}, 1 \mathrm{H})$, $7.46(\mathrm{~d}, J=3.5 \mathrm{~Hz}, 1 \mathrm{H}), 6.57(\mathrm{~d}, J=3.5 \mathrm{~Hz}, 1 \mathrm{H}), 4.59-4.57(\mathrm{~m}, 1 \mathrm{H}), 1.91-1.56(\mathrm{~m}$, $3 \mathrm{H}), 1.54-1.49(\mathrm{~m}, 2 \mathrm{H}), 1.29-1.25(\mathrm{~m}, 2 \mathrm{H}), 1.01-0.89(\mathrm{~m}, 6 \mathrm{H}) .{ }^{13} \mathrm{C} \mathrm{NMR}(50 \mathrm{MHz}$, $\left.\mathrm{CD}_{3} \mathrm{OD}\right) \delta 176.50,169.61,163.45,150.38,143.32,129.52,128.65,123.21,120.94$, 
102.66, 53.50, 38.92, 26.18, 23.41, 22.02, 21.25, 17.17, 16.49. FT-IR $\left(\mathrm{KBr}, \mathrm{cm}^{-1}\right)$ 3286.44, 2933.89, 2924.14, 2216.51, 1647.63, 1588.10, 1496.06, 1409.33, 1294.89, 1202.33, 1075.33, 1030.31, 922.54, 763.54, 667.21. ESI-MS (+) Calc. for $\left[\mathrm{C}_{18} \mathrm{H}_{22} \mathrm{~N}_{5} \mathrm{O}_{2}\right]^{+} 340.17753$, found: $340.17689[\mathrm{M}+\mathrm{H}]^{+}$. HPLC (protocol B): tR $(\min )=$ 5.38. Purity: $99.0 \%$.

3-(tert-Butyl)-N-((2S,3R)-1-((1-cyanocyclopropyl)amino)-3-hydroxy-1-oxobutan-2-yl)1-methyl-1H-pyrazole-5-carboxamide (36)

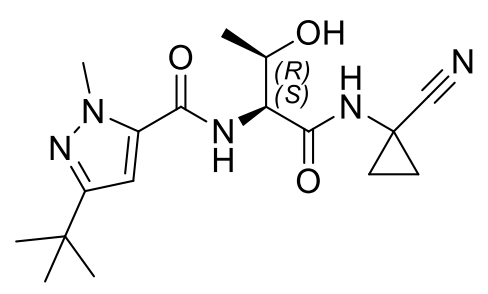

Compound $\mathbf{3 6}$ was synthesized from compound $\mathbf{2 9}$ by removal of the benzyl protecting group under mild conditions (protocol B).

Yield 40\%. Yellowish solid. $R_{f}=0.3$ (ethyl acetate). Mp. $201-202{ }^{\circ} \mathrm{C} .{ }^{1} \mathrm{H}$ NMR $(200$ $\left.\mathrm{MHz}, \mathrm{CD}_{3} \mathrm{OD}\right) \delta 6.81(\mathrm{~s}, 1 \mathrm{H}), 4.40(\mathrm{~d}, J=4.4 \mathrm{~Hz}, 1 \mathrm{H}), 4.23-4.18(\mathrm{~m}, 1 \mathrm{H}), 4.04(\mathrm{~s}$, $3 \mathrm{H}), 1.52-1.47(\mathrm{~m}, 2 \mathrm{H}), 1.32(\mathrm{~s}, 9 \mathrm{H}), 1.29-1.18(\mathrm{~m}, 5 \mathrm{H}) .{ }^{13} \mathrm{C} \mathrm{NMR}\left(50 \mathrm{MHz}, \mathrm{CD}_{3} \mathrm{OD}\right)$ ठ 174.94, 163.34, 162.74, 137.60, 122.22, 106.16, 69.42, 61.17, 39.91, 34.00, 31.94, 22.41, 21.45, 18.11, 17.83. FT-IR $\left(\mathrm{KBr}, \mathrm{cm}^{-1}\right) 3288.89,2953.92,2917.14,2214.31$, $1646.31,1589.10,1495.12,1049.31,1294.89,1200.91,1033.97,922.51,755.51$, 681.95. ESI-MS (-) Calc. for $\left[\mathrm{C}_{17} \mathrm{H}_{25} \mathrm{~N}_{5} \mathrm{O}_{3}\right]^{+} 348.20356$, found: $348.20314[\mathrm{M}+\mathrm{H}]^{+}$. HPLC (protocol B): $t_{R}(\min )=7.74$. Purity: $98.0 \%$.

Compounds 37 - 44 were synthesized from the equivalent amino Boc-protected amino acid following the general procedure for amide synthesis (method $\mathrm{C}$ ).

(S)-tert-Butyl (1-amino-1-oxo-3-phenylpropan-2-yl)carbamate (37)<smiles>CC(C)(C)OC(=O)N[C@@H](Cc1ccccc1)C(N)=O</smiles>

Yield $77 \%$. White solid. $R_{f}=0.6$ (ethyl acetate). Mp. $146-149{ }^{\circ} \mathrm{C} .{ }^{1} \mathrm{H}$ NMR $(200 \mathrm{MHz}$, $\left.\mathrm{CD}_{3} \mathrm{OD}\right) \delta 7.26-7.16(\mathrm{~m}, 5 \mathrm{H}), 4.44-4.41(\mathrm{~m}, 1 \mathrm{H}), 3.14(\mathrm{dd}, J=13.7,6.0 \mathrm{~Hz}, 1 \mathrm{H})$, $2.88(\mathrm{dd}, J=13.7,8.1 \mathrm{~Hz}, 1 \mathrm{H}), 1.23(\mathrm{~s}, 9 \mathrm{H}) .{ }^{13} \mathrm{C} \mathrm{NMR}\left(50 \mathrm{MHz}, \mathrm{CD}_{3} \mathrm{OD}\right) \delta 173.98$, 
155.60, 130.73, 124.93, 122.46, 118.22, 80.20,54.02, 37.73, 27.94. ESI-MS (+) Calc. for $\left[\mathrm{C}_{14} \mathrm{H}_{20} \mathrm{~N}_{2} \mathrm{O}_{3}\right] 264.31$, found: $287.3[\mathrm{M}+\mathrm{Na}]^{+}$.

(R)-tert-butyl (1-amino-1-oxo-3-phenylpropan-2-yl)carbamate (38)<smiles>CC(C)(C)OC(=O)NC(Cc1ccccc1)C(N)=O</smiles>

Yield 79\%. White solid. $R_{f}=0.6$ (ethyl acetate). Mp. $141-142{ }^{\circ} \mathrm{C} .{ }^{1} \mathrm{H}$ NMR $(200 \mathrm{MHz}$, $\left.\mathrm{CD}_{3} \mathrm{OD}\right) \delta 7.24-7.17(\mathrm{~m}, 5 \mathrm{H}), 4.42-4.37(\mathrm{~m}, 1 \mathrm{H}), 3.14(\mathrm{dd}, J=13.7,6.0 \mathrm{~Hz}, 1 \mathrm{H})$, $2.92(\mathrm{dd}, J=13.7,8.1 \mathrm{~Hz}, 1 \mathrm{H}), 1.43(\mathrm{~s}, 9 \mathrm{H}) .{ }^{13} \mathrm{C} \mathrm{NMR}\left(50 \mathrm{MHz}, \mathrm{CD}_{3} \mathrm{OD}\right) \delta 173.12$, 154.48, 133.36, 122.46, 121.75, 119.38, 83.51, 55.61, 38.38, 28.66. ESI-MS (+) Calc. for $\left[\mathrm{C}_{14} \mathrm{H}_{20} \mathrm{~N}_{2} \mathrm{O}_{3}\right] 264.31$, found: $287.3[\mathrm{M}+\mathrm{Na}]^{+}$.

(S)-tert-Butyl (1-amino-4-methyl-1-oxopentan-2-yl)carbamate (39)<smiles>CC(C)C[C@H](NC(=O)OC(C)(C)C)C(N)=O</smiles>

Yield 74\%. White solid. $R_{f}=0.4$ (ethyl acetate). Mp. $138-141{ }^{\circ} \mathrm{C} .{ }^{1} \mathrm{H}$ NMR $(200 \mathrm{MHz}$, $\left.\mathrm{CDCl}_{3}\right) \delta 6.58(\mathrm{~s} \mathrm{br}, 1 \mathrm{H}), 6.13(\mathrm{~s} \mathrm{br}, 1 \mathrm{H}), 5.25-4.97(\mathrm{~m}, 2 \mathrm{H}), 4.15$ (s br, 1H), $1.73-$ $1.43(\mathrm{~m}, 3 \mathrm{H}), 1.41(\mathrm{~s}, 9 \mathrm{H}), 0.92(2 \mathrm{~d}, J=10.5 \mathrm{~Hz}, 6 \mathrm{H}) .{ }^{13} \mathrm{C} \mathrm{NMR}\left(50 \mathrm{MHz}, \mathrm{CDCl}_{3}\right) \delta$ $172.34,155.95,71.56,28.57,28.18,25.08,23.21,19.25$. ESI-MS (+) Calc. for $\left[\mathrm{C}_{11} \mathrm{H}_{22} \mathrm{~N}_{2} \mathrm{O}_{3}\right] 230.30$, found: $253.3[\mathrm{M}+\mathrm{Na}]^{+}$.

(R)-tert-Butyl (1-amino-4-methyl-1-oxopentan-2-yl)carbamate (40)<smiles>CC(C)C[C@H](NC(=O)OC(C)(C)C)C(N)=O</smiles>

Yield $71 \%$. White solid. $R_{f}=0.4$ (ethyl acetate). Mp. $138-141^{\circ} \mathrm{C} .{ }^{1} \mathrm{H} \mathrm{NMR}(200 \mathrm{MHz}$, $\left.\mathrm{CDCl}_{3}\right) \delta 6.64(\mathrm{~s} \mathrm{br}, 1 \mathrm{H}), 6.21(\mathrm{~s} \mathrm{br}, 1 \mathrm{H}), 5.21-4.98(\mathrm{~m}, 2 \mathrm{H}), 4.16(\mathrm{~s} \mathrm{br}, 1 \mathrm{H}), 1.71-$ $1.45(\mathrm{~m}, 3 \mathrm{H}), 1.42(\mathrm{~s}, 9 \mathrm{H}), 0.93(2 \mathrm{~d}, J=10.5 \mathrm{~Hz}, 6 \mathrm{H}) .{ }^{13} \mathrm{C} \mathrm{NMR}\left(50 \mathrm{MHz}, \mathrm{CDCl}_{3}\right) \delta$ $172.11,155.37,71.64,28.61,28.29,25.15,23.34,19.30$. ESI-MS (+) Calc. for $\left[\mathrm{C}_{11} \mathrm{H}_{22} \mathrm{~N}_{2} \mathrm{O}_{3}\right] 230.30$, found: $253.3[\mathrm{M}+\mathrm{Na}]^{+}$. 
(S)-tert-Butyl (1-amino-3-(3-chlorophenyl)-1-oxopropan-2-yl)carbamate (41)<smiles>CC(C)(C)OC(=O)N[C@@H](Cc1cccc(Cl)c1)C(N)=O</smiles>

Yield 74\%. White solid. $R_{f}=0.4$ (ethyl acetate). Mp. $111-112{ }^{\circ} \mathrm{C} .{ }^{1} \mathrm{H}$ NMR $(200 \mathrm{MHz}$, $\left.\mathrm{CDCl}_{3}\right) \delta 7.26-7.13(\mathrm{~m}, 4 \mathrm{H}), 6.16(\mathrm{~s}, 1 \mathrm{H}), 5.75(\mathrm{~s}, 1 \mathrm{H}), 5.21(\mathrm{~d}, J=7.8 \mathrm{~Hz}, 1 \mathrm{H}), 4.42$ - $4.36(\mathrm{~m}, 1 \mathrm{H}), 3.19-2.94(\mathrm{~m}, 2 \mathrm{H}), 1.44(\mathrm{~s}, 9 \mathrm{H}) .{ }^{13} \mathrm{C} \mathrm{NMR}\left(50 \mathrm{MHz}, \mathrm{CDCl}_{3}\right) \delta 173.53$, 155.16, 138.90, 134.09, 130.04, 129.44, 127.55, 127.11, 80.31, 37.88, 28.16. ESI-MS (+) Calc. for $\left[\mathrm{C}_{14} \mathrm{H}_{19} \mathrm{CIN}_{2} \mathrm{O}_{3}\right] 298.77$, found: $321.8[\mathrm{M}+\mathrm{Na}]^{+}$.

(S)-tert-Butyl (1-amino-1-oxo-3-(pyridin-4-yl)propan-2-yl)carbamate (42)<smiles>CC(C)(C)OC(=O)N[C@@H](Cc1ccncc1)C(N)=O</smiles>

Yield $92 \%$. White solid. $R_{f}=0.2$ (ethyl acetate). Mp. $131-133{ }^{\circ} \mathrm{C} .{ }^{1} \mathrm{H}$ NMR $(200 \mathrm{MHz}$, $\left.\mathrm{CDCl}_{3}\right) \delta 8.42(\mathrm{~d}, J=5.7 \mathrm{~Hz}, 2 \mathrm{H}), 7.22(\mathrm{~d}, J=5.9 \mathrm{~Hz}, 2 \mathrm{H}), 4.35-4.31(\mathrm{~m}, 1 \mathrm{H}), 3.18$ (dd, $J=13.7,6.0 \mathrm{~Hz}, 1 \mathrm{H}), 2.81$ (dd, $J=13.7,8.1 \mathrm{~Hz}, 1 \mathrm{H}), 1.49-1.33(\mathrm{~s} \mathrm{br}, 9 \mathrm{H}) .{ }^{13} \mathrm{C}$ $\operatorname{NMR}\left(50 \mathrm{MHz} \mathrm{CDCl}_{3}\right) \delta 173.69,155.86,148.48,147.61,118.42,80.22,54.51,37.77$, 27.89. ESI-MS (+) Calc. for $\left[\mathrm{C}_{13} \mathrm{H}_{19} \mathrm{~N}_{3} \mathrm{O}_{3}\right] 265.31$, found: $266.2[\mathrm{M}+\mathrm{H}]^{+}$.

tert-Butyl ((2S,3R)-1-amino-3-(benzyloxy)-1-oxobutan-2-yl)carbamate (43)<smiles>CC(OCc1ccccc1)C(NC(=O)OC(C)(C)C)C(N)=O</smiles>

Yield $65 \%$. White solid. $R_{f}=0.5$ (ethyl acetate). Mp. $145-147^{\circ} \mathrm{C} .{ }^{1} \mathrm{H} \mathrm{NMR}(500 \mathrm{MHz}$, $\left.\mathrm{CDCl}_{3}\right) \delta 7.37-7.28(\mathrm{~m}, 5 \mathrm{H}), 6.50(\mathrm{~s}, 1 \mathrm{H}), 5.70-5.51(\mathrm{~m}, 2 \mathrm{H}), 4.62$ (q, J = 4.6 Hz, $2 \mathrm{H}), 4.34-4.31(\mathrm{~m}, 1 \mathrm{H}), 4.18-4.11(\mathrm{~m}, 1 \mathrm{H}), 1.45(\mathrm{~s}, 9 \mathrm{H}), 1.19(\mathrm{~d}, J=6.3 \mathrm{~Hz}, 3 \mathrm{H})$. ${ }^{13} \mathrm{C} \mathrm{NMR}\left(125 \mathrm{MHz} \mathrm{CDCl}_{3}\right) \delta 172.09,155.66,137.78,128.41,127.82,127.73,80.03$, 71.61, 57.13, 28.23, 27.84, 18.92. ESI-MS (+) Calc. for $\left[\mathrm{C}_{16} \mathrm{H}_{24} \mathrm{~N}_{2} \mathrm{O}_{4}\right]$ 308.37, found: $331.4[\mathrm{M}+\mathrm{Na}]^{+}$. 
tert-Butyl ((2R,3S)-1-amino-3-(benzyloxy)-1-oxobutan-2-yl)carbamate (44)<smiles>CC(C)OC(=O)NC(NC(=O)OC(C)(C)C)C(N)=O</smiles>

Yield 68\%. White solid. $R_{f}=0.5$ (ethyl acetate). Mp. $143-145^{\circ} \mathrm{C} .{ }^{1} \mathrm{H}$ NMR $(500 \mathrm{MHz}$, $\left.\mathrm{CDCl}_{3}\right) \delta 7.37-7.28(\mathrm{~m}, 5 \mathrm{H}), 6.50(\mathrm{~s}, 1 \mathrm{H}), 5.70-5.51(\mathrm{~m}, 2 \mathrm{H}), 4.62(\mathrm{q}, J=4.6 \mathrm{~Hz}$, 2H), 4.33 (s br, $1 \mathrm{H}), 4.27-4.19(\mathrm{~m}, 1 \mathrm{H}), 1.45(\mathrm{~s}, 9 \mathrm{H}), 1.19(\mathrm{~d}, J=6.3 \mathrm{~Hz}, 3 \mathrm{H}) \cdot{ }^{13} \mathrm{C}$ NMR $\left(125 \mathrm{MHz}, \mathrm{CDCl}_{3}\right) \delta 172.74,156.31,138.44,129.06,128.47,128.38,80.68$, 72.26, 57.78, 28.89, 28.49, 19.57. ESI-MS (+) Calc. for $\left[\mathrm{C}_{16} \mathrm{H}_{24} \mathrm{~N}_{2} \mathrm{O}_{4}\right] 308.37$, found: $331.4[\mathrm{M}+\mathrm{Na}]^{+}$.

Compounds $\mathbf{4 5} \mathbf{- 5 5}$ were synthesized in two steps from their precursors $\mathbf{3 7}-\mathbf{4 4}$. After removal of the Boc-protecting group (procedure B), the resulting free amine was coupled to the carboxylic acid following the general procedure for amide synthesis $(\operatorname{method} A)$.

tert-Butyl

((S)-1-(((S)-1-amino-1-oxo-3-phenylpropan-2-yl)amino)-1-oxo-3pheny/propan-2-yl)carbamate (45)<smiles>CC(C)(C)OC(=O)N[C@@H](Cc1ccccc1)C(=O)N[C@@H](Cc1ccccc1)C(N)=O</smiles>

Yield $92 \%$. White solid. $R_{f}=0.8$ (ethyl acetate). Mp. $186-188^{\circ} \mathrm{C} .{ }^{1} \mathrm{H}$ NMR $(200 \mathrm{MHz}$, $\left.\mathrm{CD}_{3} \mathrm{OD}\right) \delta 7.37-7.22(\mathrm{~m}, 6 \mathrm{H}), 7.16-7.09(\mathrm{~m}, 4 \mathrm{H}), 4.76-4.63(\mathrm{~m}, 1 \mathrm{H}), 4.34-4.20$ $(\mathrm{m}, 1 \mathrm{H}), 3.15-2.95(\mathrm{~m}, 2 \mathrm{H}), 2.91-2.62(\mathrm{~m}, 2 \mathrm{H}), 1.39(\mathrm{~s}, 9 \mathrm{H}) .{ }^{13} \mathrm{C} N \mathrm{NMR}(50 \mathrm{MHz}$, $\left.\mathrm{CD}_{3} \mathrm{OD}\right) \delta 174.36,172.35,156.09,136.44,129.04,128.35,128.27,126.78,126.64$, 79.89, 56.00, 53.78, 37.73, 37.24, 27.84. ESI-MS (+) Calc. for $\left[\mathrm{C}_{23} \mathrm{H}_{29} \mathrm{~N}_{3} \mathrm{O}_{4}\right]$ 411.49, found: $434.3[\mathrm{M}+\mathrm{Na}]^{+}$. 
tert-Butyl

((S)-1-(((R)-1-amino-1-oxo-3-phenylpropan-2-yl)amino)-1-oxo-3-

phenylpropan-2-yl)carbamate (46)<smiles>CC(C)(C)OC(=O)N[C@@H](Cc1ccccc1)C(=O)N[C@@H](Cc1ccccc1)C(N)=O</smiles>

Yield $86 \%$. White solid. $R_{f}=0.8$ (ethyl acetate). Mp. $185-187^{\circ} \mathrm{C} .{ }^{1} \mathrm{H}$ NMR $(200 \mathrm{MHz}$, $\left.\mathrm{CD}_{3} \mathrm{OD}\right) \delta 7.75-7.60(\mathrm{~m}, 6 \mathrm{H}), 7.56-7.49(\mathrm{~m}, 4 \mathrm{H}), 5.14-5.01(\mathrm{~m}, 1 \mathrm{H}), 4.72-4.57$ $(\mathrm{m}, 1 \mathrm{H}), 3.53-3.33(\mathrm{~m}, 2 \mathrm{H}), 3.29-3.00(\mathrm{~m}, 2 \mathrm{H}), 1.77(\mathrm{~s}, 9 \mathrm{H}) .{ }^{13} \mathrm{C} \mathrm{NMR}(50 \mathrm{MHz}$, $\left.\mathrm{CD}_{3} \mathrm{OD}\right) \delta 174.85,172.83,156.58,136.93,129.53,128.83,128.76,127.26,127.13$, 80.38, 56.49, 54.26, 38.22, 37.73, 28.33. ESI-MS (+) Calc. for $\left[\mathrm{C}_{23} \mathrm{H}_{29} \mathrm{~N}_{3} \mathrm{O}_{4}\right]$ 411.49, found: $434.3[\mathrm{M}+\mathrm{Na}]^{+}$.

tert-Butyl

((S)-1-(((S)-1-amino-4-methyl-1-oxopentan-2-yl)amino)-1-oxo-3phenylpropan-2-yl)carbamate (47)<smiles>CC(C)C[C@H](NC(=O)[C@H](Cc1ccccc1)NC(=O)OC(C)(C)C)C(N)=O</smiles>

Yield $83 \%$. White solid. $R_{f}=0.8$ (ethyl acetate). Mp. $164-165{ }^{\circ} \mathrm{C} .{ }^{1} \mathrm{H}$ NMR $(200 \mathrm{MHz}$, $\left.\mathrm{CD}_{3} \mathrm{OD}\right) \delta 7.24-7.20(\mathrm{~m}, 5 \mathrm{H}), 4.33-4.28(\mathrm{~m}, 1 \mathrm{H}), 4.11-4.05(\mathrm{~m}, 1 \mathrm{H}), 3.03-2.93$ $(\mathrm{m}, 2 \mathrm{H}), 1.56-1.38(\mathrm{~m}, 2 \mathrm{H}), 1.36(\mathrm{~s}, 9 \mathrm{H}), 1.26-1.24(\mathrm{~m}, 1 \mathrm{H}), 0.89(\mathrm{~d}, J=2.6 \mathrm{~Hz}$, $6 \mathrm{H}) .{ }^{13} \mathrm{C}$ NMR $\left(50 \mathrm{MHz}, \mathrm{CD}_{3} \mathrm{OD}\right) \delta 175.39,154.59,143.42,136.55,128.99,128.29$, 126.65, 84.91, 72.86, 52.36, 51.47, 27.61, 24.41, 22.20, 21.01. ESI-MS (+) Calc. for $\left[\mathrm{C}_{20} \mathrm{H}_{31} \mathrm{~N}_{3} \mathrm{O}_{4}\right]$ 377.48, found: $400.5[\mathrm{M}+\mathrm{Na}]^{+}$. 
tert-Butyl

((S)-1-(((R)-1-amino-4-methyl-1-oxopentan-2-yl)amino)-1-oxo-3-

phenylpropan-2-yl)carbamate (48)<smiles>CC(C)C[C@H](NC(=O)[C@H](Cc1ccccc1)NC(=O)OC(C)(C)C)C(N)=O</smiles>

Yield $88 \%$. White solid. $R_{f}=0.8$ (ethyl acetate). Mp. $168-170{ }^{\circ} \mathrm{C} .{ }^{1} \mathrm{H}$ NMR $(200 \mathrm{MHz}$, $\left.\mathrm{CD}_{3} \mathrm{OD}\right) \delta 7.24-7.21(\mathrm{~m}, 5 \mathrm{H}), 4.31-4.21(\mathrm{~m}, 1 \mathrm{H}), 4.11-4.09(\mathrm{~m}, 1 \mathrm{H}), 3.04-2.94$ $(\mathrm{m}, 2 \mathrm{H}), 1.57-1.40(\mathrm{~m}, 2 \mathrm{H}), 1.39(\mathrm{~s}, 9 \mathrm{H}), 1.27-1.24(\mathrm{~m}, 1 \mathrm{H}), 0.90(\mathrm{~d}, J=2.6 \mathrm{~Hz}$, $6 \mathrm{H}) .{ }^{13} \mathrm{C}$ NMR $\left(50 \mathrm{MHz}, \mathrm{CD}_{3} \mathrm{OD}\right) \delta 175.80,155.00,143.83,136.96,129.40,128.70$, 127.06, 85.32, 77.16, 73.27, 52.78, 51.89, 28.02, 24.82, 22.61, 21.42. ESI-MS (+) Calc. for $\left[\mathrm{C}_{20} \mathrm{H}_{31} \mathrm{~N}_{3} \mathrm{O}_{4}\right] 377.48$, found: $400.5[\mathrm{M}+\mathrm{Na}]^{+}$.

tert-Butyl ((S)-1-(((S)-1-amino-3-(3-chlorophenyl)-1-oxopropan-2-yl)amino)-1-oxo-3phenylpropan-2-yl)carbamate (49)<smiles>CC(C)(C)OC(=O)N[C@@H](Cc1ccccc1)C(=O)N[C@@H](Cc1cccc(Cl)c1)C(N)=O</smiles>

Yield $78 \%$. White solid. $R_{f}=0.6$ (ethyl acetate). Mp. $148-150{ }^{\circ} \mathrm{C} .{ }^{1} \mathrm{H}$ NMR $(200 \mathrm{MHz}$, $\left.\mathrm{CDCl}_{3}\right) \delta 7.38-7.26(\mathrm{~m}, 7 \mathrm{H}), 7.10-7.06(\mathrm{~m}, 2 \mathrm{H}), 6.63(\mathrm{~s} \mathrm{br}, 1 \mathrm{H}), 6.39$ (s br, $\left.1 \mathrm{H}\right), 4.81$ $-4.77(\mathrm{~m}, 1 \mathrm{H}), 4.38-4.35(\mathrm{~m}, 1 \mathrm{H}), 3.05-2.97(\mathrm{~m}, 4 \mathrm{H}), 1.41(\mathrm{~s}, 9 \mathrm{H}) .{ }^{13} \mathrm{C}$ NMR $(50$ $\left.\mathrm{MHz}_{\mathrm{CDCl}}\right) \delta 172.83,161.82,138.54,136.14,134.46,133.26,130.05,129.51$, 129.36, 129.02, 127.69, 127.36, 126.78, 80.95, 62.51, 53.21, 52.76, 38.74, 28.23. ESI$\mathrm{MS}(+)$ Calc. for $\left[\mathrm{C}_{23} \mathrm{H}_{28} \mathrm{CIN}_{3} \mathrm{O}_{4}\right]$ 445.94, found: $468.8[\mathrm{M}+\mathrm{Na}]^{+}$. 
tert-Butyl

((S)-1-((S)-1-amino-1-oxo-3-(pyridin-4-yl)propan-2-yl)amino)-1-oxo-3phenylpropan-2-yl)carbamate (50)<smiles>CC(C)(C)OC(=O)N[C@@H](Cc1ccccc1)C(=O)N[C@@H](Cc1ccncc1)C(N)=O</smiles>

Yield $71 \%$. Yellowish solid. $R_{f}=0.4$ (ethyl acetate). Mp. $155-157^{\circ} \mathrm{C} .{ }^{1} \mathrm{H}$ NMR $(200$ $\left.\mathrm{MHz}, \mathrm{CDCl}_{3}\right) \delta 8.63(\mathrm{~d}, J=5.7 \mathrm{~Hz}, 2 \mathrm{H}), 7.58-7.30(\mathrm{~m}, 7 \mathrm{H}), 4.94-4.89(1 \mathrm{H}, \mathrm{m}), 4.55$ - $4.40(\mathrm{~m}, 1 \mathrm{H}), 3.44(\mathrm{dd}, J=13.8,5.5 \mathrm{~Hz}, 2 \mathrm{H}), 3.28-2.93(\mathrm{~m}, 2 \mathrm{H}), 1.60(\mathrm{~s}, 9 \mathrm{H}) .{ }^{13} \mathrm{C}$ $\mathrm{NMR}\left(50 \mathrm{MHz}, \mathrm{CDCl}_{3}\right) \delta 173.27,172.38,148.58,140.95,136.44,135.10,128.97$,

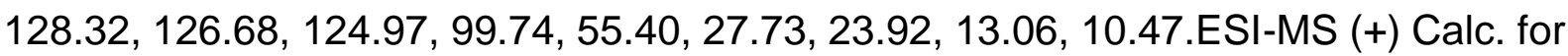
$\left[\mathrm{C}_{23} \mathrm{H}_{28} \mathrm{ClN}_{3} \mathrm{O}_{4}\right]$ 445.94, found: $468.8[\mathrm{M}+\mathrm{Na}]^{+}$.

tert-Butyl ((S)-1-(((2S,3R)-1-amino-3-(benzyloxy)-1-oxobutan-2-yl)amino)-1-oxo-3phenylpropan-2-yl)carbamate (51)<smiles>CCCCCCCCCOC(C)C(NC(=O)[C@H](Cc1ccccc1)NC(=O)OC(C)(C)C)C(N)=O</smiles>

Yield 88\%. Yellowish solid. $R_{f}=0.8$ (ethyl acetate). Mp. $161-163{ }^{\circ} \mathrm{C} .{ }^{1} \mathrm{H}$ NMR (200 $\left.\mathrm{MHz}, \mathrm{CDCl}_{3}\right) \delta 7.38-7.26(\mathrm{~m}, 7 \mathrm{H}), 7.10-7.06(\mathrm{~m}, 2 \mathrm{H}), 6.63$ (s br, 1H), 6.39 (s br, $1 \mathrm{H}), 5.65$ (s br, 1H), $5.08(\mathrm{~s} \mathrm{br}, 1 \mathrm{H}), 4.81-4.77(\mathrm{~m}, 1 \mathrm{H}), 4.38-4.35(\mathrm{~m}, 1 \mathrm{H}), 3.15-$ $2.97(\mathrm{~m}, 5 \mathrm{H}), 1.74-1.47(\mathrm{~m}, 3 \mathrm{H}), 1.41(\mathrm{~s}, 9 \mathrm{H}) .{ }^{13} \mathrm{C} \mathrm{NMR}\left(50 \mathrm{MHz}, \mathrm{CDCl}_{3}\right) \delta 172.98$, $171.90,156.38,137.70,136.53,128.99,128.42,128.13,127.64,127.58,126.75$, $80.30,74.03,71.36,60.44,38.05,27.67,20.33,15.75$. ESI-MS (+) Calc. for $\left[\mathrm{C}_{25} \mathrm{H}_{33} \mathrm{~N}_{3} \mathrm{O}_{5}\right] 455.55$, found: $478.5[\mathrm{M}+\mathrm{Na}]^{+}$. 
tert-Butyl ((S)-1-(((2R,3S)-1-amino-3-(benzyloxy)-1-oxobutan-2-yl)amino)-1-oxo-3phenylpropan-2-yl)carbamate (52)<smiles>CC(OCc1ccccc1)[C@H](NC(=O)[C@H](Cc1ccccc1)NC(=O)OC(C)(C)C)C(N)=O</smiles>

Yield $78 \%$. Yellowish solid. $R_{f}=0.8$ (ethyl acetate). Mp. $138-139{ }^{\circ} \mathrm{C} .{ }^{1} \mathrm{H}$ NMR $(200$ $\left.\mathrm{MHz} \mathrm{CDCl}_{3}\right) \delta 7.40$ - $7.27(\mathrm{~m}, 7 \mathrm{H}), 7.11-7.08(\mathrm{~m}, 2 \mathrm{H}), 6.60$ (s br, 1H), 6.43 (s br, $1 \mathrm{H}), 5.61$ (s br, 1H), 5.23 (s br, 1H), $4.81-4.78(\mathrm{~m}, 1 \mathrm{H}), 4.36-4.34(\mathrm{~m}, 1 \mathrm{H}), 3.16-$ $2.95(\mathrm{~m}, 5 \mathrm{H}), 1.39(\mathrm{~s}, 9 \mathrm{H}), 1.19-1.09(\mathrm{~m}, 3 \mathrm{H}) .{ }^{13} \mathrm{C} \mathrm{NMR}\left(50 \mathrm{MHz}, \mathrm{CDCl}_{3}\right) \delta$ 173.34, $172.27,156.74,138.07,136.90,129.35$, 128.79, 128.49, 128.01, 127.95, 127.12, 80.66, 74.40, 71.73, 60.81, 38.42, 28.04, 20.70, 16.12. ESI-MS (+) Calc. for $\left[\mathrm{C}_{25} \mathrm{H}_{33} \mathrm{~N}_{3} \mathrm{O}_{5}\right]$ 455.55, found: $478.5[\mathrm{M}+\mathrm{Na}]^{+}$.

tert-Butyl ((S)-1-(((2S,3R)-1-amino-3-(benzyloxy)-1-oxobutan-2-yl)amino)-4-methyl-1oxopentan-2-yl)carbamate (53)<smiles>CC(C)C[C@H](NC(=O)OC(C)(C)C)C(=O)N[C@H](C(N)=O)[C@@H](C)OCc1ccccc1</smiles>

Yield 76\%. Yellowish solid. $R_{f}=0.8$ (ethyl acetate). Mp. $88-91{ }^{\circ} \mathrm{C} .{ }^{1} \mathrm{H}$ NMR $(200 \mathrm{MHz}$, $\left.\mathrm{CDCl}_{3}\right) \delta 7.30-7.22(\mathrm{~m}, 4 \mathrm{H}), 7.19-7.15(\mathrm{~m}, 1 \mathrm{H}), 6.24$ (s br, 1H), 6.04 (s br, 1H), 5.36 (s br, 2H), $4.57(\mathrm{~s}, 2 \mathrm{H}), 4.56-4.52(\mathrm{~m}, 1 \mathrm{H}), 4.36-4.21(\mathrm{~m}, 1 \mathrm{H}), 4.17-4.11(\mathrm{~m}, 1 \mathrm{H})$, $1.77-1.48(\mathrm{~m}, 3 \mathrm{H}), 1.38(\mathrm{~s}, 9 \mathrm{H}), 1.13(\mathrm{~d}, J=6.4 \mathrm{~Hz}, 3 \mathrm{H}), 0.94-0.90(\mathrm{~m}, 6 \mathrm{H}) .{ }^{13} \mathrm{C}$ NMR $\left(50 \mathrm{MHz} \mathrm{CDCl}_{3}\right) \delta 172.84,171.86,155.98,137.88,128.29,127.66,127.63$, 80.38, 73.89, 71.58, 56.40, 54.01, 40.85, 28.12, 24.74, 22.92, 21.62. ESI-MS (+) Calc. for $\left[\mathrm{C}_{22} \mathrm{H}_{35} \mathrm{~N}_{3} \mathrm{O}_{5}\right]$ 421.53, found: $444.7[\mathrm{M}+\mathrm{Na}]^{+}$. 
tert-Butyl ((S)-1-(((2R,3S)-1-amino-3-(benzyloxy)-1-oxobutan-2-yl)amino)-4-methyl-1oxopentan-2-yl)carbamate (54)<smiles>CC(=O)[C@H](NC(=O)[C@H](CC(C)C)NC(=O)OC(C)(C)C)C(N)=O</smiles>

Yield 73\%. Yellowish solid. $R_{f}=0.8$ (ethyl acetate). Mp. $86-88^{\circ} \mathrm{C} .{ }^{1} \mathrm{H}$ NMR $(200 \mathrm{MHz}$, $\left.\mathrm{CDCl}_{3}\right) \delta 7.31-7.22(\mathrm{~m}, 5 \mathrm{H}), 7.20-7.11(\mathrm{~m}, 1 \mathrm{H}), 6.26(\mathrm{~s} \mathrm{br}, 1 \mathrm{H}), 6.02(\mathrm{~s} \mathrm{br}, 1 \mathrm{H}), 5.36$ (s br, $2 \mathrm{H}), 4.54(\mathrm{~s}, 2 \mathrm{H}), 4.56-4.53(\mathrm{~m}, 1 \mathrm{H}), 4.33-4.28(\mathrm{~m}, 1 \mathrm{H}), 4.16-4.11(\mathrm{~m}, 1 \mathrm{H})$, $1.76-1.48(\mathrm{~m}, 3 \mathrm{H}), 1.48(\mathrm{~s}, 9 \mathrm{H}), 1.11(\mathrm{~d}, J=6.4 \mathrm{~Hz}, 3 \mathrm{H}), 0.96-0.90(\mathrm{~m}, 6 \mathrm{H}) .{ }^{13} \mathrm{C}$ NMR $\left(50 \mathrm{MHz}, \mathrm{CDCl}_{3}\right) \delta 172.84,171.86,155.98,137.88,128.29,127.66,127.63$, 80.38, 73.89, 71.58, 56.40, 54.01, 40.85, 28.12, 24.74, 22.92, 21.62. ESI-MS (+) Calc. for $\left[\mathrm{C}_{22} \mathrm{H}_{35} \mathrm{~N}_{3} \mathrm{O}_{5}\right] 421.53$, found: $444.7[\mathrm{M}+\mathrm{Na}]^{+}$.

tert-Butyl ((S)-1-(((2S,3R)-1-amino-3-(benzyloxy)-1-oxobutan-2-yl)amino)-3-(3chlorophenyl)-1-oxopropan-2-yl)carbamate (55)<smiles>CC(C(=O)N[C@@H](Cc1cccc(Cl)c1)C(=O)NC(=O)OC(C)(C)C)=C(N)[C@H](C)OCc1ccccc1</smiles>

Yield $77 \%$. Yellowish solid. $R_{f}=0.6$ (ethyl acetate). Mp. $164-165{ }^{\circ} \mathrm{C} .{ }^{1} \mathrm{H}$ NMR $(200$ $\left.\mathrm{MHz}_{2} \mathrm{CDCl}_{3}: \mathrm{CD}_{3} \mathrm{OD} 10: 1\right) \delta 7.47$ - $7.22(\mathrm{~m}, 9 \mathrm{H}), 4.55$ - $4.37(\mathrm{~m}, 1 \mathrm{H}), 4.29$ - $4.17(\mathrm{~m}$, 2H), 3.26 (dd, J = 13.9, $5.1 \mathrm{~Hz}, 1 \mathrm{H}), 3.07-2.96(\mathrm{~m}, 1 \mathrm{H}), 2.92(\mathrm{~s}, 2 \mathrm{H}), 1.44(\mathrm{~s}, 9 \mathrm{H})$, $1.27(\mathrm{~d}, J=6.3 \mathrm{~Hz}, 3 \mathrm{H}) .{ }^{13} \mathrm{C}$ NMR $\left(50 \mathrm{MHz}, \mathrm{CD}_{3} \mathrm{OD}\right) \delta 172.84,171.76,156.24,138.90$, 137.56, 136.39,130.04, 128.85, 128.28, 127.99, 127.50, 127.44, 126.61, 80.16, 73.89, 71.22, 60.30, 49.00, 37.92, 27.53, 20.19. ESI-MS (+) Calc. for $\left[\mathrm{C}_{25} \mathrm{H}_{32} \mathrm{CIN}_{3} \mathrm{O}_{5}\right]$ 489.99, found: $513.1[\mathrm{M}+\mathrm{Na}]^{+}$.

Compounds 56 - 66 were synthesized in two steps from their precursors $45-55$. After removal of the Boc-protecting group (method B), the free amine was coupled to the selected carboxylic acid following the general procedure for amide synthesis (method B). 
$N-((S)-1-(((S)-1-A m i n o-1-o x o-3-p h e n y l p r o p a n-2-y l) a m i n o)-1-o x o-3-p h e n y l p r o p a n-2-$ yl)-3-(tert-butyl)-1-methyl-1H-pyrazole-5-carboxamide (56)<smiles>Cn1nc(C(C)(C)C)cc1C(=O)N[C@@H](Cc1ccccc1)C(=O)N[C@@H](Cc1ccccc1)C(N)=O</smiles>

Yield $79 \%$. Yellowish solid. $R_{f}=0.3$ (ethyl acetate). Mp. $109-110{ }^{\circ} \mathrm{C} .{ }^{1} \mathrm{H}$ NMR (200 $\left.\mathrm{MHz}, \mathrm{CDCl}_{3}: \mathrm{CD}_{3} \mathrm{OD} 10: 1\right) \delta 7.32-6.96(\mathrm{~m}, 10 \mathrm{H}), .6 .65(\mathrm{~s} \mathrm{br}, 1 \mathrm{H}), 6.26(\mathrm{~s}, 1 \mathrm{H}), 6.09$ (s br, $1 \mathrm{H}), 4.68-4.58(\mathrm{~m}, 2 \mathrm{H}), 3.81(\mathrm{~s}, 3 \mathrm{H}), 2.87-2.74(\mathrm{~m}, 4 \mathrm{H}), 1.11(\mathrm{~s}, 9 \mathrm{H}) .{ }^{13} \mathrm{C} \mathrm{NMR}$ (50 MHz, CDCl $\left.\mathrm{CD}_{3} \mathrm{OD} 10: 1\right) \delta 173.37,165.56,162.46,160.20,159.99,136.34$, 136.16, 134.40, 129.13, 128.39, 126.87, 126.81, 124.46, 103.30, 54.93, 53.91, 38.44, $36.34,31.69,31.28,30.27$. ESI-MS (+) Calc. for $\left[\mathrm{C}_{27} \mathrm{H}_{33} \mathrm{~N}_{5} \mathrm{O}_{3}\right] 475.58$, found: 498.7 $[\mathrm{M}+\mathrm{Na}]^{+}$.

$N-((S)-1-(((R)-1-A m i n o-1-o x o-3-p h e n y / p r o p a n-2-y l) a m i n o)-1-o x o-3-p h e n y l p r o p a n-2-$ yl)-3-(tert-butyl)-1-methyl-1H-pyrazole-5-carboxamide (57)<smiles>Cn1nc(C(C)(C)C)cc1C(=O)N[C@@H](Cc1ccccc1)C(=O)N[C@@H](Cc1ccccc1)C(N)=O</smiles>

Yield $72 \%$. Yellowish solid. $R_{f}=0.4$ (ethyl acetate). Mp. $121-122{ }^{\circ} \mathrm{C} .{ }^{1} \mathrm{H}$ NMR (200 $\left.\mathrm{MHz}, \mathrm{CDCl}_{3}: \mathrm{CD}_{3} \mathrm{OD} 10: 1\right) \delta 7.59-7.13(\mathrm{~m}, 10 \mathrm{H}), 6.88(\mathrm{~s}, 1 \mathrm{H}), 6.50(\mathrm{~s}, 1 \mathrm{H}), 6.32(\mathrm{~s}$ br, $1 \mathrm{H}), 4.92-4.82(\mathrm{~m}, 2 \mathrm{H}), 4.04(\mathrm{~s}, 3 \mathrm{H}), 3.10-2.91(\mathrm{~m}, 4 \mathrm{H}), 1.34(\mathrm{~s}, 9 \mathrm{H}) .{ }^{13} \mathrm{C} \mathrm{NMR}$ (50 MHz, CDCl $\left.\mathrm{CD}_{3} \mathrm{OD} 10: 1\right) \delta 172.94,165.13,162.04,159.77,159.56,135.92$, 135.74, 133.97, 128.70, 127.97, 126.45, 126.38, 124.04, 102.88, 54.50, 53.48, 38.01, 35.91, 31.26, 30.86, 29.84. ESI-MS (+) Calc. for $\left[\mathrm{C}_{27} \mathrm{H}_{33} \mathrm{~N}_{5} \mathrm{O}_{3}\right] 475.58$, found: 498.7 $[\mathrm{M}+\mathrm{Na}]^{+}$. 
$\mathrm{N}$-((S)-1-(((S)-1-Amino-4-methyl-1-oxopentan-2-yl)amino)-1-oxo-3-phenylpropan-2yl)-3-(tert-butyl)-1-methyl-1H-pyrazole-5-carboxamide (58)<smiles>CC(C)C[C@H](NC(=O)[C@H](Cc1ccccc1)NC(=O)c1cc(C(C)(C)C)nn1C)C(N)=O</smiles>

Yield 85\%. Yellowish solid. $R_{f}=0.3$ (ethyl acetate). Mp. $152-153^{\circ} \mathrm{C} .{ }^{1} \mathrm{H}-\mathrm{NMR}$ (200 $\left.\mathrm{MHz}, \mathrm{CDCl}_{3}: \mathrm{CD}_{3} \mathrm{OD} 10: 1\right)$ ס. $7.42-7.25(\mathrm{~m}, 5 \mathrm{H}), 6.81(\mathrm{~s}, 1 \mathrm{H}), 4.77-4.65(\mathrm{~m}, 1 \mathrm{H})$, $4.36-4.08(\mathrm{~m}, 1 \mathrm{H}), 4.08(\mathrm{~s}, 3 \mathrm{H}), 3.22-3.18(\mathrm{~m}, 2 \mathrm{H}), 1.89-1.46(\mathrm{~m}, 3 \mathrm{H}), 1.40(\mathrm{~s}$, $9 \mathrm{H}), 0.88-0.80(\mathrm{~m}, 6 \mathrm{H}) .{ }^{13} \mathrm{C} \mathrm{NMR}\left(50 \mathrm{MHz}, \mathrm{CDCl}_{3}: \mathrm{CD}_{3} \mathrm{OD} 10: 1\right) \delta$ 173.57, 168.11, 162.00, 161.25, 137.23, 135.94, 130.02, 129.31, 127.64, 104.97, 57.07, 49.00, 38.87, $32.59,31.75,30.78,24.80,23.57,21.42$. ESI-MS (+) Calc. for $\left[\mathrm{C}_{24} \mathrm{H}_{35} \mathrm{~N}_{5} \mathrm{O}_{3}\right] 441.57$, found: $464.5[\mathrm{M}+\mathrm{Na}]^{+}$.

$N-((S)-1-(((R)-1-A m i n o-4-m e t h y l-1-o x o p e n t a n-2-y l) a m i n o)-1-o x o-3-p h e n y / p r o p a n-2-$ yl)-3-(tert-butyl)-1-methyl-1H-pyrazole-5-carboxamide (59)<smiles>CC(C)C[C@H](NC(=O)[C@H](Cc1ccccc1)NC(=O)c1cc(C(C)(C)C)nn1C)C(N)=O</smiles>

Yield $72 \%$. Yellowish solid. $R_{f}=0.3$ (ethyl acetate). Mp. $131-133^{\circ} \mathrm{C} .{ }^{1} \mathrm{H}$ NMR (200 $\left.\mathrm{MHz}, \mathrm{CDCl}_{3}: \mathrm{CD}_{3} \mathrm{OD} 10: 1\right) \delta 7.45-7.28(\mathrm{~s}, 5 \mathrm{H}), 6.83(\mathrm{~s}, 1 \mathrm{H}), 4.75-4.68(\mathrm{~m}, 1 \mathrm{H}), 4.35$ - $4.14(\mathrm{~m}, 1 \mathrm{H}), 4.09(\mathrm{~s}, 3 \mathrm{H}), 3.25-3.21(\mathrm{~m}, 2 \mathrm{H}), 1.85-1.44(\mathrm{~m}, 3 \mathrm{H}), 1.42(\mathrm{~s}, 9 \mathrm{H})$, $0.88-0.83(\mathrm{~m}, 6 \mathrm{H}) .{ }^{13} \mathrm{C} \mathrm{NMR}\left(50 \mathrm{MHz}, \mathrm{CDCl}_{3}\right) \delta 176.49,171.02,164.92,164.17$, 140.15, 138.86, 132.94, 132.23, 130.56, 107.89, 76.35, 59.99, 41.79, 35.51, 34.67, 33.70, 27.72, 26.49, 24.34. ESI-MS (+) Calc. for $\left[\mathrm{C}_{24} \mathrm{H}_{35} \mathrm{~N}_{5} \mathrm{O}_{3}\right] 441.57$, found: 464.5 $[\mathrm{M}+\mathrm{Na}]^{+}$. 
tert-Butyl ((S)-1-(((S)-1-amino-3-(3-chlorophenyl)-1-oxopropan-2-yl)amino)-1-oxo-3phenylpropan-2-yl)carbamate (60)<smiles>Cn1nc(C(C)(C)C)cc1C(=O)N[C@@H](Cc1ccccc1)C(=O)N[C@@H](Cc1cccc(Cl)c1)C(N)=O</smiles>

Yield $80 \%$. Yellowish solid. $R_{f}=0.2$ (ethyl acetate). Mp. $101-103^{\circ} \mathrm{C} .{ }^{1} \mathrm{H}$ NMR $(200$ $\left.\mathrm{MHz}, \mathrm{CDCl}_{3}: \mathrm{CD}_{3} \mathrm{OD} 10: 1\right)$ б. $7.58-6.99(\mathrm{~m}, 9 \mathrm{H}), 6.47(\mathrm{~s}, 1 \mathrm{H}), 4.77-4.62(\mathrm{~m}, 2 \mathrm{H})$, $4.04(\mathrm{~s}, 3 \mathrm{H}), 3.39-2.91(\mathrm{~m}, 4 \mathrm{H}), 1.34(\mathrm{~s}, 9 \mathrm{H}) .{ }^{13} \mathrm{C} \mathrm{NMR}\left(50 \mathrm{MHz}, \mathrm{CDCl}_{3}: \mathrm{CD}_{3} \mathrm{OD} 10: 1\right)$ $\delta 172.23,172.21,161.25,161.03,137.40,136.96,135.83,135.15,130.68,129.87$, 129.23, 128.42, 128.30, 127.69, 117.62, 104.55, 55.12, 49.00, 42.41, 38.76, 38.62, 32.51, 30.78. ESI-MS (+) Calc. for $\left[\mathrm{C}_{27} \mathrm{H}_{32} \mathrm{CIN}_{5} \mathrm{O}_{3}\right] 510.03$, found: $532.9[\mathrm{M}+\mathrm{Na}]^{+}$.

$\mathrm{N}-((S)-1-(((S)-1-$ Amino-1-oxo-3-(pyridin-4-yl)propan-2-yl)amino)-1-oxo-3phenylpropan-2-yl)-3-(tert-butyl)-1-methyl-1H-pyrazole-5-carboxamide (61)<smiles>Cn1nc(C(C)(C)C)cc1C(=O)N[C@@H](Cc1ccccc1)C(=O)N[C@@H](Cc1ccncc1)C(N)=O</smiles>

Yield $66 \%$. Yellowish oil. $R_{f}=0.2$ (ethyl acetate). ${ }^{1} \mathrm{H}$ NMR $\left(200 \mathrm{MHz}, \mathrm{CDCl}_{3}\right) \delta 8.63(\mathrm{~d}$, $J=5.7 \mathrm{~Hz}, 2 \mathrm{H}), 7.58-7.30(\mathrm{~m}, 7 \mathrm{H}), 7.36-7.13(\mathrm{~m}, 7 \mathrm{H}), 6.59(\mathrm{~s}, 1 \mathrm{H}), 4.84-4.68(\mathrm{~m}$, $2 \mathrm{H}), 3.89(\mathrm{~s}, 3 \mathrm{H}), 3.35-3.07(\mathrm{~m}, 2 \mathrm{H}), 1.27(\mathrm{~s}, 9 \mathrm{H}) .{ }^{13} \mathrm{C} \mathrm{NMR}\left(50 \mathrm{MHz}, \mathrm{CDCl}_{3}\right) \delta$ $174.42,173.04,161.51,161.12,149.40,148.81,138.04,136.11,129.86,129.09$, $127.45,126.03,104.55,55.73,54.08,38.35,37.93,37.75,32.45,30.45$. ESI-MS (+) Calc. for $\left[\mathrm{C}_{26} \mathrm{H}_{32} \mathrm{~N}_{6} \mathrm{O}_{3}\right]$ 476.57, found:477.3 $[\mathrm{M}+\mathrm{H}]^{+}$. 
$N-((S)-1-(((2 S, 3 R)-1-$ Amino-3-(benzyloxy)-1-oxobutan-2-yl)amino)-1-oxo-3phenylpropan-2-yl)-3-(tert-butyl)-1-methyl-1H-pyrazole-5-carboxamide (62)<smiles>CC(OCc1ccccc1)[C@H](NC(=O)[C@H](Cc1ccccc1)NC(=O)c1cc(C(C)(C)C)nn1C)C(N)=O</smiles>

Yield 65\%. Yellowish solid. $R_{f}=0.3$ (ethyl acetate). Mp. $109-110{ }^{\circ} \mathrm{C} .{ }^{1} \mathrm{H}$ NMR $(200$ $\left.\mathrm{MHz}, \mathrm{CDCl}_{3}\right) \delta 7.30-7.08(\mathrm{~m}, 9 \mathrm{H}), 6.40(\mathrm{~d}, J=14.4 \mathrm{~Hz}, 1 \mathrm{H}), 6.26(\mathrm{~s}, 1 \mathrm{H}), 5.00-4.76$ $(\mathrm{m}, 1 \mathrm{H}), 4.52(\mathrm{~s}, 2 \mathrm{H}), 4.17-4.06(\mathrm{~m}, 2 \mathrm{H}), 3.98(\mathrm{~s}, 3 \mathrm{H}), 3.20-3.09(\mathrm{~m}, 2 \mathrm{H}), 1.27(\mathrm{~s}$, $9 \mathrm{H}), 1.11(\mathrm{~d}, J=6.2 \mathrm{~Hz}, 3 \mathrm{H}) .{ }^{13} \mathrm{C} \mathrm{NMR}\left(50 \mathrm{MHz}, \mathrm{CDCl}_{3}\right) \delta 171.79,171.19,160.58$, $160.20,137.80,136.25,134.62,129.26,128.78,128.44,127.84,127.78,127.21$, 103.32, 74.00, 71.58, 60.39, 56.64, 38.86, 38.61, 31.91, 30.49, 21.02. ESI-MS (+) Calc. for $\left[\mathrm{C}_{29} \mathrm{H}_{37} \mathrm{~N}_{5} \mathrm{O}_{4}\right] 519.64$, found:549.4 $[\mathrm{M}+\mathrm{Na}]^{+}$.

N-((S)-1-(((2R,3S)-1-Amino-3-(benzyloxy)-1-oxobutan-2-yl)amino)-1-oxo-3phenylpropan-2-yl)-3-(tert-butyl)-1-methyl-1H-pyrazole-5-carboxamide (63)<smiles>CC(O)[C@H](NC(=O)[C@H](Cc1ccccc1)NC(=O)c1cc(C(C)(C)C)nn1C)C(N)=O</smiles>

Yield $61 \%$. Yellowish solid. $R_{f}=0.3$ (ethyl acetate). Mp. $119-120{ }^{\circ} \mathrm{C} .{ }^{1} \mathrm{H}$ NMR $(200$ $\left.\mathrm{MHz}, \mathrm{CDCl}_{3}\right)$ ס.7.27 - $7.04(\mathrm{~m}, 9 \mathrm{H}), 6.37(\mathrm{~d}, J=14.4 \mathrm{~Hz}, 1 \mathrm{H}), 6.22(\mathrm{~s}, 1 \mathrm{H}), 4.97-4.73$ (m, 1H), $4.48(\mathrm{~s}, 2 \mathrm{H}), 4.14-4.03(\mathrm{~m}, 2 \mathrm{H}), 3.95(\mathrm{~s}, 3 \mathrm{H}), 3.17-3.06(\mathrm{dd}, J=11.3,5.1$ $\mathrm{Hz}, 2 \mathrm{H}), 1.23(\mathrm{~s}, 9 \mathrm{H}), 1.08$ (d, J = 6.2 Hz, 3H). ${ }^{13} \mathrm{C} \mathrm{NMR}\left(50 \mathrm{MHz}, \mathrm{CDCl}_{3}\right) \delta 171.79$, $171.19,160.58,160.20,137.80,136.25,134.62,129.26,128.78,128.44,127.84$, $127.78,127.21,103.32,74.00,71.58,60.39,56.64,38.86,38.61,31.91,30.49,21.02$. ESI-MS (+) Calc. for $\left[\mathrm{C}_{29} \mathrm{H}_{37} \mathrm{~N}_{5} \mathrm{O}_{4}\right]$ 519.64, found: $549.4[\mathrm{M}+\mathrm{Na}]^{+}$. 
$N-((S)-1-(((2 S, 3 R)-1-A m i n o-3-($ benzyloxy)-1-oxobutan-2-yl)amino)-4-methyl-1oxopentan-2-yl)-3-(tert-butyl)-1-methyl-1H3-pyrazole-5-carboxamide (64)<smiles>CC(C)C[C@H](NC(=O)c1cc(C(C)(C)C)nn1C)C(=O)N[C@@H](C(N)=O)[C@H](C)O[Na]</smiles>

Yield $73 \%$. Yellowish solid. $R_{f}=0.3$ (ethyl acetate). Mp. $177-178{ }^{\circ} \mathrm{C} .{ }^{1} \mathrm{H}$ NMR (200 $\left.\mathrm{MHz}, \mathrm{CDCl}_{3}\right) \delta .7 .27-7.20(\mathrm{~m}, 4 \mathrm{H}), 7.14(\mathrm{~d}, J=8.5 \mathrm{~Hz}, 1 \mathrm{H}), 6.42(\mathrm{~s}, 1 \mathrm{H}), 4.85-4.82$ $(\mathrm{m}, 1 \mathrm{H}), 4.62-4.52(\mathrm{~s}, 2 \mathrm{H}), 3.96(\mathrm{~s}, 3 \mathrm{H}), 3.87-3.84(\mathrm{~m}, 1 \mathrm{H}), 1.69-1.59(\mathrm{~m}, 3 \mathrm{H})$, $1.22(\mathrm{~s}, 9 \mathrm{H}) .1 .18(\mathrm{~d}, J=6.3 \mathrm{~Hz}, 3 \mathrm{H}), 0.90(\mathrm{~d}, J=6.0 \mathrm{~Hz}, 3 \mathrm{H}), 0.97(\mathrm{~d}, J=6.0 \mathrm{~Hz}, 3 \mathrm{H}$ ). ${ }^{13} \mathrm{C}$ NMR $\left(50 \mathrm{MHz}, \mathrm{CDCl}_{3}\right) \delta 172.35,171.66,160.37,160.31,137.82,134.69,128.57$, $128.00,127.74,103.21,74.07,71.71,56.24,52.12$, 39.03, 38.69, 32.02, 30.59, 25.00, 23.01, 22.0. ESI-MS (+) Calc. for $\left[\mathrm{C}_{26} \mathrm{H}_{39} \mathrm{~N}_{5} \mathrm{O}_{4}\right]$ 485.62, found: $508.5[\mathrm{M}+\mathrm{Na}]^{+}$.

$N-((S)-1-(((2 R, 3 S)-1-A m i n o-3-($ benzyloxy)-1-oxobutan-2-yl)amino)-4-methyl-1oxopentan-2-yl)-3-(tert-butyl)-1-methyl-1H3-pyrazole-5-carboxamide (65)<smiles>CC(C)C[C@H](NC(=O)c1cc(C(C)(C)C)nn1C)C(=O)N[C@H]([18OH])C(N)=O</smiles>

Yield 70\%. Yellowish solid. $R_{f}=0.3$ (ethyl acetate). Mp. $170-171^{\circ} \mathrm{C} .{ }^{1} \mathrm{H}$ NMR (200 $\left.\mathrm{MHz}, \mathrm{CDCl}_{3}\right) \delta 7.33-7.21(\mathrm{~m}, 4 \mathrm{H}), 7.15(\mathrm{~d}, J=8.5 \mathrm{~Hz}, 1 \mathrm{H}), 6.34(\mathrm{~s}, 1 \mathrm{H}), 4.85-4.82$ $(\mathrm{m}, 1 \mathrm{H}), 4.64-4.53(\mathrm{~s}, 2 \mathrm{H}), 3.98(\mathrm{~s}, 3 \mathrm{H}), 3.88-3.86(\mathrm{~m}, 1 \mathrm{H}), 1.71-1.60(\mathrm{~m}, 3 \mathrm{H})$, $1.24(\mathrm{~s}, 9 \mathrm{H}), 1.21(\mathrm{~d}, J=6.3 \mathrm{~Hz}, 3 \mathrm{H}), 0.91(\mathrm{~d}, J=6.0 \mathrm{~Hz}, 3 \mathrm{H}), 0.89(\mathrm{~d}, J=6.0 \mathrm{~Hz}, 3 \mathrm{H})$. ${ }^{13} \mathrm{C} \mathrm{NMR}\left(50 \mathrm{MHz}, \mathrm{CDCl}_{3}\right) \delta 171.72,171.02,159.73,159.68,137.18,134.05,127.94$, 127.36, 127.10, 102.58, 73.43, 71.08, 55.60, 51.49, 38.39, 38.06, 31.39, 29.95, 24.37, 22.38, 21.44. ESI-MS (+) Calc. for $\left[\mathrm{C}_{26} \mathrm{H}_{39} \mathrm{~N}_{5} \mathrm{O}_{4}\right]$ 485.62, found: $508.5[\mathrm{M}+\mathrm{Na}]^{+}$. 
$N-((S)-1-(((2 S, 3 R)-1-A m i n o-3-($ benzyloxy)-1-oxobutan-2-yl)amino)-3-(3chlorophenyl)-1-oxopropan-2-yl)-3-(tert-butyl)-1-methyl-1H-pyrazole-5-carboxamide (66)

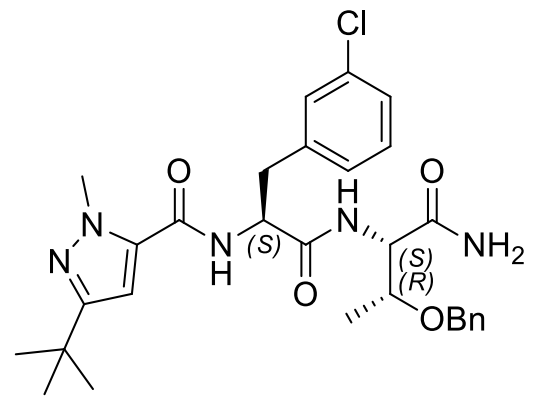

Yield $65 \%$. Yellowish solid. $R_{f}=0.2$ (ethyl acetate). Mp. $102-104{ }^{\circ} \mathrm{C} .{ }^{1} \mathrm{H}$ NMR $(200$ $\mathrm{MHz}, \mathrm{CD}_{3} \mathrm{OD}$ ) $\delta 8.59$ (d, J = 7.8 Hz, 1H), $8.03(\mathrm{~d}, J=8.4 \mathrm{~Hz}, 1 \mathrm{H}), 7.26$ (dd, $J=5.6$, $2.2 \mathrm{~Hz}, 9 \mathrm{H}), 6.59(\mathrm{~s}, 1 \mathrm{H}), 4.64-4.45(\mathrm{~m}, 3 \mathrm{H}), 4.16-4.11(\mathrm{~m}, 1 \mathrm{H}), 3.86(\mathrm{~s}, 3 \mathrm{H}), 3.27$ $-3.25(\mathrm{~m}, 1 \mathrm{H}), 3.03(\mathrm{dd}, J=14.7,10.8 \mathrm{~Hz}, 1 \mathrm{H}), 1.28(\mathrm{~s}, 9 \mathrm{H}), 1.22(\mathrm{~d}, J=6.3 \mathrm{~Hz}, 3 \mathrm{H})$. ${ }^{13} \mathrm{C}$ NMR $\left(50 \mathrm{MHz}, \mathrm{CD}_{3} \mathrm{OD}\right) \delta 174.44,173.31,162.05,161.35,140.90,139.31,136.28$, 134.96, 130.78, 130.33, 129.08, 128.62, 128.52, 128.44, 127.71, 104.84, 75.78, 72.24, $58.45,55.77,38.46,37.34,32.66,30.66,16.58$. ESI-MS (+) Calc. for $\left[\mathrm{C}_{29} \mathrm{H}_{36} \mathrm{CIN}_{5} \mathrm{O}_{4}\right]$ 554.08, found: $577.1[\mathrm{M}+\mathrm{Na}]^{+}$.

Compounds $67-77$ were synthesized by dehydration of the corresponding primary amide precursor 56 - 66 with cyanuric chloride (general procedure for dehydration of primary amide to nitrile, method $A$ ).

3-(tert-Butyl)-N-((S)-1-(((S)-1-cyano-2-phenylethyl)amino)-1-oxo-3-phenylpropan-2yl)-1-methyl-1H-pyrazole-5-carboxamide (67)<smiles>Cn1nc(C(C)(C)C)cc1C(=O)N[C@@H](Cc1ccccc1)C(=O)NCc1ccccc1</smiles>

Yield 89\%. Yellowish solid. $R_{f}=0.6$ (ethyl acetate: $n$-hexane; $6: 4$ ). Mp. $89-90{ }^{\circ} \mathrm{C} .{ }^{1} \mathrm{H}$ $\operatorname{NMR}\left(400 \mathrm{MHz}, \mathrm{CDCl}_{3}\right) \delta 7.32-7.21(\mathrm{~m}, 8 \mathrm{H}), 7.16(\mathrm{dd}, J=6.4,2.8 \mathrm{~Hz}, 2 \mathrm{H}), 6.90(\mathrm{~d}$, $J=8.2 \mathrm{~Hz}, 1 \mathrm{H}), 6.82(\mathrm{~d}, J=8.2 \mathrm{~Hz}, 1 \mathrm{H}), 6.35(\mathrm{~s}, 1 \mathrm{H}), 5.04-5.02(\mathrm{~m}, 1 \mathrm{H}), 4.82-4.80$ $(\mathrm{m}, 1 \mathrm{H}), 4.02(\mathrm{~s}, 3 \mathrm{H}), 3.21-3.07(\mathrm{~m}, 2 \mathrm{H}), 3.00-2.98(\mathrm{~m}, 2 \mathrm{H}), 1.33-1.30(\mathrm{~m}, 9 \mathrm{H})$. 
${ }^{13} \mathrm{C}$ NMR $\left(100 \mathrm{MHz}, \mathrm{CDCl}_{3}\right) \delta 170.30,160.25,160.30,135.55,134.04,133.37,129.08$, 129.04, 128.75, 128.72, 127.71, 127.26, 117.25, 103.06, 54.17, 41.48, 38.77, 38.35, 37.95, 31.75, 30.26. FT-IR $\left(\mathrm{KBr}, \mathrm{cm}^{-1}\right)$ 3300.81, 2951.21, 2909.60, 2243.70, 1677.69, 1648.55, 1544.51, 1278.15, 1232.37, 986.82, 751.92, 670.52, 524.68, 424.97. HRMS (+) Calc. for $\left[\mathrm{C}_{27} \mathrm{H}_{32} \mathrm{~N}_{5} \mathrm{O}_{2}\right]^{+}$458.25560, found: $458.2586[\mathrm{M}+\mathrm{H}]^{+}$. HPLC (protocol B): $\mathrm{t}_{\mathrm{R}}$ $(\min )=9.07$. Purity $99.0 \%$.

3-(tert-Butyl)-N-((S)-1-(((R)-1-cyano-2-phenylethyl)amino)-1-oxo-3-phenylpropan-2yl)-1-methyl-1H-pyrazole-5-carboxamide (68)<smiles>Cn1nc(C(C)(C)C)cc1C(=O)N[C@@H](Cc1ccccc1)C(=O)N[C@@H](C#N)Cc1ccccc1</smiles>

Yield 92\%. Yellowish solid. $R_{f}=0.6$ (ethyl acetate: $n$-hexane; 6:4). Mp. $98-99{ }^{\circ} \mathrm{C} .{ }^{1} \mathrm{H}$ $\operatorname{NMR}\left(200 \mathrm{MHz}, \mathrm{CDCl}_{3}\right) \delta 7.34-7.12(\mathrm{~m}, 9 \mathrm{H}), 6.91(\mathrm{~d}, J=7.9 \mathrm{~Hz}, 1 \mathrm{H}), 6.34(\mathrm{~s}, 1 \mathrm{H})$, $5.09-5.05(\mathrm{~m}, 1 \mathrm{H}), 4.94-4.91(\mathrm{~m}, 1 \mathrm{H}), 4.00(\mathrm{~s}, 3 \mathrm{H}), 3.12(\mathrm{dd}, J=13.8,6.4 \mathrm{~Hz}, 2 \mathrm{H})$, 2.98 (dd, $J=13.8,6.4 \mathrm{~Hz}, 2 \mathrm{H}), 1.30$ (s, 9H). ${ }^{13} \mathrm{C}$ NMR $\left(50 \mathrm{MHz}, \mathrm{CDCl}_{3}\right) \delta 170.75$, 160.43 , 160.33, 135.98, 134.32, 133.78, 129.42, 129.33, 129.01, 128.86, 127.99, 127.42 , 118.87, 103.48, 54.38, 41.82, 38.96, 38.48, 38.26, 31.98, 30.51. FT-IR (KBr, $\mathrm{cm}^{-1}$ ) 3350.28, 3256.30, 2953.92, 2165.27, 1638.14, 1511.6, 1307.15, 1160.05, 1086.49, 906.70, 820.89, 694.21, 669.69, 543.02. HRMS (+) Calc. for $\left[\mathrm{C}_{27} \mathrm{H}_{32} \mathrm{~N}_{5} \mathrm{O}_{2}\right]^{+}$ 458.25560, found: $458.2586[\mathrm{M}+\mathrm{H}]^{+}$. HPLC (protocol B): $t_{R}(\min )=17.32$. Purity $99.3 \%$.

3-(tert-Butyl)-N-((S)-1-(((S)-1-cyano-3-methylbutyl)amino)-1-oxo-3-phenylpropan-2yl)-1-methyl-1H-pyrazole-5-carboxamide (69)<smiles>CC(C)C[C@H](C#N)NC(=O)[C@H](Cc1ccccc1)NC(=O)c1cc(C(C)(C)C)nn1C</smiles>

Yield 84\%. Yellowish solid. $R_{f}=0.7$ (ethyl acetate: $n$-hexane; $6: 4$ ). Mp $81-82{ }^{\circ} \mathrm{C} .{ }^{1} \mathrm{H}$ $\operatorname{NMR}\left(200 \mathrm{MHz}, \mathrm{CD}_{3} \mathrm{OD}\right) \delta 7.29-7.20(\mathrm{~m}, 5 \mathrm{H}), 6.64(\mathrm{~s}, 1 \mathrm{H}), 4.80-4.69(\mathrm{~m}, 2 \mathrm{H}), 3.90$ 
(s, 3H), $3.23-2.94(\mathrm{~m}, 2 \mathrm{H}), 1.78-1.62(\mathrm{~m}, 3 \mathrm{H}), 1.27(\mathrm{~s}, 9 \mathrm{H}), 0.95-0.91(\mathrm{~m}, 6 \mathrm{H}) .{ }^{13} \mathrm{C}$ NMR $\left(50 \mathrm{MHz}, \mathrm{CD}_{3} \mathrm{OD}\right) \delta 173.33,161.87,161.51,138.07,136.59,130.36,129.56$, 127.93, 119.68, 105.02, 56.04, 49.00, 42.00, 40.04, 38.69, 32.86, 30.88, 25.80, 22.35, 22.19. FT-IR $\left(\mathrm{KBr}, \mathrm{cm}^{-1}\right) 3403.41,3309.42,3203.18,2953.92,2937.57,1695.35$, $1634.05,1523.72,1368.44,1274.46,1245.86,1168.22,835.58,702.38,669.69$, 567.54. HRMS (+) Calc. for $\left[\mathrm{C}_{24} \mathrm{H}_{34} \mathrm{~N}_{5} \mathrm{O}_{2}\right]^{+} 423.27125$, found: $424.27572[\mathrm{M}+\mathrm{H}]^{+}$. HPLC (protocol B): $t_{R}(\min )=9.16$. Purity $97.4 \%$.

3-(tert-Butyl)-N-((S)-1-(((R)-1-cyano-3-methylbutyl)amino)-1-oxo-3-phenylpropan-2yl)-1-methyl-1H-pyrazole-5-carboxamide (70)

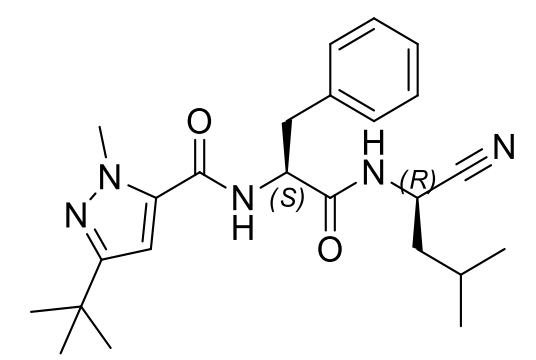

Yield 79\%. White solid. $R_{f}=0.7$ (ethyl Acetate: $n$-hexane; 6:4). Mp. $91-94{ }^{\circ} \mathrm{C} .{ }^{1} \mathrm{H}$ $\operatorname{NMR}\left(200 \mathrm{MHz}, \mathrm{CDCl}_{3}\right) \delta 7.32-7.21(\mathrm{~m}, 3 \mathrm{H}), 6.98(\mathrm{~d}, J=8.2 \mathrm{~Hz}, 1 \mathrm{H}), 6.88(\mathrm{~d}, J=$ $8.2 \mathrm{~Hz}, 1 \mathrm{H}), 6.34(\mathrm{~s}, 1 \mathrm{H}), 4.92-4.86(\mathrm{~m}, 1 \mathrm{H}), 4.77-4.71(\mathrm{~m}, 1 \mathrm{H}), 3.99(\mathrm{~s}, 3 \mathrm{H}), 3.29$ $-3.19(\mathrm{~m}, 2 \mathrm{H}), 1.63-1.46(\mathrm{~m}, 3 \mathrm{H}), 1.27(\mathrm{~s}, 9 \mathrm{H}), 0.88(2 \mathrm{~d}, J=5.9 \mathrm{~Hz}, 6 \mathrm{H}) .{ }^{13} \mathrm{C} N M R$ $\left(50 \mathrm{MHz}, \mathrm{CDCl}_{3}\right) \delta 171.28,161.15,161.04,136.68,135.04,129.97,129.56,128.05$, $119.17,104.16,55.16,41.95,39.62,39.12$, 32.67, 31.19, 25.31, 22.79, 22.53. FT-IR $\left(\mathrm{KBr}, \mathrm{cm}^{-1}\right)$ 3350.28, 3256.30, 2953.92, 2165.27, 1638.14, 1511.46, 1307.15, 1160.05, 1086.49, 906.70, 820.89, 694.21, 669.69, 543.02. HRMS (+) Calc. for $\left[\mathrm{C}_{24} \mathrm{H}_{34} \mathrm{~N}_{5} \mathrm{O}_{2}\right]^{+}$ 423.27125, found: $424.27572[\mathrm{M}+\mathrm{H}]^{+}$. HPLC (protocol B): $\mathrm{tR}_{\mathrm{R}}(\mathrm{min})=9.42$. Purity $99.1 \%$. 
3-(tert-Butyl)-N-((S)-1-(((S)-2-(3-chlorophenyl)-1-cyanoethyl)amino)-1-oxo-3phenylpropan-2-yl)-1-methyl-1H-pyrazole-5-carboxamide (71)<smiles>Cn1nc(C(C)(C)C)cc1C(=O)N[C@@H](Cc1ccccc1)C(=O)N[C@@H](C#N)Cc1cccc(Cl)c1</smiles>

Yield 50\%. Yellowish solid. $R_{f}=0.6$ (ethyl acetate: $n$-hexane; $6: 4$ ). Mp $132-133{ }^{\circ} \mathrm{C}$. ${ }^{1} \mathrm{H}$ NMR (200 MHz, CD $\left.30 \mathrm{OD} / \mathrm{CDCl}_{3}\right) \delta 7.54-7.35(\mathrm{~m}, 9 \mathrm{H}), 6.75$ (s, 1H), 5.19 - 5.11 $(\mathrm{m}, 1 \mathrm{H}), 4.51-4.48(\mathrm{~m}, 1 \mathrm{H}), 4.17(\mathrm{~s}, 3 \mathrm{H}), 3.33-3.21(\mathrm{~m}, 4 \mathrm{H}), 1.49(\mathrm{~s}, 9 \mathrm{H}) .{ }^{13} \mathrm{C}$ NMR (50 MHz, CD $\left.{ }_{3} \mathrm{OD}\right) \delta 172.23,161.25,161.03,137.40,136.96,135.83,135.15,130.68$, 130.07, 129.87, 129.23, 128.42, 128.30, 127.69, 118.18, 104.55, 55.12, 42.41, 38.76, 38.62, 32.51, 30.78. FT-IR $\left(\mathrm{cm}^{-1}\right)$ 3288.99, 2925.31, 2855.85, 2161.18, 1666.74, 1634.05, 1544.15, 1507.38, 1450.17, 1266.29, 1221.34, 1074.23, 861.75, 747.33, 706.47, 694.21. HRMS (+) Calc. for $\left[\mathrm{C}_{27} \mathrm{H}_{31} \mathrm{CIN}_{5} \mathrm{O}_{2}\right]+491.21663$, found: 492.21034 $[\mathrm{M}+\mathrm{H}]^{+}$. HPLC (protocol B): $t_{R}(\min )=9.61$. Purity $>99.9 \%$.

3-(tert-Butyl)-N-((S)-1-(((S)-1-cyano-2-(pyridin-4-yl)ethyl)amino)-1-oxo-3phenylpropan-2-yl)-1-methyl-1H-pyrazole-5-carboxamide (72)<smiles>Cn1nc(C(C)(C)C)cc1C(=O)N[C@@H](Cc1ccccc1)C(=O)N[C@@H](C#N)Cc1ccncc1</smiles>

Yield 35\%. Yellowish wax. $R=0.4$ (ethyl acetate: $n$-hexane; 6:4). ${ }^{1} \mathrm{H}$ NMR (400 MHz, $\left.\mathrm{CD}_{3} \mathrm{OD}\right) \delta 8.44$ (s br, 2H), $7.38(\mathrm{~d}, J=5.3 \mathrm{~Hz}, 2 \mathrm{H}), 7.30-7.22(\mathrm{~m}, 5 \mathrm{H}), 6.63(\mathrm{~s}, 1 \mathrm{H})$, $5.14(\mathrm{t}, J=7.5 \mathrm{~Hz}, 1 \mathrm{H}), 4.66(\mathrm{dd}, J=8.6,6.8 \mathrm{~Hz}, 1 \mathrm{H}), 3.94(\mathrm{~s}, 3 \mathrm{H}), 3.26-3.13$ (m, $4 \mathrm{H}), 1.30$ (s, 9H). ${ }^{13} \mathrm{C}$ NMR (100 MHz, DMSO- $\left.d_{6}\right) \delta 171.17,170.90,159.29,158.46$, 137.89 , 136.81, 135.23, 134.81, 129.27, 128.86, 128.13, 127.92, 126.93, 126.34, 118.94, 60.46, 53.87, 53.24, 41.15, 31.39, 30.18, 13.74. FT-IR $\left(\mathrm{cm}^{-1}\right) 3264.47$, 2953.92, 2913.05, 2851.76, 2161.43, 1662.66, 1605.45, 1548.24, 1466.62, 1204.99, 1115.10, 996.59, 800.45, 735.07, 681.95. HRMS (+) Calc. for $\left[\mathrm{C}_{26} \mathrm{H}_{31} \mathrm{~N}_{6} \mathrm{O}_{2}\right]^{+}$ 459.25085, found: $459.25627[\mathrm{M}+\mathrm{H}]^{+}$. HPLC (protocol B): $\mathrm{t}_{\mathrm{R}}(\min )=6.84$. Purity $98.6 \%$. 
N-((S)-1-(((1R,2R)-2-(Benzyloxy)-1-cyanopropyl)amino)-1-oxo-3-phenylpropan-2-yl)3-(tert-butyl)-1-methyl-1H-pyrazole-5-carboxamide (73)

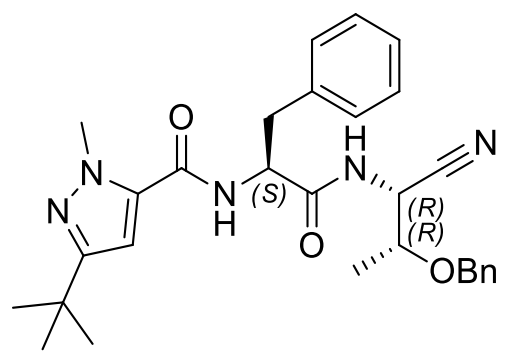

Yield $80 \%$. White solid. $R_{f}=0.5$ (ethyl acetate: $n$-hexane; 6:4). Mp. $115-116{ }^{\circ} \mathrm{C} .{ }^{1} \mathrm{H}-$ $\operatorname{NMR}\left(200 \mathrm{MHz}, \mathrm{CDCl}_{3}\right) \delta 7.35-7.26(\mathrm{~m}, 10 \mathrm{H}), 6.95(\mathrm{~d}, J=8.7 \mathrm{~Hz}, 1 \mathrm{H}), 6.61(\mathrm{~d}, J=$ $7.0 \mathrm{~Hz}, 1 \mathrm{H}), 6.30(\mathrm{~s}, 1 \mathrm{H}), 4.88-4.85(\mathrm{~m}, 2 \mathrm{H}), 4.62-4.58(\mathrm{~m}, 1 \mathrm{H}), 4.03(\mathrm{~s}, 3 \mathrm{H}), 3.82$ - 3. $78(\mathrm{~m}, 1 \mathrm{H}), 3.29-3.24(\mathrm{~m}, 2 \mathrm{H}), 1.31(\mathrm{~s}, 9 \mathrm{H}), 1.03(\mathrm{~d}, J=6.0 \mathrm{~Hz}, 3 \mathrm{H}) .{ }^{13} \mathrm{C}$ NMR $\left(50 \mathrm{MHz} \mathrm{CDCl}_{3}\right) \delta 170.30,159.83,159.62,136.42,135.27,133.75,128.67,128.41$, $128.00,127.60,127.30,126.87,116.63,102.65,72.60,70.91,53.85,44.51,38.33$, 37.60, 31.40, 29.94, 15.29. FT-IR $\left(\mathrm{cm}^{-1}\right)$ 3354.37, 3252.21, 2181.61, 1654.61, 1654.48, 1540.07, 1486.95, 1290.81, 1151.87, 1086.48, 894.44, 808.63, 710.56, 661.32, 543.02. HRMS (+) Calc. for $\left[\mathrm{C}_{29} \mathrm{H}_{36} \mathrm{~N}_{5} \mathrm{O}_{3}\right]^{+} 502.28182$, found: 502.28095 $[\mathrm{M}+\mathrm{H}]^{+}$. HPLC (protocol B): $t_{R}(\min )=9.54$. Purity $99.4 \%$.

N-((S)-1-(((1S,2S)-2-(Benzyloxy)-1-cyanopropyl)amino)-1-oxo-3-phenylpropan-2-yl)3-(tert-butyl)-1-methyl-1H-pyrazole-5-carboxamide (74).

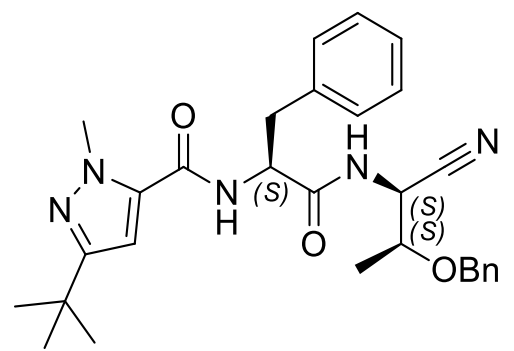

Yield $82 \%$. White solid. $R_{f}=0.5$ (ethyl acetate: $n$-hexane; 6:4). Mp. $123-124{ }^{\circ} \mathrm{C} .{ }^{1} \mathrm{H}$ $\operatorname{NMR}\left(200 \mathrm{MHz}, \mathrm{CDCl}_{3}\right) \delta 7.36-7.25(\mathrm{~m}, 10 \mathrm{H}), 6.98(\mathrm{~d}, J=8.7 \mathrm{~Hz}, 1 \mathrm{H}), 6.65(\mathrm{~d}, J=$ $7.0 \mathrm{~Hz}, 1 \mathrm{H}), 6.32(\mathrm{~s}, 1 \mathrm{H}), 4.91-4.83(\mathrm{~m}, 2 \mathrm{H}), 4.63-4.60(\mathrm{~m}, 1 \mathrm{H}), 4.05(\mathrm{~s}, 3 \mathrm{H}), 3.80$ (s br, $1 \mathrm{H}), 3.24-3.20(\mathrm{~m}, 2 \mathrm{H}), 1.33(\mathrm{~s}, 9 \mathrm{H}), 1.05(\mathrm{~d}, J=6.0 \mathrm{~Hz}, 3 \mathrm{H}) .{ }^{13} \mathrm{C}$ NMR (50 $\left.\mathrm{MHz}_{\mathrm{CDCl}}\right) \delta 171.01,160.54,160.34,137.14,135.98,134.46,129.39,129.12$, 128.71 , 128.32, 128.02, 127.59, 117.34, 103.37, 72.85, 71.15, 54.56, 45.22, 39.04, 38.32, 32.12, 30.65, 16.00. FT-IR $\left(\mathrm{cm}^{-1}\right)$ 2376.73, 2958.00, 2169.35, 1642.22, 15400.07, 1499.21, 1442.00, 1290.81, 1225.43, 1111.01, 1033.37, 988.42, 743.25, 
690.12. HRMS (+) Calc. for $\left[\mathrm{C}_{29} \mathrm{H}_{36} \mathrm{~N}_{5} \mathrm{O}_{3}\right]^{+}$502.28182, found: $502.28095[\mathrm{M}+\mathrm{H}]^{+}$. HPLC (protocol B): $t_{R}(\min )=9.43$. Purity $98.3 \%$.

N-((S)-1-(((1R,2R)-2-(Benzyloxy)-1-cyanopropyl)amino)-4-methyl-1-oxopentan-2-yl)3-(tert-butyl)-1-methyl-1H-pyrazole-5-carboxamide (75)

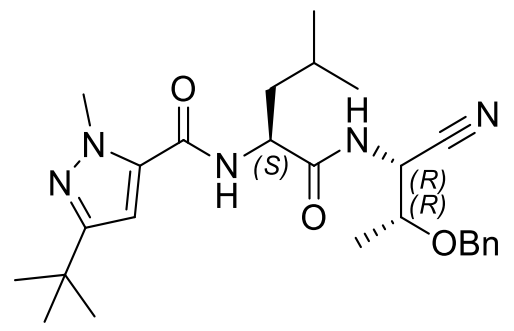

Yield 78\%. White solid. $R_{f}=0.5$ (ethyl acetate: $n$-hexane; 6:4). Mp. $96-97^{\circ} \mathrm{C} .{ }^{1} \mathrm{H}$ NMR $\left(400 \mathrm{MHz}, \mathrm{DMSO}-\mathrm{d}_{6}\right) \delta 8.93(\mathrm{~d}, J=8.1 \mathrm{~Hz}, 1 \mathrm{H}), 8.43(\mathrm{~d}, J=7.6 \mathrm{~Hz}, 1 \mathrm{H}), 7.38-7.29$ $(\mathrm{m}, 5 \mathrm{H}), 6.88(\mathrm{~s}, 1 \mathrm{H}), 5.07-5.04(\mathrm{~m}, 1 \mathrm{H}), 4.64-4.61(\mathrm{~m}, 2 \mathrm{H}), 4.59-4.56(\mathrm{~m}, 1 \mathrm{H})$, $3.97-3.94(\mathrm{~m}, 3 \mathrm{H}), 3.86-3.84(\mathrm{~m}, 1 \mathrm{H}), 1.72-1.64(\mathrm{~m}, 2 \mathrm{H}), 1.50-1.46(\mathrm{~m}, 2 \mathrm{H})$, $1.26-1.20(\mathrm{~m}, 12 \mathrm{H}), 0.93(\mathrm{~d}, J=6.3 \mathrm{~Hz}, 3 \mathrm{H}), 0.88(\mathrm{~d}, J=6.5 \mathrm{~Hz}, 3 \mathrm{H}) .{ }^{13} \mathrm{C}$ NMR $(100$ $\left.\mathrm{MHz}, \mathrm{DMSO}-d_{6}\right) \delta 172.36,159.56,158.66,137.92,134.92,128.10,127.53,127.45$, 117.82, 103.73, 73.39, 70.40, 51.05, 44.75, 38.44, 31.53, 30.31, 24.25, 22.91, 21.19, 15.69. FT-IR $\left(\mathrm{cm}^{-1}\right)$ 3378.89, 3350.28, 3186.83, 2958.00, 2116.43, 1674.91, 1650.40, 1531.90, 1368.44, 1262.20, 1160.05, 1057.89, 1033.37, 780.02, 735.07, 649.26, 604.31. HRMS (+) Calc. for $\left[\mathrm{C}_{26} \mathrm{H}_{38} \mathrm{~N}_{5} \mathrm{O}_{3}\right]$ 468.29746, found: 468.29785 [M+H] . HPLC (protocol B): $\operatorname{tR}(\min )=9.61$. Purity $98.3 \%$.

N-((S)-1-(((1S,2S)-2-(Benzyloxy)-1-cyanopropyl)amino)-4-methyl-1-oxopentan-2-yl)3-(tert-butyl)-1-methyl-1H-pyrazole-5-carboxamide (76)

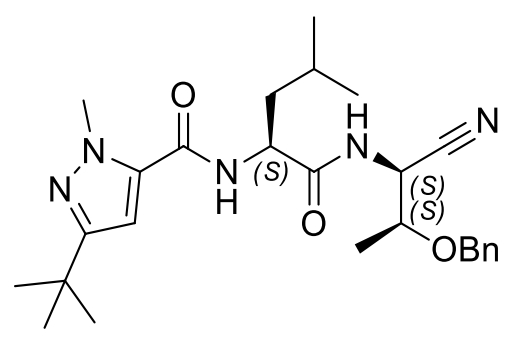

Yield $70 \%$. White solid. $R_{f}=0.5$ (ethyl acetate: $n$-hexane; $6: 4$ ). Mp. $110-111^{\circ} \mathrm{C} .{ }^{1} \mathrm{H}$ $\operatorname{NMR}\left(400 \mathrm{MHz}, \mathrm{CDCl}_{3}\right) \delta 7.27-7.20(\mathrm{~m}, 5 \mathrm{H}), 7.14(\mathrm{~d}, J=8.5 \mathrm{~Hz}, 1 \mathrm{H}), 6.42(\mathrm{~d}, J=$ $7.8 \mathrm{~Hz}, 1 \mathrm{H}), 6.33(\mathrm{~s}, 1 \mathrm{H}), 4.85-4.82(\mathrm{~m}, 1 \mathrm{H}), 4.62-4.52(\mathrm{~m}, 3 \mathrm{H}), 3.96(\mathrm{~s}, 3 \mathrm{H}), 3.87$ - $3.84(\mathrm{~m}, 1 \mathrm{H}), 1.69-1.59(\mathrm{~m}, 3 \mathrm{H}), 1.22(\mathrm{~s}, 9 \mathrm{H}) .1 .18(\mathrm{~d}, J=6.3 \mathrm{~Hz}, 3 \mathrm{H}) 1.24-1.19$ $(\mathrm{m}, 12 \mathrm{H}), 0.92-0.88(\mathrm{~m}, 6 \mathrm{H}) \cdot{ }^{13} \mathrm{C}$ NMR $\left(100 \mathrm{MHz}, \mathrm{CDCl}_{3}\right) \delta 172.10,160.65,160.51$, 
$137.21,134.43,128.66,128.23,127.92,117.45,103.16,73.69,71.80,51.75,45.28$, 40.81, 38.06, 32.10, 30.62, 25.04, 22.97, 22.13, 16.36. FT-IR $\left(\mathrm{cm}^{-1}\right) 3333.94,3284.90$, 2962.09, 2868.10, 2255.16, 1647.44, 1540.07, 1507.38, 1442.00, 1274.46, 1245.86, 988.42, 739.16, 661.52. HRMS (+) Calc. for $\left[\mathrm{C}_{26} \mathrm{H}_{38} \mathrm{~N}_{5} \mathrm{O}_{3}\right]$ 468.29746, found: 468.29785 $[\mathrm{M}+\mathrm{H}]^{+}$. HPLC (protocol B): tR $(\min )=9.56$. Purity $96.9 \%$.

N-((S)-1-(((1R,2R)-2-(Benzyloxy)-1-cyanopropyl)amino)-3-(3-chlorophenyl)-1oxopropan-2-yl)-3-(tert-butyl)-1-methyl-1H-pyrazole-5-carboxamide (77)<smiles>C[C@H](OCc1ccccc1)[C@H](C#N)NC(=O)[C@H](Cc1cccc(Cl)c1)NC(=O)c1cc(C(C)(C)C)nn1C</smiles>

Yield 50\%. Yellowish wax. $R_{f}=0.4$ (ethyl acetate: $n$-hexane; $6: 4$ ). ${ }^{1} \mathrm{H}$ NMR (400 MHz, $\left.\mathrm{CDCl}_{3}\right) \delta 7.30-7.13(\mathrm{~m}, 6 \mathrm{H}), 7.04(\mathrm{dt}, J=7.0,1.7 \mathrm{~Hz}, 1 \mathrm{H}), 6.62(\mathrm{dd}, J=17.8,8.2 \mathrm{~Hz}$, 2H), $6.25(\mathrm{~s}, 1 \mathrm{H}), 4.77-4.71(\mathrm{~m}, 2 \mathrm{H}), 4.48(\mathrm{dd}, J=36.1,11.7 \mathrm{~Hz}, 2 \mathrm{H}), 3.95(\mathrm{~s}, 3 \mathrm{H})$, $3.82-3.74(\mathrm{~m}, 1 \mathrm{H}), 3.11-3.00(\mathrm{~m}, 2 \mathrm{H}), 1.20(\mathrm{~s}, 9 \mathrm{H}), 1.08(\mathrm{~d}, J=6.3 \mathrm{~Hz}, 3 \mathrm{H}) .{ }^{13} \mathrm{C}$ NMR $\left(100 \mathrm{MHz}, \mathrm{CDCl}_{3}\right) \delta 170.73,160.54,160.12,137.80,136.91,134.84,134.30$, $130.44,129.51,128.71,128.34,128.03,127.84,127.62,117.06,103.35,73.35,71.72$, 54.28, 45.07, 39.06, 38.13, 32.07, 30.58, 16.21. FT-IR $\left(\mathrm{cm}^{-1}\right)$ 3357.24, 3264.21, $2193.15,1654.33,1538.29,1487.88,1209.18,1141.78,1036.43$, 863.33, 807.36, 701.44, 658.23, 534.57. ESI-MS (+) Calc. for $\left[\mathrm{C}_{29} \mathrm{H}_{345} \mathrm{CIN}_{5} \mathrm{O}_{3}\right]$ 536.24284, found: $536.24235[\mathrm{M}+\mathrm{H}]^{+}$.HPLC (protocol B): $\mathrm{t}_{\mathrm{R}}(\mathrm{min})=12.06$. Purity $96.5 \%$. 
Compounds $78-81$ were synthesized from compounds $62-65$ by removal of the benzoyl group through hydrogenation on $\mathrm{Pd} / \mathrm{C}$ (general procedure for removal of the benzyl protecting group, method A).

$N-((S)-1-(((2 S, 3 R)-1-A m i n o-3-h y d r o x y-1-o x o b u t a n-2-y l) a m i n o)-1-o x o-3-$

phenylpropan-2-yl)-3-(tert-butyl)-1-methyl-1H-pyrazole-5-carboxamide.(78)

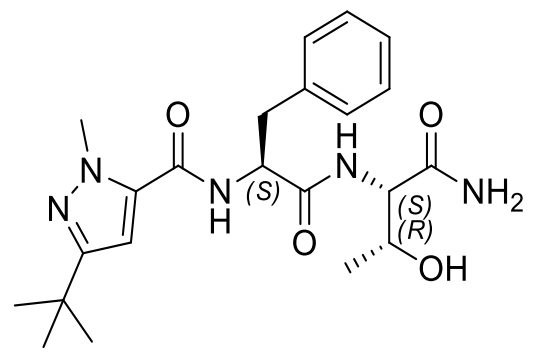

Yield 92\%. Colorless wax. $R_{f}=0.2$ (ethyl acetate). ${ }^{1} \mathrm{H} \mathrm{NMR}\left(200 \mathrm{MHz}, \mathrm{CDCl}_{3}\right) \delta 8.03$ (s, 1H), $7.36-6.94(\mathrm{~m}, 5 \mathrm{H}), 6.54(\mathrm{~s}, 1 \mathrm{H}), 4.44-4.39(\mathrm{~m}, 2 \mathrm{H}), 4.03-4.01(\mathrm{~m}, 1 \mathrm{H})$, $3.96(\mathrm{~s}, 3 \mathrm{H}), 3.18-3.14(\mathrm{~m}, 1 \mathrm{H}), 2.87(\mathrm{~s}, 1 \mathrm{H}), 1.30(\mathrm{~s}, 9 \mathrm{H}), 1.03-1.01(\mathrm{~m}, 3 \mathrm{H}) .{ }^{13} \mathrm{C}$ NMR $\left(50 \mathrm{MHz}, \mathrm{CDCl}_{3}\right) \delta 173.54,172.15,161.25,160.35,136.25,135.98,134.58$, $129.36,128.76,127.25,66.60,58.51,55.55,54.30,38.70,31.98,30.51$, 18.92. ESIMS (+) Calc. for $\left[\mathrm{C}_{22} \mathrm{H}_{31} \mathrm{~N}_{5} \mathrm{O}_{4}\right] 429.51$, found:452.4 [M+Na] $]^{+}$.

$\mathrm{N}-((S)-1-(((2 R, 3 S)-1-A m i n o-3-h y d r o x y-1-o x o b u t a n-2-y l) a m i n o)-1-o x o-3-$ phenylpropan-2-yl)-3-(tert-butyl)-1-methyl-1H-pyrazole-5-carboxamide.(79)<smiles>CC(O)[C@H](NC(=O)[C@H](Cc1ccccc1)NC(=O)c1cc(C(C)(C)C)nn1C)C(N)=O</smiles>

Yield 95\%. Colorless wax. $R_{f}=0.2$ (ethyl acetate). ${ }^{1} \mathrm{H}$ NMR $\left(200 \mathrm{MHz}, \mathrm{CDCl}_{3}\right) \delta 8.01$ (s, 1H), $7.36-6.98(\mathrm{~m}, 5 \mathrm{H}), 6.59(\mathrm{~s}, 1 \mathrm{H}), 4.42-4.38(\mathrm{~m}, 2 \mathrm{H}), 4.04-4.01(\mathrm{~m}, 1 \mathrm{H})$, $3.96(\mathrm{~s}, 3 \mathrm{H}), 3.12-3.09(\mathrm{~m}, 1 \mathrm{H}), 2.89(\mathrm{~s}, 1 \mathrm{H}), 1.33(\mathrm{~s}, 9 \mathrm{H}), 1.03-0.99(\mathrm{~m}, 3 \mathrm{H}) .{ }^{13} \mathrm{C}$ NMR $\left(50 \mathrm{MHz}, \mathrm{CDCl}_{3}\right) \delta 173.54,172.15,161.25,160.35,136.25,135.98,134.58$, $129.36,128.76,127.25,66.60,58.51,55.55,54.30,38.70,31.98,30.51$, 18.92. ESIMS (+) Calc. for $\left[\mathrm{C}_{22} \mathrm{H}_{31} \mathrm{~N}_{5} \mathrm{O}_{4}\right]$ 429.51, found: $452.4[\mathrm{M}+\mathrm{Na}]^{+}$. 
$N-((S)-1-(((2 S, 3 R)-1-A m i n o-3-h y d r o x y-1-o x o b u t a n-2-y l) a m i n o)-4-m e t h y l-1-$ oxopentan-2-yl)-3-(tert-butyl)-1-methyl-1H-pyrazole-5-carboxamide(80)<smiles>CC(C)C[C@H](NC(=O)c1cc(C(C)(C)C)nn1C)C(=O)N[C@@H](C(N)=O)C(C)O</smiles>

Yield $90 \%$. Colorless wax. $R_{f}=0.2$ (ethyl acetate). ${ }^{1} \mathrm{H} \mathrm{NMR}\left(200 \mathrm{MHz}, \mathrm{CDCl}_{3}\right) \delta 7.37$ (d, $J=3.9 \mathrm{~Hz}, 1 \mathrm{H}), 6.74-6.71(\mathrm{~m}, 2 \mathrm{H}), 6.42(\mathrm{~s}, 1 \mathrm{H}), 4.71-4.68(\mathrm{~m}, 1 \mathrm{H}), 4.42-4.38$ (m, 2H), $4.06(\mathrm{~s}, 3 \mathrm{H}), 1.71-1.68(\mathrm{~m}, 3 \mathrm{H}), 1.27(\mathrm{~s}, 9 \mathrm{H}), 1.14-1.11(\mathrm{~m}, 3 \mathrm{H}), 0.98-$ $0.92(\mathrm{~m}, 6 \mathrm{H})$. ESI-MS (+) Calc. for $\left[\mathrm{C}_{19} \mathrm{H}_{33} \mathrm{~N}_{5} \mathrm{O}_{4}\right] 395.51$, found: $418.5[\mathrm{M}+\mathrm{Na}]^{+}$.

$\mathrm{N}-((S)-1-(((2 R, 3 S)-1-$ Amino-3-hydroxy-1-oxobutan-2-yl)amino)-4-methyl-1oxopentan-2-yl)-3-(tert-butyl)-1-methyl-1H-pyrazole-5-carboxamide (81)<smiles>CC(C)C[C@H](NC(=O)c1cc(C(C)(C)C)nn1C)C(=O)N[C@@H](C(N)=O)C(C)O</smiles>

Yield 93\%. Colorless wax. $R_{f}=0.2$ (ethyl acetate). ${ }^{1} \mathrm{H} \mathrm{NMR}\left(200 \mathrm{MHz}, \mathrm{CDCl}_{3}\right) \delta 7.34$ (d, $J=3.9 \mathrm{~Hz}, 1 \mathrm{H}), 6.79-6.75(\mathrm{~m}, 2 \mathrm{H}), 6.46(\mathrm{~s}, 1 \mathrm{H}), 4.73-4.70(\mathrm{~m}, 1 \mathrm{H}), 4.45-4.41$ $(\mathrm{m}, 2 \mathrm{H}), 4.11(\mathrm{~s}, 3 \mathrm{H}), 1.77-1.74(\mathrm{~m}, 3 \mathrm{H}), 1.28(\mathrm{~s}, 9 \mathrm{H}), 1.19-1.17(\mathrm{~m}, 3 \mathrm{H}), 0.99-$ $0.91(\mathrm{~m}, 6 \mathrm{H})$. ESI-MS (+) Calc. for $\left[\mathrm{C}_{19} \mathrm{H}_{33} \mathrm{~N}_{5} \mathrm{O}_{4}\right] 395.51$, found: $418.5[\mathrm{M}+\mathrm{Na}]^{+}$.

Compounds $82-85$ have been synthesized by dehydration of the corresponding primary amide precursor $\mathbf{7 8} \mathbf{- 8 1}$ with trifluoroacetic anhydride (general procedure for dehydration of primary amide to nitrile, method B). 
3-(tert-Butyl)-N-((S)-1-(((1R,2R)-1-cyano-2-hydroxypropyl)amino)-1-oxo-3phenylpropan-2-yl)-1-methyl-1H-pyrazole-5-carboxamide (82)<smiles>C[C@@H](O)[C@H](C#N)NC(=O)[C@H](Cc1ccccc1)NC(=O)c1cc(C(C)(C)C)nn1C</smiles>

Yield $45 \%$. White solid. $R_{f}=0.7$ (ethyl acetate). Mp. $159-160{ }^{\circ} \mathrm{C} .{ }^{1} \mathrm{H}$ NMR $(500 \mathrm{MHz}$, $\left.\mathrm{CDCl}_{3}\right) \delta 7.32-7.26(\mathrm{~m}, 4 \mathrm{H}), 7.26-7.21(\mathrm{~m}, 1 \mathrm{H}), 6.65(\mathrm{~s}, 1 \mathrm{H}), 4.84-4.79(\mathrm{~m}, 2 \mathrm{H})$, $3.96(\mathrm{~s}, 3 \mathrm{H}), 3.88-3.84(\mathrm{~m}, 1 \mathrm{H}), 3.20(\mathrm{dd}, J=13.6,7.1 \mathrm{~Hz}, 1 \mathrm{H}), 3.10(\mathrm{dd}, J=13.6$, $7.1 \mathrm{~Hz}, 1 \mathrm{H}), 1.31$ (s, 9H), 1.07 (d, $J=6.3 \mathrm{~Hz}, 3 \mathrm{H}) .{ }^{13} \mathrm{C}$ NMR (125 MHz, $\left.\mathrm{CDCl}_{3}\right) \delta 173.35$, 162.06, 161.60, 138.15, 136.69, 130.42, 129.57, 127.98, 118.24, 105.04, 67.67, 56.05, 38.86, 38.68, 32.90, 30.87, 18.89, 18.55. FT-IR (KBr, $\left.\mathrm{cm}^{-1}\right)$ 3293.08, 2953.92, 2913.05, 2868.10, 1646.10, 1540.07, 1446.08, 1286.72, 1237.68, 1098.75, 922.51, 739.16, 689.30, 469.47. HRMS (+) Calc. for $\left[\mathrm{C}_{22} \mathrm{H}_{30} \mathrm{~N}_{5} \mathrm{O}_{3}\right]^{+} 412.23486$, found: 412.23811 $[\mathrm{M}+\mathrm{H}]^{+}$. HPLC (protocol B): $\mathrm{t}_{\mathrm{R}}(\min )=7.65$. Purity $97.8 \%$.

3-(tert-Butyl)-N-((S)-1-(((1S,2S)-1-cyano-2-hydroxypropyl)amino)-1-oxo-3phenylpropan-2-yl)-1-methyl-1H-pyrazole-5-carboxamide (83)<smiles>C[C@H](O)[C@@H](C#N)NC(=O)[C@H](Cc1ccccc1)NC(=O)c1cc(C(C)(C)C)nn1C</smiles>

Yield $42 \%$. White solid. $R_{f}=0.7$ (ethyl acetate). Mp. $145-147^{\circ} \mathrm{C} .{ }^{1} \mathrm{H}$ NMR $(400 \mathrm{MHz}$, $\left.\mathrm{CDCl}_{3}\right) \delta 7.31-7.23(\mathrm{~m}, 5 \mathrm{H}), 7.07(\mathrm{~d}, J=8.0 \mathrm{~Hz}, 1 \mathrm{H}), 6.67(\mathrm{~d}, J=7.5 \mathrm{~Hz}, 1 \mathrm{H}), 6.31$ $(\mathrm{s}, 1 \mathrm{H}), 4.85-4.84(\mathrm{~m}, 1 \mathrm{H}), 4.72-4.68(\mathrm{~m}, 1 \mathrm{H}), 4.15-4.10(\mathrm{~m}, 1 \mathrm{H}), 4.02(\mathrm{~s}, 3 \mathrm{H})$, $3.21-3.15(\mathrm{~m}, 2 \mathrm{H}), 1.29-1.27(\mathrm{~m}, 9 \mathrm{H}), 1.08(\mathrm{~d}, J=6.2 \mathrm{~Hz}, 3 \mathrm{H}) .{ }^{13} \mathrm{C}$ NMR $(100 \mathrm{MHz}$, $\left.\mathrm{CDCl}_{3}\right) \delta 172.41,171.26,160.58,135.89,134.27,129.38,129.14,127.65,117.25$, 103.52, 67.39, 54.76, 47.02, 39.11, 38.38, 32.09, 30.59, 19.02. FT-IR $\left(\mathrm{KBr}, \mathrm{cm}^{-1}\right)$ 3289.11, 2955.43, 2918.55, 2860.11, 1649.54, 1543.16, 1444.02, 1277.62, 1233.66, 1091.87, 944.77, 745.55, 690.34, 477.11. HRMS (+) Calc. for $\left[\mathrm{C}_{22} \mathrm{H}_{30} \mathrm{~N}_{5} \mathrm{O}_{3}\right]^{+}$ 412.23486, found: $412.23811[\mathrm{M}+\mathrm{H}]^{+}$. HPLC (protocol B): tR $(\min )=7.71$. Purity $95.7 \%$. 
3-(tert-Butyl)-N-((S)-1-((1R,2R)-1-cyano-2-hydroxypropyl)amino)-4-methyl-1oxopentan-2-yl)-1-methyl-1H-pyrazole-5-carboxamide (84)

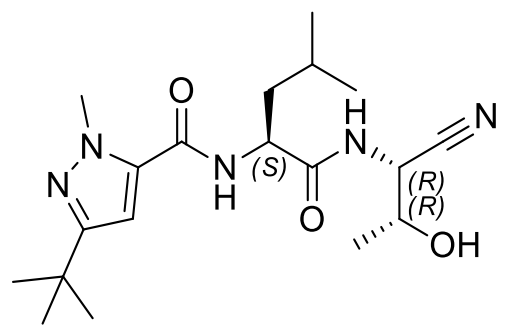

Yield $33 \%$. White solid. $R_{f}=0.5$ (ethyl acetate). Mp. $118-119^{\circ} \mathrm{C} .{ }^{1} \mathrm{H}$ NMR $(400 \mathrm{MHz}$, $\left.\mathrm{CDCl}_{3}\right) \delta 7.56-7.51(\mathrm{~m}, 1 \mathrm{H}), 6.80-6.75(\mathrm{~m}, 1 \mathrm{H}), 6.43(\mathrm{~s}, 1 \mathrm{H}), 4.87-4.83(\mathrm{~m}, 1 \mathrm{H})$, $4.65-4.63(\mathrm{~m}, 1 \mathrm{H}), 4.15-4.11(\mathrm{~m}, 1 \mathrm{H}), 4.06(\mathrm{~s}, 3 \mathrm{H}), 1.31-1.20(\mathrm{~m}, 15 \mathrm{H}), 0.97(2 \mathrm{~d}$, $J=6.2 \mathrm{~Hz}, 3 \mathrm{H}) .{ }^{13} \mathrm{C}$ NMR $\left(100 \mathrm{MHz}, \mathrm{CDCl}_{3}\right) \delta 174.32,161.62,162.14,135.77,117.22$, 104.56, 67.34, 52.68, 41.12, 38.28, 31.46, 32.15, 26.11, 23.56, 21.65, 19.03. FT-IR $\left(\mathrm{KBr}, \mathrm{cm}^{-1}\right)$ 3297.16, 2953.92, 2913.05, 2868.10, 1646.31, 1535.89, 1503.29, 1462.52, 1364.36, 1282.63, 1172.38, 1131.44, 996.59, 730.99, 592.05. HRMS (+) Calc. for $\left[\mathrm{C}_{19} \mathrm{H}_{32} \mathrm{~N}_{5} \mathrm{O}_{3}\right]^{+} 378.25071$, found: $378.25231[\mathrm{M}+\mathrm{H}]^{+}$.HPLC (protocol B): $t_{R}(\min )=8.08$. Purity $96.7 \%$.

3-(tert-Butyl)-N-((S)-1-(((1S,2S)-1-cyano-2-hydroxypropyl)amino)-4-methyl-1oxopentan-2-yl)-1-methyl-1H-pyrazole-5-carboxamide (85)

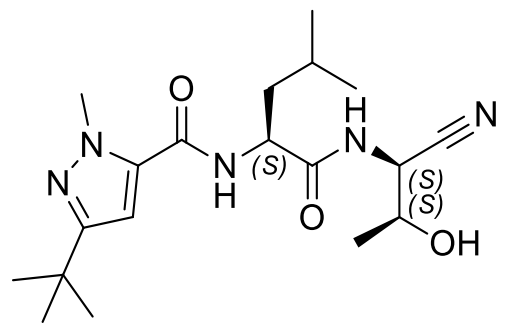

Yield $35 \%$. White solid. $R_{f}=0.5$ (ethyl acetate). Mp. $111-113^{\circ} \mathrm{C} .{ }^{1} \mathrm{H}$ NMR $(400 \mathrm{MHz}$, $\left.\mathrm{CD}_{3} \mathrm{OD}\right) \delta 6.78(\mathrm{~s}, 1 \mathrm{H}), 4.88-4.84(\mathrm{~m}, 1 \mathrm{H}), 4.65-4.60(\mathrm{~m}, 1 \mathrm{H}), 4.07-4.05(\mathrm{~m}, 1 \mathrm{H})$, $4.05(\mathrm{~s}, 3 \mathrm{H}), 1.81-1.61(\mathrm{~m}, 4 \mathrm{H}), 1.32(\mathrm{~s}, 9 \mathrm{H}), 1.26(\mathrm{~d}, J=6.3 \mathrm{~Hz}, 3 \mathrm{H}), 1.00(2 \mathrm{~d}, J=$ $6.3 \mathrm{~Hz}, 6 \mathrm{H}) .{ }^{13} \mathrm{C}$ NMR $\left(100 \mathrm{MHz}, \mathrm{CD}_{3} \mathrm{OD}\right) \delta 175.01,162.46,161.76,136.76,118.59$, 105.26, 68.00, 53.28, 41.76, 39.00, 33.07, 31.04, 26.27, 23.54, 21.94, 19.44. FT-IR $\left(\mathrm{KBr}, \mathrm{cm}^{-1}\right)$ 3293.08, 2962.09, 2917.14, 2847.67, 1646.31, 1540.07, 1458.34, 1278.55, 1131.44, 1078.32, 1000.68, 853.58, 812.71, 780.02, 730.99, 559.36. HRMS (+) Calc. for $\left[\mathrm{C}_{19} \mathrm{H}_{32} \mathrm{~N}_{5} \mathrm{O}_{3}\right]^{+} 378.25071$, found: $378.25231[\mathrm{M}+\mathrm{H}]^{+}$.HPLC (protocol B): tR $(\mathrm{min})=$ 7.94. Purity $98.6 \%$. 
Compound $\mathbf{8 6}$ was synthesized by removal of the benzyl group from compound $\mathbf{7 7}$ with DDQ (general procedure for removal of the benzyl protecting group, method B).

3-(tert-butyl)-N-((S)-3-(3-chlorophenyl)-1-(((1R,2R)-1-cyano-2-hydroxypropyl)amino)1-oxopropan-2-yl)-1-methyl-1H-pyrazole-5-carboxamide (86)<smiles>C[C@H](O)[C@@H](C)NC(=O)[C@H](Cc1cccc(Cl)c1)NC(=O)c1cc(C(C)(C)C)nn1C</smiles>

Yield 32\%. White solid. $R_{f}=0.3$ (ethyl acetate). Mp. $102-103{ }^{\circ} \mathrm{C} .{ }^{1} \mathrm{H}$ NMR $(400 \mathrm{MHz}$, $\left.\mathrm{CD}_{3} \mathrm{OD}\right) \delta 7.35-7.28(\mathrm{~m}, 4 \mathrm{H}), 6.69(\mathrm{~s}, 1 \mathrm{H}), 4.87-4.83(\mathrm{~m}, 2 \mathrm{H}), 3.99(\mathrm{~s}, 3 \mathrm{H}), 3.90-$ $3.84(\mathrm{~m}, 1 \mathrm{H}), 3.24(\mathrm{dd}, J=13.6,7.1 \mathrm{~Hz}, 1 \mathrm{H}), 3.08(\mathrm{dd}, J=13.6,6.5 \mathrm{~Hz}, 1 \mathrm{H}), 1.34(\mathrm{~s}$, $9 \mathrm{H}), 1.11(\mathrm{~d}, J=6.3 \mathrm{~Hz}, 3 \mathrm{H}) .{ }^{13} \mathrm{C} \mathrm{NMR}\left(100 \mathrm{MHz}, \mathrm{CD}_{3} \mathrm{OD}\right) \delta 175.23,163.23,151.94$, $151.48,128.04,126.57,120.30,120.10,119.52,119.45,117.86,108.12,94.92,57.55$, 45.93, 28.74, 28.56, 22.78, 20.75, 18.78. FT-IR $\left(\mathrm{KBr}_{\mathrm{cm}}{ }^{-1}\right) 3284.90,3056.07,2958.00$, 2925.31, 2868.10, 1638.14, 1556.41, 1499.21, 1462.43, 1364.36, 1270.37, 1229.51, 1098.75, 878.09, 730.99, 702.38, 453.12. ESI-MS (+) Calc. for $\left[\mathrm{C}_{22} \mathrm{H}_{29} \mathrm{CIN}_{5} \mathrm{O}_{3}\right]^{+}$ 446.19589, found: $446.19745[\mathrm{M}+\mathrm{H}]^{+}$.HPLC (protocol B): $\mathrm{tR}_{\mathrm{R}}(\mathrm{min})=8.55$. Purity $99.7 \%$.

8.1.14. Synthesis and characterization of compounds presented in chapter IV.

Scheme 11. General synthesis of compounds $87-90$ and $91-98$.

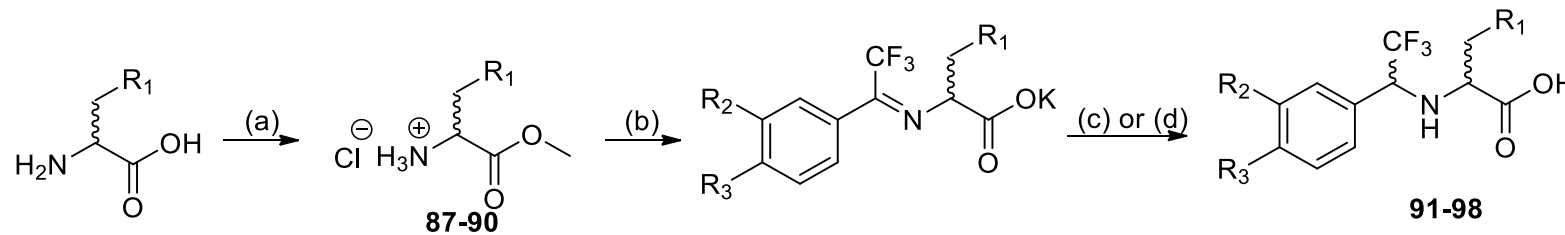

87: $\mathrm{R}_{1}=$ isopropyl

88: $R_{1}=$ phenyl

89: $R_{1}=4$-methoxyphenyl

90: $\mathrm{R}_{1}=1 \mathrm{H}$-indol-3-yl
91: $R_{1}=$ isopropyl, $R_{2}=R_{3}=H$

92: $R_{1}=$ isopropyl, $R_{2}=H, R_{3}=B r$

93: $R_{1}=$ isopropyl, $R_{2}=H, R_{3}=$ phenyl

94: $R_{1}=$ phenyl, $R_{2}=R_{3}=H$
95: $R_{1}=$ phenyl, $R_{2}=H, R_{3}=B r$ 96: $R_{1}=$ phenyl, $R_{2}=C l, R_{3}=H$ 97: $R_{1}=$ 4-methoxyphenyl, $R_{2}=R_{3}=H$ 98: $R_{1}=1 \mathrm{H}$-indol-3-yl, $R_{2}=R_{3}=H$

Reagents and conditions: (a) $\mathrm{SOCl}_{2}, \mathrm{CH}_{3} \mathrm{OH}$, reflux, $1 \mathrm{~h} \rightarrow \mathrm{rt}$, overnight; (b) $\operatorname{ArC}(=\mathrm{O}) \mathrm{CF}_{3}$, $\mathrm{K}_{2} \mathrm{CO}_{3}, \mathrm{CH}_{3} \mathrm{OH}, 50{ }^{\circ} \mathrm{C}, 18 \mathrm{~h}$; (c) $1 \mathrm{M} \mathrm{Zn}\left(\mathrm{BH}_{4}\right)_{2}$ in DME, ACN/CH $\mathrm{CH}_{3} \mathrm{OH}(5: 1),-40 /-45^{\circ} \mathrm{C}, 3 \mathrm{~h}$; (d) $\mathrm{NaBH}_{4}, \mathrm{THF}, \mathrm{rt}, 6$ h. Source: Own author. 
Scheme 12. Synthesis of compound 99.

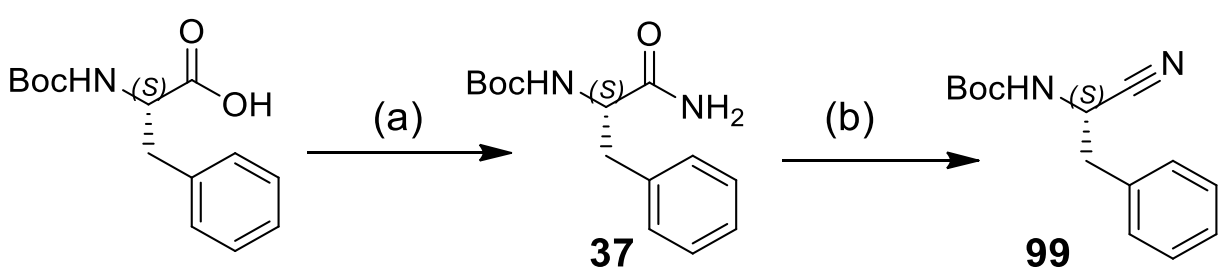

Reagents and conditions: a) Isobutyl chloroformate, $\mathrm{NH}_{4} \mathrm{Cl} 2 \mathrm{M}$, DIPEA, DMF, $0{ }^{\circ} \mathrm{C}$ to rt, $20 \mathrm{~h}$; b) TFA, $\mathrm{CH}_{2} \mathrm{Cl}_{2}, 0^{\circ} \mathrm{C}$ to rt, 2 h. Source: Own author.

Scheme 13. Synthesis of compounds $100-199$.<smiles>[R]CC(NC(C(=O)O)c1ccc([R])c([R])c1)C(F)(F)F</smiles><smiles>N#CC(N)Cc1ccccc1</smiles>

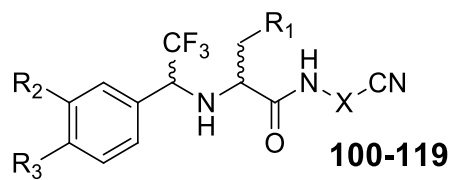

$x=S$

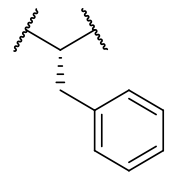

Reagents and conditions: (a) HATU, DIPEA, amine, rt, 22 h. Source: Own author.

Scheme 14. Synthesis of compounds 120 and 121<smiles>[X]NC(=O)C(CC(C)C)NC(C)c1ccc(Br)cc1</smiles>

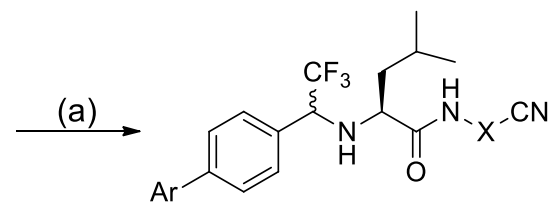<smiles>[Y]CC1(CC)CC1</smiles>

120,121

Reagents and conditions: suitable boronic acid pinacol ester, $\mathrm{PdCl}_{2} \mathrm{dppf}$, DMF, $80{ }^{\circ} \mathrm{C}, 3 \mathrm{~h}$, argon atmosphere. Source: Own author. 
Scheme 15. Synthesis of compounds 123 and 124.

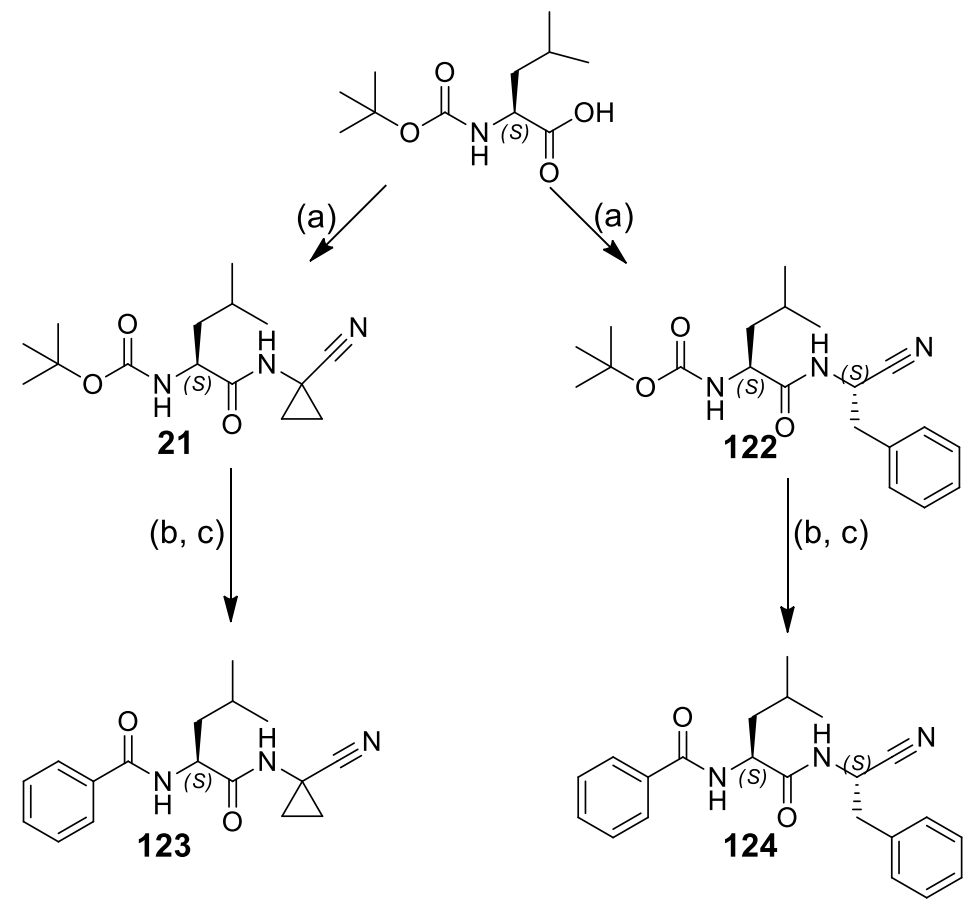

Reagents and conditions: (a) HATU, DIPEA, $\mathrm{NH}_{2} \mathrm{XCN}$, rt, $22 \mathrm{~h}$; (b) formic acid, rt, $18 \mathrm{~h}$; (c) HATU, DIPEA, benzoic acid, rt, 22h. Source: Own author.

Table 10. List of Nequimed codes of compounds described in chapter IV.

\begin{tabular}{|c|c|c|c|c|c|}
\hline \multicolumn{2}{|c|}{ Scheme 13} & \multicolumn{2}{|c|}{ Scheme 14} & \multicolumn{2}{|c|}{ Scheme 15} \\
\hline Number & $\begin{array}{c}\text { Nequimed } \\
\text { Code }\end{array}$ & Number & $\begin{array}{c}\text { Nequimed } \\
\text { Code }\end{array}$ & Number & $\begin{array}{c}\text { Nequimed } \\
\text { Code }\end{array}$ \\
\hline 100 & Neq0672 & 120 & Neq0665 & 123 & Neq0818 \\
\hline 101 & Neq0635 & 121 & Neq0820 & 124 & Neq0819 \\
\hline 102 & Neq0641 & & & & \\
\hline 103 & Neq0642 & & & & \\
\hline 104 & Neq0594 & & & & \\
\hline 105 & Neq0631 & & & & \\
\hline 106 & Neq0636 & & & & \\
\hline 107 & Neq0669 & & & & \\
\hline
\end{tabular}




\begin{tabular}{|c|c|}
\hline Number & $\begin{array}{c}\text { Nequimed } \\
\text { Code }\end{array}$ \\
\hline 108 & Neq0668 \\
\hline 109 & Neq0715 \\
\hline 110 & Neq0716 \\
\hline 111 & Neq0670 \\
\hline 112 & Neq0643 \\
\hline 113 & Neq0658 \\
\hline 114 & Neq0659 \\
\hline 115 & Neq0645 \\
\hline 116 & Neq0671 \\
\hline 117 & Neq0633 \\
\hline 118 & Neq0629 \\
\hline 119 & Neq0630 \\
\hline
\end{tabular}

Neq0587 was donated by AstraZeneca, Mölndal, Sweden

Compounds $\mathbf{8 7}$ - 90 were synthesized by the corresponding enantiomeric pure amino acids with $\mathrm{SOCl}_{2}$ (general method for the synthesis of amino esters).

1-methoxy-4-methyl-1-oxopentan-2-aminium chloride (87)<smiles>COC(=O)[C@H]([18OH])CC(C)C</smiles>

Yield 87\%. White solid. Mp. $149-151^{\circ} \mathrm{C} .{ }^{1} \mathrm{H}$ NMR $\left(400 \mathrm{MHz}, \mathrm{CDCl}_{3}\right) \delta 8.86(\mathrm{~s}, 2 \mathrm{H})$, $3.87(\mathrm{t}, J=7.0 \mathrm{~Hz}, 1 \mathrm{H}), 3.70(\mathrm{~s}, 3 \mathrm{H}), 1.76-1.58(\mathrm{~m}, 3 \mathrm{H}), 0.85(\mathrm{~d}, J=6.4 \mathrm{~Hz}, 6 \mathrm{H})$. ESIMS (+) Calc. for [ $\left.\mathrm{C}_{7} \mathrm{H}_{16} \mathrm{NO}_{2}\right]$ 145.11, found: $146.25[\mathrm{M}+\mathrm{H}]^{+}$(HUGHES et al., 2007).

1-methoxy-1-oxo-3-phenylpropan-2-aminium chloride (88)<smiles>COC(=O)[C@H](N)Cc1ccccc1</smiles> 
Yield $88 \%$. White solid. Mp. $156-160{ }^{\circ} \mathrm{C} .{ }^{1} \mathrm{H}$ NMR $\left(400 \mathrm{MHz}, \mathrm{CDCl}_{3}\right) \delta 8.86(\mathrm{~s}, 2 \mathrm{H})$, $7.36-7.23(\mathrm{~m}, 5 \mathrm{H}), 4.19-1.16(\mathrm{~m}, 1 \mathrm{H}), 3.63(\mathrm{~s}, 3 \mathrm{H}), 3.24(\mathrm{dd}, J=13.9,5.5 \mathrm{~Hz}, 1 \mathrm{H})$, 3,10 (dd, $J=14.2,5.7 \mathrm{~Hz}, 1 \mathrm{H}$ ). ESI-MS (+) Calc. for [ $\left.\mathrm{C}_{10} \mathrm{H}_{13} \mathrm{NO}_{2}\right]$ 179.10, found: 180.05 $[\mathrm{M}+\mathrm{H}]^{+}$(HUGHES et al., 2007).

1-methoxy-3-(4-methoxyphenyl)-1-oxopropan-2-aminium chloride (89)<smiles>COC(=O)[C@H]([18OH])Cc1ccc(OC)cc1</smiles>

Yield 90\%. White solid. Mp. $157-159{ }^{\circ} \mathrm{C} .{ }^{1} \mathrm{H}$ NMR $\left(400 \mathrm{MHz}, \mathrm{CDCl}_{3}\right) \delta 8.66(\mathrm{~s}, 2 \mathrm{H})$, $7.14-7.10(\mathrm{~m}, 2 \mathrm{H}), 6.87-6.83(\mathrm{~m}, 2 \mathrm{H}), 4.19-1.16(\mathrm{~m}, 1 \mathrm{H}), 3.70(\mathrm{~s}, 3 \mathrm{H}), 3.63(\mathrm{~s}$, 3H), 3.10 (dd, $J=13.9,5.5 \mathrm{~Hz}, 1 \mathrm{H}), 3.01$ (dd, $J=14.2,5.7 \mathrm{~Hz}, 1 \mathrm{H})$. ESI-MS (+) Calc. for $\left[\mathrm{C}_{11} \mathrm{H}_{15} \mathrm{NO}_{3}\right] 209.11$, found: $210.1[\mathrm{M}+\mathrm{H}]^{+}$.

3-(1H-indol-3-yl)-1-methoxy-1-oxopropan-2-aminium chloride (90)

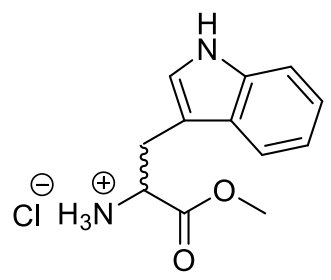

Yield 77\%. White solid. Mp. $157-159{ }^{\circ} \mathrm{C} .{ }^{1} \mathrm{H}$ NMR $\left(400 \mathrm{MHz}, \mathrm{CDCl}_{3}\right) \delta 8.66(\mathrm{~s}, 2 \mathrm{H})$, $7.14-7.10(\mathrm{~m}, 2 \mathrm{H}), 6.87-6.83(\mathrm{~m}, 2 \mathrm{H}), 4.19-1.16(\mathrm{~m}, 1 \mathrm{H}), 3.70(\mathrm{~s}, 3 \mathrm{H}), 3.63(\mathrm{~s}$, $3 \mathrm{H}), 3.10$ (dd, $J=13.9,5.5 \mathrm{~Hz}, 1 \mathrm{H}), 3.01$ (dd, $J=14.2,5.7 \mathrm{~Hz}, 1 \mathrm{H})$. ESI-MS (+) Calc. for $\left[\mathrm{C}_{12} \mathrm{H}_{14} \mathrm{~N}_{2} \mathrm{O}_{2}\right] 218.25$, found: $219.17[\mathrm{M}+\mathrm{H}]^{+}$.

Compounds 91 - 98 were synthesized from the correspoding $\mathbf{8 7 - 9 0}$ in two steps. First, it was formed the imine with the correspoding amino esters (91 - 98) and the selected trifluroacetophenone (general procedure for imine synthesis). The imine was used without further purifcation, and it was reduced to the correspoindg amine 87 - 90 (general procedure for imine reduction to amine). Characterization of compounds 9198 is reported as a mixture of diasteroisomers. NMR data lists peaks for both isomers. 
(2S)-4-methyl-2-((2,2,2-trifluoro-1-phenylethyl)amino)pentanoic acid (91)<smiles>CC(C)C[C@H](N[C@H](c1ccccc1)C(F)(F)F)C(=O)O</smiles>

Yield 32\%. White solid. Mp. $89-94{ }^{\circ} \mathrm{C} .{ }^{1} \mathrm{H}$ NMR $\left(400 \mathrm{MHz}, \mathrm{CDCl}_{3}\right) \delta 7.44-7.31(\mathrm{~m}$, $5 \mathrm{H}), 4.35(\mathrm{q}, J=7.8 \mathrm{~Hz}, 1 \mathrm{H}), 2.80(\mathrm{dd}, J=9.3,4.8 \mathrm{~Hz}, 1 \mathrm{H}), 1.87-1.69(\mathrm{~m}, 1 \mathrm{H}), 1.47$ $-1.40(\mathrm{~m}, 1 \mathrm{H}), 1.32-1.25(\mathrm{~m}, 1 \mathrm{H}), 0.79(\mathrm{~d}, J=6.7 \mathrm{~Hz}, 3 \mathrm{H}), 0.64(\mathrm{~d}, J=6.6 \mathrm{~Hz}, 3 \mathrm{H})$. ${ }^{13} \mathrm{C} \mathrm{NMR}\left(100 \mathrm{MHz}, \mathrm{CDCl}_{3}\right) \delta$ 176.0, 133.9, 129.6, 129.5, 128.9, 127.2, 124.4, 62.4, 62.1, 61.9, 56.2, 42.4, 24.5, 23.3, 21.9. ESI-MS (+) Calc. for $\left[\mathrm{C}_{17} \mathrm{H}_{18} \mathrm{~F}_{3} \mathrm{NO}_{2}\right]$ 289.29, found: $290.33[\mathrm{M}+\mathrm{H}]^{+}$.

(2S)-2-((1-(4-bromophenyl)-2,2,2-trifluoroethyl)amino)-4-methylpentanoic acid (92)<smiles>CC(C)C[C@H](N[C@H](C(=O)O)C(F)(F)F)c1ccc(Br)cc1</smiles>

$61 \%$ Yield 61\%. White solid. Mp. 85 - $90{ }^{\circ} \mathrm{C} .{ }^{1} \mathrm{H}$ NMR $\left(400 \mathrm{MHz}, \mathrm{CDCl}_{3}\right) \delta 7.67-$ $7.58(\mathrm{~m}, 1 \mathrm{H}), 7.44-7.40(\mathrm{~m}, 2 \mathrm{H}), 4.43(\mathrm{q}, J=7.6 \mathrm{~Hz}, 1 \mathrm{H}), 4.11-3.99(\mathrm{~m}, 2 \mathrm{H}), 2.82$ $(\mathrm{dd}, J=9.2,4.2 \mathrm{~Hz}, 1 \mathrm{H}), 1.86-1.71(\mathrm{~m}, 1 \mathrm{H}), 1.67-1.56(\mathrm{~m}, 2 \mathrm{H}), 1.49-1.43(\mathrm{~m}$, $1 \mathrm{H}), 1.36-1.29(\mathrm{~m}, 1 \mathrm{H}), 0.82(\mathrm{~d}, J=6.7 \mathrm{~Hz}, 3 \mathrm{H}), 0.68(\mathrm{~d}, J=6.6 \mathrm{~Hz}, 3 \mathrm{H}) .{ }^{13} \mathrm{C} \mathrm{NMR}$ $\left(100 \mathrm{MHz}_{\mathrm{CDCl}}\right) \delta$ $176.4,175.9,170.8,133.6,131.9,131.7,131.6,131.1,128.8$, 126.6, 124.4, 122.9, 63.8, 62.0, 61.7, 61.5, 61.3, 56.3, 42.3, 25.2, 24.5, 23.3, 21.9, 21.1. ESI-MS (+) Calc. for $\left[\mathrm{C}_{14} \mathrm{H}_{17} \mathrm{BrF}_{3} \mathrm{NO}_{2}\right] 368.19$, found: $369.26[\mathrm{M}+\mathrm{H}]^{+}$. 
(2S)-2-((1-([1,1'-biphenyl]-4-yl)-2,2,2-trifluoroethyl)amino)-4-methyl pentanoic acid (93)<smiles>CC(C)CC(NC(c1ccc(-c2ccccc2)cc1)C(F)(F)F)C(=O)O</smiles>

$56 \%$ Yield 56\%. White solid. Mp. $143-145^{\circ} \mathrm{C} .{ }^{1} \mathrm{H}$ NMR $\left(400 \mathrm{MHz}, \mathrm{CDCl}_{3}\right) \delta 7.72-$ $7.67(\mathrm{~m}, 6 \mathrm{H}), 7.59-7.46(\mathrm{~m}, 6 \mathrm{H}), 7.40-7.36(\mathrm{~m}, 2 \mathrm{H}), 4.48-4.39(\mathrm{~m}, 2 \mathrm{H}), 1,91-$ $1.78(\mathrm{~m}, 2 \mathrm{H}), 1.52-1.34(\mathrm{~m}, 4 \mathrm{H}), 0.90(\mathrm{~d}, J=6.6 \mathrm{~Hz}, 1 \mathrm{H}), 0.89(\mathrm{~d}, J=6.7,1 \mathrm{H}), 0.84$ (d, $J=6.7 \mathrm{~Hz}, 3 \mathrm{H}), 0.70(\mathrm{~d}, J=6.6 \mathrm{~Hz}, 3 \mathrm{H}) .{ }^{13} \mathrm{C} \mathrm{NMR}\left(100 \mathrm{MHz}, \mathrm{CDCl}_{3}\right) \delta 176.5$, 176.0, 141.4, 140.0, 139.9, 133.1, 130.1, 129.5, 129.4, 128.2, 128.1, 127.2, 127.1, 62.0 (m, 2C), 59.0, 56.3, 42.4, 42.3, 24.7, 24.5, 23.4, 23.3, 22.2, 22.0. ESI-MS (+) Calc. for $\left[\mathrm{C}_{20} \mathrm{H}_{22} \mathrm{~F}_{3} \mathrm{NO}_{2}\right] 365.39$, found: $366.16[\mathrm{M}+\mathrm{H}]^{+}$.

(2S)-3-phenyl-2-((2,2,2-trifluoro-1-phenylethyl)amino)propanoic acid (94)<smiles>O=C(O)C(Cc1ccccc1)NC(c1ccccc1)C(F)(F)F</smiles>

Yield 67\%. White solid. Mp. $160-163{ }^{\circ} \mathrm{C} .{ }^{1} \mathrm{H}$ NMR (400 MHz, $\left.\mathrm{CDCl}_{3}\right) \delta 7.41-7.12$ (m, 10H), 4.41 (q, J=7.7 Hz, 1H), $3.09-3.06(\mathrm{~m}, 1 \mathrm{H}), 2.89$ (dd, $J=13.4,5.4 \mathrm{~Hz}$, $1 \mathrm{H}), 2.81(\mathrm{dd}, J=13.4,8.1 \mathrm{~Hz}, 1 \mathrm{H}) .{ }^{13} \mathrm{C} \mathrm{NMR}\left(100 \mathrm{MHz}, \mathrm{CDCl}_{3}\right) \delta 174.8,174.7$, 138.3, 138.2, 133.7, 129.8, 129.4, 129.3, 128.8, 128.4, 126.9, 126.8, 124.6, 122.4, $62.1(\mathrm{q}, \mathrm{J}=27.9 \mathrm{~Hz}), 59.6$, 39.0. ESI-MS (+) Calc. for [ $\left.\mathrm{C}_{17} \mathrm{H}_{16} \mathrm{~F}_{3} \mathrm{NO}_{2}\right] 323.31$, found: $324.26[\mathrm{M}+\mathrm{H}]^{+}$. 
(S)-2-(((R)-1-(4-bromophenyl)-2,2,2-trifluoroethyl)amino)-3-phenyl propanoic acid (95)<smiles>O=C(O)C(Cc1ccccc1)N[C@H](c1ccc(Br)cc1)C(F)(F)F</smiles>

Yield 59\%. White solid. Mp. $98-102{ }^{\circ} \mathrm{C} .{ }^{1} \mathrm{H}$ NMR $\left(400 \mathrm{MHz}, \mathrm{CDCl}_{3}\right) \delta 7.41-7.14$ $(\mathrm{m}, 9 \mathrm{H}), 4.46(\mathrm{q}, \mathrm{J}=7.6 \mathrm{~Hz}, 1 \mathrm{H}), 3.13-3.19(\mathrm{~m}, 1 \mathrm{H}), 2,97-2.91(\mathrm{~m}, 1 \mathrm{H}), 2.86-$ $2.81(\mathrm{~m}, 1 \mathrm{H}) .{ }^{13} \mathrm{C} \mathrm{NMR}\left(100 \mathrm{MHz}, \mathrm{CDCl}_{3}\right) \delta 174.7,138.3,133.7,132.4,131.9,130.8$, 129.8, 129.3, 128.8, 128.4, 126.7, 122.1, 62.15 (q, J = 27.9 Hz), 59.6, 39.1. ESI-MS (+) Calc. for $\left[\mathrm{C}_{17} \mathrm{H}_{15} \mathrm{BrF}_{3} \mathrm{NO}_{2}\right]$ 402.20, found: $403.11[\mathrm{M}+\mathrm{H}]^{+}$.

(2S)-2-((1-(3-chlorophenyl)-2,2,2-trifluoroethyl)amino)-3-phenylpropanoic acid (96)<smiles>O=C(O)[C@H](Cc1ccccc1)N[C@H](c1cccc(Cl)c1)C(F)(F)F</smiles>

Yield 71\%. White solid. Mp. $74-77^{\circ} \mathrm{C} .{ }^{1} \mathrm{H}$ NMR $\left(400 \mathrm{MHz}, \mathrm{CDCl}_{3}\right) \delta 7.38-7.13(\mathrm{~m}$, $8 \mathrm{H}), 7.04(\mathrm{~s}, 1 \mathrm{H}), 6.93(\mathrm{~d}, J=7.7 \mathrm{~Hz}, 1 \mathrm{H}), 4.18(\mathrm{q}, J=7.0 \mathrm{~Hz}, 1 \mathrm{H}), 3.35(\mathrm{~m}, 1 \mathrm{H})$, 3.04 (dd, $J=13.8,7.1 \mathrm{~Hz}, 1 \mathrm{H}), 2.86$ (dd, $J=13.7,9.2 \mathrm{~Hz}, 1 \mathrm{H}) .{ }^{13} \mathrm{C}$ NMR $(100 \mathrm{MHz}$, $\left.\mathrm{CDCl}_{3}\right) \delta 178.5,178.2,136.1,136.0,135.8,134.7,134.7,134.5,130.1,129.9,129.6$, 129.5, 129.3, 129.2, 128.8, 128.7, 127.4, 127.3, 127.0, 126.6, 126.0, 125.6, 123.8, 123.3, 62.3-63.1 (m, 2C), 59.2, 39.2, 39.0. ESI-MS (+) Calc. for $\left[\mathrm{C}_{17} \mathrm{H}_{15} \mathrm{CIF}_{3} \mathrm{NO}_{2}\right]$ 357.08, found: $358.14[\mathrm{M}+\mathrm{H}]^{+}$. 
(S)-3-(4-methoxyphenyl)-2-(((R)-2,2,2-trifluoro-1-phenylethyl)amino) propanoic acid (97)<smiles>COc1ccc(CC(N[C@H](c2ccccc2)C(F)(F)F)C(=O)O)cc1</smiles>

Yield 56\%. White solid. Mp. 157 - $159{ }^{\circ} \mathrm{C} .{ }^{1} \mathrm{H}$ NMR $\left(400 \mathrm{MHz}, \mathrm{CDCl}_{3}\right) \delta 7.39-7.19$ $(\mathrm{m}, 6 \mathrm{H}), 7.03-7.00(\mathrm{~m}, 2 \mathrm{H}), 6.81-6.77(\mathrm{~m}, 2 \mathrm{H}), 4.38$ (q, J = $7.7 \mathrm{~Hz}, 1 \mathrm{H}), 3.69$ (s, 3H), 3.03 (dd, $J=7.5,5.8 \mathrm{~Hz}, 1 \mathrm{H}$ ), 2.81 (dd, $J=13.6,5.6 \mathrm{~Hz}, 1 \mathrm{H}$ ), 2.74 (dd, $J=13.6$, $7.7 \mathrm{~Hz}, 1 \mathrm{H}) .{ }^{13} \mathrm{C}$ NMR $\left(100 \mathrm{MHz}, \mathrm{CDCl}_{3}\right) \delta 174.7,158.3,133.7,130.7,129.9,129.4$, 129.3, 128.8, 127.1, 124.3, 113.9, 62.5, 62.2, 61.9, 61.7, 59.7, 55.4, 38.1. ESI-MS (+) Calc. for $\left[\mathrm{C}_{18} \mathrm{H}_{18} \mathrm{~F}_{3} \mathrm{NO}_{2}\right]$ 353.33, found: $354.41[\mathrm{M}+\mathrm{H}]^{+}$.

(2S)-3-(1H-indol-3-yl)-2-((2,2,2-trifluoro-1-phenylethyl)amino)propanoic acid (98)<smiles>O=C(O)C(Cc1c[nH]c2ccccc12)NC(c1ccccc1)C(F)(F)F</smiles>

Yield 56\%. White solid. Mp. $85-87^{\circ} \mathrm{C} .{ }^{1} \mathrm{H}$ NMR (400 MHz, CD $\left.{ }_{3} \mathrm{OD}\right) \delta 7.30$ (dt, $J=$ 7.8, 1.0, 1H), $7.26(\mathrm{dt}, J=8.0,0.7 \mathrm{~Hz}, 1 \mathrm{H}), 7.15-7.13(\mathrm{~m}, 1 \mathrm{H}), 7.00(\mathrm{~m}, 3 \mathrm{H}), 6.90$ $(\mathrm{d}, J=8.0 \mathrm{~Hz}, 1 \mathrm{H}), 6.82(\mathrm{~m}, 1 \mathrm{H}), 4.18(\mathrm{q}, J=7.6 \mathrm{~Hz}, 1 \mathrm{H}), 3.19(\mathrm{~d}, J=4.9 \mathrm{~Hz}, 1 \mathrm{H})$, $3.12(\mathrm{~m}, 1 \mathrm{H}), 2.91$ (dd, $J=14.2,8.3 \mathrm{~Hz}, 1 \mathrm{H}) .{ }^{13} \mathrm{C}$ NMR (100 MHz, CD $\left.{ }_{3} \mathrm{OD}\right) \delta 175.1$, 136.4, 132.0, 129.1, 128.5, 128.0, 123.2, 122.5, 119.9, 118.5, 112.2, 109.8, 91.7, 63.6, 59.0, 28.8. ESI-MS (+) Calc. for $\left[\mathrm{C}_{19} \mathrm{H}_{17} \mathrm{~F}_{3} \mathrm{~N}_{2} \mathrm{O}_{2}\right] 332.34$, found: $363.44[\mathrm{M}+\mathrm{H}]^{+}$.

Synthesis of compound 99 was performed in two steps. First, it was synthesized compound 34, as described above, and then the primary amide was dehydrated to the desired nitrile (general procedure for dehydration of primary amide to nitrile, 
method B). To confirm the absence of racemization the same synthesis was performed with Boc-D-phenylalanine and then analyzed by HPLC (see appendix B).

(S)-tert-butyl (1-cyano-2-phenylethyl)carbamate (99)<smiles>CC(C)(C)OC(=O)NCc1ccccc1</smiles>

Yield 91\%. White solid. Mp 156 - 160. ${ }^{1} \mathrm{H}$ NMR $\left(500 \mathrm{MHz}, \mathrm{CDCl}_{3}\right) \delta 7.80(\mathrm{~s}, 1 \mathrm{H}) 7.33$ - $7.23(\mathrm{~m}, 5 \mathrm{H}), 4.63(\mathrm{~m}, 1 \mathrm{H}), 3.04-3.09(\mathrm{~m}, 2 \mathrm{H}), 1.35(\mathrm{~s}, 9 \mathrm{H})$. ESI-MS (+) Calc. for [ $\left.\mathrm{C}_{14} \mathrm{H}_{18} \mathrm{~N}_{2} \mathrm{O}_{2}\right]$ 246.14, found: $245.30[\mathrm{M}+\mathrm{H}]^{+}$. HPLC (protocol A, 30:70 ACN: water): $\mathrm{t}_{R}$ $(\min )=55.80$. Purity $>99.9 \%$.

Synthesis of compounds $\mathbf{1 0 0}$ - $\mathbf{1 1 9}$ was performed by coupling the corresponding trifluoroethylamine carboxylic acid (91 -98) with 1-aminocyclopropanecarbonitrile or with (S)-2-amino-3-phenylpropanenitrile (general procedure for amide synthesis, method A). (S)-2-amino-3-phenylpropanenitrile was prepared by removal of Boc protecting group from compound 99 (general procedure for removal of the Boc protecting group, method $\mathrm{A}$ ), and it was used directly for the coupling reaction. The purity for all final compounds is over $95 \%$. When necessary, compounds were purified by HPLC equipped with a chiral column.

(S)-N-(1-cyanocyclopropyl)-4-methyl-2-(((R)-2,2,2-trifluoro-1-phenyl ethyl)amino)pentanamide (100)

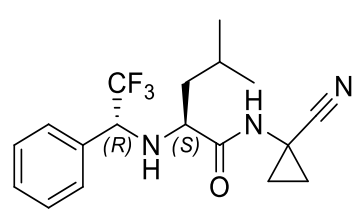

Yield $71 \%$. Colorless oil. $R_{f}=0.5$ (ethyl acetate/ $n$-hexane 70:30). $[\alpha]_{\mathrm{D}}^{24}=-108^{\circ}$ $\left(\mathrm{MeOH}, \mathrm{c}=1.03 \times 10^{-3}\right) .{ }^{1} \mathrm{H} \mathrm{NMR}\left(400 \mathrm{MHz}, \mathrm{CDCl}_{3}\right) \delta 7.66(\mathrm{~s}, 1 \mathrm{H}), 7.45-7.39(\mathrm{~m}$, $3 \mathrm{H}$ ), 7.33-7.31 (m, 2H), $3.80(\mathrm{q}, J=7.37 \mathrm{~Hz}, 1 \mathrm{H}), 3.07$ (dd, $J=9.77,3.64 \mathrm{~Hz}, 1 \mathrm{H}), 1.99$ $(\mathrm{s}, 1 \mathrm{H}), 1.64-1.42(\mathrm{~m}, 5 \mathrm{H}), 1.41-1.35(\mathrm{~m}, 1 \mathrm{H}), 1.24-1.19(\mathrm{~m}, 2 \mathrm{H}), 0.85(\mathrm{~d}, J=6.28$ $\mathrm{Hz}, 3 \mathrm{H}), 0.57$ (d, $J=7.17 \mathrm{~Hz}, 3 \mathrm{H}) .{ }^{13} \mathrm{C} \mathrm{NMR}\left(100 \mathrm{MHz}, \mathrm{CDCl}_{3}\right) \delta 174.8,133.3,129.6$, 
129.1, 128.0, 124.9 (q, $J=230 \mathrm{~Hz}$ ), 119.8, 63.8 (q, $J=30 \mathrm{~Hz}) 59.0,42.6,24.6,23.2$, 23.1, 20.9, 20.1, 16.9, 16.4. FT-IR (KBr, cm$\left.{ }^{-1}\right) 3319,2959,2253,1686,1525,1331$, 1263, 1173, 1107, 887, 704. HRMS (+) Calc. for $\left[\mathrm{C}_{18} \mathrm{H}_{23} \mathrm{~F}_{3} \mathrm{~N}_{3} \mathrm{O}\right]^{+} 354.17877$, found: 354.17926 $[\mathrm{M}+\mathrm{H}]^{+}$. HPLC (protocol A, ACN/ water 50:50): $\mathrm{t}_{\mathrm{R}}(\mathrm{min})=20.85$. After HPLC purification d.e. $=96.0 \%$.

(S)-N-(1-cyanocyclopropyl)-4-methyl-2-(((S)-2,2,2-trifluoro-1-phenyl ethyl)amino)pentanamide (101)

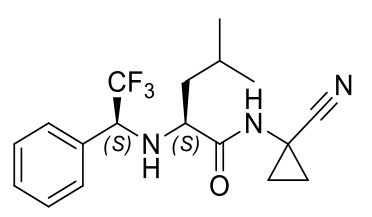

Yield 71\%. White solid. $R_{f}=0.5$ (ethyl acetate/ $n$-hexane 70:30). Mp. $144-146{ }^{\circ} \mathrm{C}$. $[\alpha]_{D^{24}}=+8^{\circ}\left(\mathrm{MeOH}, \mathrm{c}=1.02 \times 10^{-3}\right) .{ }^{1} \mathrm{H}$ NMR $\left(400 \mathrm{MHz}, \mathrm{CDCl}_{3}\right) \delta 7.42-7.37(\mathrm{~m}, 3 \mathrm{H})$, $7.34-7.32$ (m, 2H), 7.15 (s, 1H), 4.03 (q, $J=7.37 \mathrm{~Hz}, 1 \mathrm{H}$ ), 3.35 (dd, $J=8.95,4.75$ $\mathrm{Hz}, 1 \mathrm{H}$ ), 2.12 (s, $1 \mathrm{H}$ ), 1.76 (ddq, $J=13.00,8.74,6.53 \mathrm{~Hz}, 1 \mathrm{H}$ ), 1.60 (ddd, $J=13.70$, $8.81,4.78 \mathrm{~Hz}, 1 \mathrm{H}), 1.49-1.36(\mathrm{~m}, 3 \mathrm{H}), 1.00-0.96(\mathrm{~m}, 1 \mathrm{H}), 0.95(\mathrm{~d}, J=2.50 \mathrm{~Hz}, 3 \mathrm{H})$, $0.94(\mathrm{~d}, J=2.56 \mathrm{~Hz}, 3 \mathrm{H}), 0.83-0.77(\mathrm{~m}, 1 \mathrm{H}) .{ }^{13} \mathrm{C} \mathrm{NMR}\left(100 \mathrm{MHz}, \mathrm{CDCl}_{3}\right) \delta 174.8$, 134.1, 129.5, 129,0, 125.3 (q, $J=220 \mathrm{~Hz}$ ), 119.6, 64.2, 63.8 (q, $J=28.7 \mathrm{~Hz}$ ), 42.6, 24.8, 23.1, 21.7, 19.9, 16.8, 16.2. FT-IR $\left(\mathrm{KBr}, \mathrm{cm}^{-1}\right)$ 3319, 2959, 2253, 1686, 1525, 1331, 1263, 1173, 1107, 887, 704. HRMS (+) Calc. for $\left[\mathrm{C}_{18} \mathrm{H}_{23} \mathrm{~F}_{3} \mathrm{~N}_{3} \mathrm{O}\right]^{+} 354.17877$, found: $354.17926[\mathrm{M}+\mathrm{H}]^{+}$. HPLC (protocol $\mathrm{A}, \mathrm{ACN} /$ water $\left.50: 50\right): \mathrm{t}_{\mathrm{R}}(\mathrm{min})=12.91$. After HPLC purification d.e. $>99.9 \%$ 
(S)-2-(((R)-1-([1,1'-biphenyl]-4-yl)-2,2,2-trifluoroethyl)amino)-N-(1-cyano-cyclopropyl) -4-methylpentanamide (102)

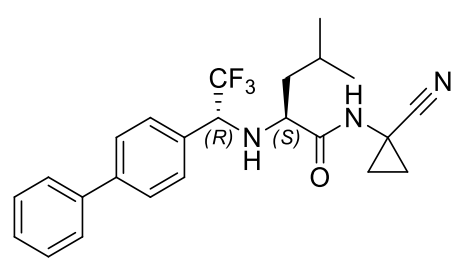

Yield 78\%. White solid. $R_{f}=0.8$ (ethyl acetate/ $n$-hexane 70:30). Mp.149-151 ${ }^{\circ} \mathrm{C}$. $[\alpha]_{D^{24}}=-126^{\circ}\left(\mathrm{MeOH}, \mathrm{c}=1.21 \times 10^{-3}\right) .{ }^{1} \mathrm{H}$ NMR $\left(400 \mathrm{MHz}, \mathrm{CDCl}_{3}\right) \delta 7.63-7.66(\mathrm{~m}$, $3 \mathrm{H}), 7.59-7.61(\mathrm{~m}, 2 \mathrm{H}), 7.45-7.49(\mathrm{~m}, 2 \mathrm{H}), 7.37-7.42(\mathrm{~m}, 3 \mathrm{H}), 3.88(\mathrm{~m}, 1 \mathrm{H}), 3.12$ (dd, J = 9.6, $2.6 \mathrm{~Hz}, 1 \mathrm{H}), 1.50-1.64(\mathrm{~m}, 4 \mathrm{H}), 1.40-1.44(\mathrm{~m}, 1 \mathrm{H}), 1.21-1.32(\mathrm{~m}, 3 \mathrm{H})$, $0.88(\mathrm{~d}, J=5.9 \mathrm{~Hz}, 3 \mathrm{H}), 0.61(\mathrm{~d}, J=6.0 \mathrm{~Hz}, 3 \mathrm{H}) .{ }^{13} \mathrm{C} \mathrm{NMR}\left(100 \mathrm{MHz}, \mathrm{CDCl}_{3}\right) \delta 174.9$, 142.6, 140.0, 132.1, 128.9, 128.5, 127.8, 127.7, 127.1, 125.0 (q, $J=220 \mathrm{~Hz}$ ), 119.8, 63.5 (q, $J=29.3 \mathrm{~Hz}$ ), 59.0, 42.7, 24.7, 23.2, 21.0, 20.1, 16.9, 16.4. HRMS (+) Calc. for $\left[\mathrm{C}_{24} \mathrm{H}_{27} \mathrm{~F}_{3} \mathrm{~N}_{3} \mathrm{O}\right]^{+} 430.21007$, found: $430.21014[\mathrm{M}+\mathrm{H}]^{+}$. HPLC (protocol $\mathrm{A}, \mathrm{ACN} /$ water $55: 45): t_{R}(\min )=17.63$. After HPLC purification d.e. $>99.9 \%$.

(S)-2-(((S)-1-([1, 1'-biphenyl]-4-yl)-2,2,2-trifluoroethyl)amino)-N-(1-cyano-cyclopropyl)4-methylpentanamide (103)

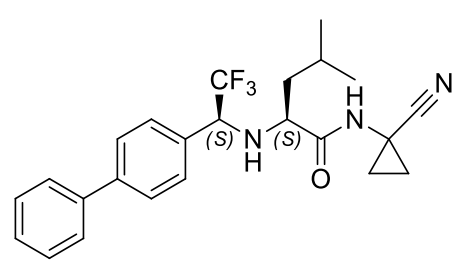

Yield 78\%. White solid. $R_{f}=0.8$ (ethyl acetate/ $n$-hexane 70:30). Mp.200 - $204{ }^{\circ} \mathrm{C}$. $[\alpha]^{24}=+38^{\circ}\left(\mathrm{MeOH}, \mathrm{c}=1.21 \times 10^{-3}\right) .{ }^{1} \mathrm{H} \mathrm{NMR}\left(400 \mathrm{MHz}, \mathrm{CDCl}_{3}\right) \delta 7.64-7.58(\mathrm{~m}, 4 \mathrm{H})$, $7.48-7.37(\mathrm{~m}, 5 \mathrm{H}), 7.20$ (s, $1 \mathrm{H}), 4.11(\mathrm{q}, J=7.3 \mathrm{~Hz}, 1 \mathrm{H}), 3.40$ (dd, $J=8.8,4.8 \mathrm{~Hz}$, $1 \mathrm{H}), 1.75-1.85(\mathrm{~m}, 1 \mathrm{H}), 1.60-1.66(\mathrm{~m}, 1 \mathrm{H}), 1.39-1.53(\mathrm{~m}, 3 \mathrm{H}), 0.99-1.04(\mathrm{~m}$, $1 \mathrm{H}), 0.98(\mathrm{~d}, J=3.2 \mathrm{~Hz}, 3 \mathrm{H}), 0.97(\mathrm{~d}, J=3.3 \mathrm{~Hz}, 3 \mathrm{H}), 0.84-0.92(\mathrm{~m}, 2 \mathrm{H}) .{ }^{13} \mathrm{C} \mathrm{NMR}$ $\left(100 \mathrm{MHz}, \mathrm{CDCl}_{3}\right) \delta 174.8,142.5,140.0,132.9,128.9,128.7,127.8,127.7,127.1$, 123.9, 119.6, 63.5 (q, $J=28.9 \mathrm{~Hz}), 60.0,42.6,24.8,23.0,21.8,19.9,16.8,16.3 .{ }^{19} \mathrm{~F}$ $\operatorname{NMR}\left(376 \mathrm{MHz}, \mathrm{CDCl}_{3}\right) \delta-73.65(\mathrm{~d}, J=7.1 \mathrm{~Hz})$. HRMS (+) Calc. for $\left[\mathrm{C}_{24} \mathrm{H}_{27} \mathrm{~F}_{3} \mathrm{~N}_{3} \mathrm{O}\right]^{+}$ 
430.21007, found: 430.21014 [M+H]+. HPLC (protocol A, ACN/ water 50:50): th (min) $=20.85$. After HPLC purification d.e. $>$ 99.9\%.

(S)-N-(1-cyanocyclopropyl)-3-phenyl-2-(((S)-2,2,2-trifluoro-1-phenylethyl)amino)propanamide (104)

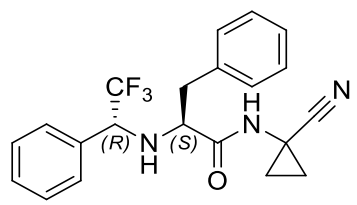

Yield 92\%. Colorless oil. $R_{f}=0.5$ (ethyl acetate/ $n$-hexane $\left.30: 70\right) .[\alpha]_{D}{ }^{24}=-60 \cong(\mathrm{MeOH}$, $\left.C=1.07 \times 10^{-3}\right)$. HRMS (+) Calc. for $\left[\mathrm{C}_{21} \mathrm{H}_{21} \mathrm{~F}_{3} \mathrm{~N}_{3} \mathrm{O}\right]^{+}$388.16312, found: 388.16379 $[\mathrm{M}+\mathrm{H}]^{+}$. HPLC (protocol A, ACN/ water 50:50): tR (min) = 21.11. (BURTOLOSO et al., 2017)

(S)-N-(1-cyanocyclopropyl)-3-phenyl-2-(((S)-2,2,2-trifluoro-1-phenylethyl)amino)propanamide (105)

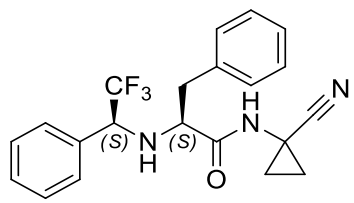

Yield 92\%. White solid. $R_{f}=0.5$ (ethyl acetate/ $n$-hexane $30: 70$ ). Mp. $141-143{ }^{\circ} \mathrm{C}$. $[\alpha]_{D^{24}}=+45^{\circ}\left(\mathrm{MeOH}, \mathrm{c}=1.07 \times 10^{-3}\right) .{ }^{1} \mathrm{H}$ NMR $\left(400 \mathrm{MHz} \mathrm{CDCl}_{3}\right) \delta 7.19-7.43(\mathrm{~m}$, $10 \mathrm{H}), 3.99$ (q, $J=7.19 \mathrm{~Hz}, 1 \mathrm{H}), 3.43(\mathrm{~m}, 1 \mathrm{H}), 3.11$ (dd, $J=13.89,5.43 \mathrm{~Hz}, 1 \mathrm{H}), 3.06$ (dd, $J=13.89,6.83 \mathrm{~Hz}, 1 \mathrm{H}), 2.03(\mathrm{~s}, 1 \mathrm{H}), 1.42-1.51(\mathrm{~m}, 2 \mathrm{H}), 1.00-1.04(\mathrm{~m}, 1 \mathrm{H})$, $0.86-0.92(\mathrm{~m}, 1 \mathrm{H}) .{ }^{13} \mathrm{C}$ NMR $\left(100 \mathrm{MHz}, \mathrm{CDCl}_{3}\right) \delta$ 173.4135.8, 133.1, 129.6, 129.3, 129.1, 129.0, 128.6, 127.5, 124.9 (q, $J=220 \mathrm{~Hz}$ ), 119.5, 63.5 (q, J = $30 \mathrm{~Hz}$ ), 60.8, 37.9, 19.9, 16.7, 16.4. FT-IR (KBr, $\left.\mathrm{cm}^{-1}\right): 3329,3246,3032,2237,1649,1539,1499$, 1456, 1263, 1171, 1126, 850, 742, $567 \mathrm{~cm}^{-1}$. HRMS (+) Calc. for $\left[\mathrm{C}_{21} \mathrm{H}_{21} \mathrm{~F}_{3} \mathrm{~N}_{3} \mathrm{O}\right]^{+}$ 388.16312, found: $388.16379[\mathrm{M}+\mathrm{H}]^{+}$. HPLC (protocol A, ACN/ water 50:50): tR (min) = 17.57. After HPLC purification d.e. > 99.9\%. 
(S)-2-(((R)-1-(4-bromophenyl)-2,2,2-trifluoroethyl)amino)-N-(1-cyanocyclo propyl)-3phenylpropanamide (106)

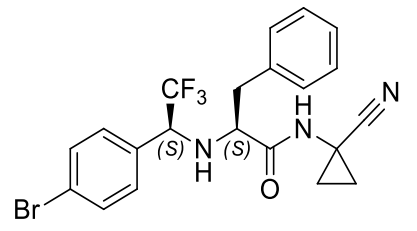

Yield $78 \%$. White solid. $R_{f}=0.3$ (ethyl acetate/ $n$-hexane 30:70). Mp $130-133^{\circ} \mathrm{C}$. $[\alpha]^{24}=-51^{\circ}\left(\mathrm{MeOH}, \mathrm{c}=1.21 \times 10^{-3}\right) .{ }^{1} \mathrm{H}$ NMR $\left(400 \mathrm{MHz}, \mathrm{CDCl}_{3}\right) \delta 7.50-7.54(\mathrm{~m}, 2 \mathrm{H})$, $7.29-7.38(\mathrm{~m}, 3 \mathrm{H}), 7.12-7.19(\mathrm{~m}, 5 \mathrm{H}), 3.97(\mathrm{~m}, 1 \mathrm{H}), 3.39(\mathrm{q}, J=6.24 \mathrm{~Hz}, 1 \mathrm{H}), 3.08$ (dd, $J=3.6,1.9 \mathrm{~Hz}, 1 \mathrm{H}), 3.05(\mathrm{dd}, J=11.8,4.6 \mathrm{~Hz}, 1 \mathrm{H}), 2.19(\mathrm{~s}, 1 \mathrm{H}), 1.45-1.52(\mathrm{~m}$, $2 \mathrm{H}), 0.92-1.06(\mathrm{~m}, 2 \mathrm{H}) .{ }^{13} \mathrm{C} N M R\left(100 \mathrm{MHz}, \mathrm{CDCl}_{3}\right) \delta$ 173.2, 135.7, 132.2, 132.0, 130.2, 129.2, 129.1, 127.5, 124.6 (q, $J=230 \mathrm{~Hz}), 123.5,119.4,62.82$ (q, J=29.0 Hz), 60.7, 38.0, 20.0, 16.7, 16.5. FT-IR (KBr, cm$\left.{ }^{-1}\right): 3339,3028,2243,1686,1491,1263$, 1170, 1124, 1010, 814, 727, 702 HRMS (+) Calc. for $\left[\mathrm{C}_{21} \mathrm{H}_{19} \mathrm{BrF}_{3} \mathrm{~N}_{3} \mathrm{O}\right]+466.07364$, found: $466.07471[\mathrm{M}+\mathrm{H}]^{+}$. HPLC (protocol A, ACN/ water 60:40): $t_{R}(\min )=12.55$. After HPLC purification d.e. $>99 \%$.

(S)-2-(((R)-1-(3-chlorophenyl)-2,2,2-trifluoroethyl)amino)-N-(1-cyanocyclo propyl)-3phenylpropanamide (107)

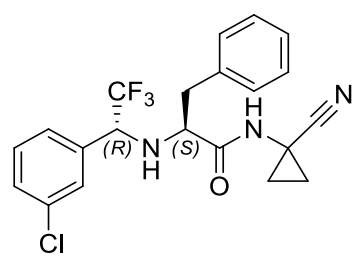

Yield 73\%. Colorless oil. $R_{f}=0.5$ (ethyl acetate/ $n$-hexane 30:70). [ $\left.\alpha\right]_{\mathrm{D}}^{24}=+77^{\circ}(\mathrm{MeOH}$, $\left.\mathrm{C}=1.21 \times 10^{-3}\right) .{ }^{1} \mathrm{H}$ NMR $\left(400 \mathrm{MHz}, \mathrm{CDCl}_{3}\right) \delta 7.66(\mathrm{~s}, 1 \mathrm{H}), 7.25-7.31(\mathrm{~m}, 4 \mathrm{H}), 7.14$ (t, $J=7.9 \mathrm{~Hz}, 1 \mathrm{H}), 7.00-6.97(\mathrm{~m}, 2 \mathrm{H}), 6.78(\mathrm{~s}, 1 \mathrm{H}), 6.70(\mathrm{~d}, J=7.7 \mathrm{~Hz}, 1 \mathrm{H}), 3.72(\mathrm{~s}$, $1 \mathrm{H}), 3.20-3.17(\mathrm{~m}, 2 \mathrm{H}), 2.63(\mathrm{dd}, J=13.5,9.9 \mathrm{~Hz}, 1 \mathrm{H}), 2.08(\mathrm{~s}, 1 \mathrm{H}), 1.55-1.65(\mathrm{~m}$, $2 \mathrm{H}), 1.17-1.32(\mathrm{~m}, 2 \mathrm{H}) .{ }^{13} \mathrm{C} N M R\left(100 \mathrm{MHz}, \mathrm{CDCl}_{3}\right) \delta 173.4,135.5,134.8,134.2$, 130.0, 129.6, 129.1, 128.8, 127.8, 127.7, 126.2, 125.9, 123.1, 119.6, 63.6, 63.3, 63.0, 62.7, 61.7, 39.2, 20.1, 16.9, 16.4. FT-IR $\left(\mathrm{KBr}, \mathrm{cm}^{-1}\right): 3336,3057,3030,2250,1683$, 1531, 1475, 1354, 1138, 1101, 897, 790, 761, 700, 514. HRMS (+) Calc. for 
$\left[\mathrm{C}_{21} \mathrm{H}_{20} \mathrm{~F}_{3} \mathrm{~N}_{3} \mathrm{ClO}\right]^{+}$422.12415, found: $422.12399[\mathrm{M}+\mathrm{H}]^{+}$. HPLC (protocol A, ACN/ water 50:50): $t_{R}(\min )=25.31$. After HPLC purification d.e. $>99 \%$.

(S)-N-(1-cyanocyclopropyl)-3-phenyl-2-(((S)-2,2,2-trifluoro-1-(4-methoxyphenyl)ethyl)amino)propanamide (108)

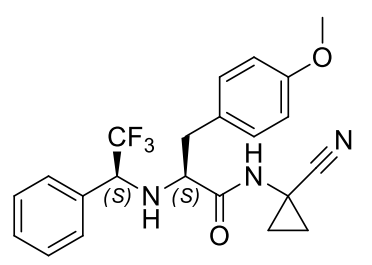

Yield 90\%. Colorless oil. $R_{f}=0.5$ (ethyl acetate/ $n$-hexane 30:70). $[\alpha]_{D}^{24}=+59.35^{\circ}$ $\left(\mathrm{MeOH}, \mathrm{c}=1.23 \times 10^{-3}\right) .{ }^{1} \mathrm{H}$ NMR $\left(400 \mathrm{MHz} \mathrm{CDCl}_{3}\right) \delta 7.42-7.36(\mathrm{~m}, 3 \mathrm{H}), 7.28-7.27$ $(\mathrm{m}, 3 \mathrm{H}), 7.13-7.10(\mathrm{~m}, 2 \mathrm{H}), 6.91-6.88(\mathrm{~m}, 2 \mathrm{H}), 4.02(\mathrm{q}, J=7.2 \mathrm{~Hz}, 1 \mathrm{H}), 3.04(\mathrm{dd}, J$ $=12.4,4.6 \mathrm{~Hz}, 1 \mathrm{H}), 3.00(\mathrm{dd}, J=12.4,4.1 \mathrm{~Hz}, 1 \mathrm{H}), 2.19(\mathrm{~s}, 1 \mathrm{H}), 1.40-1.50(\mathrm{~m}, 2 \mathrm{H})$. ${ }^{13} \mathrm{C} \mathrm{NMR}\left(100 \mathrm{MHz}, \mathrm{CDCl}_{3}\right) \delta 173.6,158.9,133.1,130.3,129.6,129.0,128.6,127.5$, 126.4, 123.6, 119.5, 114.4, 63.31 (q, J=28.8 Hz), 55.3, 36.9, 19.9, 16.7, 16.4. FT-IR $\left(\mathrm{KBr}, \mathrm{cm}^{-1}\right): 3273,3038,2237,1672,1610,1533,1512,1265,1145,1039,873,794$, 561. HRMS (+) Calc. for $\left[\mathrm{C}_{22} \mathrm{H}_{23} \mathrm{~F}_{3} \mathrm{~N}_{3} \mathrm{O}_{2}\right]^{+}$418.17369, found: 418.17435 [M+H] $]^{+}$. HPLC (protocol A, ACN/ water 50:50): $t_{R}(\min )=18.9$. After HPLC purification d.e. $>99 \%$.

(S)-N-(1-cyanocyclopropyl)-3-(1H-indol-3-yl)-2-(((R)-2,2,2-trifluoro-1phenylethyl)amino)propanamide (109)

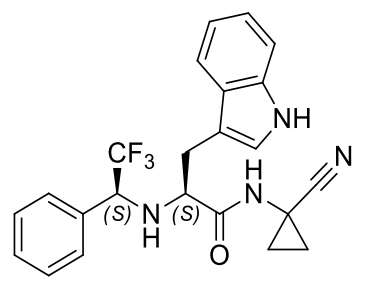

Yield 82\%. Colorless oil. $R_{f}=0.5$ (ethyl acetate/ $n$-hexane 50:50). ${ }^{1} \mathrm{H}$ NMR $(400 \mathrm{MHz}$, $\left.\mathrm{CDCl}_{3}\right) \delta 8.20(\mathrm{~s}, 1 \mathrm{H}), 7.63(\mathrm{~s}, 1 \mathrm{H}), 7.30-7.25(\mathrm{~m}, 2 \mathrm{H}), 7.11(\mathrm{~m}, 2 \mathrm{H}), 6.99-6.90(\mathrm{~m}$, $3 \mathrm{H}), 6.85(\mathrm{~d}, J=2.0 \mathrm{~Hz}, 1 \mathrm{H}), 6.68(\mathrm{~d}, J=7.2 \mathrm{~Hz}, 1 \mathrm{H}), 3.69$ (q, J = 7.6 Hz, 1H), 3.30 
(dd, $J=9.2,4.4 \mathrm{~Hz}, 1 \mathrm{H}$ ), 3.20 (dd, $J=14.4,4.4 \mathrm{~Hz}, 1 \mathrm{H}$ ), 2.87 (dd, $J=14.4,9.2 \mathrm{~Hz}$, 1H), 1.78 (br s, $1 \mathrm{H}), 1.50-1.49(\mathrm{~m}, 2 \mathrm{H}) .{ }^{13} \mathrm{C} \mathrm{NMR}\left(100 \mathrm{MHz}, \mathrm{CDCl}_{3}\right) \delta 174.7,136.5$, 132.5, 129.2, 128.6, 127.9, 127.1, 127.1, 125.0 (q, $J=279.1 \mathrm{~Hz}$ ), 123.5, 122.5, 119.9, $119.9,118.4,111.5,109.7,63.9(J=28.9 \mathrm{~Hz}), 61.0,29.3,17.0,16.5$. HRMS (+) Calc. for [ $\left.\mathrm{C}_{23} \mathrm{H}_{21} \mathrm{~F}_{3} \mathrm{~N}_{4} \mathrm{O}\right]^{+} 427.1746$, found: $427.1741[\mathrm{M}+\mathrm{H}]^{+}$. HPLC (protocol A, ACN/ water $50: 50): t_{R}(\min )=18.6$. After HPLC purification d.e. $>99 \%$.

(R)-N-(1-cyanocyclopropyl)-3-(1H-indol-3-yl)-2-(((S)-2,2,2-trifluoro-1phenylethyl)amino)propanamide (110)

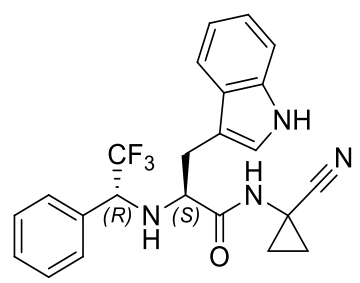

Yield 74\%. Colorless oil. $R_{f}=0.5$ (ethyl acetate/ $n$-hexane 50:50). ${ }^{1} \mathrm{H} \mathrm{NMR}(400 \mathrm{MHz}$, $\left.\mathrm{CDCl}_{3}\right) \delta 8.20(\mathrm{~s}, 1 \mathrm{H}), 7.61(\mathrm{~s}, 1 \mathrm{H}), 7.31-7.26(\mathrm{~m}, 2 \mathrm{H}), 7.12(\mathrm{~m}, 2 \mathrm{H}), 6.95-6.89(\mathrm{~m}$, $3 \mathrm{H}), 6.86(\mathrm{~d}, J=2.0 \mathrm{~Hz}, 1 \mathrm{H}), 6.68(\mathrm{~d}, J=7.2 \mathrm{~Hz}, 1 \mathrm{H}), 3.69(\mathrm{q}, J=7.6 \mathrm{~Hz}, 1 \mathrm{H}), 3.32$ (dd, $J=9.1,4.4 \mathrm{~Hz}, 1 \mathrm{H}$ ), 3.24 (dd, $J=14.3,4.4 \mathrm{~Hz}, 1 \mathrm{H}$ ), 2.88 (dd, $J=14.4,9.2 \mathrm{~Hz}$, $1 \mathrm{H}), 1.80$ (br s, $1 \mathrm{H}), 1.54-1.51(\mathrm{~m}, 2 \mathrm{H}) .{ }^{13} \mathrm{C} \mathrm{NMR}\left(100 \mathrm{MHz}, \mathrm{CDCl}_{3}\right) \delta 174.7,136.4$, 132.5, 129.2, 128.9, 127.2, 127.3, 127.2, 125.0 (q, $J=279.1 \mathrm{~Hz}), 123.5,122.3,119.9$, 119.9, 118.4, 111.2, 109.7, $63.9(\mathrm{~J}=28.9 \mathrm{~Hz}), 61.1,29.2,17.0,16.7$. HRMS (+) Calc. for $\left[\mathrm{C}_{23} \mathrm{H}_{21} \mathrm{~F}_{3} \mathrm{~N}_{4} \mathrm{O}\right]^{+} 427.1746$, found: $427.1741[\mathrm{M}+\mathrm{H}]^{+}$. HPLC (protocol A, ACN/ water 50:50): $\mathrm{t}_{\mathrm{R}}(\mathrm{min})=16.73$. After HPLC purification d.e. $>99 \%$.

(S)-N-((S)-1-cyano-2-phenylethyl)-4-methyl-2-(((R)-2,2,2-trifluoro-1-phenylethyl)amino)pentanamide (111)

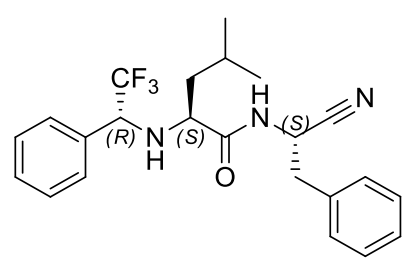

Yield 76\%. Colorless oil. $R_{f}=0.7$ (ethyl acetate/ $n$-hexane 30:70). Mp. $152-154{ }^{\circ} \mathrm{C}$. $[\alpha]_{D^{24}}=-115^{\circ}\left(\mathrm{MeOH}, \mathrm{c}=1.21 \times 10^{-3}\right) .{ }^{1} \mathrm{H}$ NMR $\left(400 \mathrm{MHz}, \mathrm{CDCl}_{3}\right) \delta 7.52(\mathrm{~d}, J=8.8$ 
$\mathrm{Hz}, 1 \mathrm{H}), 7.26-7.41(\mathrm{~m}, 10 \mathrm{H}), 5.12(\mathrm{dt}, J=8.8,7.0 \mathrm{~Hz}, 1 \mathrm{H}), 3.74-3.77(\mathrm{~m}, 1 \mathrm{H}), 3.15$ (d, $J=7.0 \mathrm{~Hz}, 2 \mathrm{H}$ ), $3.02(\mathrm{dd}, J=9.8,3.9 \mathrm{~Hz}, 1 \mathrm{H}), 1.93(\mathrm{~d}, J=9.1 \mathrm{~Hz}, 1 \mathrm{H}), 1.32-1.44$ (m, 2H), $1.19-1.25(\mathrm{~m}, 1 \mathrm{H}), 0.80(\mathrm{~d}, J=6.4 \mathrm{~Hz}, 3 \mathrm{H}), 0.49(\mathrm{~d}, J=6.3 \mathrm{~Hz}, 3 \mathrm{H}) .{ }^{13} \mathrm{C}$ NMR $\left(100 \mathrm{MHz}, \mathrm{CDCl}_{3}\right) \delta 173.4,133.8,133.3,129.5,129.3,129.0,129.0,128.0$, 127.9, 123.4, 117.9, 63.5 (q, $J=29.2 \mathrm{~Hz}$ ), 58.4, 42.7, 41.1, 38.9, 24.6, 23.1, 20.8. FTIR $\left(\mathrm{KBr}, \mathrm{cm}^{-1}\right): 3331,3360,2966,2934,2245,1672,1516,1497,1267,1107,887$, 698. HRMS (+) Calc. for $\left[\mathrm{C}_{23} \mathrm{H}_{27} \mathrm{~F}_{3} \mathrm{~N}_{3} \mathrm{O}\right]^{+} 418.17369$, found: 418.17877 [M+H]+. HPLC (protocol $\mathrm{A}, \mathrm{ACN} /$ water $50: 50): \mathrm{tR}_{\mathrm{R}}(\mathrm{min})=14.02$. After HPLC purification d.e. $>99 \%$.

(S)-N-((S)-1-cyano-2-phenylethyl)-4-methyl-2-(((S)-2,2,2-trifluoro-1-phenyl ethy)amino)pentanamide (112)

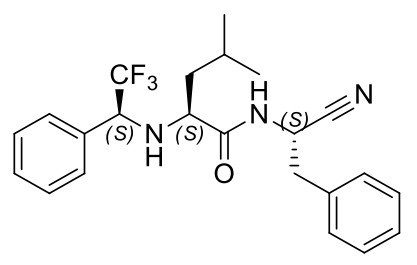

Yield 76\%. White solid. $R_{f}=0.7$ (ethyl acetate/ $n$-hexane 30:70). Mp. $125-129{ }^{\circ} \mathrm{C}$. $[\alpha]_{D^{24}}=-26^{\circ}\left(\mathrm{MeOH}, \mathrm{c}=1.21 \times 10^{-3}\right) .{ }^{1} \mathrm{H} \mathrm{NMR}\left(400 \mathrm{MHz}, \mathrm{CDCl}_{3}\right) \delta 7.39-7.39(\mathrm{~m}, 6 \mathrm{H})$, $7.22-7.19(\mathrm{~m}, 4 \mathrm{H}), 7.11(\mathrm{~d}, J=8.77 \mathrm{~Hz}, 1 \mathrm{H}), 4.90-5.00(\mathrm{~m}, 1 \mathrm{H}), 4.00(\mathrm{q}, J=7.20$ $\mathrm{Hz}, 1 \mathrm{H}$ ), 3,32 (dd, $J=8.87,4.73 \mathrm{~Hz}, 1 \mathrm{H}$ ), 3.00 (dd, $J=11.50,4.37 \mathrm{~Hz}, 1 \mathrm{H}$ ), 2.97 (dd, $J=11.50,4.28 \mathrm{~Hz}, 1 \mathrm{H}$ ), $1.99(\mathrm{~s}, 1 \mathrm{H}), 1.70$ (ddq, $J=13.04,8.79,6.54 \mathrm{~Hz}, 1 \mathrm{H}$ ), 1.51 (ddd, $J=13.75,8.85,4.76 \mathrm{~Hz}, 1 \mathrm{H}$ ), 1.34 (ddd, $J=14.21,8.92,5.58 \mathrm{~Hz}, 1 \mathrm{H}$ ), 0.91 (dd, $J=9.59,6.57 \mathrm{~Hz}, 6 \mathrm{H}) .{ }^{13} \mathrm{C} \mathrm{NMR}\left(100 \mathrm{MHz}, \mathrm{CDCl}_{3}\right) \delta 173.4,133.7,133.5,129.5,129.3$, 129.1, 129.0, 128.3, 128.0, 124.2, 117.7, 63.6 (d, $J=28.6 \mathrm{~Hz}$ ), 59.2, 42.6, 40.8, 38.8, 24.8, 23.0, 21.8. FT-IR (KBr, cm$\left.{ }^{-1}\right)$ 3331, 3360, 2966, 2934, 2245, 1672, 1516, 1497, 1267, 1107, 887, 698. HRMS (+) Calc. for $\left[\mathrm{C}_{23} \mathrm{H}_{27} \mathrm{~F}_{3} \mathrm{~N}_{3} \mathrm{O}\right]^{+} 418.17369$, found: 418.17877 $[\mathrm{M}+\mathrm{H}]^{+}$. HPLC (protocol A, ACN/ water 50:50): $\mathrm{t}_{\mathrm{R}}(\mathrm{min})=13.67$. After HPLC purification d.e. $>99 \%$. 


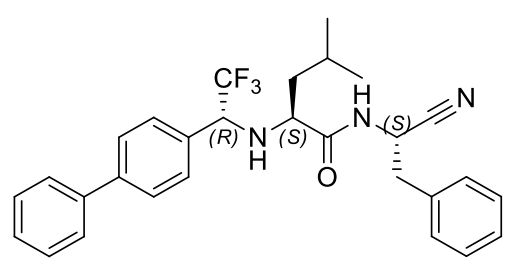

Yield 81\%. White solid. $R_{f}=0.8$ (ethyl acetate/ $n$-hexane 10:90). Mp. $173-176{ }^{\circ} \mathrm{C}$. $[\alpha]_{D^{24}}=-113^{\circ}\left(\mathrm{MeOH}, \mathrm{c}=1.1 \times 10^{-3}\right) .{ }^{1} \mathrm{H} \mathrm{NMR}\left(400 \mathrm{MHz}, \mathrm{CDCl}_{3}\right) \delta 7.57-7.64(\mathrm{~m}, 4 \mathrm{H})$, $7.43-7.48(\mathrm{~m}, 3 \mathrm{H}), 7.27-7.41(\mathrm{~m}, 8 \mathrm{H}), 5.13(\mathrm{dt}, J=8.8,7.0 \mathrm{~Hz}, 1 \mathrm{H}), 3.82(\mathrm{q}, J=7.6$ $\mathrm{Hz}, 1 \mathrm{H}), 3.16(\mathrm{~d}, J=7.0 \mathrm{~Hz}, 2 \mathrm{H}), 3.07$ (dd, $J=9.7,4.0 \mathrm{~Hz}, 1 \mathrm{H}), 1.34-1.50(\mathrm{~m}, 2 \mathrm{H})$, $1.20-1.28(\mathrm{~m}, 1 \mathrm{H}), 0.82(\mathrm{~d}, J=6.3 \mathrm{~Hz}, 3 \mathrm{H}), 0.53(\mathrm{~d}, J=6.3 \mathrm{~Hz}, 3 \mathrm{H}) .{ }^{13} \mathrm{C}$ NMR $(100$ $\left.\mathrm{MHz}_{\mathrm{CDCl}}\right) \delta 173.1,142.5,140.0,133.8,132.1,129.3,129.0,128.9,127.9,127.8$, 127.7, 127.1, 123.4, 117.9, 63.2 (q, $J=63.19 \mathrm{~Hz}), 58.5,42.7,41.0,38.9,24.6,23.1$, 20.9. HRMS (+) Calc. for $\left[\mathrm{C}_{29} \mathrm{H}_{31} \mathrm{~F}_{3} \mathrm{~N}_{3} \mathrm{O}\right]^{+}$494.23895, found: $494.24137[\mathrm{M}+\mathrm{H}]^{+}$. HPLC (protocol A, ACN/ water 60:40): $t_{R}(\min )=24.2$. After HPLC purification d.e. $>99 \%$.

(S)-2-(((S)-1-([1,1'-biphenyl]-4-yl)-2,2,2-trifluoroethyl)amino)-N-((S)-1-cyano phenylethyl)-4-methylpentanamide (114)

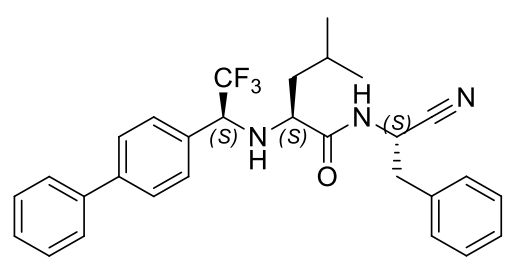

Yield 85\%. White solid. $R_{f}=0.8$ (ethyl acetate/ $n$-hexane 10:90). Mp. $164-166{ }^{\circ} \mathrm{C}$. $[\alpha]_{D^{24}}=-21^{\circ}\left(\mathrm{MeOH}, \mathrm{c}=1.1 \times 10^{-3}\right) .{ }^{1} \mathrm{H}$ NMR $\left(400 \mathrm{MHz}, \mathrm{CDCl}_{3}\right) \delta 7.60-7.57(\mathrm{~m}, 4 \mathrm{H})$, $7.47-7.44(\mathrm{~m}, 2 \mathrm{H}), 7.42-7.29(\mathrm{~m}, 6 \mathrm{H}), 7.23-7.21(\mathrm{~m}, 2 \mathrm{H}), 7.12(\mathrm{~d}, J=8.8 \mathrm{~Hz}, 1 \mathrm{H})$, $5.04(\mathrm{dt}, J=8.9,6.6 \mathrm{~Hz}, 1 \mathrm{H}), 4.07(\mathrm{q}, J=7.2 \mathrm{~Hz}, 1 \mathrm{H}), 3.37(\mathrm{dd}, J=8.9,4.7 \mathrm{~Hz}, 1 \mathrm{H})$, $3.02(\mathrm{~d}, J=6.64 \mathrm{~Hz}, 2 \mathrm{H}), 1.68-1.77(\mathrm{~m}, 2 \mathrm{H}), 1.52-1.57(\mathrm{~m}, 1 \mathrm{H}), 1.35-1.40(\mathrm{~m}$, $1 \mathrm{H}), 0.96(\mathrm{~d}, J=6.5 \mathrm{~Hz}, 3 \mathrm{H}), 0.94(\mathrm{~d}, J=6,6 \mathrm{~Hz}, 3 \mathrm{H}) .{ }^{13} \mathrm{C} \mathrm{NMR}\left(100 \mathrm{MHz}, \mathrm{CDCl}_{3}\right) \delta$ 173.3, 142.4, 140.2, 133.7, 132.3, 129.3, 129.0, 128.9, 128.8, 128.7, 128.0, 127.8, 127.7, 127.2, 124.2, 117.7, 63.4 (q, J=25 Hz), 59.2, 42.6, 40.8, 38.8, 24.9, 23.1, 21.8. FT-IR $\left(\mathrm{KBr}, \mathrm{cm}^{-1}\right)$ 3313, 2954, 1672, 1531, 1494, 1332, 1265, 1174, 736, 700. HRMS 
(+) Calc. for $\left[\mathrm{C}_{29} \mathrm{H}_{31} \mathrm{~F}_{3} \mathrm{~N}_{3} \mathrm{O}\right]^{+} 494.23895$, found: $494.24137[\mathrm{M}+\mathrm{H}]^{+}$. HPLC (protocol A, $\mathrm{ACN} /$ water $60: 40): \mathrm{tR}_{\mathrm{R}}(\mathrm{min})=15.83$. After HPLC purification d.e. $=95 \%$.

(2S)-2-\{[(1R)-1-\{[1,1'-biphenyl]-4-yl\}-2,2,2-trifluoroethyl]amino\}-N-[(1S)-1-cyano-2phenylethyl]-3-phenylpropanamide (115)

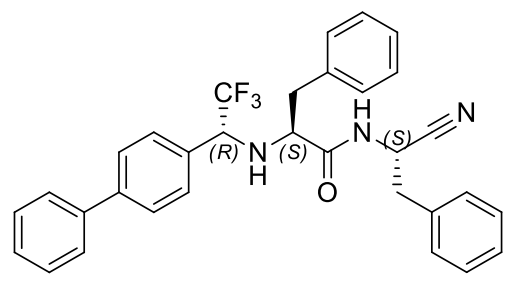

Yield 64\%. Colorless oil. $R_{f}=0.6$ (ethyl acetate/ $n$-hexane 10:90). ${ }^{1} \mathrm{H} \mathrm{NMR}(400 \mathrm{MHz}$, $\left.\mathrm{CDCl}_{3}\right) \delta 7.65(\mathrm{~d}, J=8.5 \mathrm{~Hz}, 1 \mathrm{H}), 7.55-7.53(\mathrm{~m}, 2 \mathrm{H}), 7.47-7.44(\mathrm{~m}, 2 \mathrm{H}), 7.41-7.35$ $(\mathrm{m}, 6 \mathrm{H}), 7.29-7.23(\mathrm{~m}, 5 \mathrm{H}), 6.98(\mathrm{~d}, J=7.0 \mathrm{~Hz}, 2 \mathrm{H}), 6.76(\mathrm{~d}, J=8.0 \mathrm{~Hz}, 2 \mathrm{H}), 5.14$ (q, $J=7.5 \mathrm{~Hz}, 1 \mathrm{H}$ ), $3.73(\mathrm{~d}, J=8.0 \mathrm{~Hz}, 1 \mathrm{H}$ ), $3.24-3.06(\mathrm{~m}, 4 \mathrm{H}), 2.40$ (dd, $J=14.0$, $10.5 \mathrm{~Hz}, 1 \mathrm{H}) .{ }^{13} \mathrm{C} \mathrm{NMR}\left(100 \mathrm{MHz}, \mathrm{CDCl}_{3}\right) \delta 172.1,142.1,140.1,135.8,133.8,129.4$, 129.1, 129.0, 129.0, 128.9, 128.1, 128.0, 127.7, 127.4, 127.4, 127.1, 117.8, 71.6, 64.3, 63.0, 61.1, 41.2, 39.2, 38.9. HRMS (+) Calc. for $\left[\mathrm{C}_{29} \mathrm{H}_{31} \mathrm{~F}_{3} \mathrm{~N}_{3} \mathrm{O}\right]^{+} 494.23895$, found: 494.24137 [M+H] $]^{+}$. HPLC (protocol A, ACN/ water 60:40): tR $(\min )=22.94$. After HPLC purification d.e. $=95 \%$.

(2S)-N-[(1S)-1-cyano-2-phenylethyl]-3-(4-methoxyphenyl)-2-\{[(1R)-2,2,2-trifluoro-1phenylethyl]amino\}propanamide (116)<smiles>COc1ccc(C(NC(=O)NC(C#N)c2ccccc2)C(=O)NCc2ccccc2)cc1</smiles>

Yield 75\%. Colorless oil. $R_{f}=0.6$ (ethyl acetate/ $n$-hexane 30:70). $[\alpha] \mathrm{D}^{24}=-51^{\circ}(\mathrm{MeOH}$, $\left.\mathrm{C}=1.1 \times 10^{-3}\right) .{ }^{1} \mathrm{H} \mathrm{NMR}\left(400 \mathrm{MHz}, \mathrm{CDCl}_{3}\right) \delta 7.63(\mathrm{~d}, J=9.2 \mathrm{~Hz}, 1 \mathrm{H}), 7.42-7.27(\mathrm{~m}$, 
$6 \mathrm{H}), 7.19-7.14(\mathrm{~m}, 2 \mathrm{H}), 6.89-6.86(\mathrm{~m}, 2 \mathrm{H}), 6.80-6.77(\mathrm{~m}, 2 \mathrm{H}), 6.64(\mathrm{~d}, J=7.5 \mathrm{~Hz}$, 2H), 5.30 (ddd, J = 9.1, 8.3, $6.8 \mathrm{~Hz}, 1 \mathrm{H}), 3.81(\mathrm{~s}, 3 \mathrm{H}), 3.41-3.36(\mathrm{~m}, 1 \mathrm{H}), 3.28$ (dd, J $=14.2,6.8 \mathrm{~Hz}, 1 \mathrm{H}), 3.14(\mathrm{dd}, J=14.2,8.2 \mathrm{~Hz}, 1 \mathrm{H}), 3.06-3.10(\mathrm{~m}, 2 \mathrm{H}), 2.58(\mathrm{dd}, J=$ 14.7, $10.9 \mathrm{~Hz}, 1 \mathrm{H}), 2,07$ (d, $J=10.4 \mathrm{~Hz}, 1 \mathrm{H}) .{ }^{13} \mathrm{C} \mathrm{NMR}\left(100 \mathrm{MHz}, \mathrm{CDCl}_{3}\right) \delta 172.1$, 159.0, 133.9, 132.2, 130.0, 129.2, 129.1, 129.0, 128.7, 127.9, 127.8, 127.6, 126.1, 123.3, 118.1, 114.4, 63.5, 63.2, 62.9, 62.6, 61.1, 55.3, 40.6, 39.0, 38.3. FT-IR (KBr, $\mathrm{cm}^{-1}$ ) 3352, 3311, 3030, 2839, 2937, 2360, 2245, 1682, 1612, 1514, 1456, 1252, 1126, 885, 750, 696, 548. HRMS (+) Calc. for $\left[\mathrm{C}_{27} \mathrm{H}_{27} \mathrm{~F}_{3} \mathrm{~N}_{3} \mathrm{O}_{2}\right]^{+} 482.20499$, found: 482.20566 $[\mathrm{M}+\mathrm{H}]^{+}$. HPLC (protocol A, ACN/ water 60:40): $\mathrm{t}_{\mathrm{R}}(\mathrm{min})=28.16$. After HPLC purification d.e. $>99 \%$.

(S)-N-((R)-1-cyano-2-phenylethyl)-3-phenyl-2-(((S)-2,2,2-trifluoro-1-phenyl ethyl)amino)propanamide (117)

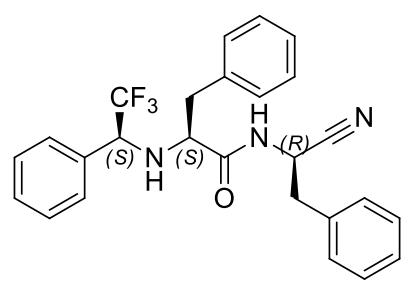

Yield 78\%. White solid. $R_{f}=0.8$ (ethyl acetate/ $n$-hexane $30: 70$ ). Mp. $92-96{ }^{\circ} \mathrm{C} .[\alpha]_{D}{ }^{24}$ $=+75^{\circ}\left(\mathrm{MeOH}, \mathrm{c}=1.4 \times 10^{-3}\right) .{ }^{1} \mathrm{H}$ NMR $\left(400 \mathrm{MHz}, \mathrm{CDCl}_{3}\right) \delta 7.40-7.29(\mathrm{~m}, 10 \mathrm{H}), 7.20$ - $7.12(\mathrm{~m}, 6 \mathrm{H}), 4.98(\mathrm{dt}, J=8.1,7.0 \mathrm{~Hz}, 1 \mathrm{H}), 3.95(\mathrm{~m}, 1 \mathrm{H}), 3.38(\mathrm{dd}, J=12.6,6.8 \mathrm{~Hz}$, $1 \mathrm{H}), 3.11$ (dd, $J=13.9,5.3 \mathrm{~Hz}, 1 \mathrm{H}$ ), 3.06 (dd, $J=13.9,6.7 \mathrm{~Hz}, 1 \mathrm{H}), 2.99$ (dd, $J=12.9$, $6.0 \mathrm{~Hz}, 1 \mathrm{H}), 2.95(\mathrm{dd}, J=12.9,6.0 \mathrm{~Hz}, 1 \mathrm{H}), 2.11$ (dd, $J=7.2,4.7 \mathrm{~Hz}, 1 \mathrm{H}) .{ }^{13} \mathrm{C}$ NMR $\left(100 \mathrm{MHz}, \mathrm{CDCl}_{3}\right) \delta 172.2,135.8,133.7,132.7,129.6,129.3,129.2,129.1,129.1$, 128.9, 128.7, 128.0, 127.5, 126.0, 123.8, 117.8, 63.4, 63.1, 62.9, 62.7, 59.8, 41.3, 38.4, 37.6. FT-IR (KBr, cm$\left.{ }^{-1}\right)$ 3360, 3302, 2966, 2935, 2245, 1672, 1514, 1497, 1373, 1267 , 1167, 1124, 1109, 887, 756, 696. HRMS (+) Calc. for $\left[\mathrm{C}_{26} \mathrm{H}_{25} \mathrm{~F}_{3} \mathrm{~N}_{3} \mathrm{O}\right]^{+} 452.19442$, found: $452.19458[\mathrm{M}+\mathrm{H}]^{+}$. HPLC (protocol $\mathrm{A}, \mathrm{ACN} /$ water $\left.60: 40\right): \mathrm{t}_{\mathrm{R}}(\mathrm{min})=18.10$. After HPLC purification d.e. $>99 \%$. 
(S)-N-((R)-1-cyano-2-phenylethyl)-3-(4-methoxyphenyl)-2-(((R)-2,2,2-trifluoro-1phenylethyl)amino)propanamide (118)<smiles>COc1ccc(C[C@H](NC(=O)Cc2ccccc2)C(=O)N[C@@H](C#N)c2ccccc2)cc1</smiles>

Yield 75\%. Colorless oil. $R_{f}=0.5$ (ethyl acetate/ $n$-hexane $\left.30: 70\right)$. $[\alpha]_{\mathrm{D}}{ }^{24}=-51^{\circ}(\mathrm{MeOH}$, $\left.\mathrm{C}=1.4 \times 10^{-3}\right) .{ }^{1} \mathrm{H}$ NMR $\left(400 \mathrm{MHz}, \mathrm{CDCl}_{3}\right) \delta 7.63(\mathrm{~d}, J=9.2 \mathrm{~Hz}, 1 \mathrm{H}), 7.42-7.27(\mathrm{~m}$, $6 \mathrm{H}), 7.19-7.14(\mathrm{~m}, 2 \mathrm{H}), 6.89-6.86(\mathrm{~m}, 2 \mathrm{H}), 6.80-6.77(\mathrm{~m}, 2 \mathrm{H}), 6.64(\mathrm{~d}, J=7.5 \mathrm{~Hz}$, 2H), 5.30 (ddd, J = 9.1, 8.3, $6.8 \mathrm{~Hz}, 1 \mathrm{H}$ ), 3.81 (s, 3H), $3.41-3.36(\mathrm{~m}, 1 \mathrm{H}), 3.28$ (dd, J $=14.2,6.8 \mathrm{~Hz}, 1 \mathrm{H}), 3.14(\mathrm{dd}, J=14.2,8.2 \mathrm{~Hz}, 1 \mathrm{H}), 3.10-3.06(\mathrm{~m}, 2 \mathrm{H}), 2.58$ (dd, $J=$ 14.7, $10.9 \mathrm{~Hz}, 1 \mathrm{H}), 2.07$ (d, $J=10.4 \mathrm{~Hz}, 1 \mathrm{H}) .{ }^{13} \mathrm{C}$ NMR $\left(100 \mathrm{MHz}, \mathrm{CDCl}_{3}\right) \delta 172.1$, 159.0, 133.9, 132.2, 130.0, 129.2, 129.1, 129.0, 128.7, 127.9, 127.8, 127.6, 126.1, 123.3, 118.1, 114.4, 63.5, 63.2, 62.9, 62.6, 61.1, 55.3, 40.6, 39.0, 38.3. FT-IR (KBr, $\mathrm{cm}^{-1}$ ) 3352, 3311, 3030, 2839, 2937, 2360, 2245, 1682, 1612, 1514, 1456, 1252, 1126 , 885, 750, 696, 548. HRMS (+) Calc. for $\left[\mathrm{C}_{27} \mathrm{H}_{27} \mathrm{~F}_{3} \mathrm{~N}_{3} \mathrm{O}_{2}\right]^{+}$482.20499, found: 482.20566 $[\mathrm{M}+\mathrm{H}]^{+}$. HPLC (protocol A, ACN/ water 60:40): $\mathrm{t}_{\mathrm{R}}(\mathrm{min})=28.17$. After HPLC purification d.e. $>99 \%$.

(S)-N-((R)-1-cyano-2-phenylethyl)-3-(4-methoxyphenyl)-2-(((S)-2,2,2-trifluoro-1phenylethyl)amino)propanamide (119)<smiles>COc1ccc(C[C@H](NC(=O)[C@H](Cc2ccccc2)NC(=O)c2ccccc2)C(F)(F)F)cc1</smiles>

Yield 75\%. Colorless oil. $R_{f}=0.5$ (ethyl acetate/ $n$-hexane $\left.30: 70\right) .[\alpha]_{D}^{24}=+48^{\circ}(\mathrm{MeOH}$, $\left.\mathrm{C}=1.4 \times 10^{-3}\right) .{ }^{1} \mathrm{H}$ NMR $\left(400 \mathrm{MHz}, \mathrm{CDCl}_{3}\right) \delta 7.41-7.31(\mathrm{~m}, 7 \mathrm{H}), 7.21-7.09(\mathrm{~m}, 6 \mathrm{H})$, $6.92-6.89(\mathrm{~m}, 2 \mathrm{H}), 4.98(\mathrm{dd}, J=15.1,7.0 \mathrm{~Hz}, 1 \mathrm{H}), 4.01(\mathrm{q}, J=7.01 \mathrm{~Hz}, 1 \mathrm{H}), 3.81$ (s, $3 \mathrm{H}), 3.35$ (t, $J=5.8 \mathrm{~Hz}, 1 \mathrm{H}), 3.07-2.94(\mathrm{~m}, 4 \mathrm{H}) .{ }^{13} \mathrm{C}$ NMR $\left(100 \mathrm{MHz}, \mathrm{CDCl}_{3}\right) \delta 172.4$, $159.0,133.8,132.8,130.4,129.6$, 129.2, 129.1, 128.9, 128.7, 128.0, 127.5, 126.1, 
123.8, 117.8, 114.5, 63.2 (q, J = 28.7 Hz), 59.8, 55.3, 41.3, 38.4, 36.5. FT-IR $\left(\mathrm{KBr}, \mathrm{cm}^{-}\right.$ 1 ) 3352, 3311, 3030, 2839, 2937, 2360, 2245, 1682, 1612, 1514, 1456, 1252, 1126, 885, 750, 696, 548. HRMS (+) Calc. for $\left[\mathrm{C}_{27} \mathrm{H}_{27} \mathrm{~F}_{3} \mathrm{~N}_{3} \mathrm{O}_{2}\right]+482.20499$, found: 482.20566 $[\mathrm{M}+\mathrm{H}]^{+}$. HPLC (protocol A, ACN/ water 60:40): tR $(\mathrm{min})=19.87$. After HPLC purification d.e. $>99 \%$.

Compounds 120 and 121 were synthesized by a Suzuki cross-coupling reaction of the aryl bromide intermediates (general procedure for Suzuki cross-coupling reaction)

(S)-N-(1-cyanocyclopropyl)-4-methyl-2-(((R)-2,2,2-trifluoro-1-(4'-fluoro-[1,1'-biphenyl]4-yl)ethyl)amino)pentanamide (120)

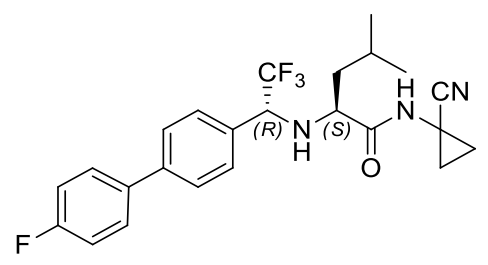

Yield $81 \%$. White solid. $R_{f}=0.7$ (ethyl acetate/ $n$-hexane $30: 70$ ). Mp $145-147{ }^{\circ} \mathrm{C}$. $[\alpha]_{\mathrm{D}^{2}}=-119^{\circ}\left(\mathrm{MeOH}, \mathrm{c}=1.4 \times 10^{-3}\right) .{ }^{1} \mathrm{H}$ NMR $\left(400 \mathrm{MHz}, \mathrm{CDCl}_{3}\right) \delta 7.64(\mathrm{~s}, 1 \mathrm{H}), 7.60$ $-7.53(\mathrm{~m}, 4 \mathrm{H}), 7.41-7.38(\mathrm{~m}, 2 \mathrm{H}), 7.17-7.13(\mathrm{~m}, 2 \mathrm{H}), 3.88(\mathrm{q}, J=7.5 \mathrm{~Hz}, 1 \mathrm{H}), 3.10$ $(\mathrm{dd}, J=9.6,3.5 \mathrm{~Hz}, 1 \mathrm{H}), 2.02(\mathrm{~d}, J=7.6 \mathrm{~Hz}, 1 \mathrm{H}), 1.64-1.48(\mathrm{~m}, 4 \mathrm{H}), 1.47-1.41(\mathrm{~m}$, $1 \mathrm{H}), 1.32-1.20(\mathrm{~m}, 2 \mathrm{H}), 0.87(\mathrm{~d}, J=6.2 \mathrm{~Hz}, 3 \mathrm{H}), 0.61(\mathrm{~d}, J=6.0 \mathrm{~Hz}, 3 \mathrm{H}) .{ }^{13} \mathrm{C}$ NMR $\left(100 \mathrm{MHz}, \mathrm{CDCl}_{3}\right) \delta 174.8,164.0,161.5,141.5,136.1,136.1,132.2,128.7,128.6$, 128.6, 127.6, 126.3, 123.5, 119.8, 115.9, 115.7, 63.5 (q, $J=29.3 \mathrm{~Hz}$ ), 59.0, 42.7, 24.7, 23.1, 21.0, 20.1, 16.9, 16.4. HRMS (+) Calc. for $\left[\mathrm{C}_{24} \mathrm{H}_{26} \mathrm{~F}_{4} \mathrm{~N}_{3} \mathrm{O}\right]+448.20065$, found: 448.20114 [M+H] $]^{+}$. HPLC (protocol A, ACN/ water 50:50): tR (min) = 28.10. After HPLC purification d.e. $>99 \%$. 
(S)-N-((S)-1-cyano-2-phenylethyl)-4-methyl-2-(((S)-2,2,2-trifluoro-1-(4-(pyrimidin-5yl)phenyl)ethyl)amino)pentanamide (121)

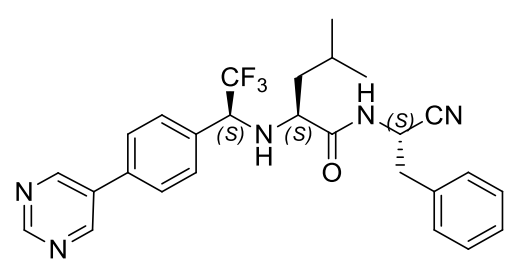

Yield 60\%. White solid. $R_{f}=0.7$ (ethyl acetate/ $n$-hexane 50:50). Mp $59-61{ }^{\circ} \mathrm{C} .{ }^{1} \mathrm{H}$ $\operatorname{NMR}\left(400 \mathrm{MHz}, \mathrm{CDCl}_{3}\right) \delta 9.22(\mathrm{~s}, 1 \mathrm{H}), 8.93(\mathrm{~s}, 2 \mathrm{H}), 7.53(\mathrm{~d}, J=8.0 \mathrm{~Hz}, 2 \mathrm{H}), 7.37$ $7.37-7.31(\mathrm{~m}, 5 \mathrm{H}), 7.23(\mathrm{~d}, J=7.6 \mathrm{~Hz}, 2 \mathrm{H}), 7.05(\mathrm{~d}, J=9.2 \mathrm{~Hz}, 1 \mathrm{H}), 5.06-5.01(\mathrm{~m}$, $1 \mathrm{H}), 4.06(\mathrm{q}, 7.2 \mathrm{~Hz}, 1 \mathrm{H}), 3.35-3.31(\mathrm{~m}, 1 \mathrm{H}), 3.05-2.97(\mathrm{~m}, 2 \mathrm{H}), 1.77-1.66(\mathrm{~m}$, $1 \mathrm{H}), 1.56-1.49(\mathrm{~m}, 1 \mathrm{H}), 1.41-1.34(\mathrm{~m}, 1 \mathrm{H}), 0.96-0.94(\mathrm{~m}, 6 \mathrm{H}) .{ }^{13} \mathrm{C} \mathrm{NMR}(100 \mathrm{MHz}$, $\left.\mathrm{CDCl}_{3}\right) \delta 173.1,157.8,155.0,135.5,133.7,129.5,129.4,129.1,128.1,127.8,117.7$, $63.66(\mathrm{~d}, J=28.7 \mathrm{~Hz}), 59.7,42.9,40.7,38.8,24.9,23.1,21.8 .{ }^{19} \mathrm{~F} \mathrm{NMR}(376.28 \mathrm{~Hz}$, $\left.\mathrm{CDCl}_{3}\right): \delta-73.49(\mathrm{~d}, J=6.6 \mathrm{~Hz})$. ESI-MS (+) Calc. for $\left[\mathrm{C}_{27} \mathrm{H}_{29} \mathrm{~F}_{3} \mathrm{~N}_{5} \mathrm{O}\right]^{+} 496.53$, found: 496.21 $[\mathrm{M}+\mathrm{H}]^{+}$. HPLC (protocol A, ACN/ water 50:50): $t_{R}(\min )=21.52$. After HPLC purification d.e. $>99 \%$.

Synthesis of compounds 123 and 124 were performed in two steps starting from BocL-leucine. First Boc-L-leucine was coupled with the selected amine (general procedure for amide synthesis, method A) to obtain compounds $\mathbf{2 1}$ and $\mathbf{1 2 2}$. Then after removal of the Boc protecting group (general procedure for removal of the Boc protecting group, method A), the free amines were coupled with benzoic acid (general procedure for amide synthesis, method $A$ ).

tert-butyl

((S)-1-(((S)-1-cyano-2-phenylethyl)amino)-4-methyl-1-oxopentan-2yl)carbamate (122)<smiles>CC(C)C[C@H](NC(=O)OC(C)(C)C)C(=O)N[C@H](C#N)Cc1ccccc1</smiles>

Yield 92\%. White solid. $R_{f}=0.7$ (ethyl acetate/ $n$-hexane $20: 80$ ). Mp $137-138{ }^{\circ} \mathrm{C} .{ }^{1} \mathrm{H}$ $\operatorname{NMR}\left(400 \mathrm{MHz}, \mathrm{CDCl}_{3}\right) \delta 7.35-7.26(\mathrm{~m}, 5 \mathrm{H}), 7.04$ (br s, 1H), $5.08(\mathrm{~m}, 1 \mathrm{H}), 4.90$ (d, J 
$=6.8 \mathrm{~Hz}, 1 \mathrm{H}), 3.06(\mathrm{~m}, 2 \mathrm{H}), 1.65-1.60(\mathrm{~m}, 2 \mathrm{H}), 1.45(\mathrm{~s}, 9 \mathrm{H}), 1.28-1.24(\mathrm{~m}, 2 \mathrm{H})$, 0.93-0.89 (m, 6H). ${ }^{13} \mathrm{C}$ NMR (100 MHz, $\left.\mathrm{CDCl}_{3}\right) \delta$ 172.2, 156.0, 134.0, 129.6, 129.1, 128.1, 118.0, 80.9, 52.9, 41.8, 40.5, 39.1, 28.4, 24.8, 23.0, 22.0. ESI-MS (+) Calc. for $\left[\mathrm{C}_{20} \mathrm{H}_{29} \mathrm{~N}_{3} \mathrm{O}_{3}\right]$ 359.46, found: $382.24[\mathrm{M}+\mathrm{Na}]^{+}$.

(S)-N-(1-((1-cyanocyclopropyl)amino)-4-methyl-1-oxopentan-2-yl)benzamide (123)<smiles>CC(C)C[C@H](NC(=O)c1ccccc1)C(=O)NC1(C#N)CC1</smiles>

Yield 60\%. White solid. $R_{f}=0.7$ (ethyl acetate/ $n$-hexane $70: 30$ ). Mp $189-191^{\circ} \mathrm{C} \mathrm{cm}^{-}$ 1. ${ }^{1} \mathrm{H}$ NMR $\left(500 \mathrm{MHz}, \mathrm{DMSO}-d_{6}\right) \delta 8.95(\mathrm{~s}, 1 \mathrm{H}), 8.59(\mathrm{~d}, J=10.5 \mathrm{~Hz}, 1 \mathrm{H}), 7.91-7.88$ $(\mathrm{m}, 2 \mathrm{H}), 7.56-7.51(\mathrm{~m}, 1 \mathrm{H}), 7.60(\mathrm{~m}, 1 \mathrm{H}), 7.48-7.44(\mathrm{~m}, 2 \mathrm{H}), 4.45-4.50(\mathrm{~m}, 1 \mathrm{H})$, $1.74-1.60(\mathrm{~m}, 2 \mathrm{H}), 1.52-1.49(\mathrm{~m}, 1 \mathrm{H}), 1.48-1.45(\mathrm{~m}, 1 \mathrm{H}), 1.12-1.09(\mathrm{~m}, 2 \mathrm{H})$, $0.97(\mathrm{~d}, J=8.2 \mathrm{~Hz}, 3 \mathrm{H}), 0.86(\mathrm{~d}, J=8.1 \mathrm{~Hz}, 3 \mathrm{H}) \cdot{ }^{13} \mathrm{C}$ NMR $\left(100 \mathrm{MHz}, \mathrm{DMSO}-d_{6}\right) \delta$ 174.17, 166.81, 134.35, 131.77, 128.59, 128.03, 121.27, 78.36, 51.87, 27.19, 26.93, 24.86, 23.44, 16.19. FT-IR (KBr, cm-1): 3265, 3045, 2959, 2931, 2872, 2243, 1683, 1540, 1541, 1490, 1301, 1327. ESI-MS (+) Calc. for $\left[\mathrm{C}_{17} \mathrm{H}_{21} \mathrm{~N}_{3} \mathrm{O}_{2}\right]$ 299.36, found: $300.67[\mathrm{M}+\mathrm{Na}]^{+}$. HPLC (protocol A, ACN/ water 45:55): tR (min) $=9.89$

$N-((S)-1-(((S)-1-c y a n o-2-p h e n y l e t h y l) a m i n o)-4-m e t h y l-1-\quad$ oxopentan-2-yl)benzamide (124)<smiles>CC(C)C[C@H](NC(=O)c1ccccc1)C(=O)N[C@@H](C#N)c1ccccc1</smiles>

Yield 79\%. White solid. $R_{f}=0.5$ (ethyl acetate/ $n$-hexane 50:50). Mp $203-205{ }^{\circ} \mathrm{C} .{ }^{1} \mathrm{H}$ NMR (500 MHz, DMSO-d6) ס $8.84(\mathrm{~d}, \mathrm{~J}=9.5 \mathrm{~Hz} 1 \mathrm{H}), 8.48(\mathrm{~d}, \mathrm{~J}=10 \mathrm{~Hz}, 1 \mathrm{H}), 7.92-$ $7.90(\mathrm{~m}, 2 \mathrm{H}), 7.57-7.53(\mathrm{~m}, 1 \mathrm{H}), 7.50-7.46(\mathrm{~m}, 2 \mathrm{H}), 7.33-7.22(\mathrm{~m}, 5 \mathrm{H}), 4.54-$ $4.48(\mathrm{~m}, 1 \mathrm{H}), 3.10(\mathrm{~d}, J=10 \mathrm{~Hz}, 2 \mathrm{H}), 1.72-1.59(\mathrm{~m}, 2 \mathrm{H}), 1.48-1.41(\mathrm{~m}, 1 \mathrm{H}), 0.9(\mathrm{~m}$, 
$2 \mathrm{H}), 0.90(\mathrm{~d}, J=8.1 \mathrm{~Hz}, 3 \mathrm{H}), 0.86(\mathrm{~d}, J=8.3 \mathrm{~Hz}, 3 \mathrm{H}) .{ }^{13} \mathrm{C}$ NMR $\left(100 \mathrm{MHz}\right.$, DMSO- $\left.d_{6}\right)$ $\delta$ 172.76, 166.75, 135.92, 134.33, 131.76, 129.82, 128.77, 128.56, 128.01, 127.50, 119.41, 51.95, 42.14, 37.57, 24.79, 23.38, 21.74. FT-IR $\left(\mathrm{KBr}, \mathrm{cm}^{-1}\right): 3286,3059,2958$, 2931, 2872, 2850, 2245, 1667, 1652, 1529, 1490, 1327, 1246, 1089. ESI-MS (+) Calc. for $\left[\mathrm{C}_{22} \mathrm{H}_{25} \mathrm{~N}_{3} \mathrm{O}_{2}\right] 363.45 .36$, found: $386.18[\mathrm{M}+\mathrm{Na}]^{+}$. HPLC (protocol $\mathrm{A}, \mathrm{ACN} /$ water $45: 55): t_{R}(\min )=17.82$. 
8.1.15. Synthesis and characterization of compounds presented in chapter $\mathbf{V}$

Scheme 16- General synthetic scheme for compounds present in chapter VI.<smiles>CC(C)(C)OC(=O)N[C@@H](Cc1ccccc1)C(N)=O</smiles><smiles>N#CC1(N)CC1</smiles>

(b)

(b)<smiles>[R]CC(NC(=O)OC(C)(C)C)C(=O)NC([R])Cc1ccccc1</smiles><smiles>[R]CC(NC(=O)OC(C)(C)C)C(=O)NC1(C#N)CC1</smiles>

21

(c)

(c)<smiles>[R]CC(NS(=O)(=O)c1ccc([R7])c([R])c1[R])C(=O)NC(C#N)Cc1ccccc1</smiles><smiles>[R]CC(NC1(C#N)CC1)C(=O)NS(=O)(=O)c1ccc([R])c([R])c1[R]</smiles>

Reagents and conditions. a) trifluoroacetic anhydride, $\mathrm{CH}_{2} \mathrm{Cl}_{2}$; b) i) formic acid, rt, $20 \mathrm{~h}$, (ii) corresponding (L)-amino acid, HATU, DIPEA, DMF, rt, $22 \mathrm{~h}$; b) formic acid, rt, $18 \mathrm{~h}$; c) (i) formic acid, rt, $20 \mathrm{~h}$, (ii) corresponding sulfonyl chloride, DIPEA, $\mathrm{CH}_{2} \mathrm{Cl}_{2}, 0^{\circ} \mathrm{C}$ to rt, $20 \mathrm{~h}$. Source: Own author.

Table 11- List of Nequimed codes of compounds described in chapter V.

\begin{tabular}{|c|c|}
\hline Number & $\begin{array}{c}\text { Nequimed } \\
\text { Code }\end{array}$ \\
\hline 125 & Neq0781 \\
\hline 126 & Neq0782 \\
\hline 127 & Neq0831 \\
\hline 128 & Neq0832 \\
\hline 129 & Neq0827 \\
\hline
\end{tabular}




\begin{tabular}{|c|c|}
\hline Number & $\begin{array}{c}\text { Nequimed } \\
\text { Code }\end{array}$ \\
\hline 130 & Neq0780 \\
\hline 131 & Neq0830 \\
\hline 132 & Neq0848 \\
\hline 133 & Neq0838 \\
\hline 134 & Neq0829 \\
\hline 135 & Neq0936 \\
\hline 136 & Neq0779 \\
\hline 137 & Neq0934 \\
\hline 138 & Neq0935 \\
\hline 139 & Neq0933 \\
\hline
\end{tabular}

Synthesis and characterization of compounds 122 and 21 have been already described above.

(S)-N-((S)-1-cyano-2-phenylethyl)-4-methyl-2-(phenylsulfonamido)pentanamide (125)<smiles>CC(C)C[C@H](NC(=O)[C@H](Cc1ccccc1)NC(=O)c1ccccc1)S(=O)(=O)c1ccccc1</smiles>

Yield $77 \%$. White solid. $R_{f}=0.6$ (ethyl acetate/ $n$-hexane 70:30). Mp. $130-131{ }^{\circ} \mathrm{C} .{ }^{1} \mathrm{H}$ NMR (400 MHz, DMSO- $\left.d_{6}\right) \delta 8.87(\mathrm{~d}, J=9.5 \mathrm{~Hz}, 1 \mathrm{H}), 8.08(\mathrm{~d}, J=10.0 \mathrm{~Hz}, 1 \mathrm{H}), 7.78$ - $7.76(\mathrm{~m}, 2 \mathrm{H}), 7.65-7.56(\mathrm{~m}, 2 \mathrm{H}), 7.38-7.26(\mathrm{~m}, 5 \mathrm{H}), 4.71-4.68(\mathrm{~m}, 1 \mathrm{H}), 3.70-$ $3.67(\mathrm{~m}, 1 \mathrm{H}), 3.00-2.87(\mathrm{~m}, 2 \mathrm{H}), 1.45-1.39(\mathrm{~m}, 1 \mathrm{H}), 1.22-1.15(\mathrm{~m}, 2 \mathrm{H}), 0.78(\mathrm{~d}, J$ $=8.5 \mathrm{~Hz}, 3 \mathrm{H}), 0.63(\mathrm{~d}, J=8.5 \mathrm{~Hz}, 3 \mathrm{H}) .{ }^{13} \mathrm{C}$ NMR $\left(100 \mathrm{MHz}\right.$, DMSO- $\left.d_{6}\right) \delta 171.58$, $141.28,135.73,132.78,129.79,129.36,128.88,127.63,126.97,119.05,54.83,42.00$, 41.73, 37.52, 24.14, 23.06, 21.64. ESI-MS (+) Calc. for $\left[\mathrm{C}_{21} \mathrm{H}_{25} \mathrm{~N}_{3} \mathrm{O}_{3} \mathrm{~S}\right]$ 399.5, found: 422.2 [M+Na] $]^{+}$HPLC (protocol A, ACN/ water 50:50): tR $(\min )=22.34$. Purity: 99\%.

(S)-2-(3-chlorophenylsulfonamido)-N-((S)-1-cyano-2-phenylethyl)-4methylpentanamide (126) 


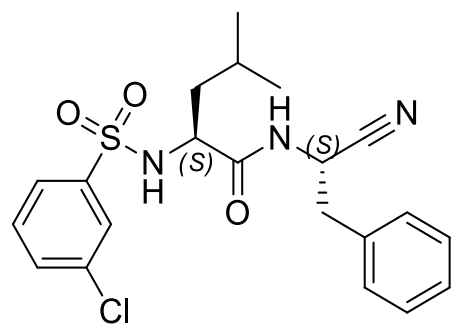

Yield 65\%. White solid. $R_{f}=0.4$ (ethyl acetate/ $n$-hexane $70: 30$ ). Mp. $139-141^{\circ} \mathrm{C} .{ }^{1} \mathrm{H}$ NMR (500 MHz, DMSO-d $) \delta 8.95$ (d, J=7.5 Hz, 1H), 8.33 (d, J=8.5 Hz, 1H), 7.78 (t, $J=2.0 \mathrm{~Hz}, 1 \mathrm{H}), 7.72-7.62(\mathrm{~m}, 1 \mathrm{H}), 7.58(\mathrm{t}, J=8.0,1 \mathrm{H}), 7.36-7.23(\mathrm{~m}, 5 \mathrm{H}), 4.69-$ $4.65(\mathrm{~m}, 1 \mathrm{H}), 3.74-3.70(\mathrm{~m}, 1 \mathrm{H}), 3.00-2.87(\mathrm{~m}, 2 \mathrm{H}), 1.50-1.45(\mathrm{~m}, 1 \mathrm{H}), 1.34-$ $1.18(\mathrm{~m}, 2 \mathrm{H}), 0.79(\mathrm{~d}, J=8.5 \mathrm{~Hz}, 3 \mathrm{H}), 0.68(\mathrm{~d}, J=8.5 \mathrm{~Hz}, 3 \mathrm{H}) .{ }^{13} \mathrm{C}$ NMR $(125 \mathrm{MHz}$, DMSO-d6) $\delta 171.35,143.25,135.63,133.97,132.76,131.52,129.77,128.71,127.69$, 126.72, 125.61, 118.92, 54.77, 42.09, 41.73, 37.53, 24.20, 23.10, 21.60. ESI-MS (+) Calc. for $\left[\mathrm{C}_{21} \mathrm{H}_{24} \mathrm{CIN}_{3} \mathrm{O}_{3} \mathrm{~S}\right]$ 433.95, found: $456.1[\mathrm{M}+\mathrm{Na}]^{+}$. HPLC (protocol A, ACN/ water 50:50): tR $(\min )=20.45$. Purity: $95.5 \%$.

(S)-2-([1,1'-biphenyl]-3-ylsulfonamido)-N-((S)-1-cyano-2-phenylethyl)-4methylpentanamide (127)

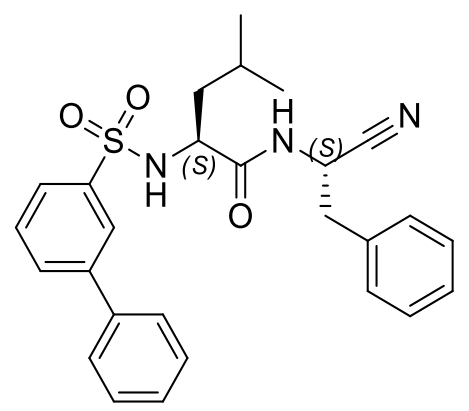

Yield 58\%. White solid. $R_{f}=0.5$ (ethyl acetate/ $n$-hexane 50:50). Mp. $187-188^{\circ} \mathrm{C} .{ }^{1} \mathrm{H}$ $\operatorname{NMR}\left(400 \mathrm{MHz}, \mathrm{DMSO}_{-\mathrm{d}}\right) \delta 8.84(\mathrm{~d}, J=8.0 \mathrm{~Hz}, 1 \mathrm{H}), 8.02(\mathrm{t}, J=1.6 \mathrm{~Hz}, 1 \mathrm{H}), 7.93-$ $7.88(\mathrm{~m}, 1 \mathrm{H}), 7.80-7.74(\mathrm{~m}, 1 \mathrm{H}), 7.71-7.68(\mathrm{~m}, 2 \mathrm{H}), 7.64\left(\mathrm{t},{ }^{3} \mathrm{~J}=8.0 \mathrm{~Hz}, 1 \mathrm{H}\right), 7.54$ - $7.50(\mathrm{~m}, 2 \mathrm{H}), 7.45-7.43(\mathrm{~m}, 1 \mathrm{H}), 7.29-7.19(\mathrm{~m}, 5 \mathrm{H}), 4.82-4.77(\mathrm{~m}, 1 \mathrm{H}), 3.68(\mathrm{q}$, $J=6.0 \mathrm{~Hz}, 1 \mathrm{H}), 3.04(\mathrm{dd}, J=13.2,6.4 \mathrm{~Hz}, 1 \mathrm{H}), 2.85(\mathrm{dd}, J=13.6,9.2 \mathrm{~Hz}, 1 \mathrm{H}), 1.25$ - $1.23(\mathrm{~m}, 1 \mathrm{H}), 1.12-1.05(\mathrm{~m}, 1 \mathrm{H}), 0.94-1.00(\mathrm{~m}, 1 \mathrm{H}), 0.67(\mathrm{~d}, J=6.4 \mathrm{~Hz}, 3 \mathrm{H}), 0.58$ $(\mathrm{d}, J=6.4 \mathrm{~Hz}, 3 \mathrm{H}) .{ }^{13} \mathrm{C}$ NMR $\left(100 \mathrm{MHz}, \mathrm{DMSO}-d_{6}\right) \delta 170.91,141.75,140.98,130.53$, 129.66, 129.32, 128.24, 128.11, 127.0, 125.6, 125.49, 125.0, 124.61, 118.77, 54.39, 41.35, 40.96, 37.43, 23.56, 22.57, 21.32. ESI-MS (+) Calc. for $\left[\mathrm{C}_{27} \mathrm{H}_{29} \mathrm{~N}_{3} \mathrm{O}_{3} \mathrm{~S}\right]$ 475.6, 
found: $476.2[\mathrm{M}+\mathrm{H}]^{+}$. HPLC (protocol $\mathrm{A}, \mathrm{ACN} /$ water $\left.50: 50\right): \mathrm{t}_{\mathrm{R}}(\mathrm{min})=22.26$. Purity: $95.2 \%$.

(S)-N-((S)-1-cyano-2-phenylethyl)-2-(4'-fluoro-[1,1'-biphenyl]-3-ylsulfonamido)-4methylpentanamide (128)<smiles>CC(C)C[C@@H](Cc1ccccc1)NC(=O)NS(=O)(=O)c1cccc(-c2ccc(F)cc2)c1</smiles>

Yield 53\%. White solid. $R_{f}=0.3$ (ethyl acetate/ $n$-hexane 50:50). Mp. $193-194{ }^{\circ} \mathrm{C} .{ }^{1} \mathrm{H}$ NMR (400 MHz, DMSO-d 6 ) $\delta 8.84$ (d, $J=8.0 \mathrm{~Hz}, 1 \mathrm{H}, \mathrm{D}_{2} \mathrm{O}$ exch.), 8.10 (br d, $J=7.5$ $\mathrm{Hz}, 1 \mathrm{H}, \mathrm{D}_{2} \mathrm{O}$ exch.), $7.99(\mathrm{t}, J=2.0 \mathrm{~Hz}, 1 \mathrm{H}), 7.87(\mathrm{~m}, 1 \mathrm{H}), 7.78-7.72(\mathrm{~m}, 3 \mathrm{H}), 7.63(\mathrm{t}$, $J=7.5 \mathrm{~Hz}, 1 \mathrm{H}), 7.39-7.35(\mathrm{~m}, 2 \mathrm{H}), 7.27-7.19(\mathrm{~m}, 5 \mathrm{H}), 4.81-4.77(\mathrm{~m}, 1 \mathrm{H}), 3.68$ (m, $1 \mathrm{H}), 3.03\left(\mathrm{dd},{ }^{3} \mathrm{~J}=13.5,6.5 \mathrm{~Hz}, 1 \mathrm{H}\right), 2.84\left(\mathrm{dd},{ }^{3} \mathrm{~J}=13.5,9.0 \mathrm{~Hz}, 1 \mathrm{H}\right), 1.26-1.24$ $(\mathrm{m}, 1 \mathrm{H}), 1.10-1.04(\mathrm{~m}, 1 \mathrm{H}), 0.93-0.99(\mathrm{~m}, 1 \mathrm{H}), 0.66\left(\mathrm{~d},{ }^{3} \mathrm{~J}=7.0 \mathrm{~Hz}, 3 \mathrm{H}\right), 0.58\left(\mathrm{~d},{ }^{3} \mathrm{~J}\right.$ $=7.0 \mathrm{~Hz}, 3 \mathrm{H}) \cdot{ }^{13} \mathrm{C}$ NMR $\left(100 \mathrm{MHz}\right.$, DMSO- $\left.d_{6}\right) \delta .170 .96,162.26\left(\mathrm{~d},{ }^{2} \mathrm{~J}=243.9 \mathrm{~Hz}\right)$, $141.71,139.88,135.34\left(\mathrm{~d},{ }^{4} \mathrm{~J}=2.0 \mathrm{~Hz}\right), 130.50,129.61,129.37,128.9\left(\mathrm{~d},{ }^{3} \mathrm{~J}=8.2 \mathrm{~Hz}\right.$ ), 128.25, 127.0, 125.11, 124.58, 118.77, 115.91 (d, $J=21.5 \mathrm{~Hz}$ ), 54.36, 41.33, 37.40, 23.59, 22.51, 21.32. ESI-MS (+) Calc. for $\left[\mathrm{C}_{27} \mathrm{H}_{28} \mathrm{FN}_{3} \mathrm{O}_{3} \mathrm{~S}\right]$ 493.59, found: 516.1 $[\mathrm{M}+\mathrm{Na}]^{+}$. HPLC (protocol A, ACN/ water 50:50): $\mathrm{t}_{\mathrm{R}}(\mathrm{min})=34.10$. Purity $>99.9 \%$. 
(S)-2-([1,1'-biphenyl]-4-ylsulfonamido)-N-((S)-1-cyano-2-phenylethyl)-4methylpentanamide (129)

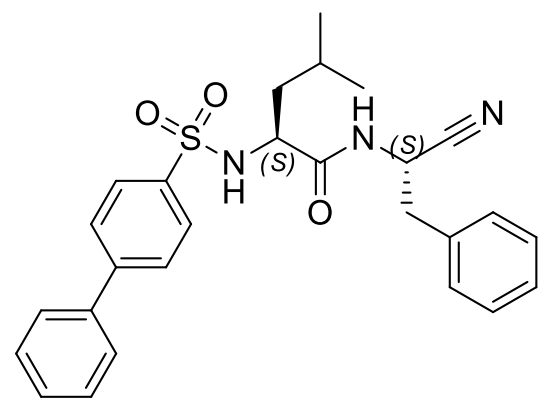

Yield 56\%. White solid. $R_{f}=0.7$ (ethyl acetate/ $n$-hexane 50:50). Mp. $181-182{ }^{\circ} \mathrm{C} .{ }^{1} \mathrm{H}$ $\operatorname{NMR}\left(400 \mathrm{MHz}\right.$, DMSO-d $\left.d_{6}\right) 8.90(\mathrm{~d}, J=8.1 \mathrm{~Hz}, 1 \mathrm{H}), 8.07(\mathrm{~d}, J=8.5 \mathrm{~Hz}, 1 \mathrm{H}), 7.72-$ $7.59(\mathrm{~m}, 4 \mathrm{H}), 7.52-7.34(\mathrm{~m}, 4 \mathrm{H}), 7.28-7.18(\mathrm{~m}, 6 \mathrm{H}), 4.82-4.75(\mathrm{~m}, 1 \mathrm{H}), 3.71$ (dd, $J=9.0,5.8 \mathrm{~Hz}, 1 \mathrm{H}), 3.09-3.03(\mathrm{~m}, 1 \mathrm{H}), 2.89(\mathrm{dd}, J=13.5,9.3 \mathrm{~Hz}, 1 \mathrm{H}), 1.33-1.25$ $(\mathrm{m}, 1 \mathrm{H}), 1.18-1.11(\mathrm{~m}, 1 \mathrm{H}), 1.01-0.96(\mathrm{~m}, 1 \mathrm{H}), 0.70(\mathrm{~d}, J=6.6 \mathrm{~Hz}, 2 \mathrm{H}), 0.62(\mathrm{~d}, J$ $=6.5 \mathrm{~Hz}, 3 \mathrm{H}) .{ }^{13} \mathrm{C}$ NMR $\left(100 \mathrm{MHz}\right.$, DMSO-d $\left.d_{6}\right) \delta 171.26,147.67,144.12,140.50$, $140.25,140.09,139.02,135.67,129.73,129.41,129.30,128.75,128.60,127.90$, $127.55,127.36,127.08,126.51,126.37,119.23,54.77,41.74,41.19,37.80,23.95$, 22.92, 21.72. ESI-MS (+) Calc. for $\left[\mathrm{C}_{27} \mathrm{H}_{29} \mathrm{~N}_{3} \mathrm{O}_{3} \mathrm{~S}\right]$ 475.6, found: $498.1[\mathrm{M}+\mathrm{Na}]^{+}$. HPLC (protocol A, ACN/ water 35:65): $t_{R}(\min )=7.10$. Purity $>99.9 \%$.

(S)-2-(3-chlorophenylsulfonamido)-N-(1-cyanocyclopropyl)-4-methylpentanamide (130)<smiles>CC(C)C[C@H](NS(=O)(=O)c1cccc(Cl)c1)C(=O)NC1(C#N)CC1</smiles>

Yield 81\%. White solid. $R_{f}=0.7$ (ethyl acetate/ $n$-hexane 70:30). Mp. $166-168{ }^{\circ} \mathrm{C} .{ }^{1} \mathrm{H}$ NMR (400 MHz, DMSO- $\left.d_{6}\right) \delta 8.87(\mathrm{~d}, J=8.1 \mathrm{~Hz}, 1 \mathrm{H}), 8.53(\mathrm{~d}, J=8.5 \mathrm{~Hz}, 1 \mathrm{H}), 7.70-$ $7.62(\mathrm{~m}, 1 \mathrm{H}), 7.59(\mathrm{t}, J=2.0 \mathrm{~Hz}, 1 \mathrm{H}), 7.55(\mathrm{dt}, J=8.0,1.5 \mathrm{~Hz}, 1 \mathrm{H})$, ), $7.49(\mathrm{t}, J=8.0$ $\mathrm{Hz}, 1 \mathrm{H}), 3.93-3.89(\mathrm{~m}, 1 \mathrm{H}), 1.61-1.54(\mathrm{~m}, 1 \mathrm{H}), 1.49-1.46(\mathrm{~m}, 1 \mathrm{H}), 1.45-1.41(\mathrm{~m}$, $1 \mathrm{H}), 1.35-1.32(\mathrm{~m}, 1 \mathrm{H}), 1.11-1.07(\mathrm{~m}, 1 \mathrm{H}), 0.87\left(\mathrm{~d},{ }^{3} \mathrm{~J}=8.5 \mathrm{~Hz}, 2 \mathrm{H}\right), 0.86\left(\mathrm{~d},{ }^{3} \mathrm{~J}=8.5\right.$ $\mathrm{Hz}, 2 \mathrm{H}) .{ }^{13} \mathrm{C}$ NMR $\left(100 \mathrm{MHz}, \mathrm{DMSO}-d_{6}\right) \delta 171.68,143.35,136.74,133.94,132.68$, 
131.42, 129.64, 127.07, 78.47, 52.83, 40.75, 28.60, 24.65, 23.31, 21.94, 20.18. ESIMS (+) Calc. for [ $\left.\mathrm{C}_{16} \mathrm{H}_{20} \mathrm{CIN}_{3} \mathrm{O}_{3} \mathrm{~S}\right]$ 369.86, found: $392.1[\mathrm{M}+\mathrm{Na}]^{+}$. HPLC (protocol A, $A C N /$ water $50: 50): t_{R}(\min )=24.15$. Purity $=96.6 \%$.

(S)-2-([1, 1'-biphenyl]-3-ylsulfonamido)-N-(1-cyanocyclopropyl)-4-methylpentanamide (131)

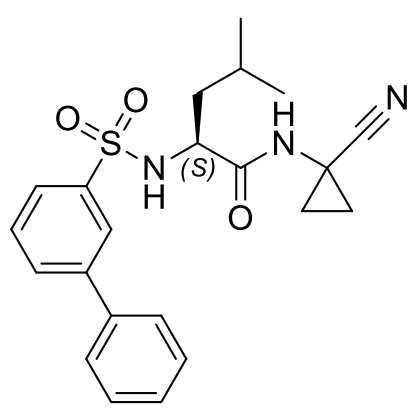

Yield 51\%. White solid. $R_{f}=0.4$ (ethyl acetate/ $n$-hexane 70:30). Mp. $163-165^{\circ} \mathrm{C} .{ }^{1} \mathrm{H}$ NMR (400 MHz, DMSO-d $) \delta 8.88(\mathrm{~s}, 1 \mathrm{H}), 8.17(\mathrm{~d}, J=8.4 \mathrm{~Hz}, 1 \mathrm{H}), 7.98(\mathrm{t}, J=1.7 \mathrm{~Hz}$, $1 \mathrm{H}), 7.93-7.89(\mathrm{~m}, 1 \mathrm{H}), 7.74-7.68(\mathrm{~m}, 3 \mathrm{H}), 7.64(\mathrm{t}, J=7.7 \mathrm{~Hz}, 1 \mathrm{H}), 7.57-7.50(\mathrm{~m}$, $2 \mathrm{H}), 7.48-7.41(\mathrm{~m}, 1 \mathrm{H}), 3.67(\mathrm{dd}, J=14.3,8.6 \mathrm{~Hz}, 1 \mathrm{H}), 1.61-1.54(\mathrm{~m}, 1 \mathrm{H}), 1.49-$ $1.46(\mathrm{~m}, 1 \mathrm{H}), 1.45-1.43(\mathrm{~m}, 1 \mathrm{H}), 1.33-1.31(\mathrm{~m}, 1 \mathrm{H}), 1.12-1.06(\mathrm{~m}, 1 \mathrm{H}), 0.89(\mathrm{~d}, J$ $=8.5 \mathrm{~Hz}, 2 \mathrm{H}), 0.83(\mathrm{~d}, J=8.5 \mathrm{~Hz}, 3 \mathrm{H}) .{ }^{13} \mathrm{C}$ NMR $\left(100 \mathrm{MHz}, \mathrm{DMSO}-d_{6}\right) \delta 171.97$, $141.47,140.60,138.45,130.29,129.47,128.91,128.01,126.62,125.11,124.42$, $120.04,53.94,41.18,23.59,22.42,21.05,19.06,15.42,14.75$. ESI-MS (+) Calc. for [ $\left.\mathrm{C}_{16} \mathrm{H}_{25} \mathrm{~N}_{3} \mathrm{O}_{3} \mathrm{~S}\right]$ 411.51, found: $412.1[\mathrm{M}+\mathrm{H}]^{+}$. HPLC (protocol A, ACN/ water 35:65): tR $(\min )=24.15$. Purity $=96.2 \%$.

(S)-2-(3-bromophenylsulfonamido)-N-(1-cyanocyclopropyl)-4-methylpentanamide (132)

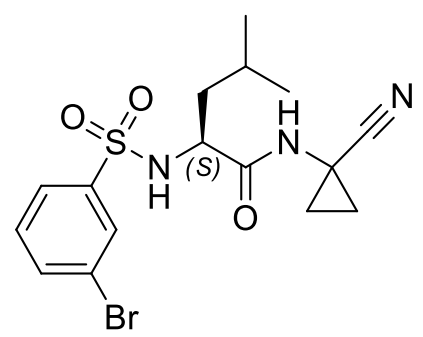

Yield 30\%. White solid. $R_{f}=0.5$ (ethyl acetate/ $n$-hexane 80:20). Mp. $175-177^{\circ} \mathrm{C} .{ }^{1} \mathrm{H}$ $\operatorname{NMR}(400 \mathrm{MHz}$, DMSO-d $) \delta 8.90(\mathrm{~s}, 1 \mathrm{H}), 8.31(\mathrm{~d}, J=8.8 \mathrm{~Hz}, 1 \mathrm{H}), 7.87(\mathrm{t}, J=1.6 \mathrm{~Hz}$, 
1H), 7.83 (ddd, $J=7.9,2.0,0.8 \mathrm{~Hz}, 1 \mathrm{H}$ ), 7.72 (ddd, $J=8.0,2.0,1.2 \mathrm{~Hz}, 1 \mathrm{H}$ ), $7.52(\mathrm{t}, J$ $=8.0 \mathrm{~Hz}, 1 \mathrm{H}), 3.71-3.67(\mathrm{~m}, 1 \mathrm{H}), 1.60-1.49(\mathrm{~m}, 1 \mathrm{H}), 1.43-1.24(\mathrm{~m}, 4 \mathrm{H}), 0.95-$ $0.91(\mathrm{~m}, 1 \mathrm{H}), 0.84(\mathrm{~d}, J=6.4 \mathrm{~Hz}, 3 \mathrm{H}), 0.75(\mathrm{~d}, J=6.4 \mathrm{~Hz}, 3 \mathrm{H}), 0.56-0.61(\mathrm{~m}, 1 \mathrm{H})$. ${ }^{13} \mathrm{C}$ NMR $\left(100 \mathrm{MHz}\right.$, DMSO-d $d_{6} \delta 172.2,143.1,135.2,131.3,128.9,125.4,121.8$, 120.2, 54.1, 41.3, 23.8, 22.6, 21.2, 19.3, 15.7, 15.1. ESI-MS (+) Calc. for $\left[\mathrm{C}_{16} \mathrm{H}_{20} \mathrm{BrN}_{3} \mathrm{O}_{3} \mathrm{~S}\right]$ 414.31, found: $437.9[\mathrm{M}+\mathrm{Na}]^{+}$. HPLC (protocol A, ACN/ water 60:40): $t_{R}(\min )=8.33$. Purity $=97.5 \%$.

(S)-2-([1, 1'-biphenyl]-4-ylsulfonamido)-N-(1-cyanocyclopropyl)-4-methylpentanamide (133)

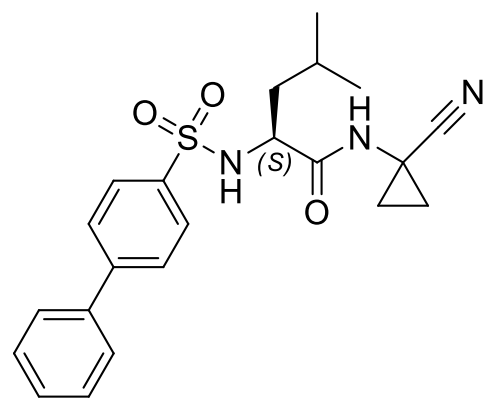

Yield 54\%. White solid. $R_{f}=0.7$ (ethyl acetate/ $n$-hexane 30:70). Mp. $185-183^{\circ} \mathrm{C} .{ }^{1} \mathrm{H}$ NMR (400 MHz, CDCl $)$ ) $8.90(\mathrm{~s}, 1 \mathrm{H}), 8.12(\mathrm{~s}, 1 \mathrm{H}), 7.93-7.80(\mathrm{~m}, 4 \mathrm{H}), 7.70(\mathrm{~d}, J=$ $7.4 \mathrm{~Hz}, 2 \mathrm{H}), 7.50$ (t, $J=7.4 \mathrm{~Hz}, 2 \mathrm{H}), 7.42(\mathrm{t}, J=7.3 \mathrm{~Hz}, 1 \mathrm{H}), 3.71-3.66(\mathrm{~m}, 1 \mathrm{H}), 1.60$ $-1.54(\mathrm{~m}, 1 \mathrm{H}), 0.90-0.80(\mathrm{~m}, 4 \mathrm{H}), 0.95-0.91(\mathrm{~m}, 1 \mathrm{H}), 0.74(\mathrm{~d}, J=6.5 \mathrm{~Hz}, 3 \mathrm{H}), 0.71$ $(\mathrm{d}, J=6.5 \mathrm{~Hz}, 3 \mathrm{H}), 0.58-0.51(\mathrm{~m}, 1 \mathrm{H}) .{ }^{13} \mathrm{C} \mathrm{NMR}\left(100 \mathrm{MHz}, \mathrm{CDCl}_{3}\right) \delta 172.50,144.17$, 139.99, 138.85, 129.32, 128.95, 128.65, 127.41, 127.35, 127.25, 120.54, 54.42, 41.62, 24.05, 22.90, 21.49, 19.56, 15.77, 15.36. ESI-MS (+) Calc. for $\left[\mathrm{C}_{22} \mathrm{H}_{25} \mathrm{~N}_{3} \mathrm{O}_{3} \mathrm{~S}\right]$ 414.51, found: $434.1[\mathrm{M}+\mathrm{Na}]^{+}$. HPLC (protocol $\mathrm{A}, \mathrm{ACN} /$ water $\left.50: 50\right): \mathrm{tR}_{\mathrm{R}}(\mathrm{min})=28.57$. Purity= $97.6 \%$. 
(4'-Fluorobiphenyl-4-yl)sulfonyl-leucyl-aminocyclopropane-nitrile (134)

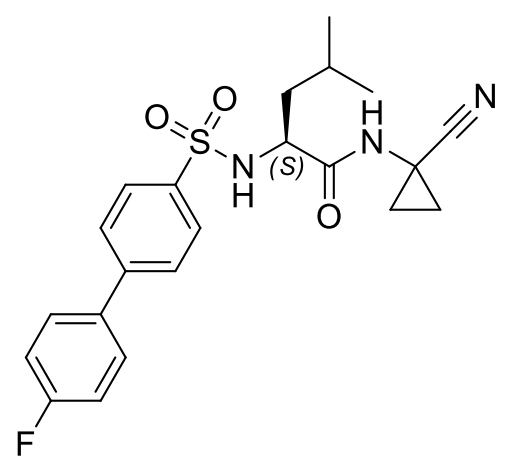

Yield 53\%. White solid. $R_{f}=0.7$ (ethyl acetate/ $n$-hexane 30:70). Mp. $199-200{ }^{\circ} \mathrm{C} .{ }^{1} \mathrm{H}$ $\operatorname{NMR}\left(400 \mathrm{MHz}, \mathrm{CDCl}_{3}\right) \delta 8.88(\mathrm{~s}, 1 \mathrm{H}), 8.14(\mathrm{~s}, 1 \mathrm{H}), 7.92-7.88(\mathrm{~m}, 4 \mathrm{H}), 7.39-7.30$ $(\mathrm{m}, 4 \mathrm{H}), 3.71-3.66(\mathrm{~m}, 1 \mathrm{H}), 1.60-1.54(\mathrm{~m}, 1 \mathrm{H}), 0.90-0.80(\mathrm{~m}, 4 \mathrm{H}), 0.95-0.91(\mathrm{~m}$, $1 \mathrm{H}), 0.74(\mathrm{~d}, J=6.5 \mathrm{~Hz}, 3 \mathrm{H}), 0.71(\mathrm{~d}, J=6.5 \mathrm{~Hz}, 3 \mathrm{H}), 0.58-0.51(\mathrm{~m}, 1 \mathrm{H}) .{ }^{13} \mathrm{C}$ NMR $\left(100 \mathrm{MHz}, \mathrm{CDCl}_{3}\right) \delta 172.01,161.56$ (d, $\left.J=243.9 \mathrm{~Hz}\right), 142.68,136.42,133.22,131.32$, 131.09, 128.95, 127.48, 127.56, 119.87, 116.95 (d, 3J = 21.5 Hz), 116.31 (d, J = 21.5 $\mathrm{Hz})$, 54.88, 41.73, 24.25, 22.91, 21.59, 19.52, 15.71, 15.37. ESI-MS (+) Calc. for $\left[\mathrm{C}_{22} \mathrm{H}_{24} \mathrm{FN}_{3} \mathrm{O}_{3} \mathrm{~S}\right]$ 429.5, found: $452.4[\mathrm{M}+\mathrm{Na}]^{+}$. HPLC (protocol A, ACN/ water 50:50): $\operatorname{tR}(\min )=10.32$. Purity $=99.6 \%$.

(S)-2-(2-chlorophenylsulfonamido)-N-(1-cyanocyclopropyl)-4-methylpentanamide (135)<smiles>CC(C)C[C@H](NS(=O)(=O)c1ccccc1Cl)C(=O)NC1(C#N)CC1</smiles>

Yield 60\%. White solid. Mp. $170-172{ }^{\circ} \mathrm{C} .{ }^{1} \mathrm{H}$ NMR (500 MHz, DMSO-d6) $\delta 8.79$ (s, $1 \mathrm{H}), 8.17(\mathrm{~d}, J=5.3 \mathrm{~Hz}, 1 \mathrm{H}), 7.91(\mathrm{dt}, J=8.1,0.7 \mathrm{~Hz}, 1 \mathrm{H}), 7.62-7.58(\mathrm{~m}, 2 \mathrm{H}), 7.51$ - $7.51(\mathrm{~m}, 1 \mathrm{H}), 3.61-3.66(\mathrm{~m}, 1 \mathrm{H}), 1.56-1.64(\mathrm{~m}, 1 \mathrm{H}), 1.48$ (ddd, $J=13.6,9.9,5.1$ $\mathrm{Hz}, 1 \mathrm{H}), 1.32-1.40(\mathrm{~m}, 2 \mathrm{H}), 1.25(\mathrm{ddd}, J=13.8,8.8,5.1 \mathrm{~Hz}, 1 \mathrm{H}), 0.88-0.84(\mathrm{~m}, 1 \mathrm{H})$, $0.81(\mathrm{~d}, J=6.7 \mathrm{~Hz}, 3 \mathrm{H}), 0.68(\mathrm{~d}, J=6.6 \mathrm{~Hz}, 3 \mathrm{H}), 0.66-0.62(\mathrm{~m}, 1 \mathrm{H}) .{ }^{13} \mathrm{C}$ NMR $(125$ $\mathrm{MHz}, \mathrm{DMSO}) \delta 172.43,138.23,134.14,131.81,131.22,130.48,127.48,120.48$, $54.55,41.14,23.93,22.91,21.13,19.56,15.80,15.38$. ESI-MS (+) Calc. for $\left[\mathrm{C}_{16} \mathrm{H}_{20} \mathrm{ClN}_{3} \mathrm{O}_{3} \mathrm{~S}\right]$ 369.8, found: $392.7[\mathrm{M}+\mathrm{Na}]^{+}$. HPLC (protocol C): $\mathrm{t}_{\mathrm{R}}(\mathrm{min})=9.19$. Purity $>99.9 \%$. 
(S)-2-(3-chlorophenylsulfonamido)-N-(1-cyanocyclopropyl)-3-phenylpropanamide (136)<smiles>N#CC1(NC(=O)[C@H](Cc2ccccc2)NS(=O)(=O)c2cccc(Cl)c2)CC1</smiles>

Yield 66\%. White solid. Mp. $193-194{ }^{\circ} \mathrm{C} .{ }^{1} \mathrm{H}$ NMR $(500 \mathrm{MHz}$, DMSO-d6) $\delta 8.88$ (s, $1 \mathrm{H}$ ), 8.54 (s, 1H), 7.62 (ddd, J=7.0, 2.5, $1.0 \mathrm{~Hz}, 1 \mathrm{H}$ ), 7.59 (t, J=2.0 Hz, 1H), 7.55 (dt, $J=8.0,1.5 \mathrm{~Hz}, 1 \mathrm{H}), 7.49(\mathrm{t}, J=8.0 \mathrm{~Hz}, 1 \mathrm{H}), 7.23-7.16(\mathrm{~m}, 3 \mathrm{H}), 7.12-7.00(\mathrm{~m}, 2 \mathrm{H})$, $3.89-3.87(\mathrm{~m}, 1 \mathrm{H}), 2.82(\mathrm{dd}, J=13.5,6.5 \mathrm{~Hz}, 1 \mathrm{H}), 2.71(\mathrm{dd}, J=13.5,7.0 \mathrm{~Hz}, 1 \mathrm{H})$, $0.80-0.77(\mathrm{~m}, 2 \mathrm{H}), 0.58-0.53(\mathrm{~m}, 2 \mathrm{H}) .{ }^{13} \mathrm{C}$ NMR (100 MHz, DMSO- $\left.d_{6}\right) \delta 171.68$, 143.35, 136.74, 133.94, 132.68, 131.42, 129.64, 128.51, 127.07, 126.44, 125.31, 120.50, 57.63, 38.90, 19.66, 16.03, 15.72. ESI-MS (+) Calc. for $\left[\mathrm{C}_{19} \mathrm{H}_{18} \mathrm{CIN}_{3} \mathrm{O}_{3} \mathrm{~S}\right] 403.8$, found: $426.4[\mathrm{M}+\mathrm{Na}]^{+}$. HPLC (protocol A, ACN/ water 50:50): tR $(\min )=11.21$ Purity= $99 \%$.

(S)-2-([1, 1'-biphenyl]-3-ylsulfonamido)-N-(1-cyanocyclopropyl)-3-phenylpropanamide (137)<smiles>N#CC1(NC(=O)[C@H](Cc2ccccc2)NS(=O)(=O)c2cccc(-c3ccccc3)c2)CC1</smiles>

Yield 71\%. White solid. Mp.168 - $170{ }^{\circ} \mathrm{C} .{ }^{1} \mathrm{H}$ NMR (500 MHz, DMSO-d6) $\delta 8.78$ (s, $1 \mathrm{H}), 8.38-8.32(\mathrm{~m}, 1 \mathrm{H}), 7.90(\mathrm{t}, J=1.7 \mathrm{~Hz}, 1 \mathrm{H}), 7.85(\mathrm{dt}, J=7.6,1.4 \mathrm{~Hz}, 1 \mathrm{H}), 7.68-$ $7.65(\mathrm{~m}, 2 \mathrm{H}), 7.62$ (dt, J=7.8, 1.3 Hz, 1H), 7.56 (t, J= $7.7 \mathrm{~Hz}, 1 \mathrm{H}), 7.54-7.49$ (m, $2 \mathrm{H}), 7.45-7.41(\mathrm{~m}, 2 \mathrm{H}), 7.19-7.15(\mathrm{~m}, 1 \mathrm{H}), 7.14-7.10(\mathrm{~m}, 1 \mathrm{H}), 7.10-7.07(\mathrm{~m}$, 2H), $3.92-3.86(\mathrm{~m}, 1 \mathrm{H}), 2.82(\mathrm{dd}, J=13.5,7.1 \mathrm{~Hz}, 1 \mathrm{H}), 2.70$ (dd, $J=13.5,8.0 \mathrm{~Hz}$, $1 \mathrm{H}), 1.25-1.22(\mathrm{~m}, 2 \mathrm{H}), 0.87-0.77(\mathrm{~m}, 1 \mathrm{H}), 0.65-0.58(\mathrm{~m}, 1 \mathrm{H}) .{ }^{13} \mathrm{C} N M R(125 \mathrm{MHz}$, DMSO) $\delta 171.44,141.89,140.98,138.87,136.48,130.65,129.81,129.34,129.26$, 128.35, 128.22, 127.05, 126.71, 125.33, 124.70, 120.20, 57.29, 38.76, 19.30, 15.74, 
15.26. ESI-MS (+) Calc. for $\left[\mathrm{C}_{25} \mathrm{H}_{23} \mathrm{~N}_{3} \mathrm{O}_{3} \mathrm{~S}\right]$ 445.5, found: $468.3[\mathrm{M}+\mathrm{Na}]^{+}$. HPLC (protocol C): tR $(\min )=10.75$. Purity $=98.5 \%$.

(S)-2-([1, 1'-biphenyl]-4-ylsulfonamido)-N-(1-cyanocyclopropyl)-3-phenylpropanamide (138)<smiles>N#CC1(NC(=O)[C@H](Cc2ccccc2)NS(=O)(=O)c2ccc(-c3ccccc3)cc2)CC1</smiles>

Yield 76\%. White solid. Mp $186-188^{\circ} \mathrm{C} .{ }^{1} \mathrm{H}$ NMR (500 MHz, DMSO-d6) $\delta 8.84-8.78$ $(\mathrm{m}, 1 \mathrm{H}), 8.34-8.26(\mathrm{~m}, 1 \mathrm{H}), 7.76-7.70(\mathrm{~m}, 2 \mathrm{H}), 7.71-7.64(\mathrm{~m}, 4 \mathrm{H}), 7.52-7.47(\mathrm{~m}$, 2H), 7.42 (tt, $J=7.3,1.6 \mathrm{~Hz}, 1 \mathrm{H}), 7.24-7.12(\mathrm{~m}, 3 \mathrm{H}), 7.14-7.08$ (m, 2H), 3.88 (app. q, $J=7.2 \mathrm{~Hz}, 1 \mathrm{H}), 2.82(\mathrm{dd}, J=13.6,6.8 \mathrm{~Hz}, 1 \mathrm{H}), 2.72(\mathrm{dd}, J=13.6,8.2 \mathrm{~Hz}, 1 \mathrm{H}), 1.34-$ $1.20(\mathrm{~m}, 2 \mathrm{H}), 0.78-0.72(\mathrm{~m}, 1 \mathrm{H}), 0.55-0.48(\mathrm{~m}, 1 \mathrm{H}) .{ }^{13} \mathrm{C}$ NMR $(125 \mathrm{MHz}$, DMSOd6) $\delta 171.55,143.97,139.97,138.85,136.59,129.42,129.26,128.56,128.26,127.28$, 127.20, 127.14, 126.68, 120.31, 57.34, 38.69, 19.37, 15.67, 15.42. HRMS (+) Calc. for $\left[\mathrm{C}_{25} \mathrm{H}_{23} \mathrm{~N}_{3} \mathrm{O}_{3} \mathrm{~S}\right]^{+}$446.1533, found: $446.1532[\mathrm{M}+\mathrm{H}]^{+}$. HPLC (protocol C): tr (min) = 10.75 Purity $=98.2 \%$.

(S)-2-(2-chlorophenylsulfonamido)-N-(1-cyanocyclopropyl)-3-phenylpropanamide (139)<smiles>N#CC1(NC(=O)[C@H](Cc2ccccc2)NS(=O)(=O)c2ccccc2Cl)CC1</smiles>

Yield 74\%. Mp $130-132{ }^{\circ} \mathrm{C} .{ }^{1} \mathrm{H}$ NMR (500 MHz, DMSO-d6) $\delta 8.77$ (s, $\left.1 \mathrm{H}\right), 8.34$ (s, $1 \mathrm{H}), 7.72$ (dd, $J=7.9,1.5 \mathrm{~Hz}, 1 \mathrm{H}), 7.56-7.49(\mathrm{~m}, 2 \mathrm{H}), 7.40-7.35(\mathrm{~m}, 1 \mathrm{H}), 7.21-$ $7.11(\mathrm{~m}, 5 \mathrm{H}), 3.87(\mathrm{t}, J=7.3 \mathrm{~Hz}, 1 \mathrm{H}), 2.85(\mathrm{dd}, J=13.6,6.5 \mathrm{~Hz}, 1 \mathrm{H}), 2.79(\mathrm{dd}, J=$ 13.6, 8.6 Hz, 1H), $1.36-1.30(\mathrm{~m}, 2 \mathrm{H}), 0.77-0.72(\mathrm{~m}, 1 \mathrm{H}), 0.60-0.55(\mathrm{~m}, 1 \mathrm{H}) .{ }^{13} \mathrm{C}$

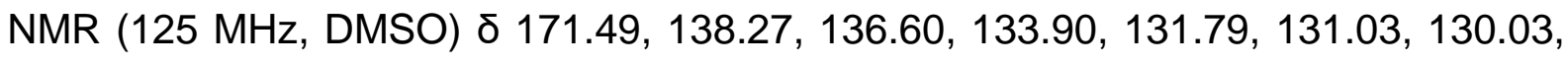


129.36, 128.20, 127.32, 126.68, 120.30, 57.62, 38.30, 19.40, 15.74, 15.45. ESI-MS (+) Calc. for $\left[\mathrm{C}_{19} \mathrm{H}_{18} \mathrm{CIN}_{3} \mathrm{O} 3 \mathrm{~S}\right]$ 403.9, found: $404.9[\mathrm{M}+\mathrm{H}]^{+}$. HPLC (protocol C): th $(\mathrm{min})=$ 9.29. Purity $=97.3 \%$. 


\subsection{Enzyme inhibition studies}

Recombinat cruzain was expressed and activated by M. Sc. Fabiana Rosini as elsewhere reported (CIANNI et al., 2018). CatL was purchased by Enzo Life Science ${ }^{\odot}$.

8.2.1. Determination of the Michaelis-Menten constants for cruzain and CatL

The enzyme kinetics assays to determine the $\mathrm{KM}$ were done at $25^{\circ} \mathrm{C}$ using a 96 -well black microplate (Corning ${ }^{\circledR}$ ) with an excitation wavelength of $360 \mathrm{~nm}$ and an emission wavelength of $460 \mathrm{~nm}$. The enzymes were activated with assay buffer $100 \mathrm{mM}$ sodium acetate $\mathrm{pH} 5.5,300 \mathrm{mM}$ of $\mathrm{NaCl}$ and $5 \mathrm{mM}$ of EDTA, containing $7 \mathrm{mM} \mathrm{DTT}, 0.014 \%$ of Triton X-100, and was then incubated in an ice bath for $20 \mathrm{~min}$. The concentrations used for the enzymes were $0.15 \mathrm{nM}$ and $1.9 \mathrm{nM}$ for cruzain, and Cat-L respectively. The reaction rate was followed for $5 \mathrm{~min}$ in the fluorimeter, in which the rate of hydrolysis of the substrate Z-Phe-Arg-AMC was monitored. A final concentration of DMSO of $5 \%(10 \mu \mathrm{L})$ in each well was used. The assays were performed in triplicates. Eight different substrate concentrations, prepared with a 0.5 dilution factor, were used.

$$
\begin{aligned}
& \mathrm{K}_{\mathrm{M}}=1.8 \pm 0.2(\mathrm{Cz}) \\
& \mathrm{K}_{\mathrm{M}}=3.3 \pm 0.2(\mathrm{CatL})
\end{aligned}
$$

8.2.2. Determination of the inhibition constant $\left(K_{i}\right)$ for cruzain and CatL

Recombinant cruzain and CatL were assayed by fluorometric assay Biotek $^{\circledR}$ SynergyTM HT) monitoring the hydrolysis rate of the fluorogenic substrate Z-Phe-Arg7-amido-4-methylcoumarin (Z-FR-AMC, Sigma-Aldrich) with fluorescence emission at $460 \mathrm{~nm}$ (excitation at $355 \mathrm{~nm}$ ) and at $37^{\circ} \mathrm{C}$. The reactions were followed over $5 \mathrm{~min}$ for fast-binding and irreversible inhibitors and over $30 \mathrm{~min}$ for compounds displaying slowbinding behavior, respectively. Enzyme kinetic assays were carried out in $200 \mu \mathrm{L}$ of a 
solution containing $100 \mathrm{mM}$ acetate buffer pH 5.5, $300 \mathrm{mM} \mathrm{NaCl}, 5 \mathrm{mM}$ DTT (dithiothreitol), $5 \% \mathrm{v} / \mathrm{v}$ DMSO (dimethyl sulfoxide), $0.01 \% \mathrm{v} / \mathrm{v}$ Triton $\mathrm{X}-100$ and $0.15 \mathrm{nM}$ Cruzain or $1.9 \mathrm{nM}$ of CatL, using Corning ${ }^{\circledR} 96$-well black flat bottom microplates. The enzyme stock aliquot was rapidly thawed at $37^{\circ} \mathrm{C}$ and kept on ice until activation, in which it was incubated for $20 \mathrm{~min}$ in the assay buffer $(100 \mathrm{mM}$ acetate $\mathrm{pH} 5.5$ and 5 $\mathrm{mM}$ DTT) followed by additional 2 min with inhibitors before the reaction to be started by the addition of the substrate (final concentration equal to $K_{M}$ of the enzyme). Visual inspection and a pre-reading of plate wells were performed to check respectively for possible precipitation and background fluorescence. None of the compounds displayed a significant fluorescence signal around $460 \mathrm{~nm}$, the emission wavelength used to monitor reaction kinetics. Thus, potential inner-filter effects did not have to be taken into account in our experiments. Analysis and manipulation of the data were performed by Sigma Plot 10.

8.2.3. Kinetic parameters determination of fast-binding inhibitors

Each experiment was performed in triplicate for each compound. Initial velocities of the substrate hydrolysis under first-order reaction were calculated by Gen5 ${ }^{\mathrm{TM}}$ Biotek $^{\circledR}$ software. The apparent inhibition constant $K_{i}^{\prime}$ was determined by non-linear regression using equation $v_{s}=V_{0} /\left(1+[l] / K_{i}^{\prime}\right)$, where $v s$ is the steady-state rate, $\mathrm{V}_{0}$ is the rate in the absence of inhibitor, and [l] is the inhibitor concentration. The true inhibition constant $K_{\mathrm{i}}$ was calculated by correction of $K_{\mathrm{i}}^{\prime}$ according to $K_{\mathrm{i}}=K_{\mathrm{i}}^{\prime} /\left(1+[\mathrm{S}] / K_{\mathrm{M}}\right)$, where $[\mathrm{S}]$ is the substrate concentration and $K_{\mathrm{M}}$ is the Michaelis constant. A control measurement in presence of the covalent reversible fast-binding inhibitor Neq0409 was done for each setup plate. All inhibitors were evaluated at seven different concentrations that were chosen based on a previous screening (percent inhibition) at $1.7 \mu \mathrm{M}$ substrate $\left(\sim K_{\mathrm{M}}\right)$ concentration (LÖSER et al., 2008). 
Figure 31. Reversible fast-binding behavior of Neq0710.

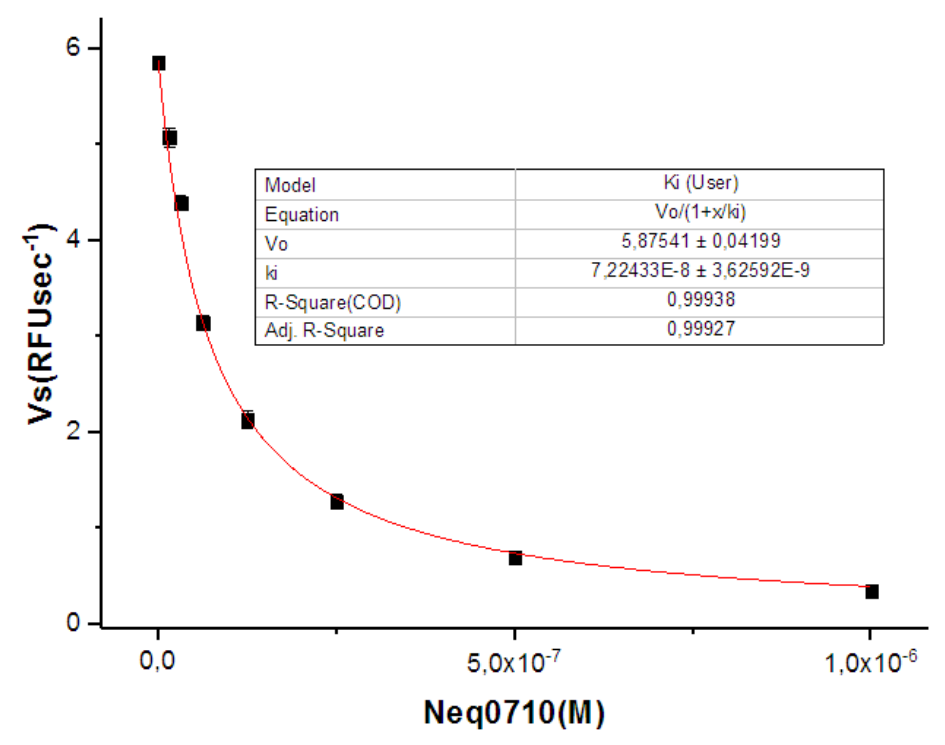

Source: Own author.

As a general example the kinetic assays for Neq0710 is reported here. Monitoring cruzain-catalyzed hydrolysis of Z-Phe-Arg-7-amido-4-methylcoumarin in the presence of increasing concentrations of compound Neq0710 (starting from $10 \mu \mathrm{M}, 7$ concentrations, dilution of 0.5 ; Figure 32). The reaction $(\mathrm{pH} 5.5,300 \mathrm{mM} \mathrm{NaCl}, 5 \mathrm{mM}$ DTT (dithiothreitol), 5\% v/v DMSO (dimethyl sulfoxide), 0.01\% v/v Triton X-100 and $0.15 \mathrm{nM}$ Cruzain) was initiated by addition of the substrate $(1.7 \mu \mathrm{M})$ after incubating the inhibitor with the enzyme for $2 \mathrm{~min}$. Fluorescence emission at $440 \mathrm{~nm}$ was measured after excitation at $360 \mathrm{~nm}$. Fluorescence units (FU) were corrected for background fluorescence. The rate of hydrolysis of Z-Phe-Arg-7-amido-4methylcoumarin was plotted versus concentrations of Neq0710. Non-linear regression gave an apparent inhibition constant $K_{i}^{\prime}=\left(1+[\mathrm{S}] / K_{\mathrm{M}}\right) K_{\mathrm{i}}=72.2 \pm 3.6 \mathrm{nM}$. The same method was applied for the others nitrile based compounds as well for CatL.

8.2.4. Kinetic parameters determination of slow-binding inhibitors

To determine the kinetic parameters associated with slow binding inhibition of cruzain, progress curves in the presence of azadipeptide nitriles Neq0676, Neq0677, Neq0689 and Neq0690 were obtained in the presence for eleven different concentrations of 


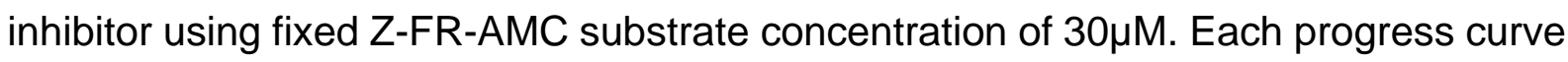
was analyzed by non-linear regression using slow-binding Equation 1 described by Morrison and Walsh (TOONE, 2008):

$$
[P]=v_{s} t+\frac{\left(v_{i}-v_{s}\right)\left(1-e^{-k_{o b s}}\right)}{k_{o b s}}+d \quad \text { (equation 1) }
$$

Whereas $[\mathrm{P}]$ is the product concentration, $\mathrm{v}_{\mathrm{s}}$ is the steady-state rate, $\mathrm{v}_{\mathrm{i}}$ is the initial rate, $k_{o b s}$ is the observed first-order rate constant, and $d$ is the offset. $v_{s}$ and $v_{0}$ values were plotted versus the inhibitor concentration [l], according to equation 2 to obtain $K_{i}^{\prime}$ :

$v_{s}=\frac{v_{0}}{1+[I] / K_{i}^{\prime}} \quad$ (equation 2)

The $K_{\mathrm{i}}$ value was calculated from equation 3 :

$K_{i}=\frac{K_{i}^{\prime}}{1+[S] / K_{M}} \quad$ (equation 3)

The apparent second-order rate constant $k_{o n}^{\prime}$ was obtained by linear regression according to equation 4 :

$k_{o b s}=k_{o n}^{\prime}[I]+k_{o f f} \quad$ (equation 4)

The true rate constant $k_{\text {on }}$ was calculated by correction of $k_{o n}^{\prime}$ according to equation 5:

$k_{o n}=k_{o n}^{\prime}\left(1+[S] / K_{M}\right) \quad$ (equation 5$)$

The first-order rate constant $k_{\text {off }}$ for the dissociation of the enzyme-inhibitor complex was calculated according to equation 6 :

$k_{o f f}=k_{o n} K_{i} \quad$ (equation 6) 
Figure 32. Slow-binding behavior of azadipeptide nitrile (Neq0677).
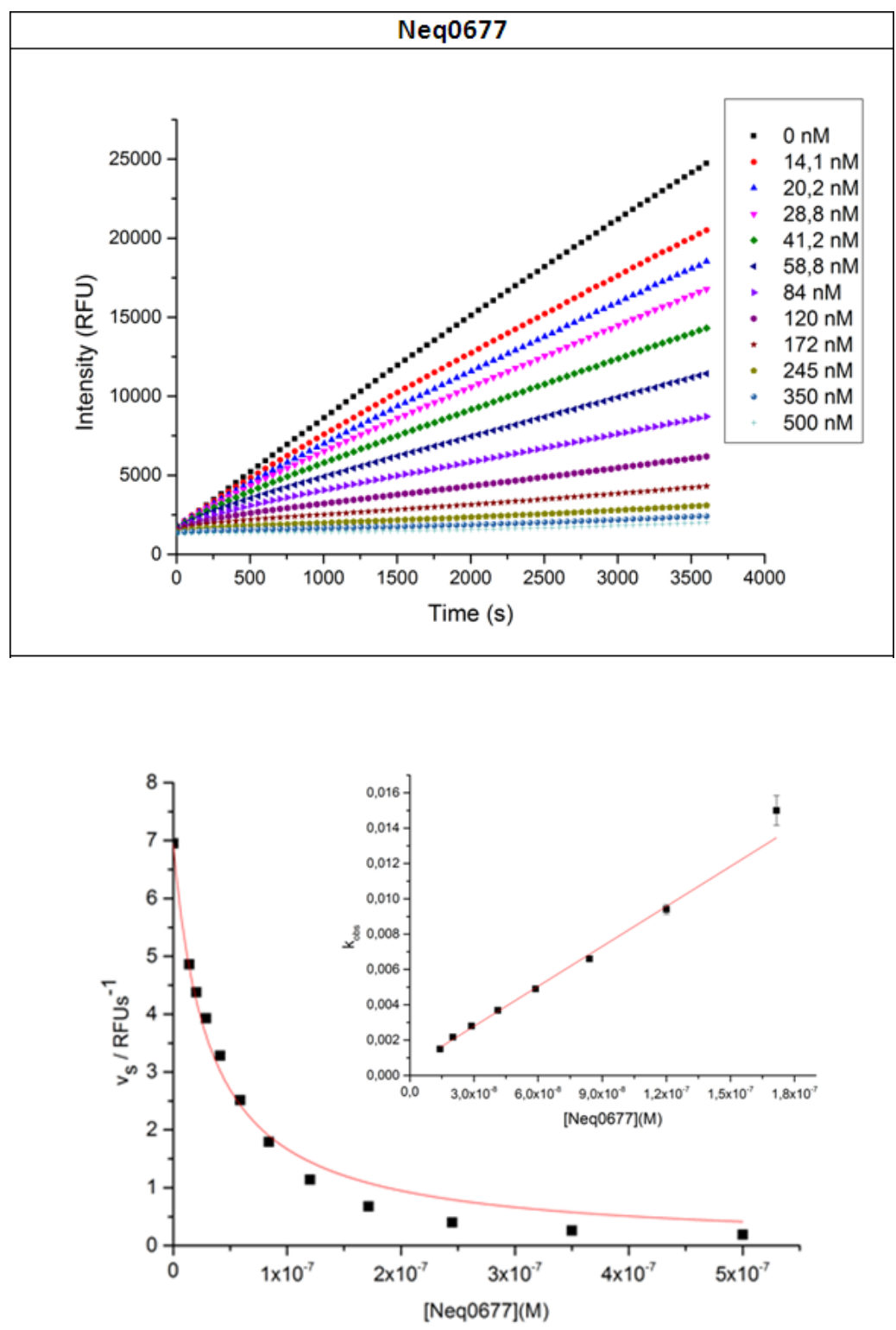

Up: Measuring RFU ( $\mathrm{sec}^{-1}$ ) Vs time (sec) for Ne0677 for $3600 \mathrm{sec}$, for eleven different concentrations. Down: Slow-binding behavior of azadipeptide nitriles. Source: Retrieved from SILVA, G. D. et al. A comparative study of warheads for design of cysteine protease inhibitors. Bioorganic \& Medicinal Chemistry Letters, v. 27, p. 5031-5035, oct. 2017.

As a general example the kinetic assays for Neq0677 are reported here. It was monitoring (Figure 7a and 7b) the cruzain-catalyzed hydrolysis of Z-Phe-Arg-7-amido4-methylcoumarin $(30 \mu \mathrm{M})$ in the presence of increasing concentrations of compound Neq0677 (eleven concentrations, from 500nM, dilution of 0.7). The reaction $(\mathrm{pH} 5.5$, $300 \mathrm{mM} \mathrm{NaCl}, 5 \mathrm{mM}$ DTT (dithiothreitol), 5\% v/v DMSO (dimethyl sulfoxide), 0.01\% $\mathrm{v} / \mathrm{v}$ Triton X-100 and $0.15 \mathrm{nM}$ Cruzain) was initiated by addition of the enzyme. 
Fluorescence emission at $440 \mathrm{~nm}$ was measured after excitation at $360 \mathrm{~nm}$. Fluorescence units (FU) were corrected for background fluorescence. Plot of the rates of hydrolysis of Z-Phe-Arg-7-amido-4-methylcoumarin versus concentrations of Neq0677. Non-linear regression gave an apparent inhibition constant $K_{i}^{\prime}=$ $\left(1+[\mathrm{S}] / K_{\mathrm{M}}\right) K_{\mathrm{i}}$. The inset is a plot of the first-order rate constants $K_{0}$ bs versus concentrations of Neq0677. Linear regression gave a second-order rate constant kon' $=k_{\mathrm{on}} /\left(1+\left([\mathrm{S}] / K_{\mathrm{M}}\right)\right.$.

\subsubsection{Assessment of reversibility mode of binding}

The reversibility of compound Neq0677, Neq0689 and Neq0690 to Cz and CatL was tested by measuring the recovery of enzyme activity after a rapid and extensive dilution of the enzyme-inhibitor complex. The inhibitor was incubated at a concentration 10 times greater than its $K_{\mathrm{i}}$ value with 100 times the concentration of the enzyme required for enzyme activity assay for $30 \mathrm{~min}$. The mixture was then diluted by a factor of 100 in the reaction buffer, containing the Z-Phe-Arg-AMC substrate at the final concentration of $7 \mu \mathrm{M}$ as controls compound Neq0570 (reversible) and E-64 inhibitor (irreversible) were used. Recovery of enzyme activity after dilution of the inhibitor $\mathrm{Cz}$ (or CatL) complex suggests a reversible inhibition mechanism for Neq0690.

Figure 33. Reversibility plot of compound Neq0690 with Cz.

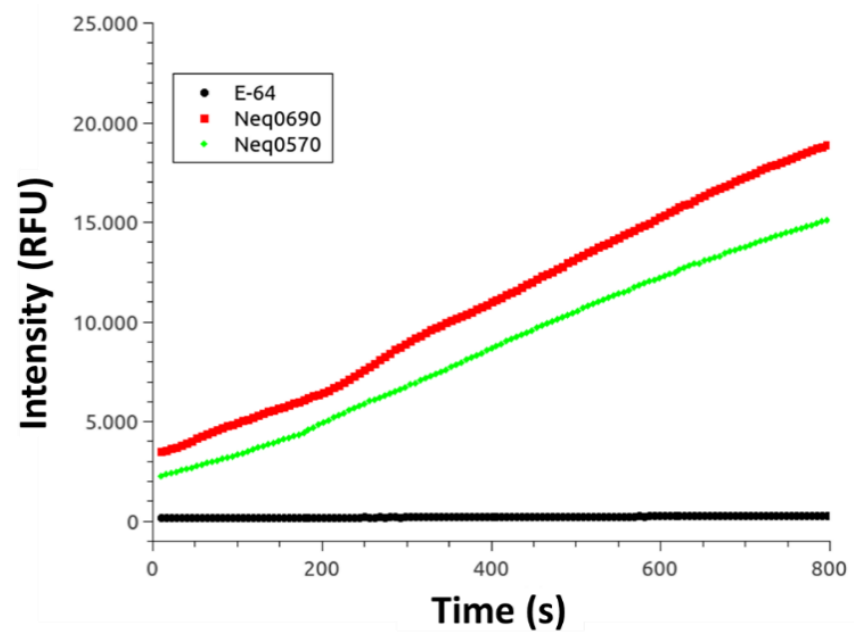


E-64 (irreversible, black line); Neq0690 (reversible, red line); Neq0570 (reversible, green line). Source: Retrieved from SILVA, G. D. et al. A comparative study of warheads for design of cysteine protease inhibitors. Bioorganic \& Medicinal Chemistry Letters, v. 27, p. 50315035, oct. 2017. 


\section{FINAL CONCLUSIONS AND OUTLOOK}

An extensive analysis of structure-activity relationships (SARs) has been performed on nitrile-based cysteine protease inhibitors. Some of the crucial reasons for inhibition of cysteine proteases in infectious diseases (Chagas and Leishmaniasis) and in humans (for instance, Chagas heart diseases) have been adequately mapped. By applying a knowledge-based design approach, we have designed and synthesized a new series of over 40 dipeptidyl nitrile inhibitors of $\mathrm{Cz}$ which has led to leverage the S3/P3 interactions, understand the role of the cyclopropane moiety in the bimolecular recognition process and map the $\mathrm{S} 1 / \mathrm{S} 1^{\prime}$ to increase affinity and selectivity around the studied PCs. Following the engineering of the hereof molecular modifications, a new generation of dipeptidyl nitriles was created as high-affinity $\mathrm{Cz}$ inhibitors. Inhibitors Neq0887, Neq0938 and Neq0940 showed trypanocidal activity, EC $\mathrm{E}_{50}$ (T. cruzi) of about $4 \mu \mathrm{M}$ in a low micromolar range, with low effect on host cell cytotoxicity ( $\mathrm{SI}>$ 20). Hence, they may be considered as new candidates for in vivo studies against the acute form of Chagas disease. Besides that, combination of P3 and P2 groups led to the first dipeptidyl nitrile synthesized in our group to have a difference in affinity between $\mathrm{Cz}$ and $\mathrm{CatL}$ over one log unit in favor of the protozoan CP. In addition, kinetic evaluation on a panel of human cathepsins resulted in three new inhibitors at one-digit CatK nanomolar concentrations (i.e. Neq0955 and Neq0958) and eight inhibitors at one-digit CatL nanomolar concentrations (i.e. Neq0953 and Neq0954).

In addition, we have performed an extensive SAR (over 25 compounds) for nonpeptidic nitrile based inhibitors reporting one-digit nanomolar $\mathrm{Cz}$ inhibition (Neq0643, Neq0659 and Neq0820) with good selectivity over CatL. This work likewise elucidates the influence of the stereochemistry of the trifluoroethylamine group in P2/P3 and displays a new way to represent a nonadditive SAR. An unexpected outcome arose after the identification of cysteine protease inhibitors at low nanomolar concentrations: most of the compounds showed no trypanocidal activity. Although this event is not uncommon, it points out the difficulty and ongoing challenge to translate enzyme inhibition to trypanocidal activity. That is, despite the scientific innovation of identifying new competitive cruzain inhibitors and the discovery of promising new candidates for 
Chagas disease, not all inhibitors act as trypanocidal agents and therefore further research is warranted.

Similarly, we have evaluated the sulfonamide bond in P3/P2 as bioisosteres of the amide bond by performing the design, synthesis and biological study of a new set of reversible inhibitors. The flat SAR for $\mathrm{Cz}$ suggests a new mode of binding that needs to be elucidated in future studies. Yet, out of the same set of compounds, the inhibitor Neq0830 exhibits a strong CatS affinity ( $p K i$ 8.4) with selectivity of more than one log unit over other mammalian CPs.

Alternative warhead effects to nitrile have been explored for $\mathrm{Cz}$ inhibition. Biochemical assays present azadipeptide nitriles with two magnitude orders higher $\mathrm{Cz}$ affinity than the corresponding dipeptide nitriles. Furthermore, azadipeptide nitriles display low micromolar potency as $T$. cruzi killers but with no selectivity in respect to the host cell. Nevertheless, the azadipeptide nitrile compound (Neq0690) was used for the generation of the first high-resolution x-Ray crystal structure of Leishmania mexicana cysteine protease $B(\mathrm{LmCPB})$.

In perspective, the synthesis of dipeptidyl nitriles should be used to map new subsites and to endeavor non-natural amino acids. In particular, the structure of Neq0940, Neq0938 and Neq0877 should be optimized to improve their pharmacokinetics and pharmacodynamics profiles. Also, research should be focused on new possible bioisosteres of the carbonyl group (i.e. oxetane, currently being pursued in our research group) of the amide bond in P3/P2 position to gain metabolic stability without loss of affinity towards $\mathrm{Cz}$. Biological studies should try to explain the lack of trypanocidal activity for low nanomolar $\mathrm{Cz}$ inhibitors as for Neq0659, Neq0643 and Neq0820 to reinforce the validation of the $\mathrm{Cz}$ as a target or to invalidate it. Based on our results, a long-term study should focus on the discovery of new warheads for cysteine protease inhibition. The intrinsic electrophile reactivity of new warheads should be considered to yield a balanced reactive profile and to prevent nonspecific off-target while forming a desirable reversible covalent bond with the opportune cysteine protease. 


\section{BIBLIOGRAPHY}

ASAAD, N. et al. Dipeptidyl nitrile inhibitors of Cathepsin L. Bioorganic \& Medicinal Chemistry Letters, v. 19, n. 15, p. 4280-4283, ago. 2009.

AVELAR, L. A. A. et al. Molecular Design, Synthesis and Trypanocidal Activity of Dipeptidyl Nitriles as Cruzain Inhibitors. PLOS Neglected Tropical Diseases, v. 9, n. 7, p. e0003916, jul. 2015.

BANDINI, M. et al. New Electrochemically Generated Polymeric Pd Complexes as Heterogeneous Catalysts for Suzuki Cross-Coupling Reactions. European Journal of Organic Chemistry, v. 2009, n. 21, p. 3554-3561, jul. 2009.

BEAULIEU, C. et al. Identification of potent and reversible cruzipain inhibitors for the treatment of Chagas disease. Bioorganic \& Medicinal Chemistry Letters, v. 20, n. 24, p. 7444-7449, dez. 2010.

BERN, C. et al. Trypanosoma cruzi and Chagas' Disease in the United States. Clinical Microbiology Reviews, v. 24, n. 4, p. 655-681, out. 2011.

BOGGILD, M. K. et al. Odanacatib for the treatment of osteoporosis. Expert Opinion on Pharmacotherapy, v. 16, n. 11, p. 1717-1726, jul. 2015.

BOWER, J. et al. Structure-based design of agents targeting the bacterial ribosome. Bioorganic \& Medicinal Chemistry Letters, v. 13, n. 15, p. 2455-2458, ago. 2003.

BRINEN, L. S. et al. A target within the target: probing cruzain's P1' site to define structural determinants for the Chagas' disease protease. Structure, v. 8, n. 8, p. 831840, ago. 2000.

BURTOLOSO, A. C. B. et al. Anti-trypanosomal activity of non-peptidic nitrile-based cysteine protease inhibitors. PLOS Neglected Tropical Diseases, v. 11, n. 2, p. e0005343, fev. 2017. 
CALABRÒ, G. et al. Elucidation of Nonadditive Effects in Protein-Ligand Binding Energies: Thrombin as a Case Study. The Journal of Physical Chemistry B, v. 120, n. 24, p. 5340-5350, jun. 2016.

CASTRO, J. A.; DEMECCA, M. M.; BARTEL, L. C. Toxic Side Effects of Drugs Used to Treat Chagas' Disease (American Trypanosomiasis). Human \& Experimental Toxicology, v. 25, n. 8, p. 471-479, ago. 2006.

CAZZULO, J. J. et al. Some kinetic properties of a cysteine proteinase (cruzipain) from Trypanosoma cruzi. Biochimica et Biophysica Acta (BBA) - Protein Structure and Molecular Enzymology, v. 1037, n. 2, p. 186-191, fev. 1990.

Chagas disease (American trypanosomiasis). Disponível em: <https://www.who.int/news-room/fact-sheets/detail/chagas-disease-(americantrypanosomiasis)>. Acesso em: jul. 2019.

CHAUHAN, S. S.; GOLDSTEIN, L. J.; GOTTESMAN, M. M. Expression of cathepsin L in human tumors. Cancer Research, v. 51, n. 5, p. 1478-1481, mar. 1991.

CHENG CHEN et al. Diastereoselective reductive amination process, [s.d.].

CIANNI, L. et al. Leveraging the cruzain S3 subsite to increase affinity for reversible covalent inhibitors. Bioorganic chemistry, v. 79, p. 285-292, set. 2018.

CIANNI, L. et al. Can Cysteine Protease Cross-Class Inhibitors Achieve Selectivity? Journal of Medicinal Chemistry, p. acs.jmedchem.9b00683, ago. 2019.

COURA, J. R. The discovery of Chagas disease (1908-1909): great successes and certain misunderstandings and challenges. Revista da Sociedade Brasileira de Medicina Tropical, v. 46, n. 4, p. 389-390, jul. 2013.

COURA, J. R.; VIÑAS, P. A. Chagas disease: a new worldwide challenge. Nature, v. 465, n. S7301, p. S6-S7, jun. 2010.

CRISTAU, H.-J. et al. Synthesis of New Arylhydroxymethylphosphinic Acids and Derivatives. Synthesis, n. 14, p. 2216-2220, jul. 2003. 
CROFT, S. L.; COOMBS, G. H. Leishmaniasis--current chemotherapy and recent advances in the search for novel drugs. Trends in Parasitology, v. 19, n. 11, p. 502508, nov. 2003.

CRUZ-CABEZA, A. J.; ALLEN, F. H. Conformation and geometry of cyclopropane rings having $\pi$-acceptor substituents: a theoretical and database study. Acta Crystallographica Section B Structural Science, v. 67, n. 1, p. 94-102, fev. 2011.

DAINA, A.; MICHIELIN, O.; ZOETE, V. SwissADME: a free web tool to evaluate pharmacokinetics, drug-likeness and medicinal chemistry friendliness of small molecules. Scientific Reports, v. 7, n. 1, p. 42717, maio 2017.

DEATON, D. N.; KUMAR, S. Cathepsin K Inhibitors: Their Potential as AntiOsteoporosis Agents. In: Progress in Medicinal Chemistry. [s.I.] Elsevier, 2004. v. 42p. 245-375.

DENG, N. et al. Elucidating the Energetics of Entropically Driven Protein-Ligand Association: Calculations of Absolute Binding Free Energy and Entropy. The Journal of Physical Chemistry B, v. 115, n. 41, p. 11902-11910, out. 2011.

DIMOVA, D.; BAJORATH, J. Advances in Activity Cliff Research. Molecular Informatics, v. 35, n. 5, p. 181-191, maio 2016.

DUNITZ, J. D.; TAYLOR, R. Organic Fluorine Hardly Ever Accepts Hydrogen Bonds. Chemistry - A European Journal, v. 3, n. 1, p. 89-98, jan. 1997.

EAKIN, A. E. et al. Production of crystallizable cruzain, the major cysteine protease from Trypanosoma cruzi. The Journal of Biological Chemistry, v. 268, n. 9, p. 61156118, mar. 1993.

FERREIRA, R. S. et al. Divergent Modes of Enzyme Inhibition in a Homologous Structure-Activity Series. Journal of Medicinal Chemistry, v. 52, n. 16, p. 50055008, ago. 2009.

GAUTHIER, J. Y. et al. The discovery of odanacatib (MK-0822), a selective inhibitor of cathepsin K. Bioorganic \& Medicinal Chemistry Letters, v. 18, n. 3, p. 923-928, fev. 2008. 
GEHRINGER, M.; LAUFER, S. A. Emerging and Re-Emerging Warheads for Targeted Covalent Inhibitors: Applications in Medicinal Chemistry and Chemical Biology. Journal of Medicinal Chemistry, v. 62, n. 12, p. 5673-5724, jun. 2019.

GILLMOR, S. A.; CRAIK, C. S.; FLETTERICK, R. J. Structural determinants of specificity in the cysteine protease cruzain. Protein Science, v. 6, n. 8, p. 1603-1611, ago. 1997.

GOMES, J. C. et al. Synthesis and structure-activity relationship of nitrile-based cruzain inhibitors incorporating a trifluoroethylamine-based P2 amide replacement. Bioorganic \& Medicinal Chemistry, v. 27, n. 22, p. 115083, nov. 2019.

HANN, M. M.; LEACH, A. R.; HARPER, G. Molecular complexity and its impact on the probability of finding leads for drug discovery. Journal of Chemical Information and Computer Sciences, v. 41, n. 3, p. 856-864, jun. 2001.

HARDEGGER, L. A. et al. Systematic investigation of halogen bonding in proteinligand interactions. Angewandte Chemie (International Ed. in English), v. 50, n. 1, p. 314-318, jan. 2011.

HUANG, L.; BRINEN, L. S.; ELLMAN, J. A. Crystal structures of reversible ketoneBased inhibitors of the cysteine protease cruzain. Bioorganic \& Medicinal Chemistry, v. 11, n. 1, p. 21-29, jan. 2003.

HUGHES, G. et al. Diastereoselective Reductive Amination of Aryl Trifluoromethyl Ketones and a-Amino Esters. Angewandte Chemie International Edition, v. 46, n. 11, p. 1839-1842, mar. 2007.

IVANOV, A. S.; ZHALNINA, A. A.; SHISHKOV, S. V. A convergent approach to synthesis of bortezomib: the use of TBTU suppresses racemization in the fragment condensation. Tetrahedron, v. 65, n. 34, p. 7105-7108, ago. 2009.

JACKSON, Y.; PINTO, A.; PETT, S. Chagas disease in Australia and New Zealand: risks and needs for public health interventions. Tropical Medicine \& International Health, v. 19, n. 2, p. 212-218, fev. 2014. 
K777 (Chagas) | DNDi. Disponível em: <https://www.dndi.org/diseasesprojects/portfolio/completed-projects/k777/>. Acesso em: 17 jul. 2019.

KENNY, P. W. The nature of ligand efficiency. Journal of Cheminformatics, v. 11, n. 1, p. 8, dez. 2019.

KENNY, P. W.; SADOWSKI, J. Structure Modification in Chemical Databases. In: OPREA, T. I. (Ed.). . Methods and Principles in Medicinal Chemistry. Weinheim, FRG: Wiley-VCH Verlag GmbH \& Co. KGaA, 2005. p. 271-285.

KIRSCHKE, H. et al. Cathepsin L. A New Proteinase from Rat-Liver Lysosomes. European Journal of Biochemistry, v. 74, n. 2, p. 293-301, abr. 1977.

KRAMER, C.; FUCHS, J. E.; LIEDL, K. R. Strong Nonadditivity as a Key StructureActivity Relationship Feature: Distinguishing Structural Changes from Assay Artifacts. Journal of Chemical Information and Modeling, v. 55, n. 3, p. 483-494, mar. 2015.

KRAMER, L.; TURK, D.; TURK, B. The Future of Cysteine Cathepsins in Disease Management. Trends in Pharmacological Sciences, v. 38, n. 10, p. 873-898, out. 2017.

LI, C. S. et al. Identification of a potent and selective non-basic cathepsin $\mathrm{K}$ inhibitor. Bioorganic \& Medicinal Chemistry Letters, v. 16, n. 7, p. 1985-1989, abr. 2006.

LOFFET, A. Peptides as Drugs: Is There a Market? Journal of Peptide Science, v. 8, n. 1, p. 1-7, jan. 2002.

LONSDALE, R. et al. Expanding the Armory: Predicting and Tuning Covalent Warhead Reactivity. Journal of Chemical Information and Modeling, v. 57, n. 12, p. 31243137, dez. 2017.

LÖSER, R. et al. Azadipeptide Nitriles: Highly Potent and Proteolytically Stable Inhibitors of Papain-Like Cysteine Proteases. Angewandte Chemie International Edition, v. 47, n. 23, p. 4331-4334, maio 2008.

LU, J. et al. Advances in the discovery of cathepsin $\mathrm{K}$ inhibitors on bone resorption. Journal of Enzyme Inhibition and Medicinal Chemistry, v. 33, n. 1, p. 890-904, jan. 2018. 
MAETZ, P.; RODRIGUEZ, M. A simple preparation of N-protected chiral $\alpha-$ aminonitriles from $\mathrm{N}$-protected $\alpha$-amino acid amides. Tetrahedron Letters, v. 38, n. 24, p. 4221-4222, jun. 1997.

MAGGIORA, G. M. On Outliers and Activity CliffsWhy QSAR Often Disappoints. Journal of Chemical Information and Modeling, v. 46, n. 4, p. 1535-1535, jul. 2006.

MARIN-NETO, J. A. et al. Pathogenesis of chronic Chagas heart disease. Circulation, v. 115 , n. 9, p. 1109-1123, mar. 2007.

MCGRATH, M. E. et al. The crystal structure of cruzain: a therapeutic target for Chagas' disease. Journal of Molecular Biology, v. 247, n. 2, p. 251-259, mar. 1995.

MONS, E. et al. The Alkyne Moiety as a Latent Electrophile in Irreversible Covalent Small Molecule Inhibitors of Cathepsin K. Journal of the American Chemical Society, v. 141, n. 8, p. 3507-3514, fev. 2019.

MONTANARI, M. L. et al. QSAR based on biological microcalorimetry. Journal of Medicinal Chemistry, v. 43, n. 18, p. 3448-3452, set. 2000.

MOTTRAM, J. C.; BROOKS, D. R.; COOMBS, G. H. Roles of cysteine proteinases of trypanosomes and Leishmania in host-parasite interactions. Current Opinion in Microbiology, v. 1, n. 4, p. 455-460, ago. 1998.

NDAO, M. et al. Reversible Cysteine Protease Inhibitors Show Promise for a Chagas Disease Cure. Antimicrobial Agents and Chemotherapy, v. 58, n. 2, p. 1167-1178, fev. 2014.

NÚÑEZ, S.; VENHORST, J.; KRUSE, C. G. Target-drug interactions: first principles and their application to drug discovery. Drug Discovery Today, v. 17, n. 1-2, p. 10 22, jan. 2012.

PAASCHE, A.; SCHIRMEISTER, T.; ENGELS, B. Benchmark Study for the CysteineHistidine Proton Transfer Reaction in a Protein Environment: Gas Phase, COSMO, QM/MM Approaches. Journal of Chemical Theory and Computation, v. 9, n. 3, p. 1765-1777, mar. 2013. 
PEREIRA, P. C.; NAVARRO, E. Challenges and perspectives of Chagas disease: a review. Journal of Venomous Animals and Toxins including Tropical Diseases, v. 19 , n. 1 , p. 34 , fev. 2013.

PRATA, A. Clinical and epidemiological aspects of Chagas disease. The Lancet. Infectious Diseases, v. 1, n. 2, p. 92-100, set. 2001.

PROKOPCZYK, I. M. et al. Integration of methods in cheminformatics and biocalorimetry for the design of trypanosomatid enzyme inhibitors. Future Medicinal Chemistry, v. 6, n. 1, p. 17-33, jan. 2014.

RENSLO, A. R.; MCKERROW, J. H. Drug discovery and development for neglected parasitic diseases. Nature Chemical Biology, v. 2, n. 12, p. 701-710, dez. 2006.

SAJID, M. et al. Cruzain : the path from target validation to the clinic. Advances in Experimental Medicine and Biology, v. 712, p. 100-115, dez. 2011.

SANI, M.; VOLONTERIO, A.; ZANDA, M. The Trifluoroethylamine Function as Peptide Bond Replacement. ChemMedChem, v. 2, n. 12, p. 1693-1700, dez. 2007.

SAXTY, G. et al. Identification of Inhibitors of Protein Kinase B Using Fragment-Based Lead Discovery ${ }^{\dagger}$. Journal of Medicinal Chemistry, v. 50, n. 10, p. 2293-2296, maio 2007.

SCHEIDT, K. A. et al. Structure-based design, synthesis and evaluation of conformationally constrained cysteine protease inhibitors. Bioorganic \& Medicinal Chemistry, v. 6, n. 12, p. 2477-2494, dez. 1998.

SCHMITZ, J. et al. Cathepsin B Inhibitors: Combining Dipeptide Nitriles with an Occluding Loop Recognition Element by Click Chemistry. ACS Medicinal Chemistry Letters, v. 7, n. 3, p. 211-216, mar. 2016.

SCHMITZ, J. et al. Cathepsin B: Active site mapping with peptidic substrates and inhibitors. Bioorganic \& Medicinal Chemistry, v. 27, n. 1, p. 1-15, jan. 2019.

SCHNEIDER, T. H. et al. Vinyl sulfone building blocks in covalently reversible reactions with thiols. New Journal of Chemistry, v. 39, n. 7, p. 5841-5853, fev. 2015. 
SEHGELMEBLE, F. et al. Sulfonimidamides as Sulfonamides Bioisosteres: Rational Evaluation through Synthetic, in Vitro, and in Vivo Studies with y-Secretase Inhibitors. ChemMedChem, v. 7, n. 3, p. 396-399, mar. 2012.

SHENDAGE, D. M.; FRÖHLICH, R.; HAUFE, G. Highly Efficient Stereoconservative Amidation and Deamidation of $\alpha$-Amino Acids. Organic Letters, v. 6, n. 21, p. 36753678, out. 2004.

SILVA, D. G. et al. A comparative study of warheads for design of cysteine protease inhibitors. Bioorganic \& Medicinal Chemistry Letters, v. 27, n. 22, p. 5031-5035, nov. 2017.

SIQUEIRA-NETO, J. L. et al. Cysteine proteases in protozoan parasites. PLoS neglected tropical diseases, v. 12, n. 8, p. e0006512, 2018.

STUMPFE, D.; BAJORATH, J. Exploring Activity Cliffs in Medicinal Chemistry: Miniperspective. Journal of Medicinal Chemistry, v. 55, n. 7, p. 2932-2942, abr. 2012.

SUDHAN, D. R.; SIEMANN, D. W. Cathepsin L targeting in cancer treatment. Pharmacology \& Therapeutics, v. 155, p. 105-116, nov. 2015.

TEAGUE, NULL et al. The Design of Leadlike Combinatorial Libraries. Angewandte Chemie (International Ed. in English), v. 38, n. 24, p. 3743-3748, dez. 1999.

TOONE, E. J. (ED.). Advances in Enzymology. Hoboken, NJ, USA: John Wiley \& Sons, Inc., 2008. v. 76

TSUCHIYA, D. et al. Direct Oxidative Conversion of Methylarenes into Aromatic Nitriles. Organic Letters, v. 15, n. 16, p. 4194-4197, ago. 2013.

TYRCHAN, C.; EVERTSSON, E. Matched Molecular Pair Analysis in Short: Algorithms, Applications and Limitations. Computational and Structural Biotechnology Journal, v. 15, p. 86-90, 2017.

URBINA, J. A. Specific chemotherapy of Chagas disease: relevance, current limitations and new approaches. Acta Tropica, v. 115, n. 1-2, p. 55-68, ago. 2010. 
VIEIRA, M. et al. Role for a P-type $\mathrm{H}^{+}$-ATPase in the acidification of the endocytic pathway of Trypanosoma cruzi. Biochemical Journal, v. 392, n. 3, p. 467-474, dez. 2005.

WIGGERS, H. J. et al. Non-peptidic Cruzain Inhibitors with Trypanocidal Activity Discovered by Virtual Screening and In Vitro Assay. PLoS Neglected Tropical Diseases, v. 7, n. 8, p. e2370, ago. 2013.

WIKLUND, P.; ROMERO, I.; BERGMAN, J. Products from dehydration of dicarboxylic acids derived from anthranilic acid. Organic \& Biomolecular Chemistry, v. 1, n. 19, p. 3396, 2003.

WRIGHT, J. A.; YU, J.; SPENCER, J. B. Sequential removal of the benzyl-type protecting groups PMB and NAP by oxidative cleavage using CAN and DDQ. Tetrahedron Letters, v. 42, n. 24, p. 4033-4036, jun. 2001.

YANG, P.-Y. et al. Design, Synthesis and Biological Evaluation of Potent Azadipeptide Nitrile Inhibitors and Activity-Based Probes as Promising Anti- Trypanosoma brucei Agents. Chemistry - A European Journal, v. 18, n. 21, p. 6528-6541, maio 2012. 
APPENDIX A

${ }^{1} \mathrm{H}$ NMR and ${ }^{13} \mathrm{C}$ NMR of key compounds.

Figure 34. ${ }^{1} \mathrm{H}$ NMR (500 MHz, DMSO- $d_{6}$ ) of compound 4 (Neq0710).

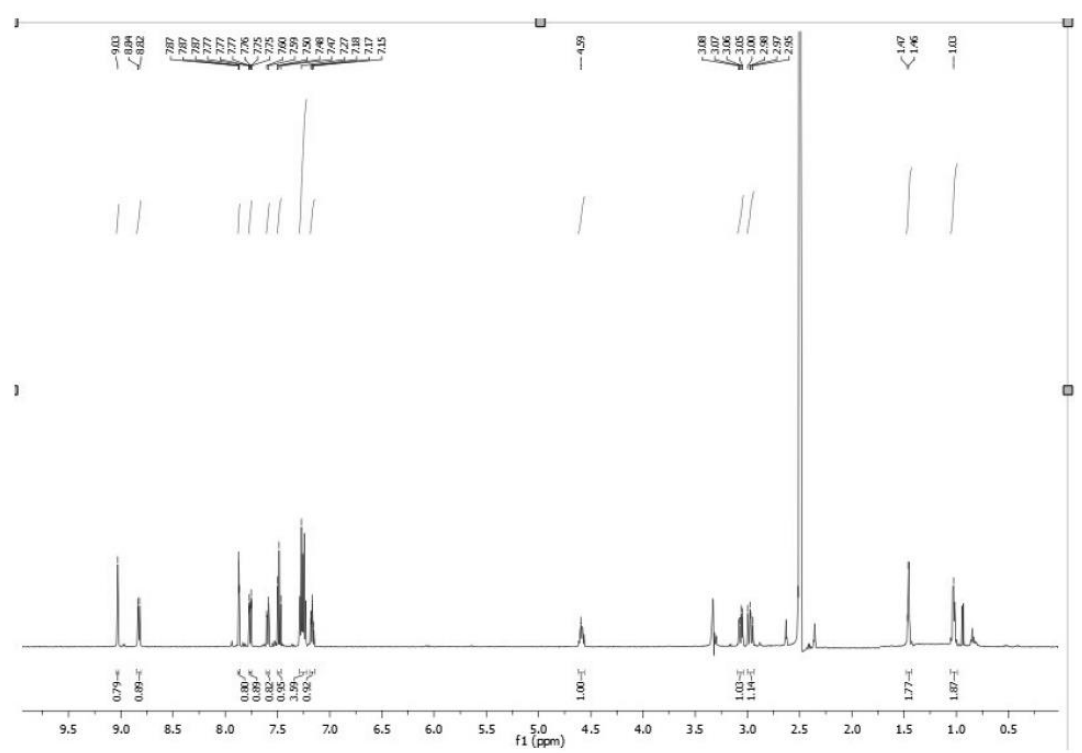

Figure 35. ${ }^{13} \mathrm{C}$ NMR (125 MHz, DMSO- $d_{6}$ ) of compound 4 (Neq0710).

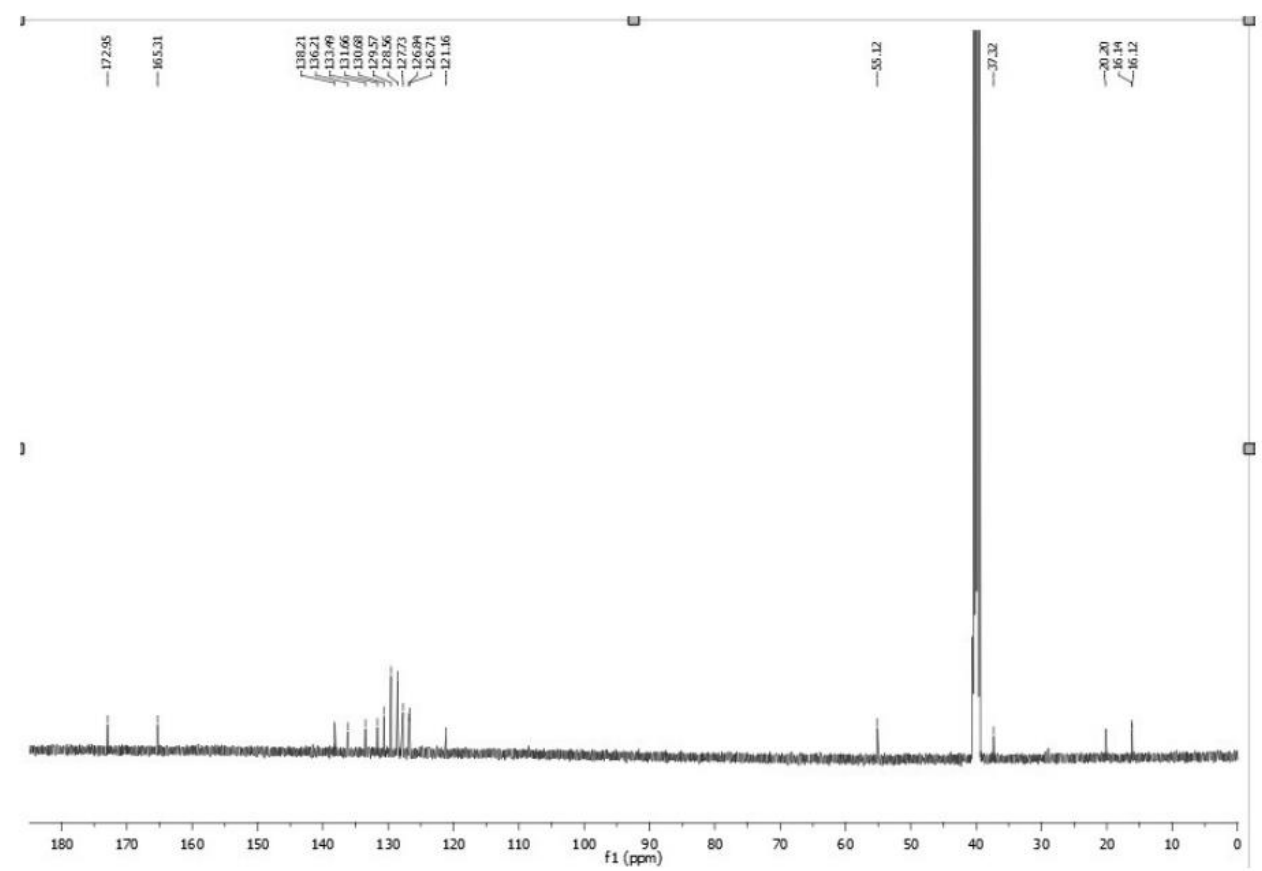


Figure 36. ${ }^{1} \mathrm{H}$ NMR $\left(500 \mathrm{MHz}\right.$, DMSO- $\left.d_{6}\right)$ of compound 6 (Neq0712).

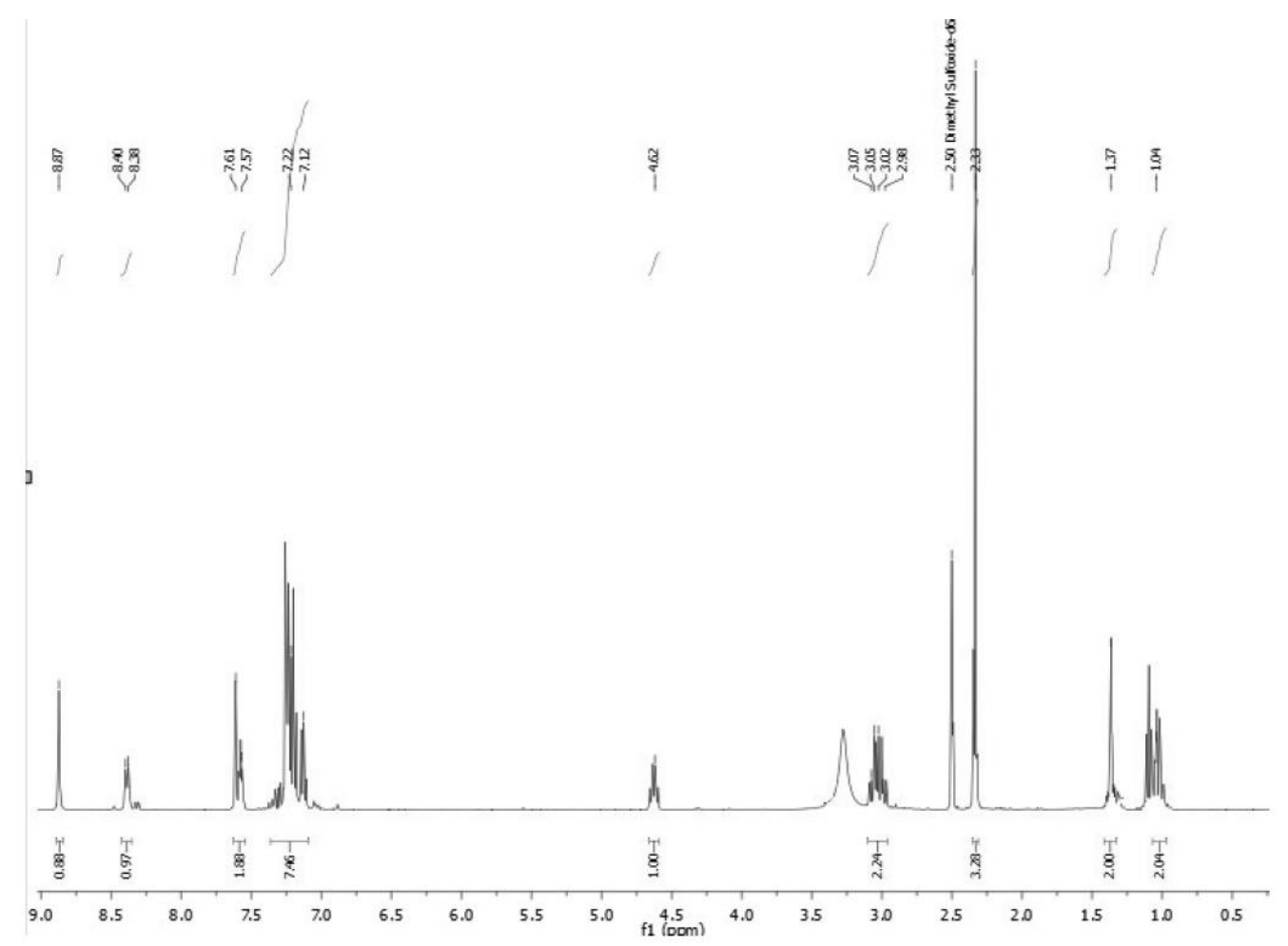

Figure 37. ${ }^{13} \mathrm{C}$ NMR (125 MHz, DMSO- $d_{6}$ ) of compound 6 (Neq0712).

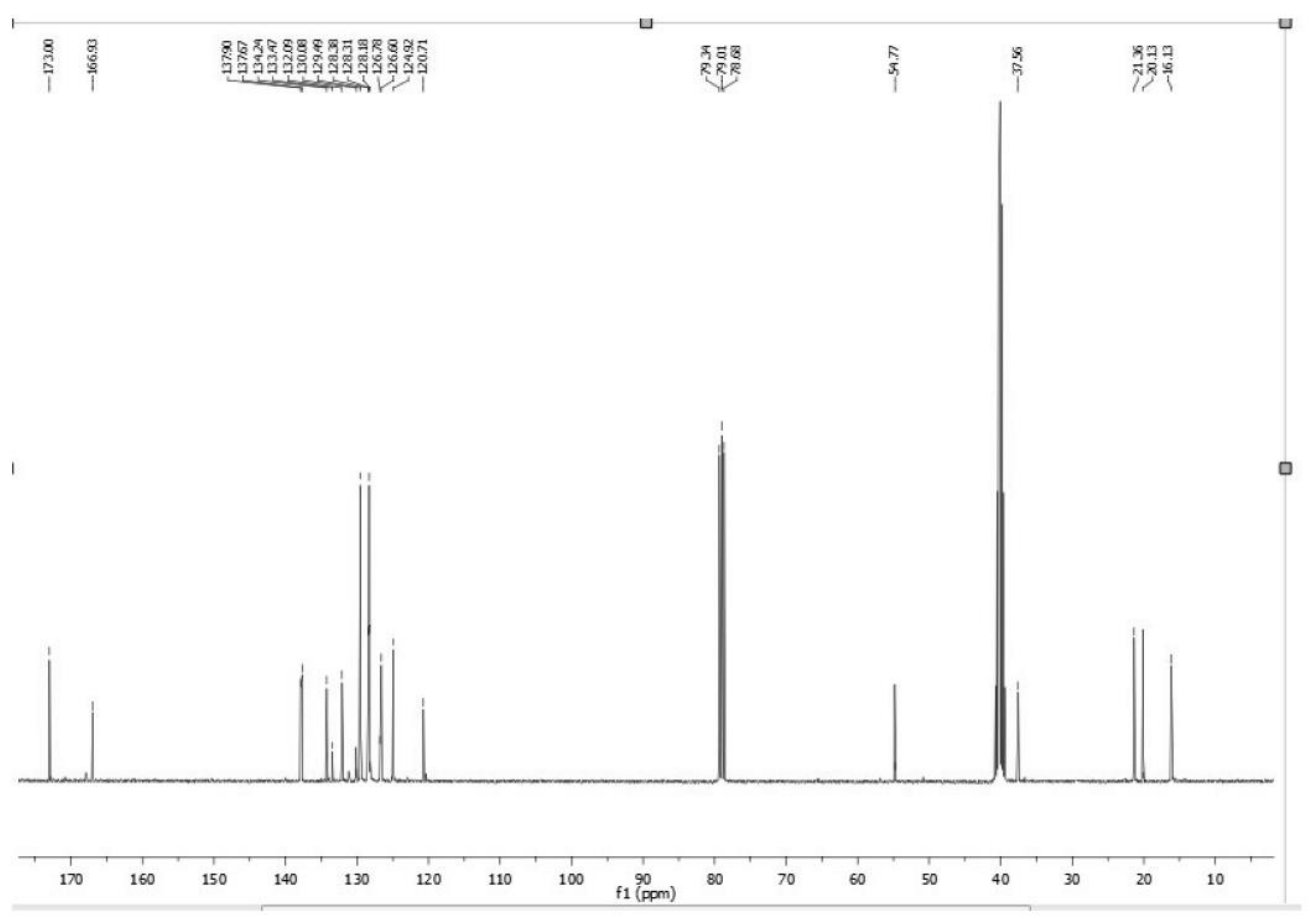


Figure 38. ${ }^{1} \mathrm{H}$ NMR $\left(500 \mathrm{MHz}\right.$, DMSO- $\left.d_{6}\right)$ of compound 7 (Neq0717).

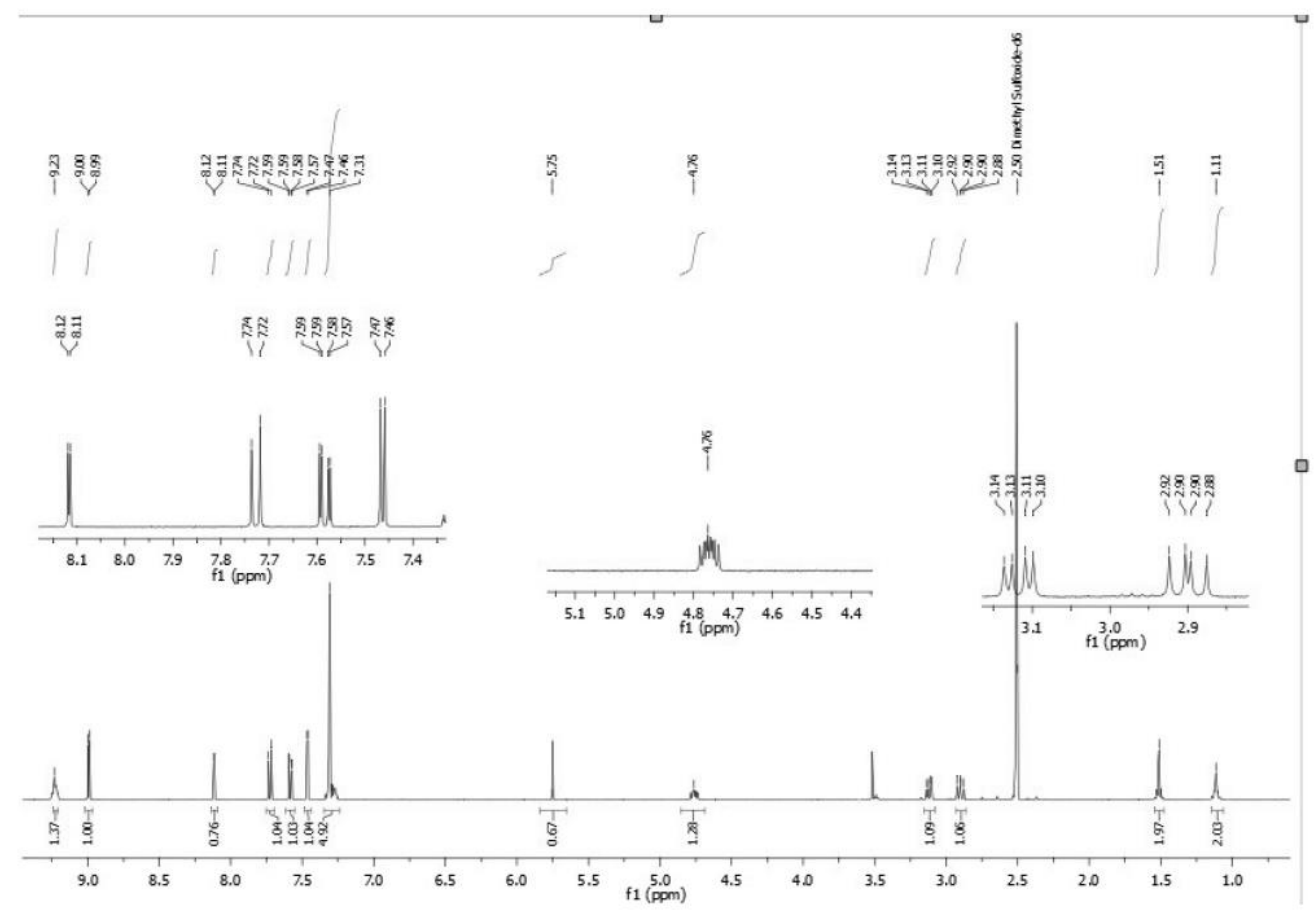

Figure $39 .{ }^{13} \mathrm{C}$ NMR (100 MHz, DMSO- $\left.d_{6}\right)$ of compound 7 (Neq0717).

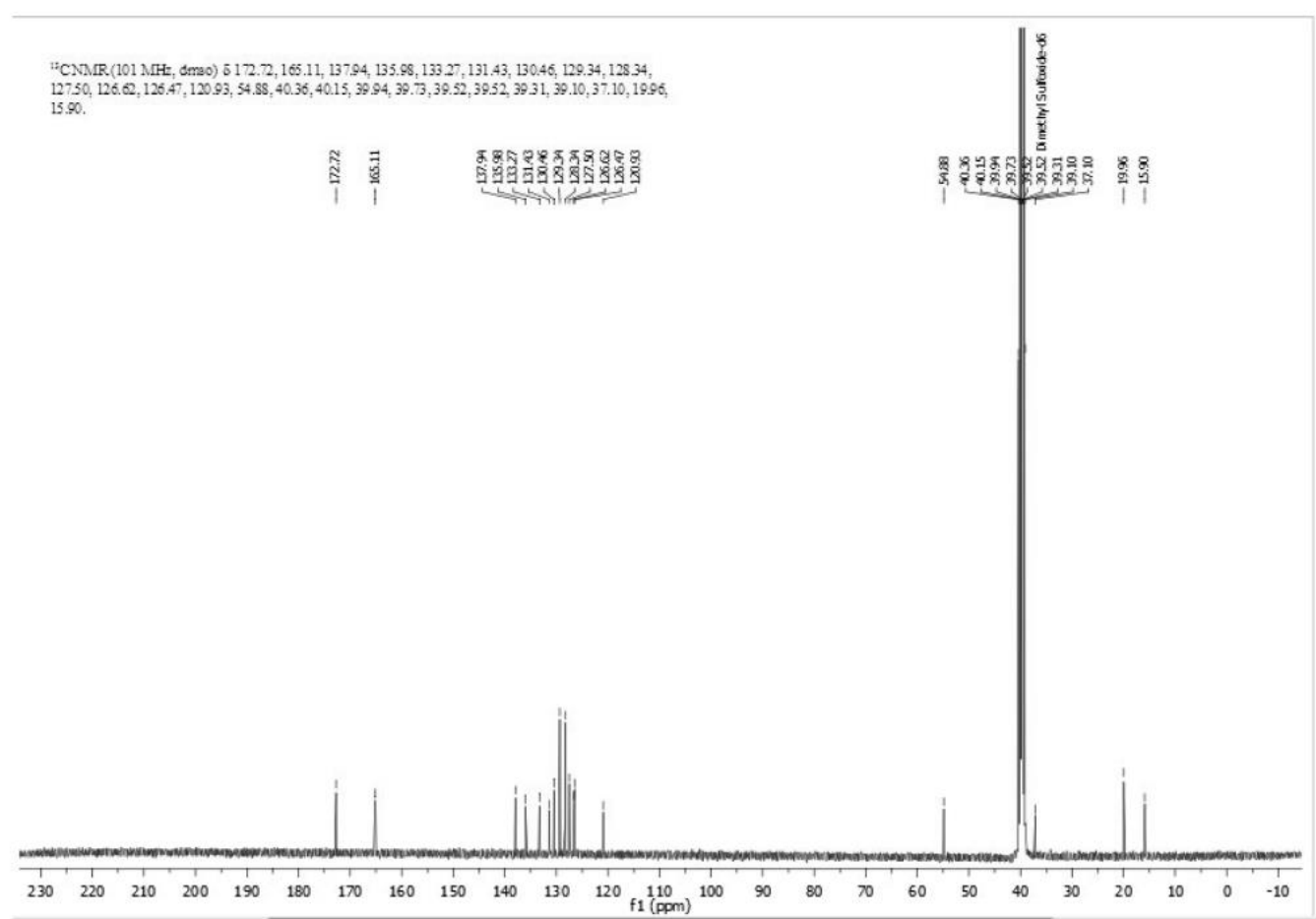


Figure 40. ${ }^{1} \mathrm{H}$ NMR $\left(500 \mathrm{MHz}\right.$, DMSO- $\left.d_{6}\right)$ of compound 9 (Neq0809).

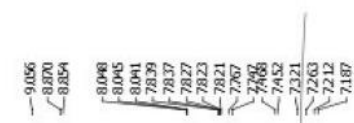

- योi?
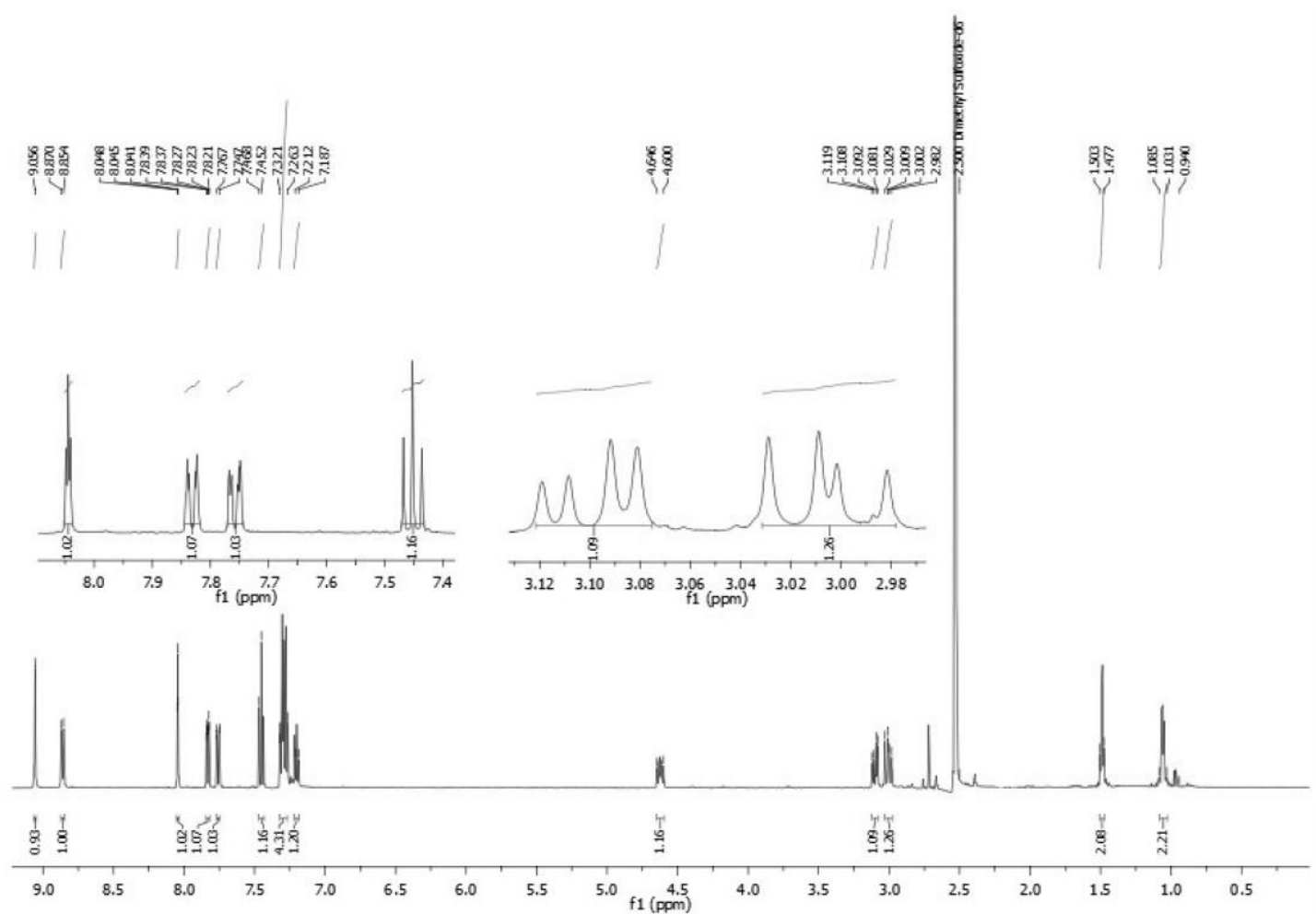

Figure 41. ${ }^{13} \mathrm{C}$ NMR (125 MHz, DMSO- $d_{6}$ ) of compound 9 (Neq0809).

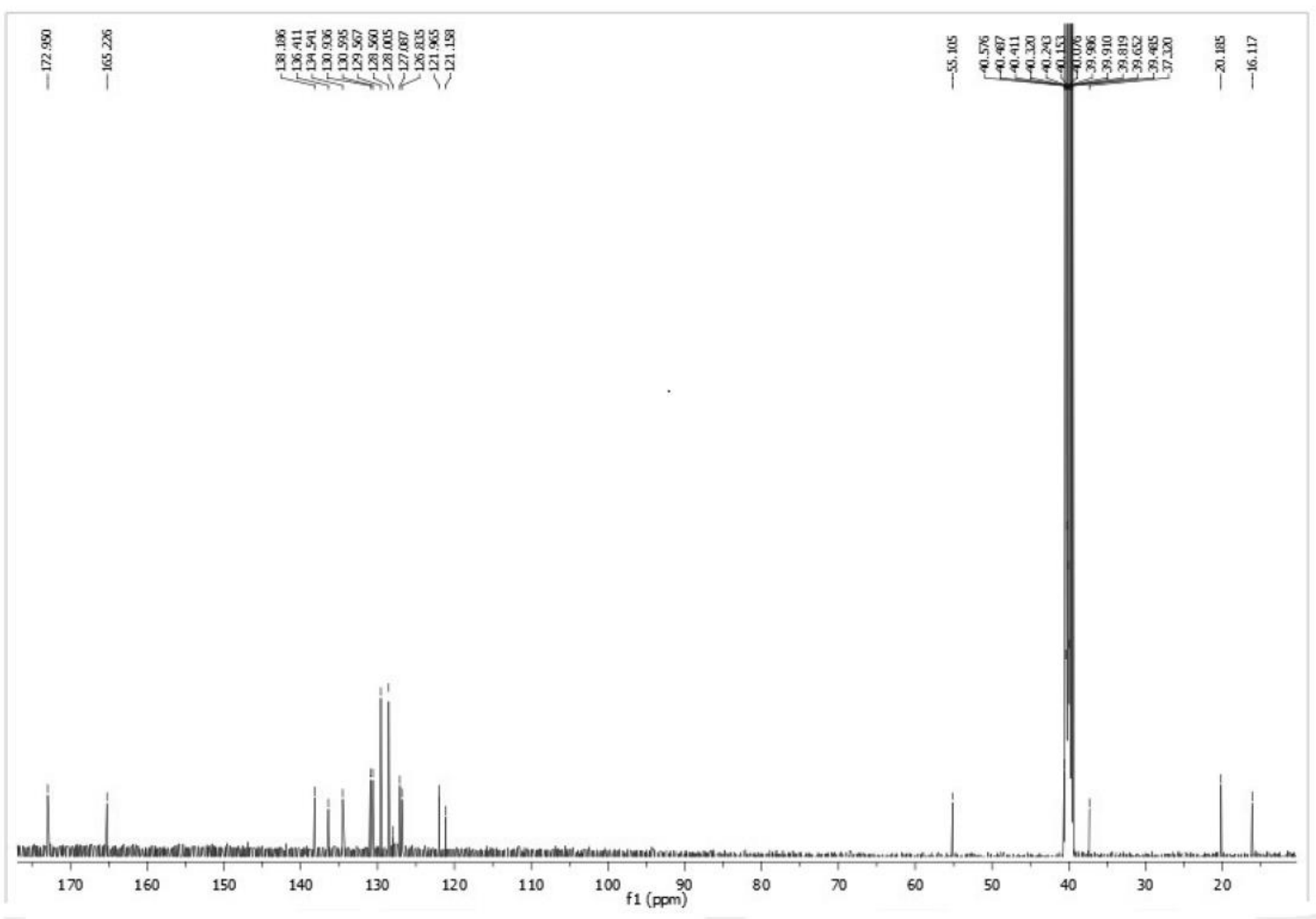


Figure 42. ${ }^{1} \mathrm{H}$ NMR (500 MHz, DMSO- $\left.d_{6}\right)$ of compound 10 (Neq0804).

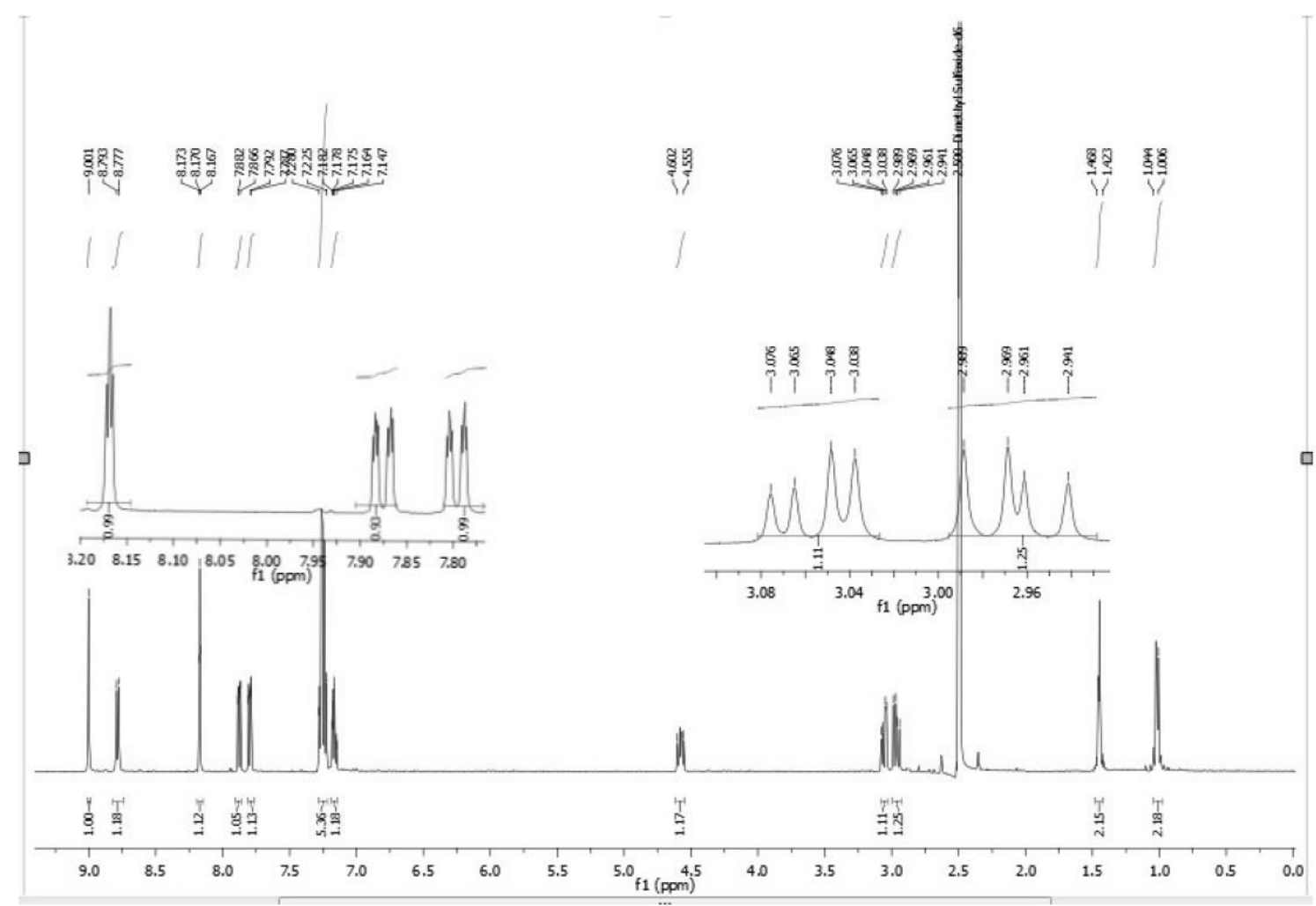

Figure 43. ${ }^{13} \mathrm{C}$ NMR (125 MHz, DMSO- $\left.d_{6}\right)$ of compound 10 (Neq0810).

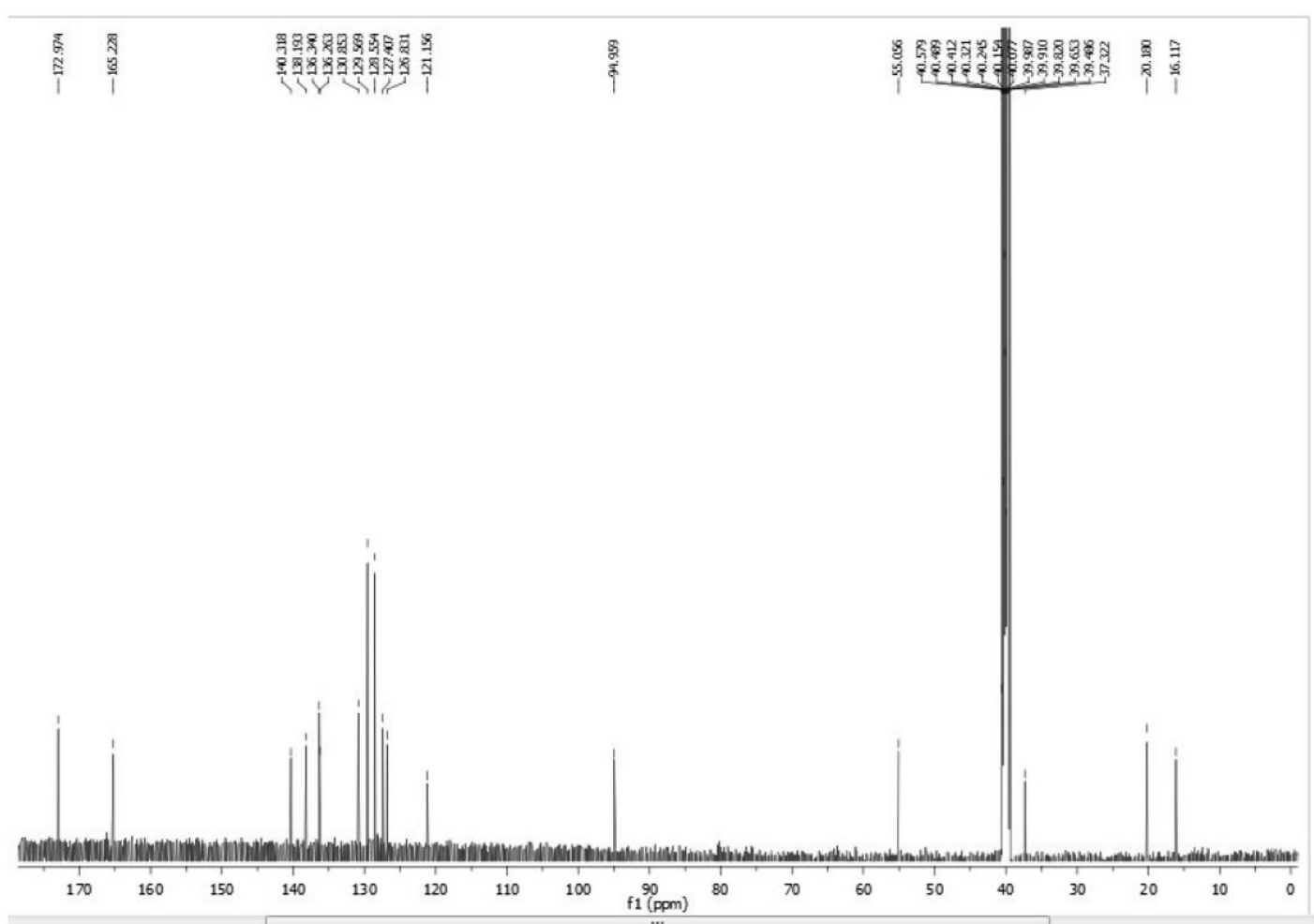


Figure 44. ${ }^{1} \mathrm{H}$ NMR (500 MHz, DMSO- $d_{6}$ ) of compound 24 (Neq0865).

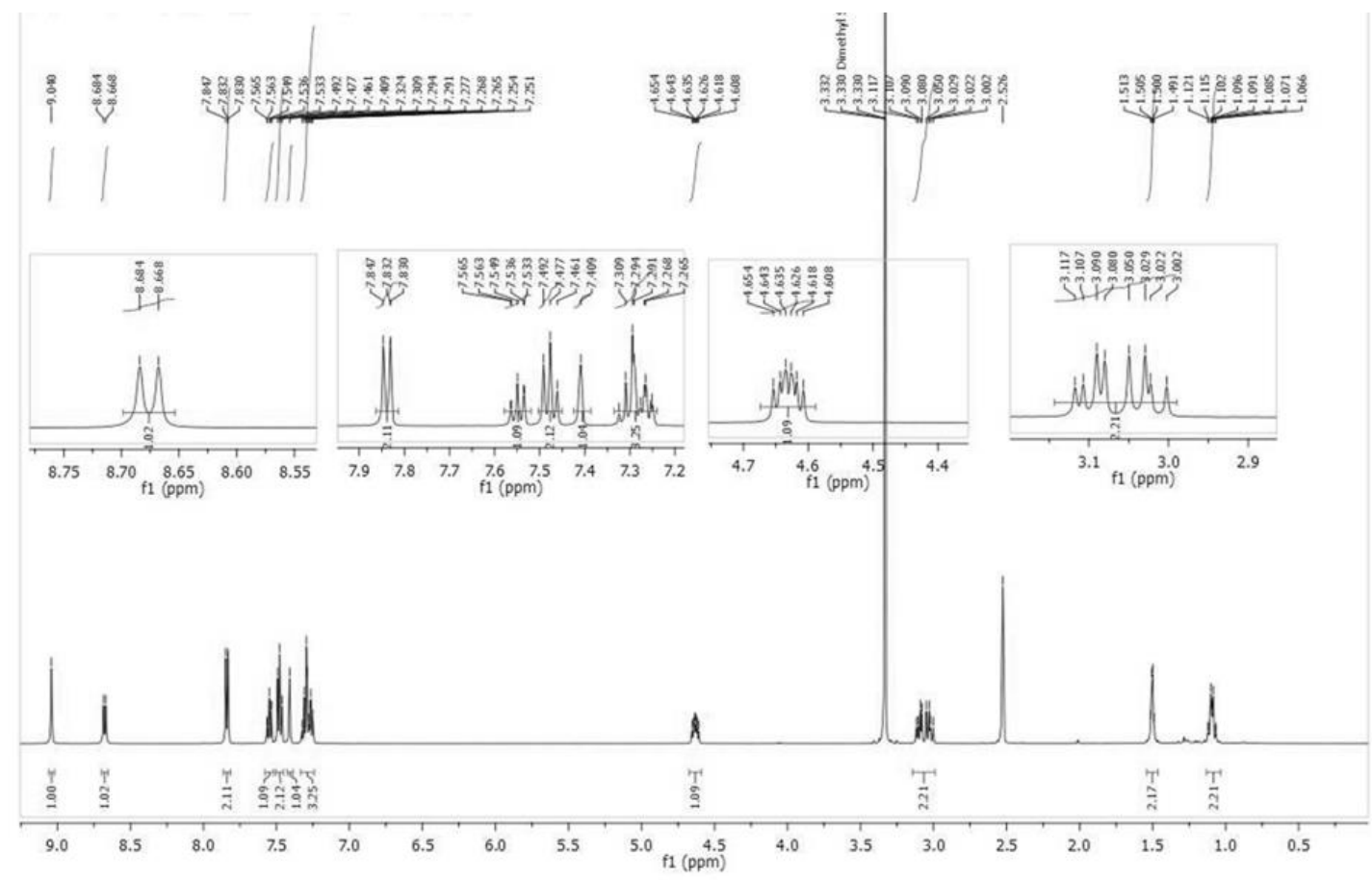

Figure $45 .{ }^{13} \mathrm{C}$ NMR $\left(125 \mathrm{MHz}\right.$, DMSO- $\left.d_{6}\right)$ of compound 24 (Neq0865).

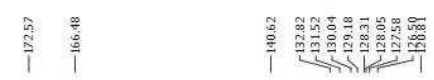

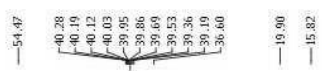
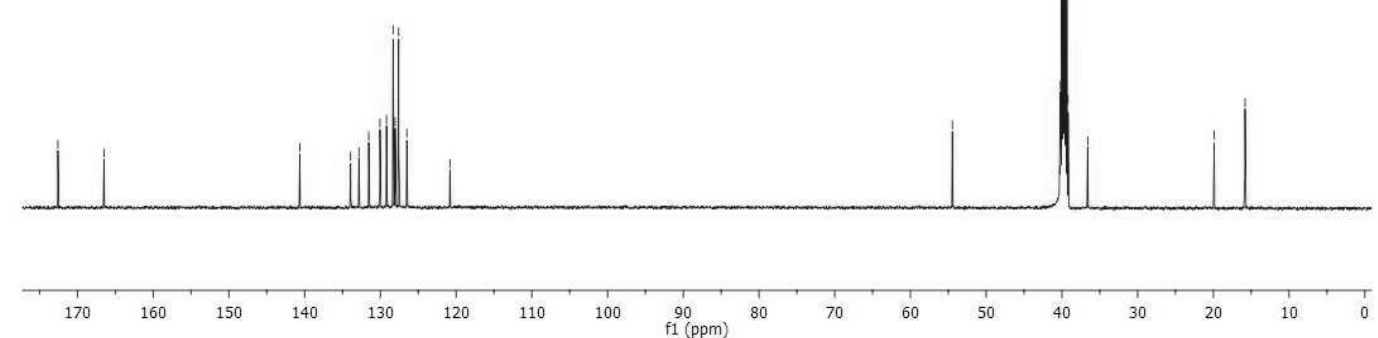
Figure 46. ${ }^{1} \mathrm{H} \mathrm{NMR}\left(200 \mathrm{MHz}, \mathrm{CDCl}_{3}\right.$ ) of compound 29 (Neq0956).

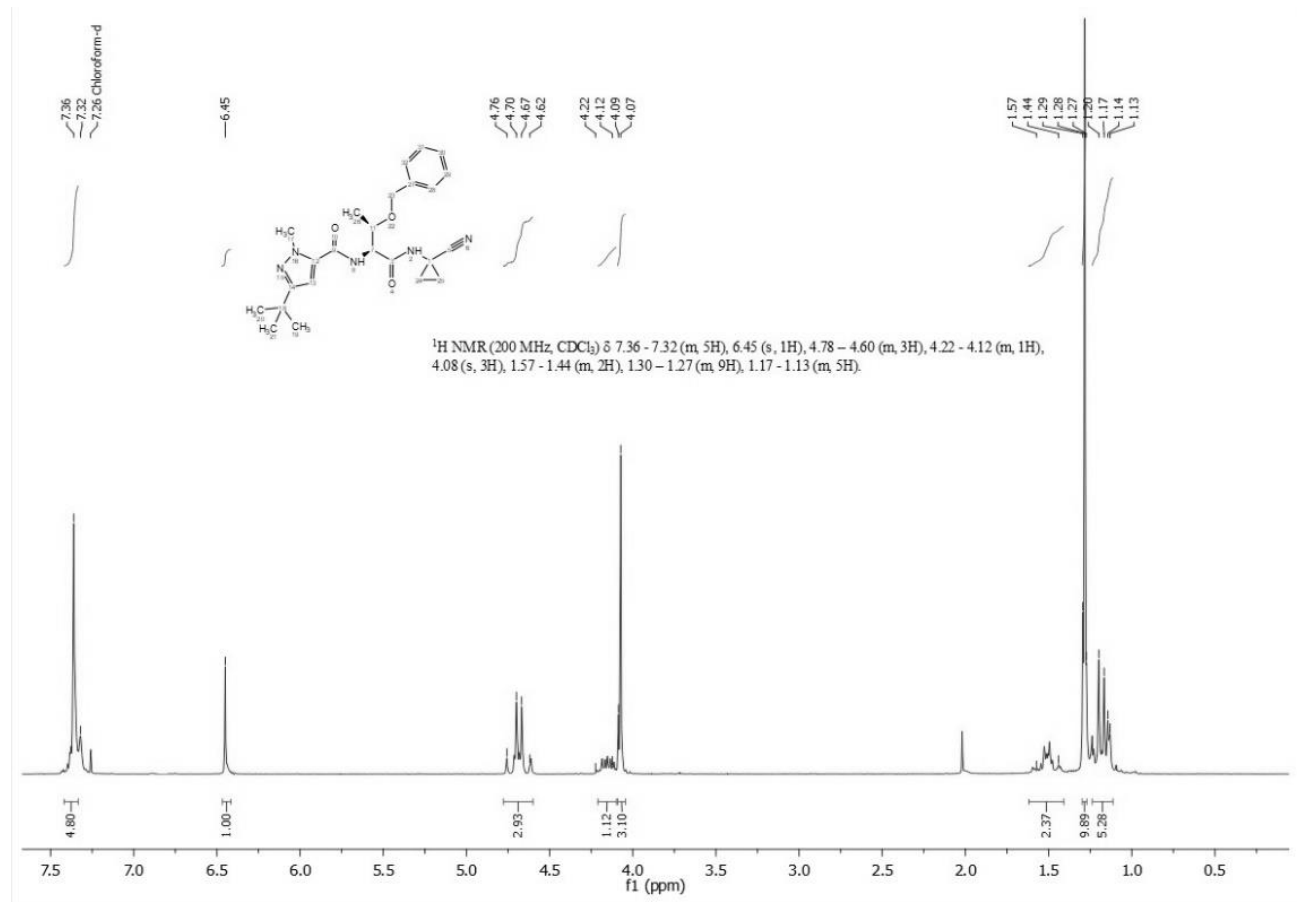

Figure 47. $\left.{ }^{13} \mathrm{C} \mathrm{NMR} \mathrm{(50} \mathrm{MHz,} \mathrm{CDCl}_{3}\right)$ of compound 29 (Neq0956).
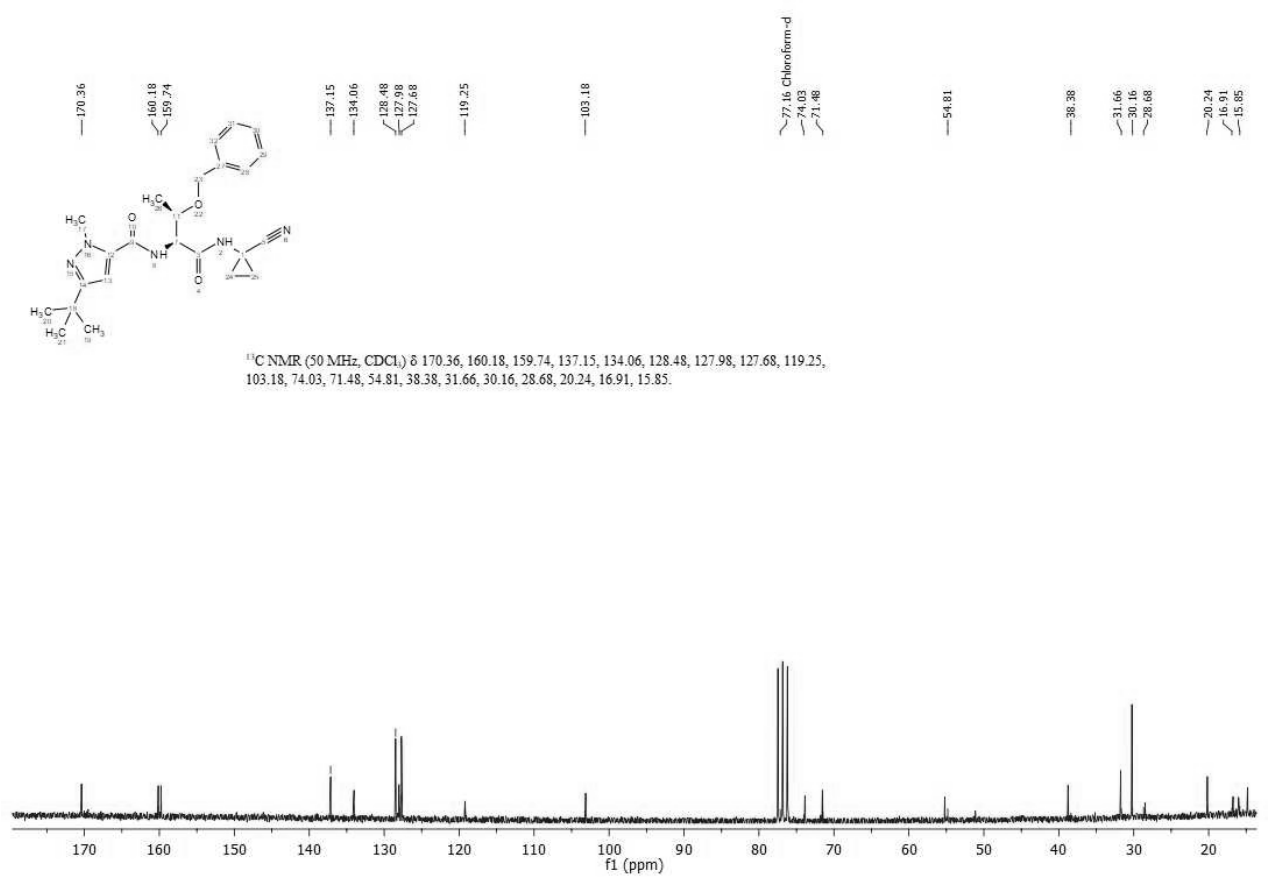
Figure 48. ${ }^{1} \mathrm{H}$ NMR (400 MHz, DMSO- $d_{6}$ ) of compound 31 (Neq0775).

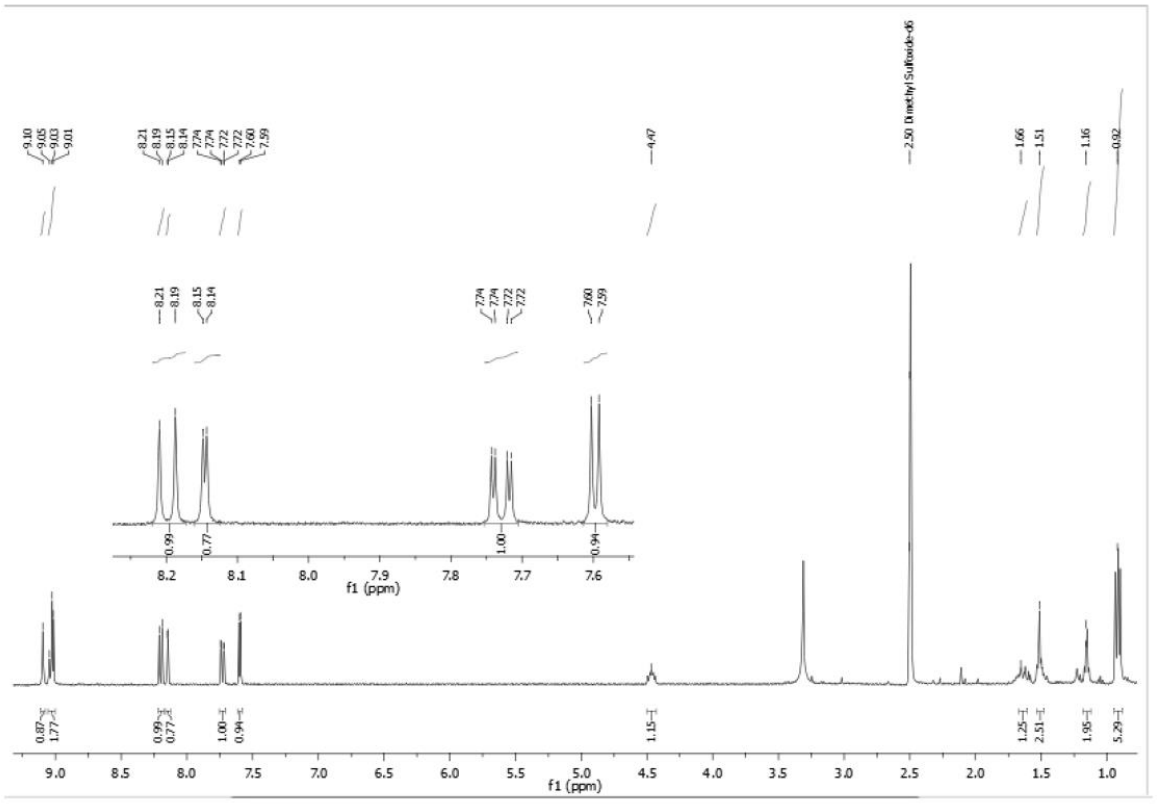

Figure 49. ${ }^{13} \mathrm{C}$ NMR (100 MHz, DMSO- $d_{6}$ ) of compound 31 (Neq0775).

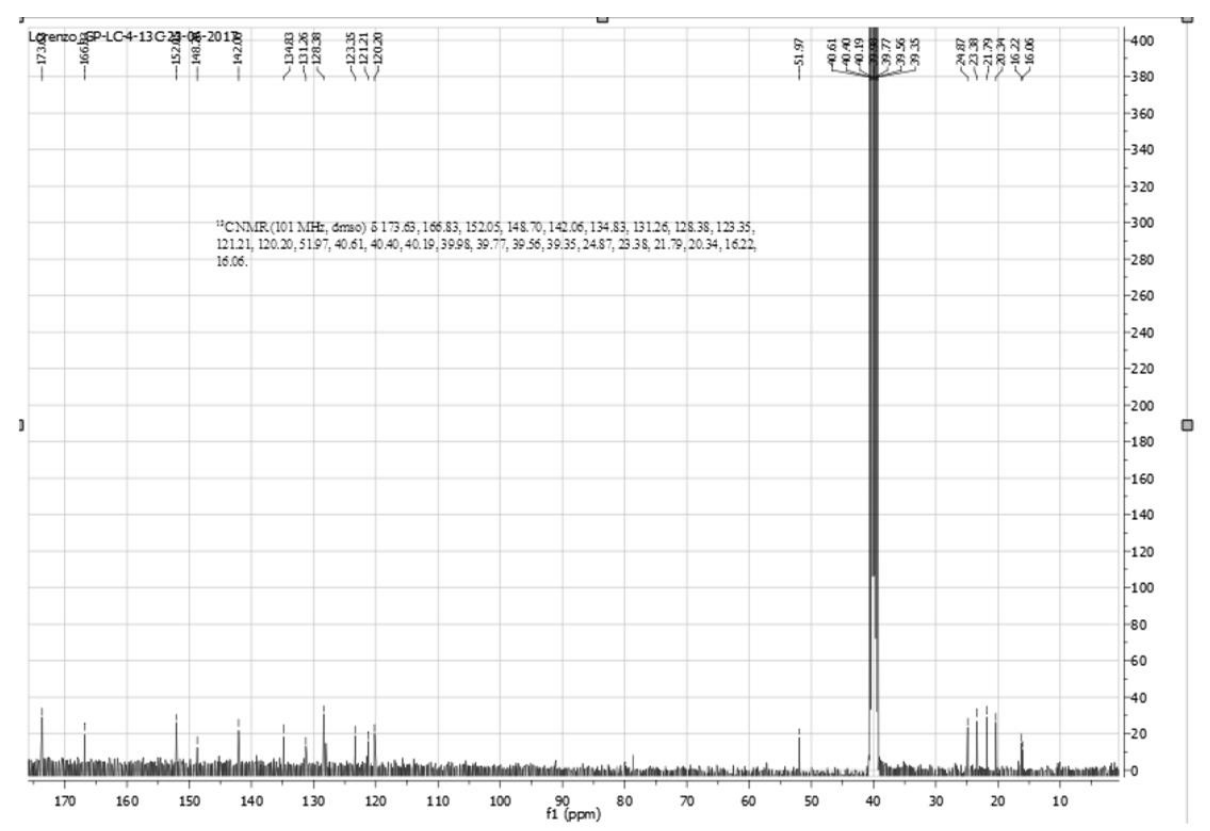


Figure 50. ${ }^{1} \mathrm{H}$ NMR (200 MHz, $\mathrm{CD}_{3} \mathrm{OD}$ ) of compound 36 (Neq0957).

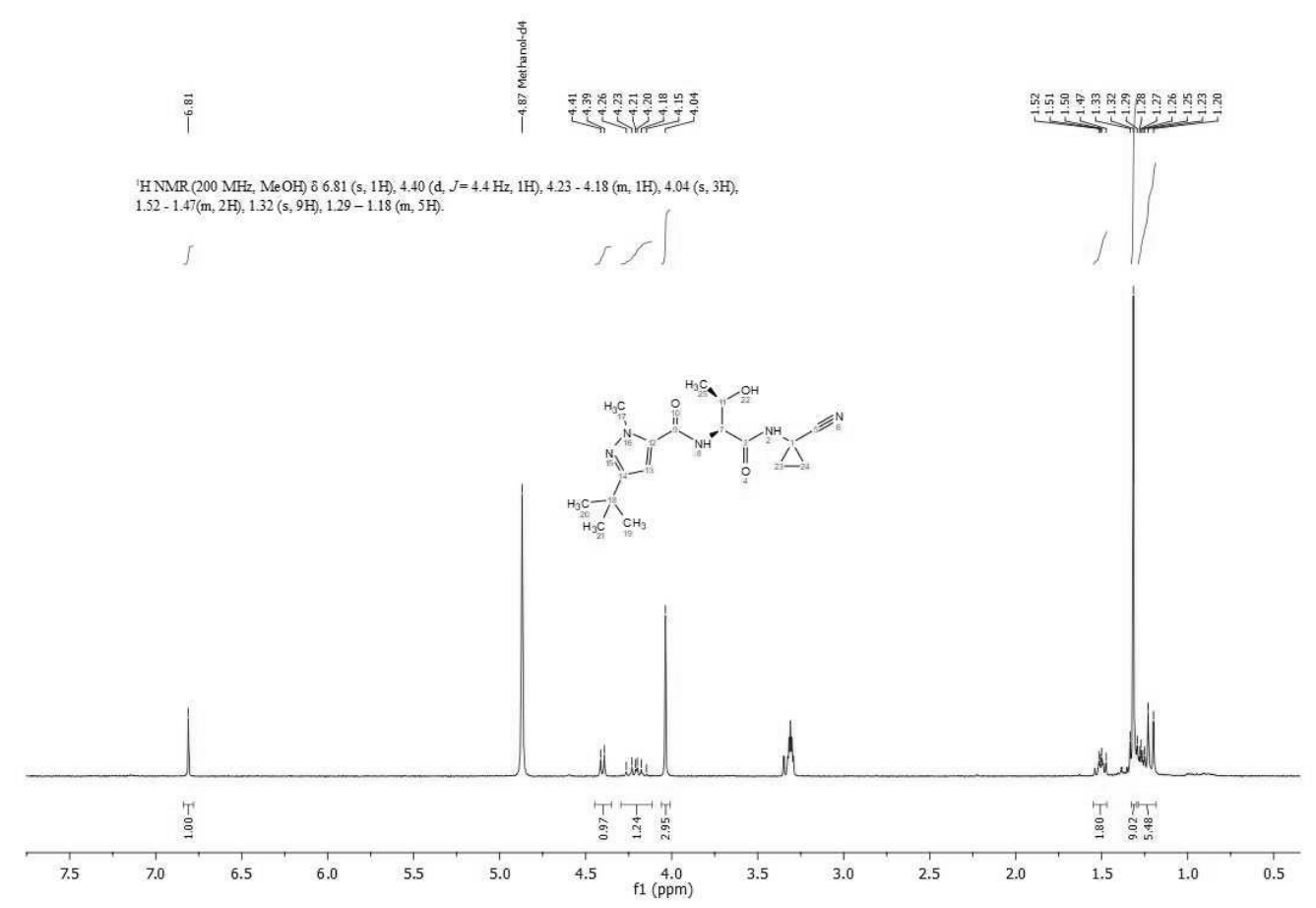

Figure 51. ${ }^{13} \mathrm{C}$ NMR (50 MHz, $\mathrm{CD}_{3} \mathrm{OD}$ ) of compound 36 (Neq0957).
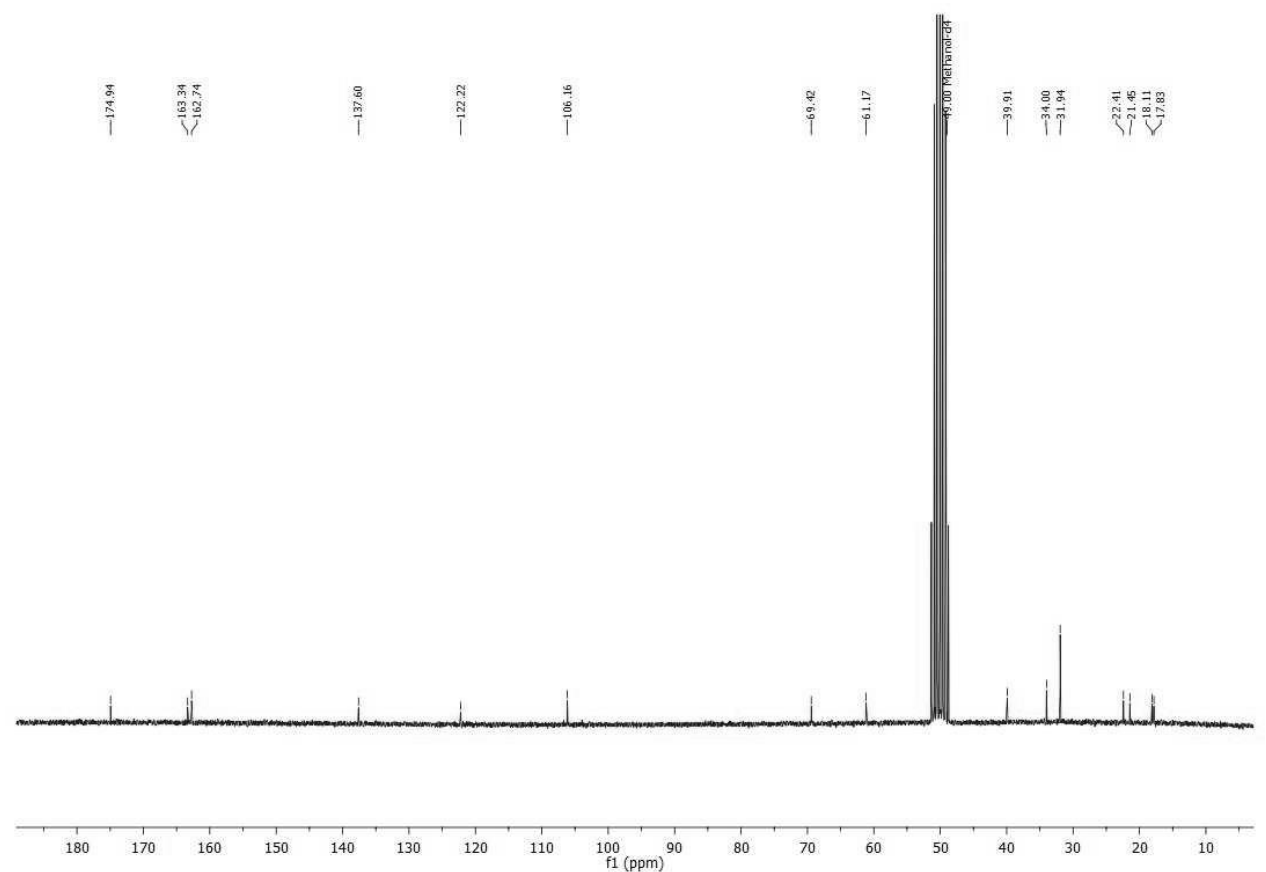
Figure 52. ${ }^{1} \mathrm{H} \mathrm{NMR}\left(400 \mathrm{MHz}, \mathrm{CDCl}_{3}\right.$ ) of compound 67 (Neq0937).

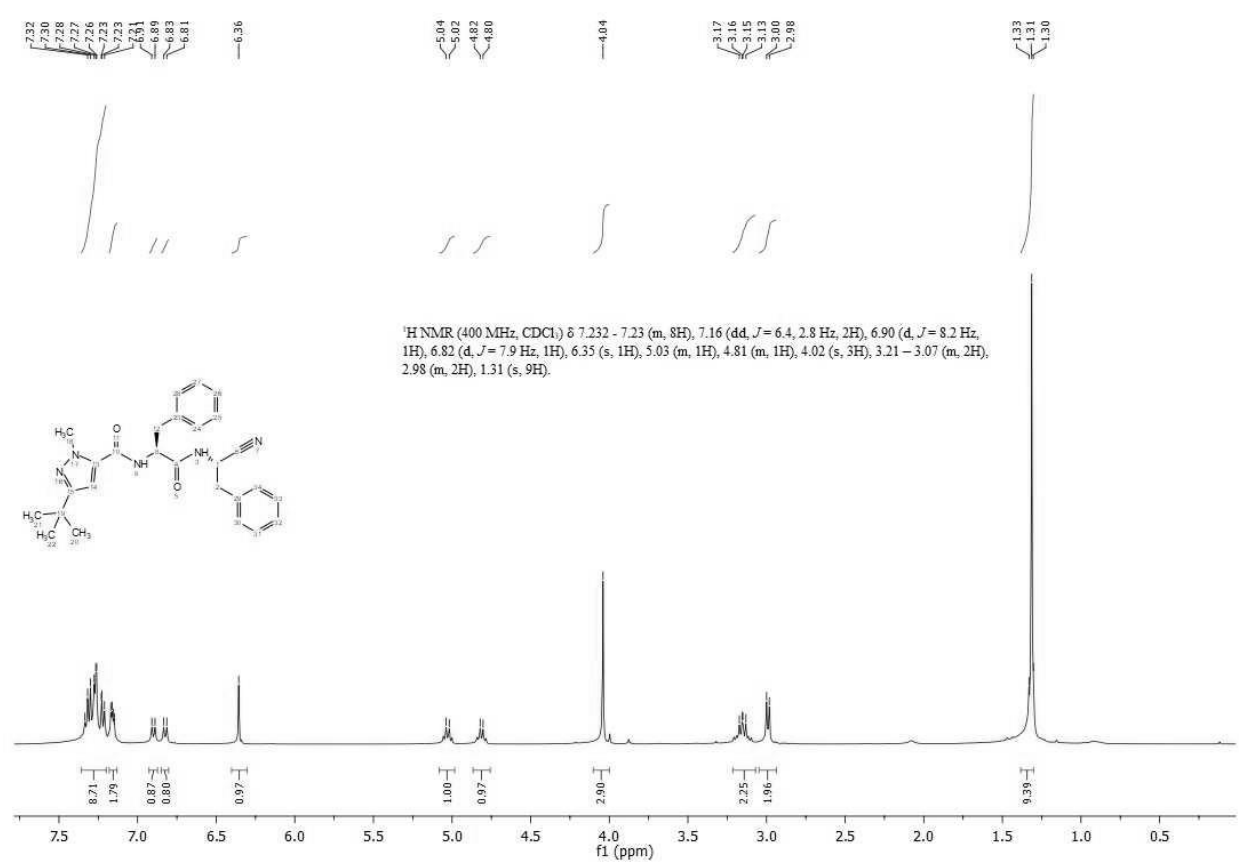

Figure 53. ${ }^{13} \mathrm{C}$ NMR $\left(50 \mathrm{MHz}, \mathrm{CDCl}_{3}\right)$ of compound 29 (Neq0956).

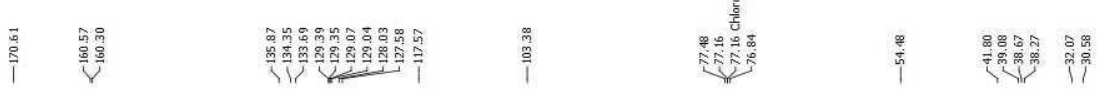

${ }^{1} \mathrm{CNMR}(101 \mathrm{MHz}, \mathrm{CDC}) \delta 170.30,160.25,159.98,135.55,134.04,133.37,129.08,129.04,128.75$ $128.72,127.71,127.26,117.25,103.06,54.17,41.48,38.77,38.35,37.95,31.75,30.26$.
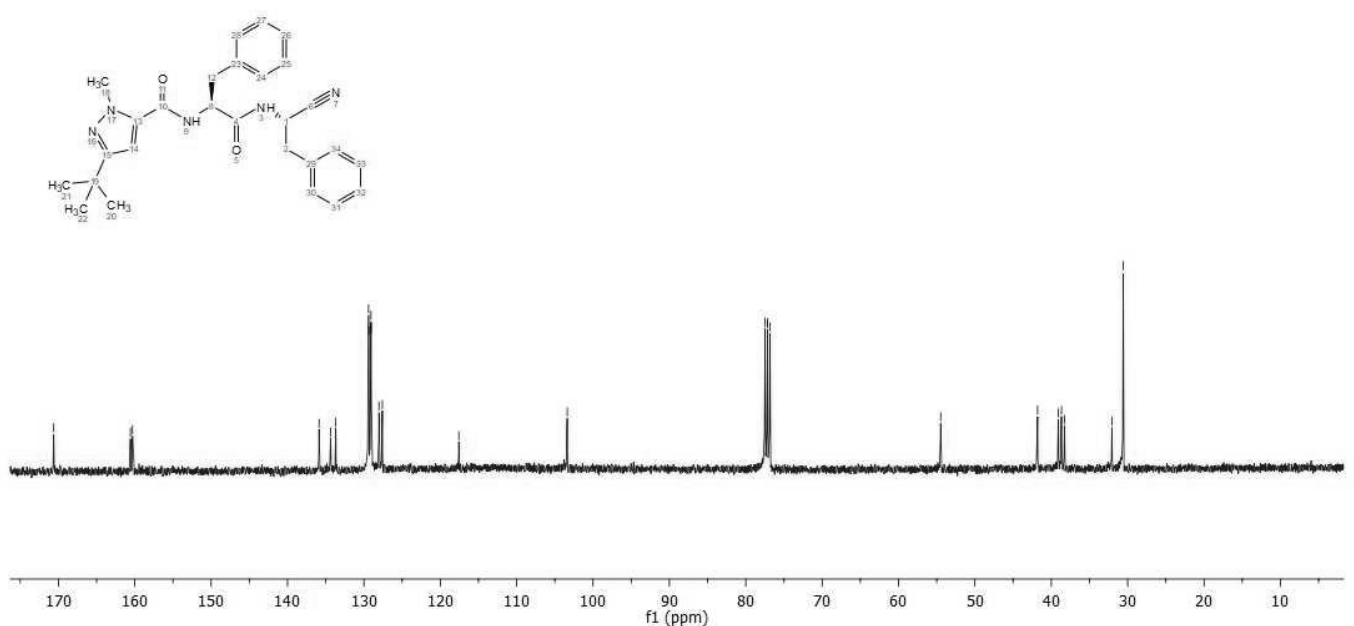
Figure 54. ${ }^{1} \mathrm{H}$ NMR (200 MHz, $\left.\mathrm{CD}_{3} \mathrm{OD}\right)$ of compound 71 (Neq0953).

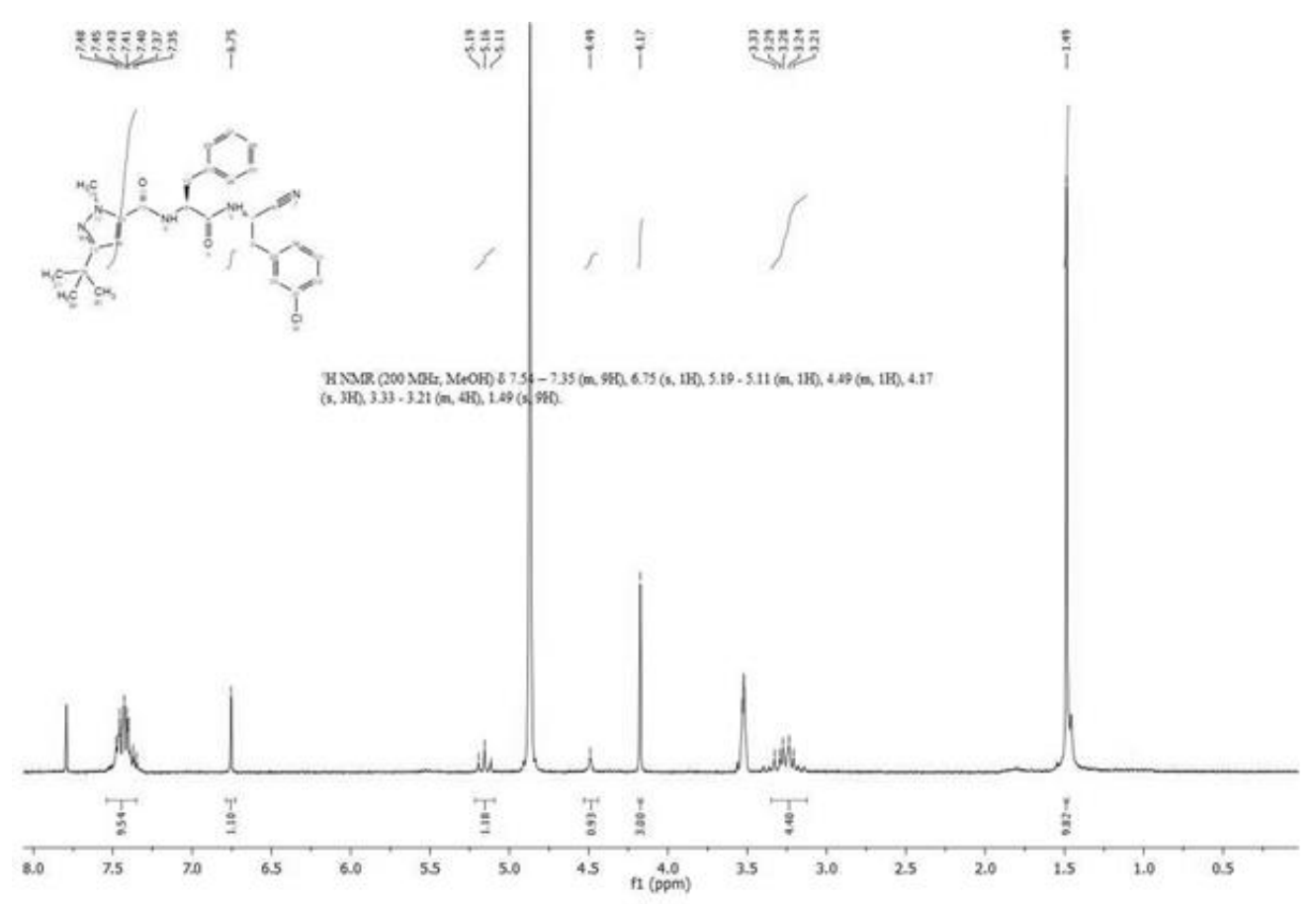

Figure 55. ${ }^{13} \mathrm{C}$ NMR (50 MHz, $\mathrm{CD}_{3} \mathrm{OD}$ ) of compound 71 (Neq0953).

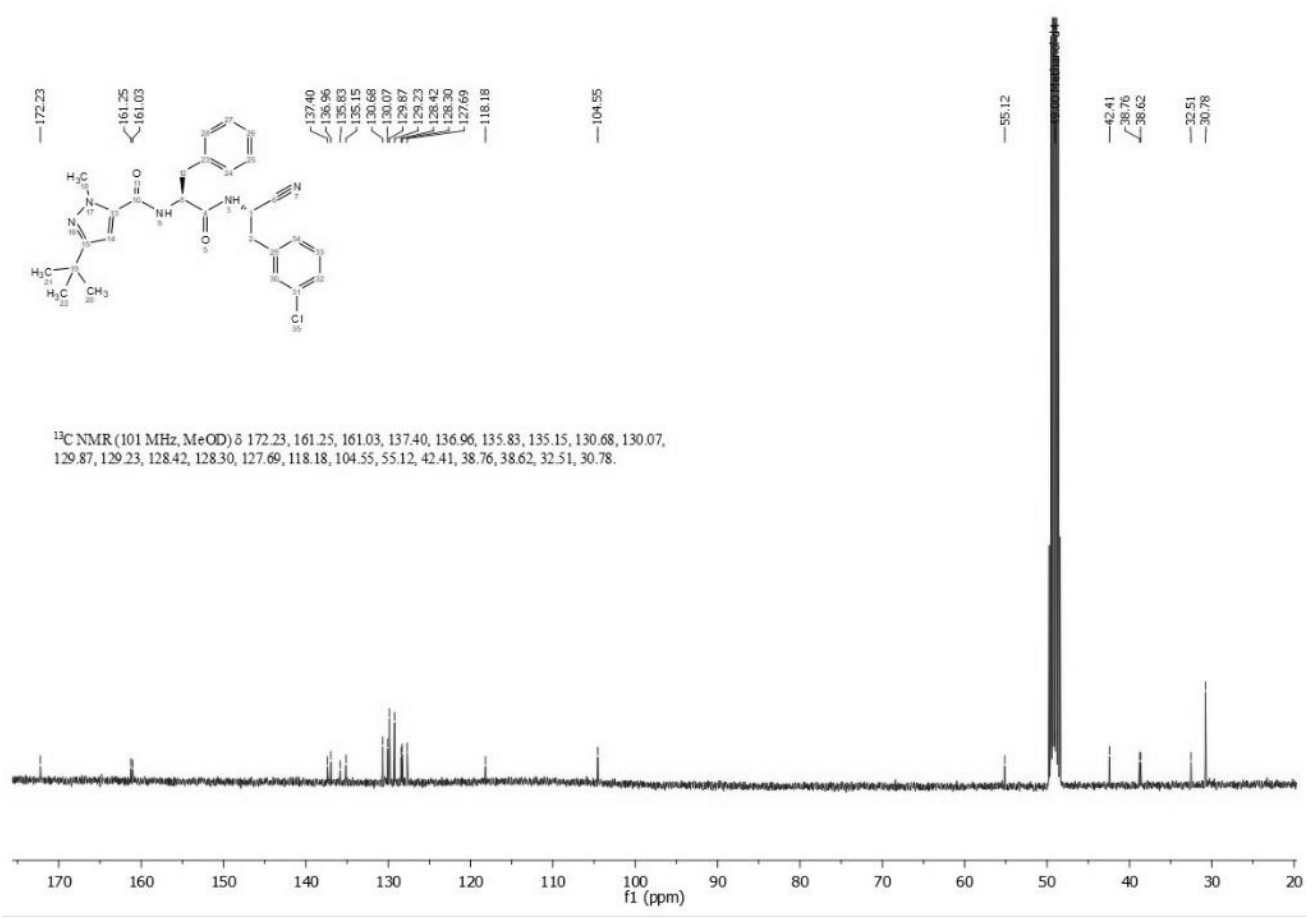


Figure 56. ${ }^{1} \mathrm{H}$ NMR (400 MHz, $\left.\mathrm{CD}_{3} \mathrm{OD}\right)$ of compound 72 (Neq0954).

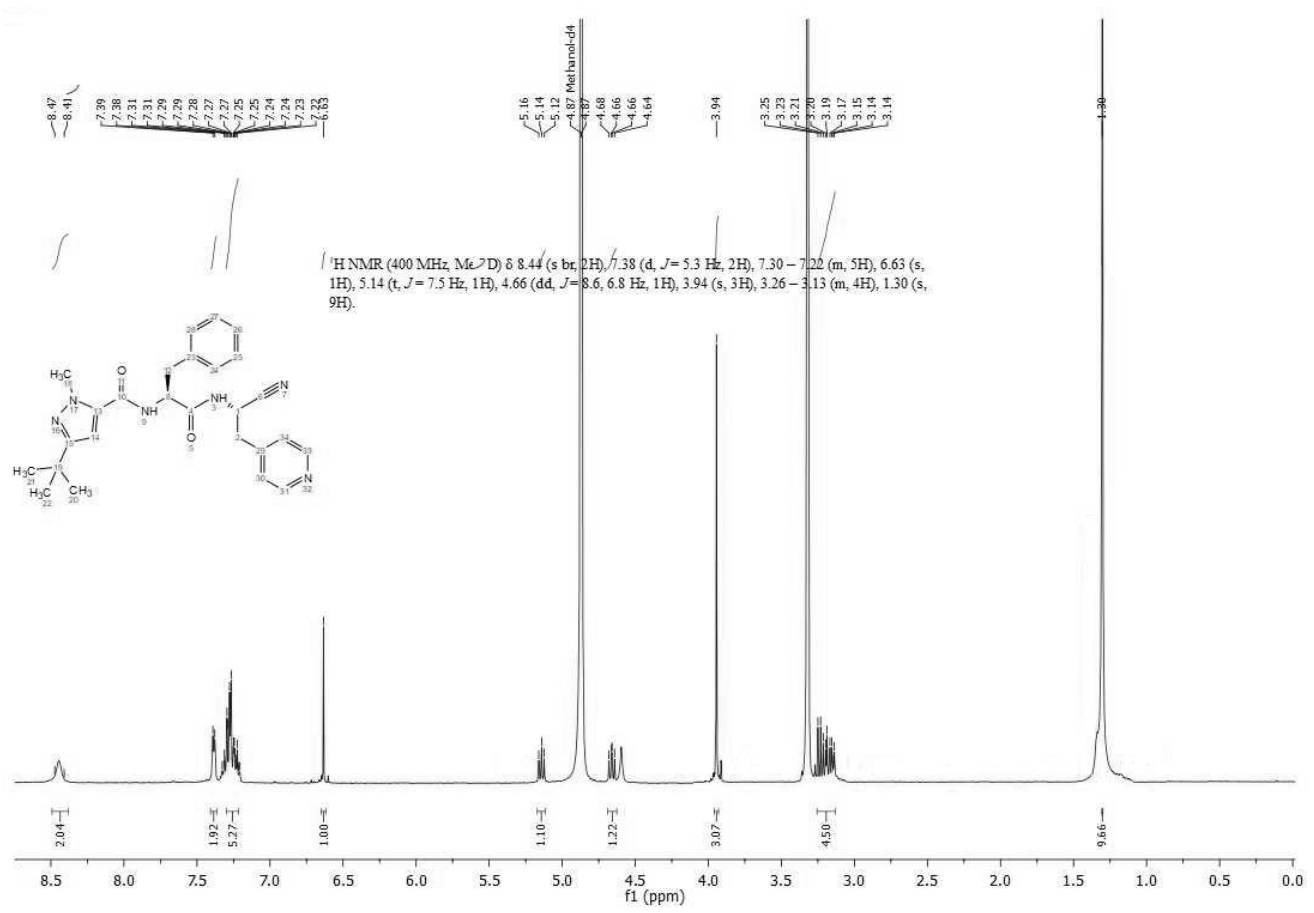

Figure 57. ${ }^{13} \mathrm{C}$ NMR (100 MHz, DMSO- $d_{6}$ ) of compound 72 (Neq0954).

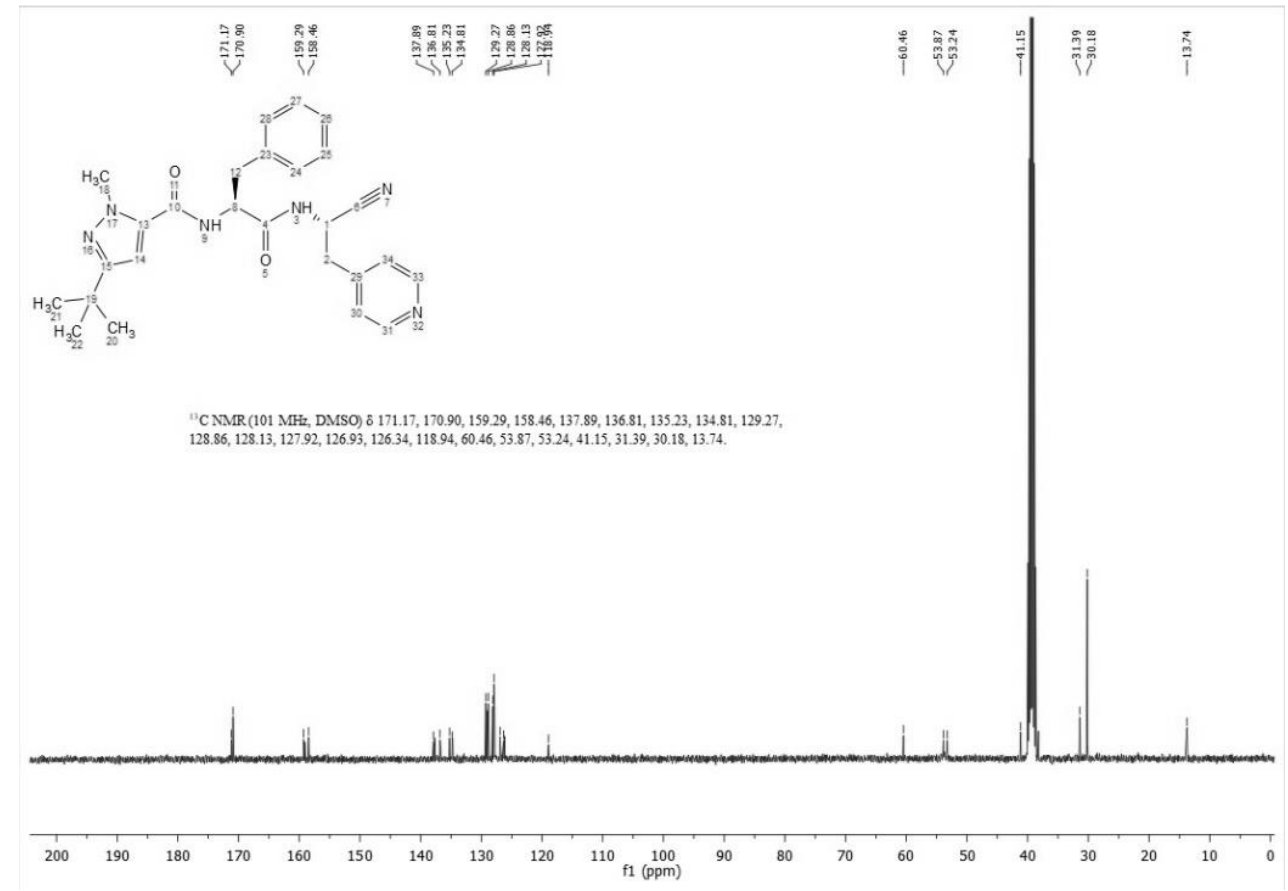


Figure 58. ${ }^{1} \mathrm{H}$ NMR (400 MHz, DMSO- $d_{6}$ ) of compound 75 (Neq0922).

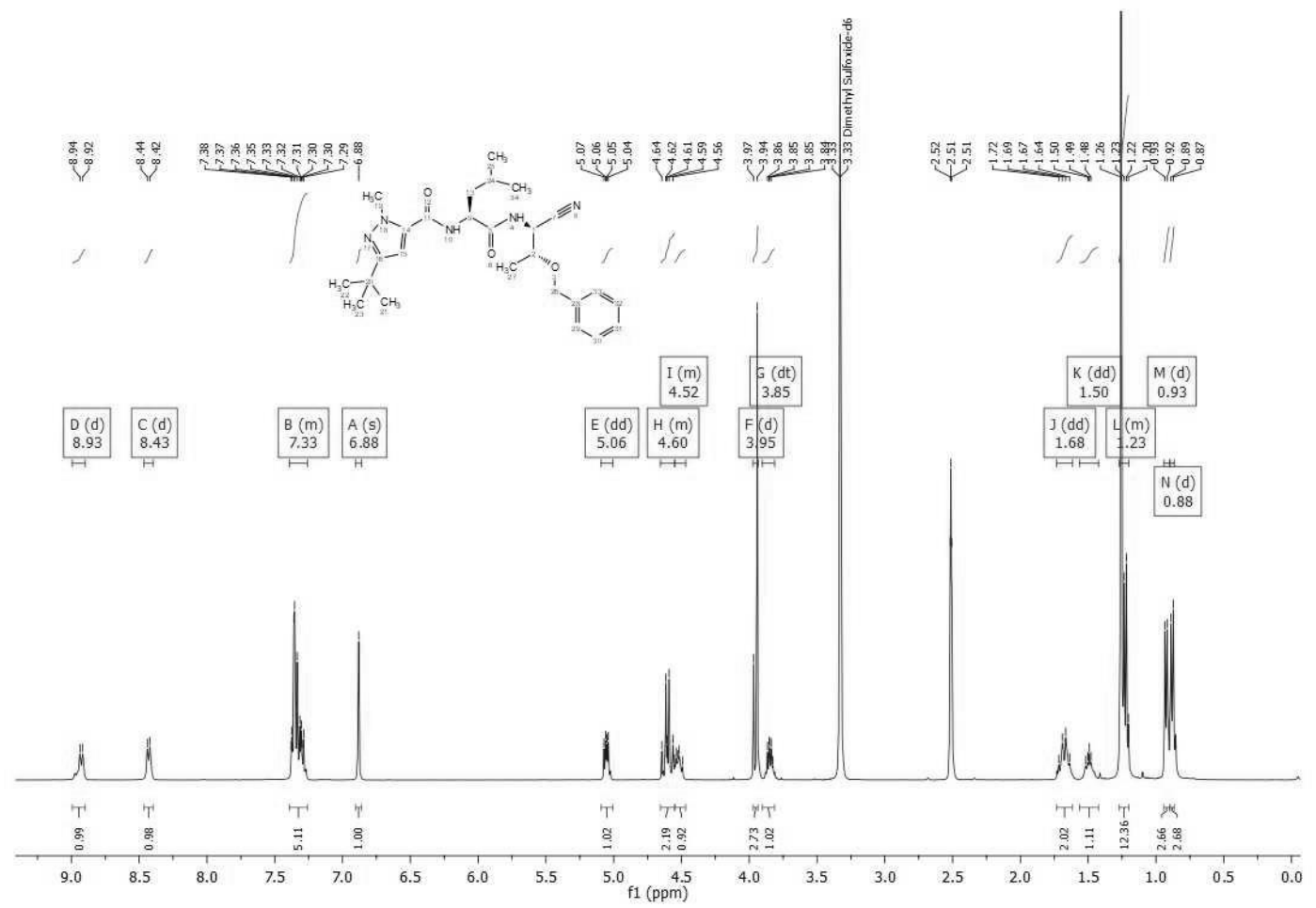

Figure 59. ${ }^{13} \mathrm{C}$ NMR (100 MHz, DMSO- $\left.d_{6}\right)$ of compound 75 (Neq0922).

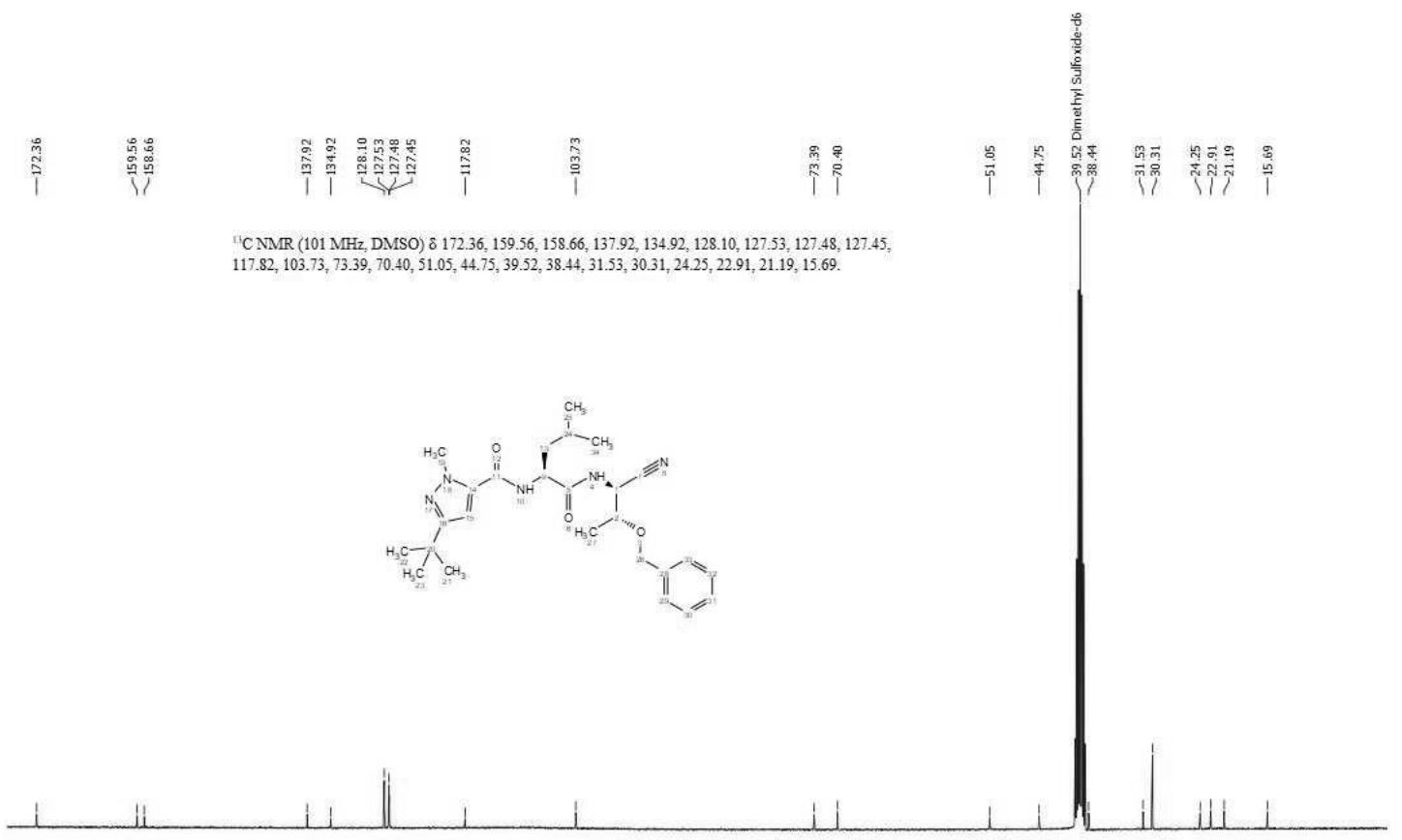

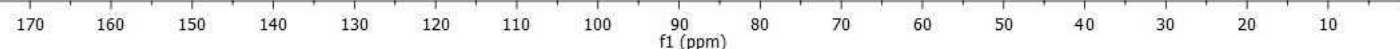


Figure 60. ${ }^{1} \mathrm{H} \mathrm{NMR}\left(400 \mathrm{MHz}, \mathrm{CDCl}_{3}\right)$ of compound 77 (Neq0877).

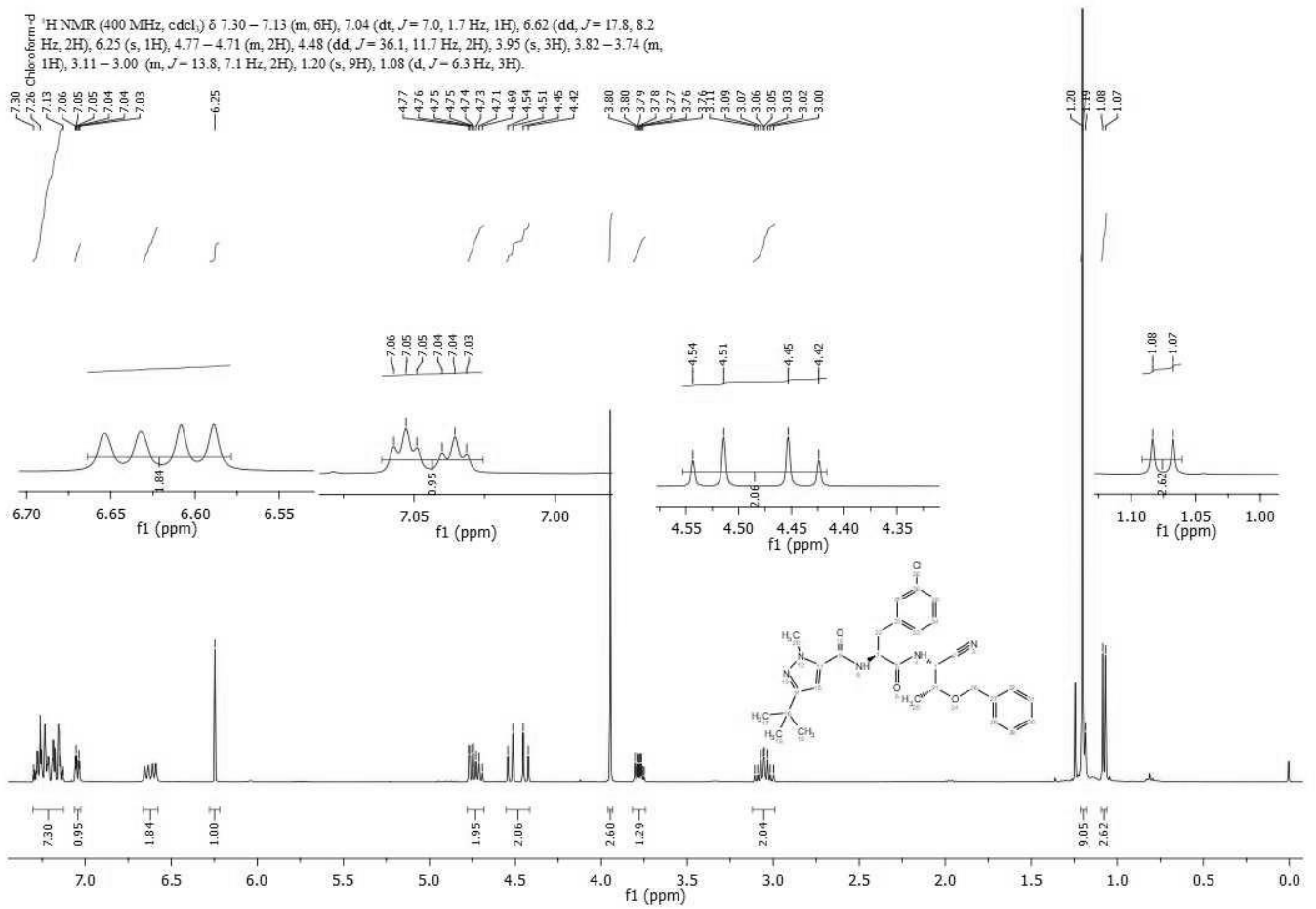

Figure 61. ${ }^{13} \mathrm{C} \mathrm{NMR} \mathrm{(100} \mathrm{MHz,} \mathrm{CDCl}_{3}$ ) of compound 77 (Neq0877).

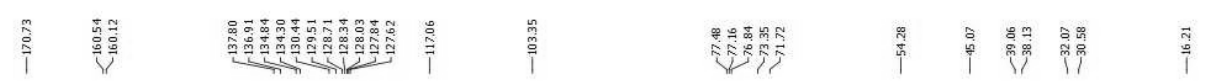

"CNMR (101 MHz, cdcl) $\delta 170.73,160.54,160.12,137.80,136.91,134.84,134.30,130.44,12951$, $128.71,128.34,128.03,127.84,127.62,117.06,103.35,77.48,77.16,76.84,73.35,71.72,54.28,45.07$ $39.06,38.13,32.07,30.58,16.21$
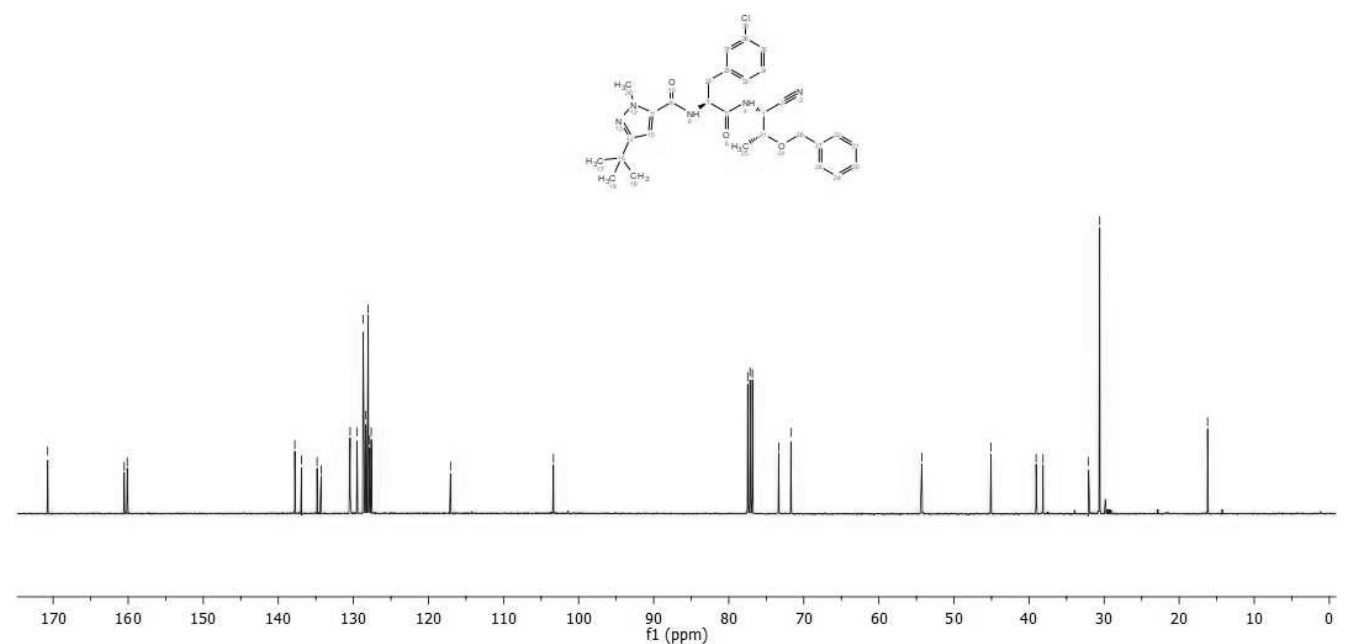
Figure 62. ${ }^{1} \mathrm{H}$ NMR $\left(400 \mathrm{MHz}, \mathrm{CDCl}_{3}\right)$ of compound 84 (Neq0942).

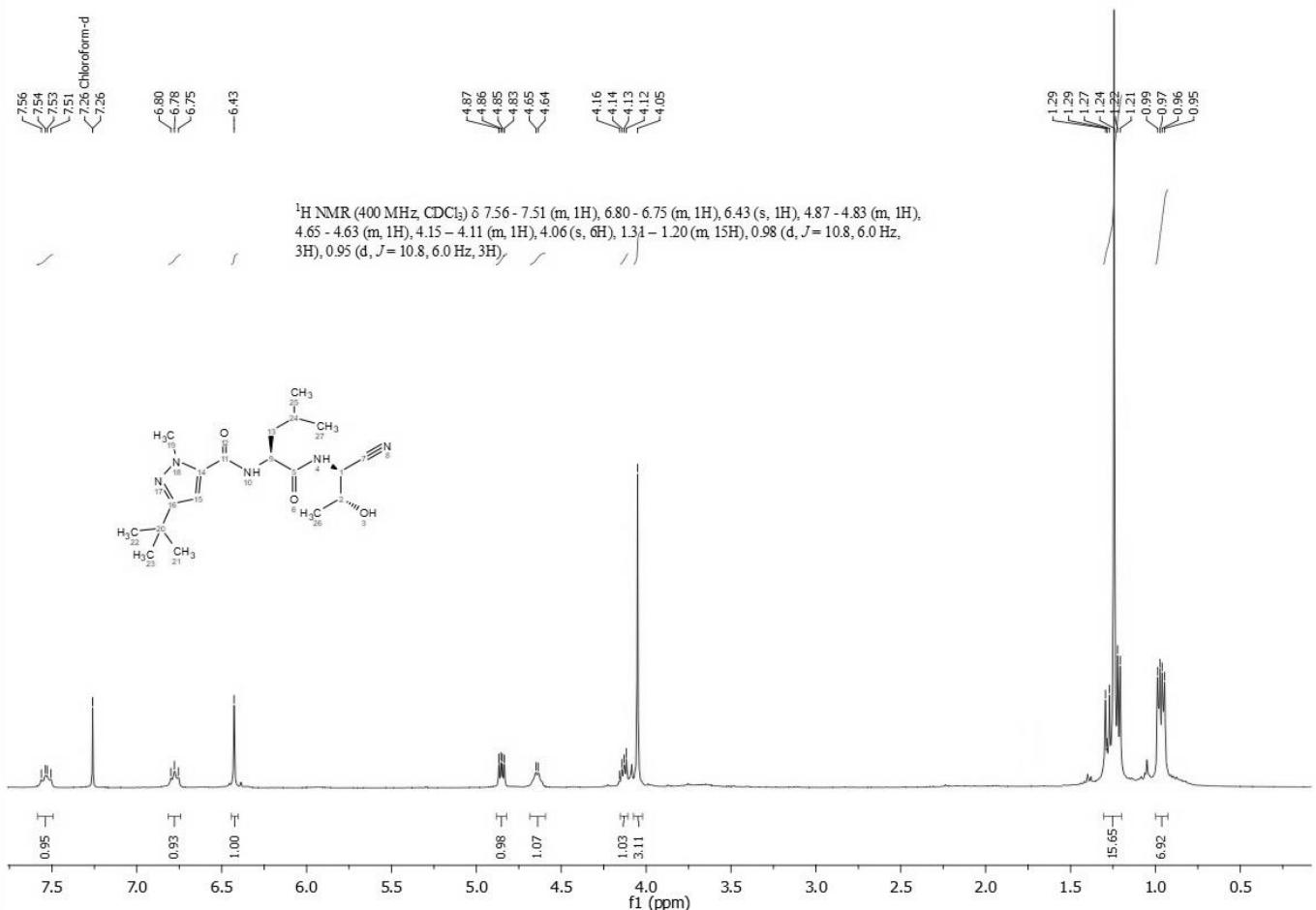

Figure 63. ${ }^{13} \mathrm{C} \mathrm{NMR}\left(100 \mathrm{MHz}, \mathrm{CDCl}_{3}\right)$ of compound 84 (Neq0942).
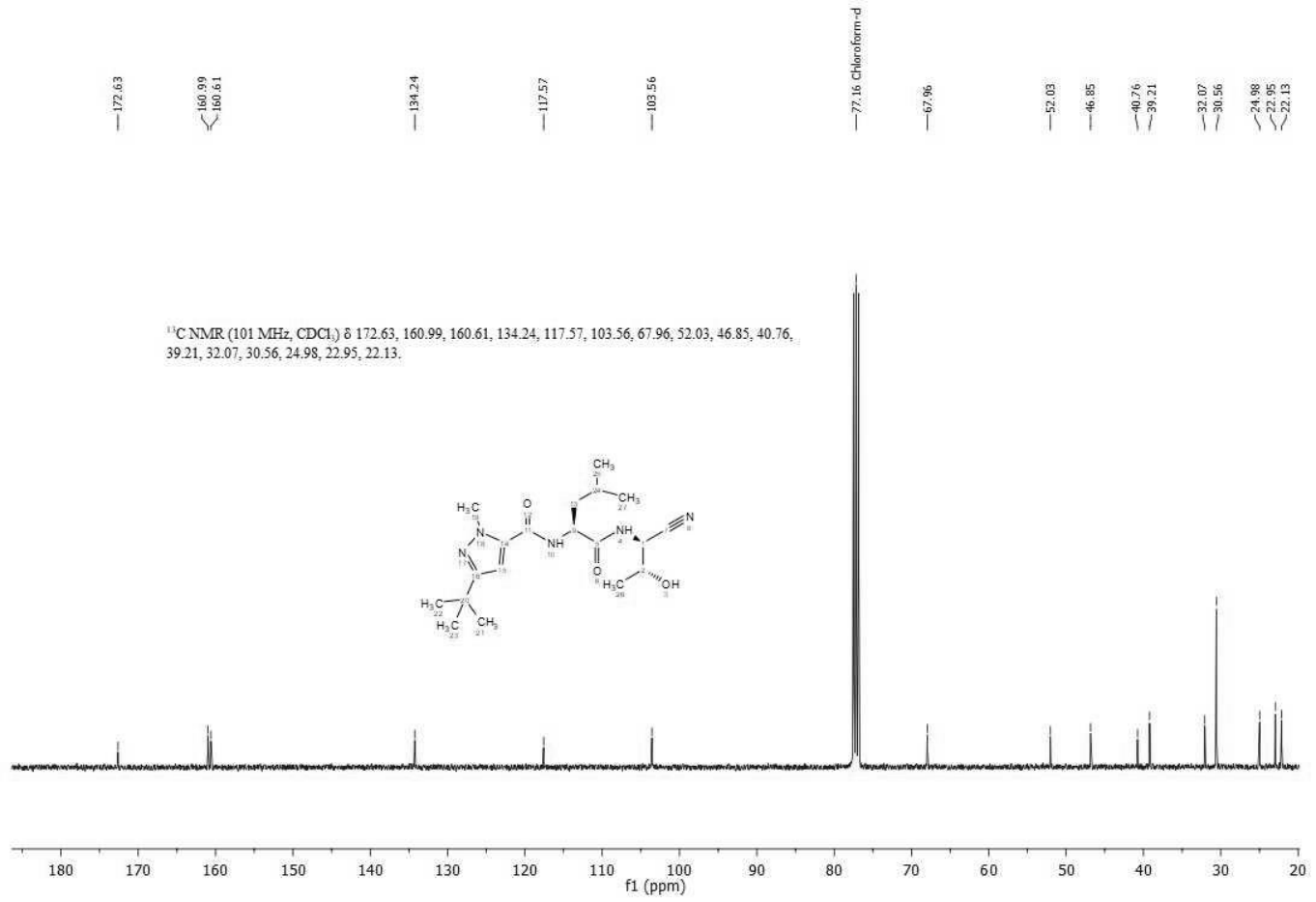
Figure 64. ${ }^{1} \mathrm{H} \mathrm{NMR}\left(400 \mathrm{MHz}, \mathrm{CD}_{3} \mathrm{OD}\right.$ ) of compound 85 (Neq0944).

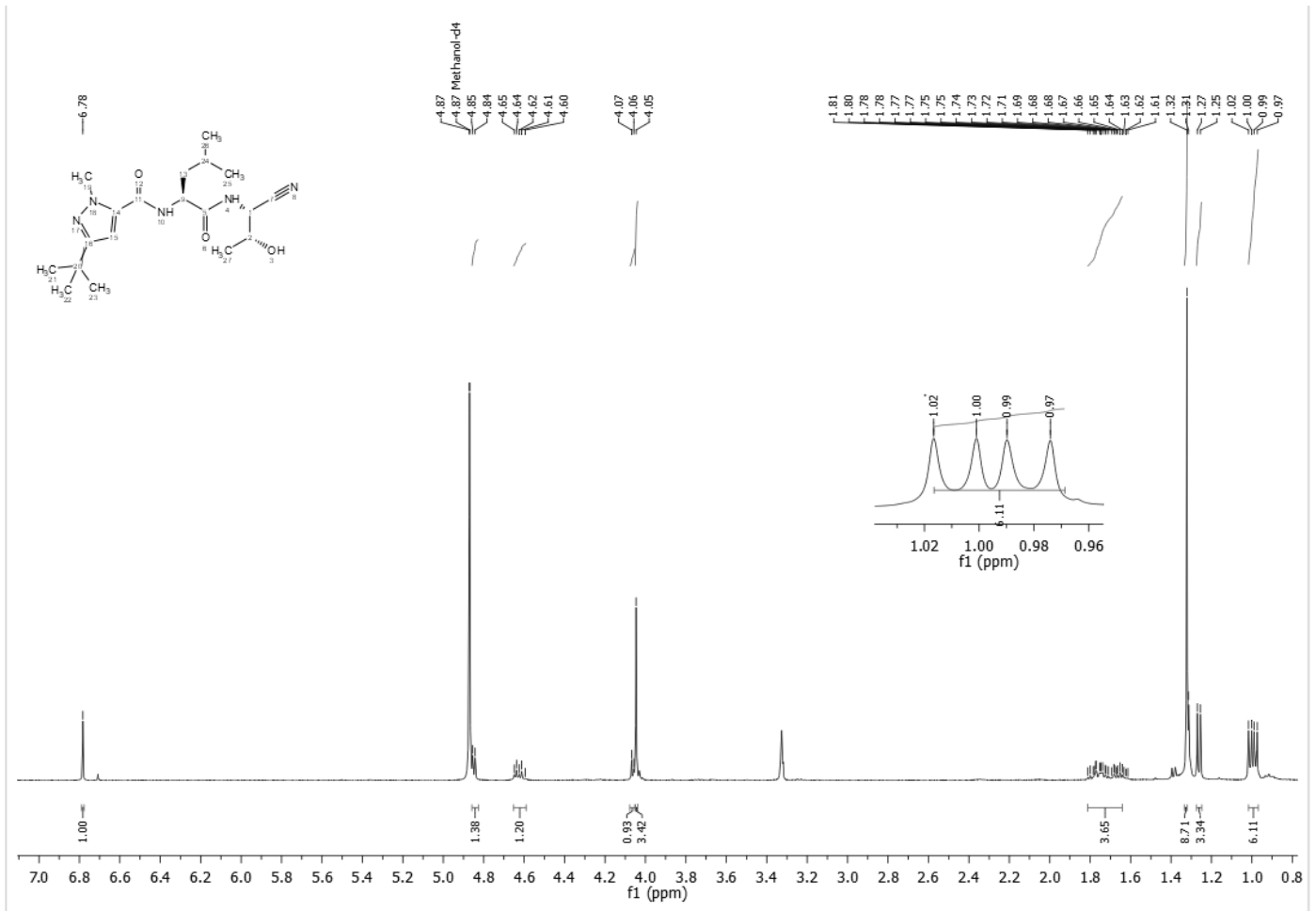

Figure 65. ${ }^{13} \mathrm{C} \mathrm{NMR}\left(100 \mathrm{MHz}, \mathrm{CDCl}_{3}\right.$ ) of compound 85 (Neq0944).

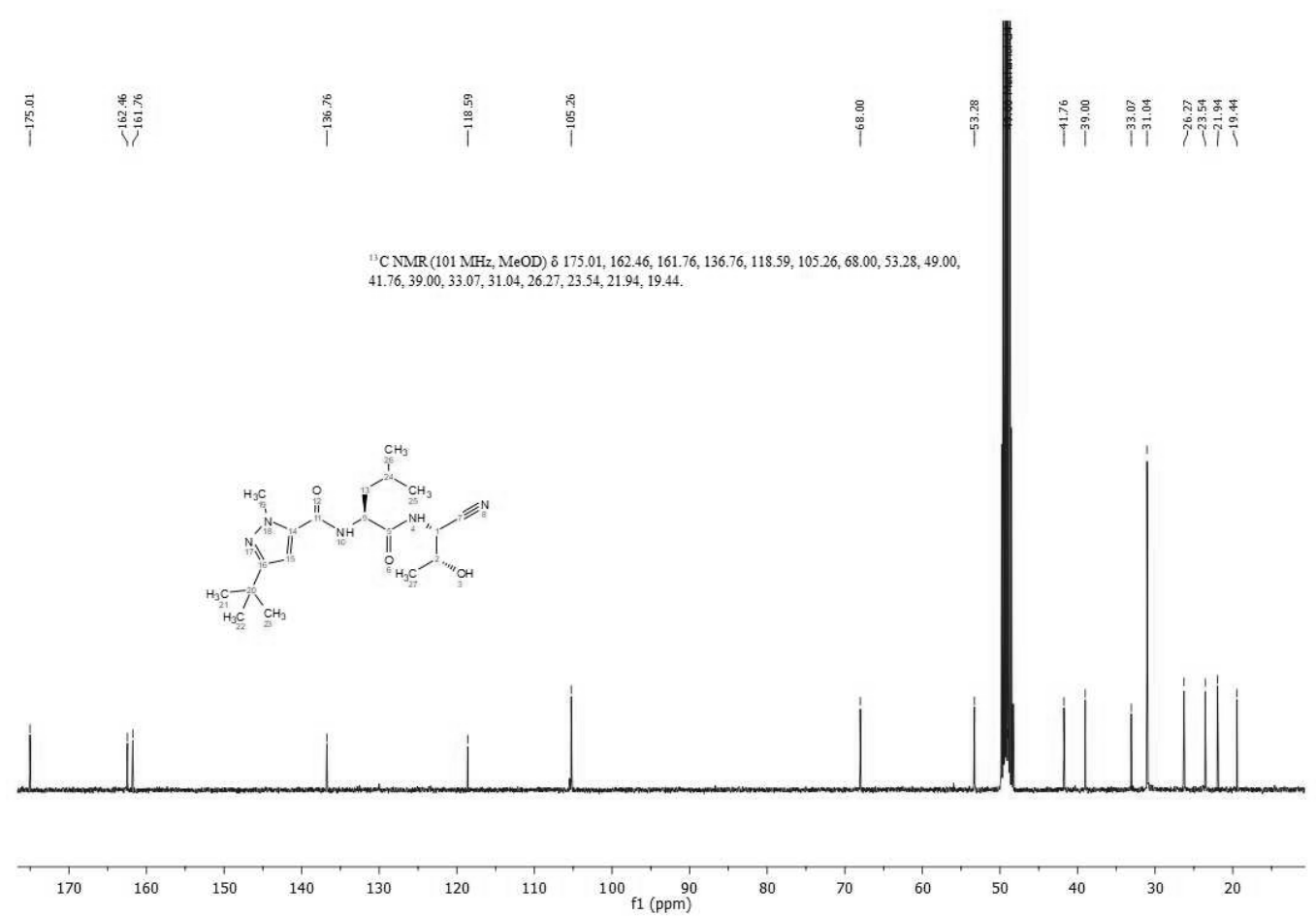


Figure 66. ${ }^{1} \mathrm{H}$ NMR (400 MHz, $\mathrm{CD}_{3} \mathrm{OD}$ ) of compound 86 (Neq0948).

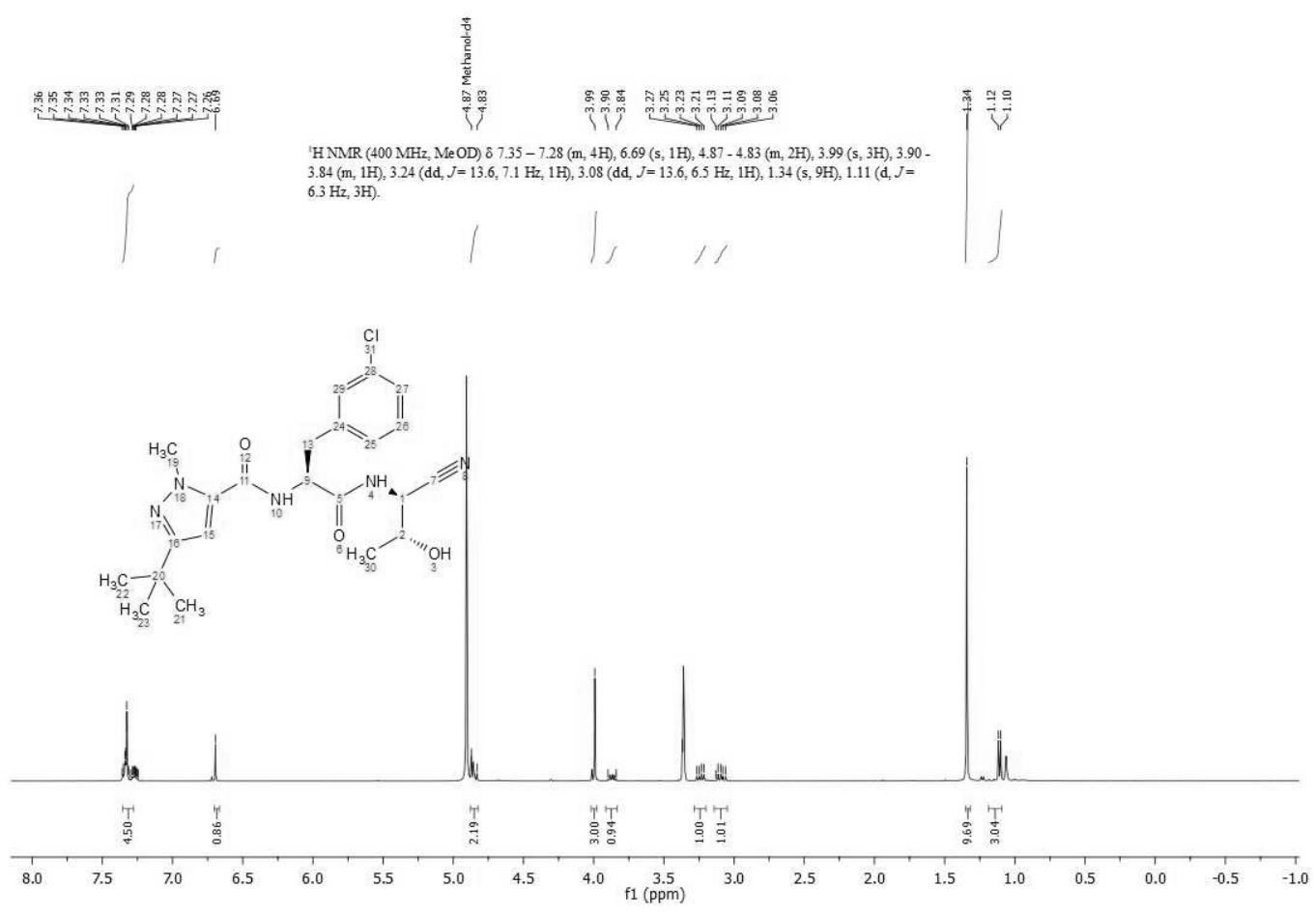

Figure 67. ${ }^{13} \mathrm{C} \mathrm{NMR}\left(100 \mathrm{MHz}, \mathrm{CDCl}_{3}\right)$ of compound 86 (Neq0948).

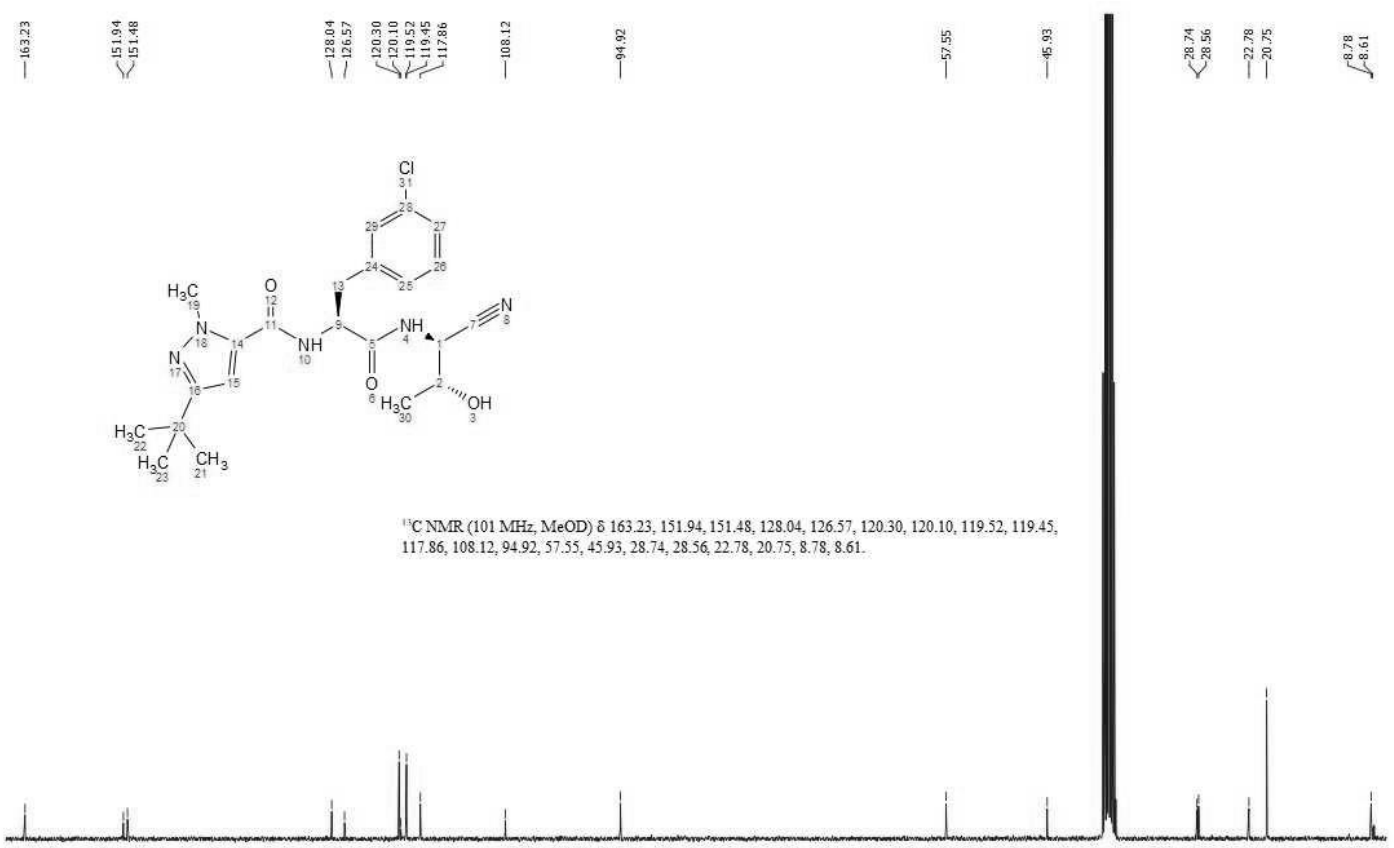

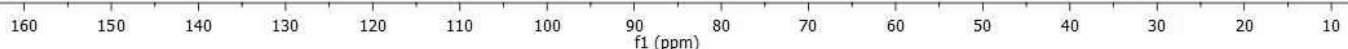


Figure 68. ${ }^{1} \mathrm{H} \mathrm{NMR} \mathrm{(400} \mathrm{MHz,} \mathrm{CDCl}_{3}$ ) of compound 111 (Neq0670).

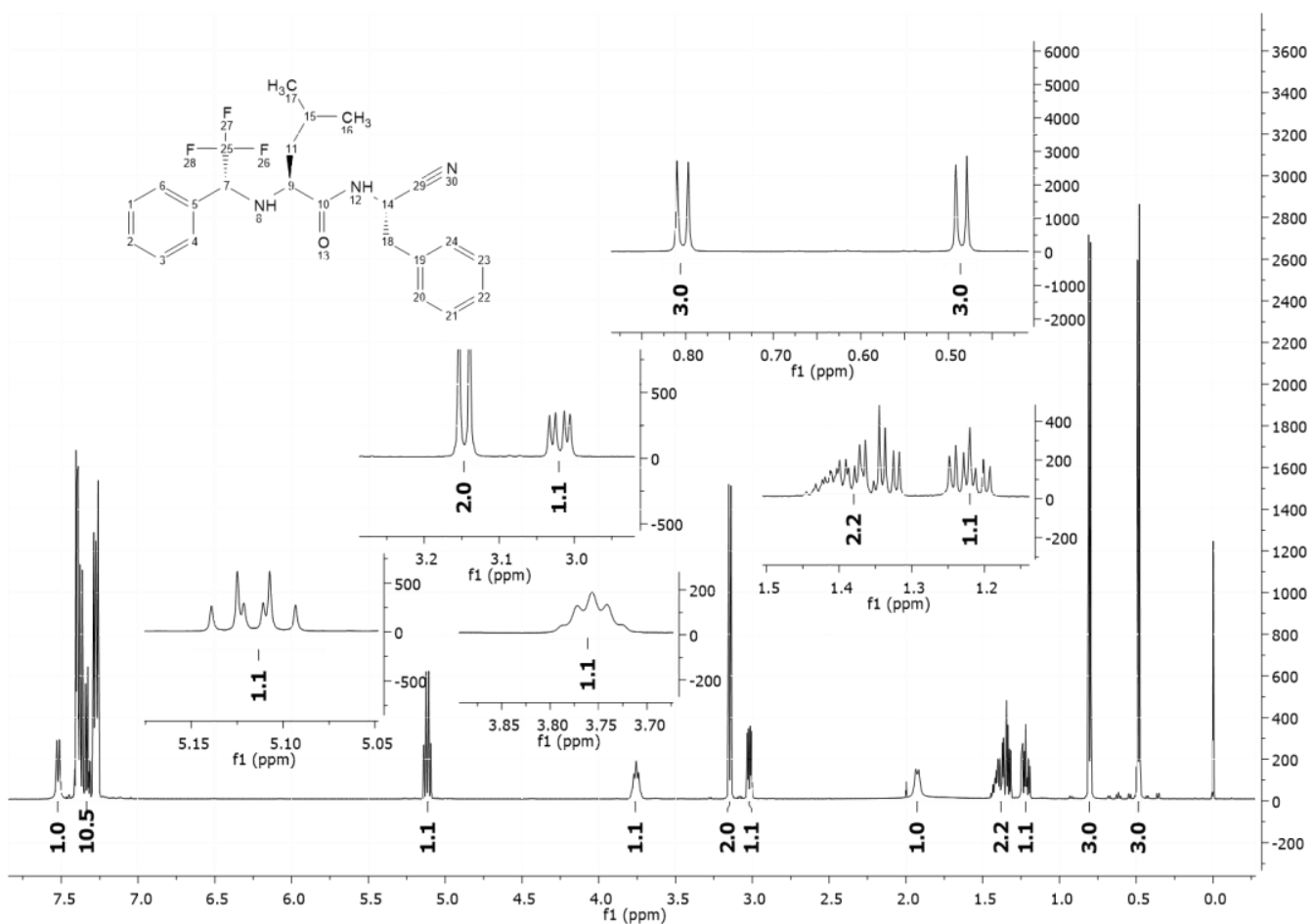

Figure 69. ${ }^{13} \mathrm{C} \mathrm{NMR}\left(100 \mathrm{MHz}, \mathrm{CDCl}_{3}\right.$ ) of compound 111 (Neq0670).

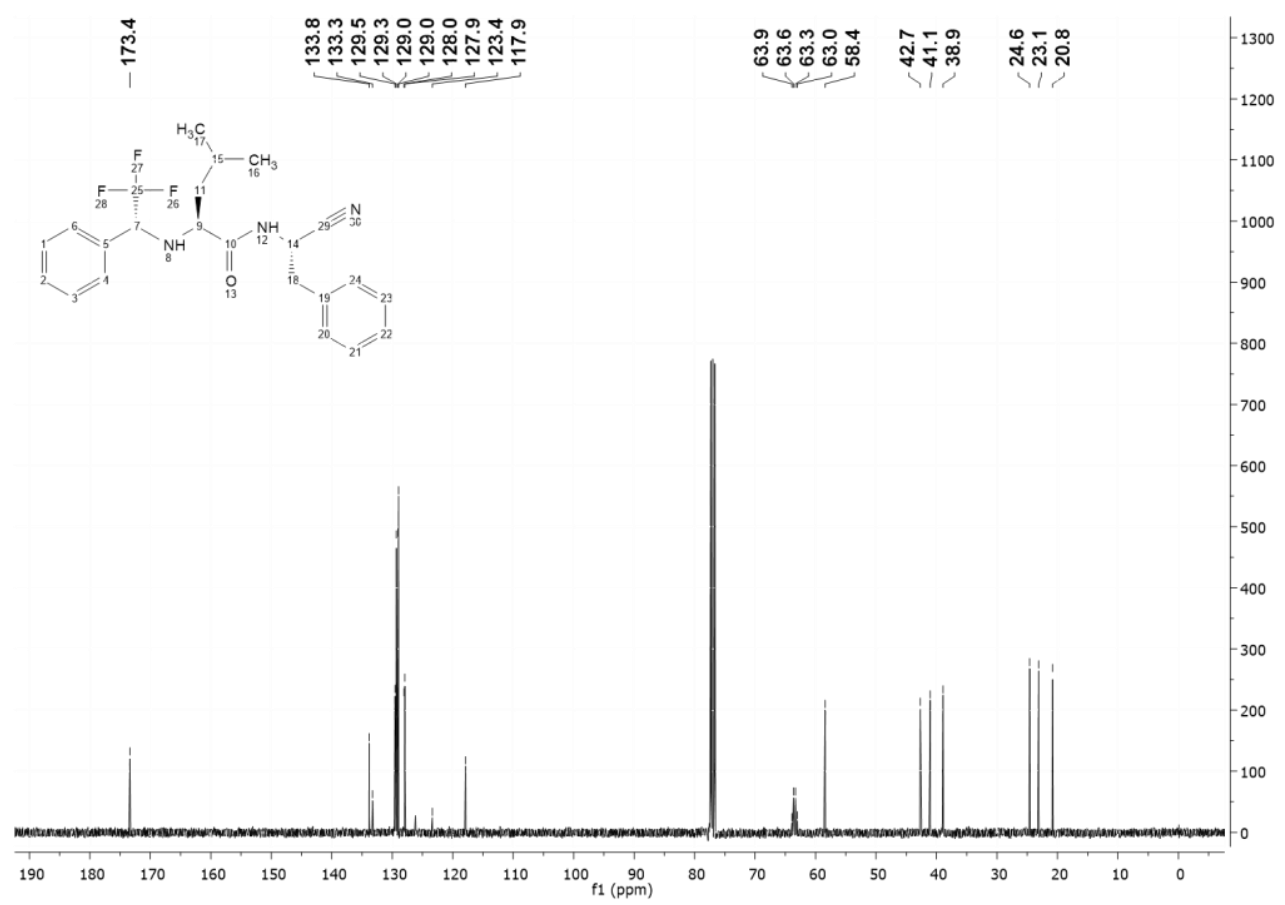


Figure 70. ${ }^{1} \mathrm{H}$ NMR $\left(400 \mathrm{MHz}, \mathrm{CDCl}_{3}\right)$ of compound 112 (Neq0643).

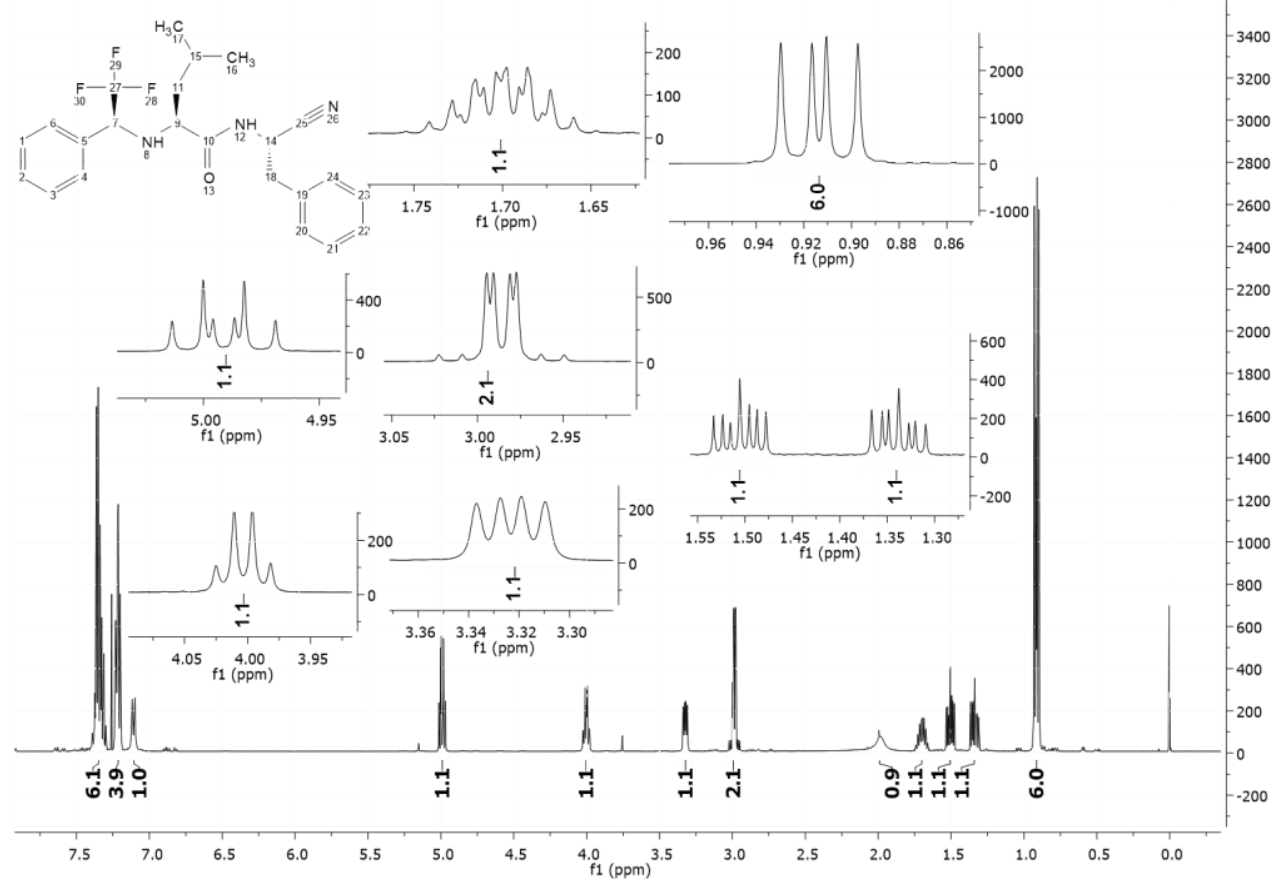

Figure $71 .{ }^{13} \mathrm{C}$ NMR (100 MHz, $\mathrm{CDCl}_{3}$ ) of compound 112 (Neq0643).

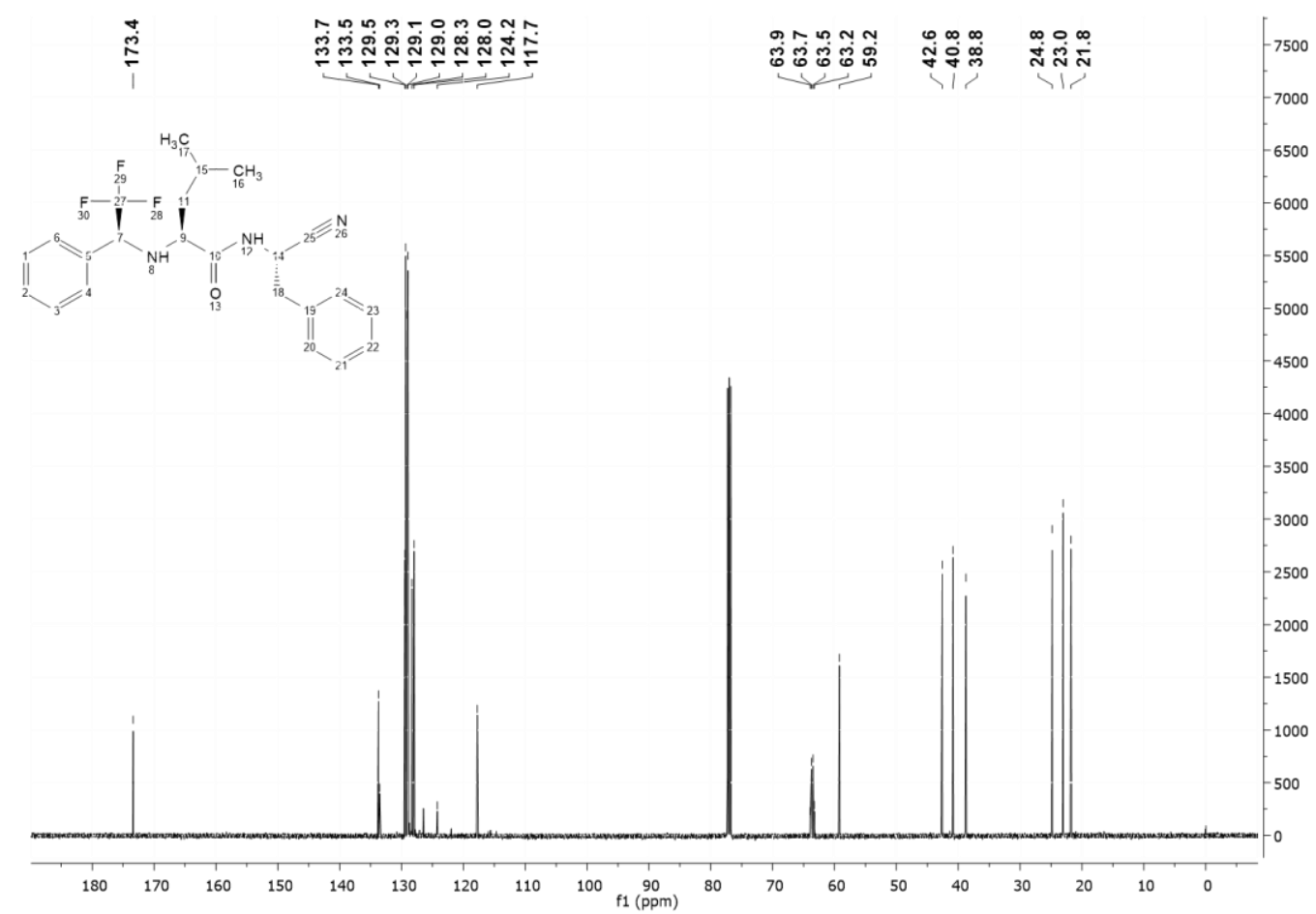


Figure 72. ${ }^{1} \mathrm{H} \mathrm{NMR}\left(400 \mathrm{MHz}, \mathrm{CDCl}_{3}\right)$ of compound 113 (Neq0658).

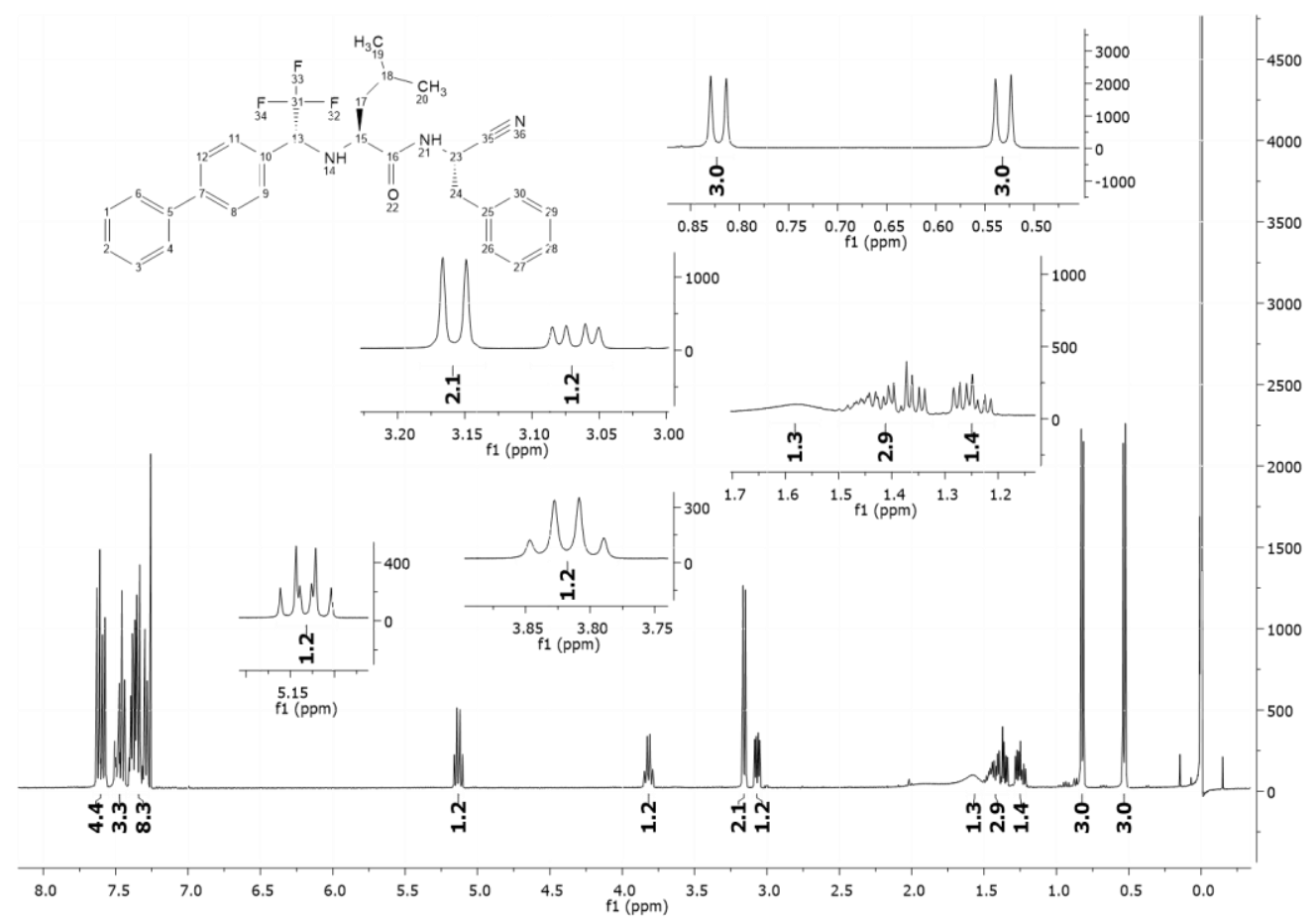

Figure 73. ${ }^{13} \mathrm{C} \mathrm{NMR}\left(100 \mathrm{MHz}, \mathrm{CDCl}_{3}\right)$ of compound 113 (Neq0658).

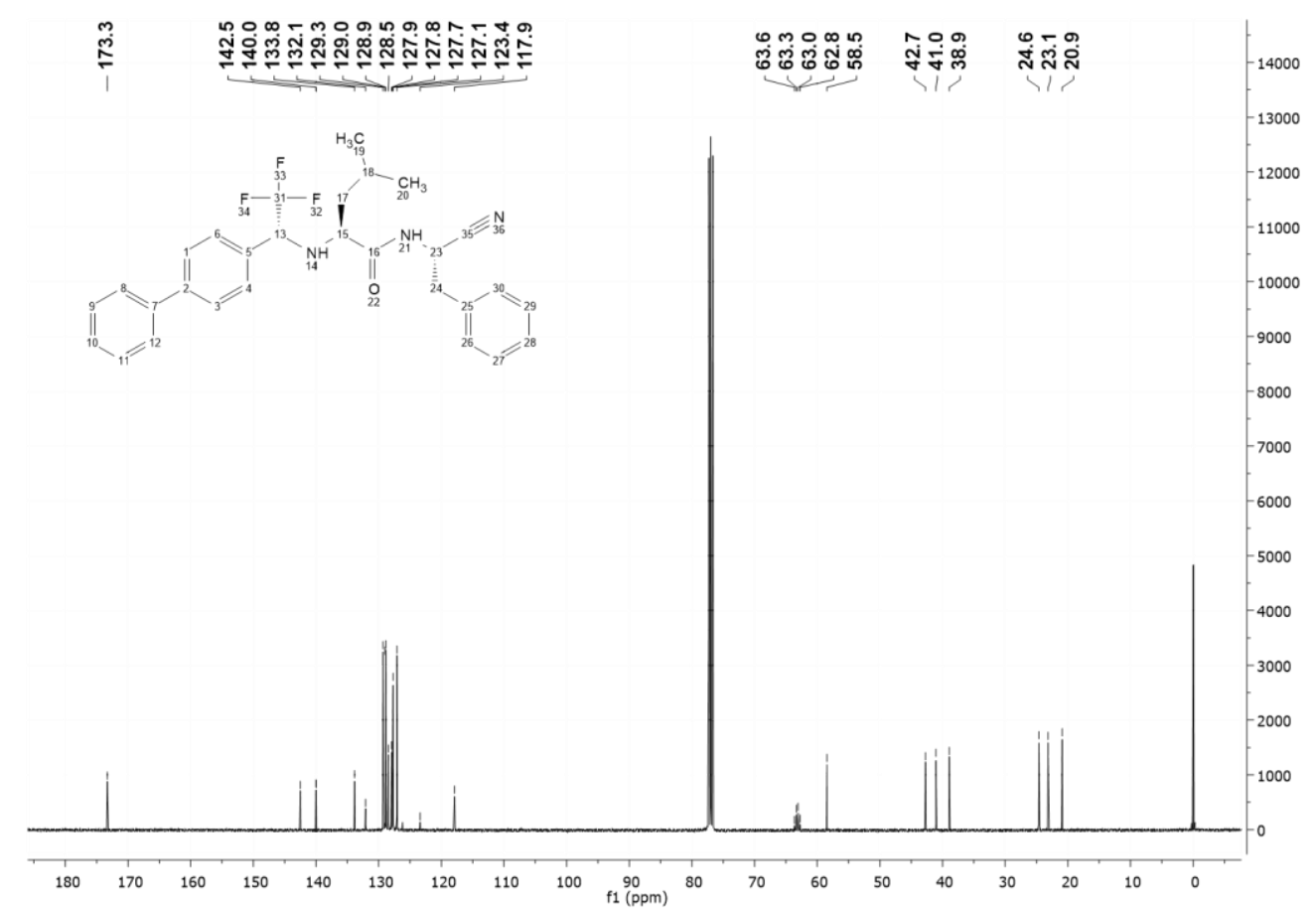


Figure 74. ${ }^{1} \mathrm{H} \mathrm{NMR}\left(400 \mathrm{MHz}, \mathrm{CDCl}_{3}\right.$ ) of compound 121 (Neq0820).

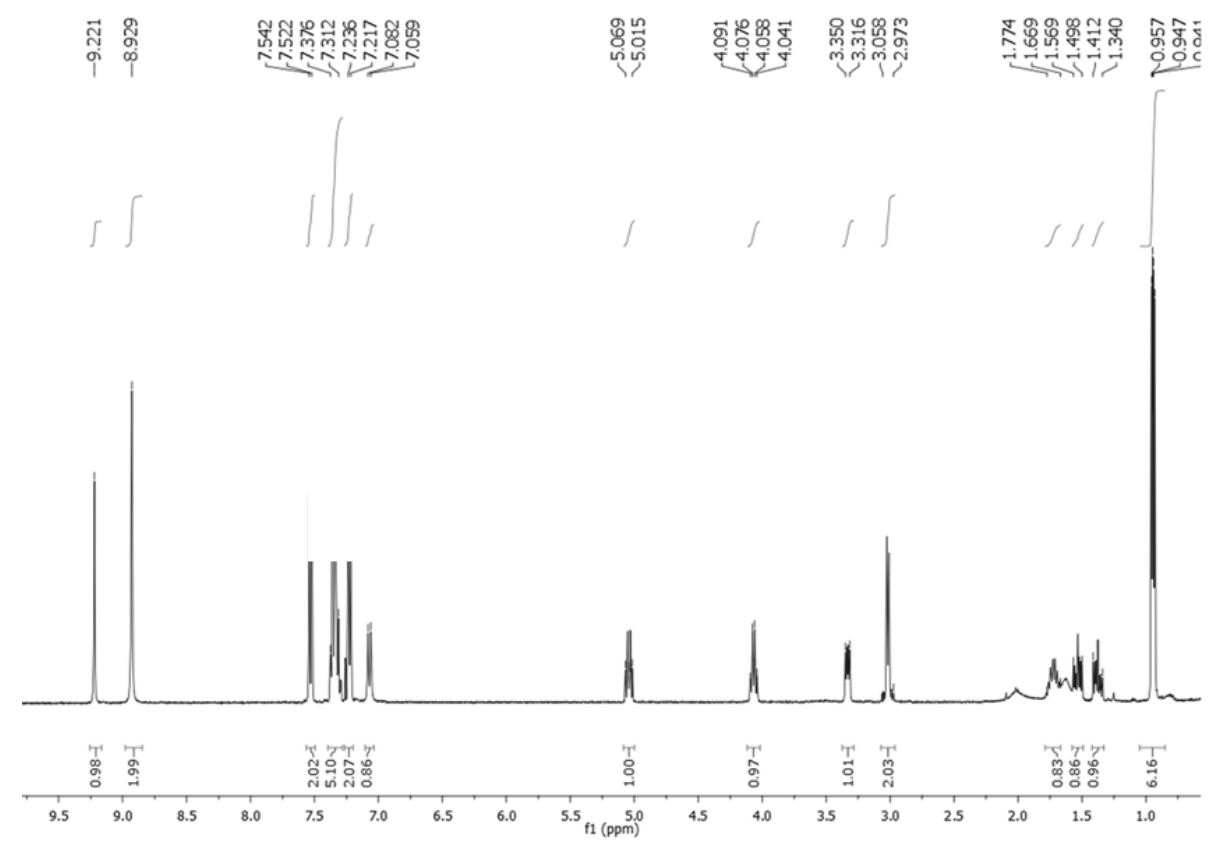

Figure 75. ${ }^{13} \mathrm{C}$ NMR (100 MHz, $\mathrm{CDCl}_{3}$ ) of compound 121 (Neq0820).

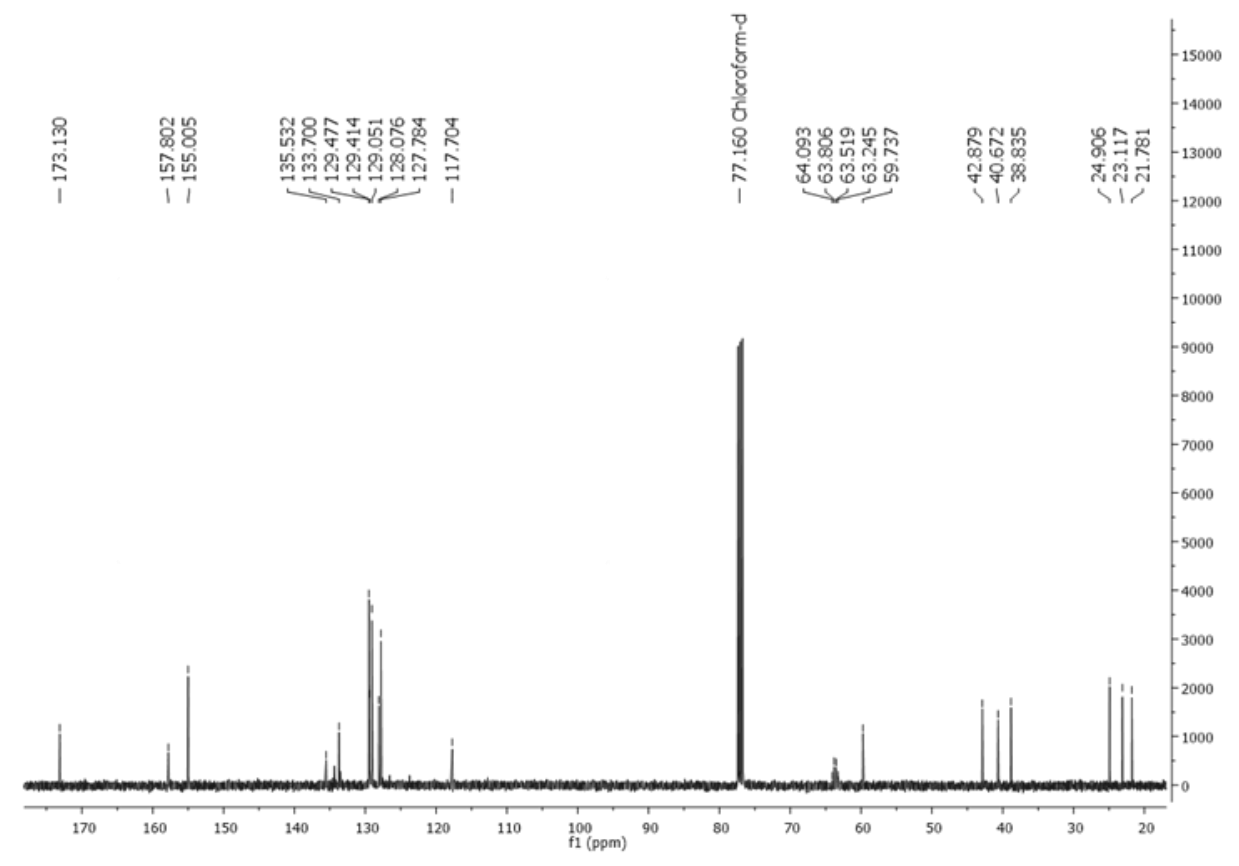


Figure 76. ${ }^{19} \mathrm{~F} \mathrm{NMR} \mathrm{(376} \mathrm{MHz,} \mathrm{CDCl}_{3}$ ) of compound 121 (Neq0820).

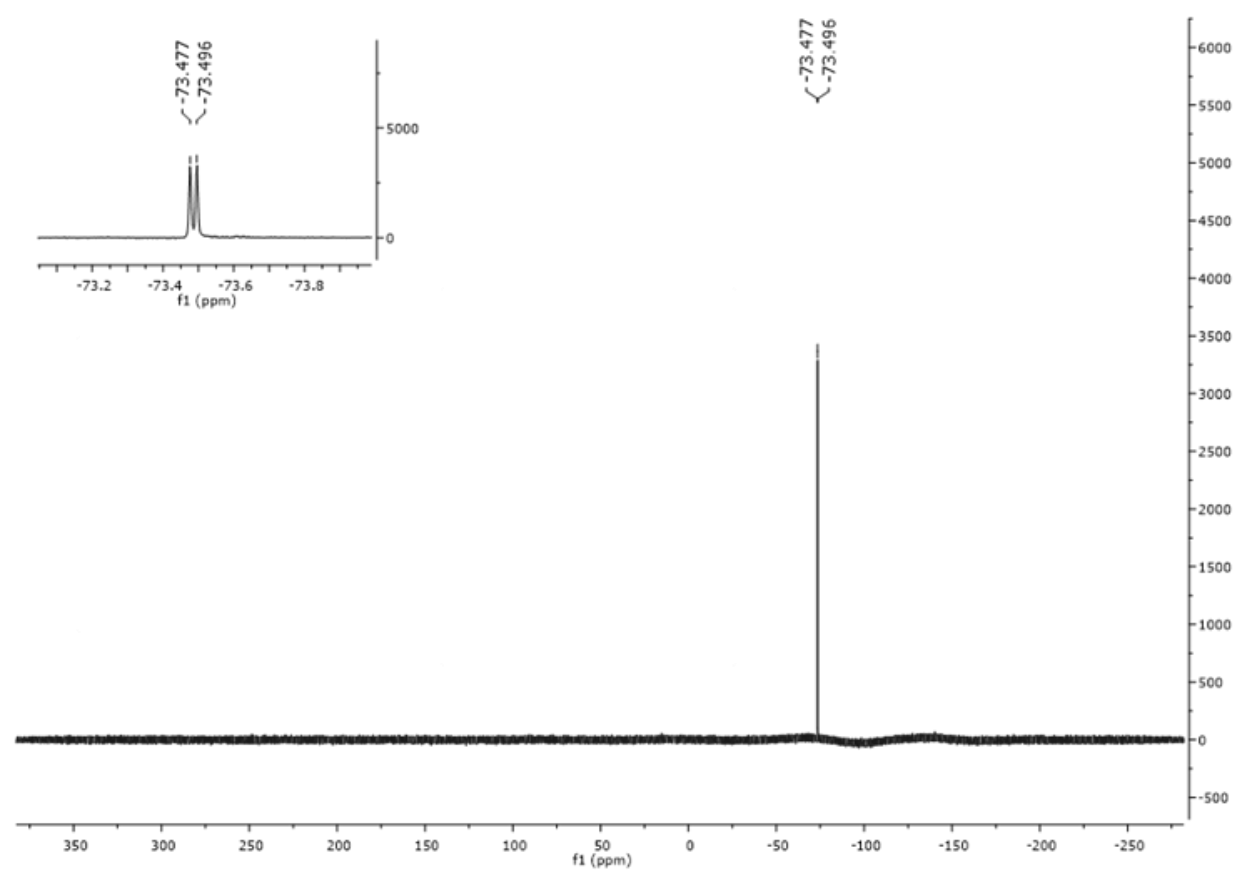


Figure 77. ${ }^{1} \mathrm{H}$ NMR (400 MHz, DMSO- $\left.d_{6}\right)$ of compound 124 (Neq0819).

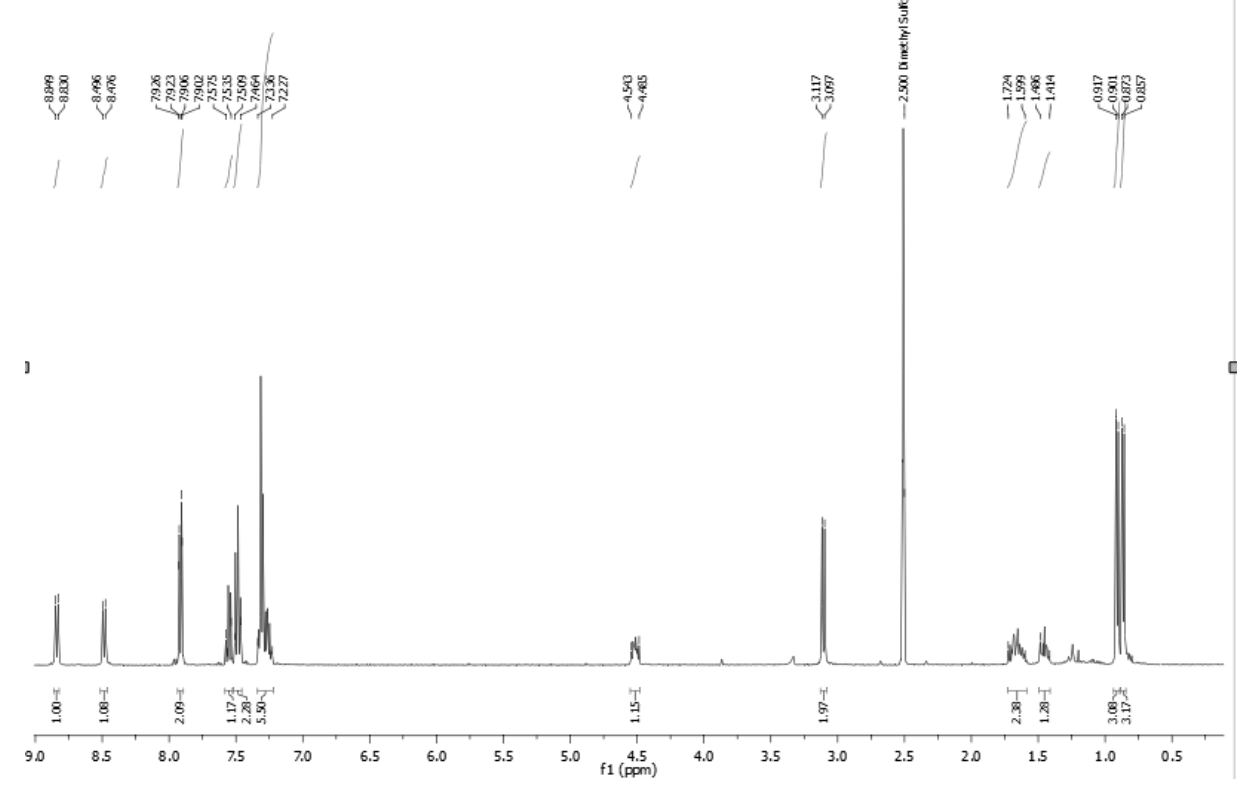

Figure 78. ${ }^{13} \mathrm{C}$ NMR (100 MHz, DMSO- $\left.d_{6}\right)$ of compound 124 (Neq0819).

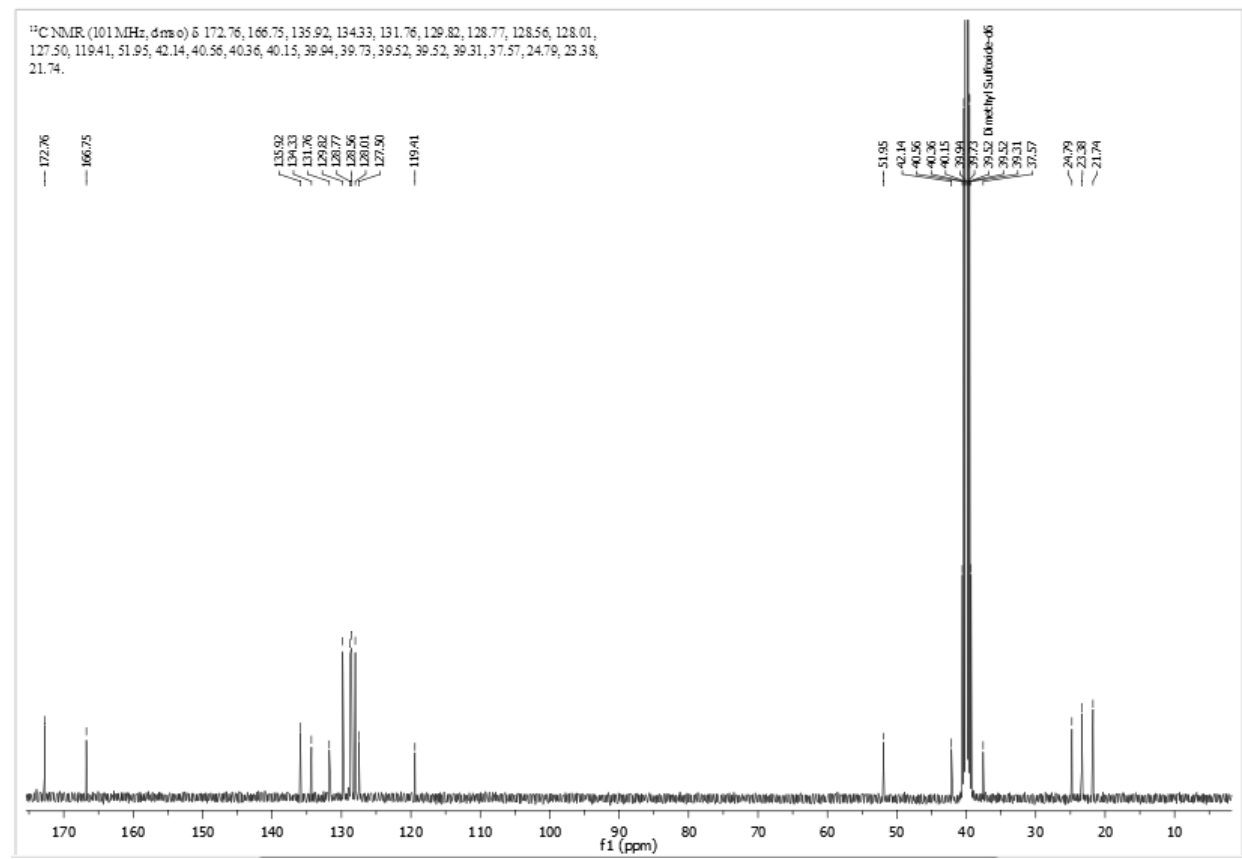


Figure 79. ${ }^{1} \mathrm{H}$ NMR (400 MHz DMSO- $d_{6}$ ) of compound 125 (Neq0781).

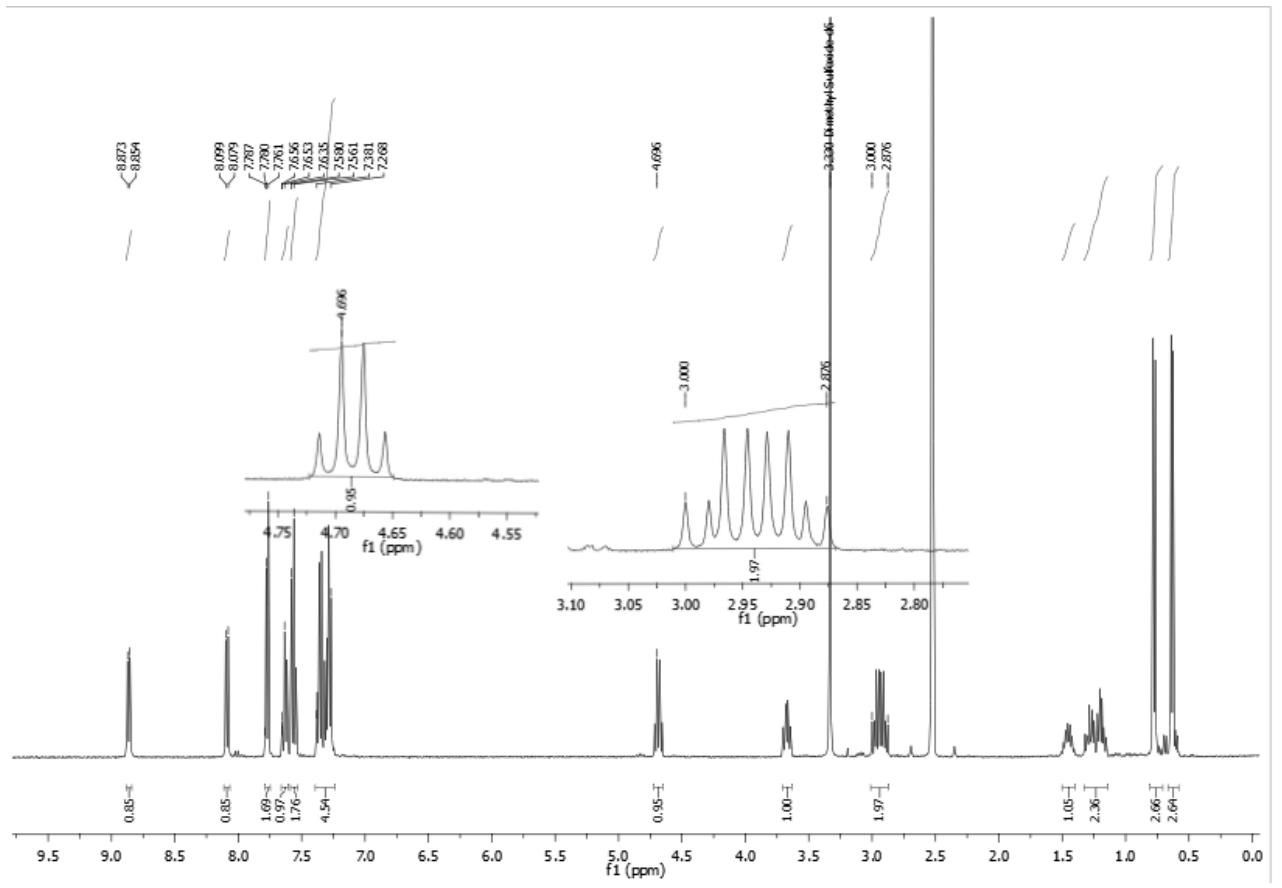

Figure $80 .{ }^{13} \mathrm{C}$ NMR (100 MHz, DMSO- $d_{6}$ ) of compound 125 (Neq0781).

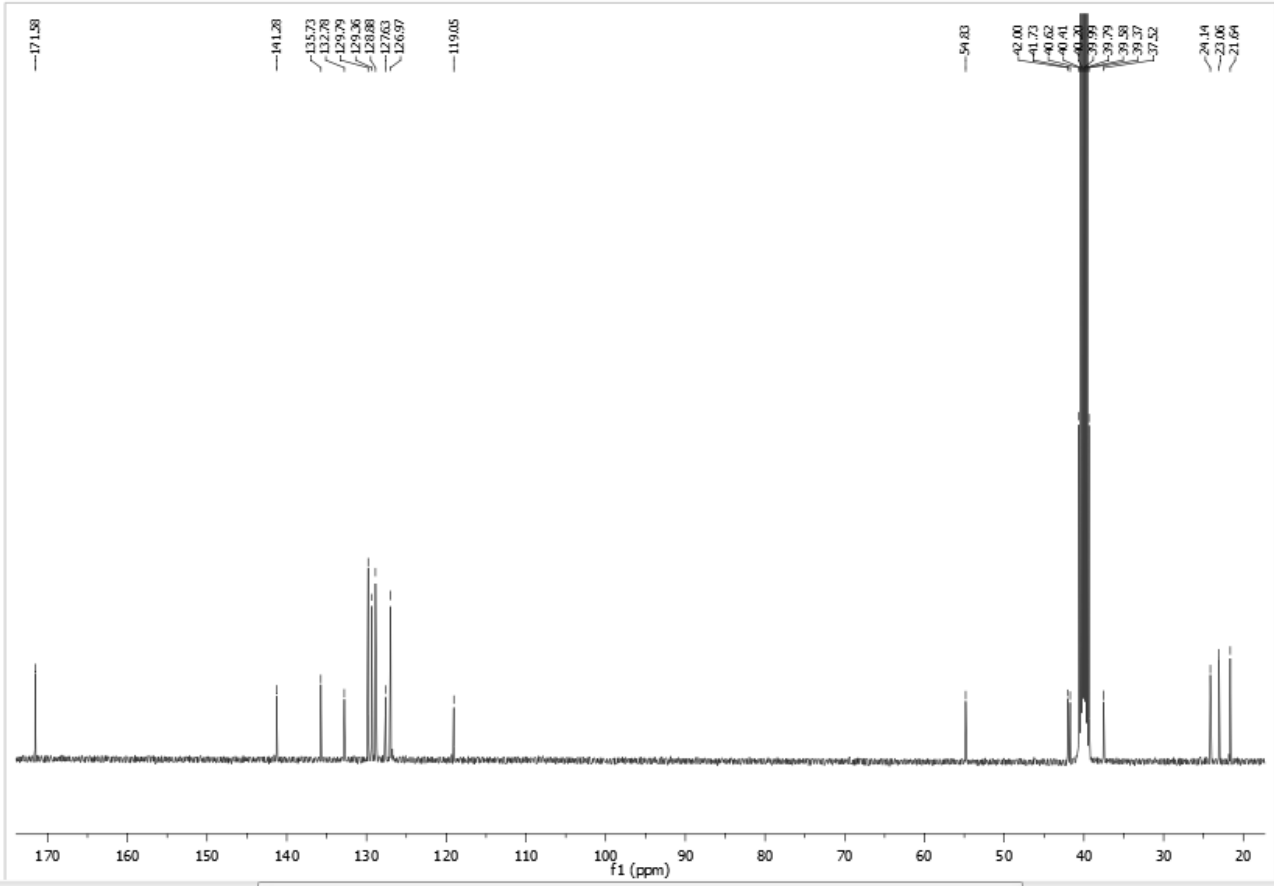


Figure 81. ${ }^{1} \mathrm{H}$ NMR (500 MHz DMSO- $d_{6}$ ) of compound 126 (Neq0782).
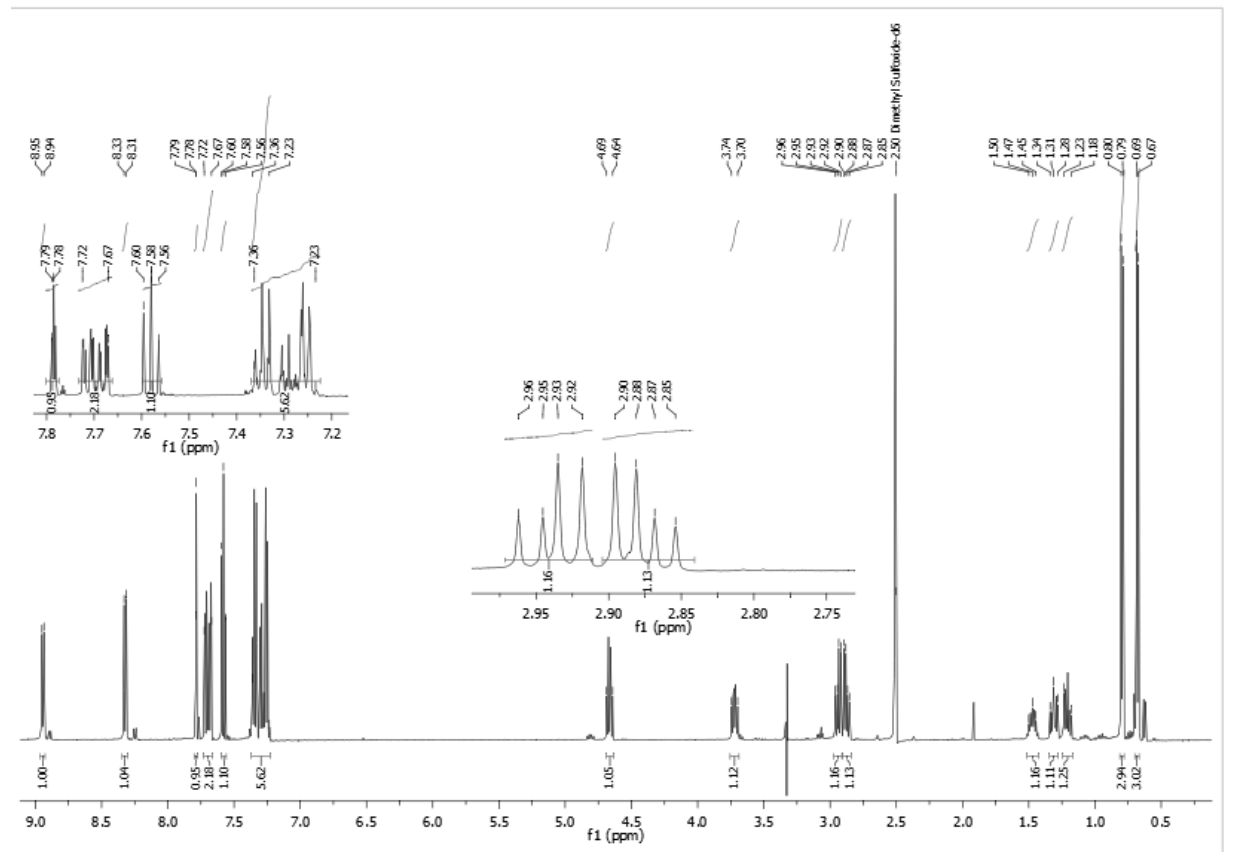

Figure 82. ${ }^{13} \mathrm{C}$ NMR (125 MHz, DMSO- $d_{6}$ ) of compound 126 (Neq0782).

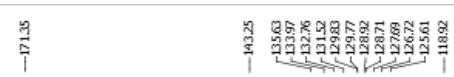

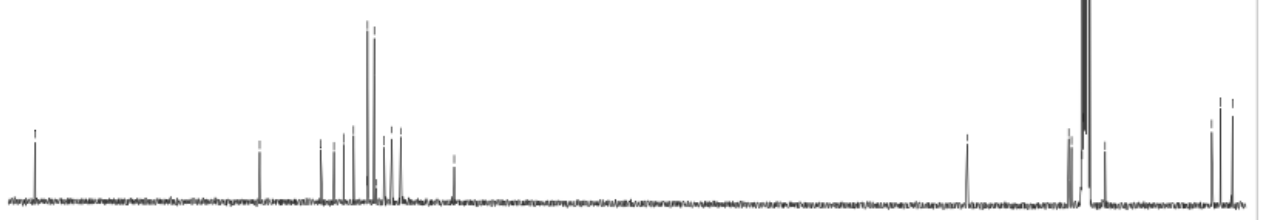

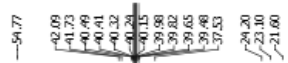

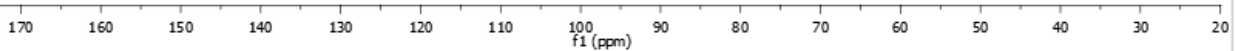


Figure 83. ${ }^{1} \mathrm{H}$ NMR (400 MHz DMSO- $d_{6}$ ) of compound 127 (Neq0831).

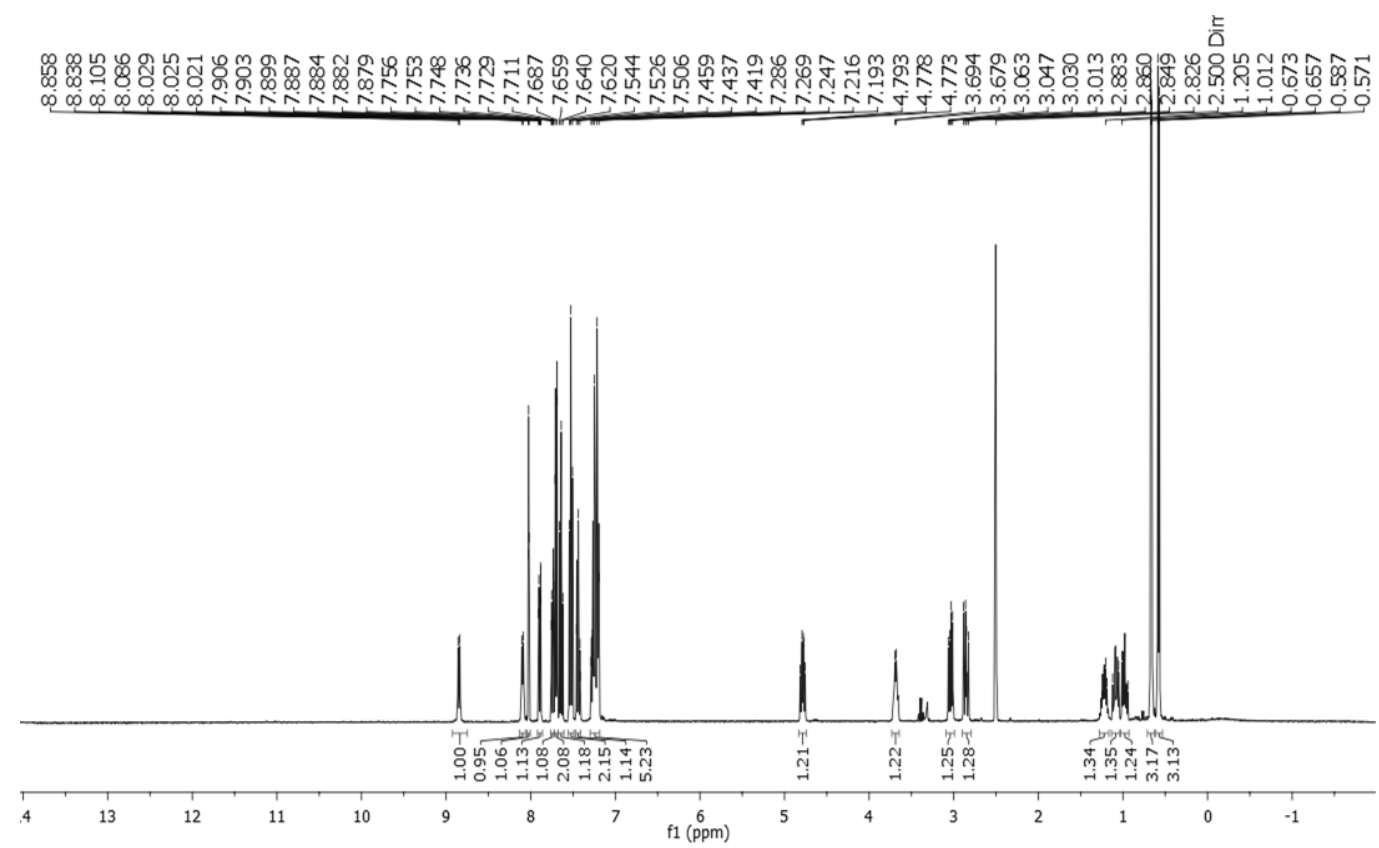

Figure 84. ${ }^{13} \mathrm{C}$ NMR (100 MHz, DMSO- $d_{6}$ ) of compound 127 (Neq0831).

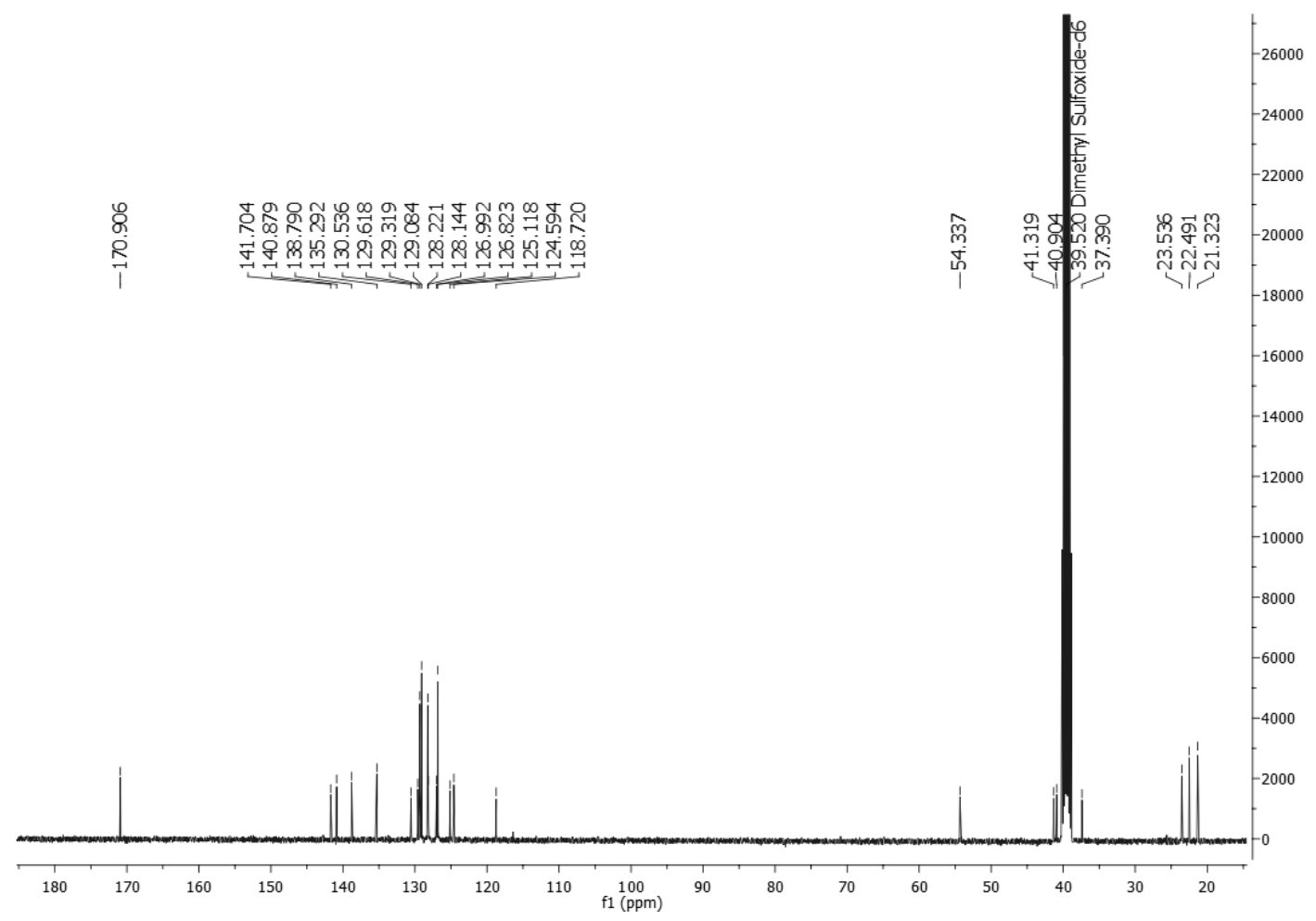


Figure 85. ${ }^{1} \mathrm{H}$ NMR (400 MHz DMSO- $d_{6}$ ) of compound 131 (Neq0830).

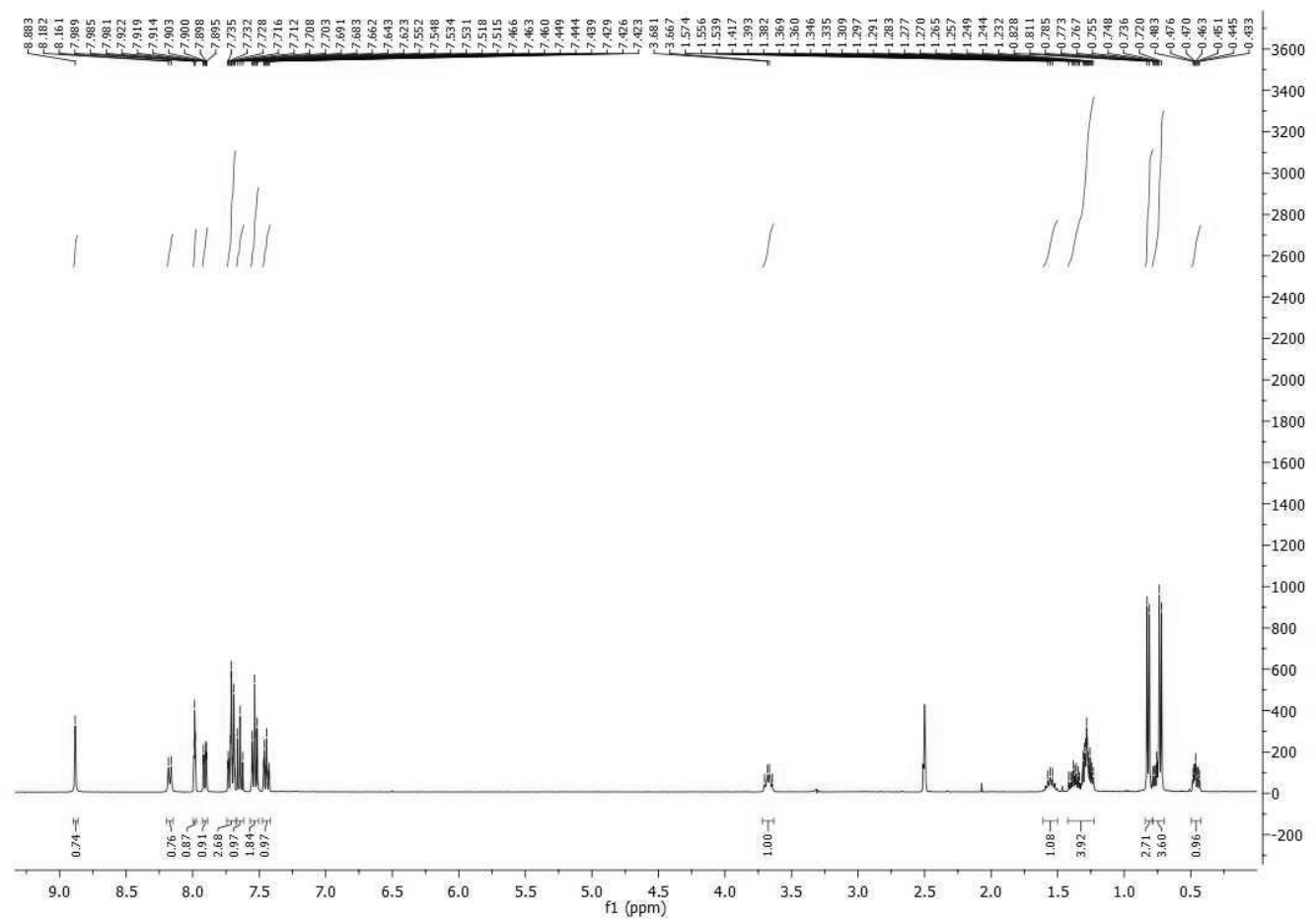

Figure 86. ${ }^{13} \mathrm{C}$ NMR (100 MHz, DMSO- $\left.d_{6}\right)$ of compound 131 (Neq0830).

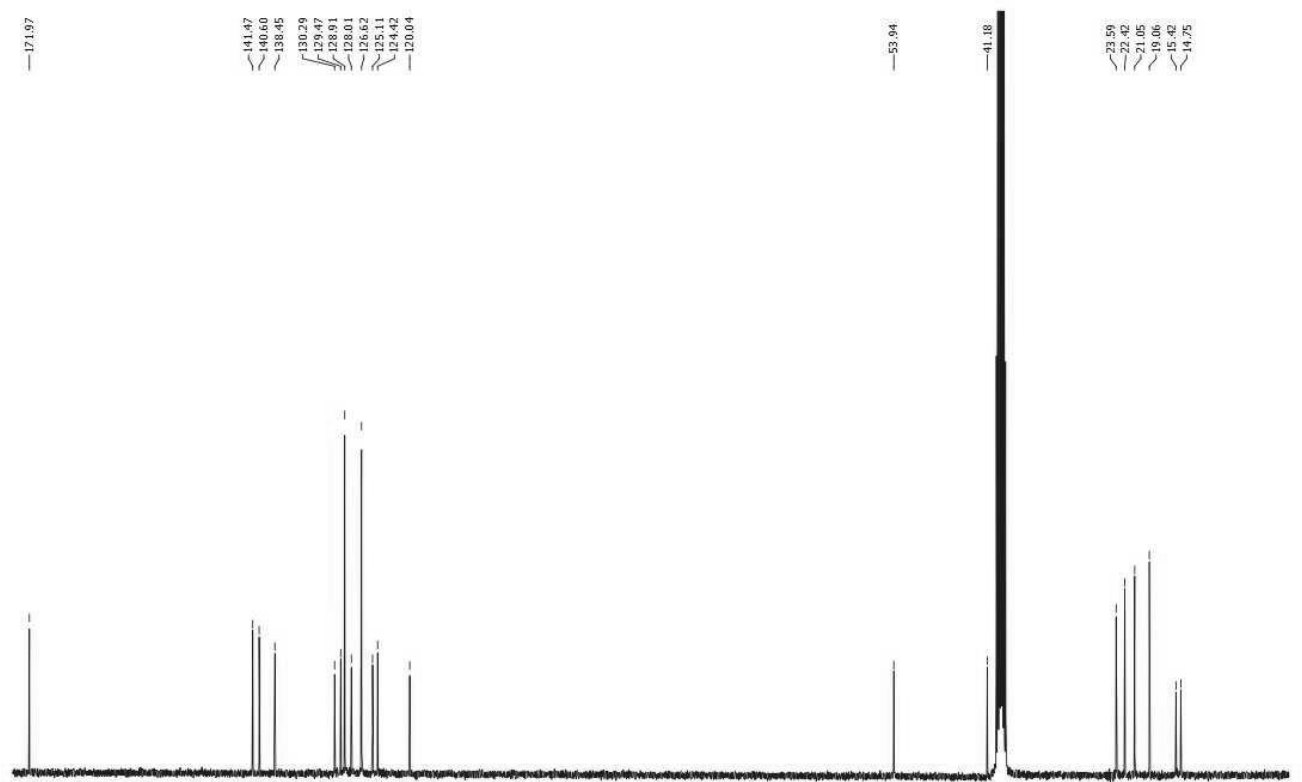

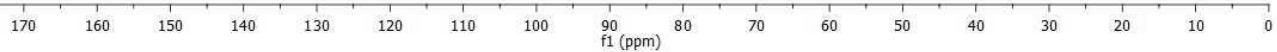


Figure 87. ${ }^{1} \mathrm{H}$ NMR (400 MHz DMSO- $d_{6}$ ) of compound 134 (Neq0838).

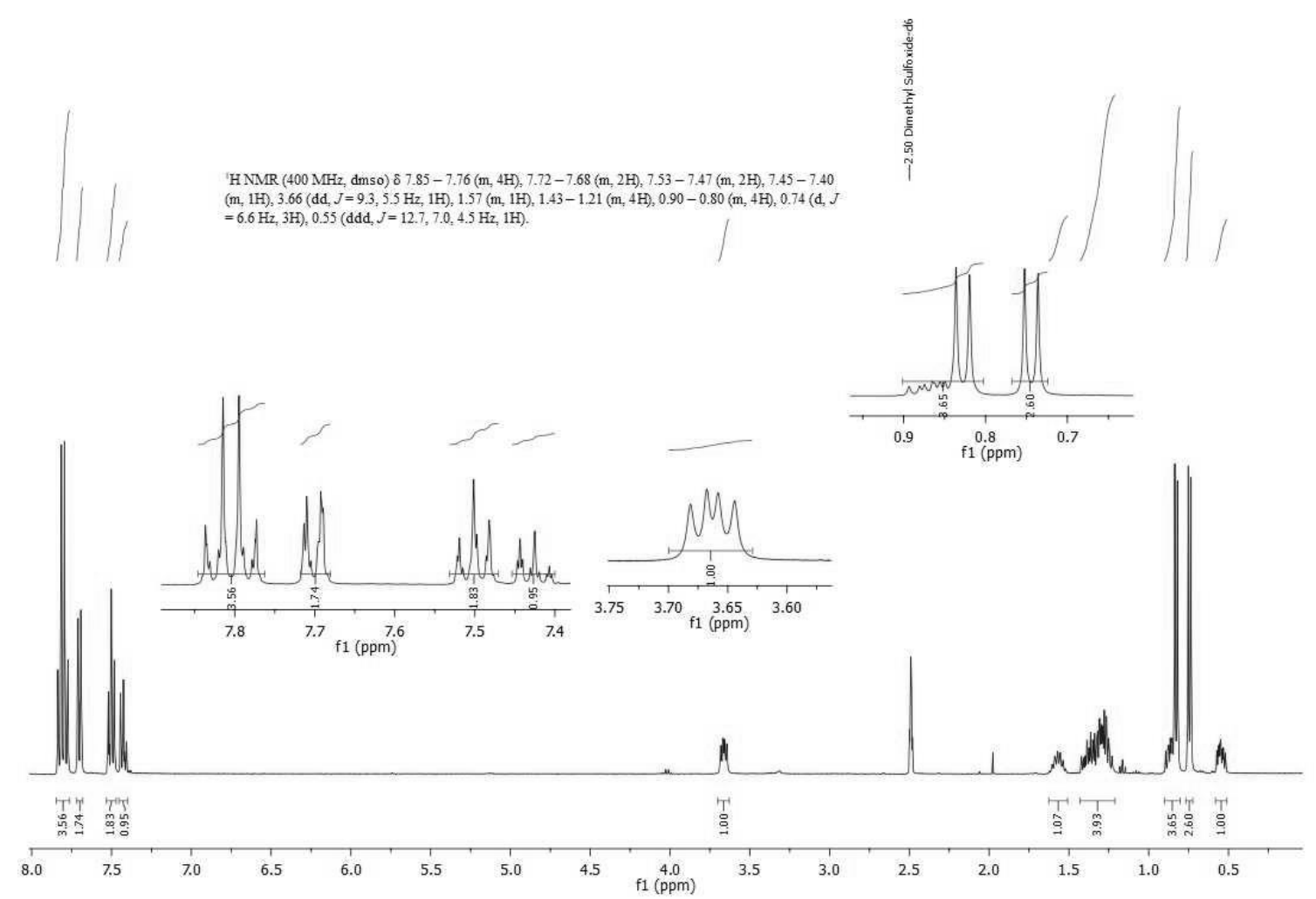

Figure 88. ${ }^{13} \mathrm{C}$ NMR (100 MHz, DMSO- $\left.d_{6}\right)$ of compound 134 (Neq0838).
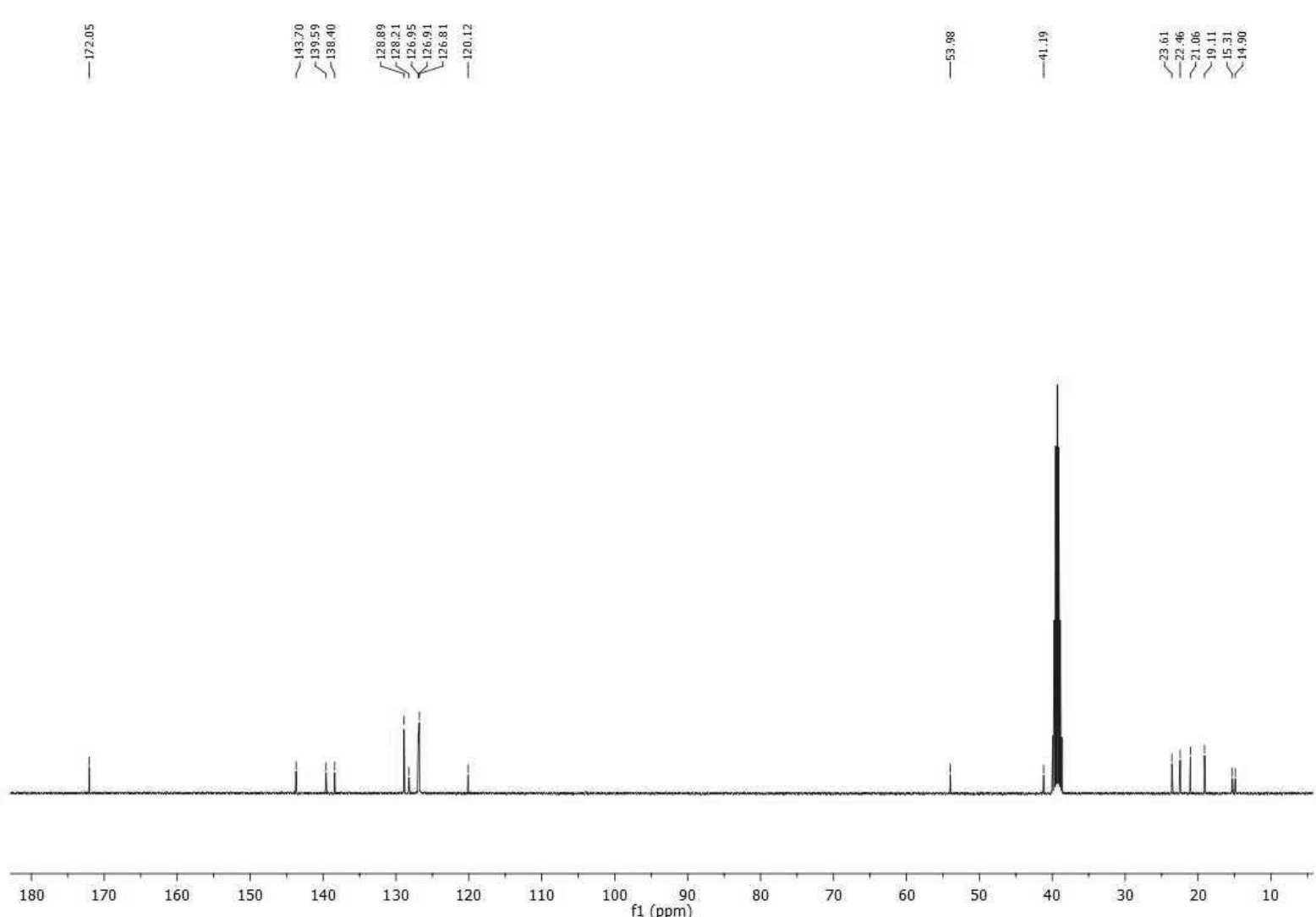


\section{APPENDIX B}

HPLC analysis to evaluate the absence of racemization in the synthetic route.

Figure 89. HPLC analysis of $R-99$.

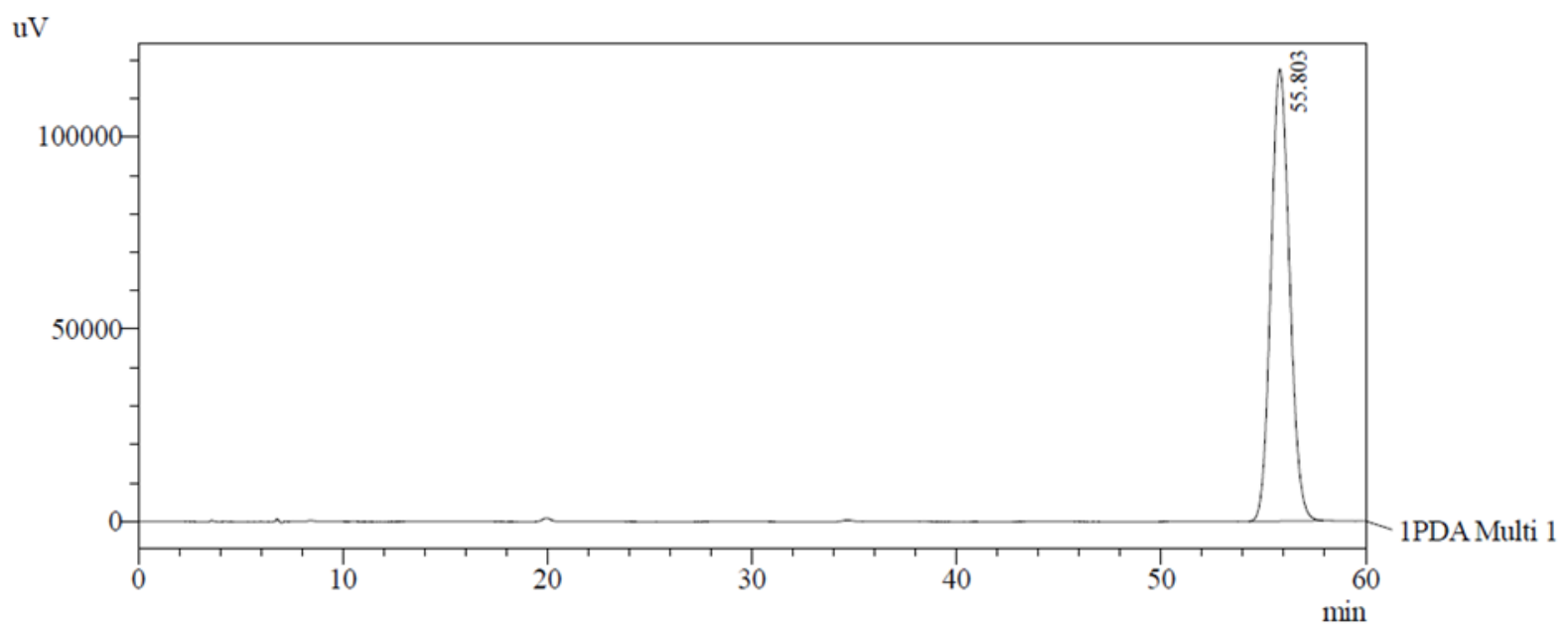

1 PDA Multi $1 / 206 \mathrm{~nm} 4 \mathrm{~nm}$

Chiralpak $^{\circledR}$ IC-5 (5 $\left.\mu \mathrm{m}\right), 250 \times 4.6 \mathrm{~mm}, \mathrm{ACN} /$ water: 30:70, $206 \mathrm{~nm}$; stop time $40 \mathrm{~min}$, flow 0.5 $\mathrm{ml} / \mathrm{min}$.

Figure 90: HPLC analysis of S-99.

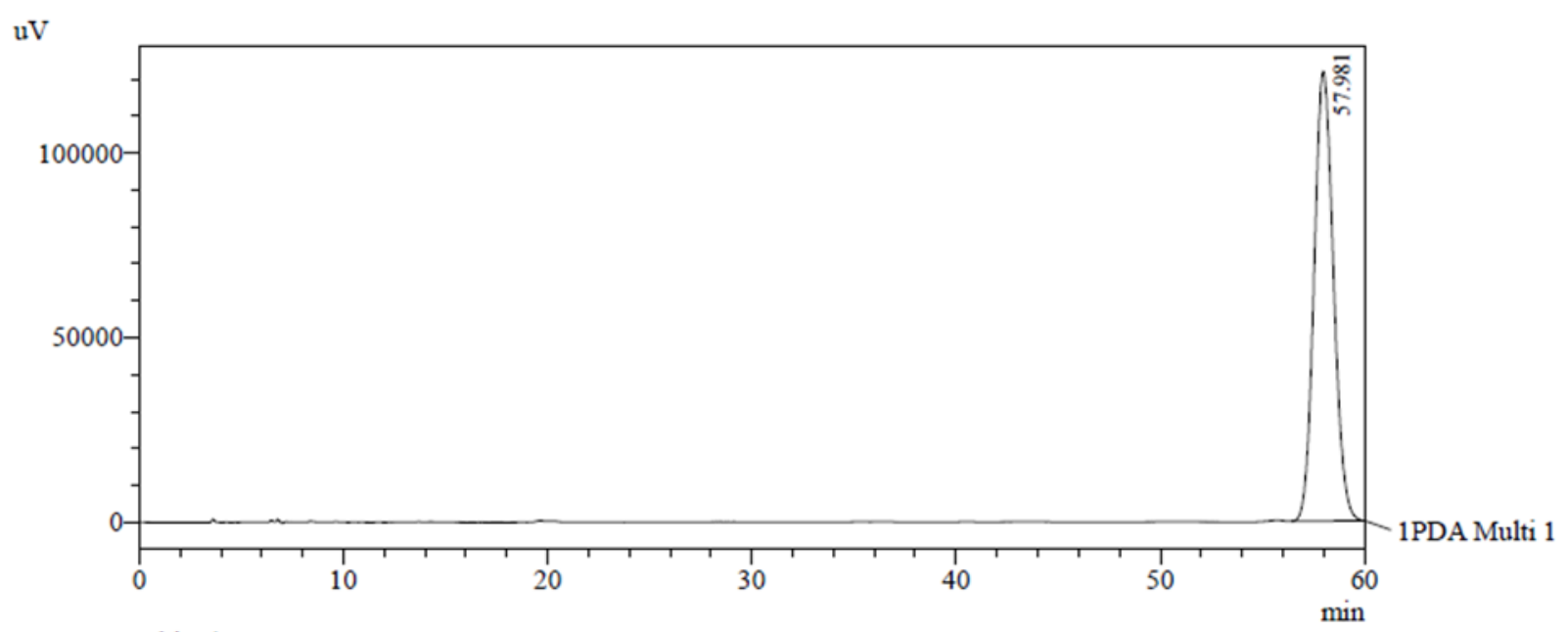

1 PDA Multi $1 / 206 \mathrm{~nm} 4 \mathrm{~nm}$

Chiralpak $^{\circledR}$ IC-5 $(5 \mu \mathrm{m}), 250 \times 4.6 \mathrm{~mm}, \mathrm{ACN} /$ water: 30:70, $206 \mathrm{~nm}$; stop time $40 \mathrm{~min}$, flow 0.5 $\mathrm{ml} / \mathrm{min}$. 
Figure 91. HPLC analysis of a mixture of $R-99$ and $S-99$.

uV

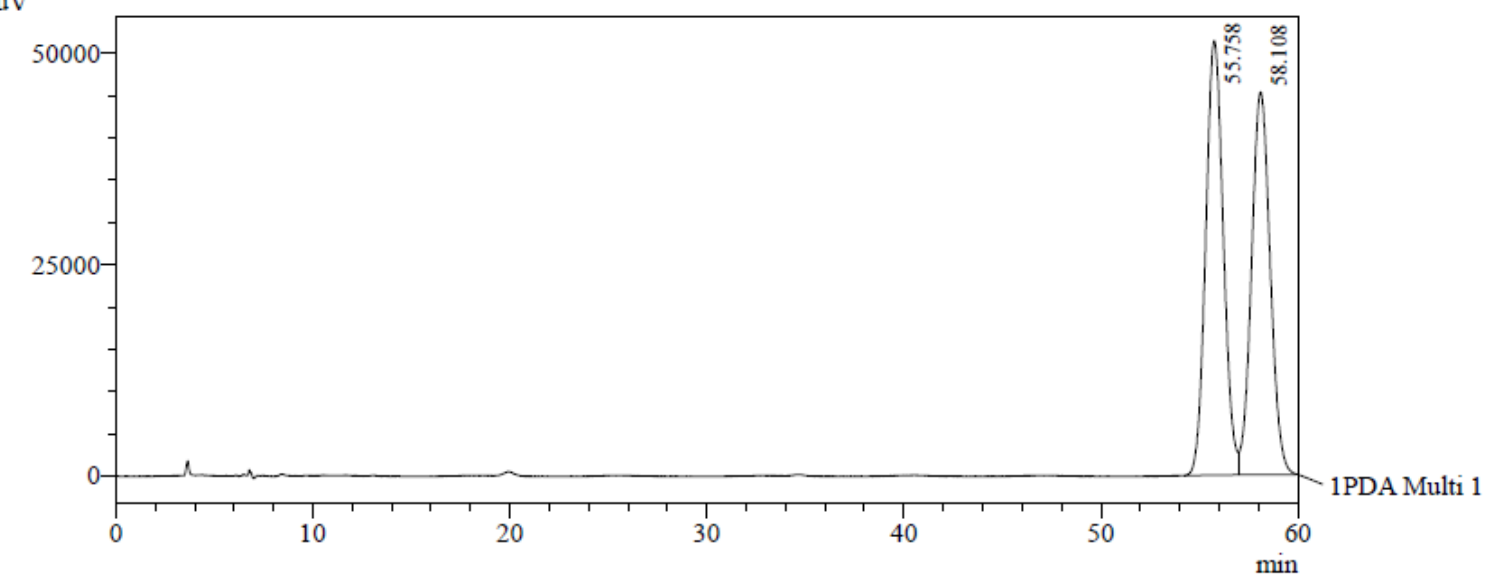

1 PDA Multi $1 / 206 \mathrm{~nm} 4 \mathrm{~nm}$

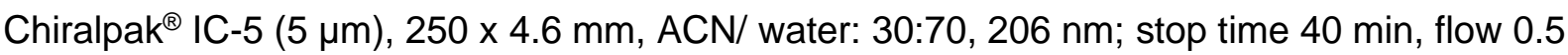
$\mathrm{ml} / \mathrm{min}$.

Figure 92. HPLC analysis of 67 (Neq0937) with Diacel column (IC-chiralpak, $250 \times 4.6 \mathrm{~mm}$, $5 \mu \mathrm{m})$.

Chromatogram

A_1 C:IHPLC $\backslash$ Sinteses\Analise_Lorenzo\A_1.1cd

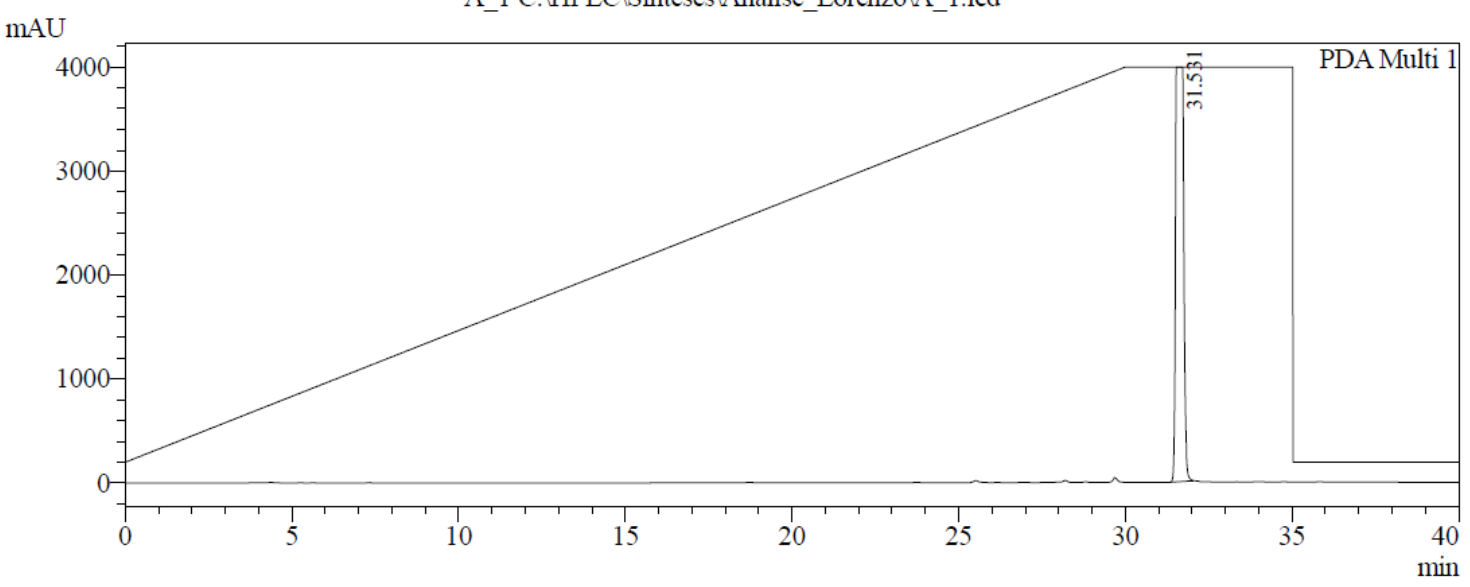

Elution was carried out with the following gradient: water (solvent $A$ ), $A C N$ (solvent $B$ ), $5 \% B$ to $100 \%$ B in $30 \mathrm{~min}$, stop time $40 \mathrm{~min}$, flow $0.5 \mathrm{ml} / \mathrm{min}$. 
Figure 93. HPLC analysis of 68 (Neq0866.1) with Diacel column (IC-chiralpak, $250 \times 4.6$ $\mathrm{mm}, 5 \mu \mathrm{m})$.

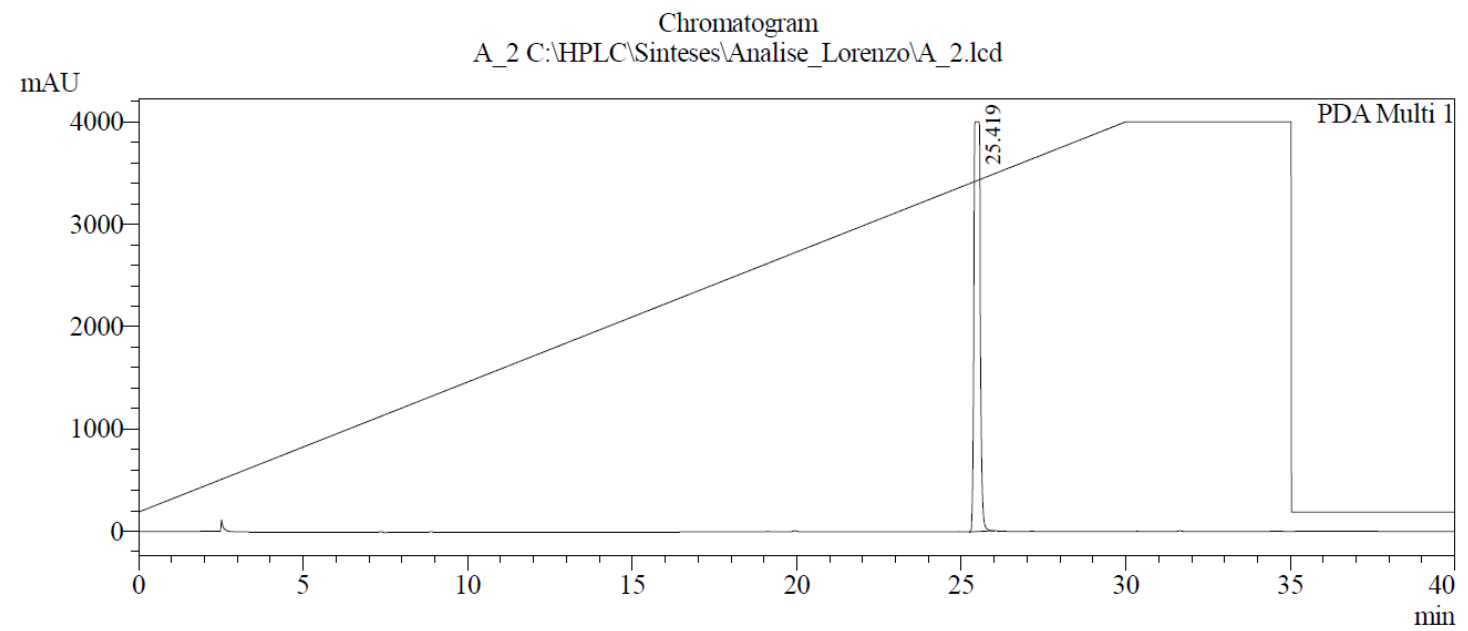

Elution was carried out with the following gradient: water (solvent $A$ ), ACN (solvent B), $5 \% B$ to $100 \% \mathrm{~B}$ in $30 \mathrm{~min}$, stop time $40 \mathrm{~min}$, flow $0.5 \mathrm{ml} / \mathrm{min}$.

Figure 94. HPLC analysis for a mixture of 67 (Neq0937) and 68 (Neq0866.1) with Diacel column (IC-chiralpak, $250 \times 4.6 \mathrm{~mm}, 5 \mu \mathrm{m})$.

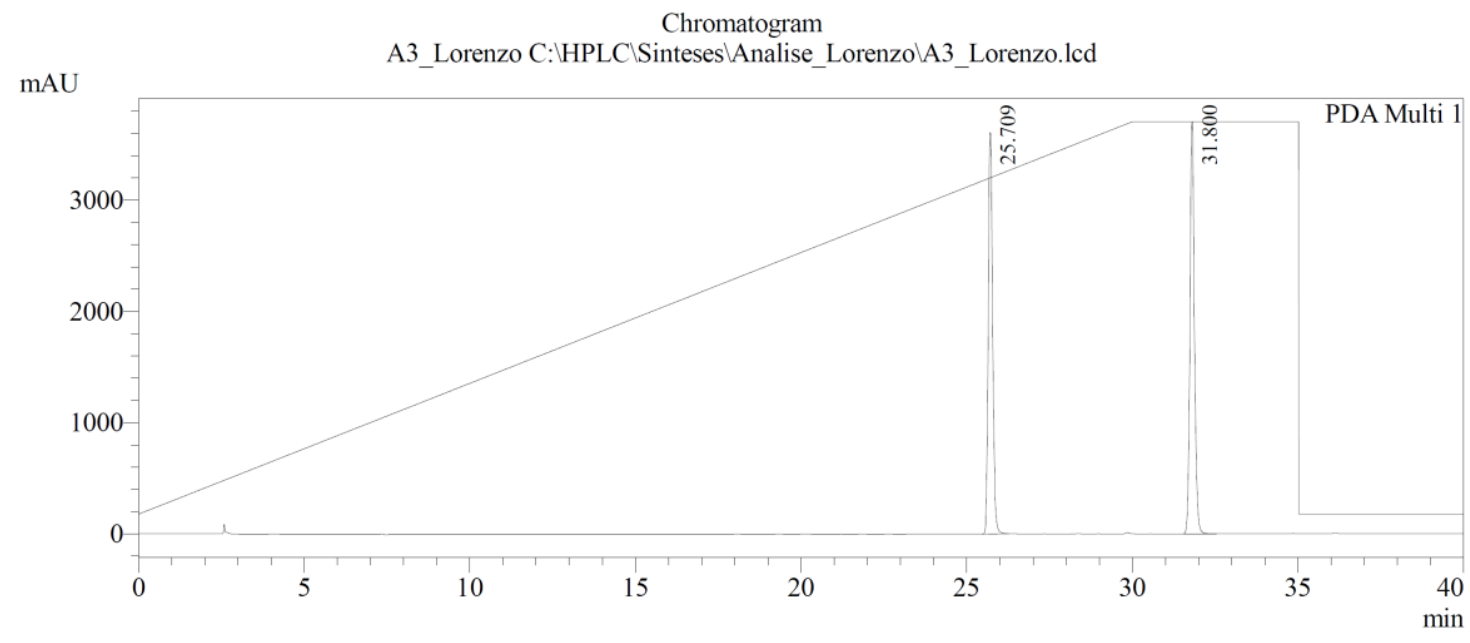

Elution was carried out with the following gradient: water (solvent $A$ ), ACN (solvent B), $5 \% B$ to $100 \% \mathrm{~B}$ in $30 \mathrm{~min}$, stop time $40 \mathrm{~min}$, flow $0.5 \mathrm{ml} / \mathrm{min}$. 
Figure 95. HPLC analysis of 73 (Neq0921) with Diacel column (IC-chiralpak, $250 \times 4.6 \mathrm{~mm}$, $5 \mu \mathrm{m})$.

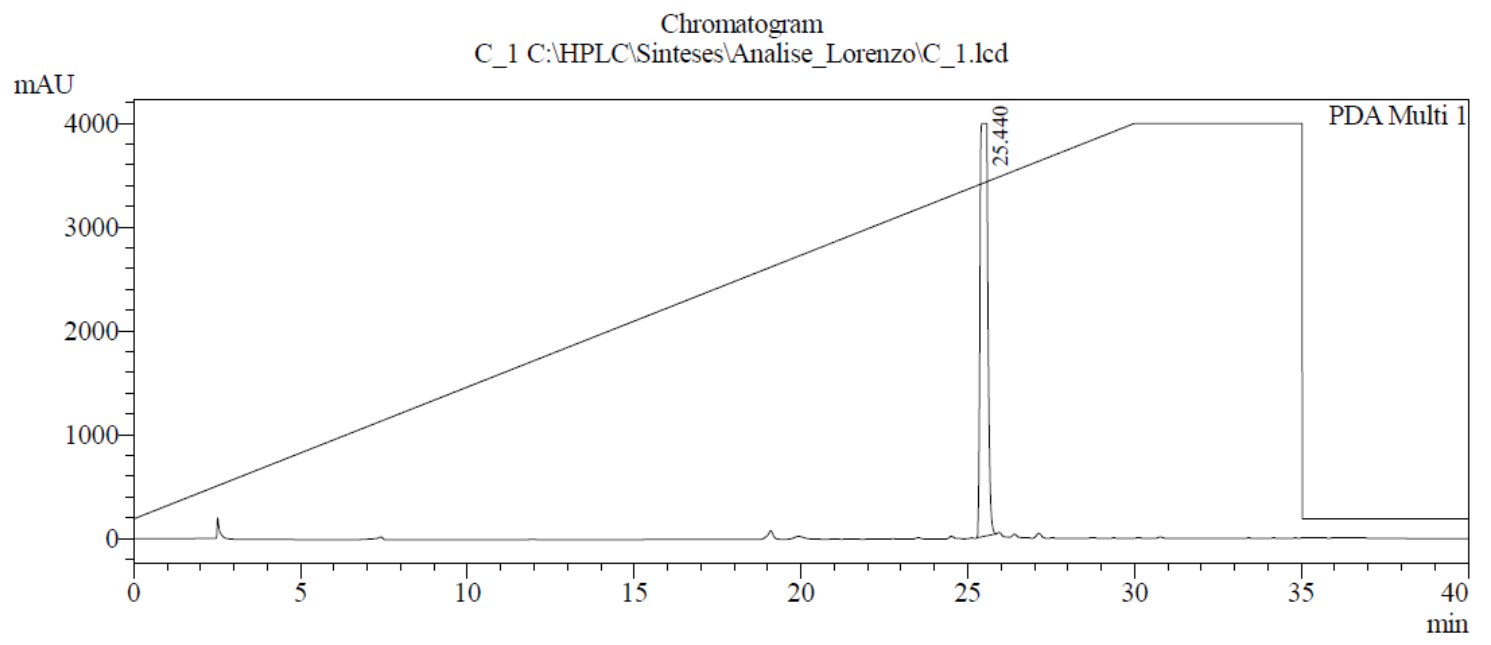

Elution was carried out with the following gradient: water (solvent $A$ ), ACN (solvent B), $5 \% B$ to $100 \% \mathrm{~B}$ in $30 \mathrm{~min}$, stop time $40 \mathrm{~min}$, flow $0.5 \mathrm{ml} / \mathrm{min}$.

Figure 96. HPLC analysis of 74 (Neq0938) with Diacel column (IC-chiralpak, $250 \times 4.6 \mathrm{~mm}$, $5 \mu \mathrm{m})$.

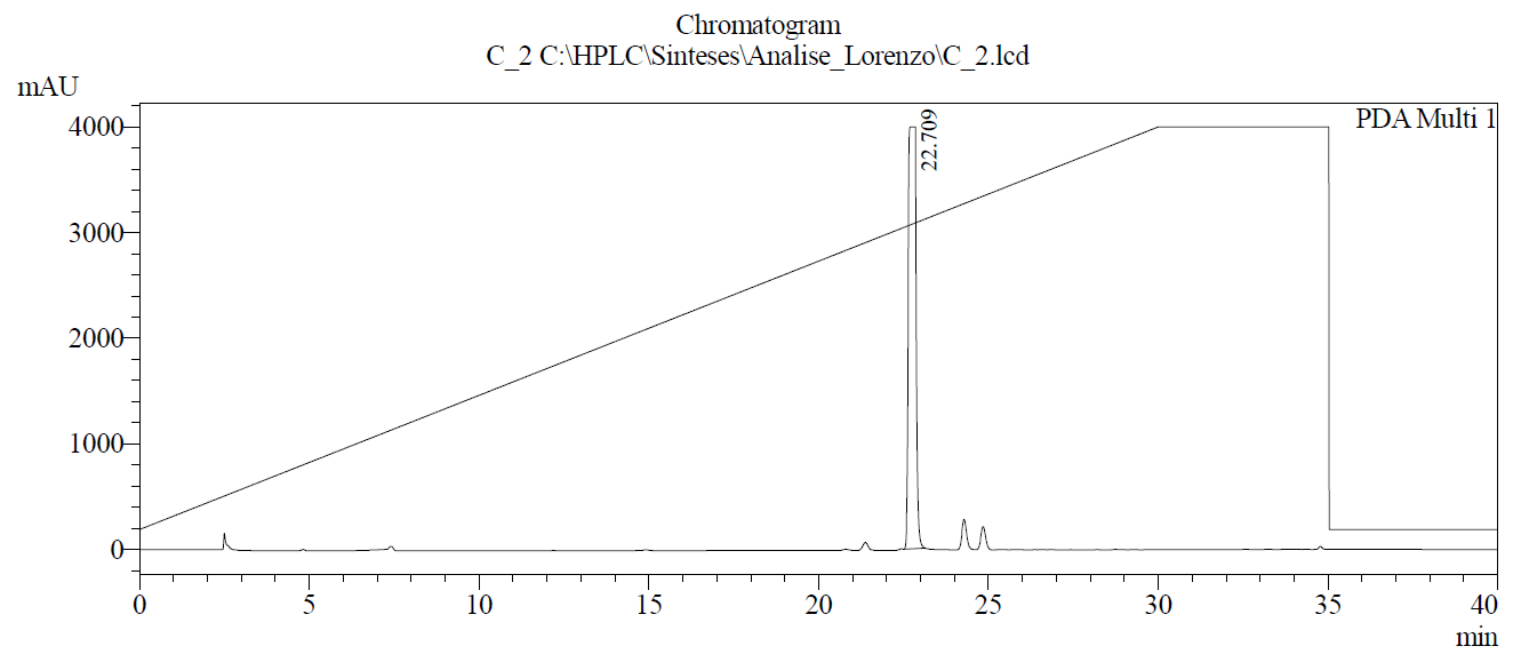

Elution was carried out with the following gradient: water (solvent $A$ ), ACN (solvent B), $5 \% B$ to $100 \% \mathrm{~B}$ in $40 \mathrm{~min}$, stop time $30 \mathrm{~min}$, flow $0.5 \mathrm{ml} / \mathrm{min}$. 
Figure 97. HPLC analysis for a mixture of 73 (Neq0921) and 74 (Neq0938) with Diacel column (IC-chiralpak, $250 \times 4.6 \mathrm{~mm}, 5 \mu \mathrm{m})$.

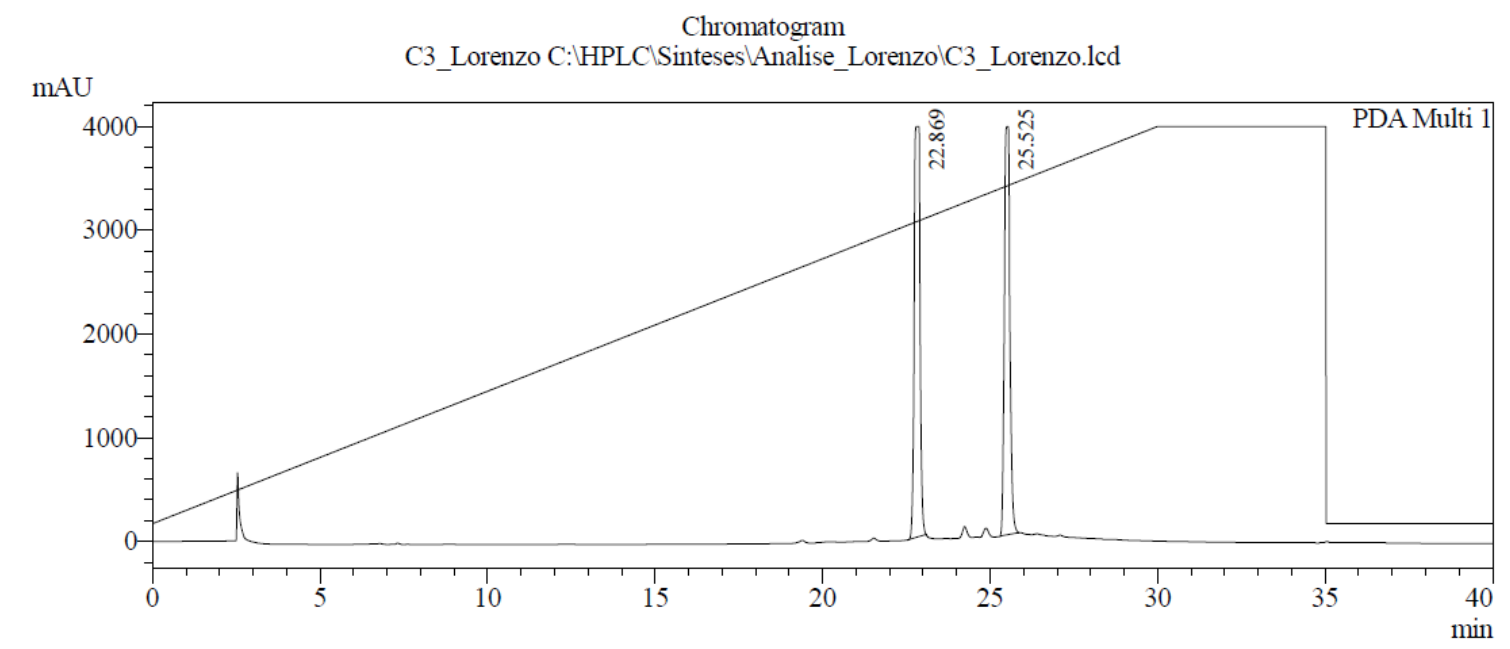

Elution was carried out with the following gradient: water (solvent $A$ ), ACN (solvent $B$ ), $5 \% B$ to $100 \% \mathrm{~B}$ in $30 \mathrm{~min}$, stop time $40 \mathrm{~min}$, flow $0.5 \mathrm{ml} / \mathrm{min}$.

Figure 98. HPLC analysis of 82 (Neq0941) with Diacel column (IC-chiralpak, $250 \times 4.6$ mm, $5 \mu \mathrm{m})$.

Chromatogram

F_1 C:LPLCISinteses\Analise_LorenzolF_1.1cd

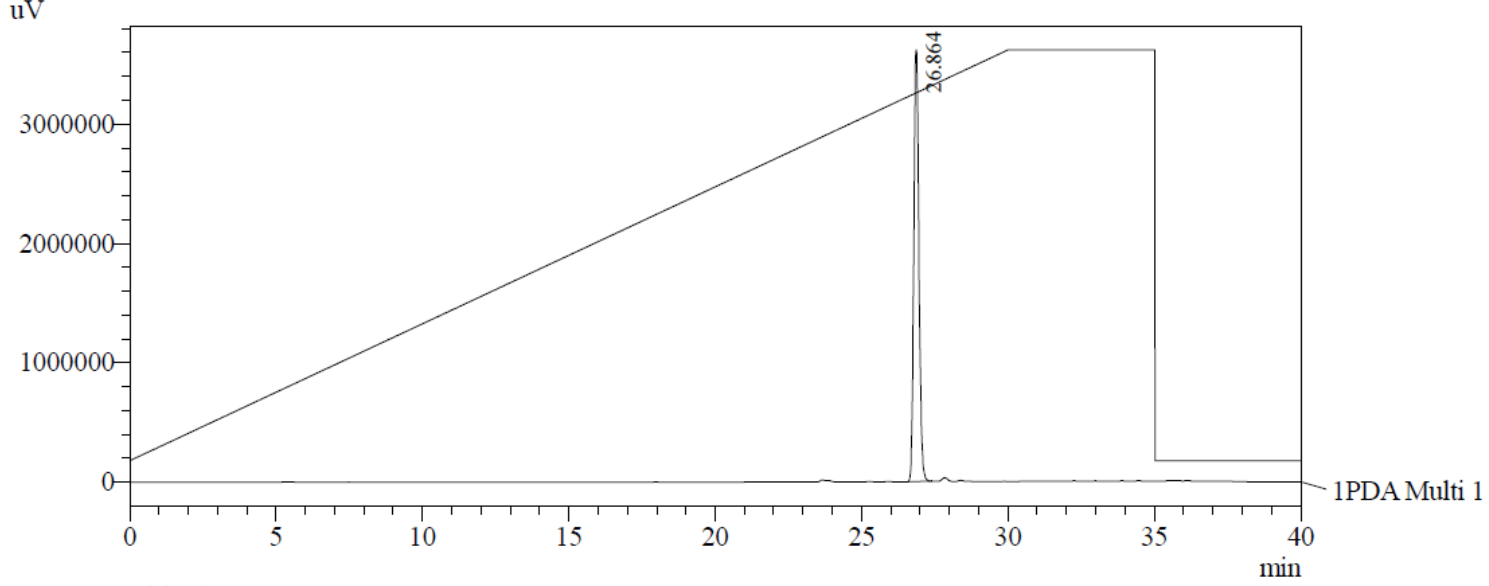

1 PDA Multi $1 / 245 \mathrm{~nm} 4 \mathrm{~nm}$

Elution was carried out with the following gradient: water (solvent $A$ ), ACN (solvent B), $5 \% B$ to $100 \% \mathrm{~B}$ in $40 \mathrm{~min}$, stop time $30 \mathrm{~min}$, flow $0.5 \mathrm{ml} / \mathrm{min}$. 
Figure 99. HPLC analysis of 83 (Neq0943) with Diacel column (IC-chiralpak, 250 x $4.6 \mathrm{~mm}$, $5 \mu \mathrm{m})$.

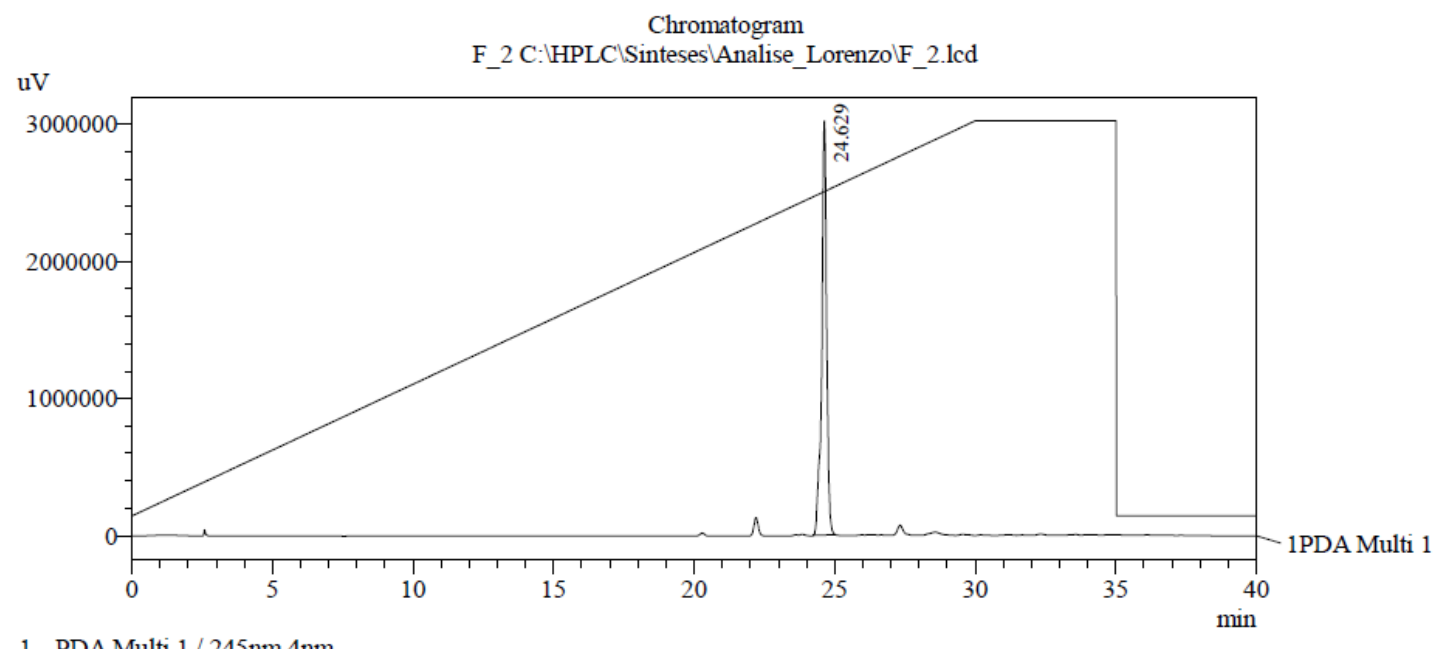

1 PDA Multi $1 / 245 \mathrm{~nm} 4 \mathrm{~nm}$

Elution was carried out with the following gradient: water (solvent $A$ ), $A C N$ (solvent $B$ ), $5 \% B$ to $100 \% \mathrm{~B}$ in $40 \mathrm{~min}$, stop time $30 \mathrm{~min}$, flow $0.5 \mathrm{ml} / \mathrm{min}$.

Figure 100. HPLC analysis for a mixture of 82 (Neq0941) and 83 (Neq0943) with Diacel column (IC-chiralpak, 250 x $4.6 \mathrm{~mm}, 5 \mu \mathrm{m})$.

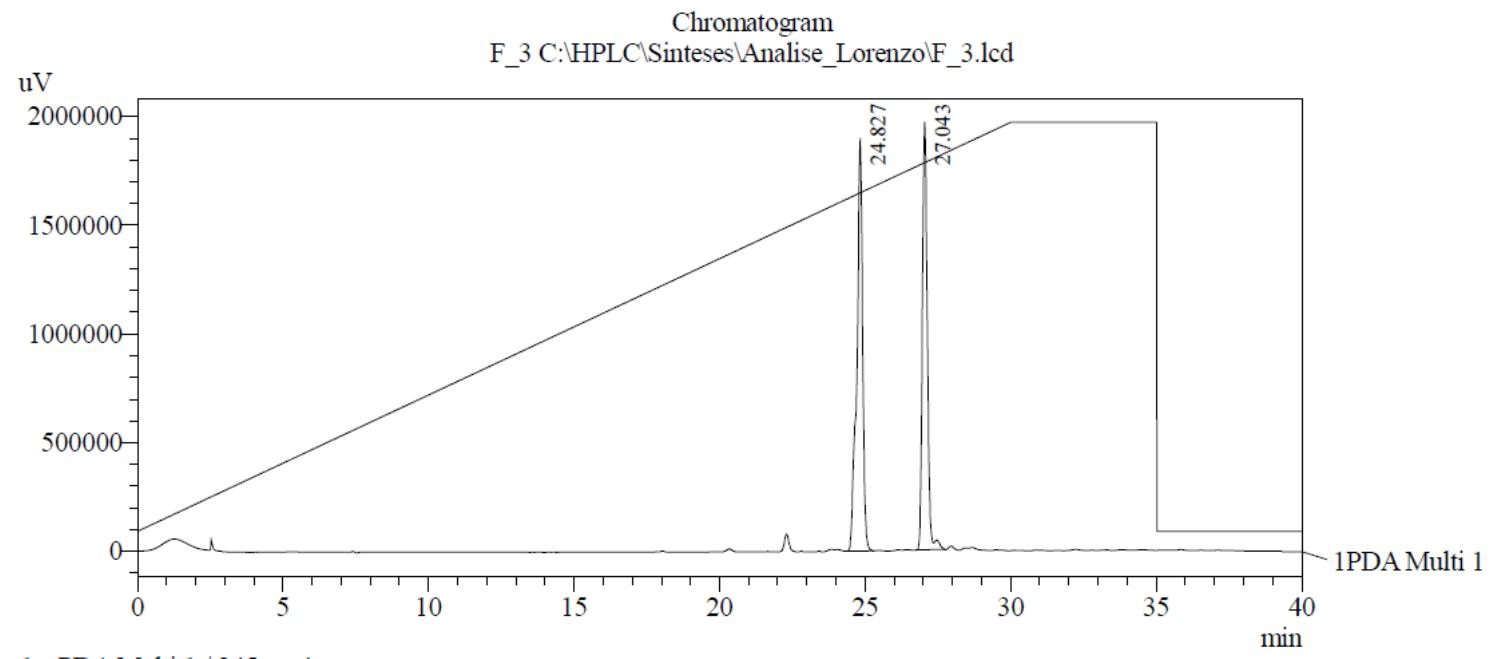

1 PDA Multi $1 / 245 \mathrm{~nm} 4 \mathrm{~nm}$

Elution was carried out with the following gradient: water (solvent $A$ ), ACN (solvent B), $5 \% B$ to $100 \% \mathrm{~B}$ in $30 \mathrm{~min}$, stop time $40 \mathrm{~min}$, flow $0.5 \mathrm{ml} / \mathrm{min}$. 